PASADO Y Memoria

Recomponer el mundo después de Napoleón: 1814 y las Restauraciones Europe after Napoleon: The 1814 Restorations

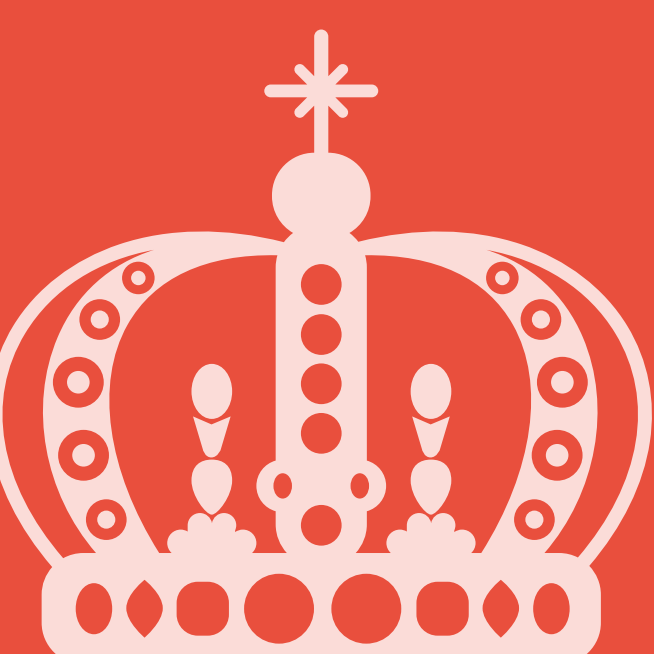

Universitat d'Alacant Universidad de Alicante 


PASADO Y MEMORIA 


\title{
PASADO Y Memoria \\ Revista de Historia Contemporánea
}

$n^{\circ} 13,2014$

$<$ http://dhcon.ua.es/pasado-memoria/>

Los números anteriores de Pasado y Memoria. Revista de Historia Contemporánea pueden consultarse en el Repositorio Institucional de la Universidad de Alicante $<$ http://rua.ua.es $>$ y en Dialnet $<$ http://dialnet.unirioja.es/ $>$

\begin{abstract}
Dirección: Mónica Moreno Seco $(U A)$
Secretaría: Rafael Fernández Sirvent $(U A)$

Consejo de Redacción: Nerea Aresti Esteban (Universidad del País Vasco), Paul Aubert (Aix-Marseille Université), Gloria Bayona Fernández (UA), Alfonso Botti (Università degli Studi di Modena e Reggio Emilia), Isabel Burdiel Bueno (Universitat de València), Jesús Cruz (University of Delaware), Pilar Folguera Crespo (Universidad Autónoma de Madrid), Salvador Forner Muñoz (UA), Víctor Gavín Munté (Universitat de Barcelona), Rosa Ana Gutiérrez Lloret (UA), Emilio La Parra López (UA), Alicia Laspra Rodríguez (Universidad de Oviedo), Jean-Philippe Luis (Université Blaise Pascal, ClermontFerrand), Alicia Mira Abad (UA), Roque Moreno Fonseret (UA), Bárbara Ortuño Martínez (CONICET-Universidad Nacional de Mar del Plata), Pedro Payá López (UA), Glicerio Sánchez Recio (UA), José Miguel Santacreu Soler (UA), Heydi Senante Berendes (UA), Francisco Sevillano Calero (UA), Mercedes Yusta Rodrigo (Université Paris 8), Rafael Zurita Aldeguer (UA).
\end{abstract}

\begin{tabular}{|c|c|c|}
\hline \multicolumn{3}{|l|}{ Consejo Asesor: } \\
\hline Carolyn P. Boyd & Conxita Mir Curcó & $\mathrm{M}^{\mathrm{a}}$ Cruz Romeo Mateo \\
\hline (Univ. of California, Irvine) & (Univ. de Lleida) & (Univ. de València) \\
\hline Jordi Canal i Morell & Javier Moreno Luzón & Fernando Rosas \\
\hline (EHESS, Paris) & (Univ. Complutense) & (Univ. Nova de Lisboa) \\
\hline Gérard Chastagnaret & Mary Nash & Ismael Saz Campos \\
\hline (Aix-Marseille Univ.) & (Univ. de Barcelona) & (Univ. de València) \\
\hline José Luis de la Granja & Ma Encarna Nicolás Marín & Alfio Signorelli \\
\hline (Univ. del País Vasco) & (Univ. de Murcia) & (Univ. degli Studi dell'Aquila) \\
\hline Gérard Dufour & Marco Palla & Manuel Suárez Cortina \\
\hline (Aix-Marseille Univ.) & (Univ. degli Studi di Firenze) & (Univ. de Cantabria) \\
\hline Ignacio Fernández Sarasola & Juan Sisinio Pérez Garzón & Julio Tascón Fernández \\
\hline (Univ. de Oviedo) & (Univ. de Castilla-La Mancha) & (Univ. de Oviedo) \\
\hline Juan Francisco Fuentes Aragonés & Manuel Pérez Ledesma & Leonida Tedoldi \\
\hline (Univ. Complutense) & (Univ. Autónoma de Madrid) & (Univ. degli Studi di Verona) \\
\hline Eduardo González Calleja & Florentino Portero Rodríguez & Ramón Villares Paz \\
\hline (Univ. Carlos III de Madrid) & $(U N E D)$ & (Univ. Santiago de Compostela) \\
\hline Elisabel Larriba & Manuel Redero San Román & Bruno Vargas \\
\hline (Aix-Marseille Univ.) & (Univ. de Salamanca) & (Univ. J-F. Champollion, Albi) \\
\hline Jesús Millán y García-Varela & Maurizio Ridolfi & Pere Ysàs Solares \\
\hline (Univ. de València) & (Univ. degli Studi della Tuscia) & (Univ. Autònoma de Barcelona) \\
\hline
\end{tabular}

Edita: Departamento de Humanidades Contemporáneas, con la colaboración del Vicerrectorado de Investigación, Desarrollo e Innovación (programa "Ayudas para la Publicación de Revistas Científicas") y de la Facultad de Filosofía y Letras UNIVERSIDAD DE ALICANTE (UA), Ap. correos 99 - 03080 Alicante (ESPAÑA)

Contacto: pasadoymemoria@ua.es

Pasado y Memoria está presente en las siguientes bases de datos y catálogos: CARHUS, ISOC-CSIC, CIRC, COPAC, Dialnet, DICE, DULCINEA, ERIH, Latindex, MIAR, ULRICH'S, RECOLECTA, RESH, SHERPA-ROMEO, SUDOC, WorldCat, ZBD.

Depósito legal: A-293-2002 • DOI: 10.14198/PASADO2014.13 • ISSN: 1579-3311 / ISSN versión electrónica: 2386-4745 


\title{
PASADO Y Memoria
}

Revista de Historia Contemporánea

\author{
RECOMPONER EL MUNDO \\ DESPUÉS DE NAPOLEÓN: \\ 1814 Y LAS RESTAURACIONES \\ EUROPE AFTER NAPOLEON: \\ THE 1814 RESTORATIONS
}


Publicaciones de la Universidad de Alicante

Campus de San Vicente s/n

03690 San Vicente del Raspeig

Publicaciones@ua.es

http://publicaciones.ua.es

Teléfono: 965903480

Fax: 965909445

(C) de la presente edición: Universidad de Alicante

ISSN: 1579-3311

Depósito legal: A-293-2002

Revisión de los abstracts en inglés:

Dra. Alicia Laspra (Universidad de Oviedo)

Diseño de portada: candela ink

Composición:

Patricia Barbero

Reservados todos los derechos. No se permite reproducir, almacenar en sistemas de recuperación de la información, ni transmitir alguna parte de esta publicación, cualquiera que sea el medio empleado -electrónico, mecánico, fotocopia, grabación, etcétera-, sin el permiso previo de los titulares de la propiedad intelectual. 


\section{ÍNDICE / SUMMARY}

Pedro Rújula López

Presentación / Foreword

Jean-Claude Caron

Entre la renovación y la reevaluación. Jalones en la historiografía

francesa sobre la Restauración

Between Renewal and Reevaluation. Milestones in French

Historiography on the Restoration

\section{Francis Démier}

Permanencia y mutaciones del Estado napoleónico bajo la

Restauración de los Borbones, 1814-1830

Continuity vs. mutation in the Napoleonic State under the Bourbons'

Restoration, 1814-1830

\section{Gonzalo Butrón Prida}

Redefinir rey y soberanía: el retorno de Fernando VII y la agonía

del Liberalismo

Reimagining King and Country: the return of Ferdinand VII and

the agony of Liberalism

Pedro Rújula López

El mito contrarrevolucionario de la «Restauración»

The counter-revolutionary myth of the «Restauration»

\section{Carmine Pinto}

Guerras europeas, conflictos civiles, proyectos nacionales. Una

interpretación de las restauraciones napolitanas (1799-1866)

European Wars, Civil Conflicts, and National Projects. The Neapolitan

Restorations (1799-1866) Revisited 
Javier Esteve Martí

El carlismo ante la reorganización de las derechas. De la Segunda Guerra Carlista a la Guerra Civil

Carlism and the Reorganization of the Rights. From Carlist War II to the Civil War

Javier Navarro Navarro

La calle rojinegra. Anarcosindicalismo, rituales de movilización y símbolos en el espacio público (1931-1936)

Red-and-Black Streets. Anarcho-Syndicalism, Rituals of Mobilization and Symbols in Public Spaces (1931-1936)

Roberto Villa García

«Obreros, no votéis». La CNT y el Frente Popular en las elecciones de 1936 173

«Workers, do not vote!». CNT and Spanish Popular Front in the 1936 general elections

Natalia Urigüen López de Sandaliano

Política de la República Federal de Alemania hacia España durante el franquismo y la transición (1949-1979)

The Federal Republic of Germany Policy towards Spain durign the Francoism Regime and the Transition to Democracy (1949-1979)

Ignacio Tébar Rubio-Manzanares

El «derecho penal del enemigo»: de la teoría actual a la práctica represiva del «Nuevo Estado» franquista

The «Enemy's Criminal Law»: From current theory to the repressive practice of the Francoist «New State»

Ana Belén Gómez Fernández

Del antifranquismo al feminismo: la búsqueda de una nueva ciudadanía del movimiento democrático de mujeres en la Transición democrática 251 From Antifrancoism to Feminism: The search for a new Citizenship of Women's Democratic Movement in Spanish Democratic Transition 
Miguel Ángel Giménez Martínez

La actividad rogatoria de las Cortes durante la Legislatura

Constituyente (1977-1979) 271

The Enquiring Activity of the Spanish Parliament during the

Constituent Legislature (1977-1979)

Manuel Lillo i Usechi

Lassassinat d'Ernest Lluch: les interpretacions diferenciades de

Gara i El Temps, dos mitjans de l'esquerra nacionalista 299

Ernest Lluch's assassination: Contrasting interpretations in two

Left-wing Nationalist Media Publications

\section{NOTAS BIBLIOGRÁFICAS Y DE INVESTIGACIÓN / BIBLIOGRAPHICAL NOTES}

Antonio Escudero

Las minas de Guelaya y la Guerra del Rif 329

The Guelaya mines and the Rif War

Juan B. Vilar

El tránsito en España del liberalismo clásico a la democracia 337

The Spanish transition from classical Liberalism to Democracy

TESIS DOCTORALES 343

RESEÑAS DE LIBROS / REVIEWS 359

AUTORES / AUTHORS 429

NORMAS PARA LA PRESENTACIÓN DE ORIGINALES 435

NORMES PER A LA PRESENTACIÓ D'ORIGINALS 439

INSTRUCTIONS FOR AUTHORS (STYLE SHEET) 443

POLÍTICA DE SECCIONES, TASA DE ACEPTACIÓN DE ARTÍCULOS Y LISTADO DE EVALUADORES EXTERNOS / SECTIONS POLICY, ACCEPTANCE RATES AND EXTERNAL REVIEWERS 



\title{
PRESENTACIÓN / FOREWORD
}

\author{
Recomponer el mundo después de Napoleón: 1814 y las restauraciones \\ Europe after Napoleon: The 1814 Restorations
}

La Restauración es un período que, desde su propia denominación, ha sido construido históricamente en relación a otros acontecimientos mayores que lo habían precedido, ya fueran la revolución y la época napoleónica en Europa o la Guerra de la Independencia en España. De este modo, su lógica interna era la de la reacción, es decir, una relación dialéctica con estos grandes acontecimientos que la dotaban de sentido en el discurso temporal. Se ha escrito recientemente, en este sentido, que la primera Restauración, en Francia, "mantuvo una relación obsesiva con los acontecimientos revolucionarios" 1 . Otro tanto podría decirse del caso español, donde la experiencia de las Cortes constituyó la referencia ineludible de un golpe de estado concebido en clave netamente contrarrevolucionaria. Como dice Miguel Artola, "la actividad legislativa de Fernando VII durante su primer año de reinado se limitó a desmontar sistemáticamente cuanto habían llevado a cabo las Cortes" ${ }^{\text {. }}$

Existen pocas dudas de que este comportamiento reactivo que pretendía la vuelta a una suerte de orden cuyo modelo de referencia estaba en el pasado es importante para entender lo sucedido en el continente europeo a partir de 1814. Sin embargo, no es suficiente para explicar las líneas de tensión que se están definiendo en los orígenes del mundo contemporáneo. La magnitud de los cambios que habían sufrido la sociedad y la economía, pero también la política y la cultura desde el estallido de la Revolución francesa hasta ese momento eran de tal magnitud que de poco servían ya la viejas fórmulas. Más allá de la voluntad de las antiguas élites para encaramarse de nuevo al poder, basada en la reivindicación de una legitimidad histórica y en la vuelta a patrones políticos

1. Goujon, Bertrand, Monarchies postrévolutionnaires, 1814-1848, Seuil, Paris, 2014, p. 59.

2. ARtola, Miguel, Los orígenes de la España Contemporánea I, Instituto de Estudios Políticos, Madrid, 1975, 2a , p. 722. 
y sociales anteriores, la realidad era que había que empezar de nuevo, hacer balance de daños y tratar de recomponer el mundo con los materiales del presente, que no eran, ni mucho menos, los de unos años atrás.

El dossier que abren estas líneas está guiado por esta voluntad de dotar de complejidad al momento histórico de la Restauración. Complejidad geográfica, ya que en muy distintos escenarios y con muy distintos protagonistas, en Francia, Italia y España, se puso en marcha un proceso común de reposición de la monarquía de los Borbones en sus antiguos feudos. Complejidad cronológica, porque los ritmos de la restauración monárquica fueron muy diferentes en su duración y en sus oscilaciones políticas pues, según donde tuvieron lugar, se vieron sometidas a oleadas revolucionarias diversas y cambios en los equilibrios de poder que alteraron sus formulaciones iniciales. Complejidad política, ya que la praxis de los Borbones restaurados no se acogió a un mismo patrón, sino que los proyectos de sus gobiernos entraron en diálogo directo con las realidades del país configurando soluciones muy diferentes que iban desde la Carta "más liberal que las Constituciones del año VII y del año XII"3 puesta en marcha por Luis XVIII para consolidarse en el poder aceptando la entrada en juego de nuevos actores; hasta la solución española, tan ciega e intransigente que fue calificada, por una persona que había trabajado en favor del golpe como el duque de Wellington, como "la más lamentable escena de opresión y desolación" preocupado, además, por que tales cotas de virulencia ultra podían desatar movimientos que afectaran a toda Europa ${ }^{4}$. Mucho más cercano al caso francés que al español, quedó el comportamiento del Reino de las Dos Sicilias donde la restauración de la monarquía borbónica en 1815 no fue acompañada de ningún intento de reconstruir el Antiguo Régimen ${ }^{5}$, tal vez porque, como ha planteado Carmine Pinto, esta no era la primera restauración del absolutismo que vivía Nápoles, ni tampoco sería la última en la primera mitad del siglo $\mathrm{XIX}^{6}$, lo que introducía un componente de negociación política en la recuperación de los equilibrios.

De los artículos que siguen, dos de ellos se dedican al caso francés. El primero constituye una amplia revisión historiográfica de la producción sobre el

3. Demier, Francis, La France de la Restauration (1814-1830). L'impossible retour du passé, Gallimard, Paris, p. 63.

4. Carta del duque de Wellington a lord Holland, Apsley House, 10 de febrero de 1816, citada por MoReno Alonso, Manuel, La forja del liberalismo en España. Los amigos españoles de Lord Holland, 1793-1840, Congreso de los Diputados, Madrid, 1997, p. 323.

5. DAVIS, John A., Napoli e Napoleone. L'Italia Meridionales e le rivoluzioni europee (17801860), Rubbettino Editore, Soveria Mannelli, 2014, p. 433.

6. Pinto, Carmine, "Crisi globale e conflitti civili. Nouve ricerche e prospettive storiografiche", en Meridiana, 78 (2013), p. 15. 
período de la Restauración. Analizando un importante número de casos, Jean-Claude Caron defiende en su texto que la desaparición de muchos de los condicionantes ideológicos que habían encasillado a este período de la historia de Francia como un contrapunto neto de la Revolución ha traído consigo un mejor conocimiento del período despojándolo de los estereotipos y dotándolo de significado propio. Esta revisión historiográfica permite comprobar los cambios que han tenido lugar recientemente y que han hecho aflorar líneas específicas y lógicas donde se vincula esta etapa no solo con el pasado sino fundamentalmente con el futuro considerándola como el arranque de muchos procesos que verán su desarrolló en el siglo XIX. El análisis del sesgo interpretativo, de las cronologías estudiadas, de los campos y sensibilidades desde los que se construyen los estudios le permite llamar la atención sobre dos cuestiones. De un lado que se ha producido una reevaluación del período caracterizada por privilegiar las continuidades en un tiempo que había venido siendo definido como de ruptura e involución; de otro que, como en otros muchos campos de estudio, se ha producido también la irrupción de la historia cultural.

Por su parte el trabajo de Francis Démier plantea el problema de la ruptura o la continuidad en el ámbito del aparato político administrativo de la monarquía restaurada francesa. Para ello analiza el funcionamiento de la estructura ministerial de Luis XVIII y la política económica llevada a cabo por sus gobiernos. El resultado no pude ser más claro. La Restauración de 1814-1815 se puso en marcha a partir de un cuerpo de altos funcionarios que habían forjado su competencia y su carrera en tiempos de la Revolución y del Imperio y no se produjo una depuración de estos empleados por el simple hecho de tener un pasado vinculado a la experiencia revolucionaria. Otro tanto sucede con la política económica, que no volvió a los patrones del Antiguo Régimen sino que se mantuvo en la línea de un liberalismo nacionalista opuesto a devolver a los territorios la autonomía de la que habían disfrutado antes de la Revolución, combinado con un proteccionismo hacia el exterior que permitiera el desarrollo progresivo de un mercado nacional. La política y la economía de la Francia restaurada hablan, por lo tanto, mucho más de compromiso con las nuevas élites de la revolución y del imperio, y con las ideas dominantes en el mundo de la administración de las últimas década, que de ruptura con las mismas.

Situados sobre una temporalidad más corta, los artículos dedicados al caso español tratan de desentrañar las complejas decisiones que se resolvieron en el entorno del poder en los escasos meses que van desde la liberación de Fernando VII de su cautiverio en Valençay hasta su llegada a Madrid en mayo de 1814. El primero de ellos, realizado por Gonzalo Butrón tiene por objetivo analizar el abanico de proyectos que circularon en los meses anteriores al golpe 
de estado protagonizado por el rey. Además de contemplar los dos planteamientos opuestos defendidos por liberales y absolutistas, deja constancia de que entraron en juego diversos proyectos intermedios. Uno de ellos, el del retorno al trono de Carlos IV, cuestionaba a Fernando VII como único aspirante a la corona española y le atraía hacia la Constitución de Cádiz donde se le reconocía como rey disolviendo con ello cualquier tipo de duda. A medida que se acercaba el desenlace, y ante los temores de una restauración del absolutismo, fueron las fórmulas transaccionales las que cobraron mayor actualidad, bien siguiendo el ejemplo de Holanda y Francia, donde se habían puesto en práctica soluciones moderadas, o bien recurriendo a fórmulas autóctonas como eran la convocatoria de Cortes tradicionales. Al final, todos estos proyectos, orientados a introducir la experiencia de los años de la invasión francesa en la solución política de que dotara a la monarquía española, fracasaron, incluso en sus versiones más moderadas, arrasados por el ciego maximalismo absolutista de Fernando.

El segundo de los artículos dedicado a España, que lleva nuestra firma, parte precisamente de este punto, preguntándose porqué el proceso restaurador español terminó siendo una excepción europea caracterizada por la negación de los cambios acontecidos y por la férrea voluntad de vuelta al pasado. Para ello se analiza el primer discurso realista surgido durante la Guerra de la Independencia dominado por un tono apocalíptico que denunciaba las profundas mutaciones que se habían producido en la vida pública española, tanto en la política, como en la sociedad y, sobre todo, en la opinión pública. Este planteamiento era contradictorio con las pretensiones de restaurar a Fernando VII en el trono en las condiciones de 1808, ya que suponía ignorar toda la experiencia de aquellos años. El elemento que permitió franquear esta contradicción fue la construcción de un mito que conectaba muy bien con el deseo de normalidad de los españoles de 1814, el mito de la restauración del orden perdido, la vuelta a la normalidad mediante un simple mecanismo taumatúrgico que consistía reponer al rey en su trono. Este mito proporcionó la coartada necesaria para justificar el golpe y trasladar todo el poder de las manos de las Cortes a las del monarca restaurado.

Finalmente el artículo de Carmine Pinto está planteado sobre una cronología larga, a través de la cual puede analizar los distintos episodios de restauración monárquica que el Reino de Nápoles sufrió durante medio siglo entre el primer regreso de los Borbones tras la breve experiencia de la República Partenopea, en 1799, y la de 1849 ya bajo el reinado de Fernando II. A través de este planteamiento de larga duración puede comprobarse que después de cada restauración el poder monárquico iba a tener mayores problemas para hacer 
frente al liberalismo forzando concesiones que le permitieran mantener el control de la situación. Y todo ello mezclado con la cuestión territorial siciliana, que veía en este tipo de movimientos liberales una forma de expresión de anhelos políticos propios. El hecho de que la resolución de muchos de estos conflictos fuera depositada por los partidarios del liberalismo en el triunfo de un proyecto nacional italiano hizo que surgiera, por oposición, un patriotismo contrarrevolucionario napolitano que se vinculó con la suerte de la monarquía. El conflicto revolución-contrarrevolución terminó adquiriendo así carácter geográfico e identificando a Nápoles con el legitimismo borbónico.

En conjunto, el dossier Recomponer el mundo después de Napoleón: 1814 y las restauraciones reúne diversas contribuciones cuyo denominador común es que huyen de visiones simplistas de la restauración borbónica europea de 1814-15, tanto porque, como decía Cayetano Valdés, el jefe político de Cádiz, era "imposible que seis años tales como los pasados desaparezcan de nuestra historia", como porque de ella arrancan muchos de los procesos que iban a definir la historia de los estados europeos en época contemporánea.

Pedro Rúulua

Universidad de Zaragoza 



\title{
Entre la renovación y la reevaluación. Jalones en la historiografía francesa sobre la Restauración ${ }^{1}$ Between Renewal and Reevaluation. Milestones in French Historiography on the Restoration
}

\author{
Jean-Claude Caron \\ Université Blaise Pascal, Clermont-Ferrand
}

Recibido: 22-VII-2014

Aceptado: 1-X-2014

\section{Resumen}

La historiografía francesa sobre la Restauración está marcada por algunos importantes jalones. Poco a poco ha ido escapando de la escritura militante para convertirse en un objeto histórico sometido a una mirada crítica. Aunque durante mucho tiempo fue un período casi abandonado, progresivamente ha ido suscitando mayor interés, algo que puede apreciarse en la ampliación de las temáticas y en el peso creciente de la historia cultural que se infiltra en la historia política, social o religiosa. A pesar de ello, la historia económica o la historia comparada de las Restauraciones en Europa se encuentran todavía en un estado embrionario, a pesar de algunas iniciativas recientemente puestas en marcha.

Palabras clave: Restauración, historiografía, síntesis, cronología, ruptura, periodización, transición, diversificación temática, reevaluación histórica, arcaísmo, modernidad, construcción nacional.

1. El corpus de obras utilizadas se limita a una sesentena de referencias. Está fundado, en parte, sobre la subjetividad, pero no pretende establecer ninguna jerarquía entre las obras citadas y aquellas que no figuran aquí. Está también construido sobre obras dedicadas solamente a la Restauración, y de otras que la incluyen en cronologías más amplias. No han sido tenidos en cuenta los artículos de revista, los diccionarios históricos ni las biografías. En este último caso, la abundancia de títulos era imposible de gestionar en el marco de este artículo. Tampoco se han incluido las tesis todavía sin publicar. Para no hacer demasiado pesadas las notas al pie de la página hemos situado al final del artículo la lista de las obras citadas, referenciadas in extenso, mientras que las notas al pie del artículo se reducen a dar cuenta del autor y año de publicación. 


\begin{abstract}
French historiography of the Restoration is marked by some important milestones. It has gradually abandoned militant writing to become a historic object submitted to a critical view. Despite having been for a long time considered as a nearly forgotten period, it has of late aroused a renewed interest which is made evident by the extension of themes, and by the increasing weight of cultural history which penetrates political, social and religious history. However, the economic history, as well as the compared history of the Restorations in Europe still remains embryonic, in spite of some recent initiatives.
\end{abstract}

Keywords: The Restoration, historiography, synthesis, chronology, break- sequenced division, transition, thematic diversification, historic revaluation, archaism, modernity, national construction.

La historiografía francesa sobre la Restauración ha sido, durante mucho tiempo, reveladora de una cuestión que puede constatarse también para otros períodos: el campo de la investigación histórica no escapa al juego de la política que, con frecuencia, se manifiesta muy presente y puede llegar a ser opresiva. ¿Es necesario emanciparse? La respuesta es que, por lo menos, conviene ser consciente de ello. No es difamatorio afirmar que, en concreto durante la Guerra Fría -pero la situación se verifica también en épocas anteriores como la Tercera República-, la historia era una disciplina ampliamente instrumentalizada por las ideologías de todo tipo. Pero, como el objeto de este artículo es la etapa de la Restauración, fue precisamente durante este período cuando la historiografía, en el auténtico sentido de la palabra, adoptó una dimensión política nueva. En relación con la guerra ideológica y política que, prolongando por otros medios los enfrentamientos del período revolucionario pretendía imponer una lectura dominante de este pasado próximo, los historiadores no escaparon de la adhesión partidaria al régimen, suponiendo que en algún caso hubieran querido sustraerse a ella. Agitando un programa semejante, la palabra "restauración" se opone a la, no menos programática, de "revolución". Los trabajos de Adolphe Thiers o los de François Mignet intentaron entonces rehabilitar en bloque lo que los teóricos contrarrevolucionarios como el abate Barruel, Joseph de Maistre, Louis de Bonald condenaban, también ellos, en bloque.

El triunfo de los liberales en 1830 durante las Tres Gloriosas se tradujo en la consolidación de una "leyenda negra de la Restauración" de la que participan, especialmente, Achille de Vaulabelle o Louis Blanc. Una legenda negra que reforzará la historiografía republicana, comenzando por Jules Michelet, haciendo de la Restauración, y pronto de la Monarquía de julio, un simple paréntesis en la historia. En el campo de los legitimistas, Jean-Baptiste Capefigue, y después Alfred Nettement, se erigieron en defensores de la Restauración. Prototipo de alto funcionario servidor del Estado y de la República, Sébastien Charléty 
trata del periodo en "la" Lavisse, esa Histoire de la France contemporaine que constituye un monumento de relato nacional de la Revolución hasta el día siguiente de la Primera Guerra Mundial. En el seno de la historia socialista dirigida por Jean Jaurès, es René Viviani, cofundador con este último de L'Humanité, quien da forma al período. Bajo la República triunfante, la historia de la Restauración se encuentra en manos de historiadores que no dudan en postularse como procuradores o como abogados del período y del régimen político que la caracteriza, la monarquía constitucional, acentuando de hecho el estereotipo de la "Restauración-reacción". Pero, como lo resume Martine Reid (2005), todavía en el tiempo presente, "la Restauración estrangulada entre el Imperio, rápidamente paso rápidamente a formar parte del conjunto de los grandes mitos nacionales, y la monarquía de Julio que verá el triunfo del liberalismo, parece decididamente condenado a figurar en el catálogo de manifestaciones de "otro tiempo""'. No obstante, el balance reciente de la historiografía de la Restauración tiende a desmentir un poco esta afirmación, que es lo que nosotros nos hemos propuesto demostrar. Ahora es posible releer el período, como invitan a hacerlo los coordinadores de un número de la Revue d'histoire du XIXe siècle consagrado a la "Restauración revisitada" (Christen-Lécuyer et Fureix, 2007), considerando el período bajo el triple ángulo de la transacción, de la recomposición y de la nostalgia ${ }^{3}$.

\section{Algunos jalones historiográficos: manuales y obras de síntesis}

Autor de la síntesis culta de referencia sobre la Restauración, el padre Guillaume de Bertier de Sauvigny (1955) se inscribe en una tradición que podría ser calificada de historia militante. Este autor abre así su estudio: "1814... Francia exhausta después de veinte años de fiebre revolucionaria y conquistadora sufre el enfrentamiento con las mismas fuerzas que había desencadenado" y su conclusión refuerza el planteamiento inicial. "Hemos sido llevados fatalmente a preguntarnos, después de concluida, si la Restauración era un régimen viable para Francia. La Revolución de 1830 parece, a primera vista, demostrar que no. Este es un mal argumento, porque esta revolución, se ha demostrado, fue un accidente perfectamente evitable ${ }^{4 "}$. En cuanto al balance de la Restauración, es poco decir que Guillaume de Bertier de Sauvigni la encuentra globalmente positiva, como otros lo decían entonces del régimen soviético: "Nunca, sin duda,

2. ReID, Martine, «Introduction», en MOLlier, ReID y Yon (2005), p. 8.

3. Christen-LéCuyer, Carole y Fureix, Emmanuel (2007), p. 10.

4. Bertier de SAUvigny, Guillaume de, La Restauration, Flammarion, 1974 (1a edic. 1955), pp. 9 y 460-462. El subrayado es nuestro. 
Francia ha estado mejor administrada, con más honestidad, desde arriba hasta abajo de la escala jerárquica, con más respeto por las leyes y los reglamentos, con más miramientos hacia los derechos de los ciudadanos, con menos abusos en el uso de los recursos públicos" ${ }^{5}$. El éxito de este estudio (reeditado en 1963 y en $1974^{6}$, traducido al ingles en $1966^{7}$, reimpreso hasta en 1998) se explica por sus incontestables calidades científicas, pedagógicas y literarias. Pero en realidad ocupaba un vacío historiográfico que solo irá siendo cubierto muy lentamente.

Si intentamos analizar las razones de lo que sería una renovación de la historia del período, podríamos sugerir que los debates historiográficos despertados por el bicentenario de la Revolución francesa en 1989 tuvieron también su impacto sobre la percepción de la Restauración, tanto que esta fue regularmente convocada en los coloquios o publicaciones para captar la herencia de la Revolución francesa entre 1814 y 1830, tuvo su lugar en los combates políticos del período e, incluso, en la apuesta por la escritura de una "historia en caliente" que ve, precisamente, la luz en este momento ${ }^{8}$. Surge también la voluntad de ciertos historiadores, comenzando por Alain Corbin, de imponer una lectura menos "cívica" o teleológica de los años 1815-1871 -por lo tanto, también de la Restauración- en beneficio de una aproximación "sensible" fundada sobre el estudio de fuentes hasta entonces poco utilizadas; de reevaluar el peso de las emociones populares, en particular las rurales; de mostrar la complejidad de la formas de creencia, de adhesión o de rechazo del discurso de las élites; y también de recurrir a introducir conceptos etnológicos o antropológicos en la "caja de herramientas" de un tipo de historiador singularmente amplio.

A pesar de ser obras de circunstancia o alimenticias, los manuales y obras de síntesis ofrecen una imagen muy fiable de la evolución historiográfica de un país. Todo esto cobra sentido, desde la cronología contemplada hasta las lagunas, ya sean reivindicadas o no. Todas las colecciones históricas dedicadas a la historia contemporánea han tomado en consideración a la Restauración. Es el caso de la célebre colección "Que sais-je?", publicada por Presses Universitaires de France, que recurre a Jean Vidalnc (1966), y después a Jean-Pierre Chaline (1998), o de la Nouvelle histoire de la France contemporaine publicada por Seuil que, sin embargo, trata como un bloque la monarquía constitucional (1814-1848). Los dos volúmenes de la colección firmados por André Jardin

5. Idem, p. 461.

6. Bajo el título: Au soir de la monarchie. La Restauration, Paris, Flammarion, 1974.

7. The Bourbon Restoration, Philadelphia, The University of Pennsylvania Press, 1966.

8. Voir Bourdin, Philippe (dir.), La Révolution, 1789-1871. Ecriture d’une histoire immédiate, Clermont-Ferrand, PUBP y Vizille, Musée de la Révolution, 2008. 
y André-Jean Tudesq (1973) constituyeron un jalón historiográfico importante, si tenemos en cuenta su amplia y duradera difusión, pero también de su título que subrayaba la primacía de un grupo, La France des notables, una expresión que se ha convertido en lugar común para designar el período. La versión reactualizada, obra de Bertrand Goujon, muestra a través de su titulo, Monarchies postrévolutionnaires (2012), su voluntad de inscribir la época en estrecha relación con la Revolución francesa. Todavía más sobrio parece el título del volumen redactado por Jean-Claude Caron, La France de 1815 a 1848 (1993), editado por Armand Colin en la colección Cursus. La secuencia abordada en los volúmenes dirigidos por François Furet (1988), Dominique Barjot, Jean-Pierre Chaline y André Encrevé (1995) o Sylvie Aprile (2010) es mucho más amplia: 1770-1880 en el primer caso, 1814-1914 en el segundo, 1815-1871 en el tercero.

Específicamente dedicadas a la Restauración, algunas síntesis recientes han renovado la percepción del período. Es el caso de la Histoire de la Restauration publicada por Emmanuel de Waresquiel y Benoît Yvert en 1996, cuyo subtítulo "El nacimiento de la Francia moderna" aparece como una suerte de manifiesto, rechazando la visión de un período caracterizado por su arcaísmo. Lo mismo sucede con La France de la Restauración, de Francis Démier aparecido en 2012, cuyo subtítulo, "El imposible retorno al pasado", pone de manifiesto la voluntad de cuestionar la habitual representación del régimen poniendo el acento sobre las tensiones ideológicas y políticas del período. ¿Qué nos dicen estos manuales y estas síntesis? En primer lugar, que la interpretación del régimen político de la Restauración en términos jurídico-constitucionales es un debate en sí mismo. Si el acuerdo es casi unánime en lo referente a que el período no es una monarquía parlamentaria -los historiadores franceses reservan la expresión para el régimen orleanista, no sin reservas muchas veces-, los puntos de vista divergen entre "monarquía constitucional" (Goujon, 2012), "monarquía limitada" (Aprile, 210) o "a medio camino entre monarquía absoluta y monarquía parlamentaria" (Caron, 1993). Estas síntesis revelan igualmente el peso persistente de la historia política y social, combinado, sin embargo, con una caída de los trabajos de historia regional que habían inspirado tantas tesis durante los años 1950-1980, y el ascenso de una historia cultural ampliada a una dimensión etnoantropológica. Pero también ponen de manifiesto las ausencias o las lagunas de la historiografía, en primer lugar de las cuales debe señalarse la historia económica, además de la historia comparada, internacional o diplomática. Por mostrar un ejemplo, la noción de Santa Alianza ha sido muy poco estudiada recientemente. Y si la historia de la producción escrita, sea cual sea su género (prensa, novela, teatro, historia, etc.) ha producido trabajos mayores, estos se inscriben raramente en una dimensión comparativa. 


\section{Variaciones cronológicas}

Las secuencias cronológicas constituyen una apropiación de la historia y revelan la intención de sus autores. Durante mucho tiempo, la Restauración ha sido estudiada de dos maneras. La primera proponía una especie de "imagen detenida" como hace Henri Houssaye (1848-1911), historiador de la Belle Époque, reduciendo la Restauración a un tiempo corto, el que se extiende entre 1814 y 1815. La tetralogía que forman su 1814 y los tres volúmenes de su $1815^{9}$ fueron auténticos best-sellers: se vendieron más de 75.000 ejemplares antes de 1914 , y continuaron su carrera en el período de entre guerras hasta superar las 90 ediciones en los años 30. Recientemente, algunos historiadores han reconsiderado el interés de este tiempo corto. Es el caso de Laurent Nagy (2012) que explora los complots bonapartistas para los años 1815-1816 o Sébastien Allard (2005) interrogando a la generación romántica de 1820.

La segunda considera a la Restauración como si fuera un bloque que abarca los años 1814/15-1830 compuesto por elementos internos muy compartimentados. El año 1814-1815, desde la primera a la segunda abdicación de Napoleón, es en sí mismo una secuencia que, desde muchos puntos de vista, aparece como un "año terrible" avant l'heure, para parafrasear a Victor Hugo en la caracterización que hizo del año 1870-1871. El período que va desde junio de 1815 hasta febrero de 1820 es estudiado para analizar el combate que se produce entre una concepción más o menos abierta o restrictiva de los derechos afirmados por la Carta, y se cierra con el asesinato del duque de Berry. Los años 1820-1827, marcados por la personalidad del duque de Richelieu, y todavía más por Villèle, están caracterizados por el retorno hacia un tradicionalismo político que se acentúa con la llegada de Carlos X al trono de Francia. Pero son los años siguientes, desde el éxito de los liberales en las elecciones del otoño de 1827 a la revolución de julio de 1830, los que dan testimonio de una evolución tanto más interesante en la medida que se inserta sobre un debate historiográfico de primera magnitud: la temporalidad y las modalidades de la transición entre dos regímenes políticos. Sobre este punto, la articulación Restauración-monarquía de julio constituye un caso único en la historia contemporánea de Francia, conservando la misma constitución después de la revolución tras realizar, simplemente, algunos arreglos.

Se entiende así el interés de la secuencia 1828-1832 adoptada por Bertrand Goujon (2012) quien relativiza de facto la ruptura que habrían significado las Tres Gloriosas. Más todavía, es la propia temporalidad de la revolución, más o menos dilatada, la que es puesta en cuestión: tres jornadas revolucionarias,

9. HoussaYe, Henry, 1814, Paris, Perrin, 1888; 1815, Paris, Perrin, 1893-1905, 3 vols. 
cierto, pero ¿quien queda arriba y quien abajo? El autor responde a esto fragmentando el quinquenio 1828-1832 en finas láminas cronológico-políticas donde se suceden "la moderación constitucional, la reacción realista, la revolución, la alternancia dinástica, la apertura a la izquierda y la recentralización conservadora ${ }^{10}$ ". Haciendo esto, Bertrand Goujon sigue los pasos de Jean Bruhat (1979) quien, en el seno de la Historie de la France contemporaine impulsada por algunos historiadores comunistas, trataba como un solo bloque los años 1827-1835, ampliando todavía más la secuencia de transición entre las elecciones del otoño de 1827, marcadas por la aparición de las barricadas en París, y las leyes sobre la prensa de septiembre de $1835^{11}$. En este sentido, deberíamos citar también a Maïte Bouyssy (2012) quien identifica un "momento frenético francés" entre 1824 y 1834, que aspira a resumir en tres palabras: la urgencia, el horror y la democracia. Por nuestra parte, la incertidumbre que prevalece al comienzo de la monarquía de julio, un factor insuficientemente valorado por los historiadores, nos impulsó a recuperar una expresión contemporánea de los años 1830-1832, "la época sin nombre" (Caron, 1993). En consecuencia, lo que se hizo para el final de la Restauración queda todavía pendiente de hacer para sus inicios: la idea de ruptura neta y radical con el Primer Imperio continua dominando la historiografía, de ahí la concomitancia entre la invasión extranjera de Francia en dos ocasiones, la caída de Napoleón y, más allá del final de su régimen, el de la secuencia revolucionaria iniciada en 1789. Sin embargo, la transición entre Primer Imperio y Restauración merecería ser revisitada en la media duración. Por ejemplo, para el período que va desde la campaña de Rusia y de sus efectos sobre la opinión pública hasta el asesinato del duque de Berry en 1820, que abre un período de reacción antiliberal muy pronunciado.

Dicho esto, numerosas obras incluyen la Restauración en una secuencia cronológica más amplia que los historiadores franceses han venido generalmente denominando "primer siglo XIX", expresión que designa generalmente los años 1815-1871, incluso, de manera más restringida los años 1814-1848 (KarilaCohen, 2008) o 1814-1851 (Caron, 1991). Como excepción, Emmanuel Fureix (2009) ha propuesto una secuencia 1814-1840 adaptada a su objeto de estudio: los funerales políticos. El trayecto de integración de la Restauración en un tiempo más largo es a la vez significativo y estimulante. Significativo porque, salvo raras excepciones, está siempre integrada al después, ese "primer siglo XIX" del que constituye el inicio, y no al antes, al período de la Revolución francesa-

10. Goujon, Bertrand (2012), p. 203.

11. Elleinstein, Jean (dir.), Histoire de la France contemporaine, t. 2, 1799-1835, Editions sociales - Livre Club Diderot, 1979. 
Primer Imperio. Solo puede señalarse aquí el carácter pionero del estudio dedicado por Maurice Agulhon (1977) al Cercle dans la France bourgeoise en los años 1810-1848 y la originalidad de la secuencia tratada por François Ploux (2002), los años 1810-1860, o Aurélien Lignereux (2008), los años 1800-1859, aunque señalando que se trata sobre todo de excepciones. Esto sugiere, por lo tanto, que la idea de ruptura que comporta la Restauración se encuentra fuertemente anclada en la cronología, como demuestra igualmente la periodización que continua prevaleciendo en la enseñanza universitaria. Su integración en ese "primer siglo XIX" se demuestra muchas veces estimulante porque, no sin el riesgo de una lectura teleológica del pasado, sitúa a la Restauración como el origen del funcionamiento de instituciones que, si bien no son parlamentarias, reconocen las nociones de derechos garantizados, de igualdad jurídica, de representación nacional y de aceptación de la ley o del impuesto, todas ellas nociones que anuncian la democracia parlamentaria que está por venir.

\section{Diversificación temática}

La diversificación de las temáticas revela hasta qué punto la historia es sensible a renovaciones de perspectiva que traducen la evolución de fuerzas en el seno de la disciplina histórica. apoyaremos nuestra propuesta sobre un número limitado de obras, pero, desde nuestro punto de vista, muy significativas de esta mutación. Poseen un punto en común: si bien todas retoman la noción de "romanticismo" hasta el punto de incluirlo en su título, todas consideran necesario redefinir este "momento romántico" para salir de una imaginería convencional. Así, hacer de los estudiantes de París unas "generaciones románticas" (Caron, 1991) sirve ante todo para plantear cómo se construye la representación socio-cultural de un grupo sometido a diversos estereotipos políticos, literarios, iconográficos de los cuales es necesario mostrar su origen y su intención para deconstruirlos mejor. Ciertos campos aparecen menos frecuentados que en otro tiempo, como la historia política o la historia religiosa. En el primer caso, se observa frecuentemente una combinación de cerrazón temática y ampliación cronológica, al estilo del estudio de la candidatura oficial estudiada por Christophe Voilliot (2005). Pero los estudios de ideología o de corrientes políticas siguen de actualidad, tanto si se trata de los sansimonianos (Picon, 2002), de los liberales del diario Le Globe (Goblot, 1995), de los doctrinarios (Craiutu, 2006) o de la derecha en general (Tort, 2013). Y si un historiador de lo político como Pierre Rosanvallon ha dedicado un amplio espacio a la Restauración en sus trabajos sobre el sufragio (1992), la representación democrática (1998) o la soberanía del pueblo (2000), igualmente ha tomado como objeto de estudio las Cartas de 1814 y de 1830, conectando así con una tradición de historia 
constitucional abandonada (1994). Esta conducta es comparable a la de Alain Laquièze (2002) que se interesa por los orígenes del régimen parlamentario, un tema que había caído en el olvido desde hacía ya algún tiempo.

En el terreno religioso, los trabajos pioneros de Claude Langlois (1974, 1984), Michel Lagrée (1977) o Philippe Boutry $(1985,1986)$ han tenido una descendencia limitada, entre la cual puede citarse el estudio de la Grande Mission de Besançon obra de Gastón Bordet (1998) o el Mythe jésuite deconstruido por Michel Leroy (1992). La historia institucional de la Iglesia resulta bastante desatendida, en particular en lo que respecta al episodio del concordato de 1817, estudiado por Antoine Roquette (2010). Es cierto, no obstante, que historia política e historia religiosa han sido profundamente renovadas gracias a la aportación más o menos masiva de conceptos traídos de otras disciplinas como la antropología o la sociología, y apoyándose sobre la poderosa ola de la historia cultural. El estudio de los pares de Francia realizado por Emmanuel de Waresquiel (2006) o también el volumen dirigido por Matthieu Brejon de Lavergnée y Oliver Tort, consagrado a la unión del Trono y del Altar (2002), ilustran esta persistencia de una historia sociopolítica, pero cruzada de un enfoque cultural. Sucede lo mismo con el estudio de la invención de los sondeos políticos al que se entrega Pierre Karila-Cohen (2008) o también de la historia del rumor tratada por François Ploux (2003).

$¿$ Que otro volumen ofrece un testimonio mejor que Repenser la Restauration (Mollier, Reid y Yon, 2005) sobre el impacto de la historia cultural sobre la relectura de la Restauración? Los títulos de las seis partes que reagrupan veintisiete contribuciones dan testimonio de ello: "Pasado y presente de la historia"; "Ideologías"; "Políticas artísticas"; "Libro, imagen, sociedad"; "Teatro, risa y sátira"; "Restauración y romanticismo". Como puede verse, se trata de un verdadero catálogo (sin atribuir a este término ningún matiz peyorativo) de las canteras de la historia cultural que, sin embargo, no olvida tampoco la dimensión socio-política de los temas. La obra pionera de François Parent-Lardeur (1981) sobre los gabinetes de lectura bajo la Restauración ilustra este punto, interesándose al mismo tiempo por los libros, las lecturas y los lectores. Como subraya Daniel Roche, es "a través de la confrontación de lo social en el espacio urbano cuando se definen las apuestas de la institución 'gabinete de lectura': de lo político a lo cultural ${ }^{12 "}$. El único límite que se puede ver al ejercicio es, a pesar de algunas raras excepciones, privilegiar las elites o, lo que es lo mismo, las categorías sociales que, de una u otra manera, tienen acceso a uno o varios

12. Roche, Daniel, compte rendu de Françoise Parent-Lardeur (1981), en Annales. Économies, sociétés, civilisations, , vol. 39, nº 1 (1984), p. 183. 
modos de expresión: filosofía, historia, periodismo, escritura de ficción, formas artísticas diversas, derecho de elección o de elegibilidad, etc., en resumen, las capacidades sancionadas por un diploma (Caron, 1991; Yannick Le Marec, 2000) o, por ejemplo, las élites integradas en el mundo de la filantropía (Duprat, 1996-1997). ¿Quiere esto decir que la Restauración constituye un caso a parte en este tema? Emmanuel de Waresquiel responde a su manera (2005) demostrando que las élites se encontraban entonces en el corazón de una producción discursiva mayor en relación con las apuestas sociales y políticas que caracterizan el período. Se puede, por otro lado, unir esta cuestión a la de las apuestas memoriales de la Revolución y del Imperio que estudia Natalie Petiteau (2012) o a la de las memorias cuya enorme producción bajo la Restauración ha sido señalada por Damien Zanone (2006).

En cuanto al resto, las fronteras entre géneros o categoría históricas se difuminan cada vez más como pone de manifiesto el estudio de los banquetes al que se ha dedicado Vincent Robert (2010), con una lectura de su objeto a la vez político, social y cultural. Y, aunque es difícil establecer los límites de la historia cultural, hay una evidencia que está fuera de toda duda: en grados diversos, se ha impuesto en la relectura el período, sea de manera autónoma, o de manera complementaria con otro tipo de aproximaciones. Ya se trate de la canción política y social -Darriulat, 2010- o de los discursos laudatorios a la gloria de los Borbones restaurados -Legoy, 2010-, se ha exhumado una gran parte de la producción literaria que ha dejado de considerarse como una mirada anecdótica o ilustrativa para ser interrogada sobre la representación que puede ofrecer del régimen de la Restauración. El registro de lo afectivo, del pathos o de la emoción es también convocada: se encuentra en La France des larmes de Emmanuel Fureix (2009), cuyo subtítulo, Deuils politiques à l'âge romantique indica que se trata -fundamentalmente, pero no exclusivamente- de una historia de lo emotivo, tan valorada por Alain Corbin. Se encuentra esta influencia en un terreno que ha conocido y conoce un importante desarrollo desde hace una veintena de años: el de la violencia o de las violencia, sean cuales sean la naturaleza y el productor. Este tema aflora en las obras de Maite Bouyssy (2012), François Jarrige (2009) o François Ploux (2002). Constituye el corazón de Les Grains du désordre, en el cual Nicolas Bourguinat (2001) estudia las respuestas del Estado ante las violencias por el trigo (2001), en los Feux de la discorde de Jean-Claude Caron (2006), que trata del recurso al incendio en los conflictos políticos o privados, o también en France rébellionnaire d'Aurélien Lignereux (2008), que abarca en todo el ámbito nacional la amplia cuestión de las resistencia a la gendarmería. Alimenta también la obra que Gilles Malandain (2011) ha dedicado a Louvel, el asesino del duque de Berry, renovando de este modo la cuestión del regicidio. 


\section{¿Una reevaluación histórica?}

Aunque intentar una rehabilitación de la Restauración no está en el punto de mira, lo que sí puede decirse es que existe una reevaluación en nombre de un necesario y saludable revisionismo histórico. Muchos de los historiadores del periodo justifican su empresa por la propia constatación de un hecho: entre el desinterés de los investigadores y la persistencia de una leyenda negra, la Restauración debe ser reevaluada, aunque solo sea para poner en evidencia las paradojas, incluso las contradicciones de un período que se debate entre dos tendencias que podrían ser denominadas como arcaísmo y modernidad. Es esta tensión manifiesta, permanente y productiva (de palabras y de actos) la que constituye la originalidad de un momento que hace frente a un "pasado que no pasa", por retomar la fórmula aplicada por Éric Conan y Henry Rousso a la Francia de Vichy ${ }^{13}$, pero también, y tal vez sobre todo, a un futuro repleto de incertidumbre.

Siguiendo los pasos de Pierre Rosanvallon, Pierre Karila-Cohen sugiere que los años 1814-1848 constituyen un "laboratorio político" de donde emerge "una racionalidad nueva, que hace de la opinión el horizonte de la acción gubernamental ${ }^{14 "}$, unido en esto a Emmanuel Fureix que define este momento político como "el de una reflexión nueva sobre la opinión pública, entendida como esfera pública burguesa, y de una inquietud sobre los 'murmullos' populares y la pluralidad de las opiniones ${ }^{15}$ ". Haciendo esto, el uno y el otro asumen estar realizando una reevaluación de la jerarquía del discurso. De la confrontación de fuentes aparentemente sin conexión surge la necesidad de una renovación metodológica, tomando en cuenta, por ejemplo, la noción de imaginario social. Paralelamente, Maïte Bouyssy invita a una lectura dinámica de las fuentes constatando, a partir de los trabajos de Alberto M. Banti, que "las cuadrículas de lectura se adaptan, se entrecruzan, se recortan, porque no existe herencia cultural que se transmita y no se trasforme ${ }^{16 "}$.

Hay, sin embargo, lagunas temáticas persistentes en la producción histórica sobre la Restauración. Al final de su imponente análisis (más de 950 páginas), Francis Démier muestra hasta qué punto lo económico, frecuentemente dejado de lado, y lo social proporcionan una plantilla de lectura esencial para comprender un régimen frecuentemente percibido prioritariamente, incluso exclusivamente, desde una perspectiva ideológica, política o cultural. Su propósito

13. Conan, Éric et Rousso, Henry, Vichy, un passé qui ne passe pas, Paris, Fayard, 1994.

14. Karila-Cohen, Pierre (2008), p. 13.

15. FUREIX, Emmanuel (2009), pp. 16-17.

16. BouYssy, Maïté (2012), p. 290. 
es un alegato en favor de lo socioeconómico como factor determinante, en una época donde un pequeño número de hombres, encarnación de una ciudadanía electoral muy limitada en un régimen estrictamente censitario, son en primer lugar productores, emprendedores o rentistas también, cuyo poder es inversamente proporcional a su número. Pero, es evidente, que este campo es poco frecuentado por los historiadores de la Restauración, igual que lo era hasta hace muy poco tiempo el de la historia militar. En este terreno, no se trata, o no solamente, de producir una historia-batalla, sino más de una historia social, política y cultural de los soldados de la Grande Armée desmovilizados (Petiteau, 2003), de los oficiales napoleónicos caídos en busca de causas que defender (Bruyère-Ostells, 2009), de los ejércitos de ocupación (Hantraye, 2005), incluso de los voluntarios que se comprometieron al lado de los movimientos de liberación nacional, como el movimiento filoheleno (Mazurel, 2013).

¿Cuál es, en definitiva, el verdadero pariente pobre de esta historiografía? Como se habrá visto en la lectura de las líneas precedentes, la producción histórica francesa reciente se encierra frecuentemente en la perspectiva franco-francesa. Existen dos explicaciones a esto. La primera es de orden cronológico: a priori, Francia constituye una suerte de excepción europea, a la vez en la fecha de origen y en la fecha de terminación del período llamado Restauración. ¿Qué otra nación -aceptando que exista como tal- se inscribe en la cronología 1814/ 1815-1830 y en el tipo de acontecimientos -con la guerra por un lado y la revolución por otro- que justifique estos límites? La segunda razón, que se deriva de la primera, es de orden historiográfico: vista desde Francia, la Restauración no cobra realmente sentido más que en una secuencia centenario que vaya desde los años 1789 (la Ilustración) hasta los años 1880 (triunfo de la "República republicana"). Se ha tenido la oportunidad de decir aquí cuantos de estos cortes cronológicos eran a la vez impuestos y pesados en la lectura del período, pero continúan todavía siendo utilizados haciendo, de facto, muy difícil la comparación internacional porque "aíslan" en cierta forma a Francia del resto de Europa.

En consecuencia, conviene reflexionar sobre la divergencia de las temporalidades, como propone la obra colectiva dedicada a las revoluciones de 1830 en Europa (Aprile, Caron y Fureix, 2013). Inscribiendo el "momento 1830" en una secuencia ampliada, los diferentes autores proponen una confrontación de las temporalidades, pero también de los conceptos (revolución), de las categorías de actores y de las políticas de Estado para elevar un panorama tan ancho como fuera posible de una Europa de las Restauraciones englobando los años 1810, 1820 y 1830. También desde esta perspectiva han sido concebidos los dos coloquios internacionales organizados en octubre de 2013 en Clermont-Ferrand 
y en junio de 2014 en París por Jean-Claude Caron y Jean-Philippe Luis, catedráticos en la universidad Blaise-Pascal de Clermont-Ferrand, bajo el título común de Rien appris, rien oublié? Les Restaurations dans l'Europe postnapoléonienne (1814-1830). El proyecto ha consistido en confrontar las historiografías (Alemania, Bélgica, España, Francia, Países Bajos, Reino Unido, Rusia y Suiza), con la intención de encontrar tanto puntos de convergencia como de divergencia, extraer temáticas transversales y particularismos nacionales. Se trata en una primera etapa de revisitar las Restauraciones como un momento de "modernización política y económica": la expresión puede parecer paradójica porque va contracorriente de una historiografía largo tiempo fundada sobre la percepción del período como un tiempo de reacción absoluta. Pero se trata igualmente de volver sobre una lectura un poco militante de las resistencias a los regímenes restaurados, y de acotar, por ejemplo, los límites de la "internacional liberal" de los años 1820. Los campos de trabajo abiertos así se presentan tanto más prometedores cuando la internacionalización de la mirada sobre las Restauraciones en Europa se cruza con una renovación conceptual, apoyándose, por ejemplo, sobre la noción de transnacionalización. Entre diversidad de experiencias y diversidad de conceptos, la historia de las Restauraciones puede pretender igualmente una internacionalización extraeuropea interrogando la evolución de las sociedades coloniales comprometidas en el mismo momento en las guerra de independencia y en la definición de la idea de nación, como en caso de la América española. Multitud de perspectivas que demuestran, si es que hiciera falta, la actualidad de la Restauración.

Traducción al castellano a cargo de PeÑa VeróN

\section{Bibliografía de las obras citadas ${ }^{17}$}

Agulhon, Maurice, Le Cercle dans la France bourgeoise, 1810-1848. Étude d'une mutation de sociabilité, Paris, Armand Colin, 1977.

Allard, Sébastien (dir.), Paris 1820. Laffirmation de la génération romantique, Bern, Berlin et alii, Peter Lang, 2005.

Aprile, Sylvie, La Révolution inachevée, 1815-1871, Paris, Belin, 2010, coll. Histoire de France.

Aprile, Sylvie, Caron, Jean-Claude et Fureix, Emmanuel (dir.), La Liberté guidant les peuples. Les révolutions de 1830 en Europe, Seyssel, Champ Vallon, 2013.

Barjot, Dominique, Chaline, Jean-Pierre et Encrevé, André, La France au XIXe siècle, 1814-1914, Paris, PUF, 1995.

Bertier de Sauvigny, Guillaume de, La Restauration, Paris, Flammarion, 1955.

17. Solo se menciona la fecha de la primera edición. 
Bordet, Gaston, La Grande Mission de Besançon, janvier-février 1825. Une fête contre-révolutionnaire, néobaroque ou ordinaire?, Paris, Éditions du Cerf, 1998.

Bourguinat, Nicolas, Les Grains du désordre. L'É tat face aux violences frumentaires dans la première moitié du XIXe siècle, Paris, Éditions de l'EHESS, 2001.

Boutry, Philippe et Nassif, Jacques, Martin l'archange, Paris, Gallimard, 1985.

Boutry, Philippe, Prêtres et paroisses au pays du curé d'Ars, Paris, Les éditions du Cerf, 1986.

Bouyssy, Maïté, L'Urgence, l'horreur, la démocratie. Essai sur le moment frénétique français, 1824-1834, Paris, Publications de la Sorbonne, 2012.

Brejon de Lavergnée, Matthieu et Tort, Olivier (dir.), LUnion du Trône et de l'Autel ? Politique et religion sous la Restauration, Paris, Presses de l'Université Paris-Sorbonne, 2012. Bruyère-Ostells, Walter, La Grande armée de la liberté, Paris, Tallandier, 2009.

Caron, Jean-Claude, Générations romantiques. Les étudiants de Paris et le quartier latin (1814-1851), Paris, Armand Colin, 1991.

Caron, Jean-Claude, La France de 1815 à 1848, Paris, Armand Colin, 1993, coll. Cursus.

Caron, Jean-Claude, Les Feux de la discorde. Conflit et incendie dans la France du XIXe siècle, Paris, Hachette-Littérature, 2006.

Chaline, Jean-Pierre, La Restauration, Paris, PUF, 1998, coll. Que sais-je?

Christen-Lécuyer, Carole et Fureix, Emmanuel (dir.), «La Restauration revisitée», Revue d'histoire du XIXe siècle, n³5 -2007/2.

Craiutiu, Aurelian, Le centre introuvable, la pensée politique des doctrinaires sous la Restauration, Paris, Plon, 2006.

Darriulat, Philippe, La Muse du peuple. Chansons politiques et sociales en France, 18151871, Rennes, PUR, 2010.

Démier, Francis, La France de la Restauration (1814-1830). L'impossible retour du passé, Paris, Gallimard, 2012, coll. Folio histoire.

Duprat, Catherine, Usage et pratiques de la philanthropie. Pauvreté, action sociale et lien social, à Paris, au cours du premier XIXe siècle, Paris, Association pour l'étude de l'histoire de la sécurité sociale, 1996-1997, 2 vol.

Elleinstein, Jean (dir.), Histoire de la France contemporaine, t. 2, 1799-1835, Editions sociales - Livre Club Diderot, 1979.

Fureix, Emmanuel, La France des larmes. Deuils politiques à l'âge romantique (18141840), Seyssel, Champ Vallon, 2009.

Furet, François, La Révolution: de Turgot à Jules Ferry. 1770-1880, Paris, Hachette, 1988.

Goblot, Jean-Jacques, La Jeune France libérale. Le Globe et son groupe littéraire, 1824-1830, Paris, Plon, 1995

Goujon, Bertrand, Monarchies postrévolutionnaires, 1814-1848, Paris, Seuil, 2012, coll. Histoire de la France contemporaine.

Hantraye, Jacques, Les Cosaques aux Champs-Élysées. Loccupation de la France après la chute de Napoléon, Paris, Belin, 2005.

Jardin, André et Tudesq, André-Jean, La France des notables, 1815-1848, Paris, PointsSeuil, 1973, 2 vol., coll. Nouvelle histoire de la France contemporaine. 
Jarrige, François, Au temps des «tueuses de bras». Les bris de machine à l'aube de l'ère industrielle, Rennes, PUR, 2009.

Karila-Cohen, Pierre, L'État des esprits. L'invention de l'enquête politique en France (18141848), Rennes, PUR, 2008.

Lagrée, Michel, Mentalités, religion et histoire en Haute-Bretagne au XIXe siècle. Le diocèse de Rennes, 1815-1848, Paris, C. Klincksieck, 1977.

Langlois, Claude, Un diocèse breton au début du XIXe siècle. Le diocèse de Vannes, 18001830, Paris, Klincksieck, 1974.

Langlois, Claude, Le Catholicisme au féminin. Les congrégations françaises à supérieure générale au XIXe siècle, Paris, Le Cerf, 1984.

Laquièze, Alain, Les Origines du régime parlementaire en France (1814-1848), Paris, PUF, 2002.

Legoy, Corinne, L'Enthousiasme désenchanté. Éloge du pouvoir sous la Restauration, Paris, Société des études robespierristes, 2010.

Le Marec, Yannick, Les Temps des capacités. Les diplômes nantais à la conquête du pouvoir dans la ville, Paris, Belin, 2000.

Leroy, Michel, Le Mythe jésuite, de Béranger à Michelet, Paris, PUF, 1992.

Lignereux, Aurélien, La France rébellionnaire. Les résistances à la gendarmerie (18001859), Rennes, PUR, 2008.

Malandain, Gilles, L'introuvable complot. Attentat, enquête et rumeur dans la France de la Restauration, Paris, Éditions de l'EHESS, 2011.

Mazurel, Hervé, Vertiges de la guerre. Byron, les philhellènes et le mirage grec, Paris, Les Belles Lettres, 2013.

Mollier, Jean-Yves, Reid, Martine et Yon, Jean-Claude (dir.), Repenser la Restauration, Paris, Nouveau Monde, 2005.

Nagy, Laurent, D’une Terreur à l'autre. Théories du complot et nostalgie de l'Empire, 18151816, Paris, Vendémiaire, 2012.

Parent-Lardeur, Françoise, Lire à Paris au temps de Balzac. Les cabinets de lecture à Paris, 1815-1830, Paris, Éditions de l'EHESS, 1981.

Petiteau, Natalie, Lendemains d'Empire. Les soldats de Napoléon dans la France du XIXe siècle, Paris, La Boutique de l'Histoire, 2003.

Petiteau, Natalie, Écrire la mémoire. Les mémorialistes de la Révolution et de l'Empire, Paris, Les Indes savantes / La Boutique de l'histoire, 2012.

Picon, Antoine, Les saint-simoniens. Raison, imaginaire et utopie, Paris, Belin, 2002.

Ploux, François, Guerres paysannes en Quercy. Violences, conciliations et répression pénale dans les campagnes du Lot (1810-1860), Paris, La Boutique de l'Histoire, 2002.

Ploux, François, De bouche à oreille. Naissance et propagation des rumeurs dans la France du XIXe siècle, Paris, Aubier, 2003.

Robert, Vincent, Le temps des banquets. Politique et symbolique d’une génération (18181848), Paris, Publications de la Sorbonne, 2010.

Roquette, Antoine, Le Concordat de 1817. Louis XVIII face à Pie VII, Paris, Le Félin, 2010. 
Rosanvallon, Pierre, Le Sacre du citoyen. Histoire du suffrage universel en France, Paris, Gallimard, 1992.

Rosanvallon, Pierre, La Monarchie impossible. Histoire des Chartes de 1814 et 1830, Paris, Fayard, 1994.

Rosanvallon, Pierre, Le Peuple introuvable. Histoire de la représentation démocratique en France, Paris, Gallimard, 1998.

Rosanvallon, Pierre, La Démocratie inachevée. Histoire de la souveraineté du peuple en France, Paris, Gallimard, 2000.

Vidalenc, Jean, La Restauration, Paris, PUF, 1966, coll. Que sais-Je?

Voilliot, Christophe, La Candidature officielle. Une pratique d'État de la Restauration à la Troisième République, Rennes, PUR, 2005.

Waquet, Françoise, Les Fêtes royales sous la Restauration ou l'Ancien régime retrouvé, Paris-Genève, Droz, 1981.

Waresquiel, Emmanuel de et Yvert, Benoît, Histoire de la Restauration, 1814-1830. Naissance de la France moderne, Paris, Perrin, 1996.

Waresquiel, Emmanuel de, L'Histoire à rebrousse-poil. Les élites, la Restauration, la Révolution, Paris, Fayard, 2005.

Waresquiel, Emmanuel de, Un groupe d'hommes considérables. Les pairs de France et la Chambre des pairs héréditaire de la Restauration, 1814-1831, Paris, Fayard, 2006.

Zanone, Damien, Écrire son temps. Les Mémoires en France de 1815 à 1848, Lyon, Presses Universitaires de Lyon, 2006. 


\title{
Permanencia y mutaciones del Estado napoleónico bajo la Restauración de los Borbones, 1814-1830

\author{
Continuity vs. mutation in the Napoleonic State under the \\ Bourbons' Restoration, 1814-1830
}

\author{
Francis Démier \\ Université de Paris Ouest Nanterre-La Défense
}

Recibido: 25-VIII-2014

Aceptado: 1-X-2014

\section{Resumen}

El regreso de los Borbones en 1814, a pesar del agresivo programa de extrema derecha que trajo consigo, según el cual pretendía acabar con el aparato del Estado centralizado por considerarlo la fuente misma del "peligro revolucionario", no mermó en ningún caso el poder de una administración que había sido muy poco depurada. El realismo ultra rápidamente demostró su incapacidad para estabilizar la economía y la sociedad mediante un compromiso histórico que, sin embargo, fue rápidamente organizado por una tecnocracia compuesta por una fusión de los despachos de la Francia anterior a 1789 y los del episodio revolucionario e imperial. Entre lecciones de Turgot y de Corbert, el Estado se hizo el guardián y el tutor de un liberalismo económico y social que dotó de un nuevo impuso a la industrialización de Francia y a la formación de un mercado nacional protegido. Esta identidad modernizadora del Estado supo evolucionar. Sobrevivió al giro a la derecha de la vida política propiciado por Villèle y, para hacer frente a las dificultades que se encontró Francia en su modernización a partir de 1828, el Estado se propuso aprender de los "métodos ingleses" que hicieron evolucionar la rigidez de la administración napoleónica.

Palabras clave: Ultrarrealismo, liberalismo, Carta, Talleyrand, Villèle.

\begin{abstract}
The return of the Bourbons in 1814, despite the accompanying aggressive program of the extreme right-wing, intended to break the centralized state apparatus, considered to be the very source of "revolutionary danger", by no means involved a reduction in the power on an administration that has been poorly purged. Ultra-realism quickly
\end{abstract}


showed itself unable to stabilize the economy and the society by means of a historic compromise that was nonetheless quickly organized by a technocracy composed of an combination of the old pre-1789 France offices and those of the revolutionary and imperial times. Under the lessons of Turgot and Colbert, the State became guardian and supervisor of a type of economic and social liberalism that provided French industrialization with new vigour. It also fostered and the creation of a protected national market. This modernising identity of the State managed to evolve. It overcame the right-oriented turn of politics promoted by Villèle. In order to meet the challenges of the French modernization process from 1828, the State decided to mirror the "English methods", thus making the rigidity of the Napoleonic administration evolve.

Keywords: Ultra-realist, Liberalism, Charter, Talleyrand, Villèle.

La dramática caída del emperador en la primavera de 1814 provocó la sensación de que el hundimiento del Gran Imperio iba también a arrastrar al Estado y que las instituciones forjadas al hilo del episodio revolucionario estaban amenazadas. Los "realistas exaltados" estaban persuadidos de que Francia era una página en blanco sobre la que podían reescribir la historia desmantelando la maquinaria administrativa napoleónica que era el soporte de una sociedad nueva a la que odiaban. Muy pronto, desde el año 1814, pero de manera todavía más visible en el momento en que dispusieron de una mayoría política en la Chambre introuvable, su análisis se revelará totalmente equivocado. Más allá de su debilidad política, el proyecto ultra se aferró muy pronto al terreno de los intereses materiales. En la Cámara, diputados de extrema derecha sin gran cultura económica pudieron comprobar rápidamente su incompetencia en una situación financiera complicada y con la producción paralizada por la ocupación. Será el antiguo aparato del estado napoleónico, casi intacto, quien tome las riendas de la actuaciones.

\section{Hundimiento del Imperio y permanencia del Estado}

El primer ultrarrealismo (ultracisme) encontró sus raíces más virulentas en los grandes puertos y circuitos coloniales -Marsella o Burdeos-afectados por el bloqueo, mucho más que en la propiedad de la tierra más prudente y todavía impregnada del liberalismo fisiócrata. El núcleo ultra de 1815 no tuvo otra alternativa, para salvar sus propias posiciones económicas y el pacto colonial, que votar leyes proteccionistas exigidas como una "razón de estado" por las manufacturas de algodón, matriz del nuevo y dinámico capitalismo nacido durante la época imperial y sostenido por la administración ${ }^{1}$. El ultracisme pudo enton-

1. Fue Delhorne, el diputado de Saint-Quentin quien, desde 1816, impuso a los ultras de las plazas portuarias la lógica de las prohibiciones de algodones a cambio de una protección del azúcar de las colonias. La puenta en marcha de un poderoso Comite de los manufactureros y comerciantes reunidos, en Lille, Saint Quentin, Rouen, inspira esta política. 
ces comprobar sus límites en esta alianza obligada entre el vencedor y el vencido de la época napoleónica, ambos partidarios de ejercer un estrecho control sobre el mercado nacional, aunque los unos para exhibir su nueva pujanza y los otros para intentar preservar sus deterioradas posiciones.

Esta primera tentativa de "regreso al pasado" no tenía ninguna posibilidad de triunfar pues sus contradicciones eran fortísimas. Por ello la disolución de la Chambre introuvable, aconsejada al rey por Decazes, pero también por las potencias aliadas que compartían la idea de que los ultras iban a conducir a Francia de nuevo a la catástrofe, no tuvo grandes dificultades, así como la llegada en 1816 de una nueva mayoría favorable a la política moderada de los constitucionales que era también, entonces, la del rey.

Esta victoria rápida de una línea "modernizadora" se explica por el hecho de que en el contexto caótico que acompaña a la caída del Imperio y en el momento en que los sistemas políticos no ofrecían ya ningún punto de amarre, una fuerte maquinaria administrativa aseguró la transición entre los dos regímenes, el Imperio y la Monarquía. Antes incluso que fuera encontrado un nuevo consenso político en la opinión pública, en el seno del Estado se estaba organizado un nuevo ajuste entre las dos Francias, la de la Revolución y la del pasado monárquico.

En unas semanas, entre abril de 1814, momento en que Napoleón pierde la batalla de Francia, y julio de 1814, cuando Luis XVIII se instala en las Tullerías, el estado se reorganizó con una extraordinaria rapidez, cuando, en el terreno político, se dudaba incluso del contenido que había de darse al nuevo régimen. Esta rapidez del Estado para responder a la urgencia del momento es especialmente reseñable en el terreno económico que jugó un papel estratégico para definir los nuevos cimientos de una Francia, a partir de ahora, enfrentada a la ocupación de los ejércitos aliados, al pillaje de los recursos y al pago de una importante indemnización de guerra. En efecto, el punto de adhesión de los notables que esperan una dirección en este pasaje tormentoso es el del despegue de una economía castigada por el bloqueo y paralizada por la guerra y su secuela de tasas. La reorganización de la actividad económica parecía necesaria también para asegurar a Francia los recursos fiscales que le permitieran hacer frente a los gastos de la ocupación y a las pesadas indemnizaciones de guerra, que habían sido las condiciones para la evacuación del territorio y la redefinición de una política independiente de la vigilancia de los aliados.

Cf. Moniteur Universel, 23 septembre 1814, y también, "Les cotonniers français face à la contrebande sous la Restauration", en Fraude, contrefaçon et contrebande de l'Antiquité à nos jours, Genève, Droz, 2007. 
Muy pronto, en el seno de la administración, se impone también la idea de que si a partir de ahora Francia quiere superar el caos y convertirse en una gran potencia Europea, debe lanzarse rápidamente hacia la industrialización, a la manera de Inglaterra. Una nación ya no se impondrá entregándose a las armas, sino comportándose como Inglaterra, poniéndose a la vanguardia de la modernidad económica.

Sin embargo, si los tecnócratas colocados o confirmados a la cabeza del Estado actuaron tan rápido fue porque sus proyectos estaban ya listos para comenzar y habían madurado bajo la Revolución y el Imperio². Estos hombres escaparán a partir de ahora del despotismo napoleónico del que se habían ido alejando desde 1808 y serán favorables a un nuevo régimen en el que las decisiones puedan ser fruto de una reflexión y de un debate limitado a las élites cultivadas partidarias de la modernización de Francia de la que ellos se harán defensores. La nueva monarquía les encaja perfectamente en su versión constitucional.

Si bien los notables esperaban del Estado una dirección firme, por lo menos parecía necesario hacer algunos cambios en el organigrama de la decisión económica que había servido para relevar al despotismo napoleónico y a una política de conquista a escala europea ${ }^{3}$. La reforma administrativa más importante es la que desmanteló el gran ministerio de Manufacturas y Comercio creado bajo el Imperio para gestionar el gran entramado creado por el bloqueo. A partir de ahora el Estado se organizará a escala de las fronteras francesas de $1792^{4}$.

El 3 de abril de 1814, un decreto incorporó al ministerio de Hacienda el de Manufacturas y Comercio5. El 5 de abril, se tomó la decisión más radical para desmantelar la antigua administración, al quedar dividida, en adelante, entre el ministerio del Interior y el de Finanzas. Desde abril de 1814, la unidad administrativa, que simbolizaba a los ojos de la opinión pública la centra-

2. Cf. DÉmier, Francis, La France de la Restauration (1814-1830). L’impossible retour du passé, Paris, Gallimard, 2012, p. 123 y ss.

3. LeVASSEUR, Émile, Histoire du commerce, Paris, A. Rousseau, 1912, t. 1, p. 540.

4. Cf. "El Emperador quiso dotar de más homogeneidad a la máquinaria y aproximar los engranajes a su personas. Creó un ministerio de comercio, le atribuyó las aduanas, las manufacturas, los consulados y el consejo de decomisos. Los consulados y las manufacturas formaron simples divisiones del ministerio... asi se hallaba ya preparada la palanca administrativa del comercio y de la industria, igualmente dispuesta para sostener la lucha que ocupaba entonces todos los pensamientos del emperador y dirigir las fuerzas nacionales por las vías pacíficas del progreso, si, por una felicidad que no llegaría a producirse, nuestra vieja enemiga nos hubiera permitido dejar las armas". GOURAUD, Charles, Histoire de la politique commerciale de la France, Paris, Durand, 1854, p. 170.

5. Cf. Almanach royal, Imprimerie nationale, 1815. 
lización económica del Emperador, salta por los aires. Se creó el 16 de mayo de 1814 una dirección general de Agricultura, Comercio, Artes y Manufacturas bajo la autoridad del ministerio del Interior que es confiado a Louis Becquey. La dirección general de Aduanas, heredera del bloqueo, es suprimida, y la administración de aduanas y derechos colocada bajo la tutela de una dirección general de Contribuciones Indirectas confiada al conde Bérenguer, consejero de Estado, y esta dirección ligada a la de Hacienda ${ }^{6}$.

Aunque las medidas tomadas pudieron afectar a una administración segura de sus prerrogativas y preocupada por su función "estratégica" en la época del bloqueo continental, bajo la superficie de medidas de circunstancias se produce la continuidad del "aparato de Estado" napoleónico. La independencia, de facto, de la administración aduanera se surge del hecho de que a partir de ahora este servicio se regirá bajo la autoridad del director general de Contribuciones Indirectas a través de un director particular que tendría a sus órdenes cuatro administradores. Como Colin de Sussy y Ferrier, sus predecesores bajo el Imperio, Saint-Cricq, el nuevo director de Aduanas, fue el personaje clave de una administración muy centralizada que disponía de amplios poderes y se vinculaba de alguna manera con la tradición imperial ${ }^{7}$.

El hermano del rey, el conde de Artois, quiso acompañar la vuelta de la monarquía con promesas demagógicas sobre la supresión de los derechos reunidos, unos impuestos sobre el consumo considerados como vitales para la supervivencia de la administración. El poder tuvo pronto que dar marcha atrás y defender las necesidades del Estado en una declaración del rey del 10 de mayo de 1814: "El Estado tiene acreedores, funcionarios, ejércitos cuyos intereses nos son tan apreciados como los contribuyentes. El gobierno necesita todos sus recursos y, cuando están debilitados por los males de la guerra, no puede sacrificar una porción significativa de ellos sin asegurar un equivalente. Así pues, la salud del Estado exige que todas las leyes sobre impuestos existentes sean respetadas y mantenidas"8.

6. DÉMIER, Francis, Marché et nation dans la France de la Restauration, Thèse d'état sous la direction de Philippe Vigier, Université de Paris X, 1992, 2628 p. (cf. 2º capítulo).

7. "Luis XVIII no tenía más que mirar a su alrrededor, más que recordar la Francia que había abandonado en 1789 , más que considerar lo que volvía a ver en 1814 , para convencerse de los méritos de esta política. En torno suyo, por otro lado, toda una generación de administradores, de manufactureros, de agricultores... formada en la escuela del Imperio, estaban allí, en sus puestos, gracias a la Carta y a la libertad política que ésta había aportado mostrando la conducta a seguir, previniendo de las medidas equivocadas, y solicitando, provocando y haciendo triunfar las buenas. El rey felizmente era un hombre destacadamente atento y sensible, y ninguna de las lecciones del pasado se había perdido para él". GOURAud, Charles, Histoire de la politique commerciale..., p. 167.

8. Moniteur Universel, 11 de mayo de 1814. 


\section{La mano tendida de las redes de Talleyrand}

Desde el mes de abril de 1814, un pequeño grupo de hombres asegura la continuidad del poder del Estado entre el hundimiento del Imperio, la Tenencia general del reino ejercida de momento por el conde de Artois y el retorno del rey a París a comienzos de mayo. Algunos aparecen en los trampolines del poder, otros juegan un rol indirecto de consejeros, la mayor parte están ligados por redes de amistad, de solidaridad, que se remontan incluso a los años anteriores a la Revolución'.

En el primer rango del núcleo dirigente, se encuentra Talleyrand, omnipresente en la toma de decisiones durante de esta larga fase de transición ${ }^{10}$. En el centro de una excepcional red de relaciones y sucesivamente presidente del Senado, presidente del gobierno provisional, persona clave tanto en las combinaciones gubernamentales como en las negociaciones entre Francia y los aliados, y ministro de Asuntos Exteriores en el gobierno del 13 de mayo de 1814. Bajo su influencia gravitan otros personajes que nos interesan para delimitar los círculos de la toma de decisiones: el abad de Montesquiou, ministro del interior en el mismo gobierno, el barón Louis, nombrado ministro de Hacienda, el conde Beugnot, ministro del Interior el 3 de abril de 1814, después de Marina el 3 de diciembre de 1814, el conde Bérenger, consejero de Estado, Director general de Contribuciones Indirectas a partir de abril, el conde de Saint-Cricq, maître de requêtes, nuevo director de la administración de aduanas bajo la tutela del conde Bérenger, el conde de Hauterive, consejero de Estado, que en 1814 ocupaba un modesto puesto de archivero del ministerio de Exteriores después de haber sido redactor de 62 tratados políticos y comerciales de Francia, pero que, a la sombra de Talleyrand, jugará un rol de consultor muy escuchado ${ }^{11}$.

Entre estas personalidades se impondrá la figura del barón Louis cuyas convicciones y experiencia jugarán un papel capital ${ }^{12}$. En la década 1780, se formó alrededor de Talleyrand un circulo de intelectuales que será un laboratorio de ideas del nuevo liberalismo económico aplicado a la Hacienda y al Comercio. Louis, subraya Charles d'Audiffret, tuvo en aquella época "relaciones frecuen-

9. Cf. Almanach Royal, 1815 , p. 548 y CLINQUART, Jean, L'administration des douanes sous le Consulat et l'Empire, 1800 1815, AHAD, Paris, 1979, p. 239. Cf. también Archives Nationales, F 12 2491. A/ F 4. 1015 / F1b 1. 532.

10. Dupuis, Charles, Le ministère Talleyrand en 1814, Paris, Plon, 1919.

11. Lefebvre, Georges, La France sous le Directoire, Paris, Ed. Sociales, 1977, p. 685.

12. Sobre el barón Louis, cf. Marquis D'AUDIFFrET, Souvenirs sur le Baron Louis, Paris, 1841; Comte de SAINT-CRICQ, Eloge du baron Louis à la Chambre des pairs, 2 juin 1838; GUENA, Yves, Le baron Louis 1755-1837, Paris, Perrin, 1999. 
tes con economistas y sobre todo con el célebre Panchaud del que fue discípulo y amigo, elevando sus jóvenes ideas a la altura de los grandes sistemas"13. Panchaud, el banquero de Ginebra, tenía una reputación de mago en los asuntos financieros ${ }^{14}$. En casa de Talleyrand, en la calle de Bellechasse, Louis Panchaud, Mirabeu, Calonne, Dupont de Nemours se mostraban apasionados en el debate sobre los efectos del tratado del comercio de 1786 con Inglaterra.

Nombrado en 1787 en una de las 21 asambleas provinciales creadas por Brienne, Louis tras la estela de Talleyrand, estuvo muy ligado a Duport, jefe de filas de los Feuillants, polo de reagrupamiento de los "liberales" que volverán al poder en 1814. En febrero de 1793, Louis se reúne con Talleyrand en Inglaterra y hace una larga estancia al otro lado del Canal en la que se vinculó con las intrigas realistas, pero también con las actividades europeas de la banca Greffulhe et Montz. Es entonces cuando Louis estudió con mucha atención el sistema de crédito ingles. Pero Louis regresa a Francia tras el 18 brumario, favorecido por la protección de Mollien, otro discípulo de Panchaud y director de la Caja de amortización, después ministro del Tesoro en 1806. Reemplazado al frente de la Caja por su amigo Bérenger, Louis es nombrado administrador del tesoro, función en la que sus relaciones internacionales, en particular con los banqueros ingleses y holandeses, van a revelarse de gran utilidad para el Estado francés en la búsqueda de crédito internacional tras la caída del Imperio. Después de la dimisión de Talleyrand en agosto de 1807, Louis, aunque se mantuvo vinculado a la obra de restauración del Estado tomó, como su protector, sus distancias con una "aventura" napoleónica bastante alejada de los "razonables" objetivos de los notables ${ }^{15}$. En el momento del hundimiento del Imperio, Mollien, arrastrado por su compromiso político, deja la responsabilidad del Tesoro a su amigo Louis que se impone como el hombre perfecto para el cometido: "Era el que mejor podía mantener el orden que yo había decidido establecer en la Hacienda. Tenía confianza en los servicios que podría prestar a Francia" 16 .

Será Louis, quien con Talleyrand, explique al Zar la necesidad del retorno de los Borbones. En el gobierno provisional que tiene a Dupont de Nemours como secretario, Louis será responsable de Hacienda, Tesoro, Manufacturas y Comercio. El 13 de mayo es nombrado ministro de Finanzas en la nueva con-

13. D'AUDIFFret, Charles, Système financier de la France, Paris, Paul Dupont, 1863, t. 3, p. 57

14. BRUGUiere, Michel, La Première Restauration et son budget, Genève, Droz, 1969, p. 211.

15. BrUguiere, Michel, Pour une renaissance de l'histoire financière, XVIIIe-XXe siècle, Paris, Comité pour l'histoire économique et financière de la France, 1992, p. 235.

16. Comte Mollien, François Nicolas, Mémoires d’un ministre des Finances, 1780-1815, Paris, Fournier, 1845, t. 1, p. 123. 
figuración ministerial. Será él quien llame a Bérenger y a Becquey e imponga claramente su sello a la nueva política del Estado. Con este equipo, llega al poder una generación que ha vivido una experiencia muy rica, a menudo europea. Son hombres cultivados, que han estado en contacto con Inglaterra, sus economistas y los medios cosmopolitas de las finanzas europeas.

El abad de Montesquiou, ministro del Interior tendrá bajo su tutela la administración económica. De temperamento muy diferente al de Louis, recorrerá sin embargo un itinerario parecido al del ministro de Hacienda. Como Louis, ligado a Talleyrand, el abad de Montesquiou jugó un papel importante durante el Directorio, momento en que se convirtió en el representante de Luis XVIII en París. Conciente de los peligros que representaba un espíritu reaccionario ciego, tomó el mando entre los monárquicos constitucionales y mantuvo estrechas relaciones desde entonces con Becquey, otra figura importante entre los "economistas" del equipo dirigente de 1814.

Reuniendo bajo su autoridad la administración de Aduanas y la de Derechos reunidos, el Conde Bérenger es uno de los "hombres influyentes" más señalados de la administración económica ${ }^{17}$. En 1814 será Louis quien llame a Berenguer, su íntimo amigo, al Consejo de Estado. La continuidad de su carrera, del Imperio a la Restauración, es impresionante. Conde del Imperio en 1808, Comendador de la Legión de Honor en 1815, Par de Francia en 1832. Esta continuidad es también la del liberalismo moderado burgués, de aquí en adelante inevitable en toda solución política. Puso a prueba el respeto del Emperador por su oposición a la extensión de la guerra a partir de 1808 y su inquietud expresaba con claridad la fractura cada vez más amplia entre los notables y el poder imperial. Su figura representa, en la órbita de los "responsables" de la economía en 1814, el legado espiritual de 1789.

El peso de Louis Becquey es también muy importante en $1814^{18}$. A la cabeza de la Dirección General de Agricultura, Comercio y Artes, es el responsable directo de la definición de la política económica. Será en la víspera de la Revolución cuando Becquey se apasione por la economía política. Elegido en la Asamblea Legislativa en septiembre de 1791, Becquey se adhiere plenamente a la Revolución pero quiere mantenerla en los limites trazados por las declaraciones de la Asamblea constituyente. La guerra y sus peligros de radicalización política le hacen inclinarse hacia el rey. Permaneció oculto durante el Terror y no reaparecerá hasta Thermidor. Miembro de los 500, contribu-

17. CLINQUART, Jean, L'administration des douanes en France sous la Restauration et la monarchie de Juillet, Neuilly, Association pour l'histoire de l'administration des douanes, 1981, p. 41.

18. Cf . Archives Becquey, Bibliothèque Thiers. 
ye a definir la opción realista constitucional bajo el Directorio. Es en esta época cuando organiza con Royer Collard, Quatremère de Quincy, Vaublanc, un "pequeño comité para preparar las bases de un acercamiento a los borbones y a la nación". Estas personalidades toman contacto con Luis XVIII que dará su confianza a este grupito que, según Beugnot ${ }^{19}$, debía preparar una "restauración del trono que fuera no el triunfo de un partido, sino la señal de la reconciliación de todos los franceses tanto tiempo divididos". El giro "conservador" del Imperio acerca a Becquey al poder que le nombra consejero de la Universidad. En mayo de 1814, tras la caída del Imperio, es el abad de Montesquiou quien habla de Becquey y de Royer Collard a Luis XVIII. Los amigos de "la agencia de París" acceden a puestos de responsabilidad: Becquey será nombrado director general de Agricultura, Comercio y Artes y Manufacturas, Royer Collard, director de la Biblioteca y Quatremère de Quincy situado al frente de los Museos reales.

Responsable de la aduana, que es la administración estratégica en el momento en que se deshacen los contornos políticos de la Francia imperial, Ferrier, un doctrinario del bloqueo, deja su puesto a Pierre Laurent Barthélémy de Saint-Cricq, "encargado provisionalmente de la administración de las aduanas", que después será designado en el nuevo puesto de Director de la Administración de aduanas bajo la tutela de Bérenger encargado de las contribuciones indirectas ${ }^{20}$. Procedente de la pequeña nobleza del Béarn en dificultades económicas, Saint-Cricq se adhiere al Imperio. En 1810 había sido director de asuntos aduaneros de los departamentos anexionados al Imperio, y en 1811 fue nombrado oficial de la Legión de Honor. Menos señalado que Ferrier por su participación en la maquinaria administrativa napoleónica, Saint-Cricq mantuvo contactos con los medios partidarios de la vuelta de los borbones. En 1814 su dinamismo y su capacidad extraordinaria de análisis eclipsaron rápidamente a otros administradores. Saint-Cricq tomó la pluma para redactar diversas ordenanzas que tuvieron por efecto, poco a poco, la liberalización de la política económica ${ }^{21}$.

El cambio en la administración se limita, de hecho, a la cabeza de la institución; el cuerpo de funcionarios, incluso los puestos de responsabilidad, sobrevive muy bien en 1814 al hundimiento del Imperio ${ }^{22}$. Esta permanencia, que

19. Comte beugnot, Jean-Claude, Vie de Becquey, Paris, Firmin Didot, 1852, p. 143.

20. Cf. gouraud, Charles, Histoire de la politique commerciale..., t. 2, p. 167.

21. ROEDERER, A.M., Etudes sur les systèmes opposés du libre-échange et de la protection, Paris, Guillaumin,1851, p. 17.

22. costaz, Claude Anthelme, Histoire de l'administration en France, de l'agriculture, des arts utiles du commerce, des manufactures, des subsistances, des mines et des usines, Paris, Huzard, 1842 , t. 3. 
atestigua el organigrama de los ministerios ${ }^{23}$, podía ofrecer a los notables la garantía de una deseada continuidad del aparato estatal cercano a los intereses fundamentales de la burguesía. El corazón del estado continua vetado a las aspiraciones de la derecha reaccionaria. Sin embargo, en la Dirección General de Agricultura, Comercio, Artes y Manufacturas, Becquey toma pronto conciencia del obstáculo que representaba la inercia de la administración imperial para la puesta en marcha del proyecto liberal que creía indispensable para relanzar la economía. Beugnot vuelve a sus métodos "originales" para renovar a los hombres clave de la máquina administrativa: "Su primer empeño fue informarse, a través de los empleados del antiguo ministerio de Comercio, de los hombres que pudieran plegar sus ideas y hábitos al nuevo espíritu que debía animar a la administración. Pronto se dio cuenta de que estos empleados, fuesen los que fuesen sus méritos y sus conocimientos, formados en el culto al bloqueo continental, a las licencias... opondrían resistencia, o una forma de inercia equivalente, a las reformas que la situación del comercio de Francia iba a necesitar. Buscó fuera un hombre dispuesto a secundarle en la puesta en marcha de estas reformas y que poseyera las aptitudes y experiencia necesarias, suficientemente bregado para superar los obstáculos que esperaba encontrar en su propia administración. Su búsqueda se mantuvo durante mucho tiempo sin éxito. Finalmente un banquero de París, Dandré, le señala en Génova, a un hombre muy distinguido y profundamente versado en materias comerciales, Emile Vicens, procedente de la burguesía protestante de Nîmes, instalado en la banca de Ginebra donde se había convertido en juez del tribunal de comercio, miembro de la cámara de comercio y del consejo municipal" ${ }^{24}$. Relacionado con los medios financieros europeos, economista reputado, gran especialista de derecho comercial, Vincens era profesor de "ciencias comerciales" en la Academia de Génova cuando Becquey le llama y le nombra jefe de la oficina de Comercio de la dirección general del Comercio, Agricultura y Subsistencias que acababa de crear, antes de convertirse en director de la misma, carrera en línea recta hasta la monarquía de Julio que le hizo consejero de Estado.

\section{Una tecnocracia liberal al frente del Estado}

Mientras que un estudio "inmediato" de las ordenanzas de la primavera de 1814 deja la impresión de improvisación y de una política hecha a impulsos en una coyuntura incierta, teniendo en cuenta las personalidades que ocupan los puestos claves del poder y de la administración, puede descubrirse, si no un pro-

23. Cf. Almanach royal, 1815.

24. Comte Beugnot, Mémoires du Comte Beugnot, Paris, Dentu, 1868, p. 34. 
grama ya definido sí al menos la existencia de una red coherente en el momento en que toma las riendas de la maquinaria estatal.

Estos hombres pertenecen prácticamente a la misma generación. Tienen entre 20 y 30 años al comienzo de la Revolución. Incluso si son descendientes de un medio aristocrático, es la Revolución quien les precipita a la vida política y todos pertenecen ideológicamente, sino sociológicamente, a una burguesía que se adhiere plenamente a los principios de 1789. Todos, sin embargo, buscarán desde 1791 el modo de fijar la evolución de Francia sobre esos cimientos primitivos. Rechazando la idea democrática, la Republica, muchos han pertenecido al grupo de los Feuillants que parece resucitar en 1814. Hostiles a una radicalización revolucionaria a partir de 1792, emigran o se esconden. Pero la emigración no significa para ellos en absoluto la ruptura con los ideales de la nueva sociedad. La emigración es también la continuación de una experiencia cultural cosmopolita como lo han sido las Luces y la experiencia de la altas finanzas con sus ramificaciones europeas. Desde 1792, han buscado la estabilidad en el marco de una monarquía constitucional. A partir de 1808 para algunos, de 1812 para otros, la adhesión al Imperio se convierte en distancia o ruptura y representan perfectamente la inquietud de los notables tradicionales ante del espíritu aventurero del Emperador. Su prudencia burguesa los confina a la revuelta discreta, a la intriga de salón o a la política de espera.

En 1814 llegan al poder con una rica cultura, pero también con una experiencia política que les incita al pragmatismo. No habiéndose nunca alejado de responsabilidades políticas, saben que Francia ha cambiado y temen los antojos reaccionarios tanto como la deriva revolucionaria. Beugnot, evocando la personalidad de Becquey, a la búsqueda de un "justo medio" económico, da una definición muy sutil de esta asociación entre la cultura y la experiencia propias de una generación enfrentada a la reorganización económica y social más allá de los extraordinarios cambios de la Revolución y el Imperio: "La lectura asidua de escritos de Turgot, de Necker, de Adam Smith, sus entrevistas con Dupont de Nemours, sus trabajos en la Asamblea legislativa, donde frecuentemente hacía de portavoz del comité de Hacienda del que formaba parte, las operaciones de banca, a las cuales se había dedicado cuando buscaba en los primeros tiempos del Imperio útiles ocupaciones, le habían servido para aprender lo que había de cierto y aplicable en las teorías tan controvertidas sobre la creación, la circulación y el consumo de la riqueza. Si bien mostraba conocimientos variados y extensos en esta materia, era evidente que la ciencia no dominaba el carácter del verdadero administrador cuyas opiniones se forjan a la luz de la experiencia más que sobre la lectura y la meditación abstracta” 25 .

25. Ibid., pp. 37. 
Lo que se dice con justicia para Becquey podría servir también, con algunos matices, para los otros grandes tecnócratas que toman la dirección económica de Francia en $1814^{26}$. Si algunos como Louis o Becquey pasaron por los negocios, esto no quiere decir que su liberalismo sea el del emprendedor o el de Jean Baptiste Say. La empresa para esta pequeña élite en el poder -a excepción quizás de Chaptal que es, antes que nada, un industrial- es sobre todo la banca y muy poco la industria. La economía política, incluida la defensa de los principios fundaméntales del liberalismo, es para ellos una ciencia de gobierno. No es cuestión de pensar que se trata de un juego de intereses privados y que a su nivel solo puede dirigirse el desarrollo. El Estado es el único que tiene las llaves de una visión sintética de la actividad económica que prima sobre el pluralismo confuso de los intereses particulares: "Cada cámara de comercio -precisaba Becquey en una circular administrativa- solo puede ocuparse de lo que le es más familiar, de lo que le afecta más de cerca. El gobierno es quien le corresponde elaborar un conjunto a partir de los elementos que reúna... en mis oficinas podremos hacer con todo ello un cuerpo completo"27.

Bajo la responsabilidad del barón Louis, en Hacienda, será Louis Becquey, nombrado director general de Agricultura, Comercio y Artes y Manufacturas, quien formule, tras el 6 de junio de 1814, en una larga circular dirigida a las cámaras de comercio, el programa de modernización y de reconstrucción de Francia que esta nueva tecnocracia liberal quiere llevar a buen puerto. No se trata para ellos de copiar a Inglaterra, a la que conocen bien, ni a sus economistas, a los que han leído mucho ${ }^{28}$. La vía francesa hacia el liberalismo no es la de Jean-Baptiste Say cuya influencia se limita a los salones. Su proyecto sintetiza de manera original la cultura económica de Turgot y la de Colbert quien será su mayor referencia desde un punto de vista operativo. Blanc de Volx, un economista, declaró entonces: "Colbert creó todo y transmitió a Francia el secreto de su pujanza... su genio, sus planes y sus grandes acciones le han convertido en inmortal" 29 .

26. Cf. GIRARD, Louis, Les Libéraux français, Paris, Aubier, 1985, p. 60.

27. BECQUeY, Louis, A Messieurs les membres composant les Chambres de commerce du royaulme "Direction générale du Commerce et des Arts et Manufactures, 6 juin 1814, Archives nationales, F 12/ 633. Cf. también DÉMIER, F., Histoire de la Chambre de commerce de Paris (la Monarchie constitutionnelle 1814-1848), Genève, Droz, 2003, p. 234.

28. Cf. CHALine, Jean-Pierre, "Modèle ou rivale? L'Angleterre vue par les Rouennais du XIXe siècle", Etudes Normandes, ${ }^{\circ} 1$, pp. 53-59; stearns, Peter, "British Industry through the Eyes of French industrialists, 1820-1848", Journal of Modern History (1965) pp. 50-61; GURY, Jean, Etudes comparatives sur l'image de la Grande Bretagne et les influences britanniques en France spécialement entre 1760 et 1830, Thèse Université de Paris IV, décembre 1988; CAMERON, Rondo, "Was England really suprior to France? Review article", Journal of Economic History décembre, 1986, p. 103.

29. BLANC DE VOLX, Jean, État commercial de la France au commencement du XIXe siècle ou du commerce français, de ses erreurs et des améliorations dont il est susceptible, Paris, Teutel 


\section{El Estado regulador del mercado}

Desde 1814, el poder ha hecho la elección de un liberalismo modulado, encuadrado en la herencia política y los contornos geográficos de la nación nacida desde la Revolución hasta el Imperio. La fórmula es simple y eficaz para animar a los emprendedores: la mayor libertad en el interior, la mayor protección hacia el exterior. En el marco político de la nación, la libertad esta asegurada al emprendedor. Pero se trata también de una política social porque apuesta por movilizar brazos y dar trabajo a escala nacional prohibiendo la entrada de trabajadores extranjeros. La elección es juiciosa porque Francia puede aprovechar un mercado de 30 millones de consumidores y porque es claro que este repliegue táctico debe servir para reconquistar el mercado internacional que no debe ser abandonado a favor de Inglaterra. Una revolución industrial comenzada a final del Antiguo Régimen y seguida activamente bajo el Imperio va a poder, de aquí en adelante, progresar a un ritmo mucho más sostenido.

Por etapas, bajo el gobierno de los constitucionales de 1816 hasta el giro de 1820, el aparato estatal francés sostiene, en efecto, esta política económica y social liberal. Hay muchos ejemplos. Desde 1814, comienza a imponer su proyecto proteccionista a pesar de las presiones ejercidas por los intereses económicos de las grandes empresas que desean emanciparse inmediatamente de las restricciones de la herencia imperial. Pone todo su interés a favor de las industrias algodoneras, persuadido de que la base del algodón es la llave del desarrollo de un capitalismo moderno. Por el contrario comienza a rechazar la ofensiva de los productores de carbón y de hierro que desean disponer de las mismas ventajas mientras que en los despachos se consideran como semi-productos y "alimentos de la industria". Es a partir de ahora cuando los despachos van a jugar un rol esencial fijando, mediante arbitrajes complejos, un nuevo consenso nacional capaz de equilibrar todos los sectores de una economía moderna todavía muy atomizada.

Frente a estas luchas de intereses se reafirma un poder económico estatal nuevo $^{30}$. Las imprecaciones de la derecha contra los "funcionarios" del Imperio, tienen muy poca influencia sobre los equipos que sabrán demostrar rápidamente que Francia no podía llevar a cabo la economía de los que estaban "capacitados" para administrar sus asuntos económicos. Bajo el gobierno de Richelieu se elaboró una dialéctica muy moderna del Estado y de los intereses particula-

et Würtz, 1803, p. 37; CROUZET, François, De la supériorité de l'Angleterre sur la France. L'économique et l'imaginaire (XVIIIe siècle-XXe siècle), Paris, Perrin, 1985.

30. Cf. VON THADDEN, Rudolf, La centralisation contestée. L'administration napoléonienne, enjeu politique de la Restauration (1814-1830), Paris, Acts Sud, 1989. 
res. Se otorgó a las cámaras de comercio un papel importante para dar a conocer las aspiraciones de los medios económicos locales y las comisiones parlamentarias se encargaron de negociar con los "despachos" la naturaleza de los compromisos que eran necesario alcanzar.

La administración de la monarquía según la Carta está comprometida desde 1814 en asegurar la construcción de una economía nacional limitando la lógica del mercado a las fronteras de Francia. Pero el otro objetivo de las oficinas de Louis, y después de Corvetto, era asegurar la victoria de la economía de mercado en el interior del territorio nacional. Ninguno de los altos funcionarios del Estado colocados en los despachos dudaba entonces de que el progreso de la economía, pero también el de la civilización moderna, encuentra su raíz en el espíritu de empresa y las reglas del mercado ${ }^{31}$. Así pues el ministro del interior encargado de las grandes líneas de la economía intervino enérgicamente para bloquear todos los intentos de restablecer las corporaciones que se habían hecho eco de las reivindicaciones del "comercio establecido" contra la desreglamentación surgida del periodo revolucionario ${ }^{32}$. Al contrario, la administración consideró necesario establecer nuevas normas para una "policía" de la industria y del comercio para que esto no se hiciera en el nivel de los oficios, sino que la competencia permaneciera en manos del Estado. Es esto lo que dió a las cámaras de comercio, a las cámaras consultivas, a los tribunales de comercio, que constituyen una bisagra, un vínculo mucho más importante entre los productores y el Estado. Es en su seno, y en relación con las oficinas y los Consejos de las Manufacturas y del Comercio, donde se irán definiendo progresivamente las noticias sobre regulaciones del mercado herederas del episodio revolucionario.

La nueva Cámara de Comercio de Paris constituye un ejemplo de esta nueva articulación entre el Estado y sus productores. Una quincena de "cónsules", bajo la vigilancia estrecha del prefecto del Sena, "presidente nato" de la Cámara, elaboran una doctrina económica liberal de acuerdo con las exigencias del aparato estatal. La Cámara misma inaugura un tipo de institución original en la que el Estado confía una parte de su actividad a agentes privados, procedentes del mundo de los negocios y de las manufacturas, pero gozando del estatuto de institución pública, teniendo como único interlocutor al Estado y disponiendo de medios fiscalizados. Esta "descentralización" del Estado en los orígenes de la Cámara, un Estado que no quiere multiplicar los funcionarios

31. DÉMIER, Francis, Marché et nation dans la France de la Restauration, Thèse d'Etat, Université de Paris X, 1992, p. 230 y ss.

32. LEVACHER-DUPLESSIS, M., Requête au roi et mémoire sur la nécessité de rétablir le corps de marchands et les communautés de des arts et métiers, Paris, Smith, 1817, p. 21. 
para conocer los resortes de la actividad económica y orientarla, no estuvo exenta de tensiones. Pero sus miembros siempre consideraron que los poderes públicos debían dirigir todas sus fuerzas a impedir cualquier marcha atrás hacia la economía de privilegio impidiendo la reaparición de monopolios, controlando las nuevas "asociaciones" de capitales y evitando las peligrosas derivas especulativas.

Sobre estos terrenos tan diferentes como "la cuestión del grano" o la puesta en marcha de importantes planes de obras públicas, se impuso progresivamente una estrecha articulación entre lo público y lo privado ${ }^{33}$. En $1820 \mathrm{Bec}-$ quey, respaldado por un importante ingeniero de puentes, Joseph Dutens ${ }^{34}$, publicará un Rapport au Roi donde proponía la puesta en marcha de un inmenso programa de acondicionamiento de 126 canales y ríos que totalizaban 25.718 kilómetros y cuyo enorme coste para la época se elevaba a 1108 millones de francos. Becquey, convencido de que el Estado no tenía vocación de convertirse en emprendedor, deseaba que el programa fuese asumido globalmente por empresas privadas, tan solo sugería, en la medida en que el coste era excepcionalmente elevado, que el Estado estimulara a lo privado por medio del aporte de subvenciones. Estos grandes tecnócratas e ingenieros que encarnan la pujanza del Estado legado por el episodio imperial, nunca tuvieron otra idea que confiar a las empresas privadas la realización del programa una vez que se hubiera trazado la armadura de redes y definido las técnicas necesarias para llegar a buen puerto. Fue porque este amplio programa chocó con la imposibilidad de las empresas privadas de poner en marcha este tipo de proyectos lo que decidió al Estado a construir él mismo la red. Sin embargo el Estado aseguró, a cambio de financiación privada, una concesión para la explotación de peajes a un consorcio de grades bancos. Las compañías financieras acreedoras del Estado fueron autorizadas entonces a la emisión de acciones basadas en los futuros beneficios para aportar el capital necesario ${ }^{35}$.

Este plan de Becquey, podía parecer la expresión de una solución estática para el desarrollo francés, la solución añorada por el pujante cuerpo de ingenieros de caminos y puentes. En realidad el Estado siempre había deseado, de

33. Cf. Skinner, S., The Market and the State. Essays in Honour of Adam Smith, Oxford, Clarendon Press, 1976; FAZY, James, Principes d'organisation industrielle pour le déploiement des richesses en France, Paris, Malher, 1830, p. 249; DuPuit, Jules, De la mesure de l'utilité publique Paris, 1844 et aussi De l'influence des péages sur l'utilité des voies de communication, Paris Guillaumin, 1849.

34. DUTENS, Joseph, Analyse raisonnée des principes fondamentaux de l'économie politique, Paris, Bachelier, 1804.

35. GEIGER, Reed, Planning he French Canals, Newark, University of Delaware Press, Denver, 1984. 
acuerdo con sus propios principios, confiar a lo privado la construcción de la red. Es la empresa privada quien se muestra débil y el Estado quien puede entonces aportar al aparato económico una infraestructura útil al capitalismo francés.

El problema del mercado nacional de grano se produjo de manera aguda tras las cosechas de 1816 y $1817^{36}$ que fueron desastrosas y que hicieron reaparecer los fantasmas de las hambrunas del Antiguo Régimen ${ }^{37}$. En un momento en que el Estado, a la manera clásica, desechaba el juego del mercado para fijar el precio por temor a los motines del trigo, el gobierno, a iniciativa de Lainé, ministro del Interior, defendió con fuerza los principios del liberalismo en materia de subsistencias y el rechazo de una política intervencionista que había sido la de la Revolución y del Imperio ${ }^{38}$.

Los despachos se contentaron con dar seguridades y ánimos, y Lainé, que quería hacer de la libertad de comercio del grano el símbolo de su adhesión a los principios del liberalismo, intentó por todos los medios favorecer las importaciones, clave para el nuevo desarrollo del negocio internacional del grano destruido por las guerras napoleónicas. "El pueblo aborrece en general a los que se ocupan del comercio de granos sin reflexionar que si esta no fuera la profesión de algunos particulares no se podría aprovisionar a las grandes ciudades y que el precio del pan sería más elevado de lo que es. Es necesario protegerles contra este odio, porque su actividad, procurando subsistencia a los locales, presta un servicio que la administración, a pesar de su buena voluntad, no podría realizarla de manera tan eficaz" ${ }^{\prime 39}$. El antiguo prefecto, Chaillou des Bars, es buen ejemplo de este "compromiso" del gobierno en una dirección liberal: "Es necesaria fuerza y energía en el gobierno, en 1816, para no dejarse llevar por los deseos irresponsables de la multitud que asocia el alto precio del grano con acciones culpables. Hemos proclamado alto y rotundamente el reconocimiento que debemos a la administración por su rechazo absoluto hacia todas las medidas que habrían perjudicado el libre transporte de las subsistencias"40.

36. Cf. Bourguignat, Nicolas, Les grains du désordre. L'Etat face aux violences frumentaires dans la première moitié du XIXe siècle, Paris Editions de l'EHESS, 2001.

37. VIARD, Paul, "La disette de 1816-1817, particulièrement en Côte d'Or", Revue Historique (1928), pp. 95-118 ; GUENEAU, Louis, "La disette de 1816-1817 dans une région productrice de blé: la Brie", Revue d' Histoire Moderne (1929), pp. 18-46.

38. DENAIS, Étienne, Histoire des l'échelle mobile des céréales en France, Paris, Larose, 1901.

39. COSTAZ, Claude Anthelme, Histoire de l'administration en France, de l'agriculture, des arts utiles, du commerce, des manufactures, des subsistances, des mines et des usines, Paris, Huzard, 1842, t. III, p. 56.

40. CHAILlOu DES baRS, Essai historique et statistique sur la législation des grains, Paris Didot, 1820 , p. 83. 
La redefinición de las relaciones entre el Estado y el mercado se impone con la creación, el 28 de abril de 1816, de una nueva Caja de amortizaciones cuya vocación era consagrar la dotación recibida regularmente del gobierno a la extinción progresiva de la deuda del estado. Su objetivo era al mismo tiempo, restablecer el crédito público y desarrollar el mercado de la deuda, para así consolidar la confianza, teniendo a la Caja a resguardo de eventuales tentativas del propio Estado. La particularidad de la institución será mantenerse a distancia del gobierno, cuya tutela se ejercía tan solo por el nombramiento de su director.

Esta línea política, que constituye la definición de un aparato de Estado moderno adaptado al progreso de una economía capitalista, fue profundamente afectado por el giro de 1820 ¿Explicaría, entonces, el fracaso de los constitucionales y la llegada progresiva con el gobierno de Villèle de una inflexión derechista la mecánica de una crisis que conduciría a la revolución de 1830? La respuesta debe ser matizada.

\section{Villèle, ¿una inflexión conservadora?}

No podemos asimilar al gobierno de Villèle con el regreso de los ultras de la Chambre introuvable. Villèle, que era hostil a la Carta, hostil al aparato del Estado napoleónico centralizado, que a sus ojos era la expresión misma de la Revolución y del despotismo, ha cambiado. Ahora está convencido de que el futuro de la monarquía solo se podrá reconstruir con la Carta y ha descubierto que las reivindicaciones de la aristocracia territorial a favor de un poder local contra el Estado centralizado le privarían en un instrumento indispensable para realizar su política.

El gobierno de Villèle es sin embargo, la expresión de una reacción política de la aristocracia departamental confrontada a una bajada brutal de la renta territorial con la llegada de los granos rusos y más profundamente de una crisis de identidad de esa nobleza que tiene el sentimiento de haber hecho mercadeo con el compromiso histórico de la Carta. A esta crisis, Villèle intenta responder dando a esta aristocrática, fuertemente enraizada en la tierra, un rol hegemónico en la vida política, ya que es la única que puede preservar un sistema de valores tradicionales y hacer respetar el orden en la pirámide social. Pero Villèle está convencido que no es posible expulsar a la burguesía de los asuntos del Estado, y tampoco lo desea. Contrariamente a muchos otros ultras, él no es hostil a los esfuerzos hechos a favor de la industria nacional. Su objetivo último no es lanzarse a un enfrentamiento con la clase media, idea acariciada por muchos ultras, sino la de buscar un compromiso con la burguesía: "Yo nací -dijo- para el fin de las revoluciones". 
Esta política, que pasa por una ley de indemnización a los emigrados, los "millones de emigrados", y algunas medidas para consolidar a la gran propiedad a través de las sucesiones, tendió, sobre todo, a extender el proteccionismo aduanero al sector agrícola, que hasta entonces no se había beneficiado más que muy discretamente. Para Villèle era una respuesta necesaria a la reacción "ultra" de los años 20 que se había presentado como la expresión de un malestar profundo de los propietarios de la tierra amenazados por la pérdida de influencia y, a la vez, por el dinamismo de las manufacturas y el debilitamiento de unas rentas que, según su parecer, no estaban dirigiendo sus pasos hacia el beneficio.

El estado bajo Decazes, había apostado por el desarrollo de un gran negocio capitalista organizado, único capaz, según él, de responder de manera anticipada a los precios elevados y a las hambrunas y no otorgaba ninguna confianza a los proyectos de los propietarios de tierras partidarios, en el marco de un proteccionismo agrícola, de crear reservas de grano confinadas en el ámbito de un mercado interior aislado. La resistencia de los Despachos a la puesta en marcha de un plan que estaba impulsado por la extrema derecha decidirá a los ultras a obtener del gobierno de Villèle una "depuración" bastante profunda de las direcciones del ministerio del interior encargado de la propiedad de la tierra. En 1821, Labiche, que estaba al frente de la división de Subsistencias, fue jubilado. Los despachos de su división fueron entonces reunidos a la tercera, dirigida por Fauchet y llamada desde entonces División de Comercio, Artes y Manufacturas, Agricultura, Haras, Subsistencias y Pesos y Medidas. Pero, Fauchat y Vincent, al frente de esta nueva división se opondrán a hacer nuevas concesiones a los propietarios ${ }^{41}$. En 1822 de Castelbajac, un ultra, fue colocado a la cabeza de Agricultura. Sin otra competencia que su compromiso político con el ala derecha de la Cámara, de Castelbajac retira a Fauchat y a Petit y coloca a Durand, Luchaire y Prévost al frente de los Despachos. El deslizamiento a la derecha de la administración termina con el nombramiento de Sirieys de Mayrinhac, diputado del Lot y ganadero, en la dirección general de la administración del Comercio, Artes y Manufacturas y Agricultura, cambio acompañado de una nueva depuración de competencia en los Despachos ${ }^{42}$.

La victoria política del partido agrario, no garantizaba una victoria económica. Ninguna medida aduanera, como había advertido desde hacia tiempo la administración, era capaz, de forma inmediata, de hacer subir el precio del grano. Acompañados de fortísimas variaciones regionales que mostrarán

41. Cf. Almanach royal, op. cit., 1822.

42. Cf. mauguin, C., Etudes historiques sur l'administration de la l'agriculture en France, Mémoires publiées par la Société d'Agriculture de France, Paris 1876, t. 2, 147. 
lo ilusorio de un mercado nacional coherente, los precios permanecieron bajos. Solo a partir de 1827 los precios subirán para alcanzar su cota más alta entre 1830 y 1833. Los circuitos internacionales de cereales fueron reducidos a la mínima expresión y el negocio se vio forzado a contorsiones absurdas para imaginar circuitos capaces de franquear el paso a los trigos rusos evitando los riesgos del fraude. Esta evolución que no afecta directamente al sector manufacturero desequilibra frecuentemente un aparato del Estado que había encontrado una coherencia muy grande durante el período de los constitucionales. El retorno de la coyuntura económica a partir de 1826 no hizo más que amplificar los problemas para abocar en noviembre de 1827 a la derrota electoral de Villèle y a su exclusión.

\section{Frente a la crisis, la tentación de los "métodos ingleses"}

El episodio Martignac, llamado al gobierno después de la salida de Villèle, fue la oportunidad para una loable tentativa de devolver al aparato del Estado una capacidad de intervención en la economía y en la sociedad que había sido hipotecada por la política de Villèle. En un contexto difícil, donde el rey no había dejado de contestar a un ministerio de centro-derecha que había tenido que sufrir después del fracaso de Villèle, la reforma del Estado bajo Martignac se presentó como una de las claves políticas para encontrar una salida a la crisis. Pero, a partir de ese momento, el debate se iba a producir en todos los frentes.

La derecha, después de haber expresado al día siguiente de caído el Imperio el deseo de ver lo local oponerse a toda la poderosa herencia centralizadora del Imperio, había abandonado sus ideas para defender, por su parte, la utilidad del poder central contra los enemigos políticos. Para la izquierda, por contra, se trataba de defender el poder local democratizado para expresar las aspiraciones de cambio; pero, claro está, proponía igualmente la cuestión de los medios financieros de los que podrían disponer estas instituciones locales sin tener que dirigirse al gobierno central.

La respuesta de Martignac fue demasiado tímida para que pudiera recuperarse una administración desprestigiada por las prácticas autoritarias que había adoptado bajo el gobierno de Villèle. La reforma Martignac dejó de lado de inmediato "la administración activa", prefectos, sub-prefectos y alcaldes cuyo puesto y función permanecen intactos. El principal cambio introducido por la reforma se apoya en el hecho de que los consejeros municipales, de barrio y generales serían elegidos y no ya nombrados por el gobierno. Pero la modalidad de elección permanecía confiada a la gran propiedad de la tierra, en la medida que el electorado y los elegibles eran extraídos de entre los sectores que pagaban mayores impuestos. Peligrosa para la derecha, esta tentativa de 
suavizar la tutela administrativa y política del Estado fue considerada como totalmente insuficiente por la oposición liberal y, finalmente, abandonada por el ministerio.

También el aparato del Estado encargado de la economía es puesto a prueba a partir de 1828. Hasta entonces, el sistema Villèle, heredero de alguna manera del prohibicionismo del Imperio, no había conocido una verdadera contestación organizada. En adelante, la caída de la derecha se vio acompañada del ascenso de una corriente liberal limitada hasta ese momento a los economistas y a los grandes negociantes y banqueros de la capital o de las ciudades del este como Estrasburgo. El movimiento, que es una de las principales componente de la caída de Villèle en las elecciones, tiene por origen el Midi rural y más particularmente las regiones productoras de vino. Algunos poderosos productores de la región de Burdeos se habían manifestado ya contrarios al proteccionismo de los manufactureros, pero, en la primavera de 1828, millares de productores, grandes y pequeños, se sumaron a la contestación. El movimiento tomó rápidamente la forma de una contestación de las decisiones tomadas desde el comienzo de la Restauración, de las decisiones que, en los medios agrícolas, se pensaba que habían sido realizadas para beneficio de los cerealistas y de las grandes industrias, en particular de los dueños de las fraguas que encarnaban el sistema de Villèle y sus nuevos privilegiados. Sobre un fondo de reivindicaciones de la viticultura, aparece la contestación de toda la Francia meridional frente a la Francia del norte que trastorna los equilibrios nacionales.

Para responder a esta profunda crisis del modelo de desarrollo francés, el conde de Saint-Cricq, director de las aduanas, promovido por Martignac como responsable de un nuevo ministerio de Comercio, llevó a cabo una reforma original de la dirección de asuntos económicos de forma que permitiera al Estado retomar las riendas de la situación en medio de una violenta batalla de intereses. El esfuerzo de Saint-Cricq para encontrar una solución a este enfrentamiento se apoyó en el nuevo ministerio de Comercio que representaba un esfuerzo de centralización de las decisiones económicas, pero que diferían, sin embargo, sensiblemente del modelo imperial. Su objetivo era dotar a Francia de un "Board of Trade" inspirado en el modelo inglés, capaz de llevar a buen puerto investigaciones, de proporcionar estadísticas que permitieran decidirse entre los intereses en conflicto y de devolver al Estado una legitimidad que por entonces estaba contestada.

La gran investigación económica que lanzará entonces sobrepasa la cuestión del viñedo y se extendía también sobre el problema del hierro, el régimen de las lanas, sobre la "preferencia exclusiva acordada al azúcar de las colonias", sobre la ampliación del tránsito... La comisión de investigación compuesta por seis 
pares, ocho diputados y cuatro altos funcionarios rompía con la rigidez administrativa de las prácticas de Villèle y entendía renovar el diálogo con el conjunto de los medios económicos. La llegada de los comisarios investigadores a las ciudades manufactureras, la movilización rápida del patronato, de los comerciantes, de los pequeños emprendedores, movilización de las que hizo amplio eco la prensa regional, pusieron de manifiesto las esperanzas de cambio. Para el Journal du Commerce, convertido en portavoz del ala avanzada del patronato liberal: "Un ministro, el de menores atribuciones de todos, el ministro de Comercio ha adquirido una importancia digna de ser envidiada por todos sus colegas. Le ha bastado con pronunciar la palabra investigación y toda la Francia industrial ha respondido...". Por todas partes el desarrollo de la investigación precipita la organización de la patronal. Se produjo, incluso, la formación de nuevas agrupaciones de la patronal liberal a partir de correspondencia y contactos mantenidos entre el Havre, Marsella y París. La investigación invitaba a preguntarse en algunos sectores que se habían convertido en "privilegiados" sobre la transformación del beneficio en renta y prolongaba, a su manera, la reflexión crítica que había llevado a un número cada vez mayor de notables a provocar la caída de Villèle.

Pero Saint-Cricq, que tenía por objetivo reintegrar progresivamente, "prudentemente", las industrias "privilegiadas" a la lógica del mercado mediante una moderada reducción de la protección, chocó con los propietarios de las fraguas, acostumbrados a una protección que -según decían- no tenía nada de conservadora sino que era necesaria para realizar las enormes inversiones que eran necesarias en el hierro, en el carbón y en los medios de comunicación, para que tomara forma en Francia un capitalismo capaz de hacer frente a Inglaterra. SaintCricq tuvo que contentarse con una modesta bajada de la protección para el hierro y el azúcar pero consiguió, cuando menos, iniciar una bajada del coste de las materias primas tan demandada por una manufactura que veía en ello la condición misma de su recuperación frente a la crisis. Nuevos drawbacks fueron establecidos y el tránsito franco de cualquier derecho. El "neocolbertismo", desde los orígenes de la Restauración, esta concepción asimétrica del sistema de cambios que preconizaba, de hecho, la importación de las materias primas a bajo precio, la protección de las manufacturas, y un esfuerzo para facilitar las salidas, había evolucionado. La fórmula no era actual ya en 1829. Esta política tendría, en adelante un nuevo nombre, la "vía inglesa". Saint-Cricq, concluyendo la presentación del nuevo proyecto de ley, tuvo mucho cuidado en demostrar que la estrategia de desarrollo que preconizaba era, de hecho, la que había consagrado "la pujanza y eficacia de Inglaterra". 
En torno a este liberalismo moderado y de un Estado que aspiraba, en adelante, a iluminar las decisiones mediante investigaciones de campo más allá de las comisiones parlamentarias, las posibilidades de hallar una vía intermedia no eran imposibles. Esta vía reformista, que había tomado forma en Inglaterra desde las iniciativas de Huskisson, exigía, no obstante, ir deprisa, aprovechar el desconcierto ocasionado por la crisis económica y utilizar también el capital político obtenido con la formación de una nueva mayoría en el giro de 1828. Pero la investigación se estancó y el aislamiento progresivo del gobierno de Martignac y de sus despachos, aislamiento considerado por Carlos X como la ocasión que estaba esperando para desembarazarse de un ministro al que nunca había apoyado, pusieron fin a esta nueva vía. Privado de su dimensión reformista y de su capacidad de maniobra, el aparato del Estado quedó reducido entonces, ante la opinión, a su imagen más desfavorable, la de una administración fiscal injusta, despótica y brutal respecto a los productores y los consumidores.

En vísperas de 1830 estalla una profunda ira contra un sistema fiscal que, en más de un aspecto, recuerda a la época final del Antiguo Régimen y excita de nuevo el odio contra la administración central y la Hacienda, sobre todos en la Francia vitícola ${ }^{43}$. Los almacenistas de vino de Burdeos hablan de "infamias de esta administración vejatoria, objeto de la execración pública y digna de ser infligida tras la conquista a un pueblo vencido en señal de su servidumbre y de su envilecimiento...". Los viticultores y los comerciantes de vino de las Bouches du Rhône se sublevan contra "los altos funcionarios y todos los ricos capitalistas del norte donde se extienden el oro, las riquezas del comercio, los milagros de la industria...".

En algunos meses, Saint-Cricq, portador de un proyecto reformista moderado de aparato administrativo, pierde la autoridad política que le habría permitido reconstruir un consenso en una Francia económica dislocada por la crisis. La derecha trata de alejarse de una vía demasiado liberal. Para los liberales, las reformas que esperaban no había llegado nunca a producirse. El Journal du commerce, punta de lanza de la burguesía liberal, tomaba sus distancias: "El ministerio parece haber dudado mucho tiempo entre diversas soluciones, y se ha decidido al fin por no elegir ninguna y dejar que las cosas en statu quo...".

Implicado en una reforma administrativa que le había llevado a retirar su proyecto de ley, Martignac no tuvo mejor suerte en el terreno de la reforma

43. D'ALMEIDA, Sylvain, Recherches sur la fiscalité française de la restauration à la Seconde République, Maîtrise d'Histoire, Université de Paris X, 1995. 
económica donde su ministro Saint-Cricq había, sin embargo, ido mucho más lejos. Pero la parálisis del aparato del Estado anunciaba otra, la del poder político frente a una crisis profunda a la que el rey creía poder hacer frente mediante un golpe de Estado.

\section{Conclusión}

Una lectura precipitada de los acontecimientos que acompañaron a la caída del Emperador en la primavera de 1814 podría hacer pensar que, con él, desaparecía también todo el aparato del Estado, una estructura administrativa autoritaria pero inspirada por los principios de la Revolución. El discurso de un realista con ganas de revancha dispuesto a condenar la centralización del Estado a la vez como origen y como consecuencia del espíritu revolucionario permitiría también pensar que, con el reinado de Luis XVIII, la vía hacia una dislocación de este poder en beneficio de un retorno hacia las provincias y la empresa de los castillos estaba abierta. La efímera esperanza de construir un nuevo reino del Midi en la época del Terror blanco muestra por el contrario que, al otro lado de la contestación del Estado, confundido con el reinado de París, existía también en la derecha el gran temor de desmontar la propia nación.

Todas estas tentativas que cuestionaban radicalmente el poder de un Estado confundiéndolo con el despotismo napoleónico fracasaron y el regreso de los Borbones, paradójicamente, confirmó la solidez de una estructura administrativa y política que, de alguna manera, sobreviviendo de un régimen al otro, demostraba que era parte constitutiva del cuerpo de la propia Francia. Esta demostración quedó de manifiesto muy pronto, desde la primavera de 1814. En la estela de Talleyrand, cuando quedó establecido el gobierno de la Carta, la máquina estática napoleónica es la que aportó las respuestas a una situación política escurridiza.

El gobierno no podía ser parlamentario, a la inglesa, elección demasiado arriesgada en una Francia donde la aristocracia era incapaz de jugar el papel de encuadrar a la sociedad. el motor del poder político, encuentra por lo tanto sus relevos en el lado del Estado, de una tecnocracia ilustrada. Es preciso estar atento, no obstante, al hecho de que este aparato de Estado, reconducido en sus atribuciones más allá de la derrota de Francia, conoció una evolución importante ligada a la caída del despotismo imperial que había acentuado los rasgos más criticados. La tecnocracia modernista y liberal, en adelante al frente de la situación, reunió hombres que habían pertenecido a los despachos del Antiguo Régimen, otros habían abrazado la causa de la Revolución, la mayor 
parte de ellos habían tenido carreras brillantes bajo el Imperio. Todos estos hombres habían cedido al cartismo y a la voluntad del Emperador, pero su proyecto de modernización de Francia era combinar -lo que no habían conseguido hasta la fecha- la eficacia de una máquina administrativa con el liberalismo económico y político que les seducía en particular en su versión inglesa.

La monarquía restaurada, cuyos perfiles inspiraron rápidamente, les permitió conciliar el impulso del Estado y la necesidad de aceptar la idea de una sociedad menos homogénea y más diversificada que la que habían deseado la Revolución y el Imperio. Asociándose en este programa tanto élites administrativas procedentes del Antiguo régimen como de la Revolución y del Imperio, fue también en el seno de esta administración donde se forjó el modelo de un compromiso histórico entre las dos Francias, compromiso que no fue el fruto de una improvisación sino que había sido largamente madurado en los espíritus al hilo del episodio revolucionario e imperial.

Si bien cierta historiografía ha subrayado frecuentemente el antagonismo entre el liberalismo económico y social y la hegemonía de un Estado poderoso heredado del absolutismo, del jacobinismo y de las exigencias militares del Imperio, fue al contrario, la pujanza de lo público en Francia a partir de 1814 constituyó un agente decisivo del anclaje de una sociedad liberal en el paisaje político tormentoso del período postrevolucionario. Con gran constancia, los equipos en el poder en los despachos sostuvieron un proyecto liberal que encontró bajo la Restauración un contexto favorable para forjar una estructura a la medida del siglo XIX.

Inspirada a la vez por Turgot y por Colbert, síntesis de un debate iniciado bajo el Antiguo Régimen, la tecnocracia liberal se dedicó, bajo el gobierno de los constitucionales, a definir una vía francesa hacia el liberalismo que, atento primero al ejemplo inglés, había asentado el liberalismo de Smith en el contexto de una nación forjada en el episodio revolucionario. Esta dirección del Estado que había faltado en la mayor parte de los países de la Europa continental se destacó en particular en la definición de una política proteccionista asociada a la desregulación y unificación del mercado interior que contribuyó a elevar a Francia al rango de segunda potencia económica mundial hasta los años 80 del siglo XIX. El giro a la derecha de la Restauración bajo Villèle solo supuso una inflexión de esta tendencia entregando los puestos claves en la dirección del sector agrícola a representantes directos de la propiedad agraria. Cuando, a pesar de la caída de Villèle, el tejido económico y social francés, enfrentado a un impass político, perdió su coherencia fue cuando desde el Estado, preocupado de utilizar los nuevos métodos del "Board of Trade", 
pudo perfilar un horizonte de recuperación. A pesar de su fracaso, que es primero el de un monarca que no había mantenido del poder del Estado más que su capacidad represiva, el aligeramiento reformista del aparato del Estado napoleónico deseado bajo Martignac, prefiguraba ya evoluciones que estaban por venir de la mano de la monarquía orleanista.

Traducción al castellano a cargo de Peña Verón 



\title{
Redefinir rey y soberanía: el retorno de Fernando VII y la agonía del Liberalismo \\ Reimagining King and Country: the return of Ferdinand VII and the agony of Liberalism
}

\author{
Gonzalo Butrón Prida \\ Universidad de Cádiz
}

Recibido: 22-VII-2014

Aceptado: 24-X-2014

\section{Resumen}

En este trabajo analizamos, a través principalmente de la prensa liberal, las alternativas políticas puestas en juego en los primeros meses de 1814 con motivo de la firma del tratado de Valençay y el retorno de Fernando VII a España. El clima de incertidumbre política generado por el silencio del rey permitió que, junto a las dos corrientes con más apoyos, las asociadas a la Constitución de 1812 y al régimen absoluto surgido del motín de Aranjuez, fueran contempladas alternativas intermedias, tanto con respecto a la monarquía, con la entrada en escena de la candidatura de Carlos IV al trono, como con respecto al régimen político, pues fueron ponderadas las virtudes de los regímenes templados de carácter postrevolucionario.

Palabras clave: Absolutismo, Liberalismo, Moderantismo, Soberanía, Fernando VII.

\begin{abstract}
This paper analyzes, mainly drawing on the Liberal press, the political options put forward in the early months of 1814 on the occasion of the Valençay treaty and the return of Ferdinand VII to Spain. The political atmosphere of uncertainty generated by the King's silence allowed for the incorporation of moderate alternatives to the political debate. Thus, besides the two more popular options, associated with the 1812 Constitution and the absolute regime emerged as a result of the Mutiny of Aranjuez, it was possible to defend, regarding the monarchy, the candidacy of Carlos IV to the throne; and concerning the political system, the positive qualities of post revolutionary, moderate. Regimes were highly valued.
\end{abstract}

Keywords: Absolutism, Liberalism, Moderate policies, Sovereignty, Ferdinand VII. 


\section{Introducción}

La perspectiva del retorno de Fernando VII a España generó, desde finales de 1813, un clima de incertidumbre política que tardaría meses en resolverse y que se tornaría pronto en tensión. Disipada la amenaza militar francesa, quedaba por resolver "La gran cuestión"1, esto es, conocer la posición del rey con respecto al orden constitucional aprobado en Cádiz.

Con un horizonte que presagiaba el inminente choque de soberanías disputadas, la decisión que tomara el todavía Deseado se presentaba como determinante. La principal contienda enfrentaba la soberanía previa a la guerra, que había encumbrado a Fernando VII como rey absoluto, con la soberanía ganada por la nación durante el conflicto, que en opinión de las Cortes legitimaba el cambio político operado en 1812. Con todo, y como veremos, también acabaría entrando en juego una tercera alternativa, la encarnada por Carlos IV, protagonista de dos abdicaciones susceptibles de ser reconocidas como forzadas, y que algunos temieron que pudieran justificar su rehabilitación por la Europa postnapoleónica como representante del orden legítimo previo a la intervención francesa.

No obstante, y pese a la concurrencia de soberanías y legitimidades, la situación estuvo desde un principio determinada por la enorme fuerza concentrada por la figura de Fernando VII, respaldado tanto por el aún poderoso Napoleón, que esperaba poder seguir utilizándolo; como por la opinión pública española, para la que se había convertido en referente político clave durante la guerra. En este contexto, Fernando, conocedor de que su apoyo podía permitir el apuntalamiento de cualquiera de las posiciones políticas en disputa, gestionaría los tiempos en beneficio propio, retrasando primero su entrada en España y, más tarde, su retorno final a Madrid.

La lucha por contar con el respaldo de Fernando fue protagonizada por igual por quienes ambicionaban su transformación en rey constitucional, que por quienes deseaban su retorno al trono absoluto, y en ambos bandos hubo quien acabó postulando opciones más templadas que las defendidas durante la resistencia al francés con tal de acercar al rey a su lado. De este modo, se oyeron voces, en el bando liberal, que llegaron a plantear la opción de una monarquía constitucional que no fuera necesariamente regida por el código de 1812, sino por una propuesta que, acorde con los postulados del liberalismo postrevolucionario, pudiera ser más asumible por el propio Fernando; en tanto que, desde el bando absolutista, las propuestas de transacción se limitaron a la promesa de reunión de cortes tradicionales asociada al Manifiesto de los Persas.

1. Título de un artículo publicado por El Conciso, 14/04/1814. 


\section{El retorno de Fernando VII: la disputa por la legitimidad}

El tratado de Valençay, firmado el 11 de diciembre de 1813, no sólo sellaba la paz entre España y Francia y acordaba la retirada de las tropas francesas, sino que también intentaba restablecer el orden dinástico español, alterado tanto por la crisis generada por el motín de Aranjuez en marzo de 1808, como por las abdicaciones de Bayona de mayo siguiente.

En ambos casos, el tratado obviaba los derechos al trono que pudieran albergar tanto Carlos IV, como José I, y se posicionaba a favor de Fernando VII. Este último reunía apoyos a priori irreconciliables, procedentes de los dos bandos enfrentados en la guerra, cuyas estrategias coincidían en cambio en la defensa de su reconocimiento como rey. De un lado, gozaba del respaldo del todavía emperador, que Emilio La Parra considera interesado en alejar al gobierno español de la órbita inglesa, e incluso dispuesto a aceptar el retorno del absolutismo a España, de ahí que contribuyera de forma determinante a la hora de proyectar el golpe de Estado de mayo de $1814^{2}$. De otro lado, conservaba, incrementado, el apoyo popular reunido en torno a su figura desde la grave crisis de Aranjuez, cuando empezó a disfrutar el tratamiento favorable de la opinión popular que acabaría convirtiéndolo en El Deseado ${ }^{3}$.

Aunque el tratado de Valençay no resolvía por completo la incógnita dinástica, el respaldo napoleónico situaba a Fernando en una posición claramente ventajosa frente a los intereses de su padre-que no había compartido exilio con él y que se encontraba en Roma tras haber vivido hasta 1812 en Francia ${ }^{4}-$, e incluso frente a los de José I, invalidado como monarca al reconocer el tratado "el orden de sucesión establecido por las leyes fundamentales de España" (art. $3^{\circ}$ ). Es más, como el todavía poderoso Napoleón apoyaba la idea del retorno de Fernando como rey absoluto ${ }^{5}$, su intervención influiría en la lucha por el encaje del rey en el nuevo marco político español.

2. La PARRA, Emilio, "Napoleón y el golpe de Estado de 1814 en España", en Huetz DE LeMPS, $\mathrm{X}$ y LuIS, J.-Ph., Sortir du Labyrinthe. Études d'Histoire Contemporaine de l'Espagne. Hommage à Gérard Chastagnaret, Madrid, Casa de Velázquez, 2012, pp. 171-191.

3. Véanse los testimonios recogidos por Antonio Calvo Maturana, que ha puesto recientemente de manifiesto lo que el 19 de marzo de 1808 y el ascenso de Fernando al trono representaron para los contemporáneos, que dieron a aquellas jornadas un carácter fundacional, llamadas a iniciar una nueva era que pusiera fin al despotismo atribuido a Godoy. CAlvo Maturana, Antonio, "'La revolución de los españoles en Aranjuez': el mito de 19 de marzo hasta la Constitución de Cádiz", Cuadernos de Historia Moderna, XI (2012), pp. 145-164.

4. En cualquier caso, el tratado aseguraba a Carlos IV una renta vitalicia suficiente para vivir con la dignidad asociada a su persona. El tratado puede consultarse en MiRAFLORES, Marqués de, Documentos a los que se hace referencia en los Apuntes histórico-críticos sobre la revolución de España, Londres, en la oficina de Ricardo Taylor, 1834, vol. I, pp. 12-15.

5. La PARRA, Emilio, "Napoleón y el golpe de Estado...", pp. 179-180. 
Tras más de cinco años de trayectorias divergentes, se acercaba el momento crítico de conciliar las legitimidades reclamadas tanto por la Regencia y las Cortes, basadas principalmente en su presentación como portadoras del respaldo de la nación; como por el propio Fernando, convencido de que no necesitaba refrendo alguno de unos derechos que poseía inherentemente.

El primero en pronunciarse fue el poder constitucional, que no solo evitó ratificar un tratado firmado al margen de su autoridad, sino que también intentó que Fernando VII aceptara el proceso de cambio político experimentado en su ausencia, que lo había transformado de rey absoluto en rey constitucional.

La Regencia, que no hay que olvidar que gobernaba en nombre de Fernando, tuvo conocimiento oficial del tratado por una carta enviada en diciembre por éste desde Valençay solicitando su ratificación, que fue entregada por el duque de San Carlos en Madrid el cuatro de enero de 1814. Conocedora de la limitación de sus poderes, la Regencia contestó el día ocho remitiendo al rey el decreto aprobado por las Cortes el primero de enero de 1811, que declaraba nulos "todos los actos y convenios del Rey durante su opresión fuera o dentro de España"6. La defensa de aquel decreto recordaba a Fernando las nuevas reglas del juego político definidas en Cádiz, y mostraba la intención del gobierno constitucional de cumplirlas más allá de que las circunstancias de 1814 ya no fueran las de 1811. De este modo, ponía de manifiesto su deseo de evitar el cumplimiento de las decisiones que el rey tomara al margen de las Cortes, y ya no sólo aduciendo una supuesta falta de libertad a la hora de la negociación en Francia, sino, lo que es más importante, tratando de restar legitimidad a todos los actos del rey fuera de España, puesto que, en su opinión, carecían "de la esencialísima e indispensable circunstancia del consentimiento de la Nación"7. Por último, no hay que olvidar que también estaba en juego un nuevo cambio de alianzas, puesto que la ratificación del tratado implicaba la ruptura con Inglaterra y el retorno al entendimiento con Francia, difícil de asumir tras la experiencia de la guerra. En este sentido, el gobierno, como reconocería el propio Luyando en abril, no deseaba arriesgar la pérdida del apoyo inglés, de modo que no solo actuó guiado por lo aprobado por las Cortes en 1811, sino también por lo acordado

6. La correspondencia también puede consultarse en Miraflores, Marqués de, Documentos a los que se hace referencia..., vol. I, pp. 15-17.

7. Decreto XIX, de 1 de enero de 1811, "Decláranse nulos todos los actos y convenios del Rey durante su opresión fuera o dentro de España: nueva protesta de no dejar las armas hasta la entera libertad de España y Portugal", en Colección de los decretos y órdenes que han expedido las Cortes Generales y Extraordinarias desde su instalación en 24 de septiembre de 1810 hasta igual fecha de 1811. Cádiz, Imprenta Real, 1811, t. I, pp. 14-15. 
con el gobierno inglés de no firmar ningún tratado de paz con Francia sin su intervención ${ }^{8}$.

Si acaso la respuesta de la Regencia no era suficientemente clara, las Cortes aprobaron el dos de febrero un nuevo decreto que regulaba el recibimiento del rey y el proceso de entrega del poder constitucional que le correspondía, en un ejercicio de demostración de fuerza que trataba de justificar la legitimidad nacional recién adquirida. Esta nueva resolución disponía la circulación del decreto original de primero de enero de 1811 e insistía, en un tono cercano a la hostilidad, en la idea de no reconocer al rey como libre, y no prestarle por tanto obediencia, hasta que jurara la Constitución en el Congreso. La cuestión era tan prioritaria para las Cortes, que el decreto regulaba con detalle todo lo concerniente al regreso del rey, desde el modo en que debía cruzar la frontera, sin fuerza armada alguna que lo acompañara, hasta el momento en que debía prestar el juramento constitucional, requisito previo imprescindible para la entrega del gobierno por parte de la Regencia; solo entonces aprobarían las Cortes un último decreto que notificara a la nación que el rey había sido "colocado constitucionalmente en su Trono"'.

La dureza del decreto provocaría, durante su discusión, la única defensa pública del absolutismo realizada durante la crisis, la protagonizada por el sevillano López Reina, que en la sesión de tres de febrero manifestó que el rey había nacido "con un derecho a la absoluta soberanía de la nación española", y que una vez de vuelta en España, era indispensable que siguiera ejerciéndola, lo que dio lugar, según informaba El Conciso, a un alboroto extremo en las Cortes, que afirmaban así su alineamiento constitucional: "Se levantaron a un mismo tiempo una multitud de diputados clamando contra el Sr. Reyna por estas expresiones, y al mismo tiempo el pueblo espectador manifestó su indignación contra este diputado, clamando que se le hiciera salir del Congreso" 10 .

8. El Conciso publicaría a final de abril de 1814 la carta enviada por Luyando, ministro interino de Estado, al embajador inglés, en la que explicaba el doble condicionante, interno y externo, de la reacción del gobierno ante el tratado de Valençay. "Documento inédito", El Conciso, 30/04/1814. No se trataba, en todo caso, de romper únicamente con Inglaterra, sino que también estaba en juego el abandono de la causa de los aliados, como ya había sido expuesto en el mismo periódico unos días antes, en el artículo "Reflexiones serias", que se preguntaba cómo era posible que el rey pudiera llegar a un entendimiento con quien había sido no sólo su enemigo, sino el de todos los españoles, y que denunciaba además que con la firma del tratado se abandonaba la causa de los aliados (El Conciso, 14/04/1814).

9. El decreto en Miraflores, Marqués de, Documentos a los que se hace referencia..., vol. I, pp. 21-23. La cursiva es nuestra.

10. El Conciso, 04/02/1814. Poco después, cuando las Cortes habían decidido abrirle causa por sus palabras, López Reina se excusó explicando que no le habían dejado terminar su discurso, que había sido interrumpido cuando iba a matizar que el rey debía seguir 
Días más tarde, el 19 de febrero, las Cortes se dirigieron a la nación en un largo Manifiesto publicado con el fin de apuntalar su posición frente al rey y en contra además de la firma del tratado. En esta ocasión, el argumento principal recurría a la habitual descalificación de Bonaparte y la consiguiente exculpación del rey, que volvía a ser presentado, como durante los años previos, como "deseado", "inocente" y "virtuoso". De este modo, el primero, tachado de "tirano execrable", habría conseguido, con "malas artes y violencias", que Fernando firmara un tratado completamente contrario a los intereses de la nación, puesto que su objetivo era, siempre en opinión de las Cortes, dividir a los españoles, separarlos "de la causa común de la independencia europea" y enfrentarlos además a los ingleses, cuando estos eran, precisamente, sus verdaderos aliados. Frente a la amenaza napoleónica, el Manifiesto apelaba a la unidad de los españoles en torno a la religión, la constitución y el rey, los tres ejes que debían constituir "el vínculo indisoluble que enlace a todos los hijos de este vasto imperio" $"$.

Despejadas las dudas sobre las intenciones de las Cortes, quedaba por conocer la reacción del rey, que evitó entrar en la activa dinámica de resoluciones y declaraciones elegida por las autoridades constitucionales y fue capaz de marcar, desde la ambigüedad y el silencio, los tiempos de su retorno. Rodeado de consejeros absolutistas, informado por el duque de San Carlos de los apoyos que podría tener su proyecto de retorno al absolutismo ${ }^{12}$, e incluso esperanzado, como señalara Joaquín Varela, en la oposición del embajador inglés a la Constitución $^{13}$, Fernando guardó silencio y evitó pronunciarse sobre sus intenciones hasta llegado prácticamente el momento de entrar en Madrid, una actitud que El Conciso acabaría por bautizar como "política misteriosa"14.

gozando de la autoridad absoluta hasta que jurara la Constitución, en CARO CANCELA, Diego (dir.), Diccionario Biográfico de Parlamentarios de Andalucía, 1810-1869, Sevilla, Centro de Estudios Andaluces, 2010, vol. II, pp. 135-136.

11. Manifiesto de las Cortes a la Nación Española, en Documentos a los que se hace referencia en los Apuntes histórico-críticos sobre la revolución de España, Londres, en la oficina de Ricardo Taylor, 1834, vol. I, pp. 23-28.

12. La PARRa, Emilio, "Napoleón y el golpe de Estado...", pp. 182-186.

13. Varela SuAnzes-CARPEgna, Joaquín, "La teoría constitucional en los primeros años del reinado de Fernando VII: El Manifiesto de los 'Persas' y la 'Representación' de Álvaro Flórez Estrada”, Alicante, Biblioteca Virtual Miguel de Cervantes, 2005, consultado en http://www.cervantesvirtual.com/obra-visor/la-teora-constitucional-en-los-primerosaos-del-reinado-de-fernando-vii---el-manifiesto-de-los-persas-y-la-representacin-delvaro-flrez-estrada-0/html/ (19/05/2014). Publicado originalmente en Estudios dieciochistas en homenaje al profesor José Miguel Caso González, Oviedo, Instituto Feijóo de Estudios sobre el Siglo XVIII, 1995, vol. II, pp. 417-426.

14. "Las tres nuevas Constituciones", El Conciso, 01/05/1814. 


\section{El rey en España: de la esperanza a la inquietud}

La conducta de Fernando VII generó todo tipo de rumores, incertidumbres y temores y sentó las bases de una dura lucha por el poder que, afrontada desde posiciones antagónicas y con armas completamente distintas, iba a prolongarse durante varios meses. La estrategia real del mutismo y la reserva sobre sus intenciones, desarrollada preferentemente en el ámbito del secreto y la intriga ${ }^{15}$, fue contestada con una actitud más combativa de parte de los comprometidos con el régimen liberal, que no dejaron de pronunciarse en todo este tiempo. En un principio, pusieron el acento en la presentación del rey como mal aconsejado, en tanto que más tarde, realmente preocupados por el riesgo de un vuelco político contrario a sus intereses, mostraron menos consideración hacia la figura del monarca.

Buen ejemplo de la primera opción lo representan las páginas de El Conciso, publicación clave del Cádiz sitiado que había seguido a las Cortes hasta Madrid, donde reapareció a mediados de enero de 1814 con el fin de mantener vivo el espíritu de guerra de pluma que consideraba clave en la derrota napoleónica ${ }^{16}$. A mediados de abril, publicaba un artículo con el significativo título de "La gran cuestión", en el que planteaba la opción del retorno de Fernando al absolutismo como un peligro real y enfrentaba dialécticamente las dos alternativas posibles, para terminar recomendando al rey que desoyera a quienes lo querían rey absoluto, reconociera los sacrificios realizados por los españoles en los últimos años y jurara la constitución, presentada como la restauradora de las verdaderas leyes de la monarquía:

"Ahora viene el Rey Fernando y le decimos: Sr. aquí tiene V.M. su trono, su cetro, su corona, su manto real, toda su autoridad. Sea V.M. rey absoluto, mande V.M. arbitrariamente, no haya otra ley que la voluntad de V.M. Estamos prontos a obedecerle como vasallos, como esclavos [...]. Ahora viene el Rey Fernando y le diremos: Sr. aquí tiene V.M. su corona ganada por el valor y heroísmo de sus leales súbditos, aquí el cetro conservado y sostenido a fuerza de víctimas sacrificadas en todos los ángulos de la Península, aquí está el manto real, teñido en la sangre que a torrentes han derramado vuestros leales súbditos

15. Emilio La Parra señala la labor del "partido antirreformador", liderado por Mozo de Rosales y Gómez Calderón, que habría estado detrás de la intervención de López Reina y que, animado por la información recibida de San Carlos y Palafox, intentó organizarse para derribar el sistema constitucional. LA PARRA, Emilio, "Napoleón y el golpe de Estado...", p. 187.

16. SÁNCHEZ HitA, Beatriz, "La imprenta en Cádiz durante la guerra de la Independencia y su relación con la prensa periódica" en CANTOS, M., DurÁN, F. y ROMERO, A. (eds.), La guerra de pluma. Estudios sobre la prensa de Cádiz en el tiempo de las Cortes (1810-1814), vol. I, Imprentas, literatura y periodismo, Cádiz, Universidad de Cádiz, 2006, pp. 84-85. 
por conservároslo, ahí está vuestro trono, echado por tierra en otro tiempo por la perfidia del enemigo y por la traición de algunos desleales españoles; y levantado ahora por la fidelidad, constancia, valor y heroísmo del pueblo español, aquí tenéis la autoridad real, limitada en el día a ejercer el poder ejecutivo de la más heroica de las naciones, aquí tenéis el código sagrado de las leyes de vuestra monarquía, de aquellas leyes que fueron de España, y que por el abuso estaban olvidadas, eludidas o abrogadas [...] Aquí tiene V.M. la Constitución de la monarquía española, jurad observarla y haced observarla"17.

Días más tarde, en el mismo periódico respondían todavía con cierto optimismo a la pregunta "¿Reconocerá Fernando VII a las Cortes de la Nación?”. El eje argumental del artículo sostenía que si hacía veinticinco días que el rey estaba en España y no había ejercido ningún acto, "ni de soberano, ni de rey constitucional", es que reconocía y acataba el decreto de dos de febrero ${ }^{18}$. Un planteamiento similar seguía entonces El loco constitucional, periódico exaltado granadino que en un artículo de título revelador - "Sobre la autoridad absoluta de los reyes"-, expresaba la esperanza de que Fernando contribuyera a sostener la constitución ${ }^{19}$.

Sin embargo, a finales de aquel mes de abril, en un contexto de creciente tensión, ambos periódicos cambiarían el tono y comenzarían a censurar el comportamiento del rey. El Conciso le recriminaría, en general, que el silencio que mantenía en Valencia daba lugar a "multitud de conjeturas" y enrarecía enormemente el ambiente político y social ${ }^{20}$; de igual modo, reiteraría la defensa abierta del carácter constitucional de la corona española y criticaría el "estado de duda en que la nación se halla sobre la resolución que Fernando VII tomará, y que se aumenta cada día más con la demora de S.M. en el viaje", mostrando una preocupación particular por el partido que tomaría la capital frente a la actitud del rey, que esperaba que fuera el de la defensa de la constitución ${ }^{21}$.

En la misma línea adoptada por El Conciso se situó El loco constitucional, que el 21 de abril se mostraba consciente de las circunstancias críticas que se vivían, pues iban a fijar la suerte de la nación, y expresaba su temor a que los malos consejeros evitaran que Fernando VII jurara la constitución. De hecho, incluso alertaba del riesgo de guerra civil, y definía sin reparo a quienes la alentaban, a saber, "los que aseguran con tono decisivo que el idolatrado Fernando no jurará, o no deberá jurar la Constitución, esos, esos son nuestros más san-

17. "La gran cuestión", El Conciso, 14/04/1814.

18. “¿Reconocerá Fernando VII a las Cortes de la Nación?”, El Conciso, 18/04/1814.

19. El loco constitucional, 14/04/1814.

20. "Sobre cosas del día", El Conciso, 25/04/1814.

21. “¿Cuál será la opinión de Madrid?”, El Conciso, 26/04/1814. 
grientos enemigos". Al mismo tiempo, y frente a la indecisión del rey, apelaban a la defensa de la constitución y, con ella, de la libertad y la independencia de los españoles, a quienes recordaban, en un tono que evocaba el "vivir libre o morir" de los revolucionarios franceses, el juramento que debían cumplir: "Este es nuestro deber, apresurémonos a llenarlo, y juremos de nuevo morir que vivir ESCLAVOS"22. El mismo periódico reafirmaría sus posiciones en un artículo publicado a principios de mayo con el significativo título de "Viva Fernando VII. La soberanía reside esencialmente en la Nación", en el que trataba de desmontar la tacha de impío y jacobino que arrastraba el principio de soberanía nacional por culpa de la propaganda absolutista. Con este fin, remitía a las teorías políticas expuestas por Roberto Berlamino doscientos años atrás, que al contar con el refrendo de la iglesia no podían ser objeto de crítica. En concreto, las teorías de Berlamino fueron utilizadas para restar entidad a la idea de la soberanía real frente a la popular, puesto que si la potestad política procedía solo de Dios y el derecho divino no la había conferido a ningún particular, no podía menos de inferirse "que se la dio a la muchedumbre [...] Luego la potestad es de toda la muchedumbre"23.

Conforme crecía la desconfianza hacia el rey, disminuía la preocupación por ocultarla. Es el caso del propio Conciso, que atribuía la apatía, la indiferencia y el "sombrío silencio" con que se había vivido en Madrid la noticia del fin de la guerra a la "larga mansión" del rey en Valencia. El tono era ya de desánimo y presagiaba, en cierto modo, el futuro golpe, pues daba cuenta de la extensión de rumores contradictorios que ponían en duda la alineación del rey con la constitución y que conformaban "una perspectiva de espanto, de asombro, de terror, de abatimiento y de mil males venideros" ${ }^{24}$. Ya en mayo, y a pesar de la falta de manifestaciones oficiales, desde las páginas del mismo periódico se consideraba abiertamente la posibilidad del alejamiento del rey de la senda constitucional: "a pocos días de la morada de S.M. en Valencia se muda la escena, entran las dudas; confírmanse las sospechas, y créese por último que el Rey no jurará la Constitución. Constérnanse todos..."25.

22. "Contestación", artículo que responde a una carta al editor firmada en Baza el 7 de abril de 1814 que exponía la inquietud existente ante la extensión de las opiniones de que Fernando "rey absoluto desde el vientre de su madre", no juraría la constitución. El loco constitucional, 21/04/1814. Las versales en el original.

23. "Viva Fernando VII. La soberanía reside esencialmente en la Nación", El loco constitucional, 03/05/1814. El artículo concluía que, estando reconocida su doctrina por la iglesia católica, apostólica y romana, Berlamino no podría ser tachado de ser "un jacobino rabioso, un francmasón, un ateo, un anarquista, un discípulo de Voltaire, de Rousseau y todo cuanto quieran o se les venga a las mentes". La cursiva en el original.

24. "Sobre los asuntos del día", El Conciso, 27/04/1814.

25. "Reflexiones", El Conciso, 02/05/1814. 
Las pautas marcadas por las opiniones particulares recogidas por El Conciso, que publicaría nuevos artículos en aquellos días que insistían en la reprobación de la conducta reservada del rey -"parece inconcebible que después de tanto tiempo que Fernando VII se halla entre sus leales súbditos, puedan ignorar éstos el modo de pensar de S.M. sobre el estado de la monarquía..."26-, fueron también expresadas de forma oficial tanto por parte de las Cortes, como por parte de otras instituciones de poder de ámbito provincial y local. En este último caso, destacan las promovidas desde Andalucía por la diputación y el ayuntamiento de Cádiz, que se unieron a las manifestaciones de apoyo al régimen y de reconvención al rey, y que, dado el protagonismo de aquella provincia en el proceso constitucional, tuvieron una amplia repercusión.

Las Cortes se dirigieron por dos veces al rey a través de sendas cartas que llegaron a conocimiento de la opinión pública gracias a su reproducción, por parte de la prensa, a principios de mayo. Fechadas respectivamente el 25 y el 30 de abril, las cartas fueron emitidas en un escenario político cada vez más enrarecido, y pueden ser interpretadas como un último intento de atraer a Fernando hacia el constitucionalismo ${ }^{27}$. Con este fin, las cartas estaban redactadas en un tono moderado y conciliador que no solo refleja una manifiesta voluntad de compromiso, sino también una mayor conciencia de lo necesaria que resultaba la legitimidad monárquica para la supervivencia del régimen constitucional.

Ambas cartas coincidían en subrayar los problemas generados por la incertidumbre creada por la prolongada presencia de Fernando VII en Valencia, pues se temía que incluso pudiera provocar la perturbación del orden público. En ellas, las Cortes recordaban al rey quiénes habían luchado por el restablecimiento de la monarquía borbónica y le transmitían "la laudable impaciencia con que la nación y sus representantes anhelan el momento en que venga V.M. a ocupar el trono que le han rescatado sus pueblos" 28 .

Conscientes del creciente cuestionamiento de su poder, las Cortes hacían valer la legitimidad de la nación que afirmaban representar, de ahí que pusie-

26. "Sic vos, non vobis...". El Conciso, 28/04/1814.

27. Por ejemplo, es reseñable que el comentario de las cartas diera de nuevo lugar a la exculpación del "virtuoso Fernando", frente a los enemigos de la monarquía, identificados como los que habían seguido a Godoy, habían firmado luego "la Constitución de Bonaparte" en Bayona y habían finalmente jurado y servido "al intruso". "Un español a sus conciudadanos" (Granada, 3 de mayo de 1814), en El loco constitucional, 03/05/1814.

28. Las Cortes al Rey (Madrid, 25/04/1814). Hemos consultado la edición de la prensa granadina, que se hizo eco de la polémica y reprodujo en mayo las dos cartas, Extraordinario de Granada, 08/05/1814, la cursiva es nuestra. El Conciso no las reprodujo, pero sí que las comentó largamente en su número de 02/05/1814, e informó igualmente de ellas el 08/05/1814, cuando explicó que el rey las había recibido, pero no contestado, ya que estaba próxima su llegada a Madrid. 
ran precisamente el acento en la larga, constante y heroica lucha de los españoles por su rey y contra "el usurpador", recordaran que ellas eran "felices intérpretes de la voluntad nacional" y solicitaran al monarca que acelerara su regreso a Madrid. La segunda misiva incorporaba, sin duda con el deseo de recabar el apoyo real, un elemento nuevo, el que vinculaba el alineamiento del rey con la constitución con la recuperación de la posición internacional de la monarquía española, puesto que no sólo había de allanar el reencuentro con las "desgraciadas provincias de Ultramar", sino también la defensa de los intereses españoles en la Europa postnapoleónica ${ }^{29}$.

El tono contenido del discurso oficial emitido desde Madrid se tornaría en amenaza velada en el caso de las representaciones dirigidas el tres de mayo por la diputación de Cádiz a la Regencia y por el ayuntamiento de Cádiz a las Cortes, que trascendieron el ámbito gaditano y andaluz, puesto que, al ser ampliamente reproducidas por iniciativa de los diputados a Cortes por Cádiz, entre otras cabeceras por el propio El Conciso, tuvieron repercusión nacional.

Las dos representaciones compartían con las Cortes la preocupación por la permanencia del rey en Valencia y por las noticias que llegaban de aquella ciudad y avisaban, sin cuidado alguno, que su compromiso con la constitución podía ser mayor que con el rey. La representación de la diputación, la más breve de las dos, lo exponía con claridad, planteando incluso la posibilidad de no reconocer fidelidad al monarca absoluto: "Ningún pueblo ama con más decisión al Rey que éste [...]; pero ningún pueblo ni provincia está más íntimamente unida a la conservación del sagrado Código que se produjo en su seno". En consecuencia, reclamaba que el rey apresurara su llegada a Madrid para que "dando un día de gloria a la nación, tranquilice el espíritu del pueblo Gaditano, que se halla agitado entre la fidelidad, respeto y temor"30.

En cuanto a la representación del ayuntamiento, comenzaba dando cuenta tanto de la amenaza de la reacción absolutista, como de la inquietud y el pesar de los gaditanos, que no entendían que el rey, en unas circunstancias tan difíciles, retrasara su llegada a la capital y evitara manifestar de una manera solemne "su conformidad con las resoluciones del Congreso". Por consiguiente, el ayuntamiento, que ya atribuía a Cádiz la etiqueta de "cuna de la libertad", anunciaba que se sacrificaría "por la observancia de la Constitución antes que verla degradada en un solo ápice", y terminaba solicitando a las Cortes que hicieran ver al rey lo peligrosa que era su ausencia de Madrid ${ }^{31}$.

29. Las Cortes al Rey (Madrid, 28/04/1814), Extraordinario de Granada, 08/05/1814.

30. Representación de la Diputación provincial de Cádiz a la Regencia, Cádiz, 03/05/1814, Suplemento al Conciso, 08/05/1814.

31. Representación del Ayuntamiento constitucional de Cádiz a las Cortes, Cádiz, 03/05/1814, Suplemento al Conciso, 08/05/1814. 
Junto a las representaciones, llegó a publicarse una carta remitida por Cayetano Valdés, jefe político de Cádiz, al ministro de la Gobernación que, fechada igualmente el tres de mayo, reiteraba la mayor fortaleza del compromiso gaditano con la constitución que con el rey, y criticaba igualmente la actitud excesivamente prudente de las Cortes. Para Valdés, no solo estaba en peligro el "extremado" amor que se profesaba en Cádiz a Fernando VII, sino la propia patria, y lo exponía de forma clara y valiente, incluyendo un comentario al borrado de la historia que apunta a su conocimiento del talante del decreto preparado por los absolutistas -el conocido "si se quitasen de en medio del tiempo"-, firmado el día cuatro por el rey en Valencia:

"Como jefe político, como general y, sobre todo, como buen español que le ama y ama a la nación, me veo en la obligación de decir sin embozo ni rodeos que la patria está en peligro, y solo la pronta venida del Rey a Madrid a hacer el debido juramento en el Congreso puede salvarla, de lo contrario preveo males que el tiempo acreditará [...] que es imposible que seis años tales como los pasados desaparezcan de nuestra historia, vuelvan las cosas al año ocho, sueño que solo puede imaginar la malicia o la ignorancia. Dígase al Rey la verdad sin rodeos ni cálculos de la buena o mala suerte que ella puede acarrearnos"32.

En todo caso, no es solo importante la interpretación que podamos hacer ahora de estas representaciones, sino también la que hicieron en su momento, y es que, a esas alturas, la situación era tan tensa que la sola noticia de la llegada de las representaciones de Cádiz movilizó a la opinión pública madrileña, que incluso antes de contar con la edición impresa de las mismas, las entendió como una advertencia de Cádiz al gobierno y al rey. Las referencias de El Conciso de nueve de mayo son relevantes al respecto:

"La llegada de un extraordinario de Cádiz excitó ayer la curiosidad pública; en breve se divulga el rumor de haber llegado dos representaciones $[\ldots]$, sin ser leídas ya se hablaba de ellas como si fueran públicas. Por ignorancia o por malicia se decía que Cádiz se separaba (!!!) del gobierno"33.

La tensión y la inquietud estaban, en última instancia, fundadas, y el tiempo daría la razón a quienes, como denunciaba al día siguiente un articulista de $E l$ Conciso, buscaban el retorno de la población a la apatía "de los tiempos anti-

32. El Conciso, 10/05/1814. La cursiva es nuestra.

33. "Madrid, 8 de mayo", El Conciso, 09/05/1814. En aquellos días la propaganda absolutista también daría cuenta de la agitación vivida en Cádiz. En concreto, presentaba a los liberales gaditanos como "perros sanguinarios y crueles enemigos de la existencia de nuestro amado Rey" y proponía un castigo ejemplar para ellos, en REDARGUMENTO. LA TROMPETA RONCA DE LA JUSTICIA contra la escandalosa Alarma de los sanguinarios Liberales de Cádiz del viernes 29 de Abril de 1814, Sevilla, imprenta de Padrino, 08/05/1814. 
guos", y se complacían "en infundir el terror y la desconfianza, en propagar rumores infaustos, en hacer pinturas de patíbulos, prisiones, proscripciones, en indicar objetos de venganzas" 34 , esto es, en presagiar un escenario funesto que no tardaría en hacerse realidad.

\section{Soberanías reales y encuentro de legitimidades: la opción de Carlos IV y la teoría del refrendo constitucional}

En estas circunstancias de notable inestabilidad, el encuentro de legitimidades no se limitó al enfrentamiento de la legitimidad constitucional, basada en el esfuerzo heroico de la nación, con la legitimidad real que, retrotraída a la situación de abril de 1808, justo antes de la salida de Fernando de España, anulaba todo lo acordado en Cádiz; sino que permitió la entrada en escena de una tercera opción, la que remitía a la soberanía doblemente perdida de Carlos IV.

En efecto, y con independencia de los movimientos que el rey padre pudiera estar realizando ${ }^{35}$, la prensa no dejó de comentar, con Fernando ya en España, los numerosos rumores que aludían al deseo de Carlos IV de ser restaurado en el trono. El argumento principal era sencillo, pues presentaba sus abdicaciones en Aranjuez y Bayona como parte de las tribulaciones que la revolución francesa y las guerras napoleónicas habían hecho sufrir a los monarcas europeos. Cerrada con tanto trabajo esta era de convulsiones para los tronos, llegaba el momento de retornar, como se negociaba en la mayoría de los estados europeos, al punto de partida previo a la revolución, esto es, al reinado de Carlos IV. Con todo, el objetivo de las primeras referencias al rey padre parece más centrado en forzar a Fernando a aceptar que la legitimidad estaba en manos de la nación, que a reconocer a Carlos cualquier opción real de recuperación de su viejo trono.

La primera alusión a los derechos de Carlos IV la encontramos a finales de abril, cuando, en este contexto de legitimidades no consolidadas, El Conciso se hizo eco del rumor que apuntaba al posible restablecimiento de Carlos en el

34. "Sobre la venida de Fernando VII', El Conciso, 10/05/1814.

35. Bayo sí que da cuenta de que Carlos IV, pasada la crítica situación de mayo, reconocería a Luis XVIII que no ambicionaba volver a ocupar el trono, de ahí que el monarca francés, que le escribiría para informarle reservadamente del objeto del congreso a celebrar próximamente en Viena, le solicitara que renovase "libremente" el acto de abdicación de Aranjuez, dando a entender, de alguna manera, que en Europa no estaba tan claro que si hubiera reclamado el trono, no se hubiera atendido su petición. La referencia a la carta de Luis XVIII en BAYO, Estanislao de Kostka, Historia de la vida y reinado de Fernando VII de España: con documentos justificados, órdenes reservadas y numerosas cartas del mismo monarca, Pio VII, Carlos IV, María Luisa, Napoleón, Luis XVIII, El Infante Don Carlos y otros personajes, Madrid, Imprenta de Repullés, 1842, t. II, pp. 69-70. 
trono. Aunque en esos momentos la opción carlina era presentada como un nuevo elemento perturbador de la crítica situación política española, lo cierto es que el discurso liberal intentó encauzarlo a favor de sus intereses, tratando de convencer a Fernando de que le iba a resultar más ventajoso aceptar que era la voluntad de la nación española, expresada a través de la constitución, la que lo confirmaba como rey, que entrar en disputas con su padre y los soberanos legitimistas sobre sus derechos a la corona de España:

"un rumor desagradable viene ahora a aumentar la crisis, en que ya por desgracia nos vemos: dícese que Carlos IV ha recurrido a los soberanos reunidos en París para indicarles que el trono de España le pertenece, y que supuesto se restablece Luis XVIII en Francia, pide ser también restablecido"36.

Días más tarde, un largo artículo analizaría los problemas que originarían, de ser ciertos los rumores, las pretensiones de Carlos IV, y planteaba ya de forma abierta los argumentos que en el primer artículo solo se intuían. Con este fin, subrayaba la contraposición de los intereses de los españoles, que en estos años de lucha solo se habían acordado de Fernando, con los de los soberanos reunidos en París, a quienes se atribuía un desconocimiento completo tanto de la situación de España, como del sentir mayoritario de los españoles. De este modo, y aunque para algunos fuera posible equiparar la posición de Carlos IV con la de Luis XVIII, el articulista no creía viable la candidatura del rey padre, puesto que "aún dando por supuesto que prestasen oídos a semejante pretensión ¿cómo la entablarían los aliados? ¿por negociación?". En este punto, llegaba el momento de hacer valer los derechos de Fernando frente a las aspiraciones de su padre, y en la opinión liberal no había mejor forma de hacerlo que apelando a la legalidad constitucional, puesto que los soberanos de la Europa legitimista solo podrían imponer sus criterios si quebrantaban el artículo 179 de la Constitución, que señalaba directamente a Fernando como rey de España. Por tanto, no tendrían otro medio de imponerlo que por la fuerza, y ya se había demostrado que la fuerza no era suficiente para someter a los españoles:

"Así pues, Carlos no puede tener esperanzas de recuperar el trono ni por transacciones diplomáticas, ni valiéndose de bayonetas. La misteriosa y perjudicialísima conducta de los consiliarios actuales de Fernando tampoco pueden dar a Carlos ninguna esperanza sobre un partido a su favor; pues aunque lo tuviera sería tan pequeño que ni merecería hacerse caso de él"37.

36. "Extracto de noticias extranjeras", El Conciso, 30/04/1814.

37. "Sobre los rumores acerca de la venida de Carlos IV", El Conciso, 04/05/1814. El mismo artículo sería reproducido por El loco constitucional el 12 de mayo. Al margen de las consecuencias que la entrada de Carlos en la disputa por el trono podía tener en la 
No se trataba, en todo caso, de una estrategia nueva, puesto que la propaganda del momento ya trabajaba en esta línea. Véase por ejemplo el catecismo constitucional publicado a finales de marzo por El loco constitucional, que en dos preguntas sucesivas distinguía, con interesada intención, entre soberano y

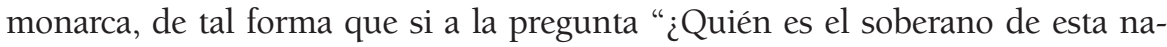
ción?" respondía que esencialmente ella misma y por su elección las Cortes, a la cuestión siguiente, "¿Quién es el actual monarca que la gobierna?", contestaba, remitiendo expresamente al artículo 179, que Fernando VII ${ }^{38}$. La distinción entre soberano y monarca reforzaba la línea argumental desarrollada a partir de la difusión de los rumores sobre las reclamaciones de Carlos IV, y permitía a los liberales presentar la jura de la constitución por parte de Fernando VII como el acto fundamental que, al alinear los intereses del soberano con los del monarca, unía la suerte de ambos.

En fin, dos nuevos artículos de El Conciso, de siete y nueve de mayo, insistirían en la idea de que la aceptación de la constitución era el mejor modo de frenar el eventual reconocimiento en Europa de las aspiraciones de Carlos IV. En ambos casos se destacaba la importancia que tenía para Fernando la jura de la constitución, puesto que, a través del ya citado artículo 179, desautorizaría las pretensiones del padre a favor de las del hijo. Por el contrario, sin constitución sería Carlos IV quien podría hacer valer unos derechos que le amparaban, y que podían dar lugar a una transacción o ajuste de carácter diplomático. La solución pasaba entonces por fortalecer la salida constitucional mediante la unión de la suerte del rey a la de la nación: "Fernando VII llamado al trono de España por la Constitución, por el voto general de la nación, por el amor de sus pueblos" 39 .

política interior española, el artículo también señalaba lo perjudicial que podía ser para la política exterior española, toda vez que podía dar lugar al fraccionamiento de las posibles compensaciones que debían recibir los españoles por su contribución a la derrota de Napoleón: "Lo que podemos presumir, sí, es que Carlos IV no dejará de hacer pretensiones, ya sea al trono de España, o sobre un nuevo establecimiento, cuando se reúna el congreso para la paz general. He aquí pues un estorbo, y no pequeño, para que la España saque todas las ventajas que debía, como parte principal en esta gran lucha: he aquí ya de qué modo se ocasionarán daños a los intereses de España; pues si en un Congreso general se admiten las pretensiones de Carlos IV, y se le fija algún establecimiento, este mismo entrará en cuenta de las ventajas que deba sacar la España, y que en realidad no sacará. Creíamos que Carlos IV, o más bien sus consiliarios, no podrían ya atraer males a los españoles. El tiempo nos dará a conocer si nos engañábamos".

38. El loco constitucional, 28 y 31/03/1814.

39. "Reflexiones que pueden venir al caso", El Conciso, 07/05/1814 y "Sobre las pretensiones de Carlos IV", El Conciso, 09/05/1814. La cita corresponde al segundo artículo. 
Una opción transaccional: la ponderación de los regímenes templados ante el riesgo de involución

En estas complicadas circunstancias, cobraron protagonismo los valedores de la viabilidad de los regímenes constitucionales en la Europa postnapoleónica. Aunque excepcionalmente llegó a anunciarse que Luis XVIII iba a restablecer y jurar la Constitución de 1792 [sic] ${ }^{40}$, lo cierto es que los dos ejemplos más citados por la prensa se alejaban del patrón gaditano, para acercarse más a los modelos moderados por excelencia del momento, los representados por la Constitución holandesa de marzo de 1814 y la Carta otorgada francesa de junio de aquel mismo año ${ }^{41}$.

Ambos modelos han sido estudiados por Matthijs Lok, que los ha caracterizado, al menos en sus primeros años de andadura, como ejemplos de la solución política que Pierre Serna definió con el oxímoron de "l'extrême-centre", esto es, como una alternativa impulsada por unas élites que, rechazando por completo los modos de la revolución, estaban dispuestas a asimilar algunas de sus ideas y de sus hombres. Esta disposición se tradujo en el establecimiento de regímenes moderados caracterizados por la fortaleza de la monarquía frente al parlamento y por la renuncia a la condena de las conductas y los alineamientos del pasado reciente. En el caso concreto de Holanda, Guillermo I no tenía intención de volver al Antiguo Régimen, pero pensaba que el legado del estado napoleónico era tan útil que no era conveniente desmantelarlo, como tampoco creyó sensato prescindir de buena parte del personal de la administración ocupada; eso sí, trató de soslayar los vínculos directos con el pasado revolucionario y, por ejemplo, recurrió al uso de términos enraizados en la tradición neerlandesa para designar las instituciones del nuevo estado ${ }^{42}$.

40. Carta particular fechada en Granada el 23 de marzo, El loco constitucional, 24/03/1814. De la difusión de noticias y rumores contradictorios, propios del desconcierto del momento, da cuenta una nueva carta, fechada en Granada el tres de mayo, y publicada en el mismo periódico, que anunciaba que Luis XVIII había sido aclamado "rey constitucional" y que los emperadores de Rusia y Austria y demás príncipes aliados habían reconocido "el derecho que tiene todo pueblo para formar sus leyes fundamentales", El loco constitucional, 03/05/1814.

41. Puntualmente también fueron incorporados a la nómina de regímenes constitucionales de interés los ejemplos de Inglaterra y Suiza. "Reflexiones", El Conciso, 02/05/1814.

42. LoK, Matthijs, "Lextrême centre est-il exportable?", Annales Historiques de la Révolution Française, 357 (2009), pp. 143-159. Dentro de la estrategia de enmascaramiento se encuentra el uso de un vocabulario prerrevolucionario en la constitución holandesa, que, por ejemplo prefirió para la Asamblea la denominación antigua de Estados Generales. El concepto original de "extrême-centre" en SERNA, Pierre, La république des girouettes. 1789-1815 et au-delà. Une anomalie politique: la France de l'extrême centre, Paris, Champ Vallon, 2005. La apuesta por el olvido, otro de los ejes de la política de "extrême-centre", 
La primera alusión hecha por El Conciso a la Constitución holandesa, muestra el temprano interés despertado por ella. Data del nueve de abril y reproduce parte del discurso dirigido por Guillermo de Orange a los holandeses para presentarles la nueva constitución ${ }^{43}$. Poco más tarde, un largo artículo, publicado también por El Conciso, vinculaba la extensión del constitucionalismo en Europa con la renovación política española. En concreto, reconocía con orgullo que los españoles no sólo habían dado ejemplo a Europa con su heroica lucha por la independencia, sino que ahora también eran imitados "hasta en las reformas de las leyes políticas", y presentaba como prueba el caso de Holanda. El articulista, que no debía conocer el caso de primera mano, destacaba que el príncipe de Orange, una vez entre sus súbditos, les había encargado la formación de una "Constitución política", y eso que podía haber continuado gobernando según las leyes antiguas, porque "ni príncipe, ni súbditos tenían recíprocas reclamaciones que hacerse". A partir de este momento, la ponderación del caso holandés daba paso a un aviso a Fernando, puesto que si el Stadhouder, presentado como el llegado, no tenía compromisos adquiridos con los holandeses - "debe sus estados a las potencias aliadas y a los nobles esfuerzos de los holandeses por espacio de 20 días"-, Fernando, presentado significativamente como el rescatado, no tenía derecho a "deshacer lo que la nación ha hecho" ${ }^{44}$. Pronto el ejemplo holandés sería asociado al francés, y la conducta de Luis XVIII y su propuesta constitucional fueron igualmente presentadas como producto de la imitación del ejemplo español: “ ¡La Francia proclamando a favor de todos una Constitución política de la monarquía!" 45 .

Aunque un análisis detallado de las propuestas holandesa y francesa habría dejado bien claro lo alejadas que estaban de la experiencia de Cádiz, la prensa liberal no dudó en presentarlas como resultado de la gran influencia ejercida por el modelo político español en Europa -"Dos naciones nos han imitado ya en el ejemplo de formar una Constitución política", afirmaba el 25 de abril un nuevo artículo de El Conciso-, estrategia que permitía formular la pregunta clave,

sería reconocida por la prensa a los Borbones franceses con motivo de la entrada en París del conde de Artois, hermano de Luis XVIII, cuando se hizo eco de que, preguntado por el Senado, el futuro Carlos X contestó que el rey "no tenía otro objeto que la felicidad de la nación; que un eterno olvido y perdón era el primer paso para ello" ("Las tres nuevas Constituciones" El Conciso, 01/05/1814).

43. "Nueva Constitución política de Holanda", El Conciso, 09/04/1814. El mismo artículo sería reproducido luego por El loco constitucional, 25/04/1814. La reproducción del discurso del Stadhouder sería completada el 30 de abril, "Sobre los negocios de Holanda", El Conciso, 30/04/1814.

44. "Sobre la resolución del Stadhouder mandando hacer una Constitución política para Holanda", El Conciso, 20/04/1814.

45. "Bonaparte ya destronado", El Conciso, 22/04/1814. La cursiva es nuestra. 
esto es, por qué, si ellas caminaban en esa línea, iban a dar los españoles "un paso retrógrado" ${ }^{46}$. Con todo, la propaganda de las primeras semanas no dejaba de reconocer que la perfección del modelo, fruto de la madurada reflexión de las cortes gaditanas, no estaba al alcance de las copias:

"En Holanda salió hecha una constitución en pocos días; en París otra en 5 días, y el rumor de hoy es que en Valencia se ha hecho otra. Nadie duda que Constituciones hechas en un santiamén han de ser mejores que la que se haya formado en un año, y se aprobase después de una larga y bien discurrida discusión" $"$.

Conforme la situación se fue complicando, y el futuro del régimen español dejó de estar asegurado, las alusiones a los procesos constitucionales de Holanda y Francia dejaron de aparecer como resultado de la influencia del ejemplo español, y empezaron a ser mostrados como los modelos a seguir. Esta inversión de papeles se percibe ya a principios de mayo cuando, en el citado contexto de creciente desconfianza hacia el rey, El Conciso publicaba un largo artículo titulado "Las tres nuevas Constituciones". El escrito analizaba primero el código español, del que destacaba, en la línea del discurso doceañista, que descansaba sobre "las leyes antiguas de España" y subrayaba igualmente que contaba con la legitimidad conferida por el apoyo de los pueblos. Pasaba luego a criticar el comportamiento del rey, que no había jurado la constitución al entrar en España, traicionando el apoyo popular recibido en la guerra. Frente a la conducta de Fernando, el articulista ponía el acento en el proceder de los monarcas holandés y francés, quienes, sin haber adquirido una deuda similar con sus pueblos, habían decidido "libre y espontáneamente" limitar su poder mediante la aprobación de sendos códigos constitucionales, que el autor del artículo presentaba interesadamente como emanados de los pueblos: "los franceses y holandeses conseguirán hacer observar su Constitución, y los españoles darán el ejemplo al contrario! El rey de Francia y el Stadhouder de Holanda jurarán la Constitución que sus pueblos hagan, y Fernando VII dudará!" ${ }^{38}$.

46. "Sobre cosas del día", El Conciso, 25/04/1814.

47. El Conciso, 27/04/1814.

48. "Las tres nuevas Constituciones", El Conciso, 01/05/1814. Esta idea sería repetida en los días finales del reinado, en los que no se quiso perder la esperanza de que Fernando siguiera el ejemplo de Luis XVIII: "la legitimidad de nuestro monarca Fernando VII en España se enlaza con la de Luis XVIII en Francia, y ¿cuando el excelso Luis restituido a su trono por voto general de la nación es benéfico con el pueblo francés, se ha de temer que Fernando, aún mucho más querido, no lo sea con sus predilectos españoles?" (Artículo sin título, firmado por J. B. P. D. C. D. S. M. en Madrid el 9 de mayo, El Conciso, 11/05/1814). 
Con el golpe de estado a punto de ser ejecutado, las llamadas a la moderación constitucional y la ponderación de los regímenes templados aumentaron. Así, el nueve de mayo las páginas de El Conciso presentaban a Inglaterra, Holanda y Francia como ejemplos de la compatibilidad entre monarquía y constitución y auguraban escaso éxito al retorno del absolutismo si se enfrentaba a la moderación: "el poder absoluto no será sino efímero, o a lo menos de muy corta duración, entre los pueblos que una vez han gustado de la libertad civil en los moderados términos que exige el bien general de una nación y la seguridad del trono"49. El loco constitucional también respaldaría, en los momentos previos al golpe, la alternativa transaccional. Lo hizo en un artículo en forma de diálogo que buscaba remedio a "la enfermedad Reinante", recordando el origen pactista de la monarquía, que se remontaba al acuerdo de los hombres reunidos en "sociedad, patria o Nación"; si bien lo más interesante, en este caso, es el aviso incluido en una nota inicial, verdadera declaración moderada de principios: "Cuidadito señores que yo quiero Reyes, pero los quiero decididamente moderados o constitucionales, porque vivo persuadido que la Monarquía moderada que es la constitucional es la que conviene más a la Europa actualmente" ${ }^{\text {. }}$.

Estas apelaciones a la moderación acabaron convergiendo con la aspiración absolutista de convocar cortes tradicionales. Esta idea, que podía resultar reaccionaria meses atrás, permitía, en el crítico contexto de mayo de 1814, albergar alguna esperanza sobre un eventual establecimiento de una monarquía moderada. De este modo, y aunque los absolutistas apenas defendieron públicamente sus ideas, no es de extrañar que quienes se aferraban a la salida transaccional conocieran sus propuestas, plasmadas por ejemplo tanto en el luego conocido como Manifiesto de los Persas, que había sido firmado el 12 de abril, como en el folleto coetáneo estudiado hace unos años por Jean-René Aymes ${ }^{51}$. Ambos coincidían en la negación de la legitimidad de la Constitución de Cádiz y en la necesidad de anular toda la obra de las Cortes, si bien es cierto que al mismo

49. Sin título, El Conciso, 09/05/1814. El mismo artículo daba a entender que la situación de Europa respaldaba el constitucionalismo, y se preguntaba qué harían todos los que habían reconocido la constitución española, incluido el zar, si ahora la veían despreciada.

50. "PE-A-ENE-PAN, O DIÁlOGO MÉDICO-PRESERVATIVO contra la enfermedad Reinante", firmado por Dr. Perogrullo, El loco constitucional, 10/05/1814.

51. Aymes, Jean-René, "Un folleto de la primavera de 1814 en el centro del pensamiento absolutista", en Aymes, J.-R., La Guerra de la Independencia (1808-1814): calas y ensayos, Madrid, CSIC/Doce calles, 2009, pp. 379-392. El folleto se titulaba Observaciones sobre los atentados de las Cortes Extraordinarias de Cádiz contra las leyes fundamentales de la Monarquía Española y sobre la nulidad de la Constitución que formaron, estaba firmado por P.D.M.R. y fue impreso por Ibarra en Madrid en mayo de 1814. 
tiempo defendían el establecimiento de un sistema político basado en las leyes fundamentales del reino, que debía permitir sentar las bases de un nuevo tiempo político a partir de la celebración de Cortes "con la solemnidad y en la forma que se celebraron las antiguas", como proponía el párrafo 141 del Manifiesto de los Persas. Con todo, las propuestas absolutistas, que podían haber dado lugar a un acercamiento entre los más centrados de uno y otro bando, fracasaron por completo, en gran medida porque la contraofensiva fernandina descansaba esencialmente en el apoyo de un importante sector del ejército, y no tanto en el de los firmantes del Manifiesto de los Persas, con quienes el rey no había adquirido compromiso alguno ${ }^{52}$. A la postre, la idea de convocar cortes y reformular las bases de la política y la legislación española creó tanta inquietud en Fernando VII, que no sólo demolió la obra de las Cortes de Cádiz, sino que ni siquiera llegó a reunir las cortes tradicionales postuladas por los diputados absolutistas. El golpe de mayo cerró así las puertas a una posible solución de compromiso, como lo han señalado tanto Roberto Breña, que cree que ésta podía haberse configurado como una opción "entre el absolutismo fernandino y el liberalismo de los diputados gaditanos (si bien con muchas más afinidades respecto al primero)" "53; como Brian Hammet, que considera que el golpe "impidió la evolución de un constitucionalismo conservador en España" ${ }^{\prime \prime}$.

52. Un análisis completo del protagonismo del rey y del ejército en el cambio político en Hammet, Brian R., La política española en una época revolucionaria, 1790-1820, México D. F., FCE, 2011 ( $2^{a}$ ed.), en especial el capítulo VII.

53. BREÑA, Roberto, El primer liberalismo español y los procesos de emancipación de América, 1808-1824. Una revisión historiográfica del liberalismo hispánico, México D. F., El Colegio de México, 2006, p. 243.

54. Hammet, Brian R., La política española..., p. 183. 


\title{
El mito contrarrevolucionario de la «Restauración»" The counter-revolutionary myth of the «Restauration»
}

\author{
Pedro Rújula \\ Universidad de Zaragoza
}

Recibido: 23-IX-2014

Aceptado: 24-X-2014

\section{Resumen}

Durante la guerra de la independencia los sectores ultra-realistas construyeron la imagen de que el mundo anterior había sido atacado en sus bases y destruidos los elementos que lo sustentaban. Una amplia publicística fue creciendo en este contexto. Sin embargo, ante el inminente regreso del rey en 1814, vieron la oportunidad de recuperar el poder perdido y cambiaron de estrategia. El mito de la recuperación del orden perdido mediante la restauración de los Borbones va a ser el instrumento del que los realistas se valdrán para negar la magnitud de los cambios vividos durante aquellos años. El presente artículo intenta explicar la importancia que tuvo la construcción del mito de la restauración para sustentar el golpe contrarrevolucionario de mayo de 1814 .

Palabras clave: Guerra de la Independencia, Fernando VII, mito, ultrarrealismo, contrarrevolución.

\section{Abstract}

During the Peninsular war, the ultra-realist sectors put forward the view that the basis of the old order had been attacked, and that its foundations had been destroyed. Widespread press activity promoting this view flourished. However, just before the return of the king in 1814 , these sectors envisaged an opportunity to recover lost power and altered their strategy. The realists turned the myth of the recovery of the

* El presente texto es una versión ampliada de la ponencia "La 'Restauration' comme mythe contre-révolutionnaire" presentada en el coloquio internacional "Rien appris, rien oublié? Les Restaurations dans l'Europe post-napoléonienne (1814-1830)", celebrado en Clermont-Ferrand el 7 y 8 de octubre de 2013. El trabajo ha sido realizado en el marco del proyecto "Restauración y monarquía en los orígenes del Mundo Contemporáneo. España y Europa, 1814-1848" (HAR2012-32604) del Ministerio de Economía y Competitividad. 
lost order through the restoration of the Bourbon dynasty into an instrument intended to deny the relevance of previous changes. This essay aims to explain the role performed by the construction of the restoration myth in supporting the counter-revolutionary coup on May 1814.

Keywords: Peninsular War, Ferdinand VII, myth, Ultra-Realism, Counter-Revolution.

El discurso realista de 1814 justificó la destrucción de la obra de las Cortes de Cádiz como una forma providencial de regresar al orden perdido ${ }^{1}$. La voluntad de restaurar la monarquía en los mismos términos que la había dejado Fernando VII a su salida de España se apoyó en una concepción estática del tiempo que consideraba la experiencia vivida en los seis últimos años como superficial y anómala, y, por lo tanto, susceptible de desaparecer sin dejar huella sobre el sólido sustrato de estructuras institucionales y sociales que constituían el Antiguo Régimen.

Este planteamiento, sin embargo, no reflejaba la percepción que los propios realistas tenían de los cambios vividos. Todo lo contrario. Durante la Guerra de la Independencia, los defensores del poder real tomaron conciencia del desafío político que suponía la convocatoria de Cortes y la proclamación de la soberanía nacional, y del profundo foso que estos hechos abrían entre el pasado y el presente. Pero, llegado el momento del regreso de Fernando VII, olvidaron las visiones apocalípticas que les habían ocupado durante algunos años, adoptaron posiciones maximalistas y se decidieron a restablecer el poder en los antiguos términos. No bastaba con una recuperación simbólica o parcial²; el hijo de Carlos IV no estaba dispuesto a compartir sus prerrogativas reales con nadie.

El resultado fue un proyecto radical de recuperación del poder real que no tiene parangón en Europa. Para ello, los responsables se apoyaron en la idea de regreso al orden perdido, de restablecimiento de las cosas tal y como consideraban que deberían haber sido siempre. La "restauración" fue para el realismo una construcción ideológica que le iba a servir como instrumento político para la conquista del poder. Apoyándose en ella, en la legitimidad del pasado, era posible negar cualquier tipo de negociación. En estas condiciones, a los agentes del cambio solo les cabía desaparecer de la escena o ser víctimas de una encarnizada persecución.

1. Sobre el uso del término realista véase Rújula, Pedro, "Realismo y contrarrevolución en la Guerra de la Independencia", en Ayer, 86/2012 (2), pp. 45-66 y LuIS, Jean-Philippe, "La construcción inacabada de una cultura política realista", en CABRERA, Miguel Ángel y Pro, Juan (coords.), La creación de las culturas políticas modernas, 1808-1833, Marcial Pons-Prensas de la Universidad de Zaragoza, 2014, pp. 319-345.

2. Como el caso francés. WARESQUiEL, Emmanuel de y YverT, Benoît, Histoire de la Restauration 1814-1830, Perrin, Paris, 2002, pp. 56-63 y Demier, Francis, La France de la Restauration (1814-1830). Limpossible retour du passé, Paris, Gallimard, 2012, cap. I. 
No había nada de natural en aquella recuperación de un pasado que, con todo lo vivido, se presentaba muy lejano. Esta es la línea argumental de las siguientes páginas: que la idea de restauración del orden perdido fue una creación intelectual, un mito fomentado por los realistas para apoyarse en él y lanzarse a la recuperación del poder en la primavera de 1814. A través de este mito podrían explicar como un simple retorno al punto de partida lo que en realidad era una traumática negación de la experiencia de la guerra que comportaría una enorme carga de violencia para la sociedad española.

\section{El retorno del rey como fuente de inspiración política}

Para la mayor parte de los españoles la Guerra de la Independencia fue vivida como una quiebra de los cimientos sobre los que se apoyaba el mundo que habían conocido hasta entonces. No les faltaba razón. La invasión de las tropas napoleónicas supuso una profunda alteración de los elementos que definían su vida. Se había hundido la monarquía borbónica, y la religión había visto seriamente modificado su estatus. Cambiaron la fiscalidad, las relaciones de propiedad y también el rostro de las autoridades tradicionales ${ }^{3}$. La política tampoco fue la misma -desde las juntas hasta las Cortes- en el territorio patriota ${ }^{4}$, donde la naturaleza del poder se vio muy alterada; y no muy distinto fue lo ocurrido en las zonas gobernadas por las autoridades josefinas ${ }^{5}$. En los seis años que el rey permaneció fuera del país todo se había alterado profundamente.

A los ojos de quienes tuvieron que padecerla, no había demasiadas dudas sobre la causa inmediata de aquella situación: la fuerza de los ejércitos imperiales que habían comenzado a extenderse por la Península en 1807 y el engaño del propio Napoleón, que había terminado con Fernando VII prisionero en Valençay y los Borbones destronados. "La ambición del tirano de la Francia -decía una de las proclamas patrióticas- ha llegado a nuestro territorio. El que pudo con la fuerza y con la astucia erigirse monarca de su nación misma, ha sabido con el engaño invadir el suelo español, y destronar la familia real, usurpando la corona al poseedor. Napoleón, llamado protector, y auxilio de

3. Por ejemplo, vid. Toreno, Conde de, Historia del levantamiento, guerra y revolución de España, Pamplona, Urgoiti, 2008, p. 305.

4. HOCQUELLET, Richard, Resistencia y revolución durante la Guerra de la Independencia. Del levantamiento patriótico a la soberanía nacional, Zaragoza, Prensas de la Universidad de Zaragoza, 2008, cap. 2.

5. Vid. MerCader Riba, Juan, José Bonaparte rey de España, 1808-1803. Historia externa del reinado, Madrid, Consejo Superior de Investigaciones Científicas, 1971 y José Bonaparte, rey de España. 1808-1813. Estructura del estado español bonapartista, Madrid, CSIC, 1983. 
un Príncipe desgraciado, ha sido el mayor enemigo que atacó su inocencia, causándole el despojo de su trono contra los más sagrados derechos"6. Detrás de todo esto, como se encargó de reiterar hasta la saciedad desde los primeros momentos la retórica patriótica, se identificaba la obra de la revolución. Era difícil que los ejércitos imperiales no fueran comparados con los de la república francesa contra los que muchos de los españoles habían combatido, o de los que habían oído hablar, algo más de una década atrás ${ }^{7}$.

Situado en el exterior el origen de los problemas, el discurso nacionalista se mostró de una eficacia arrolladora. Rey, Dios y Patria fueron la tríada que guió los pasos de los primeros que tomaron las armas. "Ea españoles, -rezaba una proclama dirigida a los cordobeses-, a las armas. Sed fieles a Dios, al Rey y a la Patria9". El rey ocupaba el centro del discurso; la religión, con el clero como propagandista, daba legitimidad a la causa y velaba por sus intereses; la patria sustanció la idea de colectivo amenazado ${ }^{10}$. El tiempo pasó y la guerra siguió invadiéndolo todo. Sin embargo, la imagen del rey distante apenas se vio afectada en su prestigio ${ }^{11}$. Todo lo contrario, se convirtió en la fuente de inspiración de los proyectos políticos futuros. En realidad, los proyectos que se forjaron en aquel país en llamas tenían profundas discrepancias entre si, pero esto, de momento, no supuso un obstáculo insalvable.

En realidad, la ausencia del monarca sirvió para reforzar la importancia de su figura en todos los proyectos políticos ${ }^{12}$. Se había convertido en una preciada materia que cada uno modelaba a según sus intereses. Mientras el rey estuviera ausente, invocarlo políticamente se convirtió casi en una garantía de éxito.

6. "Españoles, nobles fieles habitantes de la real isla de León", en Demostración de la lealtad española: colección de proclamas, bandos, órdenes, discursos, estados de Exército y relaciones de batallas publicadas por las juntas de gobierno, o por algunos particulares en las actuales circunstancias, Madrid, Imprenta de Repullés, 1808, vol. I, p. 31.

7. VÉlEz, Rafael de, Preservativo contra la irreligión o los planes de la filosofía contra la Religión y el Estado, realizados por la Francia para subyugar la Europa, seguidos por Napoleón en la conquista de España, Palma, Imprenta de Brusi, 1813, p. 6.

8. HOCQUELLET, Richard, Resistencia y revolución..., pp. 120-129.

9. "Córdoba a los españoles", en Demostración de la lealtad española..., vol. I, 1808, p. 37.

10. Rújula, Pedro, "Realismo y contrarrevolución en la Guerra de la Independencia", en Ayer, 86 (2012), pp. 45-66.

11. Esta era la opinión de Blanco White recogida en Moreno Alonso, Manuel, "La 'fabricación' de Fernando VII", en Ayer, 41 (2001), pp. 29-30.

12. VARELA SuANZES-CARPEGNA, Joaquín, «Rey, corona y monarquía en los orígenes del constitucionalismo español: 1808-1814», Revista de Estudios Políticos, 55 (1987), pp. 123-195, «La monarquía imposible: la Constitución de Cádiz durante el Trienio», Anuario de Historia del Derecho Español, LXVI (1996), pp. 653-687 y LA PARRA, Emilio, "Fernando VII, el rey imaginado", en LA PARRA, Emilio (coord.), La imagen del poder. Reyes y regentes en la España del siglo XIX, Madrid, Síntesis, 2001, pp. 35-45. 
Apenas puede entenderse la práctica homogeneidad monárquica que preside la política española entre 1808 y 1814 sin tener en cuenta que la ausencia del rey permitía un amplísimo margen de maniobra en la utilización de su imagen. Recientemente, Joaquín Varela Suanzes-Carpegna se ha referido a la ausencia de republicanos en las Cortes de Cádiz. En definitiva, afirma, que "ningún diputado se manifestó a favor de la república, porque "esta forma de gobierno se identificaba en aquella Asamblea con la democracia directa de la antigüedad, con los excesos de la Convención francesa de 1793 y con el federalismo de los Estados Unidos"13. Y, podríamos añadir, esa no era una solución deseable para casi nadie en aquel contexto con el rey ausente y la soberanía real en sus manos.

Indudablemente los dos grandes proyectos políticos desarrollados en el campo patriota, el liberal, o constitucional, y el realista, o servil, tenían su mirada puesta en el momento en que Fernando VII regresara al país. Para ellos ese sería un momento clave, el del cierre de un ciclo de excepcionalidad. No obstante, sus planes sobre el papel que debía cumplir en rey en ese escenario futuro no solo eran muy diferentes, sino irreconciliables.

De un lado, los liberales de Cádiz habían aprovechado la ausencia del rey para introducir un profundo cambio en la naturaleza del poder real sustituyendo los fundamentos pactistas del trono llegados hasta la fecha por el nuevo principio de la soberanía nacional. Habían transformado las bases del régimen monárquico que existía al comienzo de la Guerra de la Independencia en un sistema sostenido sobre la soberanía de un nuevo ente político: la nación. La llegada del rey, la reposición en su trono, era para ellos el reconocimiento de los cambios producidos hasta ese momento ${ }^{14}$. De ahí que el decreto que regulaba las condiciones de entrada del rey en España fuera muy claro en este sentido. El rey debía jurar la constitución antes de cualquier reconocimiento, solo después "darán las Cortes un Decreto con la solemnidad debida, a fin de que llegue a noticia de la nación entera el acto solemne, por el cual y en virtud del juramento prestado, ha sido el Rey colocado constitucionalmente en su Trono"15.

Por su parte los realistas aspiraban a hacer del regreso de Fernando VII un verdadero acto de restauración monárquica. Sería el cierre de un parénte-

13. Varela SuAnzes-Carpegna, Joaquín, La monarquía doceañista (1810-1837), Madrid, Marcial Pons, 2013, p. 24.

14. La PARra, Emilio, "La metamorfosis de la imagen del Rey Fernando VII entre los primeros liberales", en Cortes y revolución en el primer liberalismo español: actas de las "Sextas Jornadas sobre la Batalla de Bailén y la España Contemporánea", Jaén, Universidad de Jaén, 2004, pp. 73-95.

15. El decreto del 2 de febrero de 1814 se encuentra reproducido en la obra del Marqués de MiRAFlORES, Documentos a los que se hace referencia en los apuntes histórico-críticos sobre la Revolución de España, Londres, Oficina de Richardo Taylor, 1834, t. II, p. 22. 
sis temporal donde todo había estado fuera de su lugar. Un tiempo de excepcionalidad al que se ponía fin y abría la posibilidad de volver al punto de partida; a la sociedad del pasado, a sus principios y a su orden, a sus instituciones y a sus leyes. "Nuestro adorado Monarca -afirmaba El Fernandino-, el Señor D. Fernando VII, fue proclamado Rey en todos sus estados de América y Europa en 1808. A ningún diputado de las Cortes extraordinarias y ordinarias se le dio poder para anular o alterar esta solemne proclamación. Así es que la misma Constitución lo declara por Rey de las Españas, sin hacer depender el ejercicio de su autoridad soberana, más que de su libertad del cautiverio"16.

\section{Conciencia de los cambios}

Cuando el rey entró en Valencia, en abril de $1814^{17}$, nadie negaba la magnitud de todos los cambios que se habían producido en España durante los años anteriores. Los publicistas del realismo se habían esforzado en dibujar con tintes apocalípticos las transformaciones ocurridas desde la salida del rey del país. "Nuestra patria y nuestra religión están en peligro -proclamaba el padre Vélez-, no tanto por la irrupción que han hecho en nuestras provincias los franceses, cuanto por la multitud de prosélitos que han ganado a su partido, de que es una prueba indudable tantos periodistas y papeles públicos que se empeñan en ilustrarnos a la francesa, es decir, pervertirnos"18.

Muy claro había sido ya, en octubre de 1810, el obispo de Orense, Pedro Quevedo y Quintano, en su renuncia como miembro del Consejo Supremo de Regencia. "Parece haber sido convocadas las Cortes para decidir sobre los derechos del Rey, en conformidad de la voluntad general de la Nación [...] y se pasan en silencio los derechos anexos a la sucesión en una Corona hereditaria, el juramento de Fernando VII como Príncipe hereditario, y sucesor inmediato a la Corona, su proclamación por Rey en Madrid, y general consentimiento y aclamación general de toda España". Y consciente de las implicaciones que tenía la reunión de Cortes en estos términos afirmaba: "El Congreso Nacional ha empezado por el ejercicio y declaración de derechos y Soberanía, que ni la Nación misma, y menos sus Representantes aun en la forma más legal, tienen, ni pueden atribuirse, ofendiendo los del Soberano, y abriendo el camino de destruirlos y arrojarle del Trono, sin embargo que juran defenderlo

16. El Fernandino, 1 de mayo de 1814, p. 20.

17. García MonerRIs, Encarna y García MonerRis, Carmen, La nación secuestrada. Francisco Javier Elío. Correspondencia y Manifiesto, Valencia, Universitat de València, 2008, pp. 26-30.

18. VÉLEz, Rafael de, Preservativo contra la irreligión..., p. 135. 
[...]. Si la Soberanía reside en la Nación y en sus Representantes; si Fernando VII es Rey por la voluntad general, y su renuncia es principalmente nula por falta de ella, será forzoso convenir en que Fernando VII y sus Sucesores son los primeros vasallos de la Nación, y esta su soberana" ${ }^{19}$.

Algo más lento de reflejos, pero igualmente concluyente, se había mostrado el regente Miguel de Lardizábal. "Sé que la Soberanía -decía- no debe estar en las Cortes; pero está de hecho". Y defendía que el Consejo de Regencia "no debió consentir el despojo de la Soberanía, pues debió mantenerla hasta que pasase legítimamente a otro, que no podían ser las Cortes, porque estas representan a la Nación, sino el nuevo Gobierno que había de representar al Rey, que es el Soberano jurado y reconocido por toda la Nación y por las mismas Cortes en la mañana de aquel día". Así, Lardizábal, que al escribir su justificación vivía en París, identificaba lo sucedido en Cádiz con el proceso revolucionario francés y afirmaba que en España se había producido "la introducción y propagación de las máximas Republicanas y el Democratismo; porque proclamar la Soberanía del Pueblo y establecer la República o el Democratismo todo es uno"20.

Desde su atalaya mallorquina, algunos de los obispos huidos de sus diócesis denunciaban el peligroso avance de las ideas revolucionarias que amenazaban seriamente su dominio sobre las ideas y sus privilegios económicos. Especialmente grave consideraban el contagio entre los propios españoles, porque "las mismas máximas vestidas a la Española, y disfrazadas sagazmente bajo el pretexto de reformas por escritores domésticos que blasonan tanto de amigos de la Patria, y de Católicos Apostólicos Romanos, pueden seducir más fácilmente a los incautos bajo el falso sobrescrito de patriotas y de amigos nuestros; siendo realmente como aparecen en sus escritos, los enemigos más pérfidos de la Religión y de la Patria, y los seductores más artificiosos y más perjudiciales en España que los Franceses mismos". Y alertaban a los párrocos del "abuso de la libertad de imprenta, para fascinar al pueblo incauto con las fementidas promesas de una ilustración y felicidad eterna" y de los progresos de los "pensamientos rastreros de una filosofía mezquina". Todo ello sin olvidarse de denunciar las amenazas materiales que se cernían sobre la Iglesia, es decir, la

19. El documento, fechado en Cádiz el 3 de octubre de 1810 está reproducido en Manifiesto del Excmo. Sr. obispo de Orense a la nación española, Granada, Imprenta Nueva de Valenzuela, 1814. Las citas en pp. 4 y 7.

20. Manifiesto que presenta a la nación el consejero de Estado D. Miguel de Lardizábal y Uribe, uno de los cinco que compusieron el Supremo Consejo de Regencia de España e Indias, sobre su conducta política en la noche del 24 de septiembre de 1810, Alicante, Nicolás Carratalá Menos y Hermanos, 1811. Las citas en pp. 9, 10 y 11. 
perdida de "inmunidad" de sus propiedades, e incluso, el "proyecto de un despojo completo de los bienes de la Iglesia"21.

Esta publicística realista también se aplicó a defender el mantenimiento de la sociedad jerárquica del Antiguo Régimen. "Se sabe que en toda sociedad bien ordenada -afirmaban los obispos- hay clases de ciudadanos destinados a los ramos más importantes que la interesa, clases revestidas de las prerrogativas convenientes para el desempeño más exacto de sus respectivos ministerios. [...] Pretender igualar en consideración, y en toda suerte de derechos y obligaciones $[\ldots]$ sería confundirlo todo"22. Aunque quien más incidió en esta idea fue Joaquín Colón de Larreátegui en un texto escrito en 1811 y que tuvo mucho éxito tras la restauración. En él había defendido con fuerza la necesidad de mantener las jerarquías, el sistema estamental y las prerrogativas de cada grupo frente al cuestionamiento liberal. "Si se habla de príncipes -denunciaba-, fueron y son tiranos. Si de grandes, inútiles, viciosos y afrenta de la sociedad. Si de honores y distinciones, blasones, armas, títulos y apellidos, invenciones aéreas, productivas de ridículas vanidades. Si de jueces y tribunales, ineptos, arbitrarios y corrompidos. Si de antiguas leyes y legislaciones, las llaman godas, feudales y caducas, truncando su sentido, y desechando con vituperios las que no confrontan con sus eversivos principios. ¿Qué es esto, desgraciada España?"23.

Esos mismos argumentos, construidos para la defensa del Altar y del Trono, tanto de los franceses como de los liberales de Cádiz, iban a ser retomados por los defensores de una restauración absolutista. Su objetivo era ahora denunciar todas las transformaciones sufridas durante aquellos años, señalar a los culpables y poner de manifiesto el sacrificio y abnegación de los realistas. Para conseguirlo, no dudarían en reconocer la magnitud de unos cambios que habían afectado a todos los ámbitos de la realidad.

Defendieron que durante aquellos años se había despojado de poder a la monarquía. Se había "atentado contra las prerrogativas del trono", imponiéndole un "yugo". Se había llegado a hacer del rey un "mero ejecutor delegado, que no rey -dicen los textos-, aunque allí se le de este nombre para alucinar y seducir a los incautos y a la nación"24.

21. Instrucción pastoral de los ilustrísimos señores arzobispo de Tarragona, y obispos de Lérida, Tortosa, Barcelona, Urgel, Teruel, y Pamplona al clero y pueblo de sus diócesis, Barcelona, Imprenta del Brusi, 1814, segunda impresión. Las citas en pp. 6, 9 y 84.

22. Ibid., p. 115.

23. Colón LARREÁtegui, Joaquín de, España vindicada en sus clases y autoridades de las falsas opiniones que se le atribuyen, Madrid, Imprenta de Repullés, 1814, $2^{\mathrm{a}}$, p. 4.

24. Real decreto dado en Valencia el 4 de mayo de 1814. Gaceta extraordinaria de Madrid, 12 de mayo de 1814 , p. 517. 
El instrumento utilizado para privar de poder al rey era la "soberanía nacional", proclamada por las Cortes y de la cual se habían nombrado depositarias. De ahí se había derivado un "democratismo" que había visto sustituir por el nombre de "nacional" lo que hasta la fecha era "real". Esta forma de concebir las cosas cortó "de raíz las jerarquías sin las que no puede existir ningún gobierno monárquico" 25 . La prueba era, decían, que "apenas quedaron las provincias libres de franceses, se vieron sumergidas en una entera anarquía, y su gobierno a pasos de gigante iba a parar en un completo despotismo"26.

Los eclesiásticos se ocuparon de señalar todos los atentados sufridos por la religión durante este tiempo. En su argumento estaba la idea de que la Iglesia era la primera línea de fuego sobre la que se había abatido la revolución antes de lanzarse a disolver el resto de las instituciones sociales. En el plano de las medidas concretas mostraron su alarma por la reforma de regulares, la apropiación de bienes de la Iglesia y la abolición de la Inquisición ${ }^{27}$.

Auténtica obsesión para todos los realistas, eclesiásticos y laicos, fue denunciar la libertad de imprenta, como factor que había destruido el principio de subordinación ${ }^{28}$. Las denuncias venían de lejos. Existía toda una explicación conspirativa deudora de Barruel que servía para demostrar la perversión de los planes revolucionarios en este campo. "Para preparar los ánimos a recibir tamañas novedades $[\ldots]$ se procuró por medio de los papeles públicos [...] y abusando de la libertad de imprenta, hacer odioso el poderío real, dando a todos los derechos de su majestad el nombre de despotismo, haciendo sinónimos los de Rey y Déspota, y llamando tiranos a los Reyes" ${ }^{29}$. La libertad de imprenta había producido la aparición de una opinión pública que se revelaba contra la tradicional autoridad intelectual. "Los que no leen un papel leen otro, el que no los ha visto, habla como de oídas; a las veinte y cuatro horas de publicado un artículo contra frailes, clérigos e inquisición ya todos lo saben, todo lo hablan"30.

También señalaron como una realidad de aquellos años la disolución de los privilegios estamentales. Las Cortes habían abolido los señoríos jurisdic-

25. Representación y manifiesto que algunos diputados a las cortes ordinarias firmaron en los mayores apuros de su opresión en Madrid para que la majestad del señor don Fernando el VII, a la entrada en España de vuelta de su cautividad, se penetrase del estado de la nación, del deseo de sus provincias, y del remido que creían oportuno; todo fue presentado a S.M. en Valencia por uno de dichos diputados, y se imprime en cumplimiento de real orden, Madrid, Imprenta de Ibarra, 1814, p. 37.

26. Representación y manifiesto..., p. 14.

27. Ibid., pp. 31, 32.

28. Ibid., p. 14.

29. Real decreto dado en Valencia el 4 de ayo de 1814. Gaceta extraordinaria de Madrid, 12 de mayo de 1814, pp. 517-518.

30. Rafael de Vélez, Preservativo contra la irreligión..., p. 134. 
cionales, también las pruebas de nobleza para la entrada en el ejército y en todo parecía notarse un "empeño de atacar los derechos y jerarquía de la nobleza y de atraer al mismo tiempo en apoyo de la novación, con indultos, gracias y concesiones a la popularidad misma". Se difundió así el "veneno de la soñada igualdad"31. El cambio había sido tan profundo que incluso podía apreciarse en el lenguaje. "Hablábase de nuevo sistema, y de una transformación general hasta en los nombres que nunca habían influido en la substancia"32.

De hecho era todo el sistema político el que se había visto alterado por obra de la "nueva constitución". La Constitución de 1812, en contraste con la antigua, era considerada un "yugo" para la nación, un "atentado contra las prerrogativas del trono", un "abuso" en nombre de la "nación", consumado mediante "violencia" y suplantando la "voluntad general" con una forma de hacer las leyes ajena a la nación española. La Constitución de Cádiz consagraba "el tropel de novedades con que se habían sepultado la legislación, usos y costumbres de España". Reconocen los escritos realistas que "casi toda la forma de la antigua constitución de la monarquía se innovó", y se hizo "copiando los principios revolucionarios y democráticos de la constitución francesa de 1791"33. También se la identificaba con "la que dictó la tiranía en Bayona, y [...] la que ató las manos a Luis XVI en Francia, principio del trastorno universal de Europa" ${ }^{34}$.

En definitiva, los realistas que aguardaban la llegada de Fernando VII no tuvieron ningún inconveniente en reconocer todas las transformaciones vividas hasta la fecha y en señalar que en España se habían seguido durante los últimos años los pasos de la revolución francesa. "Los franceses atacaron de frente la religión y la nobleza; lo mismo habéis hecho vosotros. De un golpe lo derribasteis todo. Los franceses ataron al Rey, no de frente, porque veían las resultas, sino por rodeos; lo mismo hacéis vosotros. Le quitasteis la soberanía; primer ataque. Le quitasteis el tesoro; segundo ataque. Le señalasteis ruta para hacerle entrar en el carril, y conducirle por él al Congreso; tercer ataque. Habéis mandado que no se le reconozca por Rey hasta que no jure; cuarto ataque. Habéis prohibido con penas hasta de la muerte a los que hablen de Constitución, a los que aconsejen al Rey, etc.; quinto ataque..." 35 .

31. Representación y manifiesto..., pp. 15-16.

32. Ibid., p. 11.

33. Real decreto dado en Valencia el 4 de mayo de 1814. Gaceta extraordinaria de Madrid, 12 de mayo de 1814, pp. 517-517.

34. Representación y manifiesto..., p. 29.

35. Lucindo a la difunta majestad (que en paz descanse) las Cortes extraordinarias y ordinarias, [Valencia, 25 abril de 1814], p. 5. Vid. también Representación y manifiesto..., p. 34. 
A la altura de 1814, el enemigo señalado no eran ya los franceses, sino los liberales de Cádiz, a quienes se acusaba de haber actuado como los mismísimos revolucionarios del vecino país. La actuación de las Cortes de Cádiz, para ellos, se hizo "respirando la propia táctica francesa, que tanto odio les había causado, fue lo primero que se presentó a la vista. Vimos emigrados y expatriados los obispos, como en las más amargas persecuciones de la Iglesia [...]. Vimos los regulares virtualmente extinguidos, que había sido uno de los primeros cuidados de Napoleón. Vimos abandonado el cuidado de los ejércitos, cuando más se necesitaba la fuerza para acabar de lanzar al enemigo y poner una barrera impenetrable sobre los Pirineos. Vimos que hasta el sistema de hacienda se había desconcertado y hecho odioso, cuando más se necesitaba de auxilios. Y, en fin, nuestros ojos, cansados de llorar desgracias, vieron que aun no habían acabado este oficio"36.

\section{Las bases teóricas para una vuelta atrás}

Pese al reconocimiento de los importantes cambios que habían tenido lugar durante la ausencia del rey, los defensores de posiciones realistas no dieron la batalla por perdida. Ni siquiera se propusieron buscar una síntesis a la francesa. El regreso de Fernando VII fue la oportunidad para lanzarse a la reconquista del territorio cedido durante aquel tiempo. Lo hicieron apoyándose en la ola de entusiasmo popular que despertó su presencia en suelo español. Aquellas "demostraciones de amor de todos los que esperaban mi venida", a las que se refería el rey en el decreto de 4 de mayo de 1814, fueron interpretadas como un aval para la política restauradora. Una invitación a que, según sus palabras, "con mi presencia pusiese fin a estos males, y a la opresión en que estaban los que conservaron en su ánimo la memoria de mi persona, y suspiraban por la verdadera felicidad de la patria" ${ }^{37}$. Los que le acompañaron en aquellos planes de vuelta al pasado, confiados en la solidez de su posición, no dudaron en expresar ampliamente las bases teórico-políticas sobre las que se apoyaba su proyecto contrarrevolucionario.

Como hemos señalado, la religión había constituido uno de los principales baluartes para la defensa del realismo. No es de extrañar, pues, que el primer argumento en favor de la restauración del rey en sus antiguas prerrogativas fuera la Divina Providencia. "Fernando fue destinado desde la eternidad por Rey de España; debía necesariamente volver de su cautiverio, y reinar sobre noso-

36. Representación y manifiesto..., pp. 11-12.

37. Real decreto dado en Valencia el 4 de mayo de 1814. Gaceta extraordinaria de Madrid, 12 de mayo de 1814 , p. 518. 
tros, porque Dios así lo había revelado a todas las criaturas", era el argumento ${ }^{38}$. En otro lugar podía leerse esta nítida afirmación en que los propios realistas se presentan como instrumento divino en España: "La divina Providencia nos ha confiado la representación de España para salvar su religión, su Rey, su integridad y sus derechos" en el momento que se hallaba "dividida la opinión de sus vasallos, alucinados los incautos, reunidos los perversos, fructificando el árbol de la sedición, principiada y sostenida la independencia de las Américas, y amagadas de un sistema republicano las Provincias que representamos" 39 .

La restauración se apoyaba, además, en la tradición y en la legitimidad de un rey "sentado en el trono de sus mayores" 40 . Fernando VII había sido proclamado rey en 1808 y las Cortes lo confirmaron con la única salvedad de que fuera libre de cautiverio. La guerra que vino después se acometió en nombre del rey, "deseando vuestros vasallos que sus hijos muriesen en la religión de sus mayores, que volviesen a consolarse con la vista del primogénito de la casa de Borbón, y que la dinastía legítima, a quien Dios había confiado esta corona, pusiese término a tantas calamidades" 41 .

Otra fuente de autoridad para consumar el regreso al orden anterior era el apoyo del pueblo. Invocando la "voluntad de mis pueblos" 42 el rey se negaría a jurar la Constitución. Y siempre se complacería en recurrir al entusiasmo popular como una forma de legitimar su actuación. Por eso tanto los escritos oficiales como la literatura realista no dejaron de mostrar continuamente "ciudades y pueblos excitados por la acendrada lealtad y amor a su augusta persona [...] deseosos de dar un testimonio de la repugnancia y disgusto con que miran las novedades introducidas hasta aquí en el gobierno y administración del Estado, y de que S.M. ocupe el trono de sus mayores con todos sus derechos, prerrogativas y esplendor" 43 .

38. Periódico momentáneo de Valencia. El Fernandino, 1 de mayo de 1814, p. 62.

39. Representación y manifiesto..., p. 61. Vid también en el mismo sentido la circular del Ministerio de Gracia y Justicia, 15 de mayo de 1814 en la que afirma que "Dios ha puesto a su cuidado [la monarquía] por su restitución al trono" y este "pende principalmente de la divina asistencia". BALMASEDA, Fermín Martín de, Decretos del rey don Fernando VII. año primero de su restitución al trono de las Españas. Se refieren todas las reales resoluciones generales que se han expedido por los diferentes ministerios y consejos desde 4 de mayo de 1814 hasta fin de diciembre de igual año, Madrid, Imprenta Real, 1816, p. 14.

40. Circular del Ministerio de Ultramar, 24 de mayo de 1814. Fermín Martín de Balmaseda, Decretos del rey don Fernando VII..., p. 34.

41. Representación y manifiesto..., p. 11.

42. Real decreto dado en Valencia el 4 de mayo de 1814. Gaceta extraordinaria de Madrid, 12 de mayo de 1814 , p. 519.

43. Circular, 16 de mayo de 1814. Fermín Martín de Balmaseda, Decretos del rey don Fernando VII..., p. 15. 
Ese día había llegado. La vuelta al país de Fernando suponía también la recuperación de las prerrogativas históricas del monarca. "Ha llegado felizmente a nuestro seno -decía la prensa realista valenciana-, Dios le envía, sus derechos le acompañaban, el pueblo en masa con voz unánime y general lo aclama por su Rey y Soberano, el ejército desenvaina sus aceros para sostener la dignidad e independencia de su cetro. ¿Quién pues osará creerse con derecho para establecer condiciones que opongan el más leve obstáculo a su reinado...?"44. Voluntad divina, legitimidad monárquica, apoyo popular y, no hay que olvidarlo, las armas del ejército, parecían ser a sus ojos los pilares de la restauración; aunque estas últimas, las armas, no solían ocupar el primer plano en un discurso que se construía sobre la legitimidad.

Como fundamento jurídico de este retorno a la monarquía en su concepción tradicional se invocó la "antigua Constitución", la constitución histórica de la monarquía, no escrita, frente a la "nueva constitución", que era considerada como un artificio moderno. Porque, "Constitución había, sabia, meditada, y robustecida con la práctica y consentimiento general, reconocida por todas las naciones, con la cual había entrado España en el equilibro de la Europa, en sus pactos, en sus tratados, en las ventajeas de su unión y libertades, en la observancia de su derecho de gentes, y en las obligaciones de sus relaciones políticas" ${ }^{\prime 4}$. La antigua era una constitución superior porque había sido "ratificada por siglos" ${ }^{\prime 6}$ y no un producto improvisado al calor de los intereses temporales ${ }^{47}$.

Era esta antigua constitución la que reconocía al rey su soberanía. "Los monarcas gozaban de todas las prerrogativas de la soberanía y reunían el poder ejecutivo y la autoridad legislativa"48. Y también la que establecía su posición jerárquica superior en el conjunto de la sociedad. "La obediencia al rey es pacto general de las sociedades humanas, es tenido en ellas a manera de padre y el orden político que imita al de la naturaleza no permite que el inferior domine al superior". Recogía, por lo tanto, el pacto originario entre la sociedad y el monarca. El rey, a partir de ahí, disponía del poder absoluto, entendido como la soberanía plena. "La monarquía absoluta es una obra de la razón y de la inteligencia. Está subordinada a la ley divina, a la justicia y a las reglas fundamentales del estado. Fue establecida por derechos de conquista o por la sumisión voluntaria de los primeros hombres que eligieron sus Reyes"49. En todo caso, puntualizaban, que no debía confundirse poder absoluto con poder arbitrario ${ }^{50}$.

44. Periódico momentáneo de Valencia. El Fernandino, 1 de mayo de 1814, p. 20.

45. Representación y manifiesto..., p. 41.

46. Ibid., p. 62.

47. Ibid., p. 54.

48. Ibid., pp. 43 y 51 .

49. Ibid., p. 53.

50. En este sentido Javier LóPEZ Alós habla de absolutismo sui géneris por tratarse del ejercicio absoluto del poder ejecutivo, pero limitado por la instituciones y las leyes tradi- 
Uno de estos elementos de control, que tuvo mucho protagonismo en los primeros momentos de la restauración, fueron las Cortes. Los realistas invocaron unas Cortes "legítimamente congregadas", es decir, convocadas por el rey, "que la convocación a Cortes perteneció en todos tiempos y en toda monarquía al príncipe" 51 . Las Cortes encarnan la figura de un poder moderador y, al mismo tiempo, de una institución que aconseja a la autoridad real. "El cuerpo de este Congreso le constituían los tres brazos eclesiástico, militar y pueblo, compuesto de los representantes de las ciudades y villas realengas que tenían voto en Cortes [...]. Por esto el acuerdo y dictamen de las Cortes se reducía a tres votos" ${ }^{2}$.

Y, finalmente, la vuelta al orden pasaba por recuperar el discurso hegemónico. De ahí que el control de la imprenta y de la opinión, que había sido uno de los instrumentos de los que se habían valido los liberales para poner en cuestión el monopolio intelectual de la Iglesia, fuera uno de los objetivos prioritarios. Contener la imprenta para que su uso no "degenere en licencia", "pues el respeto que se debe a la religión y al Gobierno, y el que los hombres mutuamente deben guardar entre sí, en ningún gobierno culto se puede razonablemente permitir que impunemente se atropelle y quebrante" 53 . Tan importante era este aspecto, que primer decreto publicado tras el que daba carta de naturaleza al golpe, iba dirigido a regular la imprenta: "que no pueda fijarse ningún cartel, distribuirse ningún anuncio, ni imprimirse diario ni escrito alguno, sin que preceda la presentación a la persona a cuyo cargo esté el gobierno político", decía ${ }^{54}$. Pretendía así impedir "el intolerable abuso que se ha hecho de la imprenta en perjuicio de la religión y de las buenas costumbres, como igualmente que se ponga freno a las doctrinas revolucionarias, a las calumnias e insultos contra el Gobierno, y a los libelos y groserías contra los particulares" 55 .

El control de la imprenta daba satisfacción a la Iglesia y sentaba las bases para recuperar la alianza del Altar y del Trono cuyos lazos se habían estrechado en las últimas décadas ante la amenaza revolucionaria. El realismo del discurso de los publicistas católicos era el contrapunto del apoyo a la Iglesia que esperaban de la monarquía restaurada. Al final, elevar la monarquía sobre sus

cionales. Entre el trono y el escaño. El pensamiento reaccionario español frente a la revolución liberal (1808-1823), Madrid, Congreso de los Diputados, 2011, pp. 207-210.

51. Representación y manifiesto..., p. 41.

52. Ibid., p. 48.

53. Real decreto dado en Valencia el 4 de mayo de 1814. Gaceta extraordinaria de Madrid, 12 de mayo de 1814 , p. 519.

54. Ministerio de Gracia y Justicia, 4 de mayo de 1814. Fermín Martín de Balmaseda, Decretos del rey don Fernando VII..., p. 11.

55. Ibid., p. 12. 
antiguas bases era: "Para que mis vasallos vivan prósperos y felices en una religión y un imperio estrechamente unidos en indisoluble lazo. En lo cual, y en solo esto, consiste la felicidad temporal de un Rey y un reino que tienen por excelencia el título de Católicos" $"$.

\section{Conclusión: posiciones maximalistas de un realismo contrarrevolucionario}

En la primavera de 1814, los realistas españoles eran conscientes de la magnitud de los cambios que había sufrido el país durante los seis años anteriores. Sin embargo, esto no fue un obstáculo que detuviera sus planes de recuperar el poder. Para hacerlo se apoyaron en la idea de restauración, que adoptó diversas formas, como la "restitución" del soberano ${ }^{57}$, o la del monarca que recupera el "trono de sus mayores" 58 , la del rey virtuoso que "se acerca ya a sentarse en su trono" ${ }^{59}, \ldots$ Los periódicos hablan de descansar, de que se habían terminado los sobresaltos, de que retornan con el rey "la virtud y la justicia", de que Fernando había "empuñado ya el soberano cetro que nosotros no habíamos cedido a ningún otro" ${ }^{60}$. Con la llegada de Fernando VII "vimos restablecido el orden en España, puestos en su antiguo vigor los fueros de Castilla, y sentado a nuestro benigno Monarca en el trono de sus mayores"61.

La idea del orden restablecido domina toda esta publicística del retorno. Mediante ella se transmite la noción de estar asistiendo a una vuelta a la normalidad, casi un proceso natural guiado por la lógica de los acontecimientos. Son los juegos del lenguaje que envuelven la acción política y la dotan de una sorprendente eficacia en momentos críticos.

En realidad la restauración de Fernando VII como rey absoluto fue un acto cargado de violencia que nada tenía de natural. Fue un proyecto radical que negaba la experiencia colectiva que, como el tiempo se encargaría de demostrar, era ya irreversible. El decreto del 4 de mayo de 1814, donde se da forma concreta al golpe, recogía con toda su crudeza este acto de negación. Literalmente decía que declaraba la Constitución y los decretos de las Cortes nulos y sin

56. Real decreto dado en Valencia el 4 de mayo de 1814. Gaceta extraordinaria de Madrid, 12 de mayo de 1814 , p. 519.

57. Relación sucinta, pero verídica, de las extraordinarias demostraciones de alegría con que se ha distinguido esta ciudad de Palma, capital del reino de Mallorca por el feliz y deseado regreso de su amantísimo soberano el Sr. D. Fernando VII al trono de sus mayores, compuesta por un amante la Religión y del Rey, Palma, Imprenta de Felipe Guasp, 1814, p. 20.

58. La Atalaya de la Mancha en Madrid, miércoles 4 de mayo de 1814, p. 264.

59. Ibid., martes 10 de mayo de 1814 , p. 313.

60. Ibid., viernes 13 de mayo de 1814 , p. 348.

61. Manifiesto de todo lo ocurrido en Madrid con motivo del Decreto del Rey de 4 de mayo..., Reimpreso en Cádiz, Oficina de don Nicolás Gómez de Requena, 1814. 
valor "como si no hubiesen pasado jamás [...] y se quitasen de en medio del tiempo" 62 .

La idea de restauración del orden fue, en la España de 1814, el artificio político-ideológico utilizado por los realistas para recuperar el poder que habían perdido en las Cortes de Cádiz. Y dentro de los realistas se incluyen religiosos y militares, nobles y cortesanos, empleados públicos en todos los niveles de la administración, etc. Se apoyaron, es cierto, en el cansancio de la sociedad española después de muchos años de guerra, de inestabilidad y de sacrificios. También se valieron del prestigio que seguía teniendo el rey ausente porque ni siquiera los liberales se habían decidido a prescindir de su figura y aun confiaban en las posibilidades de contar con Fernando VII para sus proyectos. "Prometámonos un tiempo feliz de prosperidad y beneficencia -decía uno de sus periódicos-, que sucederá a los de calamidad y miseria que hemos experimentado; y que así como después de la tormenta viene la serenidad, así con la llegada de nuestro deseado monarca Fernando llegará la bonanza, apareciendo el iris de favor para templar tantas borrascas en que nos vimos sumergidos, dimanadas de la arbitrariedad y tiranía del gobierno intruso de Napoleón"63.

Estos factores, que sin duda reforzaban la posición de los realistas, les hubieran permitido negociar favorablemente las condiciones del regreso del rey ${ }^{64}$. Pero eso no fue suficiente para quienes anhelaban recuperar su posición de 1808. Adoptaron una actitud maximalista que, no solo provocaría un durísimo período de represión y exilio para los liberales, sino que también inyectaría una gran inestabilidad a la solución. El español fue un modelo de restauración contrarrevolucionaria inspirado en posiciones intransigentes que provocará la polarización de dos proyectos políticos enfrentados, el realista y el liberal, que se excluían mutuamente. Las luchas entre ambos, que marcan los orígenes de la época contemporánea en España y se extienden a lo largo de tres décadas, tenían aquí su origen, en la restauración monárquica de 1814.

62. Real decreto dado en Valencia el 4 de mayo de 1814. Gaceta extraordinaria de Madrid, 12 de mayo de 1814 , p. 520.

63. El Conciso, 11 de mayo de 1814, $n^{\circ} 116$, p. 924.

64. El ejemplo francés como referencia de moderación estaba en el ambiente: "La legitimidad de nuestro monarca Fernando VII en España, se enlaza con la de Luis XVIII en Francia: y ¿cuándo el excelso Luis restituido a su trono por voto general de la nación, es benéfico con el pueblo francés, se ha de temer que Fernando, aún mucho más querido, no lo sea con sus predilectos españoles". El Conciso, 11 de mayo de 1814, n 116, p. 924. 


\title{
Guerras europeas, conflictos civiles, proyectos nacionales. Una interpretación de las restauraciones napolitanas (1799-1866)
}

\author{
European Wars, Civil Conflicts, and National Projects. \\ The Neapolitan Restorations (1799-1866) Revisited
}

\author{
Carmine Pinto \\ Universitá degli Studi di Salerno
}

Recibido: 22-VII-2014

Aceptado: 1-X-2014

\section{Resumen}

La elección de examinar la contrarrevolución a través de sus mayores éxitos, las cuatro restauraciones victoriosas, y su derrota, la restauración fallida, puede enriquecer las perspectivas tradicionales sobre la resistencia y la crisis del Reino de las dos Sicilias. Los conflictos europeos, las guerras civiles, las construcciones estatales y la creación de identidades nacionales modernas son fenómenos que se entrecruzan con la complicada historia del reino napolitano. A través de la perspectiva de las restauraciones, bien dinásticas (1799 y 1815), o bien absolutistas (1821 y 1849), podemos insertar en un esquema interpretativo general la dialéctica entre conflicto interno y crisis internacionales, la interrelación con la formación de las ideas y adscripciones nacionalistas y la comparación con la contrarrevolución en el mundo borbónico. El paradigma del conflicto nos permite también el contraste con el más amplio mundo borbónico, francés y, sobre todo, iberoamericano. De este modo podemos reflexionar tanto sobre el éxito del legitimismo napolitano como sobre los términos de su derrota en 1860 y sobre las razones de su reciente fortuna en el imaginario colectivo italiano.

Palabras clave: Restauración, Reino de Nápoles, Bourbon, guerra civil, contra revolución.

\begin{abstract}
Examining counter-revolution through its greater achievements, that is, the four winning restorations, and also their disastrous fall, that is, the defeated restoration, may contribute to enrich traditional perspectives on the Kingdom of the Two Sicilies' resis-
\end{abstract}


tance and the crisis. European conflicts, civil wars, state constructions and modern national identity shaping are phenomena which intertwine the complicated history of the Neapolitan Kingdom. It is from the perspective of the dynastic (1799 and 1815) and absolutist restorations (1821), that we may insert in a general interpretative scheme the controversy between internal conflict and international crisis, their relationship with the shaping of ideas and nationalist affiliation and, finally, their comparison with the counter-revolution in the Bourbon world. The paradigm represented by this conflict allows for a contrast with the wider French and Spanish-American Bourbon world. We may thus consider both the success of Neapolitan legitimism and its collapse in 1860, as well as the reasons for its recent recovery in the Italian collective awareness.

Keywords: Restoration, Kingdom of Naples, Bourbons, civil war, counter-revolution.

\section{Cuestiones historiográficas y discurso público}

"Generales, oficiales y soldados de Gaeta. La suerte de la guerra nos separa... La traición interna, el asalto de revolucionarios extranjeros, la agresión de un Estado que decíase amigo, nada os ha domado ni cansado. Entre sufrimientos de toda clase, pasando por campos de batalla, afrontando las traiciones más terribles del hierro y del plomo, habéis venido a Capua y a Gaeta, marcando de heroísmo las ribas del Volturno y las orillas del Garigliano, desafiando durante tres meses en estas murallas los esfuerzos de un enemigo dueño de toda la potencia de Italia. Por vosotros está a salvo el honor del ejército de las Dos Sicilias; por vosotros vuestro soberano puede tener la cabeza alta, y en la tierra del exilio donde esperará la justicia de Dios, el recuerdo de vuestra heroica lealtad le será dulcísimo consuelo en las desventuras... no os digo adiós sino hasta luego. Conservadme mientras tanto vuestra lealtad, como os conservará su gratitud y su afecto vuestro rey" ${ }^{1}$.

El 14 de febrero de 1861, Francisco II dejó la fortaleza de Gaeta. Su rendición, después de meses de asedio, fue anunciada con esta proclama, dedicada a los soldados protagonistas de la última defensa del Reino de las Dos Sicilias. No era solo una despedida. El rey de Nápoles declaró su voluntad de volver para restaurar la dinastía legítima. Fue tomado en serio. El mito de la reconquista del reino y el recuerdo de las precedentes restauraciones victoriosas animaron una resistencia legitimista que duró casi un decenio. Todavía en los años setenta del siglo XIX bandas lideradas por ex militares borbones se encontraban en las montañas de los Apeninos. El último fusilamiento de un "brigante" fue ordenado en Potenza en 1875. Diez años después fue capturado un guerrillero fugitivo desde 1861, Cosimo Giordano.

1. Proclama reale ai Popoli delle Due Sicilie, Gaeta 14 febbraio 1861, firmato Francesco, manifesto a stampa. 
El mito de una renovada restauración borbónica tenía bases sólidas. El reino de las Dos Sicilias había conocido, antes de la crisis de 1860, cuatro regímenes revolucionarios (republicano en 1799, imperial en 1806, liberal constitucional en 1820 y en 1848), pero también cuatro restauraciones absolutistas (1799, $1815,1821,1849)$. Se trataba de un caso único, respecto a otros movimientos contrarrevolucionarios. Las esperanzas de Francisco II eran comprensibles. El legitimismo napolitano que había mostrado una extraordinaria capacidad de resistencia a las fuerzas del imperio napoleónico y de la revolución liberal, podía oponerse también al nacionalismo italiano. Una tesis aún fuerte en la memoria del Mezzogiorno de la que son testimonios recientes una gran cantidad de libros de éxito, portales electrónicos, asociaciones o eventos².

En general, las celebraciones del 150 aniversario de la Unificación (2011) han estimulado una discusión amplia sobre el Risorgimento italiano. Algunos estudiosos han ponderado las instituciones de los viejos estados y ha recibido mucha atención la historiografía sobre la narración romántica nacionalista y su hegemonía en la península ${ }^{3}$. La crisis final del Reino de las Dos Sicilias ha sido el argumento más controvertido y viciado por la retórica del conflicto político que se debate entre una visión tradicional, que considera inevitable la Unificación, y una lectura que describe una violenta destrucción de los antiguos estados italianos. La actualidad historiográfica y cultural del tema ha planteado la necesidad de renovar métodos y fuentes, sin buscar una revancha sobre las tendencias historiográficas de los decenios pasados o sobre las retóricas coyunturales. De este modo, aun partiendo de los resultados de las interpretaciones consolidadas en el siglo XX, centradas en las características

2. Alianello, Carlo, La conquista del sud, Milano, Rusconi, 1972; Topa, Michele, I Briganti di Sua Maestà, Napoli, Fausto Fiorentino Editore, 1993; Viglione, Massimo, La Vandea italiana. Le insorgenze controrivoluzionarie dalle origini al 1814, Milano, Effedieffe, 1995; SelvagGi, Roberto Maria, Ferdinando II di Borbone - Storia di un sovrano napoletano. Trent'anni di regno tra progresso e reazione, Roma, Newton, 1996; Pellicciari, Angela, Risorgimento da riscrivere, Milano, Ares, 1998; DE BIASE, Erminio, L'Inghilterra contro il regno delle Due Sicilie, Napoli, Controcorrente, 2002; Del BocA, Lorenzo, Indietro Savoia, Storia controcorrente del Risorgimento, Casale Monferrato, Piemme, 2003; Izzo, Fausto, I lager dei Savoia, Napoli, Controcorrente, 1999; CAmpolieti, Giuseppe, Re Franceschiello, L'ultimo sovrano delle Due Sicilie, Milano, Mondadori, 2005; D’AmOre, Fulvio, Uccidete José Borges, Napoli, Controcorrente, 2010; Di Fione, Gigi, Controstoria dell'unità d'Italia - Fatti e misfatti del Risorgimento, Milano, Rizzoli, 2010; SAlera, Luciano, La storia manipolata, Napoli, Controcorrente, 2009.

3. BAnTI, Alberto Mario, La nazione del Risorgimento. Parentela, santità e onore all'origine dell'Italia unita, Torino, Einaudi, 2006; BANTI, Alberto Mario y GINSBORG, Paul (coords.), Il Risorgimento, Torino, Einaudi, 2007; MerigGI, Marco, Gli stati italiani prima dell'Unità. Una storia istituzionale, Bologna, Il Mulino, 2002; Spagnoletti, Angeloantonio, Storia del Regno delle Due Sicilie, Bologna, Il Mulino, 1997. 
del movimiento revolucionario meridional y en las fracturas, de tipo social o territorial, internas del viejo estado napolitano, se ha ampliado el horizonte a nuevas líneas de investigación ${ }^{4}$. El estudio de la guerra y del conflicto civil se ha convertido en un terreno de innovación historiográfica, dado que el Reino de las Dos Sicilias fue el principal lugar de experimentación del enfrentamiento fratricida entre italianos en el siglo XIX ${ }^{5}$.

Este paradigma ha hecho posible una mayor atención, además de al nacionalismo italiano, al movimiento legitimista napolitano, todavía poco conocido y estudiado. En este sentido, la elección de examinar la contrarrevolución a través de sus mayores éxitos, las cuatro restauraciones victoriosas, y su desastrosa derrota, la restauración fallida puede enriquecer otras perspectivas consolidadas $^{6}$. El paradigma del conflicto sirve también para romper con la dimensión regional situando el fenómeno en el contexto mucho más amplio del mundo borbónico, francés y, sobre todo, iberoamericano ${ }^{7}$. Guerras civiles, formación o transformación de nuevos estados, creación de identidades nacionales modernas son por tanto fenómenos que se entrecruzan con la complicada historia del reino napolitano. A través de la perspectiva de las restauraciones, ya sea dinásticas (1799 y 1815) o absolutistas (1821 y 1849), podemos insertar en un esquema interpretativo general la dialéctica entre conflicto interno y

4. Della Peruta, Franco, I Democratici e la rivoluzione italiana, dibattiti ideali e contrasti politici all' indomani del 1848, Milano, Feltrinelli, 1958; RomeO, Rosario, Risorgimento e capitalismo, Bari, Laterza, 1959; BERTI, Giuseppe, I democratici e l'iniziativa meridionale nel Risorgimento, Milano, Feltrinelli, 1961; LePRE, Aurelio, Storia del Mezzogiorno d'Italia, Napoli, Liguori, 1986; Petrusewicz, Marta, Come il meridione divenne una questione. Rappresentazioni del sud prima e dopo il Quarantotto, Rubbettino, Soveria Mannelli, 1998; MACRI, Paolo, Ottocento. Famiglia, élites e patrimoni a Napoli, Bologna, Il Mulino, 2002; Galasso, Giuseppe, Storia del Regno di Napoli, V, Il Mezzogiorno borbonico e risorgimentale (1815-1860), Torino, UTET, 2006; CROCE, Benedetto, Storia d'Europa nel secolo decimonono, Milano, Adelphi, 2007 (ed. or. 1928); Gramsci, Antonio, Il Risorgimento, Roma, La riflessione, 2008 (ed. or. 1949); De LoREnzo, Renata, Borbonia felix. Il Regno Delle Due Sicilie alla vigilia del crollo, Roma, Salerno, 2013.

5. Lupo, Salvatore, L’unificazione italiana. Mezzogiorno, rivoluzione, guerra civile, Roma, Donzelli, 2011; PINTO, Carmine, "1857. Conflitto civile e guerra nazionale nel Mezzogiorno", Meridiana, $\mathrm{n}^{\circ} 69$ (2011), pp. 171-200.

6. Sutherland, Donald, France 1789-1815: Revolution and Counterrevolution, New York, Oxford University Press, 1986; ScHnuR, Roman, Rivoluzione e guerra civile, Milano, Giuffré, 1986; Viola, Paolo, Il crollo dell'antico regime. Politica e antipolitica nella Francia della rivoluzione, Roma, Donzelli, 1993; Tilly, Charles, Le rivoluzioni europee 1492-1992, Roma-Bari, Laterza, 1993; RANZATO, Gabriele (coord.), Guerre fratricide. Le guerre civili in età contemporanea, Torino, Bollati Boringhieri, 1994; Di RIENzo, Eugenio (coord.), Nazione e controrivoluzione nell'Europa contemporanea 1799-1848, Milano, Guerini e associati, 2004.

7. Pinto, Carmine, "Crisi globale e conflitti civili. Nuove ricerche e prospettive storiografiche". Meridiana, no 78 (2013), pp. 9-30. 
crisis internacionales, entramado con la formación de ideas y afiliaciones nacionalistas, la comparación con la contrarrevolución en el mundo borbónico. De este modo podemos reflexionar tanto sobre el éxito del legitimismo napolitano como sobre los términos de su caída en 1860 y las razones de su reciente fortuna en el imaginario colectivo italiano.

\section{Las restauraciones dinásticas. Crisis internacionales y conflictos civiles}

Las primeras restauraciones fueron un producto explícito de la gran guerra europea. En Nápoles, la oleada revolucionaria de los años noventa se insertó en las tensiones que desde hacía años movilizaban a los defensores de los antiguos privilegios y a los centralizadores ilustrados (en Sicilia, por ejemplo, el virrey Caracciolo estuvo en el centro del enfrentamiento entre la tendencia absolutista napolitana y la constitucionalista liberalizante siciliana ${ }^{8}$ ). En un breve período de tiempo esta confrontación fue superada y desapareció sustituida por proyectos políticos y contrastes ideológicos muy diferentes ${ }^{9}$. En el reino meridional emergieron las primeras redes francófilas (represiones y condenas de 1794-7), mientras la relación del estado borbónico con la guerra europea se recrudeció con la operación relámpago del almirante francés Latouche Tréville en Nápoles y la alianza naval con la Inglaterra de Fernando IV, seguida de la expedición napolitana a Toulon ${ }^{10}$.

La crisis, iniciada con la campaña italiana de Napoleón, estalló con la caída del estado pontificio, la intervención militar en Roma y la inmediata reacción francesa. La invasión estuvo acompañada del pronunciamiento de los revolucionarios napolitanos, provocó la ocupación del reino continental, la fuga a Sicilia del rey y la proclamación de la República Partenopea. El Mezzogiorno se convirtió en un sangriento teatro donde se mezclaron la guerra entre los franceses y la coalición enemiga (con la prepotente presencia de Nelson), el conflicto civil entre republicanos y sanfedistas y las tensiones sociales en las provincias. La república, aunque efímera y lacerada, movilizó fuerzas importantes. La guerra, que implicó con intensidad a cada ciudad y a cada pueblo, cambió para siempre la historia del reino y mostró por primera vez, como escribió Cuoco, la

8. SCHIPA, Michelangelo, Il regno di Napoli al tempo di Carlo di Borbone, Milano-Roma-Napoli, Albrighi e Segati 1923; Venturi, Franco, Settecento riformatore. Da Muratori a Beccaria, Torino, Einaudi, 1969; RAO, Anna Maria, Il regno di Napoli nel Settecento, Napoli, Guida, 1983.

9. De RugGIERo, Guido, Il pensiero politico meridionale nei secoli XVIII e XIX; Bari, Laterza, 1954.

10. BARRA, Francesco, Il Mezzogiorno nelle relazioni internazionali, en Storia del Mezzogiorno, Napoli, Edizioni del Sole, 1991. 
existencia de naciones opuestas ${ }^{11}$. Solo en los seis meses de 1799 en los cuales se enfrentaron la República y la Santa Fede se contaron decenas de miles de muertos ${ }^{12}$.

El derrumbamiento de la república, provocado por la ofensiva aliada y el ejército de la Santa Fede de Ruffo, dio paso a la Primera restauración borbónica en Nápoles ${ }^{13}$. El primer acto fue la masacre de los máximos responsables republicanos y el masivo encarcelamiento de sus partidarios. El régimen buscó después una tranquilidad internacional con el apoyo de los ingleses y la paz con Francia para estabilizar el reino a través de un vínculo externo. La estrategia de confiar también el equilibrio, o la protección, a las grandes potencias, ha explicado Galasso, será durante decenios el pilar de la política borbónica (junto a la alianza con la Iglesia y algunos sectores populares) ${ }^{14}$. Se decidieron algunas moderadas reformas antifeudales para buscar el consenso de la opinión pública menos conservadora del reino, pero no fueron capaces de resolver la inestabilidad financiera y la petición de cambios políticos (frecuentemente tenían una intención punitiva, como la abolición de los privilegios materiales de la nobleza). El indulto (1800) evitó que se continuara con la masacre de los republicanos (que eligieron la vía del exilio en masa). Finalmente, los protagonistas de la contrarrevolución fueron masivamente incorporados a la aristocracia y a las estructuras del estado para crear una nueva base legitimista. La Primera restauración consiguió clausurar la fase de emergencia, pero no pacificó el reino, ni obtuvo un auténtico reconocimiento internacional ${ }^{15}$. El elemento más evidente fue la ruptura con una parte importante de los notables y de la intelectualidad, del ejército y de los funcionarios, que se alinearon con la república (y luego, a escala mucho mayor, con el imperio), pensando en la modernización del reino y en su propia inserción en una élite paneuropea que sustituyera a la integrada en el viejo mundo borbónico. Al mismo tiempo, alrededor de la dinastía se congregaron partes importantes de la aristocracia, de

11. Cuoco, Vincenzo, Saggio storico sulla rivoluzione di Napoli, Manduria, Lacaita, 1998

12. Ilari, Virginio, Crociani Piero y Paoletti Ciro, Storia militare dell'Italia giacobina (17961802), Roma, USSME, 2001.

13. Croce, Benedetto, La rivoluzione napoletana del 1799. Biografie, racconti, ricerche, Bari, Laterza, 1912; Petraccone, Claudio, Napoli nel 1799. Rivoluzione e proprietà, Napoli, Morano, 1989; RAO, Anna Maria (coord.), Napoli 1799 fra storia e storiografia, Napoli, Vivarium, 2002; Di Francesco, Antonino, 1799. Una storia d'Italia, Milano, Guerini e Associati, 2004.

14. Galasso, Giuseppe, Storia del Regno di Napoli, V, Il Mezzogiorno borbonico e napoleonico (1734-1815), Torino, UTET, 2006.

15. Piero, Pieri, "Il regno di Napoli dal luglio 1799 al marzo 1806", ASPN, no LII (1926), pp. 136-286; Blanch, Luigi, Scritti storici, Bari, Laterza, 1945; RaO, Anna Maria, Esuli: l'emigrazione politica italiana in Francia: 1792-1802, Napoli, Guida, 1992. 
los notables locales, del ejército, con una mayor prevalencia de la iglesia y de las clases populares, que hicieron de la contrarrevolución un proyecto alternativo, con una ideología propia y un diseño político, frecuentemente heredero de la misma tradición ilustrada, fundado sobre el objetivo de una restauración que combinó los valores de la lealtad monárquica y aquellos de la tradición napolitana ${ }^{16}$. Si en 1799 la gran masacre entre los napolitanos encontró un analista de éxito en el volumen del exilado republicano Cuoco, al otro lado de la barricada estuvo el padre sanfedista Cimbalo, autor de uno de los superventas del momento, con el volumen que describía la emocionante marcha del cardenal Ruffo. Se definió, en conclusión, un pensamiento contrarrevolucionario, dotado también de una dialéctica interna muy semejante a aquella que se había desarrollado en el campo contrario, pero basada en un bloque político y social que reunía instituciones y grupos sociales, reivindicando en la nueva relación entre Iglesia y trono un formidable cemento ideológico ${ }^{17}$.

La Primera restauración no consiguió neutralizar el conflicto interno, convertido en el elemento central de la lucha política y del desarrollo del estado. Cuando se reanudó la guerra europea la ruptura volvió a plantearse estrechamente vinculada a la crisis internacional. La ruptura de la paz de Amiens, la torpe política de los borbones (una confusa ambigüedad entra Napoleón e Inglaterra), llevaron a una segunda invasión francesa (1806). El rey y la corte se trasladaron a Palermo, bajo la protección inglesa. Inició el Decenio, con la presencia de dos reyes (José Bonaparte y luego Joaquín Murat), marcado por la inserción del reino en la política europea de Napoleón y por la ruptura definitiva con las formas y las prácticas de la ilustración dieciochesca. Las más importantes reformas administrativas de la historia napolitana (institucionalización de las comunidades locales y provinciales, del consejo de estado y de las nuevas magistraturas, abolición del feudalismo y promulgación de los códigos), registraron la adhesión masiva de sectores importantes del Mezzogiorno al nuevo régimen y a la política napoleónica a través de las instituciones políticas y del ejército ${ }^{18}$. Esta elección de campo no impidió la continuación de un sangriento conflicto civil que una vez más se mezcló con la guerra en curso

16. LEONI, Francesco, Storia della controrivoluzione in Italia (1789-1859), Napoli, Guida, 1975; Mascilli Migliorini, Luigi, Il mito dell'eroe, Napoli, Guida, 2003; De Lorenzo, Renata, Murat, Roma, Salerno, 2011.

17. LEONI, Francesco, Il pensiero controrivoluzionario in Italia, Napoli, Istituto editoriale del Mediterraneo, 1972.

18. CORTESE, Nino, L'esercito napoletano e le guerre napoleoniche (Spagna, Alto Adige, Russia, Germania), Napoli Ricciardi, 1928; SCOTTI Douglas, Vittorio (coord.), Gli italiani in Spagna nella guerra napoleonica (1807-1813). I fatti, i testimoni, l'eredità, Alessandria, Edizioni dell'Orso, 2006. 
en el Mediterráneo y en Europa. La política borbónica tuvo que renovarse para enfrentarse al éxito de los napoleónicos, aceptando la constitución siciliana (1812), participando en la política inglesa e intentando ofrecer nuevas perspectivas a sus partidarios. El reino conoció todo el repertorio posible de la violencia política: presencia en los ejércitos europeos, actividades secretas, organizaciones paramilitares, guerrilla rural, movilizaciones de aparatos logísticos, conflictos locales ${ }^{19}$. Los contrarrevolucionarios tenían que enfrentarse con una poderosa crisis, pero en el fuego del conflicto reforzaron la identificación con un patriotismo leal y católico que contraponer al proyecto paneuropeo imperial napoleónico.

Las consecuencias de la guerra determinaron la Segunda restauración borbónica en 1815. La derrota de Murat (y su fusilamiento) puso fin para siempre a la experiencia francesa. El nuevo estado, el Reino de las Dos Sicilias, en el interior del ajedrez geopolítico definido en Viena, se presentó como la mayor potencia italiana: exponentes de su clase dirigente (el príncipe de Canosa) pensaban incluso en una expansión por la península ${ }^{20}$. La tradición nacional no había estado ni siquiera cuestionada en el Decenio francés (Murat había impuesto en 1811 la nacionalización napolitana a los funcionarios extranjeros) y por tanto la Restauración apuntó hacia una política de equilibrios y pacificación, bajo la égida del comprensivo y atento imperio Habsburgo, con la construcción de un nuevo edificio estatal: el Reino de las Dos Sicilias. Los resultados del conflicto civil condicionaron la Segunda restauración, pero en la dirección opuesta a 1799. El gobierno de Fernando I, con la política de la amalgama, representada por Luis de Médici y sostenida por Metternich, intentó cerrar la fractura interna, a través de la conservación de las instituciones de los napoleónicos y la integración de funcionarios, notables y militares muratianos en el aparato del estado (convención de Casalanza, 1815). Al mismo tiempo, el compromiso con la Iglesia (concordato de Terracina, 1818), cerró las fracturas dieciochescas entre los borbones y el mundo eclesiástico ${ }^{21}$.

19. VALENTE, Angela, Gioacchino Murat e l'Italia meridionale, Torino, Einaudi, 1927; SAVARESE, Giacomo, Tra rivoluzioni e reazioni. ricordi di Giuseppe Zurlo, Torino, Einaudi, 1941; Della Peruta, Franco, Esercito e società nell'Italia napoleonica, Milano, Angeli, 1988; Woolf, Stuart, Il Risorgimento italiano, Torino, Einaudi, 1981; LePrE, Aurelio (coord), Studi sul Regno di Napoli nel Decennio francese (1806-1815), Napoli, Liguori, 1985; BARRA, Francesco, Il decennio francese nel Regno di Napoli (1806-1815). Studi e ricerche, Salerno, Plectica, 2008.

20. MATURI, Walter, "Il Congresso di Vienna e la Restaurazione dei Borboni a Napoli", Rivista Storica Italiana, $\mathrm{n}^{\circ} 3$ (1938), pp. 32-72.

21. Maturi, Walter, Il Concordato del 1818 tra la Santa Sede e le Due Sicilie, Firenze, Le Monnier, 1929; Borzomati, Pietro, Chiesa e società meridionale. Dalla Restaurazione al $2^{\circ}$ dopoguerra, Roma, Studium, 1982. 
La Segunda restauración llevó hasta las últimas consecuencias las líneas de la monarquía administrativa, combinando las nuevas formas y estructuras del poder con el objetivo de dilatar las dimensiones del consenso y de la integración en el régimen ${ }^{22}$. En el plano ideológico, considerando el decenio como mera ocupación, sus cambios fueron asimilados insertándolos en las tradiciones jurídicas meridionales. La dinastía había asegurado el retorno a la independencia del antiguo estado napolitano, juntando el espíritu reformador borbónico dieciochesco y la resistencia antifrancesa (presentada como una guerra de liberación liderada por el pueblo) ${ }^{23}$. Además, para consolidar el poder de la corona, fue perfeccionada y extendida a Sicilia la monarquía administrativa, ahora duramente hostilizada por el autonomismo insular ${ }^{24}$. La política de Médici se basaba en la idea de que el equilibrio internacional y la pacificación interna podían estabilizar el reino y determinar una modernización definitiva del nuevo organismo estatal, manteniendo un compromiso entre lo viejo y lo nuevo, entre el absolutismo dieciochesco y el reformismo francés ${ }^{25}$. El régimen subestimó el alcance de la ruptura político-ideológica, que también había obligado a Fernando IV a conceder la constitución en Sicilia (1812), a José Bonaparte a ponerla en marcha en Bayona (1808, inmediatamente abandonada por su sucesor) y a Murat a hacer lo mismo en los últimos días de su reinado (1815). Un fenómeno evidente en la consolidación de una masiva oposición política clandestina, multiplicada bien por los efectos de la retirada de la constitución (en Sicilia) o bien por las consecuencias políticas y psicológicas de la posguerra en el Mezzogiorno ${ }^{26}$.

Esta profunda politización condicionó las dos restauraciones, en el centro de las cuales estuvo siempre la cuestión de la legitimidad y del restablecimiento de la dinastía, pero en el interior de retóricas y proyectos políticos modernos. La contrarrevolución napolitana contrapuso un modelo de legitimidad basado en la transmisión dinástica y el patriotismo leal a uno de tipo primero republicano-revolucionario, luego imperial paneuropeo. El conflicto por la titularidad

22. Ghisalberti, Carlo C., Contributo alla storia delle amministrazioni preunitarie, Milano, Giuffré, 1963; Galasso, Giuseppe, Potere e istituzioni in Italia. Dalla Caduta dell'impero romano ad oggi, Torino, Einaudi, 1974.

23. De Angelis, Francesco, Storia del Regno di Napoli sotto la dinastia borbonica, Napoli, Morosino, 1817.

24. Tomeucci, Luigi, Genesi del conflitto tra la Sicilia e I Borboni (1734-1817), Bologna, Zanichelli, 1964; Romeo, Rosario, Il Risorgimento in Sicilia, Roma-Bari, Laterza, 1970.

25. Scirocco, Alfonso, Dalla seconda restaurazione alla fine del regno, en Storia del Mezzogiorno...

26. MATURI, Walter, La politica estera napoletana dal 1815 al 1820, Rivista Storica Italiana, $\mathrm{n}^{\circ} 4$ (1939), pp. 226-272; RoMEo, Rosario, Mezzogiorno e Sicilia nel Risorgimento, Napoli, ESI, 1963. 
del poder no cuestionó la identidad nacional napolitana, pero provocó una escisión entre las diversas hipótesis de soberanía dinástica y de colocación ideológica. Las dos restauraciones respondieron a estos desafíos con dos políticas diferentes, si no opuestas, en 1799 y en 1815 , pero no consiguieron neutralizar las desavenencias políticas, ideológicas, territoriales, justamente por la interrelación entre el conflicto interno y la guerra europea.

\section{Las restauraciones absolutistas. Conflictos civiles y proyectos nacionales}

La formación de tradiciones y culturas políticas contrapuestas, difusas y radicadas en todos los rincones del estado, ofreció un terreno fértil a aquellos que aplaudieron la revolución en España de $1820^{27}$. Solo la profundidad de la desavenencia político-ideológica puede explicar los términos del motín napolitano, después de una Restauración moderada que durante cinco años había tutelado a todos los protagonistas de las etapas pasadas. El embajador austriaco escribió que podía esperarse la revolución en cualquier lugar, también en la luna, pero no en Nápoles ${ }^{28}$. Esta vez fueron los liberales napolitanos y los autonomistas sicilianos, no un ejército extranjero, quienes determinaron la crisis del reino. El movimiento carbonario había aglutinado a todos los descontentos y opositores, haciendo emerger la hostilidad de amplios estratos de la población contra la política de la Restauración. Sicilia, una vez retirada la constitución, se había convertido en un elemento de inestabilidad continua. $\mathrm{Al}$ inicio de la revolución, los carbonarios obtuvieron el apoyo de los militares muratianos. El rey concedió inmediatamente la constitución y soportó la formación de un gobierno liberalizante, controlado por exponentes moderados. El movimiento revolucionario estaba, no obstante, fragmentado entre las facciones carbonarias, además de entre constitucionales y exmuratianos ${ }^{29}$. Además, tuvo que sofocar la revuelta autonomista de Sicilia, fragmentando ulteriormente el frente revolucionario, obligado a librar una lucha sin cuartel justamente con sus aliados potenciales ${ }^{30}$. Pocos meses después Fernando I llegó al Congreso de la Santa Alianza en Ljiubliana (que decidió la intervención contra las revoluciones mediterráneas), y luego volvió a Nápoles junto al ejército habsburgo. El ejército napolitano fue derrotado rápidamente, y el absolutismo restaurado por una fuerza de ocupación austriaca.

27. SPINI, Giorgio, Mito e realtà della Spagna nelle rivoluzioni italiane del 1820-21, Roma, Perrella, 1950.

28. Schipa, Michelangelo, Il regno di Napoli sotto i Borboni, Napoli, Pierro, 1900.

29. Colletta, Pietro, Storia del reame di Napoli. Dal 1734 al 1825, Torino, Pomba, 1853; LEPRE, Aurelio, La rivoluzione napoletana del 1820-21, Roma, Editori Riuniti, 1967.

30. CORTESE, Nino, La prima rivoluzione separatista siciliana, 1820-1821, Napoli, Libreria Scientifica, 1951. 
La Tercera restauración tuvo caracteres genuinamente político-institucionales, no había la necesidad de restablecer la soberanía de la dinastía. El régimen borbónico intentó crear una renovada comunidad política de tipo conservador absolutista, reforzando el poderoso bloque social que había constituido a partir de 1799. La consolidación del estado pasó también por la creación de organismos consultivos (queridos por Metternich) en el Mezzogiorno y en Sicilia, para intentar superar el creciente alejamiento entre Nápoles y la isla. En todo caso, ni siquiera la Tercera restauración consiguió solucionar el desencuentro entre revolución y contrarrevolución, por la presencia ya consolidada de tradiciones políticas liberales y la fractura con buena parte de las élites sicilianas. El conflicto civil, aunque limitado, quedó como el instrumento de la organización de las luchas entre facciones y proyectos políticos generales. Desde aquel momento la Constitución devino un instrumento siempre aborrecido por los borbónicos, salvo pocas excepciones (como Pietro Ulloa): era la premisa natural de la guerra civil o de la crisis del estado. Todavía diez años más tarde del final del estado napolitano, Filippo Pisacane, aristócrata y coronel de caballería (hermano del famoso revolucionario Carlo), en el exilio con la familia real hasta su muerte, sostuvo que fue la elección de la Constitución la que determinó la caída del Reino: la pluma rehúsa detallar la serie de los hechos llevados a cabo, bajo el manto de la más vil hipocresía para que el rey cayera en el lazo de conceder franquía al Pueblo"31. El régimen realizó una dura represión de todos los protagonistas del régimen constitucional (además del motín de julio), pero el liberalismo napolitano y siciliano quedó como una fuerza de oposición consistente, dotado de una resonancia internacional multiplicada por los miles de exiliados ${ }^{32}$.

Además de castigar al enemigo interior, en el decenio sucesivo se sentaron la bases para la renovación borbónica de los años treinta y sobre todo para superar la penosa tutela internacional, confirmada por la ocupación austriaca, que si bien había sido solicitada por el rey, no por eso resultaba menos humillante ${ }^{33}$. Precisamente para quebrar la conexión entre las intervenciones internacionales y los conflictos internos, el nuevo rey, Fernando II, intentó una política de nacionalización del estado, reforzando un ejército fiel al trono, convirtiendo la alianza con la Iglesia en un acuerdo de hierro, intentando una consistente

31. Pisacane, Filippo, Un poco più di vero su fatti d'armi operati da resti dell'Esercito Napolitano nel 1860 e sulle cagioni che li produssero pel Duca di San Giovanni, Napoli,1874.

32. IsABella, Maurizio, Risorgimento in esilio: l'internazionale liberale e l'età delle rivoluzioni, Roma-Bari, Laterza, 2011.

33. Cingari, Gaetano, Mezzogiorno e Risorgimento. La Restaurazione a Napoli dal 1821 al 1830, Bari, Laterza, 1976; DAVIS, John, Naples and Napoleon. Southern Italy and the European Revolutions 1780-1860, Oxford, Oxford University Press, 2009. 
apertura económica y una moderada integración de los exmuratianos y de las élites sicilianas. Su programa nacional aseguró el éxito de la Tercera restauración, pero ni siquiera su acción consiguió integrar viejas y nuevas corrientes de oposición política que, como en los decenios pasados, se insertaron en las fracturas sociales, territoriales y morales del reino. La revolución de 1848 confirmó la conexión entre crisis externas y fracturas internas, con una novedad importante: constitución y absolutismo empezaron a entrelazarse con palabras clave como unificación o independencia, mezclando reivindicaciones autonomistas, constitucionalismo liberal, democracia radical, nacionalismo italiano. La primera insurrección fue en Palermo, en enero de 1848. El rey concedió la Constitución. Durante algunos meses acompañó las peticiones del gobierno moderado, luego, utilizando las divisiones entre los liberales y la derrota de los nacionalistas italianos en el valle padano, empezó a desmoronar el edificio constitucional ${ }^{34}$. En pocos meses demolió la revolución. En 1849 la contrarrevolución napolitana fue la de mayor éxito en Italia. Fernando II fue el principal representante del legitimismo de su generación, capaz de derrotar por sí solo el movimiento liberal napolitano y siciliano. Había superado la insurrección siciliana, reprimido las revueltas de Cilento y Calabria, acabado en pocas horas con las barricadas napolitanas del 15 de mayo, obteniendo declaraciones de lealtad de parte de las élites locales que se colocaban siempre en la frontera entre conservación y cambio.

La Cuarta restauración, como la precedente, no tuvo que restablecer el edificio monárquico o la autonomía del estado. La máquina administrativa y represiva continuó funcionando con eficiencia, sectores importantes del reino conservaron la fidelidad al trono y al estado, fue promovida la política económica del rey y estimulado el orgullo nacional. Sin embargo, precisamente la voluntad de radical autonomía del rey acentuó las fracturas internacionales e internas, rompiendo el esquema tradicional de la política borbónica que confiaba a las grandes potencias las garantías últimas de la existencia del reino. Ingleses y franceses establecieron un progresivo aislamiento (el caso más famoso fue el de las cartas de Lord Gladstone), reforzando una opinión pública internacional que consideraba a las Dos Sicilias como un auténtico anacronismo histórico ${ }^{35}$. Además, la dura represión del movimiento liberal (derrotado también en sus

34. Paladino, Giuseppe, La rivoluzione napoletana del 1848, Milano, Vallardi, 1914; MosCaTI, Ruggero, Ferdinando di Borbone nei rapporti diplomatici austriaci, Napoli, ESI, 1947; idem, I Borboni d'Italia, Roma, Newton Compton, 1973; Brancato, Francesco, La Dittatura garibaldina nel Mezzogiorno e in Sicilia, Trapani, Celebes, 1965.

35. ZAzo, Alfredo, La politica estera del Regno delle Due Sicilie nel 1959-60, Napoli, Miccoli, 1940; Di Rienzo, Eugenio, Il Regno delle Due Sicilie e Le Potenze Europee. 1830-1861, Soveria Mannelli, Rubbettino, 2012. 
modestos intentos de los años cincuenta), no consiguió detener la radicalización en el Mezzogiorno. En fin, la resolución fallida de la cuestión siciliana convenció a las élites insulares de que su causa solo podría solucionarse en el ámbito del proyecto nacional italiano ${ }^{36}$. Todo ello hizo todavía más complicado el intento de restaurar una política absolutista tradicional sobre la base de los principios de 1815 y de 1821 en la Italia donde se extendía el romanticismo nacionalista panitaliano.

En el decenio de la cuarta restauración esta apertura se hizo cada vez más radical. El debate sobre la definición geográfica, burocrática e ideológica del estado, permite identificar los materiales de una renovada confrontación entre proyectos estatales ${ }^{37}$. Una parte importante del Mezzogiorno eligió definitivamente la patria italiana ideada por los liberales, como parte de una frontera cultural más amplia, dotada también en el Reino de las Dos Sicilias de una tradición política característica, que tenía la propia legitimidad en decenios de revoluciones y conspiraciones, se identificaba en la libertad constitucional y compartía un proyecto con las fuerzas ideológicamente hegemónicas en la península (apoyadas por la opinión pública liberal europea). A este proyecto nacional el legitimismo meridional contrapuso una patria napolitana con un pasado dividido, basado en la renovación de la monarquía administrativa, en un paternalismo afectuoso que, junto al rigor de las leyes, debía garantizar el bienestar de los súbditos y la defensa de las antiguas tradiciones, en la independencia y en la fidelidad dinástica. En los años de la tercera y, sobre todo, de la cuarta restauración estos sentimientos adquirieron nuevos significados, llegando a reconstruir la unidad cultural del pueblo napolitano a través de una idea de comunidad nacional dotada de un sentido de pertenencia territorial, política y cultural. La nación era una herencia que se impulsaba avalada por

36. GuARDione, Francesco, Le reazione borbonica in Sicilia e il trionfo della rivoluzione unitaria, Palermo, Sanzo, 1929; Moscati, Ruggeri, Il Mezzogiorno d'Italia nel Risorgimento, Firenze-Messina, D'Anna, 1953; RendA, Francesco, Risorgimento e classi popolari in Sicilia, Milano, Feltrinelli, 1968; Riall, Lucy, La Sicilia e l'unificazione italiana. Politica liberale e potere locale (1815-1866), Torino, Einaudi, 2004.

37. Anderson, Benedict, Imagined Communities: Reflections on the Origin and Spread of Nationalism, London, Verso, 1993; Hutchinson, John y SMith Anthony D. (coords.), Nationalism, Oxford, Oxford University Press, 1994; Breully, John, Nationalism and the State, Manchester, Manchester University Press, 1993; Gellner, Ernst, Nations and Nationalism, Oxford, Blackwell, 1983; Hastings, Anthony, The Construction of Nationhood: Ethnicity, Religion and Nationalism, Cambridge, Cambridge University Press, 1997; Hobsbawm, Eric J., Nations and Nationalism Since 1780: Programme, Myth, Reality, New York, Cambridge University Press, 1990; SMith, Anthony D., The Ethnic Origins of Nations. Oxford, Blackwell, 1998. 
las generaciones precedentes. Rechazada la solución constitucional, el patriotismo era la única respuesta posible al desafío nacionalista italiano ${ }^{38}$. La última restauración absolutista se fundó precisamente en el desencuentro con la élite panitaliana. 1848 había confirmado que la patria se identificaba con quien defendía la autonomía y las tradiciones. Fernando II, recordó Ruggero Moscati, "napolitano, él sentía la 'nación napolitana', no la nación italiana", no había solicitado la intervención de los ejércitos extranjeros para sofocar la revolución, reivindicando una legitimación nacional del viraje autoritario ${ }^{39}$.

La última restauración era la demostración de que en el legitimismo napolitano nación y libertad política no siempre iban juntas. El resultado de las últimas dos restauraciones fue una neta división ideológica y cultural, que contrapuso en el mismo país la patria napolitana y la italiana, mezclando las afiliaciones con los proyectos nacionales, haciendo difícil, si no imposible, conciliar el conflicto interno iniciado sesenta años antes. Rechazadas todas las mediaciones, el problema de la constitución devino una insuperable diferencia entre dos visiones del desarrollo del reino. La consecuencia fue una línea de demarcación entre aquellos que se agruparon alrededor del trono y de las antiguas tradiciones del estado, y aquellos otros que, como escribió Croce, consideraron agotados los deberes de la monarquía borbónica y, por tanto, del propio estado napolitano ${ }^{40}$.

\section{¿Una contrarrevolución victoriosa? Una hipótesis de comparación}

La contrarrevolución napolitana era parte de un relevante fenómeno internacional y, sobre todo, del colapso del sistema borbónico iniciado con la caída de la monarquía francesa. La napolitana tenía además raíces comunes con el mundo iberoamericano en la tradición imperial de los Habsburgo en la cual Galasso, Musi y Villari han colocado la original historia nacional napolitana ${ }^{41}$.

38. CAcCiATORe, Andrea, Esame della Storia del Reame di Napoli di Pietra Colletta dal 1734 al 1825, Napoli, Stabilimento Tipografico, 1850; MuSEI, Mauro, Storia civile e militare del regno delle Due Sicilie sotto il governo di Ferdinando II. Dal 1830 al 1849, Napoli, Poliorama, 1850; Cala' Ulloa, Pietro, De' fatti dell'ultima rivoluzione derivanti da' giudizi politici del reame di Napoli, Napoli, Stamperia Reale, 1854; Rassegna degli errori e delle fallacie pubblicate dal sig. Gladstone in due sue lettere indirizzate al conte di Aberdeen sui processi politici nel reame delle Due Sicilie, Napoli, Fibreo, 1851; Di Gregorio, Eugenio, L'astro nella tenebra. Ovvero l'immortale Ferdinando II re del regno delle Due Sicilie negli orrori dell'ultima rivoltura fino all'attualità, Napoli, Capasso, 1852.

39. Moscati, Ruggero, I Borboni d'Italia..., p. 122.

40. Croce, Benedetto, Storia del Regno di Napoli, Milano, Adelphi, 1992.

41. Musi, Aurelio (coord.), Alle origini di una nazione: antispagnolismo e identità italiana, Milano, Guerini e Associati, 2003; VILlaRI, Rosario, Un sogno di libertà. Napoli nel declino di un impero (1585-1648), Milano, Mondadori, 2012; Galasso, Giuseppe, Alla periferia dell'impero. Il Regno di Napoli nei secoli XVI-XVII, Torino, Utlet, 1994. 
Todas sufrieron una grave crisis de legitimidad, fueron después comprometidas en el enfrentamiento entre liberalismo y absolutismo, y finalmente transformadas en naciones independientes, estados modernos o regiones en el centro de innovadoras experiencias institucionales, frecuentemente mediante una larga repetición de conflictos internos ${ }^{42}$. El legitimismo napolitano se desarrolló en el interior del largo proceso de experimentación de ideas y formas de organización política iniciado con las guerras de la Revolución ${ }^{43}$. El programa al cardenal Ruffo antes de su expedición en el Mezzogiorno estuvo entre los primeros documentos orgánicos en Europa, de mano de un poder institucional, que determinó los objetivos políticos, ideológicos y operativos de la contrarrevolución ${ }^{44}$. No era por tanto una herencia del pasado, sino una consecuencia de la fractura europea entre revolución y contrarrevolución ${ }^{45}$. Cuando se presentó como un movimiento político de masas, en 1799, en el ámbito de la movilización contrarrevolucionaria que convulsionó Francia, Suiza, Holanda y Bélgica, los napolitanos fueron los únicos en tener éxito, creando un potente precedente simbólico y realizando, bajo la égida inglesa, la Primera restauración.

También en el Decenio la contrarrevolución se colocó en un contexto de este tipo, la resistencia de los napoleónicos determinó un estado de guerra permanente y sentó las premisas para legitimar la Segunda restauración, si bien no llegó a movilizar fuerzas comparables a la guerrilla española. La experiencia de la doble invasión (Nápoles 1806-Madrid 1808) admite un cuadro comparativo con el espacio político heredero de las coronas de Carlos III. En España, 1808 avivó un proceso de intensa politización que no se detuvo con la restauración de 1815 y continuó, como ha escrito Rújula, hasta 1840, preparando el terreno a los partidos y movimientos políticos españoles del XIX ${ }^{46}$.

42. Centeno, Miguel Angel, Blood and Deb. War and Nation-State in Latin America, Pennsylvania, The Pennsylvania State University Press, 2002; Regan, Patrick, Sixteen Million One: Understanding Civil War, Boulder, Paradigm, 2009, Pinto, Carmine, La "guerra civil borbónica". Crisis de legitimidad y proyectos nacionales entre Nápoles y el mundo iberoamericano, Santiago de Chile, FEC, 2014.

43. FuRET, François y Richet, Denis, La Révolution française, Paris, Fayard, 1973; idem, Penser la Révolution française, Paris, Gallimard, 1978.

44. Battaglini, Mario, La Repubblica Napoletana, Città di Castello, Bonacci, 1992; Von Helfert, Joseph Alexander, Fabrizio Ruffo. Rivoluzione e controrivoluzione di Napoli dal novembre 1798 all'agosto 1799, Firenze, 1885.

45. Совв, Richard, Reactions to the French Revolution, London, New York, Oxford University Press, 1972; GodECHOT, Jacques, The counter-revolution: doctrine and action, 1789-1804, New York, H. Fertig, 1971; MARTIN Jean-Clement, I bianchi e i blu. Realtà e mito della Vandea nella Francia rivoluzionaria, Milano, SEI, 1989.

46. Hamnett, Brian, La Política Española en Una Época Revolucionaria, 1790-1820, México, Fondo de Cultura Económica, 1985; Cuenca Toribio, José Manuel, La Guerra de la Independencia: un conflicto decisivo, 1808-1814, Madrid, Encuentro, 2006; EsDaile, 
Los defensores del absolutismo en los años veinte, y los carlistas después, no tendrán dificultad en colocar ahí sus propias raíces. En ambos países mediterráneos la restauración legitimista fue posible también gracias a su base interclasista y militante, capaz de un proyecto político adecuado al conflicto interior por el poder y la ideología. Se trata de un modelo comparable con el discutido para la América borbónica donde, superando el concepto de las guerras de la independencia como liberación de naciones preexistentes o conflictos entre grupos populares nativos y colonizadores españoles propietarios de tierras y capital, se ha puesto el conflicto y la crisis de la monarquía en el centro del análisis de las revoluciones de independencia ${ }^{47}$. En todo el espacio de la vieja monarquía, una crisis generalizada puso en discusión la legitimidad del poder, movilizando ambiciones, lealtades y programas, todo lo contrario que convergentes en las élites españolas, napolitanas o americanas. Un particular esquema de fragmentación del concepto de soberanía que asignó al conflicto interno un rol que no tuvo equivalentes análogos en el imperio Habsburgo o en el ruso, por no hablar de Inglaterra o Prusia.

El legitimismo napolitano fue parte de una contrarrevolución producida por el conflicto civil europeo y americano que alcanzó su momento culminante en 1814-1816. Un fenómeno común a casi todo el mundo borbónico, además de a buena parte de Europa, de Santa Fe a Caracas, de Madrid a Palermo (el Río de la Plata fue un caso raro), pero rápidamente puesto en discusión por la resistencia del liberalismo europeo y los independentistas americanos al sistema de Viena. Las restauraciones fueron solo una etapa de un largo proceso de creación de comunidades políticas contrapuestas marcado por la formación de los conceptos de autonomía o por el tema de la invasión extranjera, por el nacimiento de contrapoderes territoriales y organizaciones políticas o militares. Cuando la batalla por la constitución dividió una vez más el mundo borbónico, liberalismo y democracia, legitimismo y neoabsolutismo se encontraron

Charles, The Peninsular War. A New History, New York, Palgrave Macmillan, 2003; Fraser, Ronald, Napoleon's Cursed War: Spanish Popular Resistance in the Peninsular War, 1808-1814, New York, London, Verso, 2008; Rújula, Pedro y CANAL, Jordi (coords.), Guerra de Ideas. Política y Cultura en la España de la Guerra de Independencia, Madrid, Marcial Pons, 2012.

47. Gandía, Enrique de, La independencia americana, Buenos Aires, Los libros del mirasol, 1960; Tutino, John, From Insurrection to Revolution in Mexico: Social Bases of Agrarian Violence, 1750-1940, Princeton, Princeton University Press, 1986; GuERRA, FrançoisXavier, Modernidad e independencias: ensayos sobre las revoluciones hispánicas, Madrid, MAPFRE, 1992; RODRíGUEZ, Jaime, Revolución, independencia y las nuevas naciones de América, Madrid, Fundación Mapfre-Tavera, 2005; Pérez Vejo, Tomás, Elegía criolla. Una reinterpretación de las guerras de independencia hispanoameriacanas, México, Tusquets, 2010. 
en todas partes, si bien a través de iliterarios nacionales diferentes. 1820 ofrece un modelo que evidencia la fragmentación del espacio de la antigua monarquía católica, unificado por la oleada revolucionaria y por la resistencia legitimista, pero quebrado por resultados diferentes ${ }^{48}$. Los regímenes borbónicos no fueron capaces de ofrecer espacios de participación y de intervención a los contestatarios políticos o regionales; en cambio, una vez más ninguno o casi ninguno de los viejos enemigos de Napoleón conoció conflictos internos análogos (Inglaterra, Rusia, Prusia, el Imperio austriaco, los Países Bajos, Dinamarca, Suecia). La victoria de la revolución en América (independencia y formación de las naciones) y la de la contrarrevolución en Europa (intervención internacional en España e Italia) produjo una fractura decisiva: las conexiones globales se redujeron a la diversa influencia de los imperios inglés y francés (que en el Mediterráneo habían ocupado definitivamente el papel de España), a los intercambios de ideas o modelos políticos, a los desplazamientos de exiliados y aventureros en ambos lados del Atlántico.

Los conflictos civiles, producto de la crisis de legitimidad originaria, continuaron, haciendo posible una hipótesis comparativa. En los territorios del otro lado del Atlántico, después de los años veinte, el final del control imperial fue seguido, casi siempre, de guerras internas, raramente resolutivas, que consolidaron, divisiones y comunidades políticas alternativas, alternando treguas, paces confusas o acuerdos. Estos conflictos tenían a veces líneas comunes con la Europa borbónica (la vinculación con la Iglesia católica, la relación entre centro y periferia, entre grupos urbanos y clases rurales) pero raramente pusieron en discusión las nuevas identidades nacionales o hicieron regresar los modelos tradicionales. En el mundo latinoamericano el desencuentro directo entre revolución y contrarrevolución, en los términos tradicionales, había concluido. Como han escrito Pérez-Vejo y López-Álves, el conflicto interno quedó como una regla en gran parte de aquel espacio político, desde México hasta Colombia o Uruguay. Era una confrontación entre liberales y conservadores, federalistas y centralistas, caudillos y centros urbanos, sobre diversos proyectos de nación y estado más que sobre complejos objetivos de poder que continuaron hasta final de siglo ${ }^{49}$.

Revolución y contrarrevolución continuaban batiéndose en España, pero al revés. El liberalismo español impidió a sus enemigos dar un vuelco a los resultados del cambio constitucional, y fue capaz de mantener el poder superando

48. Brown, Matthew y Paquette, Gabriel J. (coords.), Connections after Colonialism: Europe and Latin America in the 1820s., Tuscaloosa, University of Alabama Press, 2012.

49. López-Alves, Fernando, La formación del estado y la democracia en América Latina 1830-1910, Barcelona, Norma, 2003. 
definitivamente la derrota de los años veinte, aunque el carlismo, como ha explicado Canal, consiguió superar la crisis del legitimismo europeo de los años setenta del siglo XIX ${ }^{50}$. En todo caso, no lograría conquistar la cumbre de las instituciones solo controladas por el absolutismo en el Reino de las Dos Sicilias. En Nápoles, en 1849, la Cuarta restauración fue el momento de mayor éxito del legitimismo napolitano respecto a la contrarrevolución europea, pero justamente esto lo confinó en sus límites tradicionales, incapaz de absorber diversas concepciones de estado (la constitución) o de territorio (Sicilia). El resultado fue que, cuando el conflicto civil se entrecruzó con la gran guerra del Risorgimento (1859-61), justamente el éxito de la contrarrevolución y de sus victoriosas restauraciones multiplicó su aislamiento internacional y el peso de la fractura interna, contribuyendo de forma decisiva a la implosión del estado y a su desaparición. Al contrario, en los otros estados herederos del mundo borbónico, este conflicto se transformó (en España) o estaba definitivamente superado (en América Latina), y no devino nunca una cuestión de contraposición entre diversas identidades estatales. Solo en Nápoles el no resuelto conflicto entre revolución y contrarrevolución acabó por identificarse con las adscripciones nacionales, contraponiendo una patria (napolitana) a otra patria (italiana), dejando una herencia explosiva al jovencísimo heredero de Fernando II.

\section{La restauración fallida}

La muerte del rey evidenció las contradicciones de la última restauración borbónica. Los meridionales filoitalianos, reforzados por el consenso internacional y por la agresiva política de Cavour, participaron en masa en la revolución de 1860. El nuevo rey y sus hombres más próximos pensaron invertir la política de Fernando II, modificando los caracteres del bloque dominante, consolidado prácticamente desde 1799 , y aceptando liquidar el aparato puesto en pie por el padre durante la última restauración (1849), a cambio de la alianza con un sector liberal moderado ${ }^{51}$. La concesión de la constitución provocó, sin embargo, la implosión del reino. El patriotismo napolitano empezó a fragmentarse, el italiano se unifico definitivamente. Entre junio y septiembre de 1860, las tropas borbónicas se desbandaron, los liberales meridionales toma-

50. Canal, Jordi, El carlismo. Dos siglos de contrarrevolución en España, Madrid, Alianza Editorial, 2000; idem, Banderas blancas, boinas rojas. Una historia política del carlismo, 18761939, Madrid, Marcial Pons, 2006; Rújula, Pedro, Contrarrevolución. Realismo y Carlismo en Aragón y el Maestrazgo, 1820-1840, Zaragoza, Prensas de la Universidad, 2011.

51. MACRY, Paolo, Unità a Mezzogiorno. Come l'Italia ha messo insieme i pezzi, Bologna, Il Mulino, 2012. 
ron el control de las provincias y Garibaldi, que había liderado la enésima revuelta siciliana, entró triunfalmente en la capital ${ }^{52}$.

No hubo una transición pacífica. En septiembre, justo en el momento de mayor éxito de la revolución, empezó una poderosa contrarrevolución que duró años. El conflicto entre fidelidad dinástica y constitucionalismo liberal que había marcado durante medio siglo la política meridional y caracterizado las últimas dos restauraciones, quedó en segundo plano. Fue la guerra entre los dos nacionalismos, italiano y napolitano, la que obligó a la sociedad meridional a posicionarse definitivamente, adoptando un modelo nacional o defendiendo otro (Sicilia había elegido casi en bloque la Unificación). El ejército borbónico mostró voluntad de combatir. Solo la invasión piamontesa lo derrotó definitivamente. Luego, después de Gaeta, los partidarios de la dinastía intentaron una nueva restauración, en nombre del rey y de la independencia de las Dos Sicilias. La movilización rural (il Brigantaggio) duró varios años. También la alta jerarquía eclesiástica rechazó radicalmente la revolución unitaria. Solo un obispo (de 89) se adhirió al nuevo régimen, pero la Iglesia, aun no reconociendo el nuevo estado, evitó un dramático ajuste de cuentas. El significado general de la crisis se hace más claro en el interior del sistema internacional: si las primeras restauraciones fueron consolidadas por el cuadro de alianzas europeas, la última fracasó por su aislamiento casi completo.

A pesar de su fracaso, en los años siguientes la celebración de la defensa de la independencia de las Dos Sicilias devino el momento constitutivo de la identidad borbónica napolitana ${ }^{53}$. El mito de la restauración fallida estaba directamente vinculado a la reelaboración de un conflicto civil ininterrumpido que había marcado los decenios precedentes. En la memoria legitimista el enemigo interno era el responsable de la disolución de una compacta comunidad nacional. El político legitimista Scamaccia Luvarà escribió que durante más de sesenta años, desde 1794, los traidores se habían apartado en "secretos concilios... apoyando descarados los perjuicios de la patria..." ${ }^{44}$. La narración legitimista buscó en los sucesos de las restauraciones las razones de la propia reivindicación nacional, pero fue sobre todo la última defensa del reino el corazón de la epopeya borbónica, un mito en el cual no faltaban los elementos simbólicos, con su intensa capacidad de sugestión mitográfica: la

52. PinTo, Carmine, "La rivoluzione disciplinata del 1860. Cambio di regime ed élite politiche nel Mezzogiorno italiano", Contemporanea, $n^{\circ} 1$ (2013), pp. 39-68.

53. Casalena, Maria Pia (coord.), Antirisorgimento. Appropriazioni, critiche, delegittimazioni, Bologna, Pendragon, 2013.

54. Insogna, Angelo, Francesco secondo Re di Napoli, Storia del Reame delle Due Sicilie, Napoli, Gambella, 1898, pp. LV-LVII. 
bandera y la comunidad, el himno nacional y el rey, la independencia y la defensa frente al agresor extranjero, el héroe y el traidor.

Veteranos y militantes escribieron decenas de volúmenes de memorias, panfletos y ensayos. Todos, como el capitán Tommaso Cava, procedente de una familia de antiguas tradiciones militares, reivindicaron que "el ejército napolitano defendió la independencia Nacional" ${ }^{55}$. En la memoria de la generación de los combatientes de las Dos Sicilias la comunión entre el rey y los defensores de la patria se extendió a un concepto de nación más amplio. El mayor de artillería Pietro Quandel, hijo de un personaje importante de las jerarquías militares borbónicas, escribió en su relación del asedio de Gaeta que:

"La guarnición ha estado siempre sostenida por el pensamiento de cumplir con un deber sacro y mantener la fidelidad jurada, y ha sido incitada a cumplir con el ejemplo que les llevaron Sus Majestades el Rey Francisco II y la Reina María Sofía, y Sus Altezas Reales el Conde de Trani y el Conde de Caserta, que han compartido constantemente con los defensores de la Plaza peligros, privaciones, incomodidades" 56 .

Se desarrolló una épica colectiva que inmortalizó la voluntad de resistencia de los napolitanos a través de una serie de imágenes y temas eficaces para delinear identidad y autoconciencia: el desprecio por la prepotencia del extranjero, la traición, la llamada del rey, los héroes y los soldados populares. Lealtad y resistencia eran los puntos de partida insustituibles de esta narración que completó un recorrido que sirvió para unir definitivamente la nueva reivindicación nacional con el antiguo patriotismo representado por la unión con la casa real. Estas líneas confluyeron con la crítica legitimista de la Unificación, renovando la identidad patriótica borbónica justo cuando Italia devino una realidad y empezaban a transformarse los nacionalismos europeos ${ }^{57}$. La fuerza de esta reelaboración no superó nunca el círculo de los supervivientes y de la memoria partidaria, si bien estuvo acompañada de una nutrida propaganda legitimista europea, sobre todo, francesa ${ }^{58}$. La formación discursiva del nuevo patriotismo borbónico perdió rápidamente, por lo tanto, su eficacia. En la Europa de finales del XIX eran los estados quienes diseñaban las tradiciones polí-

55. Cava, Tommaso, Difesa nazionale napoletana di Tommaso Cava, capitano dello Stato Maggiore dell'Esercito delle Due Sicilie, Capo dello Stato Maggiore della Piazza di Capua durante l'assedio del 1860, Napoli, s.n., 1863.

56. Quandel, Pietro, Giornale della difesa di Gaeta da novembre 1860 a febbraio 1861, Roma, Angelo Placidi, 1863, p. 329.

57. Chabod, Federico, Lidea di nazione, Bari, Laterza, 1962; Hobsbawm, Eric J. y Ranger, Terence (coords.), Linvenzione della tradizione, Torino, Einaudi, 1987; Viroli, Maurizio, Per amore della Patria. Patriottismo e nazionalismo nella storia, Roma-Bari, Laterza, 1995.

58. Croce, Benedetto, Uomini e cose della vecchia Italia, Bari, Laterza, 1927. 
ticas nacionales. También en el Mezzogiorno los nacionalistas italianos construyeron un edificio basado en las ceremonias de conmemoración, en la glorificación de los patriotas y de los héroes de la independencia a través de los símbolos oficiales que construyeron la nueva religión de la patria. Los veteranos y los nostálgicos borbónicos eran excluidos del nuevo fenómeno de la instrucción primaria nacional, de las ceremonias públicas o de la masiva inauguración de monumentos. A pesar de todo esto, un sector minoritario del Mezzogiorno dio vida a una combativa batalla política, a menudo estrechamente vinculada al movimiento católico conservador, representada por viejos aristócratas (a partir de las familias que regresaron a Nápoles después de 1870), ex militares, sacerdotes, gentes del medio rural, arropados por periódicos como La discussione, el Contemporaneo, La libertà cattolica, L'Italia Reale, el Vero guelfo, la Lotta, la Indipendenza, el Guelfo dell'indipendenza del Mezzogiorno y asociaciones (la Asociación borbónica estuvo activa en Nápoles hasta 1914). El mito de la restauración fallida arraigó en el fondo de una tradición y de una cultura y floreció en las crisis más agudas y en los momentos de reivindicación del Mezzogiorno: las publicaciones periódicas napolitanas de finales del XIX, la cultura populista de la segunda Posguerra, o la social radical de los años setenta. En el 150 aniversario, con mayor impacto, tuvieron lugar decenas de eventos: la conmemoración del general carlista Borges en presencia de todos los herederos de la familia real borbónica, la de los caídos en la fortaleza de Gaeta, los monumentos o las tarjetas postales de guerrilleros legitimistas como el sargento Romano en Apulia. Todos ellos son elementos que explican cómo aún hoy puede apreciarse el peso del intento de nacionalización del régimen borbónico que, unido a las críticas al estado unitario, ha contribuido a reforzar el paradigma excepcional de la historia meridional.

En todo caso, este sentimiento, en tanto que difuso, no tuvo nunca la fuerza para poner en tela de juicio los resultados de la revolución de 1860. Hasta aquel momento el Mezzogiorno había experimentado la república, la monarquía absoluta, el centralismo administrativo napoleónico, el absolutismo borbónico y la monarquía constitucional regional. Había conocido guerras civiles e internacionales, cuatro invasiones extranjeras, modelos políticos y visiones ideológicas opuestas. Las cuatro restauraciones, entre 1799 y 1849 , habían evidenciado la capacidad de la monarquía borbónica y de los antiguos estados italianos de renovarse, mostrando una potencial carga modernizadora abierta a una ulterior evolución posible y capaz de enfrentarse con estas dinámicas. Las propias restauraciones borbónicas, sin embargo, no habían conseguido asimilar las fracturas históricas del Mezzogiorno. La cuestión siciliana, las desavenencias sociales y sobre todo las político-ideológicas, el enfrenta- 
miento con el liberalismo, la formación de opuestas identidades nacionales en el mismo estado, habían convertido en perenne el conflicto civil ${ }^{59}$. El fracaso de las restauraciones estuvo en su fallida asimilación y luego en la incompleta resolución del problema nacional napolitano e italiano. El éxito de la contrarrevolución fue también su condena, porque fragmentó una unidad política hasta entonces coherente. Un caso único respecto a todos los estados y los territorios herederos de la monarquía católica, donde la derrota de la contrarrevolución había modificado el proceso de integración de las comunidades nacionales. Al contrario, en Nápoles, la radicalización del enfrentamiento entre estado monárquico borbónico y oposición política liberal modeló un concepto de nacionalismo alternativo y no logró encontrar una síntesis. Las últimas restauraciones llevaron a cabo una fórmula nacional que permaneció siempre incompleta y dividida, a diferencia del Piamonte saboyano, que en el nacionalismo italiano encontró la síntesis entre sus dos componentes internos también radicales (olvidando para siempre el rigor legitimista de los Saboya en 1815 y en $1821^{60}$ ). La guerra de 1860-66 representó la última respuesta a la presencia de diferentes formas de ver y representar el estado, y los cambios de la política y de la sociedad. Caído el reino y fallida la última tentativa de restauración, el resultado fue que sus élites estuvieron obligadas a desempeñar un rol secundario en el nuevo orden italiano, mientras que el Mezzogiorno devino progresivamente una de las cuestiones más problemáticas para la nueva nación.

59. PinTo, Carmine, "Tempo di guerra. Conflitti, patriottismi e comunità politiche opposte nel Mezzogiorno d'Italia (1859-1866)", Meridiana, no 76 (2013), pp. 57-84.

60. PASSERIN D'EnTREves, Ettore, L'Ultima battaglia politica di Cavour, i problemi dell' unificazione italiana, Torino, Ilte, 1956; Viarengo, Adriano, Cavour, Roma, Salerno, 2010; RoMEO, Rosario, Cavour e il suo tempo (1842-1861), Roma-Bari, Laterza, 2012. 
E S T U D I O S

S T U D I E S 



\title{
El carlismo ante la reorganización de las derechas. De la Segunda Guerra Carlista a la Guerra Civil \\ Carlism and the Reorganization of the Rights. From Carlist War II to the Civil War
}

\author{
Javier Esteve Martí \\ Universitat de València
}

Recibido: 25-IV-2014

Aceptado: 21-VII-2014

\section{Resumen}

En 1936 el carlismo no combatió con el objetivo prioritario de imponer a su propio rey, ni siquiera por un proyecto político propio. Este hecho sólo puede comprenderse en el contexto de procesos como la crisis del legitimismo monárquico o la reordenación de las derechas españolas. Este artículo se plantea el estudio de cómo el carlismo participó de la nueva sociedad de masas y del parlamentarismo, lo que facilitó una serie de acercamientos a grupos de derechas, especialmente a algunos de los que participarían del nacionalismo reaccionario. Ello favoreció conjunciones, más o menos sólidas o duraderas, que se vieron estimuladas por el colapso del sistema de la Restauración y el auge de movimientos políticos como el anticlericalismo, el socialismo o el anarquismo.

Palabras clave: Carlismo, Legitimismo, Nacionalismo reaccionario, Amalgama contrarrevolucionaria.

\section{Abstract}

In 1936 Carlists did not fight with the main objective of imposing their own king, not even for a particular political project. This fact can only be understood in the context of processes like the crisis of monarchical legitimacy or the reordering of the Spanish right wing parties. This article considers the study of how Carlism participated in the

* El autor participa en el proyecto "De la dictadura nacionalista a la democracia de las autonomías: política, cultura, identidades culturales" [HAR 2011-27392], financiado por el Ministerio de Economía y Competitividad. Agradece sus consejos, correcciones y dirección a Jesús Millán y $\mathrm{M}^{\mathrm{a}}$ Cruz Romeo. 
new mass society and in parliamentarianism, which facilitated a series of approaches to rights groups, especially to some of those who would join reactionary nationalism. This favoured more or less strong or long-lasting links, which were stimulated by the collapse of the Restoration system and the rise of political movements such as anti-clericalism, socialism or anarchism.

Key words: Carlism, Legitimacy, Reactionary Nationalism, Conter-revolutionary amalgam.

A finales de febrero de 1876, las últimas tropas carlistas cruzaban la frontera franco-española y se clausuraba un conflicto que comenzó durante el reinado de Amadeo, se prolongó durante toda la I República y quedó sentenciado tras la restauración de la monarquía en la persona de Alfonso XII. Pese al célebre ¡Volveré! de Carlos VII, el carlismo ponía fin a su etapa insurreccional y se cerraba una época de guerra civil casi perpetua ${ }^{1}$. La derrota bélica causó una grave crisis en las filas del carlismo, que quedó sumido en un estado de desmovilización y parálisis que incluso le llevó a ser definido como un movimiento político en vías de extinción. Especialmente porque la entronización de Alfonso XII dio al traste con la amalgama contrarrevolucionaria, propiciando la deserción de los liberales conservadores y de parte de la jerarquía eclesiástica². Además, el carlismo se vio afectado por sonados cismas como el pidalista, el cabrerista y sobre todo el integrista en 1888 y el mellista en $1919^{3}$.

Pero el carlismo sobrevivió a todas estas vicisitudes y el 19 de julio de 1936, los requetés se lanzaron a las calles de Pamplona y ganaron Navarra para el bando sublevado contra la legalidad republicana. Los carlistas, llegados de los villorrios aledaños, se concentraron en la Plaza del Castillo: era el encuentro entre el campo y la ciudad. ${ }^{4}$ Se integraban -en lo que fue una apuesta claramente

1. En la Restauración la partida, la guerrilla y la insurrección a campo abierto se convirtieron en fenómenos residuales. Fueron sustituidos por el militarismo y más tarde por la paramilitarización, fenómenos que no ponían tan directamente en peligro la estructura legal y de partido carlista como si lo hacían movimientos subversivos aislados como el de la Octubrada, GONZÁlez CALlejA, Eduardo, "Aproximación a las subculturas violentas de las derechas antirrepublicanas españolas (1931-1936)", Pasado y memoria: Revista de historia contemporánea, $\mathrm{n}^{\circ} 2$ (2003), p. 114.

2. El concepto amalgama contrarrevolucionaria es descrito en CANAL, Jordi, El carlismo: dos siglos de contrarrevolución en España, Madrid, Alianza, 2000, p. 121. En cuanto al atractivo de la Restauración para los sectores que la abandonaron, debe tenerse en cuenta que esta suponía la salvaguarda del orden, la propiedad y la moralidad, REAL, Javier, El carlismo vasco. 1876-1900, Madrid, Siglo XXI de España, 1985.

3. Sobre las diferentes escisiones, CANAL, Jordi, "Las muertes y resurrecciones del carlismo. Reflexiones sobre la escisión integrista de 1888", Ayer, no 38 (2000), pp. 115-135.

4. UGARTE, Javier, La nueva Covadonga insurgente: orígenes sociales y culturales de la sublevación de 1936 en Navarra y el País Vasco, Madrid, Biblioteca Nueva, 1998. 
mayoritaria pero no unánime en las filas carlistas- en el seno de una nueva alianza contrarrevolucionaria que, en esta ocasión, ya no luchaba con el objetivo prioritario de entronizar al pretendiente carlista. La marcha de Oriamendi, clásico himno del movimiento, reflejaba con una alteración en su letra, aunque pudiera tener mucho de impuesta desde arriba, el cambio de realidad que vivía el carlismo. Ya no se trataba de que "venga el rey de España a la Corte de Madrid", ahora era suficiente con "que los boinas rojas entren en Madrid".

¿Qué había ocurrido en ese lapso de sesenta años? En general puede hablarse de una crisis del legitimismo y de un reforzamiento del antiliberalismo que no fue acompañado del crecimiento del carlismo, sino de una relativa pérdida de su importancia. El objetivo de este texto es perfilar ese contexto, así como una serie de transformaciones, nunca predeterminadas y fruto de procesos discontinuos, que favorecieron el acercamiento del carlismo a los distintos grupos de derechas que confluyeron en torno al nacionalismo reaccionario. Un nacionalismo reaccionario que llevaba tiempo prefigurándose antes de aparecer conformado como una verdadera cultura política, y en cuyo trasfondo ideológico tuvieron mucha influencia los principios tradicionalistas. En atención a todo esto, en este artículo se presentará también, aunque de forma breve, el prolífico intercambio de hombres e ideas que tuvo lugar en las derechas españolas durante las primeras décadas del siglo XX. Intercambios que, a largo plazo, facilitaron objetivos prioritarios y reclamaciones comunes, lo que explica el masivo seguimiento que entre las distintas culturas o subculturas políticas de derechas españolas tuvo el alzamiento militar de 1936.

Comenzando por los cambios acontecidos en el carlismo, hay que atender a J. Canal cuando afirma que la recuperación de este tras la última derrota bélica fue inicialmente posible mediante su adaptación al sistema político parlamentario, por más que la idiosincrasia belicista pervivió, motivando la fundación del requeté. Ello causaría que ya no pudiese presentarse como una alternativa global al sistema liberal, convirtiéndose en un grupo que participaba -aunque desde los márgenes- en él ${ }^{5}$. Así pues, el carlismo sobrevivía, pero el precio pagado era el de una progresiva transformación a través de una utilización posibilista del sufragio universal masculino, el foro parlamentario y la estructura partidaria ${ }^{6}$. Suponía una aceptación parcial de la transigencia políti-

5. MORAL, Antonio, "Nación y Estado en el pensamiento carlista del siglo XIX", en RUIZ, José Ignacio y SOSA, Igor (dirs.), Identidades confesionales y construcciones nacionales en Europa (ss. XV-XIX), Alcalá de Henares, Universidad de Alcalá de Henares, 2012, pp. 231-232.

6. J. Caspistegui, entre otros, ha destacado la rapidez de la asunción por parte del carlismo de casi todos los instrumentos necesarios para entrar en la disputa por los sufragios, incluyendo el uso y el abuso del caciquismo, CASPISTEGUI, Javier, "Paradójicos reaccionarios: la modernidad contra la República de la Comunión Tradicionalista", El Argonauta español, no 9 (2012), <http://argonauta.revues.org/1409> [consultado: 08-VIII-2014] 
ca y de la teoría del mal menor. El carlismo, en este contexto, llevó a cabo un auténtico proceso de reorganización política centrado en la propaganda, el periódico, la tribuna, el asociacionismo y el fin del retraimiento electoral ${ }^{7}$.

Ahora bien, este remozamiento es difícilmente extrapolable al terreno ideológico y militar, lo que favoreció tanto una pérdida progresiva de una parte importante de sus bases como el desarrollo de una clara dependencia respecto del Ejército. Un caso paradigmático, buena muestra de esa tendencia, es el de la relación del general Valeriano Weyler con el carlismo. En los últimos años del siglo XIX, el carlismo creyó (y trabajó para que así fuese) en la posibilidad de que el general mallorquín, antiguo capitán general de Cuba y considerado un héroe, encabezase un giro del ejército español hacia la causa carlista. Manuel Polo y Peyrolón, líder carlista valenciano que fue diputado y senador, hizo notar en sus memorias que esta idea llegaba hasta las más altas esferas del carlismo, afirmando que el marqués de Cerralbo y Vázquez de Mella eran, a la altura del cambio de siglo, "weyleristas fanáticos"8. Polo y Peyrolón también recordaba que estando en el palacio de Loredán con Carlos VII, su secretario Francisco Melgar recibió un telegrama en que se reproducían una serie de compromisos por parte del general para con la causa. De acuerdo con su narración, el príncipe proscrito "se puso muy contento". La propia familia real carlista mostraba, por tanto, entusiasmo respecto a Weyler, en consonancia con unas bases populares carlistas que coleccionaban estampas y retratos del que en teoría estaba llamado a ser su nuevo líder militar9.

La creencia en la posibilidad de atraerse al estamento militar a través de la propaganda estaba arraigada, por lo demás, en el carlismo. Ello explica que con el tiempo los carlistas agasajasen a aquellos militares que, en un ambiente convulso, actuaban con fuerza contra elementos de la izquierda. En esta línea se entiende, por ejemplo, que la cúpula del jaimismo valenciano felicitase junto al resto de elementos monárquicos al general Echagüe por mantener el orden en la ciudad. En ocasiones, esta clase de adhesiones a militares causaba cierto malestar en las filas carlistas, como ocurrió con el propio Polo y Peyrolón, que se mostró crítico con el a la sazón líder del carlismo valenciano Manuel Simó por considerar que la adulación llegaba demasiado lejos en atención al hecho

7. CANAL, Jordi, El carlismo..., p. 234.

8. Los cuadernos en que Polo escribió sus memorias se hallan depositados en la Real Academia de la Historia. Para esta mención en concreto, he consultado POlO Y PEYROLÓn, Manuel, Memorias de un sexagenario, t. 3, p. 303. Cabe señalar que una parte destacable de estas memorias ha sido publicada en los últimos tiempos: URCELAY ALONSO, Javier, Memorias políticas de M. Polo y Peyrolón (1870-1913): crisis y reorganización del carlismo en la España de la Restauración, Madrid, Biblioteca Nueva, 2013.

9. POlo y PEYROLÓn, Manuel, Memorias de un sexagenario, t. 3, p. 204. 
de que Echagüe servía a la monarquía alfonsina. Críticas muy parecidas a las que lanzó contra el alcalde de Algemesí, igualmente jaimista, que premió a dicho general con una calle en su honor en este municipio valenciano ${ }^{10}$.

Pese al mencionado anquilosamiento de su ideología y estrategias militares, ello no debe llevar, en todo caso, a pensar en un carlismo inmóvil frente al cambio, pues desde las últimas décadas del siglo XIX fue empapándose de estatalismo, imperialismo y nacionalismo, lo que posibilitó la construcción de nexos entre el tradicionalismo y el pujante nacionalismo reaccionario. Estas corrientes, que recorrieron casi transversalmente el espectro político español, se vieron agudizadas por el discurso regeneracionista, que frente a la crisis nacional apuntaba a una profunda reforma del funcionamiento del Estado, el fortalecimiento de la nación española frente al auge de otros nacionalismos (internos y alternativos) y una recreación imperial africana. Gracias a estos cambios puede esbozarse la existencia de continuidades, aunque a veces sean difusas y complicadas de seguir, entre esa ideología decimonónica inficionada de la filosofía eclesiástica predominante desde el siglo XVIII, de romanticismo y de legitimismo monárquico, y la extrema derecha nacionalista, irracional y corporativa que fue conformándose a comienzos del nuevo siglo ${ }^{11}$.

La presencia del carlismo en el espacio público, que se fomentó con la mencionada reorganización, le puso en contacto con las demás fuerzas políticas de derechas y nacionalistas, favoreciendo las transferencias de personas y de ideas con aquellas con las que más tenía en común. Por otra parte, el salto al ruedo político y la concurrencia a las elecciones acabó enfrentando al carlismo con una realidad desmoralizadora que siempre había tratado de obviar: no era mayoritario en la sociedad española ${ }^{12}$. Es más, el paso del tiempo lo enfrentó, incluso, con la realidad de su progresiva pérdida de influencia en la vida política española, por más que se continuó empleando la salvaguarda mental de que los católicos, aunque sólo ante un agravamiento de la situación, se habían de decantar hacia su principal defensor. En ocasiones, como en el caso de las palabras del militar y diputado carlista Joaquín Llorens, estos paños calientes iban acompañados de referencias claramente despectivas hacia los católicos que transigían

10. POlo y PEYRolón, Manuel, Memorias de un sexagenario, t. 6, pp. 189-192.

11. Las definiciones de ambos fenómenos en ARÓstegui, Julio, "Estudio preliminar", en VÁZQUeZ DE MELla, Juan, Una antología política, Oviedo, Junta General del Principado de Asturias, 2002, p. XXXIV.

12. Al respecto de esa pérdida de centralidad política, J. Aróstegui afirmó que a partir de la Restauración fue el obrerismo el que se convirtió en agente de las mutaciones de la sociedad española, ARÓSTEGUI, Julio, "El carlisme en la dinàmica dels moviments liberals espanyols, formulació d'un model", en CANAL, Jordi (coord.), El carlisme. Sis estudis fonamentals, Barcelona, L'Avenç, 1993, pp. 65-66. 
con el liberalismo: "será preciso que ardan las iglesias para que esos católicos de papel de estraza salgan de su marasmo"13.

En todo caso, el alcance de la reorganización política fue muy diferente en las diversas regiones en que el carlismo se hallaba asentado. Este proceso, iniciado por el marqués de Cerralbo (1889) y que tenía por eje los Círculos carlistas, se extendió especialmente en Cataluña y el País Valenciano. Por el contrario, en Navarra, sometida desde antaño a una profunda carlistización, los cambios fueron menos sensibles, aunque la expansión de los Círculos fue destaca$b e^{14}$. En las provincias vascas fue más importante el hecho de que en Vizcaya la competencia del nacionalismo vasco restó seguimiento al tradicionalismo nacionalista español, que había sido importante salvo en la capital. Un tanto de lo mismo ocurrió en la provincia de Guipúzcoa, en la que el nacionalismo vasco tardó más tiempo en arraigar entre la población pero en la que el carlismo también tuvo que competir duramente con el integrismo, que contaba con bastiones de la importancia de Azcoitia, en el distrito de Azpeitia.

\section{La crisis del legitimismo}

El carlismo, en estos sesenta años, vio disminuir su importancia en el panorama político, en el contexto de un proceso discontinuo y jamás predeterminado -paralelo a la erosión del régimen liberal, los años de la dictadura y la posterior proclamación de la II República- en que se produjo el engrosamiento de las filas del antiliberalismo no legitimista. Pese a esa tónica general, no debe considerarse este decaimiento como un proceso lineal. Así pues, acontecimientos concretos como la Octubrada (1900), un desbaratado intento de levantamiento, tuvieron una incidencia poderosa en la organización carlista, que sufrió un importante retroceso. También vivió cierto marasmo a partir de la segunda década del siglo XX, del que salió tras la proclamación de la II República. Asimismo, se produjeron cambios destacables que afectaron a los territorios de implantación del carlismo, pudiendo señalarse la pujante organización del partido, protagonizada por Manuel Fal Conde, en la Andalucía republicana ${ }^{15}$.

13. Carta de Joaquín Llorens a Polo y Peyrolón (Madrid, 3 de junio de 1901). RAH. Sign. 9-33-8-7895

14. CASPISTEGUI, Javier, "¿Carlismo en Navarra o Navarra carlista?: paradojas de una identidad conflictiva entre los siglos XIX y XX", en El carlismo en su tiempo: geografías de la contrarrevolución. Actas de las I Jornadas de estudio del carlismo, Pamplona, Gobierno de Navarra, 2008, pp. 205-244.

15. Resulta significativo el resultado obtenido en las elecciones generales de 1933, en las que la Comunión Tradicionalista obtuvo un acta de diputado por la ciudad de Sevilla y dos por la provincia de Cádiz, unos resultados importantes en una zona nunca especial- 
Pero la imagen general de retroceso es innegable. Incluso dentro de la cultura política tradicionalista, de la que el carlismo era una subcultura principalmente distinguida por el legitimismo, la cuestión dinástica fue perdiendo peso. En ello fue fundamental el desarrollo de la teoría de las dos legitimidades, expuesta en el carlismo por la princesa de Beira (1864) con el objetivo de deslegitimar a Juan $\mathrm{III}^{16}$. Esta teorización acabó volviéndose en contra del propio pretendiente a favor del cual se había orquestado. Y es que, con justificaciones similares a las llevadas a cabo por ésta, con el paso del tiempo los integristas -así como otros disidentes como el padre Corbató- abandonaron a Carlos VII por considerarlo ilegítimo por ejercicio, bien fuera por haberse liberalizado o por mantener una postura cesarista ${ }^{17}$. Lo mismo ocurriría más tarde con Jaime III, que en su juventud había vivido ciertos escándalos por considerarse sus posturas próximas a las del liberalismo ${ }^{18}$.

En un limbo entre el tradicionalismo y el liberalismo, con los que mantenía una relación variable teñida de posibilismo, el legitimismo dinástico perdió progresivamente fuerza entre las filas del conservadurismo español. La adaptación del Ralliement francés ejecutado por la Iglesia católica fue aquí mucho más sencilla ya que, en vez de una república, el régimen establecido era una monarquía que otorgaba a la religión un papel privilegiado ${ }^{19}$. La proximidad de la jerarquía eclesiástica respecto a la dinastía alfonsina, como había ocurrido ya en tiempos de Isabel II, causó auténticos estragos en el carlismo, afectado por la infidelidad de una Iglesia de la que se tenía por único defensor. El propio Manuel Polo y Peyrolón reflexionó, en un claro tono de amargura, al respecto de esta aparente contradicción:

"No lo he comprendido nunca. Los carlistas españoles componemos el único partido que ha derramado a torrentes su sangre por la Religión y por la Iglesia, y sin embargo los altos dignatarios de ésta, que fueron en definitiva los únicos

mente representativa para el carlismo. Los resultados electorales pueden consultarse en El Siglo Futuro, 22-XI-1933, "Diputados tradicionalistas", p. 1.

16. MORAL, Antonio, "Nación y Estado..., pp. 228-229.

17. CANAL, Jordi, "Las muertes y resurrecciones... y CoRBATó, José Domingo, Exposición a Don Carlos de Borbón y Austria-Este sobre carlismo y españolismo, Valencia, Biblioteca Españolista, 1904, p. 7.

18. Sobre las acusaciones de liberalismo hechas a don Jaime trataré más adelante. Por ahora baste decir que, como en el caso de su padre, también fue tachado de absolutista, en esta ocasión por Víctor Pradera, DELGADO, Ander, "Víctor Pradera: mártir de España y de la causa católica", en QUiroga, Alejandro y DEL ARCO, Miguel Ángel (eds.), Soldados de Dios y apóstoles de la patria. Las derechas españolas en la Europa de entreguerras, Granada, Comares, 2010, p. 70.

19. GONZÁLEZ CUEVAS, Pedro, "Tradicionalismo, catolicismo y nacionalismo: la extrema derecha durante el régimen de la Restauración (1898-1930)", Ayer, nº 71 (2008), p. 28. 
favorecidos, no pueden ver a sus favorecedores, y trabajan cuanto pueden contra ellos" 20 .

Más allá del daño ideológico que causaba al carlismo la aparente distancia de la alta jerarquía eclesiástica, que no se extendía necesariamente al clero más humilde, el mencionado Ralliement también conllevó la aparición de agrupaciones católicas que transigían con el liberalismo y competían con el carlismo por un público similar. Si inicialmente la fundación de la Unión Católica de Pidal (1881) se saldó con un sonado fracaso, lo cierto es que el acatamiento -pragmático y transitorio- por parte de la jerarquía eclesiástica del peculiar liberalismo de la Restauración fue fundamental para la aproximación de lo que B. Urigüén calificó como derechismo católico liberal al Turno dinástico ${ }^{21}$. Además, el fracaso de la Unión Católica no fue el final del liberalismo católico, pues más allá del propio partido liberal conservador, fue destacable la aparición de las Ligas católicas, así como también de otros partidos y sindicatos de filiación católica.

La desvalorización de la dinastía legítima se extendió, incluso, entre los propios carlistas. La entronización de Carlos VII fue especialmente importante ante el crítico contexto causado por las muertes reales posteriores a la Ortegada (1860) y por la traición de Juan III. Pero el prestigio del duque de Madrid, acrecentado durante la contienda, fue desmoronándose a partir de 1874 debido a una serie de escándalos que se vieron agravados por su inactividad ante la crisis finisecular. En este contexto, las críticas más benévolas culparon de su pasividad a su esposa María Berta, si bien las hubo mucho más duras, pudiendo citarse las de Joan Bardina, que calificó a Carlos VII de nulidad en cuanto a la dirección de causas ${ }^{22}$. Un número importante de las críticas hacia Carlos VII se dirigieron a la vida sentimental de éste, marcada primero por escándalos y más tarde por el impopular matrimonio con María Berta, que aparentemente le alejó de los hijos tenidos con su anterior esposa ${ }^{23}$.

20. POlO y PEYROLÓn, Manuel, Memorias de un sexagenario, t. 3, p. 249.

21. URIGÜEN, Begoña, Orígenes y evolución de la derecha española: el neo-catolicismo, Madrid, Centro de Estudios Históricos, 1986.

22. CANAL, Jordi, Banderas blancas, boinas rojas: una historia política del carlismo, 1876-1939, Madrid, Marcial Pons, 2006, p. 35.

23. Los ataques al príncipe proscrito por su relación con una joven húngara le llegaban en forma de burla desde la prensa liberal, como puede verse en el largo artículo "Agridulces" de Manuel Sancho en El Heraldo de Madrid, 2-VII-1892. Más interesante aún es el artículo escrito por el célebre republicano valenciano Vicente Blasco Ibáñez en Don Quijote, 6-VII-1899, en que se hace burla de la anterior promiscuidad de Carlos VII para pasar después a tratar sobre el control que $\mathrm{M}^{\mathrm{a}}$ Berta ejercería sobre su esposo. Así, Blasco define a don Carlos como un hombre "algo averiado por las heridas de las batallas de Venus" y dice de María Berta que "inmediatamente se adivina que aquella mon- 
Lo mismo le ocurrió a Jaime III (pretendiente carlista al trono desde 1909), criticado en numerosas ocasiones por no haber contraído matrimonio y acusado de mantener un estilo de vida disoluto. En este caso las críticas también fueron numerosas, pudiendo destacarse las de Vázquez de Mella, que lamentaba su escasa religiosidad. Manuel Polo y Peyrolón, yendo algo más lejos, dejó anotado en sus memorias que "a D. Jaime de Borbón y Borbón, heredero de la Jefatura de esta gran Casa Real, de la legitimidad española y de la representación católico-monárquica de su augusto padre, le tenían sin cuidado los principios, base y fundamento de su posición y prestigio en el mundo" 24 . Alfonso Carlos, del que también se habían vertido críticas por su papel en la Segunda Guerra Carlista, evidentemente no era el candidato idóneo, pues a la muerte de su sobrino Jaime (1931) ya superaba los 80 años de edad y no contaba con descendencia directa ${ }^{25}$.

Si anteriormente la figura del monarca legítimo había sido fundamental para el tradicionalismo, como sostiene P. Rújula cuando afirma que era el único capaz de unir a todos bajo una misma bandera y proporcionaba al movimiento una línea de referencia y continuidad temporal ${ }^{26}$, el pleito dinástico acabó relegado a una posición periférica, lo que complicó la diferenciación del carlismo

jita es la que tiene las llaves de la despensa". En cuanto a las críticas a María Berta, estas fueron abundantes por parte de carlistas como Francisco Melgar, antiguo secretario de Carlos VII que achacó a esta su cese tras la Octubrada y siguió odiándola durante toda su vida. Según Polo, Melgar llegó a acusarla públicamente de odiar a la patria y a la causa carlista. Así se recoge en POLO Y PEYROLÓn, Manuel, Memorias de un sexagenario, t. 6 , pp. 300-305.

24. POlo y Peyrolón, Manuel, Memorias de un sexagenario, t. 4, p. 302. También antes de la muerte de Carlos VII, Polo se sumía en el pesimismo y afirmaba: "si pues no se casa nunca, y además inspiran fundadas sospechas de liberalismo sus ideas, el porvenir católico-monárquico que nos espera, no necesita comentarios". En cuanto a las sospechas de liberalismo, también se hacía eco la prensa rival, y en ese sentido El País, 4-V1907, en "El equívoco carlista", le acusaba de ser más liberal que cualquiera de los ministros del gobierno maurista. E. González Calleja ha señalado, en la misma línea, que la desaparición de Jaime III favoreció la reintegración del mellismo en el carlismo, puesto que al hijo de Carlos VII lo consideraban los mellistas sospechoso de criptoliberalismo, GONZÁLEZ CALLEJA, Eduardo, "Hacia una nueva guerra carlista (1931-1939)", en aróstegui, Julio, CANAL, Jordi y GONZÁlez CAlleja, Eduardo, Las guerras carlistas. Hechos, hombres e ideas, Madrid, La Esfera de los Libros, 2003, p. 106.

25. Francisco Melgar, de acuerdo con Polo y Peyrolón, que coincidía con su tesis, opinaba que Alfonso Carlos era un santo imbécil: "santo porque sus virtudes privadas y prácticas huelen verdaderamente a Santidad, pero imbécil porque es hombre de ningún alcance y no ha hecho ni aconsejado en toda su vida a su hermano más que necedades". Así se apunta en POlO y PEYROLÓn, Manuel, Memorias de un sexagenario, t. 3, pp. 309-311.

26. RÚJUla, Pedro, "La guerra civil en la España del siglo XIX: usos políticos de una idea", en CANAL, Jordi y GONZÁLEZ CALleja, Eduardo, Guerras civiles. Una clave para entender la Europa de los siglos XIX y XX, Madrid, Casa de Velázquez, 2012, p. 50. 
del resto de grupos de la cultura política tradicionalista ${ }^{27}$. En esta línea, P. González Cuevas ha señalado a Víctor Pradera como una figura fundamental en la aproximación de las derechas nacionalistas españolas durante los años de entreguerras. Ya en el seno del mellismo, había vivido un inicial acercamiento a la Unión Patriótica y por tanto al alfonsismo, con el que ya había convivido en el Partido Social Popular (1919-1923). Más tarde, en el contexto de la II República fue uno de los principales promotores de Acción Española (1931-1936) y de la fundación del Bloque Nacional. No obstante, llegó a proponer la unión dinástica borbónica sugiriendo para ello que Jaime III renunciara a sus derechos y Alfonso XIII abdicase en su hijo Juan, que a cambio debía aceptar el ideario tradicionalista ${ }^{28}$.

Víctor Pradera destacó, pues, en un periodo en que el tradicionalismo de raíz carlista fue dejando de lado la cuestión dinástica, ante el devenir de los acontecimientos, para confraternizar con ideas corporativas, organicistas y directamente golpistas ${ }^{29}$. Se produjo, por tanto, la progresiva confusión de las distintas subculturas políticas tradicionalistas, y estas también se aproximaron al nacionalismo reaccionario y al nacionalcatolicismo. No obstante, resulta significativo el temprano interés del maurismo por la figura de Vázquez de Mella, y ya mucho más tarde, el acercamiento de parte del carlismo al partido alfonsino Renovación Española (1933-1936) en el contexto de la II República. La aproximación, que una vez más cabe tener en cuenta que ni era un fenómeno predeterminado ni se dio sin discontinuidades, tuvo su mejor representación en la formación de Tradición y Renovación Española e implicaba un alejamiento evidente del legitimismo, así como también el acercamiento a un proyecto de claro corte autoritario. Autoritarismo que había calado en gran parte de la derecha española, lo que explicaría el apoyo inicial de diversos grupos sociopolíticos al golpe primorriverista. También lo hizo en el carlismo, y así a principios de siglo el carlista Enrique Gil Robles, pese a pretender limitar el poder del Estado, acep-

27. Pese a esta afirmación, no comparto visiones como la de J. Fontana, tendentes a negar cualquier importancia al componente dinástico del carlismo y que han sido rebatidas por J. Canal. Sí considero, como este último autor, que en realidad la cuestión dinástica no fue esencial en el carlismo, idea que desarrolla en CANAL, Jordi, "El rey de los carlistas: reflexiones sobre las palabras, las personas y las cosas", en Por Dios, por la Patria y el Rey. Las ideas del carlismo. Actas de las IV Jornadas de estudio del carlismo, Pamplona, Gobierno de Navarra, 2011, pp. 245-249.

28. La trayectoria política de Víctor Pradera puede estudiarse en DELGADO, Ander: "Víctor Pradera...

29. GONZÁlEZ CUEVAS, Pedro, Acción Española. Teología política y nacionalismo autoritario en España (1913-1936), Madrid, Tecnos, 1998, p. 51. 
tó que este se impusiese sobre la resistencia de la nación con el objetivo de vigorizar el espíritu nacional ${ }^{30}$.

\section{El carlismo y el nacionalismo reaccionario}

Fue indudable la existencia de una auténtica crisis del legitimismo carlista. Pero lo que realmente puso en jaque su preponderancia en el panorama de la derecha española fue la aparición de una serie de desarrollos ideológicos e intelectuales que con el tiempo confluirían en lo que algunos autores conocen como nacionalismo reaccionario. I. Saz afirma que éste no se formalizó en una auténtica cultura política hasta la década de 1930, pero también que sus inicios serían anteriores y que aun como conglomerado indeterminado tuvo efectos en el conjunto de las derechas españolas ya a principios de siglo ${ }^{31}$. Si durante el siglo XIX el carlismo había sido la cabeza indiscutible de la derecha antiliberal, la crisis finisecular remató un proceso que ya venía de tiempo atrás y que llevó a un ambiente generalizado -especialmente visible en las élites intelectuales- de nacionalismo español contrario a un sistema liberal en el que no se confiaba.

En el caso francés, cuyo estudio es necesario por sus resonancias al otro lado de los Pirineos, la crisis, iniciada en Sedán y con hitos como la Comuna, Fachoda y el affaire Dreyfus, favoreció el desarrollo del nacionalismo antiliberal. Lo mismo ocurrió en España, donde el mito de la decadencia no dio pie tanto a soluciones palingenésicas como a respuestas que combinaban referentes nacionalistas preliberales con la idea de la esencialidad católica de España, desarrollada por Menéndez Pelayo pero propia del tradicionalismo español. Ejerciendo al tiempo como compilador y renovador de la tradición, Menéndez Pelayo la adaptó a un discurso regeneracionista, desarrollista y nacionalista, lo cual permitía a esta conectar con el ambiente generado por la crisis finisecular. La figura del intelectual cántabro fue fundamental, principalmente por el calado de su discurso, pues pese a comulgar con el constitucionalismo canovista, una parte importante del conjunto de las derechas pudo reivindicar su figura (como sucedería con autores como Donoso Cortés) convirtiéndose por tanto en elemento de convergencia ${ }^{32}$.

El pensamiento de Menéndez Pelayo tuvo también efectos en el propio carlismo, que a su proyecto católico y tradicionalista sumó la aceptación de ese

30. miLláN, Jesús, "La retropía del carlismo. Referentes y márgenes ideológicos", en SUÁREZ CORTINA, Manuel (ed.), Utopías, quimeras y desencantos. El universo utópico en la España liberal, Santander, Ediciones de la Universidad de Cantabria, 2008, p. 271.

31. SAZ, Ismael, Las caras del franquismo, Granada, Comares, 2013, pp. 27-30.

32. BotтI, Alfonso, Cielo y dinero: el nacionalcatolicismo en España (1881-1975), Madrid, Alianza, 1992. 
nacionalismo contemporáneo que estaba representado en España por Menéndez Pelayo y que no era incompatible con, entre otros, el patriotismo galdosiano. Una incorporación que no fue demasiado complicada, pues al fin y al cabo muchos de los supuestos de Menéndez Pelayo enlazaban con el primer carlismo, ya que pueden encontrarse fórmulas muy próximas a las suyas en autores como el barón de Juras Reales. Dentro del tradicionalismo (y en general de todas las corrientes políticas españolas) se produjo un empoderamiento del nacionalismo a la altura del cambio de siglo. No hace falta fijar el objetivo en el propio carlismo, sino que resulta más interesante centrarse en otra de las figuras intelectuales con incidencia en toda la derecha española, Emilia Pardo Bazán. En El saludo de las brujas (1899), una de sus novelas menos conocida y de corte romántico, la escritora gallega situó la defensa de la identidad nacional como una idea ubicada muy por encima de las banderías políticas ${ }^{33}$.

Esta novela, sobre la que poco se ha escrito, se centra en las desventuras del hijo bastardo del monarca de la imaginaria Dacia, que reside en París distanciado de su pasado hasta que su padre enferma y parece va a morir sin descendencia. Frente a la amenaza de que la sucesión recaiga en el duque Aurelio, que se halla muy próximo a Rusia y que por tanto puede suponer un peligro para la integridad nacional, los partidarios de la monarquía tradicional y los liberales acuden a tratar con Felipe, rogándole que acepte la corona. Así, en la obra de Emilia Pardo Bazán la nación se perfila como elemento de unión entre tradicionalismo y liberalismo, y su pervivencia se sitúa muy por encima del supuesto peligro que pueden representar movimientos como el republicanismo o el socialismo.

Por el camino, la escritora gallega lleva a cabo un realce de la figura del monarca, principalmente a través de los pensamientos de la amada de Felipe, Rosario, que no por casualidad es de origen chileno y, por tanto, también español. Ahora bien, el final de la novela es decorazonador, y puede ser significativo del pesimismo reinante entre una intelectualidad que añoraría la reunión de políticos tradicionalistas y aquellos que defendían un "liberalismo respetable", un liberalismo no soberanista. Y es que en El saludo de las brujas, superadas las iniciales dificultades, aparentemente Felipe se consolida como único candidato al trono. Es entonces cuando el espíritu de partido aparece en escena y salta por los aires la alianza entre tradicionalistas y liberales. Pese a que la cruenta muerte de Felipe es causada por un hombre del duque Aurelio, subyace la idea de que la pérdida de una vida noble, y del bien más preciado -que es la nación-, se relacionaría directamente con la incapacidad de alcanzar un consenso político.

33. pardo bazÁn, Emilia, El saludo de las brujas, Madrid, Espasa-Calpe, 1966. 
Auge del nacionalismo, por tanto, que fue un elemento transversal en las derechas españolas. Con respecto al desarrollo del nacionalismo reaccionario, I. Saz ha señalado que el conservadurismo español fue extremando progresivamente el peso de los elementos religiosos y nacionalistas en su discurso. Este fenómeno, especialmente visible a partir del periodo de entreguerras, supuso una progresiva ruptura con respecto al conservadurismo liberal y condujo al nacionalismo reaccionario a mantener el antiguo objetivo carlista de acabar con el sistema liberal y, especialmente con su manifestación más perturbadora, la democracia. Asimismo, el nacionalismo reaccionario mantenía una retórica elitista en que no se invocaba al pueblo sino a las instituciones históricas, es decir, la Monarquía, la Iglesia y el Ejército. Además, el nacionalismo reaccionario sostenía un corporativismo orgánico conservacionista, que no se cuestionaba el orden social ni la modernización económica y mantenía un discurso regionalista y descentralizador. Por último, no hacía apología de la violencia como elemento constitutivo, aunque no se oponía frontalmente a ella en un contexto en que los recelos decimonónicos hacia esta habían retrocedido entre la burguesía ${ }^{34}$.

Como resulta fácil de entrever, ninguno de estos planteamientos chocaba frontalmente con los defendidos históricamente por el carlismo. La religión y la nación siempre habían tenido un lugar privilegiado en éste, que les concedía un puesto de preferencia en su trilema "Dios, Patria y Rey"35. En cuanto al vigor de los ataques del carlismo frente al liberalismo y la democracia, no creo que sea necesario insistir ${ }^{36}$. Que el carlismo no preconizaba un brusco cambio del panorama social también es obvio, aunque sí es cierto que el auge de la cuestión social le hizo participar en el debate, por más que tendió a recurrir a soluciones basadas en la caridad de los ricos y la conducta cristiana de los empre$\operatorname{sarios}^{37}$. La valorización de las instituciones históricas también era clara en el carlismo, que de hecho pretendía devolverles su papel tradicional, afectado por el liberalismo y la división de poderes. El regionalismo y la descentralización también eran elementos constitutivos del carlismo y respecto a la violencia, pese a que había sido practicada con profusión, nunca se había concebido como elemento regenerador.

34. SAZ, Ismael, Las caras..., pp. 15-16.

35. La preponderancia de la nación en desarrollos ideológicos carlistas puede observarse en personajes como Enrique Gil Robles, millán, Jesús, "La retropía del carlismo..., pp. 255-282. El mismo autor va a publicar próximamente un artículo en la revista Alcores en que se podrá observar un ejemplo precoz de nacionalismo español en las filas carlistas a través del estudio de la figura del tercer Barón de Juras Reales, Lluís Maria de Moixó, nacido en 1781.

36. El ejemplo más célebre de crítica desde el tradicionalismo puede hallarse en SARDÁ Y SALvany, Félix, El liberalismo es pecado. Cuestiones candentes, Barcelona, Alta Fulla, 1999.

37. EsteVe Martí, Javier, "El tradicionalisme en l'ascens del nacionalisme de masses: el pare Corbató", Recerques, no 65 (2012), pp.124-125. 
Así, resulta evidente que el nacionalismo reaccionario tenía varios puntos comunes con el tradicionalismo, lo que favorecía acercamientos, sí, pero también lo ponía en competencia por un mismo público. Por ejemplo, unas "masas católicas neutras" que, dependiendo de la situación sociopolítica, podían ser un interesante caladero para ellos. No obstante, menudearon desde ambas partes las llamadas a "católicos incoloros" o "patriotas españoles", lo que muestra la voluntad de alcanzar a un público extenso con proclamas supuestamente apolíticas-simplemente patrióticas-en un intento de concentrar a las derechas mediante la presuposición de que los intereses nacionales eran defendidos por élites políticas naturales. En un contexto en que la derecha se presentaba como adalid del nacionalismo económico, no resulta complicado identificar estos llamamientos con referencias empleadas por las dictaduras primorriverista y franquista, que presentaban su régimen como defensor del desarrollismo técnico y las ideas sanas.

En esta línea puede interpretarse la proclama que Manuel Polo y Peyrolón hizo con motivo de las elecciones generales de 1901. Su carta, enviada desde la sierra de Albarracín, iba dirigida "a los electores todos de la circunscripción valenciana en general, y por modo especialísimo a los electores católicos neutros o de cualquiera fracción política". En ella trataba de convencerles de que depositasen su confianza en él, para lo cual exponía un programa esencialmente católico, consensuado con la Iglesia y asimismo comprometido con los intereses económicos valencianos. En ese sentido, el escrito parecía querer defender intereses innegables, en el sentido de neutros, cuando se comprometía "a procurar, por último, con verdadero empeño, cuanto convenga a los intereses religiosos, morales, agrícolas, industriales, comerciales, marítimos y tributarios de la nación, de la región valenciana, y singularmente de la católica Valencia"38.

Por otra parte, la crisis del sistema del Turno no sólo fue importante para el desarrollo del nacionalismo reaccionario, sino que favoreció que una fracción importante del conservadurismo dinástico, encabezada aunque no liderada por Maura, se radicalizase, aproximándose al autoritarismo antidemocrático ${ }^{39}$. El maurismo, como gran parte de las derechas españolas, asumió también el referido énfasis en el catolicismo y la monarquía como elementos fundamentales

38. Luz Católica, 16-V-1901, "Remitido. A los electores de la circunscripción de Valencia", p. 16.

39. Se produjo, como décadas atrás, con Antonio Aparisi Guijarro como protagonista, el giro de parte del liberalismo conservador hacia posiciones contrarrevolucionarias, MILLÁN, Jesús, "Contrarrevolució i mobilització a l'Espanya contemporània", en CANAL, Jordi (coord.), El carlisme. Sis estudis fonamentals, Barcelona, L'Avenç, 1993, p. 188. La diferencia es que en esta ocasión, ya entrado el siglo XX, el beneficiario directo de esta defección no fue el carlismo. 
y fundadores de la nación. Por otra parte, la dispersión de los mauristas fue trascendental para el progresivo acercamiento de las derechas. Un sector, encabezado por Ángel Ossorio, colaboró con la ACNP y el tradicionalismo mellista en la fundación del Partido Social Popular, cuyo principal objetivo era aplicar los planteamientos católicos sociales. Por el contrario, Antonio Goicoechea y una parte destacable del maurismo radicalizaron sus posturas, alistándose en las filas de Renovación Española ${ }^{40}$.

Retomando el asunto del legitimismo, el lector habrá notado que para las derechas, el nacionalismo reaccionario, así como también para el maurismo, la monarquía se constituía como uno de los pilares del nuevo Estado. El problema para el carlismo es que las menciones que se hacían del monarca habían cambiado de tono respecto a las realizadas en el siglo XIX. Hay casos especialmente interesantes, como por ejemplo el de Eugeni d'Ors. Este era uno de los máximos representantes de la defensa del imperio como solución a las tensiones regionalistas y de la monarquía como elemento de unión entre las diferentes naciones españolas, en una teorización que compartía parcialmente con el tradicionalista Víctor Pradera ${ }^{41}$. Su proyecto, ahora bien, no pasaba por la dinastía proscrita, y una muestra de ese ambiente puede encontrarse en los acercamientos de la burguesía catalana a la figura del joven Alfonso XIII a comienzos de siglo. En la misma línea puede referirse el discurso que predicaba la heterogénea Acción Española, en sintonía con el monarquismo místico de un Charles Maurras que simpatizó con la monarquía alfonsina y admiró a Cánovas del Castillo.

\section{La respuesta del carlismo}

El carlismo, en convivencia con estas nuevas trayectorias ideológicas, así como también con los fenómenos que afectaban a la sociedad y los retos del nuevo siglo, contó con un amplio margen de reacción. Y es que este movimiento nunca se caracterizó por una gran rigidez dogmática ni por la inmutabilidad de algunos de sus rasgos más profundos, lo cual explica su larga supervivencia. Esta característica fundacional del carlismo favoreció que, lanzados sus hombres a la arena política, se generase un volumen de respuestas amplio, variable en el tiempo y en ocasiones incluso contradictorio. El carlismo se definía, entre otras

40. Sobre el maurismo, ROMERO, Francisco, "Antonio Maura: el gran incomprendido", en QUIROGA, Alejandro y DEL ARCo, Miguel Ángel (eds.), Soldados de Dios y apóstoles de la patria. Las derechas españolas en la Europa de entreguerras, Granada, Comares, 2010, pp. 1-28.

41. FUENTES, Maximiliano, "Tensions i contradiccions, Charles Maurras i Eugeni d'Ors dins l'ambient intel-lectual de les primeres dècades del segle XX", en PLA, Xavier (ed.), Maurras a Catalunya, elements per a un debat, Barcelona, Quaderns Crema, 2012, pp. 86-109. 
cosas, por su defensa del catolicismo y el regionalismo -aunque con matices-, lo que le condujo a coyunturales connivencias y colaboraciones con el asociacionismo católico y la Solidaritat catalana. Ambos fenómenos, que en un principio parecían reforzar al carlismo, acabaron por restarle efectivos.

Si personajes como Alfredo Brañas o José María de Pereda parecían ofrecer la cooptación de los crecientes movimientos regionalistas, la realidad es que pronto el desarrollo de los nacionalismos complicó la situación para el carlismo. La pérdida de base social en el País Vasco (especialmente en la provincia de Vizcaya) ante la aparición del PNV es evidente ${ }^{42}$. En el caso de Cataluña, pronto el carlismo hubo de asumir la imposibilidad de protagonizar un catalanismo que se acercaba a posiciones posibilistas e incluso republicanas ${ }^{43}$. Además, la cuestión regional y nacional causó graves problemas en el seno del carlismo, provocando fuertes peleas entre los que aceptaban el pacto coyuntural con los nacionalistas y los que se oponían a este.

Un claro ejemplo de intransigencia respecto a los nacionalismos alternativos es el de Víctor Pradera, que cuando en 1918 se analizaba la validez del acta electoral de Balmaseda (Vizcaya), obtenida teóricamente por el nacionalista vasco Ramón de la Sota, empleó como argumento para que este fuese desposeído el hecho de que, en efecto, no era español ${ }^{44}$. En general, el carlismo, pese a aceptar el regionalismo como uno de sus elementos fundadores, no toleraba iniciativas demasiado osadas en ese sentido, como también demuestra la expulsión del partido de Joan Bardina y de la revista Lo Mestre Titas (1897-1900). En esta línea, no falta quien sostiene que el cisma mellista no se debía tanto a las diferentes posturas frente a la Gran Guerra como a las divergencias en cuanto a cuestiones como el legitimismo, el espacio que el carlismo debía desempeñar en el escenario político español y la relación con el autonomismo ${ }^{45}$.

Una de las principales reacciones del carlismo fue la de participar, de forma discontinua y sin una estrategia prefijada, del progresivo acercamiento de las

42. Pueden analizarse, como representativos, los resultados de las elecciones generales de 1936. El peso del carlismo en Guipúzcoa y Vizcaya era ya mínimo, pues en la primera el PNV obtenía 4 escaños y el Frente Popular los dos restantes, mientras que en la segunda los tres escaños iban a parar al PNV (y los seis de Bilbao se repartían entre el Frente Popular, con 4 y el PNV, con dos). Por contra, en Álava la Comunión Tradicionalista mantenía su importancia, ganando las elecciones y unos de los dos escaños (obteniendo el restante el Frente Popular). En <http://www.historiaelectoral.com/ e1936.html> [consultado: 24-IV-2014]

43. CANAL, Jordi, "¿En busca del precedente perdido? Tríptico sobre las complejas relaciones entre carlismo y catalanismo a finales del siglo XIX", Historia y política, no 14 (2005), pp. $45-84$.

44. DELGADO, Ander, "Víctor Pradera..., p. 67.

45. CANAL, Jordi, El carlismo.., pp. 250 y 271-272. 
derechas acontecido durante las primeras décadas del siglo XX, en el contexto de la formación de una suerte de amalgama postliberal cuyo objetivo máximo era impulsar la recuperación nacional. Un fenómeno para el cual sin duda fue favorable la existencia de límites difusos entre las diferentes corrientes, así como también la tendencia personal a transitar y colaborar por y con distintas plataformas. Un caso representativo es el del ya citado Víctor Pradera, que transitó del carlismo al mellismo y colaboró activamente con el Partido Social Popular y con Acción Española. Este caso no es único, no solamente en las filas del carlismo, sino también en el resto de la derecha española. Por poner un ejemplo, Joan Estelrich, que inició su trayectoria en el carlismo, se empapó de maurrasianismo, participó en el nacionalismo catalán, fue diputado por la Lliga de Cambó y acabó apoyando la sublevación frente a la II República ${ }^{46}$. No cabe duda de que, como sostienen A. Quiroga y M. A. del Arco, las culturas políticas del universo conservador español fueron fluidas y cambiantes ${ }^{47}$.

Ya se ha mencionado que el tradicionalismo mellista y en especial Víctor Pradera participaron activamente en la formación del Partido Social Popular, que también fue fomentado por el diario católico El Debate. En sus páginas, mediada la segunda década del siglo y con el apoyo de sectores mauristas, surgió el debate en torno al minimismo, que venía a ser la oferta de una gran coalición de derechas ante el auge de los partidos de izquierda y la crisis del conservadurismo ${ }^{48}$. La creación de este frente antirrevolucionario suponía, como siempre conllevó la reunión de las derechas para el carlismo, la necesidad de renunciar a ciertos principios. Por ello la cúpula carlista se opuso coyunturalmente a la participación en el frente, aunque hubo toda una constelación de respuestas, que van desde las dudas de Vázquez de Mella a la clara aceptación de Salvador Minguijón, que no consideraba el tradicionalismo posibilista como una renuncia, sino como una herencia del pensamiento de Torras y Bages, Balmes o Aparisi y Guijarro ${ }^{49}$.

46. COLL-VINENT, Sílvia, "Joan Estelrich y Charles Maurras: història d'una seducció", en PLA, Xavier (ed.), Maurras a Catalunya, elements per a un debat, Barcelona, Quaderns Crema, 2012.

47. QUiRoga, Alejandro y Del ARCo, Miguel Ángel, Soldados de Dios y apóstoles de la patria. Las derechas españolas en la Europa de entreguerras, Granada, Comares, 2010, p. XI.

48. CANAL, Jordi, El carlismo..., p. 267.

49. SEvilla, Francisco, Sociedad y regionalismo en Vázquez de Mella. La sistematización del carlismo, Madrid, Actas, 2009. En el debate sobre la unión de las derechas, además de Minguijón, también jugaron un papel relevante personajes como Severino Aznar, Víctor Pradera y más tarde Vázquez de Mella, ARÓsTEGUi, Julio, "La ideología", en ARÓsTEGUI, Julio, CANAL, Jordi y GONZÁLEZ CALlejA, Eduardo, Las guerras carlistas. Hechos, hombres e ideas, Madrid, La Esfera de los Libros, 2003, pp. 192-195. 
En la práctica, la idea de un frente antirrevolucionario -que tenía como precedente las alocuciones en favor de la unidad de todos los católicos-abundó en el discurso carlista y en el del conjunto de las derechas españolas en las primeras décadas del siglo XX. Es más, las alianzas derechistas se materializaron en más de una ocasión, y en algún caso contaron con el apoyo del carlismo oficial. Pese a que incluso durante la II República hubo dirigentes -como Fal Conde- que defendieron la autonomía respecto al resto de las derechas, la impresión general es la de un progresivo acercamiento, con altibajos ciertamente, pero especialmente fuerte en algunas regiones y entre las bases populares. Por otra parte, en la constitución de esa nueva alianza reaccionaria, no sólo participaron partidos políticos, sino también diversos grupos sociales cuyo principal interés era la defensa del orden y la religión. Y el carlismo también interactuó con ellos, en un proceso que una vez más se vio marcado por el acercamiento. Múltiples son los autores que consideran que el carlismo ejerció recurrentemente como bastión del orden, por más que, paradójicamente, lo había atacado con una estrategia armada y violenta contraria a las preferencias socioculturales de la burguesía decimonónica.

En el marco del siglo XIX, J. Millán afirmó que su edificio político podía refugiar a quienes desconfiaban de que la sociedad pudiese regularse a sí mis$\mathrm{ma}^{50}$. El carlismo finisecular se orientó hacia unos núcleos urbanos en que se libraba la verdadera batalla por el poder y donde el orden social estaba especialmente amenazado ${ }^{51}$. Y es en ese contexto en el que parece tomar cuerpo la idea de que la vieja alianza entre trono y altar tenía que ser sustituida por la del altar y la caja fuerte ${ }^{52}$, con la participación destacada de un Ejército al que el carlismo había comenzado a apelar ya durante el siglo anterior. Un buen ejemplo de la pujante alianza contrarrevolucionaria se encuentra en la Barcelona posterior a la Gran Guerra, donde el auge del anarquismo fue respondido desde el carlismo con el impulso del requeté y los Sindicatos Libres (1919), que confluyeron con el somatén y fueron empleados por las élites sociales -y algo más tarde por el propio Primo de Rivera- como elementos mantenedores del orden. En un mismo sentido amalgamático se había formado tiempo atrás el Comité de Defensa Social (1908), que reunía personalidades diversas y se encontraba

50. millán, Jesús, "Popular y de orden: la pervivencia de la contrarrevolución carlista", Ayer, no 38 (2000), pp. 24-25.

51. OlCina, Evarist, Carlisme i autonomia al País Valencià, Valencia, Eliseu Climent, 1976, pp. 240-245.

52. BURLEIGH, Michael, Poder terrenal: religión y política en Europa de la Revolución Francesa a la Primera Guerra Mundial, Madrid, Taurus, 2005, p. 244. 
a medio camino entre el carlismo, el integrismo, el catalanismo conservador, el maurismo y el catolicismo social ${ }^{53}$.

La aparición del carlismo como un pilar en la defensa del orden urbano le hizo recuperar protagonismo en una Barcelona en que el sindicalismo y el anarquismo gozaban de gran protagonismo. En este mismo sentido Manuel Polo y Peyrolón creyó comprender que Manuel Simó -con el que mantuvo una relación poco afectuosa y el cual se hizo con el mando regional del carlismo en Valencia a partir de 1909- y el jaimismo valenciano se vieron favorecidos por la pujanza del anticlericalismo canalejista. De acuerdo a lo que Polo anotó en sus memorias, Canalejas, con su actitud, "hizo en tres meses más carlistas que D. Carlos en treinta años" 54 . Todo lo contrario, en su opinión, ocurría con el maurismo, "que acentuaba orientaciones absorbentes hacia la derecha, que restaron vigor y argumentos al carlismo". De lo que no cabe duda, para Polo, es que la Semana Trágica y el derrumbamiento del Partido Conservador, "empujaron a muchas personas religiosas y de orden hacia el jaimismo simonista valenciano, como única esperanza" 55 . Por tanto, la caracterización del carlismo como bastión del orden también resultó favorable para su recuperación en la ciudad de Valencia.

En general, debe recordarse que el éxito de la revolución bolchevique fue fundamental para la fragua de la "guerra civil europea", en cuyo contexto se produjo la aproximación de muchos intelectuales y grupos políticos al conservadurismo autoritario. Favoreció, además, la reunión de las derechas, pues a la postre el peligro revolucionario se erigió en problema fundamental ante el que no debían ahorrarse esfuerzos ni rechazarse posibles aliados. La progresiva orientación del carlismo hacia el autoritarismo y el acercamiento al resto de las derechas puede seguirse a través de varios casos, aunque en esta ocasión me he decantado por el valenciano, cuya evolución acabó convirtiéndolo en un movimiento difícilmente diferenciable en el seno de la alianza contrarrevolucionaria. En Valencia, ciudad dominada desde finales del siglo XIX por el republicanismo blasquista -aunque el carlismo era una fuerza importante-, encontramos un caso temprano de acercamiento de las derechas que puede rastrearse a través de la correspondencia entre Elías Tormo y Manuel Polo y Peyrolón. El primero, miembro del Partido Conservador, ofreció al líder local carlista un pacto ya en 1907, presentándolo como una "cruzada" ${ }^{5}$.

53. GONZÁlEz CALLEJA, Eduardo y DEL REY, Fernando, La defensa armada contra la revolución. Una historia de las guardias cívicas en la España del siglo XX, Madrid, CSIC, 1995, pp. 126-127.

54. POlo y Peyrolón, Manuel, Memorias de un sexagenario, t. 5, pp. 297-298.

55. Ibid., p. 340.

56. Carta de Elías Tormo a Manuel Polo y Peyrolón (27 de enero de 1907, Valencia). RAH. 
En un principio todo apunta a que la rápida quiebra del turno dinástico en varias de las circunscripciones de la provincia y la debilidad de los partidos alfonsinos (especialmente en la capital valenciana), contribuyeron a que el partido carlista gozase de una posición privilegiada. Algo similar ocurría en la provincia de Castellón, si bien el partido carlista debió afrontar aquí una serie de problemas que, en la práctica, demuestran las diferentes respuestas que en su seno se produjeron frente a la concurrencia electoral. En Castellón, el carlista barón de Benicasim seguía la estrategia de obtener posiciones de poder local sin importar que los candidatos carlistas se presentasen bajo el título de conservador, liberal, canalejista o incluso republicano. Por esta razón, había sido desautorizado por el partido, lo cual no impedía que siguiese controlando a las masas carlistas de la región ${ }^{57}$. Este hecho resulta destacable, pues es demostrativo de la peculiar relación entre los dirigentes del carlismo y sus seguidores, que permitía un trasvase de lealtades electorales poco problemático. Esta particularidad, que fue un hecho estructural, convertía al carlismo en un socio apetecible para el resto de las derechas españolas. Y es que en la formación de partidos de masas la capacidad de los líderes carlistas -mayoritariamente de extracción burguesa- para arrastrar a las masas y con ellas sus votos, adquiría una importancia fundamental.

En Valencia, pese a que el carlismo mantuvo una relación conflictiva con la Liga Católica -cuya aparición contó con el apoyo de una parte importante del tradicionalismo-, menudearon las alianzas electorales coyunturales con esta, así como también con el conservadurismo. Ahora bien, el propio Carlos VII, en 1903, llegó a desautorizar estos contactos para el caso de que abarcasen a partidos liberales que sostenían posturas anticlericales. El tiempo y el auge de la crisis social y política llevaron a que, ya en la segunda década del siglo, el carlismo se aproximase en términos más estables al conservadurismo dinástico. Así, a partir de 1917 puede hablarse claramente de la formación de un auténtico bloque de derechas, en que convivían carlistas, clericales y liberales conservadores.

También resulta representativa la creación del Diario de Valencia, que tuvo lugar durante el año 1911. En él, con el fin de atraer al mayor público posible, la cuestión legitimista quedó relegada hasta el punto de que algunos llegaron a afirmar que el diario se había convertido en un "papelucho liberal". V. Comes sostiene que el carlismo valenciano relativizó su antiliberalismo y relegó el viejo pleito dinástico para poder sintonizar con el conjunto de la derecha valenciana $^{58}$. En este sentido, no resulta sorprendente que en 1919 Manuel Simó y

57. POlo y Peyrolón, Manuel, Memorias de un sexagenario, t. 6, pp. 179-180.

58. COMES, Vicent, "¿Aislamiento o apertura a la sociedad?: un giro estratégico en el carlismo valenciano, 1909-1911", en El siglo XX: balance y perspectivas. Actas del V Congreso de la 
Luis Lucia siguiesen los pasos de Vázquez de Mella -arrastrando a la mayoría del carlismo del País Valenciano- y acabasen aceptando una monarquía alfonsina que, a su vez, variaba sus posiciones respecto al liberalismo ${ }^{59}$.

La evolución del partido carlista valenciano, como ya hemos visto, le acercó a los diferentes grupos conservadores y católicos. Y esto, a la larga, fue en su perjuicio. Más allá de la importancia que pudiese tener la progresiva inclinación del Partido de Unión Republicana Autonomista hacia la derecha, la principal pérdida de público la sufrió el partido con la fundación de la Derecha Regional Valenciana ${ }^{60}$. No sólo se llevó a una parte importante de la élite intelectual tradicionalista (como es el caso de Manuel Simó o Luis Lucia), sino que además compitió con el carlismo por un público similar. Y lo hizo, para más inri, empleando como órgano de expresión el antiguamente carlista Diario de Valencia. La transferencia de ideas y hombres entre el carlismo y la derecha se saldaba, por tanto, con la defección de una parte importante del tradicionalismo -que primero se había mostrada contraria al jaimismo y favorable al mellismodel ideal del legitimismo dinástico.

No obstante, la DRV, como la CEDA, mantuvo posturas accidentalistas respecto a la forma de gobierno, siendo paradigmático el caso de Lucia, que, producido el golpe de 1936, se proclamó fiel a la República. El legitimismo dinástico cedió, definitivamente, frente a la preponderancia del conservadurismo económico y las doctrinas católicas. Este cambio permitió a la DRV liderar a la derecha valenciana durante la II República. Integrada en la CEDA, aunque arrollada por el Frente Popular en las elecciones de 1936, obtuvo el nada desdeñable número de seis diputados. Ningún escaño consiguió por contra la Comunión Tradicionalista, que incluso perdió el que tenía en 1933 el que luego sería primer alcalde de la Valencia franquista, Joaquín Manglano.

\section{Conclusiones}

El carlismo acabó por asociarse con grupos políticos cuyos proyectos no distaban mucho, y cada vez lo harían menos, del propio. Ahora bien, si antes los carlistas habían sido el núcleo entorno al cual se habían construido las puntuales amalgamas contrarrevolucionarias, ahora sólo serían un componente más de las nuevas alianzas. El universo conservador de las primeras décadas del siglo

Asociación de Historia Contemporánea, Valencia, Fundación Cañada Blanch, 2000, pp. 321-326.

59. MORENO, Javier, "El rey de los liberales", en MORENO, Javier (ed.), Alfonso XIII, un político en el trono, Madrid, Marcial Pons, 2003, pp. 151-186.

60. valLS, Rafael, La Derecha Regional Valenciana: el catolicismo político valenciano (1930/1936), Valencia, Alfons el Magnánim, 1992. 
$\mathrm{XX}$ es una realidad que requiere urgentemente de un amplio estudio. Y es que a partir de la crisis de 1898 se comienza a generar un ambiente, potenciado por el colapso de la Restauración y los cambios sociales, económicos y políticos, en que las clases acomodadas, diversas instituciones y, aún más destacadamente, un grupo heterogéneo de intelectuales -de orígenes ideológicos diversos y hasta contrapuestos- fomentan un discurso postliberal, nacionalista y confesional. Se va generalizando un contexto en que, en un proceso no predeterminado y extremadamente complejo, se acabaría por fraguar el apoyo a la sublevación militar de 1936.

El carlismo participó progresivamente de esta corriente, privilegiando el elemento nacionalista y confesional en su discurso, hasta el punto de que su alejamiento del legitimismo dinástico difuminó sus límites con el resto de los grupos de la cultura política tradicionalista, así como también con el nacionalismo reaccionario. Y llegada la hora de la guerra, pese a ciertas reticencias de la dirigencia, el carlismo volcó sus energías en alcanzar una victoria que, en el contexto de la visión catastrofista propia de las derechas españolas, se antojaba como una última oportunidad para la regeneración patriótica. Pero la victoria franquista supuso, entre otras muchas cosas, la crisis definitiva del carlismo, que quedaría convertido en un movimiento subalterno y, con el tiempo, marginal. Esta vez por acción del dictador, el carlismo completó un proceso que había comenzado por iniciativa propia: la reunión con las derechas reaccionarias. 


\title{
La calle rojinegra. Anarcosindicalismo, rituales de movilización y símbolos en el espacio público (1931-1936)
}

\author{
Red-and-Black Streets. Anarcho-Syndicalism, Rituals of \\ Mobilization and Symbols in Public Spaces (1931-1936)
}

\author{
Javier Navarro Navarro \\ Universitat de València ${ }^{1}$
}

Recibido: 10-VI-2014

Aceptado: 10-IX-2014

\section{Resumen}

Este artículo se centra en el análisis de la tipología, características y evolución de algunos de los diversos rituales de movilización y simbolos desplegados en el espacio público por las distintas organizaciones y núcleos de militantes de signo confederal y anarquista en España durante los años de la Segunda República, antes del estallido de la sublevación militar de julio de 1936. Entre ellos: huelgas, insurrecciones revolucionarias, mítines, manifestaciones, excursiones, entierros de militantes, etc. El propósito de estas acciones era claro: tanto la cohesión y reafirmación identitaria internas, como la proyección externa del movimiento. Con estas estrategias de acción colectiva, que suponían una "salida" al espacio público, se trataba de hacer visible allí la fuerza del movimiento y reafirmar la presencia física de este, sus reivindicaciones y aspiraciones. Esta visibilidad se reforzaba mediante el despliegue de los símbolos propios: himnos, canciones, banderas, etc.

1. Mi agradecimiento a Rafael Cruz y Ferran Archilés por sus orientaciones e información bibliográfica sobre el tema, así como a Lara Campos, quien me ha permitido amablemente consultar varios capítulos del original de su libro sobre las conmemoraciones, festejos oficiales y espacio público durante la Segunda República, de próxima aparición. El autor participa del proyecto I+D+I, HAR 2011-27559 ("Democracia y culturas políticas de izquierda en la España del siglo XX: desarrollos y limitaciones en un marco comparativo") del Ministerio de Economía y Competitividad, financiado con fondos FEDER, y del Grupo de investigación Prometeo/2012/046, "Grup d'Estudis Històrics sobre les Transicions i la Democràcia", de la Generalitat Valenciana. 
Palabras clave: CNT, Anarquismo, España, Segunda República, Acción colectiva, Rituales, Símbolos.

\begin{abstract}
This article focuses on the analysis of the typology, characteristics and evolution of some of the rituals of mobilization and symbols that Spanish anarchist and anarchosyndicalist organisations displayed in public spaces during the years of the Second Republic, before the July 1936 military uprising: strikes, revolutionary insurrections, rallies, demonstrations, tours, partisans' funerals, etc. The aim of all these actions was clear: both internal cohesion and identity reaffirmation, and external projection of the movement. With these collective action strategies, anarcho-syndicalists tried to be present in public spaces, to make the movement strength visible and to reinforce their demands and aspirations. This visibility was enhanced by displaying its own symbols: hymns, songs, flags, etc.
\end{abstract}

Key words: CNT, Anarchism, Spain, Second Republic, Collective action, Rituals, Symbols.

\title{
La Marsellesa y los Hijos del Pueblo
}

El día 14 de abril de 1931, Enrique Marco Nadal, obrero ferroviario de diecisiete años y que pocos meses después sería nombrado secretario del comité local de la Federación Nacional de la Industria Ferroviaria (CNT) de Valencia, se hallaba trabajando en la céntrica Estación del Norte de la ciudad:

"Mi operario y yo nos encontrábamos reparando el Tubo Seco de una de las locomotoras que circulaban por la Demarcación de Valencia cuando a pesar del grueso muro que nos aislaba de la calle oímos los cánticos y cantares de los que minuto a minuto engrosaban la manifestación de la calle. Miramos a nuestro alrededor y, al ver que eran muchos los Ferroviarios que abandonaban el trabajo para sumarse a los manifestantes, hicimos lo propio. Alcanzada la calle, nos dimos cuenta de que los manifestantes iban bajo un mar de banderas republicanas, rojas y rojinegras (...) Ante la electrizante sacudida que sufrieron nuestros cuerpos a la vista de la manifestación, nos sumamos a ella con el mono del trabajo que vestíamos por no habernos cambiado de ropa para salir a la calle del puesto de trabajo. Los manifestantes nos pasamos el día dando VIVAS A LA REPÚBLICA y entonando los improvisados cantares que se nos ocurrían. Vivas y cánticos que en algunas ocasiones nos fueron interrumpidos por su cuenta por el Anarquista ANTONIO BADAL y el comunista Ángel Gaos que se ponían frente a nosotros agitando los brazos para que nos parásemos y les escucháramos diciéndonos: "-¡Compañeros! No creáis que la República va a resolver los problemas que tiene España y mucho menos el Mundo del Trabajo. No creáis que tardará el día en que vertáis lágrimas de sangre por el resultado de la farsa en que hoy tomáis parte" (...) Ya bastante entrada la noche disolvióse la manifestación y encaminóse cada cual hacia su casa con la ilu- 
sionada esperanza de lo que esperaban del nuevo régimen en el corazón. Esperanzas e ilusiones que se verían defraudadas antes de lo que esperaban" ${ }^{2}$.

Por su parte, el militante anarquista "Helios", que escribiría un año después sobre aquel día en las páginas del semanario de la CNT valenciana, Solidaridad Obrera, relataba la manifestación que se formó en la ciudad para liberar al "único preso social" recluido por entonces en la Cárcel Modelo de Valencia: Manuel Martí. Según Helios, en esa manifestación, convocada por la CNT, el tricolor republicano primaba en las banderas y el himno que se entonaba era $\mathrm{La}$ Marsellesa $a^{3}$.

Poco más de dos semanas después, con ocasión del Primero de Mayo, la CNT de Barcelona organizó una concentración y mitin en el Palau de Belles Arts, bajo el eslogan: "Primero de Mayo contra el Paro, la Inflación y por la Rebaja de los alquileres". Según Solidaridad Obrera, acudieron 100.000 obreros barceloneses. Diversos grupos y militantes anarquistas, contrarios a la estrategia "sindicalista" del núcleo dirigente confederal por entonces, se presentaron al evento con banderas rojinegras confeccionadas por primera vez para la ocasión y octavillas en las que también se había impreso la enseña bicolor y las siglas CNT-FAI, con la declaración: "Primero de Mayo, Fiesta Internacional de gimnasia revolucionaria". Estos militantes permanecieron fuera del recinto y se dirigieron también desde sus camiones-tribuna a la multitud que no había podido entrar. Uno de ellos, Juan García Oliver, años después ministro de la República, reivindicaba para sí posteriormente en sus memorias la idea de la confección del famoso emblema rojinegro de la Confederación y las mencionadas octavillas y describía así el ambiente de aquella mañana de mayo:

"Fue una mañana de mucho movimiento. Los trabajadores de Barcelona iban en grupos al mitin. ¿A qué mitin? Se produjo cierta confusión. A la misma hora y muy próximos uno al otro, se celebraban el oficial de la CNT y el nuestro, mezcla de CNT, FAI y Comisiones de Inquilinos y de Mujeres del Servicio doméstico.

Algo llamaba la atención de los obreros barceloneses y de cuantos transitaban por los paseos laterales del Arco de Triunfo: las cinco enormes banderas rojinegras del anarcosindicalismo y la totalmente negra del anarquismo. La rojinegra -un rectángulo en dos escuadras- por el vivo contraste del negro y el rojo, fue rápidamente admitida como enseña de una revolución largamente esperada por el proletariado español. La gente, cuya mayoría saliera de sus casas, con

2. MARCO NADAL, Enrique, Bordeando mis recuerdos... (memorias), Valencia, 1992, manuscrito inédito, p. 38 (las mayúsculas, en el original).

3. HELIOS, "Del momento. De lo escrito y por escribir en la Historia", Solidaridad Obrera (Valencia), 19-III-1932. 
el ánimo de no perderse el mitin sindicalista del palacio de Bellas Artes, como si de pronto se diera cuenta de que la promesa del futuro estaba estrechamente vinculada a la bandera rojinegra, se detenía ante nuestro camión, flanqueado por las seis enormes banderas rojinegras ondeando al viento.

Y ya no se iban. Se quedaban en espera de escuchar algo distinto de lo que hubieran tenido que oír en el otro mitin, el de los líderes del anarcosindicalismo" 4 .

Los oradores siguieron con sus discursos y el mitin continuó. Al final, terminados los discursos, expuestas las conclusiones y aprobadas estas, como era costumbre, se comenzó a formar la manifestación que acudiría hasta el Palau de la Generalitat, en la Plaza Sant Jaume, entonces Plaza de la República. El número de personas fue creciendo a medida que se bajaba por el Paseo de Sant Joan, la Ronda de Sant Pere y la Plaza de Cataluña, para enfilar las Ramblas, hasta llegar a unas 150.000 personas, también según Solidaridad Obrera. En la manifestación, al frente de la cual iban "dos camiones ocupados por mujeres proletarias, y grandes banderas con los anagramas de las organizaciones confederal, internacional y anarquista", se entonaban himnos revolucionarios, en particular Hijos del Pueblo. Al llegar a la Plaza de la República, esta se encontraba repleta de gente. La comisión organizadora pudo acceder al Palau de la Generalitat para entregar las conclusiones, pero, en el momento en que otra comisión quiso acceder al edificio, comenzó un tiroteo en el que intervinieron la policía, los militantes libertarios armados (aquellos que García Oliver había detectado en el mitin, "no menos de cien compañeros...con su pistola entre pantalón y barriga") y, según fuentes cenetistas, francotiradores y pistoleros del Libre que también dispararon contra los trabajadores. El choque finalizó con la llegada de efectivos militares, vitoreados por la multitud, que acabaron con el tiroteo, y con las palabras desde el balcón del Palau de la comisión organizadora de la manifestación, el consejero de la Generalitat Joan Casanovas y finalmente el propio presidente Macià, todos en términos conciliadores. El balance final fue de un policía muerto y de dos policías y diez obreros heridos ${ }^{5}$.

4. GarCía Oliver, Juan, El eco de los pasos. El anarcosindicalismo en la calle, en el Comité de Milicias, en el gobierno, en el exilio, París, Ruedo Ibérico, 1978, pp. 116-117.

5. La narración de los hechos, en Solidaridad Obrera (Barcelona), 3-V-1931 y Tierra y Libertad (Barcelona), 8-V-1931, además del relato de García Oliver en la obra citada en la nota anterior. Otro testimonio, en: PEIRATS VALls, Josep, De mi paso por la vida. (Memorias). Selección, edición y notas de Susana Tavera García y Gerard Pedret Otero. Prólogo Enric Ucelay-Da Cal, Barcelona, Flor del Viento, 2009, pp. 176-178. Véase también: EALHHAM, Chris, La lucha por Barcelona. Clase, cultura y conflicto, 1898-1937, Madrid, Alianza Editorial, 2005, pp. 183-184. 
En pocos días, los compases de La Marsellesa, melodía indiscutiblemente hegemónica en la cultura republicana, radical y obrerista española, habían cedido aparentemente su protagonismo a los Hijos del Pueblo, el "himno revolucionario anarquista", elegido como tal en el Segundo Certamen Socialista celebrado en Barcelona en 1889. Aún faltaban dos años para que se publicara en el Suplemento de Tierra y Libertad una adaptación española de la partitura de la conocida Varsoviana polaca: esta versión, con letra de Valeriano Orobón Fernández, se titularía Marcha Triunfal, aunque sería más célebre por su subtítulo: A las barricadas. El nuevo himno confederal desbancaría a Hijos del Pueblo, en especial desde los años de la guerra civil y posteriormente, hasta nuestros días.

\section{Una cultura propia}

En las páginas que siguen se esboza una aproximación a la tipología, características y evolución de algunos de los diversos rituales de movilización y aparatos simbólicos desplegados en el espacio público por las distintas organizaciones y núcleos de militantes de signo confederal y anarquista en España durante los años de la Segunda República, antes del estallido de la sublevación militar de julio de 1936. El propósito de estas acciones era claro: tanto la cohesión y reafirmación identitaria internas (con la construcción y consolidación de una identidad "cenetista" o "libertaria" y del sentimiento de pertenencia de sus miembros a una familia social y política) como la proyección externa del movimiento. Con estas estrategias de movilización colectiva, que suponían una "salida" al espacio público, se trataba de hacer visible allí la fuerza del movimiento y reafirmar la presencia física de este, sus reivindicaciones y aspiraciones. Esta visibilidad se reforzaba mediante el despliegue de los símbolos propios: himnos, canciones, gritos y proclamas, banderas, estandartes, pancartas y carteles con siglas, alegorías, etc., que funcionaban así como repertorios simbólicos, que a la vez que representaban valores y permitían la autoidentificación, llamaban a la acción ${ }^{6}$.

6. El estudio de los recursos culturales (discursos, actitudes, valores, prácticas, mitos, rituales, símbolos, etc.) y de su importancia en la configuración de las identidades y culturas políticas y en la puesta en marcha de la acción colectiva, se ha ido incorporando en los últimos años al utillaje metodológico y las perspectivas de análisis de la historiografía española. Especialmente influyente fue la publicación del volumen de CRUZ, Rafael y PÉREZ LEDESMA, Manuel (eds.), Cultura y movilización en la España contemporánea, Madrid, Alianza Universidad, 1997. En el capítulo "La cultura regresa al primer plano", firmado por el primero de estos autores, se subrayaban con claridad los elementos esenciales y los referentes bibliográficos básicos de aquellas interpretaciones que inciden en la construcción social de la acción colectiva y en la consideración de la importancia de los elementos culturales-identitarios en ese proceso. 
Manifestaciones, mítines, conferencias y actos de "afirmación", huelgas o insurrecciones fueron algunas de las acciones que mostraban ese interés por estar presentes o controlar en su caso el espacio público, tal como hicieron en esos años otras culturas políticas. Podríamos incluir asimismo prácticas y "ritos de paso" que expresaban el deseo de escapar del control religioso, y en la medida de lo posible del Estado, y que implicaban también una "salida" a la calle: inscripción civil de recién nacidos; matrimonios o uniones libres; y, sobre todo, entierros laicos de militantes.

Cabe integrar aquí, además, ceremoniales que formaban parte de una política propia de conmemoraciones: actos en recuerdo de fechas del calendario obrero y revolucionario especialmente destacadas para el movimiento libertario, como fueron a lo largo de su historia los aniversarios del 18 de marzo (Comunne de París), 11 de noviembre (ejecución de los mártires de Chicago) y 1 de mayo, 13 de octubre (fusilamiento de Ferrer y Guardia), o el 19 de julio y el 20 de noviembre (muerte de Durruti) a partir de los años de la guerra ${ }^{7}$. Junto a estos, conviene incorporar asimismo aquellos actos de "homenaje" celebrados en honor de figuras destacadas, como Ferrer y Guardia, Anselmo Lorenzo, Durruti, etc. En general, estos dos últimos tipos de eventos (conmemoraciones y homenajes), también manifestaciones simbólicas de afirmación revolucionaria, solían tener lugar en los locales de centros y entidades de la trama asociativa confederal y ácrata (sindicatos, ateneos, sedes de grupos, JJLL o Mujeres Libres), y bajo la forma de "veladas", una de las prácticas socioculturales más comunes en el mundo libertario ${ }^{8}$. No obstante, se celebraban asimismo en teatros y cines de pueblos y ciudades, casas del pueblo y sociedades obreras, etc., en mayor medida durante el período 1936-1939. Fue precisamente en la contienda, con la mayor presencia de los anarcosindicalistas en el espacio público, cuando fueron habituales también los actos de inauguración de lápidas o inscripciones en recuerdo de determinados personajes (y que incluían discursos, ofrendas de flores, música, etc.), rotulación de calles, colocación de estatuas, monumentos, etc.

7. En relación con la conmemoración de los primeros, hasta inicios del siglo XX, véase: LITVAK, Lily, Musa libertaria. Arte, literatura y vida cultural del anarquismo español (1880-1913), Barcelona, Antoni Bosch Editor, 1981 y MORALES MUÑOz, Manuel, Cultura e ideología en el anarquismo español (1870-1910), Málaga, Diputación Provincial, 2002. Para los dos últimos, en especial a partir de 1939 (a los que habría que añadir la conmemoración del 14 de abril, solo en las filas de los sectores "posibilistas"): HERRERín, Ángel, La CNT durante el franquismo. Clandestinidad y exilio (1939-1975), Madrid, Siglo XXI, 2004, pp. 363-369.

8. NAVARRo navarRo, Javier, A la revolución por la cultura. Prácticas culturales y sociabilidad libertarias en el País Valenciano, 1931-1939, Valencia, Universitat de València, 2004, pp. 265-318. 
En definitiva, todas estas prácticas constituían formas y rituales de movilización en los que se desplegaban tradiciones míticas y simbólicas que habían ido definiéndose, consolidándose, transformándose y evolucionando lo largo de la trayectoria del movimiento libertario. Formaban parte integrante de esta cultura política ${ }^{9}$. Obras muy relevantes sobre la historia del anarquismo español entre el último tercio del siglo XIX e inicios del XX han hecho mención de una $u$ otra manera a la presencia ya de estas acciones que implicaban una proyección hacia el espacio público, aludiendo así a mítines, manifestaciones, huelgas o insurrecciones y también, aunque en menor medida, a los otros tipos de rituales citados: conmemoraciones, actos de afirmación, veladas, conferencias, "ritos de paso", etc. ${ }^{10}$ Sin embargo, no se les ha dedicado una atención específica que incidiera en su estudio como tales prácticas ${ }^{11}$.

9. Seguimos aquí una definición del concepto de "cultura política" que concibe esta como "una especie de código y un conjunto de referentes (especialmente creencias, valores, memoria específica, vocabulario propio, sociabilidad particular, ritualizada o no) formalizados en el el seno de una familia o de una tradición políticas, y que le confieren una identidad propia (...) Lo que significa, concretamente, que una cultura política es un conjunto de representaciones que aglutina a un grupo humano en el plano político, es decir, una visión del mundo compartida, una común lectura del pasado, una proyección en el futuro vivida conjuntamente. Y que desemboca, en el combate político cotidiano, en la aspiración a una u otra forma de régimen político y de organización socio-económica, al mismo tiempo que en normas, creencias y valores compartidos". SIRINELLI, JeanFrançois, "Éloge de la complexité ", en RIOUx, Jean-Pierre y SIRINELLI, Jean-François (dirs.), Pour une histoire culturelle, París, Seuil, 1997, p. 438 (traducción propia). En esta misma línea : BERNSTEIn, Serge (dir.), Les cultures politiques en France, París, Seuil, 1999.

10. Para esa época cabe destacar aquí por supuesto dos obras de referencia esenciales sobre la cultura y la ideología anarquistas en España, donde se aludía a estas cuestiones: LITVAK, Lily, Musa libertaria... (con una mayor profundidad en capítulo V: "El proletariado militante", pp. 131-182) y ÁlVAREZ JUNCO, José, La ideología política del anarquismo español (1868-1910), Madrid, Siglo XXI, 1991 ( $1^{a}$ ed. 1976), así como otros artículos de este último autor, entre ellos: "La subcultura anarquista en España: racionalismo y populismo", en Culturas populares. Diferencias, divergencias, conflictos, Madrid, Universidad Complutense, 1986. También: MORALES muÑoz, Manuel, Cultura e ideología.... Asimismo, Clara Lida también ha reflexionado en torno a los rituales del movimiento en el último tercio del XIX, en especial durante los períodos de clandestinidad. Un ejemplo: LIDA, Clara E., "Clandestinidad y cultura en el discurso anarquista", Revista de Occidente, 129, 1992. Referencias sobre estas prácticas (en concreto sobre los que hemos llamado "ritos de paso"), en: NÚÑEZ FLORENCIO, Rafael, El terrorismo anarquista, 1888-1909, Madrid, Siglo XXI, 1983, p. 118 y HerRerín, Ángel, Anarquía, dinamita y revolución social. Violencia y represión en la España de entre siglos (1868-1909), Madrid, Los Libros de la Catarata, 2011, pp. 53 o 210, entre otras. Descripciones de mítines, conferencias o veladas en los primeros tiempos de la Internacional en España, en: Lorenzo, Anselmo, El proletariado militante, Madrid, Alianza Editorial, 1974.

11. Recientemente: MORALES MUÑOZ, Manuel, "Rituales, símbolos y valores en el anarquismo español, 1870-1910", en LiDA, Clara E. y YANKELECich, Pablo (comps.), Cultura y política del anarquismo en España e Iberoamérica, México D.F., El Colegio de México, 
Asimismo, y en general, aunque existen ya numerosas investigaciones sobre distintos aspectos de la cultura anarquista y anarcosindicalista en España ${ }^{12}$, ha sido menos común el estudio concreto de los mitos, rituales y símbolos vinculados al mundo ácrata. Pese a las frecuentes referencias en la historiografía (que puedan haber extendido la engañosa percepción de un tema ya suficientemente tratado), la literatura y los medios de comunicación, o la repetición icónica de muchas de las imágenes asociadas a ellos en la fotografía, documentales y largometrajes, o en la televisión, en especial de aquellas relacionadas con el verano revolucionario de 1936, no han sido habituales los trabajos que aborden específicamente su análisis.

Por supuesto, los libertarios no fueron una excepción a la hora de poner en juego este abanico de formas ritualizadas de acción política, donde se movilizaban una serie de símbolos compartidos. La historiografía española ha ido subrayando en los últimos años la importancia de estas estrategias de intervención en el espacio público en los procesos de construcción de las identidades colectivas y de sus símbolos a lo largo de la época contemporánea, por ejemplo en lo que se refiere a la puesta en marcha de políticas de memoria o conmemorativas y los llamados "usos públicos del pasado" o "de la historia", y en la conformación de las identidades nacionales, como en el caso del nacionalismo español ${ }^{13}$.

A partir de finales del siglo XIX, en el marco general de la irrupción de la nueva política "de masas" y de un fuerte impulso en la creación de las identidades colectivas, la Restauración proporcionó en el caso español el contex-

2012. En ese mismo volumen: LIDA, Clara E., "Organización, cultura y prácticas políticas del anarquismo español en la clandestinidad". Véase también: MARIN, Dolors, Anarquistas. Un siglo de movimiento libertario en España, Madrid, Ariel, 2010. Sobre la confección de una memoria e historia libertarias propias: TAVERA, Susanna, "La historia del anarquismo español: una encrucijada interpretativa nueva", Ayer, 45, 2002 (1) y MARTíN NIETO, Isaac, "El mito del paraíso revolucionario perdido. La guerra civil española en la historia militante libertaria", Ayer, 89, 2013 (1). En cuanto a los mítines: DALMAU I RIBALTA, Antoni, "El míting anarquista, una forma de cultura popular (Barcelona, al tombant del segle XX)", Segle XX. Revista catalana d'Història, 6 (2013).

12. Un intento de síntesis interpretativa en torno a esta cuestión, en: NAVARRO NAVARRO, Javier, "Los educadores del pueblo y la "revolución interior". La cultura anarquista en España", en CASANOVA, Julián (coord.), Tierra y Libertad. Cien años de anarquismo en España, Barcelona, Crítica, 2010.

13. Un ejemplo del estudio de la "política de memoria", en: MICHONNEAU, Stéphane, Barcelona: memòria i identitat. Monuments, commoracions i mites, Vic, Eumo, 2002. En cuanto al nacionalismo español, y por citar solo dos títulos recientes significativos: SAZ, Ismael y ARCHILÉs, Ferran (eds.), La nación de los españoles. Discursos y prácticas del nacionalismo español en la época contemporánea, Valencia, Universitat de València, 2012, y MORENO LUZÓN, Javier y NÚÑEZ SEIXAS, Xosé M. (eds.), Ser españoles. Imaginarios nacionalistas en el siglo XX, Barcelona, RBA, 2013. 
to sobre el cual se intensificarían estos procesos de construcción identitaria (nacionales, de clase, etc.) y, paralelamente, un escenario de pugna entre distintas culturas políticas que renovaron sus estrategias de movilización, situando la calle en el centro de sus reivindicaciones y desarrollando auténticos programas de presencia en (y ocupación de) el espacio público, al tiempo que codificaban sus repertorios simbólicos, mitos fundacionales y prácticas rituales. Estas últimas fueron incluyendo actividades de afirmación o confraternización (entre ellas, por ejemplo, las celebradas en fechas señaladas del calendario conmemorativo propio, en homenaje a acontecimientos o personajes especialmente relevantes para la familia política en cuestión) que tendieron a salir de círculos, ateneos y locales propios para proyectarse también sobre calles y plazas.

Es el caso, por ejemplo, del carlismo a principios del siglo XX, con sus mítines, manifestaciones (incluyendo aquí las procesiones católicas), banquetes multitudinarios y grandes reuniones al aire libre y romerías -los aplecs en el caso catalán-, como ha señalado Jordi $\mathrm{Canal}^{14}$. O de los republicanos, con sus jornadas conmemorativas propias (11 de febrero, aniversario de proclamación de la Primera República; 29 de septiembre, de 1868), mítines y "meriendas democráticas" lerrouxistas, etc ${ }^{15}$. Así pues, republicanos, carlistas, nacionalistas catalanes o vascos, fuerzas políticas de distinta índole y también sindicatos u organizaciones provenientes del emergente movimiento obrero pugnaron a lo largo de las primeras décadas del siglo XX por la intervención y la conquista física y simbólica del espacio público. En cuanto al obrerismo, su presencia en la calle a través de manifestaciones, mítines (rituales del nuevo repertorio de la acción colectiva que expresan tan bien ese paso a una nueva forma de hacer política), en la celebración del Primero de Mayo y, por supuesto, en las huelgas generales desde inicios del siglo, era vista siempre desde el poder como una amenaza a lo establecido y era traducida habitualmente en términos de alteración del orden público:

"Frente al orden de los grupos socialmente hegemónicos, por tanto, se oponía el 'desorden popular'; y de hecho, su ocasional conquista del espacio central de las ciudades por los sectores populares era siempre visto como una penetración espacialmente anárquica por los grupos acomodades. La subver-

14. CANAL, Jordi, "Espacio propio, espacio público. La sociabilidad carlista en la España mediterránea en la etapa de entresiglos", en SÁNCHEZ SÁNCHEZ, Isidro y VILLENA ESPINOSA, Rafael (coords.), Sociabilidad fin de siglo. Espacios asociativos en torno a 1898, Cuenca, Ediciones de la Universidad de Castilla-La Mancha, 1999, pp. 146-149.

15. Entre otras obras: GABRIEL, Pere, "Los días de la República. El 11 de febrero", Ayer, 51, 2003, p. 44; CULLA, Joan Baptista, El republicanisme lerrouxista a Catalunya (1901-1923), Barcelona, Curial, 1986, p. 66. También sobre estas pràcticas del lerrouxismo: ÁlVAREZ JUNCO, José, El Emperador del Paralelo. Lerroux y la demagogia populista, Madrid, Alianza Editorial, 1990, pp. 388-397. 
sión social se acompañaba, de hecho, de una paralela subversión en el espacio (...) En efecto, durante las jornadas de 1902 y 1909, aunque efímeramente, las capas populares tomarán la calle apropiándose de ella e imponiendo una visión peculiar del urbanismo. El símbolo de este orden espacial subvertido es la barricada (...) Al igual que la manifestación puede aparecer como un salto a la calle, que es ocupada por quienes habitualmente no la poseen, la barricada es un emblema de la ruptura del orden urbanístico, con su interrupción de los tráficos urbanos habituales y el levantamiento de su arquitectura contrapuesta a la pulcritud y monumentalidad burguesa de los edificios que la flanquean; la barricada impone por tanto nuevos usos al espacio urbano y torpedea otros y, singularmente, el del transporte y movilidad de las tropas (...) se destruyen o se asaltan, por ejemplo, los símbolos de la hostilidad institucional de la Iglesia (los conventos), del Estado (la comisaría) o de la opresión económica (las casetas de consumos); y se celebran casi a diario mítines mientras las calles son recorridas por manifestaciones o piquetes, que imponen un contramodelo de orden y una apropiación efectiva, aunque fatalmente poco duradera, del espacio" 16 .

Por lo que se refiere al movimiento libertario, serían precisamente la huelga general de Barcelona de 1902 y, sobre todo, la Semana Trágica de 1909, con su combinación de un "viejo" (con el motín como elemento central) y un "nuevo" repertorio de acción colectiva, con el recurso cada vez más frecuente a la huelga, el mitin o la manifestación pública, las fechas a partir de las cuales se irían asentando progresivamente estos nuevos rituales de movilización. Todo ello se produjo en paralelo a la creación y ulterior consolidación (lentamente a lo largo de la segunda década del siglo XX) de una nueva plataforma sindical, la CNT, sin que ello supusiera, sin embargo -ni entonces ni posteriormente, como veremos-, la desaparición de formas más tradicionales de protesta ${ }^{17}$.

\section{La política en la calle. La Segunda República}

La Segunda República, y el marco político y social de nuevas libertades ciudadanas y democráticas que inauguró, proporcionaron, tras el paréntesis de la dictadura primorriverista, el contexto idóneo para la revitalización de toda

16. URÍA, Jorge, "Lugares para el ocio. Espacio público y espacios recreativos en la Restauración española“, Historia Social, 41, 2001, p. 93.

17. Un buen seguimiento de la evolución del repertorio de acción colectiva del movimiento libertario español en el contexto de la Restauración está presente en los dos libros de GONZÁlEZ CALLEJA, Eduardo, La razón de la fuerza. Orden público, subversión y violencia política en la España de la Restauración (1875-1917), Madrid, CSIC, 1998 (véase especialmente p. 449-453 y epilogo, pp. 535-554, en relación a lo dicho sobre los cambios en el repertorio de acción colectiva y la Semana Trágica como "movimiento transicional de protesta"), y El máuser y el sufragio. Orden público, subversión y violencia política en la crisis de la Restauración (1917-1931), Madrid, CSIC, 1999. 
una serie de rituales de movilización asociados a las diversas identidades políticas. Se multiplicaron las manifestaciones, concentraciones o mítines, algunos de estos últimos multitudinarios y celebrados en teatros, cines, plazas de toros o estadios de fútbol. En ese sentido, la calle y el espacio público en general -"llenos", "ocupados" o "tomados"- se convirtieron más que nunca en ámbitos de expresión de esas culturas políticas y territorios de disputa a diferentes niveles. Tal como señala Lara Campos:

"El espacio público, no sólo el abierto, como plazas y calles, sino también el cerrado, como teatros, cines o estadios, había adquirido un valor político y simbólico poco imaginable a inicios de esa misma centuria. La política en los años treinta, como advirtieron personajes tan poco habituados al manejo de las masas hasta entonces, como Miguel Maura, Gil Robles o Manuel Azaña, ya no se hacía únicamente en los parlamentos; ni siquiera la tribuna periodística daba cabida suficiente a la voluntad de expresión, de comunicación y de persuasión de todos aquellos que sintieron que tenían algo que decir respecto a la vida política de España. Tomar la calle se convirtió en símbolo del poder ciudadano en una democracia en ciernes" 18 .

Las medidas del nuevo gobierno provisional, la Constitución y la política de los ejecutivos republicano-socialistas del bienio 1931-1933 plantearían, por ejemplo, la limitación del amplio y privilegiado usufructo del espacio público del que venía gozando la Iglesia católica a través de las innumerables procesiones, festejos del calendario litúrgico, monopolio de los cementerios, omnipresencia en el nomenclátor callejero, etc. Esta presencia había crecido durante el período restauracionista (por ejemplo con un renovado impulso constructivo y urbanístico) y se complementaba con la actividad de las asociaciones confesionales o de las organizaciones políticas vinculadas a la Iglesia. El conflicto que se plantearía haría que esta y todas sus entidades afines se movilizaran con fuerza en contra de aquellas iniciativas y pusieran en marcha un repertorio de acciones que incluía la abierta politización de rituales católicos fuera de los templos, como peregrinaciones, concentraciones, procesiones, bendiciones, etc., a lo que habría que añadir su dominio abrumador del espacio público en determinadas regiones, como fue el caso de Navarra ${ }^{19}$.

18. Por otro lado, en general, "ocupar físicamente el espacio público tanto a través de manifestaciones callejeras como literarias, se convirtió, durante el periodo de entreguerras, en una forma simbólica de apropiarse de aquello relacionado con la esfera pública". Ambas citas, en: CAMPOS PÉREZ, Lara, Instrumento de la nación republicana. Conmemoraciones oficiales, festejo y espacio público durante la Segunda República. En prensa. Original facilitado por la autora.

19. CRUZ, Rafael, En el nombre del pueblo. República, rebelión y guerra en la España de 1936, Madrid, Siglo XXI, 2006. pp. 58-62; UGARTE, Javier, La nueva Covadonga insurgente. 
Pero, en general, la extraordinaria movilización política que se vivió a partir de 1931, y en la que tendría un papel decisivo la juventud ${ }^{20}$, llegó a todos los sectores políticos. Tal como señala Julián Casanova, en un principio la proclamación de la Segunda República permitió a las fuerzas progresistas y al movimiento obrero, "antes que nada ocupar de nuevo el espacio público y poner en marcha todos los ritos movilizadores que identificaban a republicanos, socialistas y anarquistas desde comienzos de siglo. Manifestaciones con banderas y música, himnos revolucionarios y, sobre todo, el mitin: esas grandes fiestas donde se mezclaba la fiesta, la propaganda y las incitaciones a la acción revolucionaria"21. La fiesta cívica del 14 de abril, con su despliegue de banderas tricolores, proclamas e himnos como La Marsellesa, inauguró una nueva etapa que encontró en la calle un escenario idóneo para expresarse.

\section{La calle vivida, la calle vetada, la calle asaltada}

A esa celebración, como vimos, se sumarían también los cenetistas, aunque la ocupación festiva de la calle que supuso la jornada de abril acabaría muy pronto. Desde el punto de vista confederal, el punto de inflexión no sería ese primero de mayo de 1931 al que antes aludíamos, sino la serie de huelgas que tendrían lugar desde el final de la primavera y a lo largo del verano, así como los conflictos con las fuerzas de orden público del nuevo régimen que se desencadenarían a partir de entonces. El clima vendría presidido desde esos momentos por la creciente frustración de las expectativas creadas, el descontento político con la presencia del socialismo y el sindicalismo ugetista en el gobierno -con el control de los resortes del poder y del mercado de trabajo que ello conllevaba-, la política de orden público de carácter represivo y a la larga el progresivo deterioro del contexto económico, sobre todo por el aumento del desempleo. Todo ello en un ambiente marcado por la división de la organización confederal entre dirigentes y militantes "sindicalistas", por un lado, y militantes de sindicatos "radicales" y miembros de los grupos de acción, por otro; división que se traduciría dos años más tarde en una escisión orgánica.

"La revolución impulsada por los anarquistas ha de tener a la calle por teatro y al pueblo por actor", se decía poco antes del cambio de régimen desde

Orígenes sociales y culturales de la sublevación de 1936 en navarra y el País Vasco, Madrid, Biblioteca Nueva, 1998.

20. Souto Kustrín, Sandra: Paso a la juventud. Movilización democrática, estalinismo y revolución en la República Española, Valencia, Universitat de València, 2013.

21. CASANOva, Julián, De la calle al frente. El anarcosindicalismo en España (1931-1939), Barcelona, Crítica, 1997, p. 14. 
el diario portavoz de la CNT, Solidaridad Obrera ${ }^{22}$. Y efectivamente, también para el mundo confederal, "salir" a la calle, estar presente en ella y "controlarla" en la medida de lo posible ${ }^{23}$, resultaba esencial en este nuevo contexto, prolongando el clima de movilización que había traído la República, bien para fortalecer el sindicato y garantizar las conquistas obreras (como sostenía la dirección "sindicalista" de la Confederación), bien para aprovechar la coyuntura e ir más allá de la República burguesa promoviendo acciones insurreccionales que precipitaran el advenimiento del comunismo libertario, como defendían los sectores "faístas"24.

Pero más allá de eso, para la propia esencia de la CNT y del mundo libertario asociado a ella resultaba básico el contacto con la calle, en el entorno de los barrios obreros donde se arraigaba, extensión natural de las fábricas y talleres donde se empleaban sus afiliados y militantes. En esos barrios -en Barcelona, els "barris" a los que alude Chris Ealham o la "periferia" a la que se refiere José Luis Oyón ${ }^{25}$-, en esos lugares de sociabilidad popular cotidiana, se mantenía un vínculo permanente con el "pueblo trabajador", haciéndose la CNT (a través por ejemplo de sus comités de barriada) portavoz de sus diferentes demandas sociales (vivienda, trabajo, subsistencias, educación, etc.) y constituyéndose así una auténtica "esfera pública proletaria" en la que vivía inmersa la organización confederal ${ }^{26}$. Las luchas extrasindicales (como lo fue por ejemplo la huelga de inquilinos de Barcelona de 1931 en protesta por los altos precios de los alquileres) no eran en absoluto secundarias; las tácticas de movilización de la CNT se solapaban así con formas de resistencia y acción comunitarias y cimentaban el arraigo social de la central anarcosindicalista. Un ejemplo de esta imbricación lo constituía también el caso de los ateneos, auténticos cen-

22. Solidaridad Obrera (Barcelona), 31-III-1031.

23. Tal como señala Santos Juliá, el objetivo del movimiento libertario era permanecer "con su presencia física en el nuevo espacio de la lucha, la calle, ocupándolo". JULì, Santos, Madrid, 1931-1934. De la fiesta popular a la lucha de clases, Madrid, Siglo XXI, 1984, p. 183.

24. Esta última etiqueta, tan reiterada por la historiografía y la literatura sobre el tema, resulta más que discutible si se utiliza para algo más allá de hacer simple referencia a una actitud muy presente dentro del mundo libertario en estos momentos y que se resumiría con este término. Respecto a la lógica de la superación de la República de abril: UCELAY, Enric y TAVERA, Susanna, "Una revolución dentro de otra: la lógica insurreccional en la política española, 1924-1934", Ayer, 13, 1994.

25. EALHAM, Chris, La lucha por Barcelona...; OYÓn, José Luis y GALLARDo, Juan José (coords.), El cinturón rojinegro. Radicalismo cenetista y obrerismo en la periferia de Barcelona, 1918-1939, Barcelona, Carena, 2004 y oyón, José Luis, La quiebra de la ciudad popular. Espacio urbano, inmigración y anarquismo en la Barcelona de entreguerras, 1914-1936, Barcelona, Ediciones del Serbal, 2008.

26. EALHAM, Chris, La lucha por Barcelona..., pp. 78-104. 
tros de sociabilidad barrial, integrados en la vida de estas áreas urbanas, infradotadas de servicios, y que atendían necesidades de educación, relación social y ocio, aunque no exclusivamente ${ }^{27}$. En definitiva, para Anna Monjo, una de las razones que explican la "consistencia y cohesión de la organización confederal" en estos años es el hecho de que ésta no se limitaba a la "propia práctica sindical", sino que se extendía también "por vías extrasindicales, que tenían como escenario el lugar de trabajo, la calle, el barrio, los espacios de ocio":

"A partir del Sindicato y del Ateneo, como centros difusores de las ideas libertarias en el barrio, más concretamente a partir de los militantes y los simpatizantes, la situación política en que se encuentra la Confederación y la clase obrera en su conjunto, es debatida y discutida en lugares variados, bares, tabernas, empresas, tiendas, etc. En estos ámbitos a menudo se podía descubrir una conversación en torno a temas sociales del momento en los que estaba implicada la CNT. Este hecho demuestra la penetración en los barrios y lugares de trabajo de la fuerza hegemónica de la CNT como única representante de los intereses de la clase obrera, y, a la vez, de la capacidad de las ideas libertarias de impregnar el día a día, al ofrecer la posibilidad de un futuro, quizás, mejor"28.

El militante Ramón Quiles recuerda el ambiente que se vivía por entonces en la barriada de Russafa (Valencia):

"Había un ambiente de ideas...En el barrio había un casino, "El Casino del Rincón", que era de tendencia republicana. Se mascaba la cosa ideológica...en las calles todo el mundo comentaba, había corridas, escapadas...Había turnos en el gobierno, que si los republicanos, que si los blasquistas. Había efervescencia respeto a todas estas cosas y todo eso formaba parte de una manera de pensar"29.

Más allá de estos barrios obreros donde su arraigo resultaba evidente, la relación del mundo confederal y ácrata con el espacio público a lo largo del período 1931-1936 se caracterizó por el recurso a unos repertorios de movilización a los que nos referiremos en el punto siguiente y, sobre todo, por una intermitencia marcada por los vaivenes de su relación con el marco político. A partir de mediados de 1931, las políticas de orden público establecidas por los

27. NAVARRO NAVARRO, Javier, Ateneos y grupos ácratas. Vida y actividad cultural de las asociaciones anarquistas valencianas durante la Segunda República y la Guerra Civil, Valencia, Biblioteca Valenciana, 2002.

28. MONJo, Anna, "Afiliados y militantes: la calle como complemento del sindicato cenetista en Barcelona de 1930 a 1939", Historia y Fuente Oral, 7, 1992, pp. 95-96. Véase también su libro: Militants. Participació i democràcia als anys trenta, Barcelona, Laertes, 2003, pp. 378-381.

29. Entrevista del autor a Ramón Quiles Donet, 5-6-1997. 
ejecutivos republicano-socialistas, con su monopolio del control y ocupación de la calle y de regulación de su uso (plasmadas en leyes como la Ley de Defensa de la República de ese año y posteriormente la Ley de Orden Público de 1933), restringieron enormemente los márgenes de la acción directa confederal, no solamente en lo que se refería a la proscripción de las huelgas al margen de los cauces establecidos legalmente (jurados mixtos), sino asimilando también las protestas extrasindicales amparadas por la CNT (parados, inquilinos, vendedores ambulantes, etc.) a problemas de orden público. Todo ello fue interpretado desde gran parte del movimiento libertario en clave represiva (con el recurso gubernamental a unas fuerzas de seguridad de insuficientes recursos, mal coordinadas y cuyo manejo de los conflictos resultaba de desenlace imprevisible), como restricción de sus libertades civiles y exclusión de la organización confederal del espacio público ${ }^{30}$. Este fue uno de los factores que favoreció la legitimación de las tesis radicales en el seno del movimiento libertario, el descrédito de las posiciones reformistas y contemporizadoras con la República y la apuesta por la superación revolucionaria de esta, en un camino que conduciría a los defensores de estos principios al control de la organización confederal.

Entre 1932 y 1933, al recurso a la huelga se unió el nuevo rumbo táctico que tomó el cenetismo, con un ciclo insurreccional que planteaba la conquista revolucionaria del espacio público, como pudo verse en aquellas localidades donde fue proclamado efímeramente el comunismo libertario. La represión de estos levantamientos condujo a una espiral de enfrentamiento que se saldó con "masivas intervenciones policiales en los barrios, más protestas anarquistas, la detención de cientos de militantes y la desarticulación de los sindicatos a cargo de las autoridades"31. La movilización, el número de huelgas y la presencia libertaria en la calle en general decrecieron sustancialmente a lo largo de 1934 y, tras el aplastamiento de la revolución de octubre, durante 1935. El despertar de la izquierda que fue viviéndose a lo largo de este último año, con los mítines y las campañas por la amnistía de los presos de octubre, tardó en llegar a una organización confederal dividida y exhausta, en la que los signos de parálisis resultaban evidentes ${ }^{32}$. El momento abierto con la preparación de

30. CRUZ, Rafael, En el nombre del pueblo..., pp. 34-42. Este autor añade: "Continuando una larga costumbre, renovada por la Ley de Orden Público de 1933, los ministros de la Gobernación, los gobernadores civiles y los alcaldes restringieron de manera constante y arbitraria el uso de los espacios públicos y abiertos para realizar reclamaciones sociales, porque buena parte de esas autoridades consideró el orden como un derecho estatal más importante que el derecho de reunión" (p. 118).

31. Ibid, p. 63

32. CASANOva, Julián, De la calle al frente..., p. 139. 
la campaña electoral de febrero de 1936 y, sobre todo, tras el triunfo del Frente Popular, inauguró un nuevo contexto de oportunidades, en el que se incrementó la acción sindical en el campo y en las ciudades, con nuevas huelgas, pero en el que la prioridad dentro de la CNT fue la reconstrucción de la organización y la reunificación de la familia confederal, oficializada con el congreso de Zaragoza de mayo. En la España de la primavera de 1936, en la que se renovó la lucha por el dominio de la calle y se revitalizaron las formas de movilización toleradas y no toleradas (desde reuniones, asambleas, mítines, manifestaciones, entierros, marchas, huelgas, etc., en el caso de las primeras, a acciones ilegales y violentas entre las segundas), la participación cenetista y su proyección al espacio público no se mostraron de manera especialmente singularizada.

\section{Rituales de movilización}

La huelga, la manifestación o el mitin formaron parte de los nuevos repertorios de acción colectiva que el movimiento obrero, entre otros, contribuyó a consolidar a lo largo de las primeras décadas del siglo XX, en contraposición a la hegemonía del motín hasta entonces, aunque ello no significa que no siguieran conviviendo con otras formas de protesta anteriores y relacionadas con el consumo y la subsistencia o vinculadas a tradiciones comunitarias ${ }^{33}$. Los libertarios acudieron a aquellos con reiteración a lo largo de la década de los treinta. Asimismo, tal como comentábamos, su vinculación con causas extrasindicales vinculadas a demandas relacionadas con su medio social hacía que su repertorio de acción colectiva incluyera variadas formas de protesta relacionadas con desempleados, inquilinos, trabajadores inmigrantes o poco cualificados y habitantes en general de los barrios obreros y las periferias industriales, como ocurría en Barcelona. Al referirse a la respuesta libertaria ante el control de la calle y las medidas de orden público de las autoridades republicanas, Rafael Cruz alude al variado y ecléctico repertorio de acción colectiva del movimiento confederal y ácrata:

"Los anarquistas aprovecharon el repertorio de formas tradicionales de acción de las comunidades locales. Levantaron barricadas, construyeron hogueras con los enseres religiosos de las iglesias asaltadas, boicotearon procesiones y otros rituales religiosos, convocaron manifestaciones y mítines, reunieron asambleas, se enfrentaron con la policía y realizaron prácticas de extorsión,

33. CRUZ, Rafael, "El mitin y el motín. La acción colectiva y los movimientos sociales en la España del siglo XX", Historia Social, 31, 1998. También: GIL ANDRÉs, Carlos, Echarse a la calle. Amotinados, huhelguistas y revolucionarios (La Rioja, 1890-1936), Zaragoza, Prensas Universitarias de Zaragoza, 2000. 
expropiación y castigo de los adversarios. Convocaron, además, decenas de huelgas con los instrumentos de costumbre en la estrategia anarcosindicalista. A moldear estas formas de acción, bien fueran convencionales, transgresoras o violentas, se sumó el control policial de la calle"34.

La calle era el lugar donde debía expresarse el "gesto viril", "mitología movilizadora" de tanta importancia para el movimiento confederal y anarquista. Para Julián Casanova, "los gestos y las gestas eran materia importantísima. Un gesto era cualquier cosa que hiciera a un obrero, a una pequeña localidad, a una ciudad, 'dignos' de pasar a la historia por haber sabido 'luchar valientemente por sus reivindicaciones'. Un gesto era, por ejemplo, un mitin, una huelga, una manifestación de protesta, una huelga general" 35 . Pero también lo fueron las acciones violentas que jalonaron la dinámica de determinados grupos de militantes durante estos años, coincidiendo con esta época de "anarquismo militarizado" entte 1932 y 1936, de control radical de la Confederación por parte de los sectores "faístas", abierto enfrentamiento con el regimen republicano y amplia autonomía y margen de acción del grupismo ${ }^{36}$.

34. CRUZ, Rafael, En el nombre del pueblo..., p. 63

35. CASANOVA, Julián, De la calle al frente..., pp. 74-75. Santos Juliá había subrayado ya la importancia de este hecho en la cultura cenetista y anarquista de los años treinta: "Cualquier acción vale en la medida en que sea una gesta o un gesto que entraña o anuncia acciones futuras, tanto por su valor ejemplar y como punto de referencia para siempre como por su fuerza de arrastre de la multitud. El gesto, una vez consumado, queda en efecto para siempre y a él se podrán referir y por él se podrán medir en adelante todos los que accedan a la lucha". JULIÁ, Santos, Madrid, 1931-1934..., pp. 181182. Véase también de ese autor, sobre esta idea, entre otros trabajos: "Fieles y mártires. Raíces religiosas de algunas prácticas sindicales en la España de los años treinta", Revista de Occidente, 23 (abril 1983), pp. 68-75 y "Poder y revolución en la cultura política del militante obrero español", en Peuple, mouvement ouvrier, culture dans l'Espagne Contemporaine. Cultures populaires, cultures ouvrières en Espagne de 1840 à 1936, Presses Universitaires de Vincennes, Université Paris VIII, 1990, pp. 183-185.

36. “... enfrentamientos a tiros con las fuerzas del orden y con sindicalistas rivales, más tarde también con falangistas, que se cobraban vidas tanto entre los libertarios como entre sus oponentes; atentados, no pocos mortales, contra patronos, obreros rivales, policías, funcionarios de prisiones, políticos o militares; explosiones de petardos y bombas (alguna con víctimas mortales), atracos a mano armada, extorsiones económicas, sabotajes, lanzamiento de artefactos incendiarios, acopio de armas y explosivos, etc. También reventamientos de mítines, derechistas, socialistas o treintista, que derivaban a veces en enfrentamientos a tiros". Álvarez Chillida, Gonzalo, "Negras tormentas sobre la República. La intransigencia libertaria", en DEL REY, Fernando (dir.), Palabras como puños. La intransigencia política en la Segunda República española, Madrid, Tecnos, 2011, pp. 90-91. La expresión "anarquismo militarizado" es utilizada por EALHAM, Chris, La lucha por Barcelona..., pp. 213-238. Tal como señala este último autor, la acción armada "expropiadora" (asaltos a bancos o incautaciones de nóminas, cobro de "impuestos revolucionarios" a patronos y empresas, etc.) guarda relación en esos momentos con la crisis financiera de la CNT y la necesidad de hacer frente a la pérdida de afiliación, 
Pero era lógicamente en el levantamiento revolucionario donde se ejemplificaba el gesto y se dignificaba de manera más clara la acción. En los pueblos y localidades donde prendieron las insurrecciones revolucionarias de 1932 y 1933, se repitió un esquema más o menos similar que incluyó, siempre en mayor o menor medida según los casos: la salida a la calle de grupos de militantes libertarios armados desde los locales sindicales de la población en cuestión; la toma (o el intento de toma) del cuartel de la Guardia Civil y del Ayuntamiento después de reducir y desarmar a las fuerzas de seguridad y de detener al personal municipal (y en su caso también a personas de orden o burgueses de la localidad); la proclamación del comunismo libertario mediante bandos o proclamas; la interrupción de las comunicaciones telefónicas, la instalación de barricadas y el bloqueo de las vías de acceso al municipio. Si había tiempo para ello antes de la llegada de las fuerzas de orden que acababan finalmente con el levantamiento, poniendo en fuga a aquellos militantes, a estas iniciativas se unían medidas como el cierre de comercios, la requisa de alimentos y la puesta en marcha de políticas de abastecimiento, la abolición del dinero, etc. Todo ello se acompañaba de acciones de fuerte contenido simbólico y que expresaban esa nueva ocupación revolucionaria del espacio público, como la sustitución de la bandera republicana por la rojinegra en el balcón del Ayuntamiento, la quema/destrucción de los registros municipales y judiciales o las manifestaciones que difundían por las calles de la localidad el mensaje del advenimiento del comunismo libertario, con el despliegue de banderas o vivas a la revolución ${ }^{37}$.

No obstante, fue quizás la huelga la forma de acción donde más reiteradamente se mostró la presencia anarcosindicalista en las calles durante los años treinta. Allí, en la vía pública, se vivía la huelga como prolongación del conflicto en la fábrica o el taller, con la concentración de los trabajadores, los choques de los piquetes con los esquiroles o las fuerzas de seguridad, el variado abanico de formas de boicot (corte de líneas telefónicas, colocación de artefactos explosivos, etc.) que acompañaba a los conflictos más vivos o prolongados, el corte del transporte público en las ciudades y en definitiva la interrup-

el incremento del volumen de sus presos y el cierre de su prensa, sindicatos y locales por parte de las autoridades durante estos años, al convertirse en un medio de conseguir fondos que permitiera hacer frente a esta situación, lo que "incrementó la relación de dependencia de la CNT con respecto a los grupos" (p. 231). En todo caso, el "ilegalismo" y la dinámica expropiadora formaban parte de una tradición arraigada en el movimiento libertario, como describe MARIN, Dolors, Clandestinos. El maquis contra el franquismo, 1934-1975, Barcelona, Plaza y Janés, 2002, pp. 46-52.

37. Una síntesis interpretativa de todo este ciclo insurreccional, en: CASANOva, Julián, De la calle al frente..., pp. 102-131. 
ción del ritmo habitual de la vida cotidiana que suponían en especial las huelgas generales ${ }^{38}$.

Junto a este tipo de acciones fueron muy frecuentes también durante los años republicanos otras formas del repertorio de movilización de los anarcosindicalistas, como los mítines o manifestaciones. A pesar de las limitaciones e intermitencias que, como hemos visto, acompañaron el acceso de los libertarios a la calle en este período, estos proyectaron a través de ellas sus rituales y símbolos en el espacio público y sirvieron asimismo como mecanismos de afirmación y reforzamiento de la identidad de grupo.

El mitin era el ritual de movilización política por excelencia, donde se concentraban todas las energías militantes y a través del cual se expresaba pública ("llenando" grandes teatros, plazas de toros, estadios de fútbol, etc.) y simbólicamente el vigor y la consistencia de la organización. La prensa propia colaboraba ampliamente en este proceso, anunciando desde días antes el acto -sobre todo si se trataba de un "mitin-monstruo" o de cierre de una determinada campaña-, sus objetivos, contenidos y participantes, y creando una atmósfera propicia para lo que tenía que convertirse en la fiesta del movimiento. Según Álvarez Junco:

"Los mítines son llamados con frecuencia "fiestas". Y la fiesta es, a la vez, exaltación de la comunidad -expresión eufórica de la regularidad de la vida socialy trasgresión del orden. En la medida en que se nos presentan como serena ocupación del espacio público por masas imponentes, son la afirmación de un nuevo colectivo social como fuente de legitimidad, esto es, como base de nuevas normas. Pero en tanto que fiestas no establecidas por los poderes existentes, tienen un significado subversivo" ${ }^{139}$.

De hecho, este carácter lúdico estaba presente desde las horas previas al mitin. Los militantes partían de sus centros y entidades respectivas (sindicatos, ateneos, agrupaciones locales, etc.), con las banderas, pancartas, etc., propias de éstos, y avanzaban en grupos hacia el lugar donde tendría lugar aquél, coreando canciones, lemas, etc. Eso era solo el preludio de lo que había de convertirse en un acto de reafirmación y de exaltación de la propia identidad, plasmado en ese "ambiente indescriptible" -expresión tantas veces repetida en la pren-

38. Para la actividad huelguística de la CNT en Cataluña y su relación con los principales conflictos laborales, véase: VEGA, Eulàlia, Entre revolució i reforma. La CNT a Catalunya (1930-1936), Lleida, Pagès Editors, 2004. De la misma autora, para el caso valenciano: Anarquistas y sindicalistas durante la Segunda República. La CNT y los Sindicatos de Oposición en el País Valenciano, Valencia, Alfons el Magnànim, 1987. Para Madrid: JULIÁ, Santos, Madrid, 1931-1934...

39. ÁlvareZ junCo, José, El Emperador del Paralelo..., p. 393. 
sa- que ofrecían los lugares donde se celebraban los mítines: exposición de banderas y pancartas en los asientos y gradas, interpretación de himnos proletarios por el auditorio, aplausos a los oradores (y "comunión sentimental" con ellos), entonación de proclamas, etc. El 27 de marzo de 1932 se celebró en la Plaza de Toros de Valencia un mitin pro-deportados y presos organizado por el Comité Regional de la CNT de Levante y la Federación Local de Sindicatos Únicos de aquella ciudad; a él asistieron unas 20.000 personas. En la crónica del acto publicada en la prensa confederal se señalaba:

"De las férreas barandillas de los palcos penden grandes carteles, pintorescos y alusivos, de Sindicatos y entidades libertarias. Junto a la presidencia las familias de los deportados -sus compañeras, sus pequeñuelos- muestran su tristeza y su emoción que se traduce en el ambiente en doloroso henchimiento de saludable sentimentalidad"40.

Durante la década de los treinta, los mítines confederales y anarquistas -que podían recibir distintas denominaciones, según la finalidad específica que se perseguía al organizarlos: "de afirmación", "protesta", "solidaridad", etc.solían celebrarse en salas de la trama asociativa propia o, más frecuentemente, en teatros o cines locales, e incluso en plazas de toros, dependiendo de la envergadura del evento en cuestión. En cuanto al esquema del acto, se mantuvo en lo sustancial el heredado de este tipo de ritual desde finales del siglo $\mathrm{XIX}^{41}$, con un presidente que tomaba primera la palabra y establecía los parámetros del encuentro y la intervención de los sucesivos oradores. Al final, se recogían las conclusiones, que solían ser aprobadas y aclamadas, tras lo cual se coreaban lemas o eslóganes y se entonaban himnos y canciones, enlazando con la salida de los asistentes. Hasta ahí, y en lo básico de estas características formales, los mítines anarcosindicalistas no se diferencian demasiado de los celebrados por otras fuerzas obreristas y progresistas en estos años. Sin embargo, sí que se detecta en el caso de los libertarios un carácter menos cerrado, con una mayor tendencia a la petición de palabras a cargo de asistentes para apuntar o rebatir lo dicho, reclamando un turno libre de intervenciones y "controversia" ${ }^{42}$, lo cual podía tender a hacer perder el control del acto con esas y otras

40. Véase: "Mitin pro-deportados y presos...", Solidaridad Obrera (Valencia), 2-IV-1932. Al final de la narración se recogen las representaciones asistentes y los lemas que inscribieron en sus banderas y pancartas.

41. DAlmau i Ribalta, Antoni, "El míting anarquista..."

42. Asimismo, una modalidad de mitin que podía organizarse, también con una amplia tradición desde finales del XIX, y en el que solían participar los libertarios, era el "de controversia", con la intervención de oradores de distintos signo ideológico pero próximos dentro del obrerismo y la izquierda: en este caso de anarquistas con socialistas o comunistas, o, dentro de la familia libertaria, "sindicalistas" con "faístas", por ejemplo. 
participaciones teóricamente espontáneas. En los años republicanos, y dentro de la división y batalla internas que vivió la CNT en este período, fue también común la presencia en los mítines confederales de militantes que acudían a "reventar" el mitin, habitualmente "faístas" que increpaban a los oradores sindicalistas y treintistas y tomaban la palabra (lo que también se hacía en mítines de otras fuerzas políticas), lo cual solía acabar en enfrentamientos y la disolución del acto.

Así, en función de múltiples variables, el evento podía concluir con el esquema previsto o continuar en la calle con manifestaciones, disturbios, etc. Por otra parte, en el entorno del mitin se desarrollaban otras actividades militantes: recaudaciones pro presos o venta de prensa, libros o folletos en stands o "carros" que allí llevaban los grupos y jóvenes libertarios. No hay que olvidar asimismo el papel que cumplía la prensa propia, al "prolongar" al día siguiente o en jornadas sucesivas el acto con la narración detallada del mismo, las intervenciones de los oradores, las referencias al público asistente y las fotografías. Ello resultaba fundamental como caja de resonancia, amplificando la dimensión movilizadora, adoctrinadora y cohesionadora del acto. Podríamos hablar, por tanto, de auténticos mítines "de papel" ${ }^{33}$, y lo mismo ocurría con otros rituales a los que aludimos en estas páginas.

Al referirse al mitin anarquista de finales del siglo XIX, Antoni Dalmau señala que, a diferencia de otras formaciones políticas de su tiempo, distingue a los libertarios el hecho de no concebir sus actos como "una exhibición calculada de un cierto modelo de organización o de una ostentación de algún tipo de poder, o como un acto esencialmente pensado de propaganda de cara al exterior". Es por esa razón que "no encontraremos casi nunca ni escenografías estudiadas y grandilocuentes, ni los rituales planificados y profundamente simbólicos como los que, por ejemplo, son tan usuales en aquellos mismos años en la órbita del lerrouxismo". Si bien es cierto que existe una acentuada voluntad entre los ácratas por alejarse de las formas más convencionales de la política, y un especial énfasis en la austeridad, la sencillez y el "anhelo de huir de la ostentación y el exbicionismo", con el fin de "buscar un modelo de reunión pública que se atenga a las condiciones de vida, más sencillas y más humildes, de la patuleia y de todas las clases populares", no coincido con Dalmau en que de ello se deduzca "la escasa o nula voluntad de utilizar el mitin como un gran elemento de proyección pública" ${ }^{44}$. En mi opinión, siempre (y también en el tránsito del siglo XIX al XX) estuvo presente la doble dimensión de estos

43. CRUZ, Rafael, En el nombre del pueblo..., p. 95.

44. DALmau i Ribalta, Antoni, "El míting anarquista...", p. 64 (traducción propia). 
rituales -interna, con el reforzamiento de la identidad propia, y externa, con su salida, presencia y visibilidad en el espacio público-, aunque el autor reconoce que con el crecimiento de la movilización en décadas posteriores habría que matizar aquella caracterización:

"Ciertamente, con el paso del tiempo y la expansión del movimiento anarcosindicalista, los actos rituales de los anarquistas irán volviéndose más ricos y complejos, más cargados de elementos adicionales de afirmación y movilización, hasta alcanzar su paroxismo en los años de la revolución y la guerra civil de 1936-1939: en esta época las necesidades del momento impusieron de forma casi imperativa la acentuación de símbolos y de rituales específicos y la ocupación permanente y visible, casi obsesiva, de toda suerte de espacios públicos" 45 .

También es cierto que existió siempre una corriente crítica dentro del movimiento libertario contra este tipo de actos, e incluso contra la oratoria y la propaganda verbal en general (en contraposición a la lectura y al ejemplo ético de la conducta del militante), desde un impulso iconoclasta y opuesto al liderazgo que fue muy habitual, por ejemplo, entre los individualistas ${ }^{46}$. En todo caso, esta era una opinión que podía manifestarse de cuando en cuando, pero que no era en absoluto mayoritaria. Por el contrario, confederales y ácratas recurrieron habitualmente a este ritual de movilización, aunque sí que era muy común en sus filas contraponer el "hondo sentir" de los mítines propios con el exhibicionismo, la mera repetición de consignas y el caudillaje "mitinero" que supuestamente caracterizaban los realizados por otras fuerzas políticas (republicanos, socialistas, comunistas durante la contienda de 1936-1939, etc.), una crítica que fue creciendo a medida que en la década de los veinte y treinta se incrementaba la movilización de distinto signo político en toda Europa y se perfeccionaban las técnicas propagandísticas y de persuasión de masas.

La crítica se extendía también, obviamente, a las fiestas oficiales, en este caso de la nueva República, consideradas celebraciones frívolas que no hacían sino mostrar la distancia que separaba el régimen burgués del sufrimiento del auténtico pueblo trabajador:

"Ya han llegado los compañeros ministros en su viaje de excursión (...) Los elementos oficiales ya han movilizado a todas sus huestes para salir a esperarles, acompañarles y agasajarles (...) La ciudad está de fiesta (...) está engalanada oficialmente: se siente honrada con tan alta y meritoria distinción por parte de estos meritorios y fatigados ciudadanos, cansadísimos en el trabajo de reden-

45. Ibid, pp. 64-65 (traducción propia).

46. Un ejemplo es el de Felipe Aláiz, con su folleto Para que la propaganda sea eficaz, Barcelona, Comité Regional de Juventudes Libertarias de Cataluña, s.d. [1938]. Véase: NAVARRO NAVARRO, Javier, A la revolución por la cultura..., pp. 45-46. 
ción nacional. Recepciones oficiales; excursiones de visita; fiestas...todo lo que pueda distraer y divertir a tan meritorios ciudadanos, se hace, se hará y se seguirá haciendo para darle más vistosidad y realce a las oficiosidades republicanas (...) Mientras la ciudad arde en fiestas, los lugares proletarios están viviendo oficialmente también el viacrucis de la miseria y del dolor"47.

En alguna ocasión, se subrayaba incluso que el mitin cenetista no se encerraba en los locales y centros afines, sino que se desarrollaba al aire libre (lo cual era cierto solo en algunos casos); ello conectaba por otra parte con la preferencia anarquista por los espacios abiertos, sinónimos de libertad y vida natural. Un ejemplo es la siguiente crónica de unos actos celebrados en Torrent (Valencia) en abril de 1932, en conmemoración de la proclamación de la República, y donde puede observarse la contraposición mencionada:

"Una simple pizarra anunciando el acto y colocada en estrecha calle, es lo suficiente para que corra la noticia cual reguero de pólvora; la gente acude ansiosa a escuchar a los hombres de la CNT. Allá, en un pequeño casino, silencioso como si nada importara, quedan unos cuantos republicanos (entre ellos Just), celebrando el primer aniversario. Y es al aire libre el acto, el amplísimo local de la casa social de los trabajadores se llena de gente, mujeres, hombres y también los mozalbetes que con espabilado rostro abandonan sus juegos para oír a sus hermanos mayores" 48 .

Asimismo, y en la línea educacionista y pedagogista que caracterizaba los medios ácratas, fue habitual la consideración positiva de una actividad como la organización de conferencias, práctica cultural muy común en la cultura libertaria ${ }^{49}$. Estas podían ser de muy diversa temática y tipo, desde las de carácter más propagandístico y adoctrinador a las de divulgación cultural y sobre una amplia variedad de temas. Solían celebrarse en los locales de la trama asociativa ácrata, pero en ocasiones, cuando se trataba de ponentes muy conocidos y de prestigio dentro del movimento libertario, podían convertirse en actos multitudinarios, equiparables a los mítines. Es el caso, por ejemplo, del "apóstol" Domingo Germinal, un auténtico profeta del ideario anarquista en tierras valencianas y muy famoso por su convincente discurso, profundamente emocional y pasional, que hacía vibrar a su auditorio. Domingo Germinal reunió al parecer en mayo de 1932 a siete mil personas $(i)$ en el Teatro Serrano de Valencia, con una conferencia titulada "Capitalismo, Sindicalismo y Ciencias Sociales", y a doce mil en julio de ese año, esta vez sobre el tema "Evolución y Revolución", en la Plaza de Toros de Alicante:

47. "Realidades", Solidaridad Obrera (Valencia), 9-IV-1932.

48. "Campañas de propaganda. Torrente", Solidaridad Obrera (Valencia), 24-IV-1932.

49. NAVARRO NAVARRO, Javier, A la revolución por la cultura..., pp. 49-63. 
"Bastó el simple anuncio del acto en unos pasquines y octavillas para que el pueblo de Alicante en masa acudiese al local donde se celebraba, a pesar de la inseguridad del tiempo, que amenazaba lluvia. En las tres horas que duró la conferencia tuvo el compañero Germinal pendiente de sus labios a todo el auditorio, al que hizo historia de la evolución y progreso de la Humanidad y demostró de modo irrefutable la falsedad de la política internacional. Contra la opinión de los que creen en la incapacitación del pueblo para vivir una sociedad libre, expuso tales razones y argumentos que deshizo rotundamente tal criterio pesimista. Terminó su disertación con un llamamiento al deber que tenemos para con nuestros presos y deportados y entre entusiastas vivas a la FAI y a la Revolución social, finalizó el acto, que resultó magnífico en todos conceptos"

Las manifestaciones que recorrían las calles (generalmente del centro de la ciudad o localidad respectiva), con ocasión de alguna fecha destacada o en el marco de alguna campaña o una reivindicación concreta, fueron asimismo expresiones de este intento de salir al espacio público. Fueron muy diversas, como variadas fueron las causas y contextos en los que se convocaron. Aunque el período republicano auguraba una mayor normalidad en esta práctica -frente la prohibición de las manifestaciones públicas por parte de las autoridades militares durante la dictadura primorriverista-, sin embargo las especiales circunstancias que vivió el movimiento libertario entre 1931-1936, como estamos viendo, hizo más irregular, intermitente y accidentado el recurso a ellas, aunque no por ello menos frecuente.

Para el obrerismo, como sucedía en el Primero de Mayo, este tipo de rituales simbolizaban la ocupación-dominación simbólica del espacio público por parte del pueblo trabajador, un ejemplo visible de su capacidad de movilización, a la vez que un ejercicio identitario de reafirmación interna. Los recursos simbólicos empleados en estos actos solían incluir en el caso libertario las banderas rojinegras y las pancartas con siglas o lemas de la organización; a veces, acompañaba también a los manifestantes una banda de música que interpretaba canciones o himnos como "Hijos del Pueblo" o "A las barricadas", aunque ello fue más común durante la guerra. En general, cenetistas y anarquistas acudían a estas manifestaciones solos, casi nunca en conjunción con otras fuerzas obreras, lo que no es sino la expresión de sus diferencias con éstas, así como la reafirmación de la idea de la "soledad" en la lucha social que formó parte del discurso del movimiento libertario durante estos años ${ }^{51}$.

Un ejemplo de ello son los primeros de mayo que tienen lugar durante el período republicano, cuando la confrontación con los socialistas en el gobierno

50. "Una conferencia en Alicante", Solidaridad Obrera (Valencia), 16-VII-1932.

51. Véase: Juliá, Santos, Madrid, 1931-1934..., p. 181. 
se acrecentó. Las críticas a la frivolidad socialista en esta celebración se incrementaron, acentuándose además por el hecho de que los ejecutivos del primer bienio lo convirtieran en fiesta oficial de la República, "pervirtiendo" así su carácter original. Sin embargo, tal como ha destacado la historiografía, ya prácticamente desde sus orígenes la interpretación del Primero de Mayo desde el movimiento libertario no adquirió la connotación festiva que sí tuvo para los socialistas. A diferencia de estos, que la entendieron como una oportunidad de celebración del poder obrero y de autoidentificación de la clase trabajadora, emanada de la campaña por la jornada de las ocho horas y el congreso de París de 1889, y que solia concluir con una petición a las autoridades, la lectura ácrata incidía en el acontecimiento-recuerdo: la ejecución de los mártires de Chicago en 1887, con toda su carga dramática, una efemérides que debía incitar a la reflexión y al luto, y cuya carga reivindicativa no podía cerrarse con una serie de peticiones legales sino con la convocatoria de la huelga general. ${ }^{52}$

Frente a la jornada celebrada por los socialistas o republicanos, los anarcosindicalistas convocaron paralelamente durante estos años manifestaciones alternativas (en solitario) y, en especial, mítines de afirmación, con recuerdo a mártires y víctimas del movimiento -vinculando cada vez más simbólicamente a los mártires de Chicago con las nuevas víctimas de la represión republicana-, colectas para los presos, planteamiento de reivindicaciones laborales y sociales, etc., y pugnando en definitiva por el espacio público y el espacio político de las clases trabajadoras con otra familias obreristas.

Si bien esta jornada se asociaba también simbólicamente a la primavera, a la naturaleza renacida como metáfora del despertar de la clase obrera, como ocurría asimismo en el caso socialista, esa dimensión celebrativa, lúdica y festiva la recogían de una manera más clara en el movimiento libertario otro tipo de rituales que no solían tener una fecha fija ni carácter multitudinario, y que eran organizados de manera autónoma por numerosos grupos y núcleos de militantes. Nos referimos a las "jiras" y excursiones dominicales de carácter campestre, que constituían una actividad habitual de la sociabilidad ácrata y cuya importancia no conviene desdeñar. Dentro de la cultura anarquista, estas prácticas suponían pasar un día en libertad, en la montaña o la playa, convivien-

52. ÁlVAREZ JunCo, José, La ideología política..., pp. 549-554; DE LA CALLE VELASCO, Dolores, "El Primero de Mayo y su transformación en San José Artesano", Ayer, 51,2003, donde puede verse también la bibliografía sobre el tema, entre ella el libro de RIVAS, Lucía, Historia del Primero de Mayo en España desde 1900 hasta la II República, Madrid, UNED, 1987. También: PÉREZ LEDESMA, Manuel, "La formación de clase obrera: una creación cultural", en CRUZ, Rafael y PÉREZ LEDESMA, Manuel (eds.), Cultura y movilización..., pp. 229-230 y HERRERín, Ángel, Anarquía, dinamita y revolución social..., pp. 71-76. 
do con compañeros de inquietudes similares -y sus familias-, recreando así en la medida de lo posible el espacio simbólico de la acracia y el comunismo libertario, y reforzándose de esta manera la identidad del grupo. Cubrían necesidades de esparcimiento y diversión, a la vez que podían ofrecer en su caso una utilidad desde el punto de vista propagandístico (con posibles mítines, discursos, venta de prensa) u organizativo (reuniones entre distintos grupos y comités, asambleas, etc.), eludiendo el control policial y gubernamental. En general se desarrollaban en ellas actividades de tipo lúdico (juegos, canciones), formativas (charlas, debates, lecturas) y también de tipo naturista o nudista en el caso de aquellos grupos seguidores de estas ideas ${ }^{53}$.

Estas jiras y excursiones no constituían desde luego una actividad exclusiva del movimiento libertario, ya que eran también muy comunes entre otras familias políticas en estos años, por ejemplo entre las agrupaciones socialistas. Pero, a diferencia de las ya mencionadas "meriendas democrácticas" republicanas o de los aplecs carlistas, no implicaban grandes concentraciones colectivas y tenían un carácter fuertemente descentralizado. En relación al tema que nos ocupa, pueden considerarse también rituales movilizadores que expresaban una salida al espacio público. Además de las actividades desarrolladas en su lugar de encuentro, las marchas a pie o en tren que emprendían los grupos de militantes hasta llegar allí constituían auténticas manifestaciones, ya que en ellas se desplegaban las banderas, se cantaban canciones y se coreaban himnos. En alguna ocasión, tenían lugar incidentes con la guardia civil y otras fuerzas de seguridad ${ }^{54}$.

Por último, cabe hacer referencia a otros rituales de movilización que tienen que ver con lo que hemos caracterizado inicialmente como "ritos de paso": los entierros de militantes, las inscripciones de los recién nacidos en el Registro o los matrimonios civiles o "libres", que también servían para mostrar la propia presencia en las calles, sobre todo en el caso de los primeros, en los que nos detendremos brevemente. Todas estas prácticas formaban parte de una tradición laica, librepensadora y progresista que recogieron los libertarios y que expresaba -en el terreno ideológico, ético y simbólico- el deseo de escapar del control religioso sobre los ritos esenciales de la propia vida.

Tal como ha subrayado Rafael Cruz, asistimos desde 1880 en España a una "extensa dinámica movilizadora fúnebre" que convirtió los entierros civiles en "manifestaciones de identidad laicista y antigubernamental", formas de oposición al estatus privilegiado de la Iglesia y la restricción de los derechos civiles en beneficio de ella durante el régimen de la Restauración. Así, los ritua-

53. NAVARRO NAVARRO, Javier, A la revolución por la cultura..., pp. 319-333.

54. Ibid, pp. 323-324. 
les fúnebres funcionaron en el caso de republicanos, libertarios y otras fuerzas obreristas como expresiones de protesta, "contraceremonias religiosas de pedagogía cívica o de clase" que actuaban como prácticas esenciales de reivindicación de una determinada identidad ${ }^{55}$. Estos actos pasaron a integrarse así en los repertorios propios de movilización desde una doble dimensión: la manifestación y exposición públicas de la legitimidad, respetabilidad y superioridad de un determinado ideario y, por otro -internamente-, como mecanismos de reforzamiento de una identidad colectiva y de la cohesión grupal, estrechando y actualizando (resucitando) los vínculos que unían a los miembros de una determinada familia política y consolidando el compromiso de estos ${ }^{56}$.

En el contexto general de la Europa de entreguerras, donde el culto a los muertos adquirió un gran protagonismo, en la construcción de las identidades colectivas (especialmente de la nación) y en los procesos de lucha política entre grupos rivales, durante la Segunda República española el recurso a estas políticas de la muerte y los rituales fúnebres se incrementó notablemente, al relacionarse con la competencia política y el enfrentamiento público.

También en el caso libertario los rituales fúnebres funcionaron como mecanismos de movilización durante los años republicanos. En primer lugar, continuaron actuando como ejercicios de laicidad militante. La prensa confederal recogía con frecuencia noticias y anuncios sobre ceremonias de este tipo que, especialmente en las poblaciones más pequeñas, eran motivo de roces y enfrentamientos con las autoridades eclesiásticas u oficiales, sobre todo con las primeras, resistentes a la hora de acatar la nueva legislación republicana. A menudo, y como solía ocurrir en la narración en prensa de estos actos en general, siempre se enfatizaba el elevado número de personas que habían formado parte del cortejo fúnebre, lo que mostraba el apoyo popular y legitimaba la causa:

"Igualada. ANTICLERICALISMO EN ACCIÓN. Parece que por aquí la gente se va acostumbrando a prescindir de los 'servicios' de los curas. En dos semanas, se han efectuado cinco entierros civiles. El que menos, llevó cien personas de comitiva, y el que más, rebasó la cifra de mil. Así fue de concurrido -a pesar de la lluvia- el entierro de la joven Filomena Camins. Nada, que el 'gori-gori' va cayendo en desuso" 157 .

55. CRUZ, Rafael, "Introducción” y "El sabor fúnebre de la política española entre 1876 y 1940", en CASQUETE, Jesús y CRUZ, Rafael (eds.), Políticas de la muerte. Usos y abusos del ritual fúnebre en la Europa del siglo XX, Madrid, Los Libros de la Catarata, 2009, pp. 921 y 73-105 respectivamente.

56. CASQUETE, Jesús, "El poso agridulce de la ausencia: vectores de las políticas de la muerte", Ibid., pp. 340-342.

57. "Igualada. Anticlericalismo en acción", Solidaridad Obrera (Barcelona), 3-IV-1936. 
Estos entierros, como rituales de afirmación de la propia identidad, eran ceremonias donde se desplegaban los símbolos propios, con banderas, coronas de flores con lemas o colores alusivos a la organización confederal o anarquista, etc., y contaban con una liturgia propia. En ocasiones, la comitiva-formada mayoritariamente por trabajadores: compañeros, familiares o vecinos- estaba acompañada por una banda que interpretaba marchas fúnebres, mientras todos marchaban en silencio por las calles de la población respectiva, conciliando así el respeto y el homenaje al fallecido con la afirmación revolucionaria. En el sepelio civil podía intervenir también algún militante o dirigente sindical leyendo un discurso ${ }^{58}$. Éste fue el caso del entierro de un minero de Villar del Arzobispo (Valencia), muerto en accidente de trabajo cerca de Domeño a finales de octubre de 1932, y a quien se dio sepultura en su localidad natal durante el transcurso de un acto al que acudieron militantes cenetistas de los pueblos vecinos. Se trataba, por cierto, del primer entierro civil realizado en Villar:

"Al sacar el cadáver de la casa paterna, la música entona la marcha fúnebre al paso de la comitiva, recorriendo las calles más céntricas de la población. Más de cinco mil personas de ambos sexos y diferentes clases acompañaron el féretro hasta el cementerio, donde el compañero Peñarrocha, de Liria, dirigió la palabra (...) A continuación hacen uso de la palabra los compañeros Pastor, de Villar; y Julián Martínez, de Bugarra, los cuales, después de apostrofar al actual régimen capitalista, dan un saludo a la concurrencia y a la revolución social" 159 .

El grado máximo de ritualización en estos actos se alcanzaba, lógicamente, cuando el fallecido era un mártir del movimiento. Ésta es la crónica aparecida en prensa del entierro de un militante caído en 1931 en un tiroteo con la policía:

"A la hora señalada, por los patios del Hospital Clínico no podían entrar los compañeros que iban llegando para rendir el último tributo al hermano asesinado. Un pelotón de guardias de seguridad quería escoltar a la fúnebre comitiva, pero a una indicación de los camaradas de la FAI se retiraron. Hasta Colón acompañaron el féretro unos siete mil trabajadores. Llegaron hasta el Cementerio Nuevo más de tres mil camaradas, que anduvieron cuatro kilómetros. El amigo Gardeñas pronunció unas palabras alusivas al acto y recordó que la emancipación de los trabajadores se consigue a trueque de la vida de los trabajadores. Fue enterrado nuestro compañero en el nicho número 84 de la Vía

58. "El 20 del pasado mayo tuvo lugar en Denia el entierro del camarada Manuel Balboa, honesto militante proletario, muy estimado en la localidad. Acudieron unas 600 personas al sepelio civil, leyendo en esa oportunidad el presidente de la Unión Obrera Deniense un sentido discurso". "De Denia", Tierra y Libertad (Barcelona), 14-VI-1935.

59. "Desde Villar del Arzobispo. Una víctima más", Solidaridad Obrera (Valencia), 12-XI1932. 
Igualdad, recinto civil; en la misma vía reposan los restos de Francisco Ferrer Guardia, en el nicho número $237^{160}$.

Los rituales fúnebres libertarios funcionaron también como parte de la estrategia de movilización por la que circuló la tendencia que se impuso en la batalla interna dentro de la CNT durante los años republicanos. La apelación a los mártires, a la sangre derramada por los militantes que desde 1931 iban a caer en las calles durante las huelgas, las insurrecciones o los enfrentamientos con las fuerzas de seguridad o las fuerzas rivales, sirvió para apuntalar el triunfo de los sectores más definidamente "anarquistas" dentro de la organización confederal, con una retórica que se apoyaba en la legitimidad que otorgaba el ejemplo de los compañeros que habían perdido la vida en la lucha revolucionaria, así como en la deuda contraída con ellos.

\section{Conclusiones}

Nuestra intención era, como señalábamos al inicio, esbozar una aproximación a los distintos rituales de movilización que el movimiento libertario español puso en marcha en el espacio público en el contexto de la democracia republicana de 1931-1936. Estos se acompañaban del despliegue de diferentes aparatos simbólicos propios y cumplían, como ocurría con otras culturas políticas, una doble función: la cohesión y el reforzamiento identitarios internos, por un lado, y la visibilidad y reafirmación externas, mostrando públicamente la fuerza, protesta, reivindicaciones y aspiraciones propias. Pese a las frecuentes referencias y alusiones a ellos en la historiografía sobre el anarquismo y anarcosindicalismo en España, esos rituales y símbolos no han sido objeto todavía de estudios específicos y tampoco para el período mencionado. El objetivo de estas páginas no era un análisis en profundidad de dichas prácticas, que excedería con creces los límites del presente texto, sino situar en la medida de lo posible los parámetros de futuras investigaciones en torno a este ámbito y apuntar el desarrollo de vías de estudio que aquí quedan solo anunciadas.

A lo largo de esos años, los libertarios hicieron uso de un amplio y muy diverso repertorio de acción colectiva, en primer lugar con el recurso a las nuevas formas de movilización que habían estado cada vez más presentes durante las primeras décadas del siglo XX -la huelga, el mitin o la manifestación-, por parte de un movimiento que pivotaba ahora alrededor de una poderosa organización sindical propia, la CNT. La huelga adquirió así un rol protagonista como ritual de movilización. También se recurrió a manifestaciones y

60. R.M., "Carta de Barcelona. Una manifestación de duelo", Solidaridad (Valencia), 30-V1931. 
mítines. Evidentemente, los anarquistas habían frecuentado estas prácticas en el pasado. Pero ahora, en la década de los treinta, en el contexto general de movilización de masas del período de entreguerras y en el de la creciente competencia política que abrió la democracia republicana, con unas fuerzas políticas que trataban de reafirmar su presencia y fuerza en el espacio público, manifestaciones y mítines revistieron también aquí un carácter más multitudinario, escenificando adhesiones y mostrando la sintonía con la voluntad popular. A pesar de toda una tradición que intentaba mantener distancias respecto a los excesos de la oratoria y la propaganda verbal, de su insistencia en el carácter abierto de los mítines y en la "controversia", o del recurso a la organización de grandes conferencias cuyos contenidos iban más allá del "mitineo" electoralista, el uso ácrata de los mítines en clave movilizadora, así como el abanico de elementos que en estos rituales se desplegaban, no se diferenciaron de los de otras fuerzas políticas.

Los anarcosindicalistas trataron de contraponer también durante el período republicano "la calle", su espacio "natural", a los vicios de la política parlamentaria, en este caso de la democracia liberal, y ello impulsó su salida al espacio público con renovadas fuerzas. Asimismo, para aquellos resultaba esencial mantener el vínculo que les unía a las demandas y reivindicaciones de los barrios obreros donde se ubicaban sus bases sociales, todo lo cual se materializó en protestas urbanas "extrasindicales" contra el estado de la vivienda, las infraestructuras o las carencias en materia de salud, educación o cultura. Por otro lado, el enfrentamiento con los gobiernos republicanos del primer bienio a través de huelgas, protestas o insurrecciones generó una espiral represiva que se materializó en leyes y normativas que restringieron la presencia libertaria en la calle, lo que contrastó enormemente con las expectativas de movilización que había despertado en un primer momento la democracia republicana. Tampoco puede entenderse la relación del movimiento ácrata con el espacio público en estos años sin tener en cuenta su división interna y las tensiones que ello provocó, la competencia por el control de la CNT, la escisión orgánica y el triunfo de las tesis "radicales" dentro del sindicato, que llevaron entre otras cosas a la apuesta por la estrategia de "gimnasia revolucionaria" y de superación inmediata de la República burguesa en el período 1932-1933, con proclamaciones del comunismo libertario en diversas localidades con un formato que recordaba al del motín y la insurrección presentes en este movimiento desde finales del siglo XIX.

En ese contexto, el recurso a las manifestaciones públicas en las filas anarquistas durante estos años fue irregular, intermitente y accidentado. Por lo que se refiere a la actitud ante el Primero de Mayo, manifestación del obrerismo por excelencia, los ácratas expresaron su oposición a la interpretación socia- 
lista -en clave lúdica, autoafirmativa y legalista- de esta fiesta de los trabajadores, en un discurso muy similar al que habían mostrado en décadas anteriores, reforzado ahora argumentalmente por la presencia socialista en los ejecutivos republicanos. No hay que olvidar, por otra parte, el uso libertario de una práctica cuya importancia no ha sido suficientemente valorada: las "jiras" y excursiones dominicales, con un componente cultural e identitario muy reforzado, sin fecha fija y frecuentes a lo largo del año especialmente con la llegada del buen tiempo. Desde luego, no fue una actividad exclusiva de los anarquistas, pero estos sí que recurrieron habitualmente a ella. Las jiras y excursiones tenían una dimensión de ocio y festiva, a la vez que de sociabilidad y cohesión internas. En ellas se desplegaba la simbología libertaria (canciones, banderas) en pequeños grupos, permitían escapar en general del control policial de las calles (aunque no siempre) y cumplían subsidiariamente funciones propagandísticas y organizativas (celebración de asambleas, plenos, etc.) en períodos de represión, cierre de locales, suspensión de prensa, etc.

Los "ritos de paso" fueron también otras prácticas que los anarquistas y anarcosindicalistas proyectaron hacia las calles, con las comitivas que acompañaban las inscripciones de los recién nacidos en el Registro, los matrimonios o uniones "libres" y los entierros civiles. Respondían a una tradición librepensadora, radical y de vocación secularizadora, y eran expresión de una cultura común anticlerical compartida con los republicanos y la izquierda obrerista. Estos rituales fueron comunes en las filas libertarias ya desde las últimas décadas del siglo XIX y a lo largo de la década de los treinta mantuvieron, sobre esos moldes, su liturgia, simbología y constantes básicas, sumándose ahora a la campaña secularizadora promovida desde la legislación republicana. En esos años, por otro lado, los rituales fúnebres adquirieron en general un mayor protagonismo político como mecanismos movilizadores y de reafirmación militante, en medio de la competencia política democrática. Los anarquistas y anarcosindicalistas participaron de esta tendencia, con el entierro de los compañeros caídos en huelgas, manifestaciones, insurrecciones o enfrentamientos en las calles con la policía o sus enemigos políticos. La apelación a estos mártires no era ni mucho menos nueva en el movimiento ("Mártires de Chicago"; muertos en los motines, ocupaciones y choques con la fuerza pública en el XIX; ejecutados en la represión gubernamental ante los atentados de fines de ese siglo y principios del XX; asesinados en la época del pistolerismo ${ }^{61}$ ) y sirvió ahora de nuevo como elemento de movilización tanto para desvelar la "verda-

61. Sobre este ascendiente de la figura del mártir, véase la bibliografía citada en la nota 35. Para el período entre finales del XIX e inicios del XX, también: HERRERín, Ángel, Anarquía, dinamita y revolución social..., p. 82 y 176-180. 
dera" actitud de las autoridades republicanas ante el pueblo trabajador, como para legitimar las posiciones que, en el interior de las propias filas, postulaban por la superación revolucionaria inmediata de dicho régimen y el abandono de las estrategias contemporizadoras con él.

En cuanto a los repertorios simbólicos (himnos, canciones, proclamas; banderas, estandartes, pancartas, carteles con siglas, alegorías, etc.) desplegados por los libertarios en estos rituales, cabe destacar la irrupción de nuevos elementos procedentes de una tradición ya propia del anarcosindicalismo y no estrictamente deudores de la herencia común del obrerismo decimonónico o incluso del anarquismo finisecular. Destacaron en particular la bandera rojinegra, cuyo uso fue cada vez mayor en la década de los treinta, y el himno cenetista A las barricadas, aunque su consagración definitiva vendría ya a partir de julio de 1936. Lo mismo sucedería desde entonces con la introducción de nuevas fechas en el calendario libertario de conmemoraciones (19 de julio-revolución social; 20 de noviembre-muerte de Durruti) o de figuras en su panteón de personajes ilustres (el propio Durruti, tras su muerte).

En definitiva, el juego de rituales en el espacio público desplegado por los anarquistas y anarcosindicalistas en este período se tradujo en una compleja dinámica que combinó continuidades con respecto a moldes anteriores de la tradición obrerista y del propio movimiento ácrata desde fines del XIX, junto con cambios y adaptaciones al nuevo contexto republicano democrático y la política de masas del período de entreguerras. No obstante, las transformaciones más llamativas en este repertorio vendrían a partir de la etapa iniciada con la sublevación militar de julio de 1936, con la asunción de parcelas de poder por parte de los libertarios y la competencia planteada con otras fuerzas políticas en el interior de la España republicana. 


\title{
«Obreros, no votéis». La CNT y el Frente Popular en las elecciones de 1936 «Workers, do not vote!». CNT and Spanish Popular Front in the 1936 general elections
}

\author{
Roberto Villa García \\ Universidad Rey Juan Carlos, Madrid
}

Recibido: 11-XII-2013

Aceptado: 7-IV-2014

\section{Resumen}

Este artículo pretende aclarar la postura de la CNT y la FAI ante las elecciones generales de 1936. Se analiza cómo tradujeron los propagandistas de ambas organizaciones las ponencias electorales aprobadas en sus Plenos durante la campaña electoral. La comparación con la propaganda anarcosindicalista de noviembre de 1933 y el análisis de las concepciones dispares que la CNT y las izquierdas coaligadas en el Frente Popular mantenían sobre la amnistía y el peligro fascista, cuestionan que en 1936 se produjera una convergencia de intereses entre ambas y, por tanto, un relajamiento en las posiciones apolíticas y antielectorales de aquélla.

Palabras Clave: España, Segunda República, Elecciones, CNT, Anarquismo.

\begin{abstract}
This article aims to explain the position of CNT and FAI in the general elections of 1936. It analyzes how propagandists of both organizations understood the instructions, approved in their plenary meetings, during the election campaign. A comparison with anarcho-syndical propaganda of November 1933, as well as an analysis of the different points of view that CNT and the leftist coalition called Popular Front had about amnesty and fascist danger, challenge the idea that they shared similar interests in 1936 and that laxity in the anarchist position against politics and elections took place therein.
\end{abstract}

Keywords: Spain, Second Republic, Elections, CNT, Anarchism. 
"Las elecciones que se avecinan... no resolverán el problema de fondo planteado entre la reacción y la revolución... El obrero que vota es siempre conejillo de Indias de los partidos... No puede ni debe interesarle ni la República del 14 de abril ni la del 19 de noviembre." Estos fragmentos del editorial de Solidaridad Obrera de 14 de febrero de 1936, condensan los mensajes que se repitieron en la prensa y los mítines de la CNT y la FAI durante la campaña electoral para las generales de ese año. Lo inminente de la apertura de las urnas, donde contenderían dos grandes coaliciones, el Frente Popular y las diversas candidaturas sustentadas por la CEDA, no varió un ápice su postura. Ese periódico estaba, el mismo día de los comicios, trufado de manifiestos, reseñas de mítines y artículos donde se hablaba de "farsa electoral", y se calificaba la propaganda de "chillonería inútil". El sufragio era "origen de nuestro dolor, zozobra y esclavitud" y "reacción del barbarismo gubernamental", y se defendía, literalmente, que antes que "suicidarse" votando, mejor era que el elector lo hiciera de verdad, tirándose por un barranco ${ }^{1}$.

Esto no suponía una novedad, habida cuenta de que el rechazo al sufragio y a las elecciones era parte de las tradiciones antipolíticas de la CNT y la FAI ${ }^{2}$, por más que en la práctica lo poliédrico de los movimientos anarquistas y anarcosindicalistas, "la diversidad y heterogeneidad del conjunto de utopías libertarias" y lo descentralizado de la organización sindical, permitieran interpretaciones heterodoxas. De hecho, las elecciones de la Segunda República constituyeron ejemplos de lo uno y de lo otro. En 1933 y, como se verá, también en 1936 hubo campaña abstencionista. Y en ambas hubo organizaciones anarcosindicalistas que tácitamente invitaron a sus afiliados a apoyar a determinadas candidaturas. Por no hablar de la cantidad no despreciable de militantes que desobedecían por propia iniciativa cualquier consigna abstencionista ${ }^{4}$. Lo que parece indicar que, más que un dogma, para no pocos anarcosindicalistas el abstencionismo era una táctica que podía aplicarse en función de sus propios intereses 5 .

1. Solidaridad Obrera: 14 y 16-II-1936.

2. Este "antipoliticismo" se entendía como rechazo de toda concomitancia con las instituciones burguesas. Lo que suponía oponerse a todos los partidos y al parlamentarismo y, por ende, propugnar el abstencionismo electoral. BERNECKER, Walter, "Acción Directa y violencia en el anarquismo español", Ayer, no 13 (1994), p. 149.

3. TAVEra, Susanna, "La historia del anarquismo español", Ayer, no 45 (2002), p. 36.

4. Vilanova, Mercedes, "Anarchism, Political Participation, and Illiteracy in Barcelona between 1934 and 1936", American Historical Review, vol. 97, no 1 (1992), pp. 96-120. Villa García, Roberto, La República en las Urnas, Madrid, Marcial Pons, 2011, pp. 269-274. KelSEY, Graham, Anarcosindicalismo y Estado en Aragón, Zaragoza, Gobierno de Aragón, 1994, p. 313. Pereira, Dionisio, A CNT na Galiza, Santiago, Laiovento, 1994, p. 126.

5. RÜDIGER, Helmut, El anarcosindicalismo en la revolución española, Barcelona, CNT, 1938, p. 12. 
Esto dejaba entrever que, aparte de los vínculos que los sindicatos trababan con su pertenencia a la CNT, a escala local podían existir alianzas con determinados sectores políticos. Y era así por la misma idiosincrasia del movimiento sindical. Para valorar el impacto real de las consignas abstencionistas, no debe olvidarse la cantidad de militantes que formaban parte de la CNT por consideraciones utilitarias y profesionales, sin asumir el ideal ácrata. A los que cabría sumar los anarcosindicalistas que no se sentían impelidos por estas consignas, al discurrir que el activismo político y la intervención en la esfera institucional no incumbían a la $\mathrm{CNT}^{6}$.

Pero que se relativice no quiere decir que la actitud de este sindicato ante las elecciones fuera irrelevante. Que no pudiera controlar el voto de todos sus afiliados no obsta para que la postura que adoptase el comité nacional o los regionales no influyese en los cuadros de la organización. Amén de aquellos militantes cenetistas cuya única vía de politización había sido su sindicato y enfocaban la política a través de las concepciones asimiladas en él ${ }^{7}$. Aunque la CNT no fuese el factor que decidía los resultados electorales en la Segunda República ${ }^{8}$, debía ser tenida en cuenta en las circunscripciones donde contaba con arraigo, y el triunfo de una u otra candidatura se presentaba especialmente incierto. De ahí el interés que suscitaba entre los diversos partidos la postura que adoptase el anarcosindicalismo ante las elecciones.

Las generales de 1936 no podían constituir una excepción. Más bien lo contrario, habida cuenta no sólo del equilibrio entre los contendientes, sino del carácter trascendental, a suma cero, que adquirió la disputa entre las diversas candidaturas 9 . Además, en febrero de 1936 los Consejos de Guerra y los Tribunales de Urgencia no habían finalizado su labor, con lo que un número indeterminado de presos aún esperaban ser juzgados por su participación en la insurrección de octubre de 1934. Otros habían comenzado a cumplir la pena

6. UCELAY, Enric, La Catalunya Populista, Barcelona, La Magrana, 1982, pp. 102-104. CASANOvA, Julián, De la calle al frente. El anarcosindicalismo en España, Barcelona, Crítica, 1997, p. 83. Molas, Isidre, El sistema de partits polítics a Catalunya, Edicions 62, Barcelona, 1972, p. 132.

7. Aquí se entiende politización como un proceso por el que los ciudadanos conectan sus intereses individuales a causas políticas colectivas y asumen sus postulados ideológicos, tomando conciencia de que su satisfacción se ventila más allá de la política local. Vid. FORD, Caroline, "The use and practice of tradition in the politicization of rural France during the nineteenth century", en VV.AA., La Politisation des campagnes au XIX siècle, Roma, EFR, 2000, p. 328.

8. Tuñón de Lara, Manuel, "La Segunda República", en VV.AA., La Crisis del Estado: Dictadura, República, Guerra, Labor, Barcelona, 1981, p. 215.

9. Tusell, Javier, Las elecciones del Frente Popular en España, Madrid, Edicusa, 1971, vol. 1, pp. 196-219. 
impuesta, y varios militantes de los partidos obreros habían marchado al extranjero para eludir su detención. Las izquierdas coaligadas en el Frente Popular hicieron causa común para conseguir la amnistía de todos ellos, amén de la readmisión para los huelguistas despedidos durante esos días.

Precisamente sobre la amnistía se han construido los relatos que defienden un cambio de actitud por parte de la CNT y la FAI ante esas elecciones. Las memorias e historias de los autores anarquistas coinciden en que, a pesar de que formalmente no abandonaron su apoliticismo, el tono de las resoluciones de sus organismos directivos fue más ambiguo y formulario que en 1933. Esto habría sido fruto de la actitud de la militancia cenetista y de una parte de sus dirigentes favorable a apoyar al Frente Popular y conseguir así la libertad de los presos. La ambivalencia de la CNT y la FAI habría facilitado que se dejara en "libertad de acción" a sus afiliados para que pudieran votar, y permitido que no hubiera campaña abstencionista. Ambos hechos habrían resultado vitales para que en 1936 triunfaran las izquierdas, de la misma forma que el abstencionismo de 1933 las hizo fracasar ${ }^{10}$. Junto a la necesidad de libertar a los presos, el giro de los anarcosindicalistas en 1936 también habría tenido que ver, según estos autores, con una cierta solidaridad con las otras izquierdas obreras ante la "amenaza fascista y reaccionaria" que representaba la CEDA. Abad de Santillán recordaba que "la abstención era el triunfo de Gil Robles, y... la restauración de los viejos poderes monárquicos y clericales", ergo "el triunfo de las derechas esta vez sería la implantación de un régimen fascista en España por vía legal"11.

10. Abad de Santillán, Diego, Memorias, Barcelona, Planeta, 1977, p. 254. Por entonces destacado miembro de la FAI y director de Tierra y Libertad, Abad afirmó que, con el asenso de casi todas las organizaciones de la CNT, no se hizo campaña abstencionista y que "ni en las publicaciones de la F.A.I. ni en los diarios y periódicos de la C.N.T... se encontrará recomendaciones para no votar." Vid. también LORENZO, César M., Les anarchistes espagnols et le pouvoir, París, Seuil, 1969, p. 91; Peirats, José, La CNT en la revolución española, París, Ruedo Ibérico, 1971, vol. 1, p. 111; García Oliver, Juan, El eco de los pasos, París, Ruedo Ibérico, 1978, p. 168; Gómez CASAs, Juan, Historia de la FAI, Bilbao, Zero, 1977, p. 210; e Historia del anarcosindicalismo español, Bilbao, Zero, 1978, p. 239.

11. Abad de SAntillán, Diego, ¿Por qué perdimos la guerra?, Buenos Aires, Iman, 1940, p. 36; y De Alfonso XIII a Franco, Buenos Aires, TEA, 1974, p. 288. Dirigentes de los Sindicatos de Oposición como Juan Peiró llevaban meses insistiendo en ello, como constatan BRAdEMAS, John, Anarcosindicalismo y revolución en España, Barcelona, Ariel, 1973, p. 155; y Julí́, Santos, Orígenes del Frente Popular en España, Madrid, Siglo XXI, 1979, pp. 131-132. La amplitud semántica con que anarquistas y anarcosindicalistas entendían el fascismo es bien analizada en MACARRO, José Manuel, La Utopía Revolucionaria: Sevilla en la Segunda República, Sevilla, Caja de Ahorros, 1985, pp. 355-356; y Álvarez Chillida, Gonzalo, "Negras tormentas sobre la República", en Rey Reguillo, Fernando (dir.), Palabras como puños, Madrid, Tecnos, 2011, pp. 93-97. 
Aunque contextualizando el giro de la CNT en función de sus necesidades estratégicas y tácticas, y con una evaluación más racional de su influencia electoral, buena parte de la historiografía asumió estas tesis. Grosso modo, coincide en que la CNT y la FAI habrían apoyado solapadamente al Frente Popular no iniciando una propaganda abstencionista a gran escala. La disminución de la abstención y el aumento del voto a las izquierdas así lo atestiguarían ${ }^{12}$. Sin romper con esa percepción general, algunos estudios revelaron matices en la actitud de algunos comités regionales y locales de la CNT. De modo que mientras unos insistieron en proclamar la inutilidad del voto, aunque con un tono más moderado que en 1933, otros ni se esforzaron en disuadir a sus afiliados de que participaran en las elecciones. De esto último resultarían ejemplos convincentes la CNT asturiana o la Federación Local de Zaragoza ${ }^{13}$.

Sólo el trabajo de José Manuel Macarro se desmarca de los anteriores. En el contexto que estudia, Sevilla, afirma que sí hubo campaña abstencionista en 1936 y que esta no reflejó, siquiera sutilmente, un cambio de posición de los anarcosindicalistas hacia las "izquierdas políticas". Cierto que la propaganda abstencionista no alcanzó gran intensidad, pero Macarro aduce que no fue tanto producto de las vacilaciones de los directivos de la CNT a causa de la amnistía o el peligro fascista, sino de la debilidad de la organización sevillana a principios de $1936^{14}$.

La relativa importancia que suele otorgarse a la postura de la CNT ante las elecciones, la capacidad de influir en sus cuadros y militancia más comprometida, y la relevancia de las elecciones del Frente Popular como objeto de estudio, justifican un análisis del tipo de propaganda que anarquistas y anarcosindicalistas desarrollaron en 1936. Este trabajo pretende aclarar el contexto y el significado de las resoluciones de la CNT y de la FAI respecto de los comicios de ese año y cómo se plasmaron en la propaganda realizada. Esto es, se tratará el desarrollo de la campaña abstencionista de 1936, y si sus motivos e intensidad respondieron o no al objetivo de coadyuvar al triunfo del Frente Popular, o al menos de no entorpecerlo. Se atenderá de forma especial a analizar en qué medida puede hablarse de una convergencia de intereses entre la

12. Marcaron la pauta los, por lo demás, valiosos estudios de TuSELL, Javier, Las elecciones..., pp. 221-226; Brademas, John, Anarcosindicalismo..., pp. 162-163; Payne, Stanley G., La revolución española, Barcelona, Ariel, 1971; y Juliá, Santos, Orígenes..., p. 133.

13. BARRIO, Ángeles, Anarquismo y anarcosindicalismo en Asturias, Madrid, Siglo XXI, 1988, p. 414; CASANOVA, Julián, Anarquismo y revolución en la sociedad rural aragonesa, Madrid, Siglo XXI, 1985, p. 61; CARo, Diego, La II República en Cádiz, Cádiz, Diputación, 1987, pp. 253-255; y PereIRA, Dionisio, A CNT..., p. 126. Eso sí, la mayoría de los estudios provinciales apenas refieren la postura de la CNT en sus respectivos territorios.

14. Macarro, José Manuel, La Utopía..., pp. 442-443. 
CNT y el Frente Popular en 1936 alrededor de la amnistía y el peligro fascista, y si ambas cuestiones eran entendidas de la misma forma por los dirigentes anarcosindicalistas y los de la coalición de izquierdas. No se abordarán, al menos de forma detallada, las discusiones habidas en los organismos directivos de la CNT y la FAI, bien conocidas gracias a los trabajos citados; ni tampoco los efectos de la campaña abstencionista sobre los resultados electorales, cuestión que merecería otro artículo.

No es ociosa una advertencia sobre las fuentes primarias. La campaña se ha reconstruido básicamente a través de la prensa anarcosindicalista disponible, y no sólo la de mayor tirada. También se han consultado los escasos periódicos de difusión local que continuaban publicándose entre finales de 1935 y principios de 1936. Como se sabe, la suspensión de garantías constitucionales y la desarticulación y dispersión que sufrieron las organizaciones de la CNT y la FAI entre 1934 y 1935, afectaron a la mayoría de sus periódicos, entre ellos CNT que no reaparecería hasta la Guerra Civil. Por desgracia, los fondos de ambas organizaciones ayudan poco a suplir esta laguna ${ }^{15}$. De todas formas, la pervivencia de los órganos de prensa más representativos y su notable implicación para difundir artículos, manifiestos, discursos y reseñas de actos públicos ha servido al propósito que se pretendía: obtener una valiosa panorámica del desarrollo de la propaganda cenetista, del significado de sus lemas y de la controversia con otras organizaciones políticas.

\section{¿Un acercamiento al Frente Popular?}

El 28 de enero de 1936, la conferencia regional de los sindicatos cenetistas de Cataluña aprobó la ponencia que debía definir su postura ante las elecciones. Suponía la ratificación de los principios "apolíticos" de la CNT, y un espaldarazo a la iniciación de una campaña "antipolítica y abstencionista" que mostrase a los trabajadores "la ineficacia del voto", pues este no aseguraba la contención del fascismo o la libertad de los presos. Pero podían apreciarse dos matices respecto a 1933. El primero, la afirmación de que la propaganda debía hacerse "sin estridencias ni demagogias", lo que suponía calificar así la campaña de aquel año. Y el segundo, que no se hiciese referencia alguna a un movimiento

15. CNT, en CHECA, Antonio, Prensa y partidos políticos durante la II República, Salamanca, Universidad, 1989, p. 77. En los diversos archivos consultados no se han encontrado actas de reuniones regionales de la CNT en que se abordase la cuestión electoral, exceptuando Cataluña. La galaica, de diciembre de 1935, no la trató, y la levantina, de febrero de 1936, se remitió a las instrucciones del Pleno nacional. Igualmente parcas son las actas del Congreso nacional de mayo de 1936, donde sólo se refieren recriminaciones a militantes de Gijón y Zaragoza por no secundar la consigna abstencionista. 
revolucionario que, como el de diciembre de 1933, se desencadenara justo después de las elecciones ${ }^{16}$.

No muy distinta fue la ponencia electoral aprobada el 29 de enero por el pleno de regionales de la CNT. Se refrendó la oposición a los "procedimientos parlamentarios y democráticos burgueses" y, por extensión, a todos los partidos, "sin inclinarse a la derecha ni a la izquierda, impulsados por arranques pasionales." Pero se ratificaban unas conclusiones aprobadas en mayo de 1935 en el sentido de rebajar el tono de la campaña abstencionista de 1933 y procurar que la propaganda no cayera en "demagogias perniciosas". Tampoco hubo referencia a una insurrección como consecuencia del resultado electoral, algo que se repitió en la ponencia aprobada por el pleno peninsular de la FAI el 1 de febrero. En una declaración más contundente ésta ratificó su posición "antiparlamentaria y por ende antielectoral". Claro que los "faístas" trataron poco las elecciones, centrados como estaban en diseñar un flamante Comité de Preparación Revolucionaria para articular "las fuerzas orgánicas insurreccionales", y proveerse de "material de combate para la revolución"17.

Estos matices respecto a las resoluciones de 1933 han sido interpretados como una especie de declaración de no beligerancia hacia el Frente Popular. En realidad, esta percepción es fruto de considerar la campaña abstencionista de 1933, que es la referencia de comparación usualmente utilizada, únicamente en función de las relaciones de la CNT con los gobiernos "social-azañistas", sin considerar que esa campaña respondía ante todo a lógicas internas del propio sindicato, impuestas por la previa adopción de la táctica insurreccional. Por tanto, el objetivo de la propaganda abstencionista de 1933 no había sido la de castigar a Azaña y los socialistas privándoles del apoyo de los electores anarcosindicalistas, como consecuencia de la supuesta instrumentalización de la legislación laboral en beneficio de la UGT, o por la represión de los movimientos insurreccionales. En realidad hacía poca falta. Precisamente eran estas razones las que abonaban que, a priori, el PSOE y la izquierda republicana pudieran esperar poco apoyo anarcosindicalista en las elecciones generales de 1933, con o sin propaganda abstencionista. La CNT llevaba meses martilleando a sus militantes con la competencia desleal y el "enchufismo" practicados por los socialistas

16. CRT DE CATAluña, Memorias de la Conferencia Regional extraordinaria, Barcelona, 1936, pp. 94-101.

17. Actas del Pleno Nacional de Regionales de la CNT, Madrid, 1936; y Memoria del pleno peninsular de la FAI, Barcelona, 1936. Centro Documental de la Memoria Histórica (CDMH), FA-00061 y F-03713, respectivamente. Dictámenes, en Solidaridad Obrera, 2 y 7-II-1936. 
desde el Ministerio de Trabajo, además de con los encarcelamientos y deportaciones de anarquistas y, por supuesto, con Casas Viejas ${ }^{18}$.

De hecho, si en 1933 la CNT hubiera decidido orientar el voto de sus seguidores, los beneficiarios no hubieran sido las izquierdas sino el Partido Radical y sus aliados electorales de la extrema izquierda republicana (federales, social-revolucionarios, Izquierda Radical-Socialista). A pesar de las notables divergencias ideológicas, en la campaña de 1933 los radicales coincidieron con la CNT en oponerse al creciente control del mercado de trabajo por la UGT en algunas provincias, y en abjurar de los excesos represivos de los gobiernos de Azaña. Además, Lerroux ofreció una amplia amnistía dirigida no sólo a los comprometidos en la Sanjurjada, sino también a los anarquistas encarcelados durante el primer bienio. Por eso, en la medida en que la CNT pudiera influir en el abstencionismo de los suyos, lo coherente era que los que pretendían ganar su voto fuesen los principales damnificados ${ }^{19}$.

La campaña abstencionista de 1933 no estuvo orientada tanto a penalizar a las izquierdas como a legitimar una insurrección post-electoral apartando del proceso político a la "clase trabajadora" en general y a la militancia anarcosindicalista en particular. Uno de los impulsores máximos de esta estrategia, Buenaventura Durruti, lo había revelado con naturalidad: "Si el día 20 hemos conseguido una abstención electoral de más del 50 por 100, le diremos al Gobierno: ¡Basta ya! ¡No nos representáis! Y si controlamos un millón de trabajadores que tienen en sus manos la industria y el transporte, la revolución estará hecha con sólo querer"20. Lo intenso de la campaña de 1933 se explica porque una parte importante de la CNT se había marcado como estrategia la apertura de un nuevo proceso revolucionario a través de la táctica insurreccional, en una dinámica "provocación-represión" que ese sector, aleccionado por la FAI, pensaba que se retroalimentaría en su beneficio ${ }^{21}$. El vínculo entre la campaña abstencionista y la insurrección posterior no vino sólo anudado por

18. Casanova, Julián, De la calle..., pp. 54-60. Villa García, Roberto, La República..., p. 248. Macarro, José Manuel, "Sindicalismo y política", en Juliá, Santos (ed.), Política en la Segunda República, Madrid, Marcial Pons, 1995, pp. 143-146.

19. Villa García, Roberto, La República..., pp. 354-357.

20. Solidaridad Obrera, 14-XI-1933. Lo volvió a afirmar en 1936: "la C.N.T. hizo la campaña abstencionista del 33 porque quería ir al hecho revolucionario." Paulino Díez, dirigente histórico del sindicato, confirmó que: "la abstención electoral no se hizo para que triunfaran las derechas... la C.N.T. cumplió con su deber, requirió las armas, se situó en la calle y se vio sola." Ibid., 8 y 11-II-1936.

21. UCelay, Enric y TaVera, Susanna, "Una revolución dentro de otra: la lógica insurreccional en la política española", Ayer, no 13 (1994), pp. 115-146. Villa GarCía, Roberto, "La CNT contra la República: la insurrección revolucionaria de diciembre de 1933", Historia y Política, no 25 (2011), pp. 177-205. 
el compromiso de los anarcosindicalistas, formalizado en su Pleno de Regionales de 2 de noviembre de 1933, de desencadenar esta última si "triunfasen las tendencias fascistas" en las elecciones ${ }^{22}$. También se notó con ahínco en una propaganda que hacía apología de la violencia y llamamientos a la preparación del movimiento revolucionario. Y en la interpretación extrema de lo que entonces se llamó "abstención activa", que se tradujo en el boicot violento de las elecciones. El órgano de prensa del sindicato, CNT, apeló a que sus militantes se armaran e impidieran a los electores acudir a votar, destruyendo papeletas y urnas electorales, y agrediendo a candidatos y miembros de mesa. Que no era mera retórica se demostró en provincias como Madrid, Barcelona, Badajoz, Cádiz, Ciudad Real, Málaga, Oviedo y Valencia, donde menudearon este tipo de acciones durante todo el proceso electoral ${ }^{23}$.

A comienzos de 1936 los recursos humanos, organizativos y económicos de la CNT eran más exiguos que en 1933. Tras octubre de 1934, la clausura de sus centros, la dispersión de sus sindicatos, la baja en las cotizaciones y la detención de destacados militantes habían diezmado la organización, y sólo a partir del segundo semestre de 1935 comenzaron las labores de reconstrucción $^{24}$. En esas condiciones, las posibilidades de desempolvar la táctica insurreccional se antojaban nulas. De esto se habían apercibido incluso los dirigentes que dos años antes habían apostado firmemente por esa táctica, entre ellos los más proactivos de las regionales aragonesa y catalana.

Por tanto, eran las circunstancias, más que un giro táctico, las que imponían un compás de espera ante las elecciones de 1936. Dado que no era posible comprometerse a nuevas acciones insurreccionales, no podía repetirse una campaña abstencionista como la de $1933^{25}$. Por tanto, la renuncia a una propaganda "estridente" y "demagógica" no tenía por qué significar necesariamente una rebaja de las críticas a los partidos de izquierda. Sólo suponía la negativa a entender la campaña abstencionista como prólogo y catalizador de una insurrección en ciernes. Como apuntaba Solidaridad Obrera, en 1936 las circunstancias aconsejaban "una propaganda abstencionista, pero no violenta..."

Es verdad que, en principio, una crítica menos acerada podía beneficiar indirectamente al Frente Popular, porque el recuerdo de los sucesos de 1934

22. BRAdEMAS, John, Anarcosindicalismo..., p. 108.

23. CNT, 16 y 17-XI-1933. Violencias, en Villa GarCía, Roberto, La República..., pp. 302-307, 321 y 427.

24. Casanova, Julián, De la calle..., p. 139. Macarro, José Manuel, La Utopía..., p. 440.

25. Casanova, Julián, De la calle..., p. 143, ya subrayó que lo que diferenciaba al abstencionismo de 1933 respecto al de 1936 no fue la cuestión de los presos, sino que en 1936 "a nadie se le ocurrió anunciar la revolución para el día siguiente de las elecciones".

26. Solidaridad Obrera, 29-I-1936. 
y los presos de Octubre estaba más fresco entre la militancia cenetista que Bata y Casas Viejas. Pero la mayoría de sus dirigentes se encargaron de que no olvidaran lo que habían supuesto para la CNT los gobiernos del primer bienio. Que no hubo asomo de acercamiento entre este sindicato y el Frente Popular lo prueba, desde luego, el rechazo contundente a las sugestiones de colaboración electoral que procedían de las izquierdas, aún las reducidas solamente a obtener una amnistía para los "presos políticos y sociales" 27 .

No se reeditó lo sucedido en las elecciones municipales y generales de 1931, cuando Solidaridad Obrera había llegado a decantarse por un apoyo velado a las candidaturas republicanas, y la CNT mantenía relaciones con políticos de la Esquerra, republicanos federales y social-revolucionarios ${ }^{28}$. En 1936, hubo reafirmación de "antipoliticismo" y negativas a cualquier contacto oficial u oficioso con el PSOE o la izquierda republicana. Ni siquiera la inclusión de candidatos "próximos" a la CNT como Ángel Pestaña o el abogado sindicalista Benito Pabón relajó esta posición ${ }^{29}$. Cierto que, a instancias de la regional catalana, se barajó la posibilidad de ofrecer un pacto de alianza revolucionaria a la UGT pero, de forma parecida a la propuesta de febrero de 1934, era de sindicato a sindicato, para perseverar en la vía insurreccional, y siempre que la UGT rompiese "toda colaboración política y parlamentaria con el régimen burgués". Esto es, nada que significase una colaboración electoral ${ }^{30}$.

A pesar de los intentos de algunos destacados militantes por reconducir la posición de la CNT, y no entorpecer un posible triunfo de las izquierdas ${ }^{31}$,

27. Estos requerimientos oficiosos, pues no procedían de las directivas de los partidos del Frente Popular, fueron numerosos en prensa y mítines, y algunos tan conocidos como los de Largo Caballero en enero de 1936. Ejemplos, en El Socialista, 25-XII-1935, y 3, 11 y 14-I-1936; Mundo Obrero, 8-I-1936; La Batalla, 24-I-1936; y El Sindicalista, 11 y 18-I-1936.

28. Molas, Isidre, El sistema..., pp. 130-131. Álvarez Chillida, Gonzalo, "Negras...", pp. 49-62. Macarro, José Manuel, La Utopía..., p. 443.

29. Solidaridad Obrera, 17-XII-1935; y 8 y 12-II-1936.

30. Ibid., 28-1-1936. Casanova, Julián, De la calle..., p. 134. Macarro, José Manuel, "Sindicalismo...", p. 162. En realidad, había razones para pensar que la CNT no estaba muy interesada en el pacto y que con la propuesta más bien buscaba desacreditar el pedigrí revolucionario de la UGT. Vid. BRADEMAS, John, Anarcosindicalismo..., pp. 160163; y UCELAY, Enric, La Catalunya..., p. 245.

31. Abad de Santillán, Diego, ¿Por qué..., p. 36; y Memorias, p. 253, afirma que promovió una reunión de prominentes afiliados de la CNT y la FAI, que acordaron evitar que Solidaridad Obrera y Tierra y Libertad hicieran "bandera de la abstención". Las gestiones de Abad se añadían al supuesto acuerdo que alcanzaron García Oliver, Durruti y Ascaso con José Antonio Trabal, representante de Companys, por el que aquéllos se comprometían "a impedir que se realizase propaganda antielectoral". Si triunfaban las izquierdas, Companys suministraría armas a los cenetistas. Vid. GarCía Oliver, Juan, El eco..., pp. 167-168. UCELAY, Enric, La Catalunya..., p. 245, cuestionó la eficacia de estas gestiones. 
las discusiones habidas en la regional catalana, apenas reflejaron disonancias sobre la conveniencia de prescindir de una campaña "antipolítica" en beneficio del Frente Popular. Los republicanos de izquierda se mostraban ansiosos de que al menos Solidaridad Obrera cesara de "invitar a los obreros a que no voten" ${ }^{\prime 2}$. Si como apunta Peirats, una parte de los dirigentes catalanes promovió la convocatoria de la conferencia regional con la esperanza de proscribir cualquier referencia a la abstención electoral ${ }^{33}$, la mayoría de los delegados pronto les sacaron del error. Incluso el mismo planteamiento de la cuestión estuvo a punto de suponer la censura de la dirección. Por si fuera poco, una misiva enviada por el Secretariado de la AIT, supuestamente redactada por un Eusebio Carbó al tanto de la maniobra, reforzó las posiciones antielectorales a ultranza. Sintomático del ambiente era que, mientras se discutía esta cuestión, Solidaridad Obrera publicara un artículo durísimo contra los dirigentes de los partidos obreros, que "jamás han tenido, tienen ni tendrán... otro deseo que el de comer a dos carrillos... sin importarles un comino la emancipación de la clase trabajadora." Las numerosísimas intervenciones contra cualquier invitación solapada a ir a votar, y a favor de hacer campaña abstencionista contra todos los políticos por igual, sepultaron las más tibias del delegado del sindicato de Oficios Varios de Tarragona que, apoyado por unos pocos, planteó la posibilidad de una campaña contra la política, "pero no decir no votar." Incluso una tímida propuesta que hablaba de "libertad de decisión" de los militantes de la CNT fue borrada de la ponencia electoral ${ }^{34}$.

Pocos días después, el pleno peninsular de la FAI ratificó estas posiciones. Las regionales del Centro, Levante y Cataluña mostraron su disposición, incluso, a repetir una campaña como la de 1933, a lo que Asturias y Aragón se opusieron porque podría perjudicar a los presos y debilitar las organizaciones, máxime cuando la CNT y la FAI no estaban en condiciones "de hacer la revolución social si triunfan las derechas." La alternativa fue una amplia propaganda que, como muestra el dictamen final de la FAI, sirviera para alentar la abstención, y no para apoyar al Frente Popular ${ }^{35}$.

La postura oficial de la CNT la estableció definitivamente su comité nacional en un manifiesto que explicaba el dictamen aprobado en el Pleno de Regionales, y que hizo circular a menos de dos semanas de las elecciones. En él

32. El Sol, 28-I-1936.

33. Peirats, José, De mi paso por la vida, Barcelona, Flor del Viento, 2009, p. 285.

34. CRT de Cataluña, Memorias de la Conferencia..., pp. 56-72 y 83-94. Solidaridad Obrera, 28 y 29-I-1936; Ahora, 29-I-1936; y La Vanguardia, 30-I-1936. PeIRATS, José, La CNT..., pp. 107-109.

35. Las actas vienen transcritas en Gómez CASAS, Juan, Historia de la FAI, p. 206. 
tampoco se atisbó auxilio alguno, explícito o tácito, al Frente Popular. Por el contrario, el comité parecía inclinarse por un triunfo de las derechas, ya que aunque con ellas en el poder "se extremarían los medios represivos", no podrían "abatir de una manera fulminante a las fuerzas de oposición" y provocarían, entonces, "un nuevo alzamiento de todos los enemigos de la dictadura. A eso tienden nuestras preocupaciones y el estímulo que propagamos abiertamente." Mientras que si triunfaban las izquierdas, el movimiento obrero sería reprimido, dando tiempo a que "la España negra se discipline con programa y milicias, en tanto que el proletariado... descuidado en la propia preparación, por haber depositado confianza en una tutela gubernamental impotente, se vería impedido para contraatacar, y el aplastamiento sería definitivo." Paradójicamente, la reafirmación de los principios apolíticos evitó que estos argumentos se concretaran en un apoyo a la CEDA y sus aliados, que parecían ser los que posibilitaban la revolución. Desde luego, el comité nacional dejó claro a qué debían atenerse las izquierdas: "Dense por contestados quienes ingenuamente soñaron con nuestro auxilio directo en la reposición de la farsa electoral" ${ }^{36}$.

\section{Una campaña abstencionista}

Con matices, los manifiestos publicados por las Regionales y las Federaciones Locales más importantes reprodujeron con fidelidad el mensaje. "Frente a todos estamos en la contienda electoral, con nadie pactamos, ni pactaremos", anunciaba la de Sevilla, porque con todos los partidos "tenemos viejas cuentas que saldar." En Alicante, otro manifiesto de la CNT local recordaba las crueldades del primer bienio y llamaba a la abstención contra el "conglomerado llamado Frente Popular." A dos días de las elecciones, la Federación Local de Sindicatos Únicos de Barcelona, después de atacar las inconsecuencias revolucionarias de Largo Caballero, insistió en que "no iremos a las urnas, no aconsejaremos a los trabajadores que acudan a ellas." Hasta en Asturias, donde pareció que la CNT no entorpecería un triunfo del Frente Popular, hubo militantes que repartieron folletos criticando a los socialistas y pidiendo que no se votara a las izquierdas ${ }^{37}$.

Este tipo de retórica fue usada incluso por dirigentes que, como Abad de Santillán, negaron posteriormente haber participado en la campaña abstencionista. Abad escribió editoriales en Tierra y Libertad, órgano de la FAI, en que equiparaba a izquierdas y derechas como las dos caras de un mismo régimen

36. El manifiesto, en Solidaridad Obrera, 6-II-1936.

37. Ibid., 14-II-1936. Macarro, José Manuel, La Utopía..., p. 443. ABC, 6-II-1936. El Debate, 4-II-1936. 
capitalista tan feroz como fracasado. Ante un eventual triunfo de la izquierda, sostenía que: "el pueblo advertirá, una vez más, que el cambio de los personajes del retablo gubernativo no aumenta su ración escasa... Y comprenderá que no valía la pena... favorecer la reconquista del poder por quienes no han hecho otra cosa... que reprimir a sangre y fuego... el derecho a la vida y a la libertad"38. Tampoco en los mítines hubo apelaciones sutiles a desobedecer las resoluciones abstencionistas de los órganos directivos. Sólo en Teruel y Zaragoza, pocos días antes del Pleno de regionales de la CNT, Miguel Abós habló de "dejar en libertad" a los militantes que quisieran expresar públicamente su apoyo a las izquierdas ${ }^{39}$.

Otros casos, sin embargo, no están tan claros. Las reseñas de los discursos de Durruti, que según algunas memorias alentó a votar a las izquierdas, invitan a pensar lo contrario. Por ejemplo, en sus mítines de Calahorra, Haro y Logroño condenó ante un grupo de ugetistas que se utilizase a los muertos de Asturias para hacer política. Incluso se permitió aconsejarles "que no se fíen de sus jefes", pues los republicanos de izquierda con quienes ahora se aliaban "no han dado otra cosa al pueblo que fusiles, ametralladoras y guardias de Asalto." Y que ni se les ocurriera pedir a la CNT "lo que no puede darles ni conceder... a vuestra petición de votos os contestaremos con un NO rotundo" 40 . Otro de los que posteriormente sería criticado por aparecer en un acto junto un candidato del PSOE fue el dirigente de la CNT andaluza Vicente Ballester. No obstante, su presencia no parecía injustificada ya que no era un mitin electoral, sino un acto sindical "contra la pena de muerte, el fascismo y las leyes represivas" en el que participaban UGT, CNT y los Sindicatos Autónomos. Además, el candidato socialista, Rafael Calbo, concurría como dirigente ugetista. Más aún, si la presencia de Ballester debía suponer un espaldarazo al Frente Popular, lo cierto es que éste no se dio por enterado. Antes al contrario, desalentó a su auditorio de acudir a las urnas: "Nosotros no creemos en la política... El manifiesto de las izquierdas no responde a las necesidades del pueblo." Y se permitió criticar su "alicorta amnistía"41.

Los casos de Abós, Durruti y Ballester son los que se han presentado como ejemplos de heterodoxia pro-izquierdista, pero en realidad parece que sólo el primero hizo declaraciones equívocas, y días antes de las resoluciones defini-

38. Tierra y Libertad, 7-I-1936. Más ejemplos en Ibid., 24 y 31-I-1936.

39. El Socialista, 8 y 23-I-1936; y Heraldo, 22-I-1936.

40. Solidaridad Obrera, 7, 8 y 11-II-1936. Al contrario que Abad de SANTILlán, Memorias..., p. 252, Abel Paz (Durruti en la revolución española, Barcelona, Laia, 1986, pp. 113-118) resaltó su actitud contraria a cualquier aproximación al Frente Popular.

41. Solidaridad Obrera, 13-II-1936. 
tivas de la $\mathrm{CNT}^{42}$. Además, las reseñas que sobre otros mítines reprodujo la prensa, anarcosindicalista o no, revelan que pocos le emularon. Al contrario, el resto de los oradores predicó abiertamente el abstencionismo. El matiz diferenciador es que mientras unos dirigentes de la CNT se atenían de forma más rigurosa a lo prescrito en los dictámenes, bajando el tono respecto a 1933, otros, sobre todo los vinculados a la FAI, abundaron en descalificaciones tan duras como las de entonces. "No podemos fiarnos de los revolucionarios políticos", diría José España, de la Regional Levantina, en Almazora (Castellón), "porque... es el Parlamento quien conquista a estos falsos revolucionarios, para servir la causa despótica del capital." Abundando en el argumento, Jaime Escalé atacó a Largo Caballero en Salamanca, pues "dice que la expropiación hay que hacerla violentamente en la calle" al tiempo se alía con los republicanos, lo que demostraba que su "campaña demagógica... sólo se hacía para cazar incautos". "Ni nos inclinamos a un lado ni a otro", sentenció José Sabín, de la Regional Andaluza, en La Algaba (Sevilla): "Estamos... frente a todo lo que represente tiranía y opresión, que es estar frente al capitalismo y al Estado." "El día que la C.N.T. y el anarquismo", afirmó Manuel Pérez en un mitin conjunto con García Oliver y Federica Montseny en Barcelona, "colaboren directa o indirectamente en las luchas políticas, habrá desaparecido para siempre"43.

Es verdad que, en algunos mítines, los oradores cenetistas expresaron que su auditorio era libre de votar si lo deseaban. Pero frases como éstas salieron a la palestra sólo cuando asistían miembros de otras organizaciones obreras, sobre todo de UGT. Y acompañadas, además, de abundantes apelaciones a la inutilidad del sufragio y del parlamento. Manuel Pérez espetó a los afiliados de la Casa del Pueblo en Sitges y Reus: "Nosotros... no votamos. Vosotros podéis hacer lo que os plazca; después de las elecciones, veremos quién se equivocó." El proletariado podía ir a votar, sí, pero de qué servía si "votando a las izquierdas no mejorar[ía] la situación... del pueblo", como les recordaba Abós; si, como afirmó en diferentes localidades aragonesas Ballester: "la C.N.T. no cree en la democracia" pues era "necesario hacer la revolución social." Si alguien vota "que no se sienta luego defraudado" porque, como Miguel Chueca, de la Regional Aragonesa, afirmó ante un grupo de ugetistas en Santander, el sistema electoral es "perfectamente inútil"

42. Además, Abós acabó endureciendo su posición durante el mes de febrero, haciendo apología de la campaña de 1933. Ibid., 7-II-1936.

43. Ibid., 28-XII-1935, 26-I, y 6 y 8-II-1936. Esta pequeña muestra constituye un ejemplo de una campaña de propaganda más amplia, con decenas de mítines por toda España e imposibles de citar por razones de espacio, en la que los oradores de la CNT insistieron en criticar a la República y al Parlamento, en afirmar su equidistancia con izquier- 
Las críticas contra las izquierdas arreciaron con la publicación del manifiesto del Frente Popular. El diario de cabecera anarcosindicalista lo calificó de "reaccionario" y de "un engaño más", y se congratuló de que las siglas cenetistas no figurasen "en ese manifiesto, que humilla y envilece a quienes se dicen representantes de la clase trabajadora." Vicente Ballester llegó a preguntarse en Zuera (Zaragoza) cómo no se había retirado la representación obrera de la coalición de izquierdas. Con menos diplomacia, García Oliver afirmó en Igualada (Barcelona) que el manifiesto: "es tan mezquino... que él nos da la medida de las intenciones de los futuros gobernantes." Los ataques fueron aún más duros con el manifiesto del Front d'Esquerres de Cataluña, al que se calificaba de "bloque de impotentes". "El paraíso que nos prometen", comentó Solidaridad Obrera "es la vuelta al régimen autonómico, de tan funesta memoria para los trabajadores." Definía a los políticos de la Esquerra como "estos bravos técnicos de la rebelión que pusieron un enorme coraje para... escapar por las alcantarillas." Terminaba el comentario con dos apelaciones a la abstención, pues "poner la confianza en este frente de izquierdas es como querer retener el agua con las manos abiertas" 45 .

Esta postura desesperaba a los partidos de la izquierda obrera, que semanas antes habían esperado sacar a la CNT del abstencionismo. Para Ramón Magre, del POUM, el anarcosindicalismo actuaba "como lo hubiese hecho setenta o cien años atrás: inhibiéndose o peor aún, combatiendo la acción electoral". El Socialista titulaba un editorial advirtiendo que abstenerse suponía "votar a las derechas" y preguntaba a la CNT si era "táctica aconsejable dejar abandonados en los presidios a los camaradas caídos en las redadas de la reacción." "Abstenerse es un crimen... porque hacen el juego a la reacción", insistió el comunista José Díaz en Madrid. En varios mítines organizados por la coalición de izquierdas, llegó a afirmarse que la CNT y la FAI estaban "vendidas a la reacción". Quienes más irritados se mostraron fueron los afiliados del Partido Sindicalista que, en calidad de excenetistas, esperaban algún respaldo del anarcosindicalismo para contrapesar el enorme desequilibrio a favor del obrerismo marxista en el Frente Popular. De hecho, precisamente porque procedían de la CNT, captaron mejor los matices del mensaje anarcosindicalista. Si bien se felicitaban de que no se repitiera la campaña de 1933, recusaron los

das y derechas, en negarse a colaborar con las "izquierdas políticas" y en descalificar el falso revolucionarismo de Largo Caballero. La reiteración de estos mensajes fue continua, hasta el mismo día de las elecciones. Más ejemplos en los semanarios o publicaciones mensuales Campo Libre, 18 y 25-I, y 1 y 8-II-1936; y Tiempos Nuevos, 1-II-1936. Interesan también las ediciones de febrero de Brazo y Cerebro y Solidaridad. 44. Solidaridad Obrera, 5, 6 y 8-II-1936.

45. Ibid., 17 y 28-I, y 1 y 6-II-1936. 
lemas abstencionistas de los mítines cenetistas: "Los que en estos momentos", advertía su órgano de prensa, "hagan campaña de abstención, son... enemigos del proletariado." Como además la postura de la CNT se endureció con el paso de los días, los sindicalistas pasaron de esperanzadas peticiones de voto a constantes recriminaciones. Así, Solidaridad Obrera imitaba "a los monárquicos, a los caciques, a los clericales", mientras que la FAI era "responsable del estado ruinoso y calamitoso de la nave confederal" y los dirigentes de la CNT parecían "espíritus en quiebra" 46 .

Actitudes tan irreductibles comenzaron a crear problemas entre ugetistas y cenetistas. El 1 de febrero, Largo Caballero no pudo terminar su mitin en la sede de la Sociedad Obrera de Carcagente (Valencia). Varios cenetistas le increparon porque les pidió el voto y alentó a la participación en las elecciones. La trifulca fue tal que Caballero hubo de salir protegido del pueblo. Cuatro días más tarde, en Vich, varios asistentes a un mitin cenetista se marcharon insultando a Antonio Ortiz y García Oliver por propugnar el abstencionismo y atacar el manifiesto de las izquierdas. En un mitin en Bilbao, celebrado el día 10, Durruti fue sonoramente abucheado por el público socialista tras criticar a Prieto y Largo Caballero ${ }^{47}$. En Madrid, sendos tiroteos entre sus militantes se habían saldado, un mes antes, con un ugetista muerto y un afiliado de cada central heridos graves ${ }^{48}$. En este contexto, no era de extrañar que, cuando un periodista inquirió a Azaña sobre una posible participación de los cenetistas en las elecciones, éste le atajase con displiciencia: “¡Ah! ¿Van a votar a Gil-Robles?”49.

\section{La amnistía como indulto}

Mención especial merece la amnistía. Su reivindicación constante por la CNT durante la campaña de 1936 constituyó el punto de contacto más importante de los anarcosindicalistas con el Frente Popular. Además, por su carga sentimental, la amnistía era un factor de movilización poderoso y una causa capaz de solidarizar a las diferentes organizaciones obreras. La prensa de la época y buena parte de la historiografía la consideraron una coyuntura lo suficientemente eficaz como para romper el abstencionismo anarquista. Los propios cenetistas reconocían la habilidad con que los partidos del Frente Popular hicieron bandera de la amnistía. Como destacó el que sería su secretario general pocos

46. Ibid., 30-I, 7 y 15-II-1936. La Batalla, 23-I-1936. El Socialista, 31-I y 11-II-1936. El Sindicalista, 18-I, y 1 y 8-II-1936.

47. Solidaridad Obrera, 14 y 19-II-1936. ABC, 3-II-1936. La Vanguardia, 4-II-1936. El Socialista, 11-II-1936.

48. Heraldo, 10 y 11-I-1936. ABC, El Socialista y El Sol, 11-I-1936.

49. Venegas, José, Andanzas y recuerdos de España, Montevideo, s.e., 1943, p. 217. 
meses después, Mariano Rodríguez Vázquez: "A los presos se les espera verlos en libertad tan pronto el Parlamento izquierdista tome posesión... Del mejoramiento de la vida; de la desaparición del paro forzoso... ya nadie se acuerda. Una avalancha de sentimentalismo ramplón obstrucciona los cerebros... impide pensar... imposibilita ver claro"50. Por eso, las referencias a la amnistía en mítines y prensa de la CNT y la FAI se han interpretado a modo de consignas para incitar a su militancia a votar a las izquierdas.

Pero lejos de solidarizarse o simpatizar con la campaña pro-amnistía del Frente Popular, la prensa cenetista y muchos dirigentes del sindicato no ocultaron su incredulidad y desprecio. "Cartelones pintarrajeados... llevan a cabo una propaganda partidista, haciendo sonar a los presos y el dolor de las madres", apuntaba Solidaridad Obrera: "Después del engaño, la falta de pudor. Se basan en motivos sentimentales para cazar el voto de los que no creen en la eficacia de la política." La CNT y la FAI advirtieron que esa propaganda era el señuelo de unas "izquierdas políticas" con poca credibilidad para hablar de amnistías. Para Manuel Pérez, los trabajadores no debían fiarse, pues Azaña ya se había negado a concederla durante el primer bienio "para los dieciséis mil trabajadores que tenía la C.N.T. en presidios y cárceles de España." En el mitin de clausura del Pleno de Levante, el dirigente regional de la CNT, Pérez Feliú, abundó en el argumento: "Los que llevan a los hombres a la cárcel, mal pueden hacer por sacarlos" 51 .

La amnistía por la que abogaba la CNT poco tenía que ver con la de las izquierdas, ni en el significado ni en el procedimiento. A diferencia de la amnistía de los "delitos político-sociales" consagrada en el programa del Frente Popular, los dirigentes cenetistas definieron la suya, en una resolución del Pleno de regionales, como un indulto general, que incluyera los delitos comunes y permitiera vaciar las cárceles. A diferencia de "derechas e izquierdas" que "desdeñaban siempre" a los presos comunes, la CNT los consideraba víctimas de la "funesta constitución social, burguesa y cruel, que todos padecemos"

No era la única divergencia. Los anarcosindicalistas no dejaron de advertir en sus propagandas que una amnistía que no viniera acompañada de la supresión de la pena de muerte y de las "leyes represivas", como llamaban a las leyes de Orden Público y de Vagos y Maleantes, sería una estafa, pues con posterioridad las cárceles volverían a llenarse y continuarían dictándose condenas a la pena capital. Recordaban que, por esas razones, la amnistía prometida por el Partido Radical en las elecciones de 1933 no había sido suficiente

50. Solidaridad Obrera, 5-II-1936.

51. Ibid., 7, 11 y 15-II-1936. La Revista Blanca, 24-I-1936.

52. Solidaridad Obrera, 4 y 15-II-1936. 
para templar su campaña abstencionista. Y que el tiempo les había dado la razón, porque esa amnistía fue restrictiva y sólo le había seguido más represión. De los dirigentes de izquierdas no cabía esperar nada diferente. A fin de cuentas, éstos habían sido los que aprobaron esas "leyes absurdas, represivas e ignominiosas" y quienes dejaron la pena de muerte vigente en el fuero militar. Luego las Cortes del segundo bienio sólo tuvieron que restablecerla en el código penal civil. Aunque el Frente Popular hablaba en su manifiesto de reformar estas leyes, dejó claro que no las derogaría. Por eso, no cabía hacer diferencias, en palabras de Abad de Santillán, entre "los métodos de gobierno del primer bienio republicano-socialista y los del segundo, radical-cedista." Lo único que ocurría en 1936 es que esas "leyes represivas que antes se empleaban contra nosotros, últimamente fueron aplicadas también a nuestros perseguidores y torturadores" $" 53$.

La prensa y los oradores de la CNT y la FAI no sólo enfilaron sus baterías contra la política "represiva" de Azaña, sino también contra la de Companys en Cataluña que, "clausuró nuestros sindicatos, allanando el camino por el que iban a precipitarse las derechas." Así las cosas, el voto no era más que el "acto que tiene la virtud de elegir al que luego repartirá estopa a diestro y siniestro." En este punto, no está de más recordar que la campaña de la CNT y la FAI a favor de la abolición de las "leyes represivas" no se hacía para preservar las libertades reconocidas en la Constitución. Por el contrario, como recordó el comité nacional de la $\mathrm{CNT}$, clamaban por su derogación porque impedían "el desarrollo del movimiento obrero revolucionario", esto es, el libre desenvolvimiento de sus actividades conspirativas ${ }^{54}$.

Si distinto era el significado de la amnistía, diferente también era el procedimiento. Los anarcosindicalistas despreciaban el prurito legalista de las izquierdas, por el cual sólo las Cortes podían decretar la amnistía. Para ellos, ésta debía venir fruto del esfuerzo de las "masas trabajadoras", mediante la movilización y la protesta continua. En realidad, la CNT y la FAI, de forma coherente a su reivindicación de los métodos revolucionarios, consideraban que la amnistía debía ser alcanzada por la fuerza o, al menos, por la coacción al poder público. En un mitin en San Feliú de Llobregat (Barcelona), Dionisio Eroles advirtió a su audiencia que ésta se conseguiría no votando, sino afiliándose a la CNT "por ser la única central obrera que se encuentra en condiciones... de arrancar de las manos del verdugo a los trabajadores." "Para la libertad de todos los presos", afirmó en otro acto Durruti, "nos encontraréis siempre, no en las

53. Tierra y Libertad, 24-I-1936.

54. Solidaridad Obrera, 23 y 24-12-1935, 17 y 30-I, y 2 y 5-II-1936. 
urnas, sino... en la calle." Los presos cenetistas de León, al tiempo que apelaban a su organización para que no cayese en el "cepo de la política" por la amnistía, se negaban a deber su libertad a los políticos: "Saldremos a la calle igualmente, cuando el clamor del pueblo trabajador exija de los poderes públicos nuestra liberación." La capacidad de movilización y los medios disponibles definían el tipo de presión a utilizar. Se demostraría en los días posteriores a las elecciones, cuando los anarquistas adquirieron un papel destacado en las manifestaciones y los conatos de asalto a varias prisiones ${ }^{55}$.

\section{Los anarquistas y el peligro fascista}

Como se apuntó al inicio, la contención del fascismo, asociado a un triunfo de las derechas en 1936, ha sido considerada como otra de las coyunturas donde podían converger las izquierdas coaligadas y el anarcosindicalismo. Algunos dirigentes de la CNT pensaban que, como la furibunda campaña de 1933 había sido causa directa de la victoria de la CEDA, si volvían a repetirse tales circunstancias, Gil-Robles establecería un régimen dictatorial desde el poder, a semejanza de Hitler o Dollfuss ${ }^{56}$.

Pero no había coincidencia en cuanto a las posibles soluciones. El anarcosindicalismo, proyectando su antipoliticismo también sobre esta cuestión, no compartía con la coalición de izquierdas que la lucha contra el fascismo se plantease en el terreno electoral. Para aquel, el fascismo era ante todo fruto del estado de crisis y descomposición del capitalismo, de hecho su último recurso para sobrevivir. Suponía ante todo el establecimiento de un "Estado despótico" con una "pretensión totalitaria de dominarlo todo", "un vasto complejo de ideas y de aspiraciones liberticidas", como lo definían las resoluciones de la FAI, que aspiraba a evitar la "emancipación definitiva del proletariado". Y su advenimiento estaba vinculado inextricablemente al recurso a la violencia, porque el fascismo no se detenía ante barreras de tipo legal ni hacía caso de la legitimidad otorgada por las urnas. Así las cosas, los cenetistas consideraban ingenuos los intentos de detener el avance del fascismo con coaliciones electorales. "Al fascismo no se le contiene por decreto", afirmó el órgano de la FAI, "como no se hace por decreto la revolución". David Antona lo explicitó más: "Al fascismo no se le combate con papeletas, se le combate por sus mismos procedimientos, por la violencia." Para los cenetistas, los casos de Alemania

55. Caso de las de Madrid, Barcelona, Alicante, Oviedo, Gijón o Zaragoza. Vid. Casanova, Julián, Anarquismo..., p. 62; BARRIO, Ángeles, Anarquismo..., p. 415; y BradeMAS, John, Anarcosindicalismo..., p. 165. Citas de Solidaridad Obrera, 28 y 30-I-1936.

56. Tusell, Javier, Las elecciones..., p. 217. 
y Austria resultaban ilustrativos, porque consideraban que su movimiento obrero lo había fiado todo al sufragio. "Cuando llegó la hora decisiva", afirmó Abad de Santillán, "el papel de los sufragios se los llevó el viento y los trabajadores quedaron frente a los cuerpos armados de la nueva tiranía, indefensos, traicionados." "El voto", corroboró Solidaridad Obrera, "hace que los trabajadores se entreguen confiados en brazos de una democracia impotente e históricamente fracasada. Por eso la C.N.T. pone especial empeño en que los trabajadores no sean desviados del camino de la lucha directa, que tiene en Asturias su más elevada significación" 57.

Por tanto, la solución a la "violencia bestial del adversario" pasaba por un movimiento insurreccional estrictamente proletario que condujera a la abolición del "régimen capitalista". El Pleno de regionales de la CNT, en su Sexta Ponencia, lo expresó con claridad: "Que al fascismo se le presente batalla... con las mismas armas de que se valiere" y "para este fin se procurará la aproximación de todos los trabajadores... sobre bases y objetivos revolucionarios, al margen de toda acción política y sin pactar con los partidos", lo que volvía a cerrar la puerta a cualquier colaboración electoral. Lo expresó con claridad, entre "frenéticos aplausos", Francisco Ascaso en Barcelona: "Calvo Sotelo ha dicho recientemente que si las derechas no triunfan en las próximas elecciones... ellos destruirían el Parlamento, lo arrasarían todo. Nosotros no aceptamos la acción parlamentaria, y... también lo destruiremos y lo arrasaremos todo" ${ }^{\text {. }}$.

No obstante, la insuficiencia de los procedimientos democráticos para contener al fascismo no era lo que más distanciaba a la CNT del Frente Popular. Había un obstáculo mayor. Para una parte sustancial de los dirigentes cenetistas la democracia, también producto del capitalismo, era intrínsecamente reaccionaria. Por tanto, todo el que colaboraba con la democracia retrasaba la emancipación revolucionaria del proletariado y, por ende, facilitaba el advenimiento del fascismo. "Derechas e izquierdas se mueven dentro del ámbito capitalista y, en el Gobierno, realizan una misión conservadora que las enfrenta abiertamente con el proletariado. Por eso las izquierdas, e incluso el propio socialismo parlamentario... han servido siempre de freno y han posibilitado el triunfo fascista." De ahí que nada importara "la comedia electoral", y menos que el frente de izquierdas hablase en nombre de la democracia, porque: "democracia y dictadura no son términos opuestos, sino idénticos... Tanto la democracia como la dictadura del fascismo significan la... humillación forzosa

57. Juliá, Santos, Orígenes..., pp. 125-126. Solidaridad Obrera, 18-XII-1935, 30-I, y 7-II1936. Tierra y Libertad, 24-I-1936.

58. Solidaridad Obrera, 24-XII-1935 y 4-II-1936. Tierra y Libertad, 24-1-1936. 
ante una divinidad superior, que es el Estado." En la respuesta "cordial" pero negativa de Solidaridad Obrera a los requerimientos de colaboración electoral de El Socialista, el órgano de la CNT no dejó de recordar que el PSOE no era lo mismo en el gobierno que en la oposición: "Esta actitud cordial de hoy se trocará en acritud cuando sean nuevamente Poder." Para la CNT era paradójico que se intentara "resucitar la situación izquierdista" y se le otorgase la virtualidad "de ser un freno al fascismo por ella provocado." En realidad, la lucha estaba entablada no entre la democracia y el fascismo, sino entre "la revolución y la reacción." Por ello, la alternativa era que la CNT abanderase "un verdadero frente revolucionario de todo el proletariado libertario" que preparase la "transformación de la sociedad" 59.

Por si fuera poco, había otra divergencia insalvable con las "izquierdas políticas". Cenetistas y faístas no detectaban la amenaza fascista sólo en las derechas coaligadas. Gil-Robles podía ser el "adversario más encarnizado que se ha cruzado en el camino del proletariado en los últimos tiempos", sí, pero si triunfaba el Frente Popular "tendríamos una dictadura izquierdista que se traduciría... por nuevas leyes de represión, de mordaza al pensamiento libre, de aplastamiento de toda crítica y de toda oposición... Las izquierdas harían del Estado algo propio, de partido, y luego impondrían a toda la población ese criterio. Y sustituirían la Providencia de Gil-Robles o de Hitler por el ídolo estatal." "El fascismo está en la derecha, en el centro y en la izquierda", repetía Solidaridad Obrera y "si triunfan las izquierdas la reacción se entronizará, las cárceles se llenarán de seres humanos y la libertad será escarnecida. Y si triunfan las derechas pasará igual." A quienes hablaban de Gil-Robles o Calvo Sotelo, la CNT les contestaba que la izquierda republicana no difería mucho de las derechas, pues constituía "un fascismo... salpicado de figuras masónicas". Sus dirigentes eran "los más rabiosos e implacables persecutores de los obreros organizados", y recordaban que, con los escamots, "Cataluña, durante el predominio esquerrano, navegaba a velas desplegadas hacia el nacionalfascismo"60.

Pero es que el fascismo no era el único peligro con el que debía vérselas la CNT y la FAI. A veces ni siquiera parecía prioritario. En sus memorias, Abad de Santillán, luego de alertar sobre la amenaza fascista, afirmó sin recato que si las derechas hubieran decretado la amnistía antes de las elecciones, los anarcosindicalistas habrían redoblado su campaña abstencionista sin importarles lo que saliese de las urnas. Además, los cenetistas llamaron la atención en 1936 no sólo sobre los peligros del "totalitarismo fascista", sino también de "la dictadu-

59. Solidaridad Obrera, 18, 20 y 27-XII-1935; y 4 y 7-II-1936. Tierra y Libertad, 31-I-1936. 60. Tierra y Libertad, 24-I-1936. Solidaridad Obrera, 6 y 7-II-1936. 
ra del proletariado... igualmente reaccionaria, regresiva, destructiva de la libertad y de la dignidad humana", que no pretendía acabar con el Estado opresor sino conquistarlo para sus propios fines, contrarios a la emancipación del proletariado. Con menos diplomacia, el comité pro-presos de la Regional Andaluza pidió la abstención total porque el triunfo de las izquierdas significaría "aupar un fascismo rojo". Esta posición no sería secundada por los Sindicatos de Oposición, entonces fuera de la disciplina cenetista. Éstos se cuidaron bien de diferenciar a los otros sectores proletarios, y a la coalición de izquierdas en general, del fascismo que para ellos representaban únicamente las derechas ${ }^{61}$.

\section{Epílogo}

La campaña abstencionista no varió un ápice, siquiera los últimos días antes de las elecciones. El 13 de febrero, Isaac Puente se felicitaba porque la CNT "había resistido el halago de la amnistía" y "había sabido destacar su personalidad frente a los actores de la farsa." Y es que para él no valía la pena prestar atención a los dos frentes electorales en lucha porque, en realidad, "ni las izquierdas son la revolución, ni las derechas el fascismo", ya que "ni el fascismo, ni la revolución, tienen necesidad de las urnas para imponerse." Incluso desde su estricto individualismo ácrata, Federico Urales, que un mes antes había pedido "inhibirse por completo" de las elecciones para no "restar un solo voto a las izquierdas", no ahorró en calificativos ("espectáculo repugnante y puerco", "lucha entre gitanos") para pedir a dos días de las votaciones la abstención. Así las cosas, la prensa de centro-derecha daba por descontado que, a excepción de sectores significativos de Aragón y Asturias, la mayoría de los afiliados a la CNT no votaría al Frente Popular ${ }^{62}$.

$\mathrm{Ni}$ siquiera sus periódicos relajaron las críticas a las izquierdas cuando se patentizó su victoria electoral, que despreciaron. "No nos interesa el triunfo de uno de los grandes sectores ni el triunfo del otro... Pronto veréis trabajadores que... si experimentáis alguna variación, será en el sentido del empeoramiento." Sólo se ensalzó a las multitudes que, congregadas en las calles y frente a las cárceles, pedían la amnistía sin atender a trámites legales: “¡Hay que

61. Abad de Santillán, Diego, De Alfonso..., pp. 287-290; y Memorias, p. 253. Solidaridad Obrera, 17-XII-1935. MACARRO, José Manuel, La Utopía..., p. 443. Los SSOO., en BraDEMAS, John, Anarcosindicalismo..., p. 155; y VEGA, Eulalia, Anarquistas y Sindicalistas, Valencia, Alfons el Magnànim, 1987, pp. 218-219.

62. Solidaridad Obrera, 13 y 16-II-1936. La Revista Blanca, 14-II-1936. Ahora, 13 y 14-II-1936. El Sol, 15-II-1936. 
poner en libertad inmediatamente a todos los presos! ¡El pueblo se unifica para exigir a sus presos, todos sus presos!" ${ }^{33}$.

Es verdad que la CNT y la FAI pidieron a sus militantes que se mantuvieran vigilantes ante los rumores de golpe militar, pero cuidándose de aclarar que su oposición era meramente instrumental. El triunfo sobre los supuestos golpistas debía ser aprovechado para derribar la República e implantar, a su vez, el comunismo libertario. Porque el proletariado no debía "sostener una democracia envilecida, sino... saltar por encima de todas las barreras hacia la abolición del capitalismo y del Estado." "Si los conjurados rompen el fuego", advertía en un comunicado el comité nacional de la CNT, "hay que llevar el gesto de oposición a las máximas consecuencias, sin tolerar que la burguesía liberal y sus aliados marxistas quieran detener el curso de los hechos", porque, en definitiva, las ideas libertarias debían ser "el valladar inexpugnable contra el instinto autoritario de blancos y rojos" ${ }^{14}$.

Conviene volver a subrayar que aquí no se cuestiona que hubiera anarcosindicalistas con una percepción distinta de lo que se ventilaba en la disputa electoral y que, por tanto, votaran al Frente Popular. El movimiento anarcosindicalista era complejo y no todo estaba agrupado, en febrero de 1936, en la CNT. Los Sindicatos de Oposición tenían una visión más positiva de lo que significaba la coalición de izquierdas. Incluso la misma pertenencia a la CNT no garantizaba la abstención de sus militantes. Además, el hecho de que la FAI no pudiera acometer un nuevo boicot, como en 1933, y la misma debilidad en que se encontraba la organización cenetista dificultaban una campaña abstencionista de altos vuelos, sobre todo en comparación con la enorme actividad proselitista que desplegaron en 1936 los partidos políticos. El claro aumento de la participación en estas elecciones, y también el triunfo del Frente Popular pudieron ser indicadores de lo ineficaz de la campaña abstencionista. Quizás por eso los autores anarquistas construyeron, años después, un relato que reinterpretaba de forma más heroica la realidad. Sin duda, la CNT quedaba mejor retratada para la posteridad como el factor clave que permitió la victoria de las izquierdas, y por tanto la derrota del "fascismo vaticanista" de Gil-Robles, que como un actor irrelevante o, incluso, como colaborador accidental de los que acabaron apoyando la sublevación militar de julio de 1936.

Lo que este trabajo discute es que la CNT, y menos la FAI, culminara un giro táctico que le llevase a coadyuvar a la victoria electoral del Frente Popular. No hubo peticiones, veladas siquiera, de votar a las izquierdas por parte de

63. Tierra y Libertad, 21-II-1936. Solidaridad Obrera, 18-II-1936.

64. Solidaridad Obrera, 14, 16 y 18-II-1936. 
sus organismos directivos. Pero es que en su propaganda oral o escrita apenas había nada que dejase entrever otra cosa que la abstención. Por el contrario, se siguió afirmando rotundamente la inutilidad de las elecciones y el deber de no apuntalar con el voto al "Estado opresor". Y, desde luego, a excepción de Asturias, y no toda, y de Zaragoza, hubo campaña abstencionista allí donde la CNT contaba con arraigo. Si algún militante esperaba un acercamiento al Frente Popular, aunque fuese por los presos o por la "amenaza fascista", la propaganda de la CNT le desengañó pronto. Porque ésta se cuidó bien de aclarar que su amnistía nada tenía que ver con la que defendían las izquierdas, que la amenaza fascista no sólo se focalizaba en Gil-Robles y que el bolchevismo, por muy proletario que fuese, era igual de peligroso. Hubo algún gesto hacia la UGT, a la espera que retomase la vía insurreccional, pero las "izquierdas políticas" fueron zaheridas con un rigor no distinto al de las derechas. Las únicas innovaciones que se permitieron respecto a 1933 fueron la renuncia a publicitar una insurrección tras las elecciones, que las circunstancias hacían casi imposible; y la crítica a la represión del movimiento revolucionario de Octubre de 1934, pero sazonada con recordatorios sobre las políticas represivas del bienio "social-azañista".

Cierto que pudo haber diferencias de tono de unos oradores a otros, pero el mensaje fue sustancialmente el mismo. Además, no se suavizó conforme se acercaba el día de las elecciones sino que, por el contrario, se hizo más claro y contundente. La CNT no sólo rechazó cualquier colaboración electoral con el Frente Popular, sino que cuanto más insistían los dirigentes de otros sectores de la izquierda obrera en sacar a los anarcosindicalistas de la abstención, con mayor fruición los descalificaban los oradores y la prensa cenetistas. Por eso, independientemente de que hubiera o no anarcosindicalistas que votasen al Frente Popular, lo que está claro es que la victoria de la coalición de izquierdas debió poco a la CNT, que no la sintió como propia. Desde luego, el recibimiento de Solidaridad Obrera al nuevo gobierno de izquierdas fue tan hostil que la censura intervino para tachar las invectivas contra Azaña y Casares Quiroga, el odiado ministro de Casas Viejas. Ante el cambio de situación política, la CNT se mostraba impertérrita: "En el alborear de ese triunfo de izquierdas... nosotros estamos en el mismo sitio: frente a todos los políticos... Vamos a precipitar nuestra marcha... para liquidar un régimen monstruoso que amenaza devorarnos" ${ }^{\prime 65}$.

65. Ibid., 21-II-1936. 


\title{
Política de la República Federal de Alemania hacia España durante el franquismo y la transición (1949-1979)*
}

\author{
The Federal Republic of Germany Policy towards Spain during \\ Francoism and the Transition to Democracy (1949-1979)
}

\author{
Natalia Urigüen López de Sandaliano \\ Universidad Nacional de Educación a Distancia (UNED), Madrid
}

Recibido: 27-III-2014

Aceptado:21-VII-2014

\section{Resumen}

En este artículo se realiza un análisis de la evolución de la política que la República Federal de Alemania (RFA) desarrolló hacia España durante las tres décadas que separan la creación del joven Estado federal y la entrada en vigor de la Constitución Española. Sin tratar de abarcar todos y cada uno de los asuntos que la caracterizaron, se pretende estudiar la conformación de los grandes vectores que la articularon y su paulatina transformación, en sintonía con la evolución internacional y la de ambos países.

Palabras clave: "Tradicional Amistad", Democracia Cristiana, CDU, SPD, Equipo Demócrata Cristiano del Estado Español, Fundación Konrad Adenauer, UCD, Fundación Friedrich Ebert, Fundación Hanns Seidel, Fundación Friedrich Naumann.

\begin{abstract}
In this article we analyse the development of the of the German Federal Republic policy towards Spain during the three decades that separate the creation of the young federal State and the establishment of the new Spanish Constitution. Rather than covering all the issues that characterised that period, we will try to study the formation of those large vectors that articulated that relationship and its gradual transformation, in line with international evolution and also with the evolution of both countries.
\end{abstract}

* Este artículo forma parte del trabajo de investigación de la autora para la presentación de la tesis doctoral titulada: "El papel de la democracia cristiana alemana en la transición española". 
Keywords: "Traditional Friendship", Christian Democracy, CDU, SPD, Equipo "Demócrata Cristiano del Estado Español", Konrad Adenauer Foundation, UCD, Friedrich Ebert Foundation, Hanns Seidel Foundation, Friedrich Naumann Foundation.

\section{Introducción}

Las relaciones entre España y la República Federal de Alemania (RFA), desde la creación de ésta última en 1949, tuvieron una evolución peculiar debido al fuerte condicionamiento impuesto por el contexto internacional de la Guerra Fría, pero sobre todo por la diferencia estructural existente entre un nuevo estado democrático alemán con pretensiones de ejemplaridad y una de las últimas dictaduras del continente, a su vez sometida al aislamiento internacional. Pasaron varios años antes de que la "tradicional amistad", que tanto daño había hecho a los ojos de los aliados durante la Guerra Civil española y la Segunda Guerra Mundial, se restableciera y consolidara. La relación entre ambos países, si bien es cierto que benefició al régimen franquista, fue también importante como impulsora de los esenciales cambios sociopolíticos que llevarían a España a convertirse en los años setenta en una democracia. Desde antes de la muerte de Franco en noviembre de 1975, es destacable la implicación de la RFA en el proceso de transición española, materializándose en la ayuda e interlocución a diferentes niveles, desde el gubernamental hasta el de partidos y el de fundaciones políticas.

\section{Las relaciones hispano-alemanas durante los primeros años de postguerra mundial}

Durante los primeros cuatro años de postguerra, los países aliados ocupantes del territorio que a continuación conformó la RFA no permitieron las relaciones bilaterales hispano-alemanas. España pagaba así las consecuencias de ser una de las dictaduras que aún perduraban en el continente europeo y, por encima de ello, el que Franco hubiera mantenido su amistad con Hitler hasta prácticamente el final de la guerra. De hecho, España llevó a cabo una política acomodaticia respecto al conflicto bélico. Si en sus inicios se declaró neutral, en junio de 1940 cambiaba su status oficial al de "no beligerancia", para volver a la neutralidad a finales de 1943, cuando comenzaba a perfilarse la victoria de los aliados. En cualquier caso, la postura de España favoreció a los países del Eje. Suministró a Alemania wolframio, materia prima muy codiciada en los momentos de guerra. Puso a disposición de Hitler una división de voluntarios, la llamada División Azul, para luchar en el frente ruso al lado de la Wehrmacht 
contra el comunismo. Permitió que la Gestapo y otros servicios secretos alemanes se instalaran en la Península y el Protectorado de Marruecos, y a su vez acogió a numerosos ciudadanos alemanes que se establecieron en España ${ }^{1}$.

La resolución 39(I) de Naciones Unidas (febrero de 1946) llevó al bloque occidental a congelar las relaciones diplomáticas con España, hasta el punto de cerrar Francia la frontera pirenaica. España quedó aislada, siendo considerado el régimen franquista como una amenaza para la paz y seguridad internacional ${ }^{2}$.

Por su parte, Alemania quedó dividida en cuatro partes y sometida al Consejo Aliado de Control, careciendo de soberanía durante los primeros años de postguerra y por lo tanto de una política exterior propia. En consecuencia, las relaciones hispano-alemanas entre 1945 y 1949 fueron en realidad las relaciones entre España y los tres países ocupantes del territorio alemán occidental, es decir, Estados Unidos, Francia e Inglaterra. La prioridad de éstos fue acabar con cualquier posible vestigio de nacionalsocialismo en territorio español a través del programa Safehaven, implementado en 1944 y por el cual los aliados perseguían cuatro objetivos: eliminar la ayuda indirecta que los países neutrales seguían proporcionando a Alemania mediante relaciones comerciales y financieras; inmovilizar todos los activos e inversiones alemanas en estos países, incluyendo materias primas, mercancías elaboradas, depósitos bancarios, etc.; impedir la fuga de bienes y capitales de nacionalsocialistas; y finalmente restituir los bienes robados a sus dueños legítimos ${ }^{3}$. En paralelo, los aliados comenzaron a exigir el desmantelamiento de la red de espionaje alemán que se había constituido en España y la expulsión de una larga lista de ciudadanos alemanes.

Tanto para Alemania como para España, el factor decisivo que contribuyó al cambio de situación fue el inicio de la Guerra Fría. La escalada de rivalidad, que se había ido produciendo entre Estados Unidos y la Unión Soviética hasta 1947, llevó a las potencias occidentales a sustituir su ideología antifascista por un férreo anticomunismo. Este cambio forzado permitió reinsertar a España y la RFA en el nuevo orden internacional.

1. COLLADO, Carlos, "España y los agentes alemanes 1944-1947. Intransigencia y pragmatismo político", Espacio, Tiempo y Forma, Serie V, Historia Contemporánea, no 5 (1992), pp. 431-482; MORENo, Xavier, La División Azul: Sangre española en Rusia, 1941-1945, Barcelona, Crítica, 2006; viÑAs, Ángel, Franco, Hitler y el estallido de la Guerra Civil. Antecedentes y consecuencias, Madrid, Alianza Editorial, 2001.

2. Sobre el aislamiento del régimen franquista en los primeros años de postguerra véase PORTERO, Florentino, Franco aislado. La cuestión española (1945-1950), Madrid, Aguilar, 1989.

3. Sobre el programa Safehaven véase Collado, Carlos, Angst vor dem "Vierten Reich". Die Alliierten und die Ausschaltung des deutschen Einflusses in Spanien, 1944-1958, Paderborn, Schöningh, 2001; COllado, C., España, refugio nazi, Madrid, Temas de hoy, 2005. 


\section{La reconstrucción de la tradicional amistad durante los años cincuenta}

España, relegada en el escenario internacional con su posición periférica dentro del continente europeo y con una economía muy atrasada, ocupó un puesto secundario en la política exterior de la RFA en los años cincuenta, al no poder contribuir a ninguno de los asuntos que preocuparon a ésta en aquella época: el restablecimiento de su soberanía, la unificación de ambas Alemanias y la construcción de la Comunidad Europea ${ }^{4}$. De las cuestiones fundamentales para la RFA sólo una afectaba también a España: reforzar la defensa de Europa occidental contra la amenaza soviética.

Las relaciones entre ambos países comenzaron a restablecerse a partir de 1949. La RFA valoró muy positivamente el respeto por parte del gobierno español a la doctrina Hallstein ${ }^{5}$. También tuvo muy en cuenta el apoyo invariable de su "tradicional amigo" a la postura de Bonn en la "cuestión alemana" dentro de los círculos internacionales y en concreto, desde 1955, en la Organización de Naciones Unidas, a la cual la RFA no pertenecía.

Tres ideas básicas constituyeron el punto de partida de la política exterior de la joven RFA hacia el régimen de Franco y se mantuvieron constantes hasta la desaparición de éste: la no injerencia en los asuntos internos del país, dejando de lado la naturaleza antidemocrática del franquismo; la necesidad de olvidar viejos resentimientos de la época de la Segunda Guerra Mundial y la postguerra; y el apoyo a la integración de España en la OTAN y la Comunidad Económica Europea (CEE). A través de esta última idea el gobierno federal buscó favorecer el incremento de las relaciones económicas bilaterales, promover la estabilidad social y política en España, así como fomentar la evolución y liberalización del régimen ${ }^{6}$.

4. Sobre los pilares fundamentales sustentadores y los objetivos perseguidos por la política exterior de la RFA a partir de 1949 véase HANRIEDER, Wolfram F., Germany, America, Europe: Forty Years of German Foreign Policy, Yale, Yale University, 1989; LAPPENKÜPER, Ulrich, Die Außenpolitik der Bundesrepublik Deutschland 1949 bis 1990, Munich, Oldenburg, 2008; PFETSCH, Frank R., Die Außenpolitik der Bundesrepublik Deutschland von Adenauer zu Merkel, Schwalbach, Wochenschau Verlag, 2011; SCHÖLlGEN, Gregor, Die Außenpolitik der Bundesrepublik Deutschland. Von den Anfängen bis zum Gegenwart, Munich, Beck, 1999.

5. Según la doctrina Hallstein, enunciada en 1955, la RFA era el único país con derecho a representar internacionalmente al pueblo alemán y por lo tanto se consideraría el establecimiento de relaciones de cualquier país con la República Democrática de Alemania (RDA) como un acto hostil de ese país hacia la RFA.

6. Sobre las relaciones bilaterales entre ambos países durante los gobiernos demócrata cristianos de Konrad Adenauer y Ludwig Erhard véase ASCHMAnN, Birgit, "Treue Freunde..."? Westdeutschland und Spanien 1945-1963, Stuttgart, Franz Steiner Verlag, 1999; LEHMANN, Walter, Die Bundesrepublik und Franco-Spanien in den 50er Jahren, Munich, Oldenburg 
El carácter dictatorial del franquismo y su anterior vinculación con el nacionalsocialismo no jugaron un papel relevante en las relaciones bilaterales durante los gobiernos de Konrad Adenauer, dando Bonn mayor importancia a otro tipo de valores comunes de los dos países como fueron el anticomunismo y el cristianismo. Debido a la limitada capacidad de acción exterior, la elección de sus prioridades y la prudencia política, el gobierno alemán no tuvo excesiva prisa en reiniciar sus relaciones directas con el régimen franquista. Mientras que España contaba ya con una embajada en Bonn desde la primavera de 1951, hasta 1952 no se estableció la primera embajada de la RFA en Madrid, a la que siguieron en los años siguientes una serie de consulados en diferentes ciudades españolas. El mayor problema alemán fue encontrar un perfil adecuado para sus representantes diplomáticos en España, ya que el gobierno federal quiso evitar cualquier posible vinculación anterior de sus candidatos con el nacionalsocialismo ${ }^{7}$.

Durante los primeros años de existencia de la RFA, los objetivos de la política exterior de Adenauer hacia España fueron: el restablecimiento de relaciones diplomáticas, la defensa de los intereses comerciales alemanes en territorio español y la prestación de asistencia consular a los miles de ciudadanos alemanes que residían en España. A estas tres metas hay que añadir una cuarta a la que Bonn dio gran importancia: la recuperación por parte alemana de las propiedades del Tercer Reich en España, propiedades que el régimen se había estado apropiando desde 1945 aprovechando la cobertura que le otorgaba el programa Safehaven de los aliados. Alemania occidental, en pleno proceso de reconstrucción moral, política y económica, dio con ello los primeros pasos, bajo vigilancia aliada, hacia el restablecimiento de unas relaciones "nuevas", libres de toda carga del pasado.

La RFA decidió apoyar a España en sus esfuerzos por salir del aislamiento internacional, siendo su objetivo principal el refuerzo del bloque occidental. Bonn valoraba tanto el anticomunismo de España y el uso que podía hacerse

Verlag, 2006; NIEHus, Gerlinde Freia, Außenpolitik im Wandel. Die Außenpolitik Spaniens von der Diktatur Francos zur parlamentarischen Demokratie, Frankfurt, Vervuert, 1989; SANZ, Carlos, España y la República Federal de Alemania (1949-1966): Política, Economía y Emigración entre la Guerra Fría y la distensión, tesis doctoral inédita. Universidad Complutense de Madrid, 2005; WEBER, Petra Maria, Spanische Deutschlandpolitik 1945-1958. Entsorgung der Vergangenheit?, Frankfurt, Verlag Breitenbach, 1992.

7. Los acuerdos de Petersberg, que permitían a la RFA establecer relaciones diplomáticas y comerciales con los países occidentales, se habían firmado en noviembre de 1949, pero España no estaba en la lista de prioridades establecida por los aliados. Sobre el establecimiento de las primeras embajadas en sendos países véase ASCHMAnN, Birgit, "Treue Freunde..."?..., pp. 201-223. 
de éste, como su posición estratégica. El gobierno federal siguió muy de cerca los convenios defensivos firmados entre España y Estados Unidos en 1953, por los cuales se autorizaba el establecimiento de bases americanas en suelo español. Igualmente, la visión alemana del aspecto geoestratégico de España le llevó, desde su propio ingreso en la OTAN en 1955, a apoyar de una u otra manera la admisión española. Sin embargo, durante los años en que Konrad Adenauer estuvo al frente de la Cancillería, un apoyo demasiado explícito al régimen franquista aún constituyó un tema polémico. A nivel nacional, los socialdemócratas alemanes en la oposición se oponían a la entrada de España en la OTAN. En el ámbito internacional, un intento de cooperación militar bilateral fuera de la Alianza Atlántica y de la Unión Europea Occidental chocaba con la oposición frontal de Estados Unidos, Francia, Gran Bretaña y otros países occidentales, como pudo comprobarse con el intento fallido de establecer unas bases militares alemanas en España en 1960'.

Junto al cauce oficial en las relaciones bilaterales entre ambos gobiernos existió también una paradiplomacia extraoficial, desarrollada a través de instituciones como el Centro Europeo de Documentación e Información (CEDI) o el Comité Internacional para la Defensa de la Civilización Cristiana (CIDCC), entre otros ${ }^{9}$. El CEDI fue una asociación privada fundada en 1952 por personalidades destacadas de la vida pública española. Su creación buscaba una unión bajo el signo de un movimiento cristiano europeo, con el objetivo de superar el aislamiento al que se veía sometida la élite franquista ${ }^{10}$. A través del

8. Respecto a los intentos de cooperación bilateral entre ambos Estados y el intento fallido de establecer depósitos militares en España véase Collado, Carlos, "Planes militares de Adenauer en España", Espacio Tiempo y Forma. Serie V, Historia Contemporánea, $\mathrm{n}^{\circ} 4$ (1991), pp. 97-116; COLLADO, C., "El proyecto de las bases militares alemanas en España", BERNECKER, Walter (ed.), España y Alemania en la Edad Contemporánea, Frankfurt, Vervuert Verlag, 1992, pp. 231-255.

9. Para más información sobre el CEDI véase ASChMAnN, Birgit, "Treue Freunde...”?..., pp. 425-435; AschmanN, B., "La República Federal de Alemania y la imagen de Alemania en España, 1945-1963", Ayer. Revista de Historia Contemporánea no 69 (2008), pp. 129-154; BENEYTO, Juan, "Las asociaciones de Amistad durante el franquismo", Revista de Estudios Políticos (Nueva Época), no 71, enero-marzo 1991, pp. 210-212; GROSSMANn, Johannes, Die Internationale der Konservative. Transnationale Elitenzirkel und private Aussenpolitik in Westeuropa seit 1945, Munich, Oldenburg Verlag, 2014; MORENO, Antonio, "El Centro Europeo de Documentación e Información. Un intento fallido de aproximación a Europa, 1952-1962", tusell, Javier et alii (eds.), El régimen de Franco (1936-1975), Madrid, UNED, 1993, pp. 459-474; wEBER, Petra Maria, "El CEDI: promotor del Occidente cristiano y de las relaciones hispano-alemanas de los años cincuenta", Hispania, LIV/3, $\mathrm{n}^{\circ} 188$ (1994), pp. 1077-1103; WEBER, P. M., Spanische Deutschlandpolitik 1945-1958. Entsorgung der Vergangenheit, Breitenbach, Saarbrücken Lauderdale, 1992, pp. 205-268. Sobre el CIDCC véase fundamentalmente BENEYTO, Juan, "Las asociaciones de Amistad durante el franquismo"..., pp. 212-218; SANZ, Carlos, España y la República Federal de Alemania..., pp. 450-457.

10. WEBER, Petra Maria, "El CEDI: promotor del Occidente cristiano...", p. 1078. 
CEDI se crearon vías de comunicación entre determinadas personalidades políticas españolas de ideología nacionalcatólica (Alfredo Sánchez Bella, Alberto Martín Artajo y José Ignacio Escobar, entre otros) y círculos católicos de Baviera identificados con la Abendländische Aktión (de inspiración católica y occidental "Abendland"). Los miembros de ambas asociaciones coincidían durante los años cincuenta en las reuniones que se celebraban en El Valle de los Caídos o en El Escorial por parte del CEDI y en la Abendländische Akademie en Eichenstatt por parte alemana. Hanns Seidel (ministro-presidente de Baviera), Heinrich von Brentano (ministro de Exteriores), diversos presidentes de los Länder, Franz Josef Strauss (por aquel entonces Ministro de Energía Atómica), varios diputados del Bundestag, incluido su vicepresidente Richard Jaeger, periodistas, obispos y aristócratas bávaros, etc., se encontraban entre los asiduos que asistían a los encuentros organizados por ambos foros. Se establecieron así contactos entre personalidades de una misma visión cristiana, conservadora y "occidentalista". El Auswärtiges Amt, nunca apoyó oficialmente las actividades del CEDI, sin embargo supo aprovechar los contactos que se establecían a través de las reuniones que se celebraban anualmente. Los utilizó como canales de comunicación extraoficial con el gobierno español y a la vez para hacer propaganda en el exterior de su posicionamiento en asuntos como la división de Alemania, la situación de Berlín o las perspectivas de reunificación. A Adenauer le llegaba la información que por parte alemana se recogía en los congresos. Una vez que en los años sesenta se normalizaron los cauces oficiales entre la RFA y España, el valor del CEDI como vía de comunicación disminuyó ${ }^{11}$.

El CIDCC fue otro foro de diplomacia paralela que permitió estrechar las relaciones entre el régimen franquista y la RFA en los años cincuenta y sesenta. A esta institución pertenecieron José Solís, Manuel Fraga y el general Muñoz Grandes, entre otros. Nació de una iniciativa italiana, pero su base fue siempre alemana. Ligado a la democracia cristiana a nivel internacional, mientras ésta se mantuvo en el poder en la RFA, el CIDCC fue subvencionado en parte por el gobierno alemán. Organizaba cursos, conferencias y comunicaciones con contenido político, cultural y propagandístico de ideología conservadora y anticomunista $^{12}$.

Otro de los aspectos en los que la RFA fue importante para España es el ámbito económico, aunque en un principio las relaciones estuvieron marcadas por la incertidumbre. Inicialmente fueron EEUU, Reino Unido y Francia, a través del Consejo Aliado de Control, los que reabrieron los cauces comerciales

11. SANZ, Carlos, España y la República Federal de Alemania..., pp. 434-450.

12. BENEYTO, Juan, "Las asociaciones de Amistad durante el franquismo"..., pp. 212-213. 
con España mediante un convenio firmado entre Madrid y la Trizona a finales de 1948. Sin embargo, la situación de partida era totalmente contraria entre ambos países: España sometida a la autarquía, que se tradujo en el retraso del crecimiento económico del país durante toda la década de los años cincuenta; la RFA integrada en el capitalismo internacional, desarrollando una espectacular reconstrucción desde 1948, cuyo motor de arranque fue la ayuda del Plan Marshall, de la que España había sido excluida. Alemania occidental siguió la vía del multilateralismo en sus relaciones económicas exteriores, mientras que España no tuvo más opción que seguir la vía bilateral. El gobierno español cambió de táctica a raíz de los Tratados de Roma, pero hasta entonces transcurrió una década de estancamiento. La RFA fue un proveedor de productos y maquinaria absolutamente necesarios para la industrialización del país, mientras que Alemania occidental veía en España un proveedor de productos alimenticios esenciales y de materias primas necesarias para su reconstrucción. Bonn alcanzó hacia 1952 el primer objetivo que se había propuesto, la recuperación de su puesto en el mercado español, terreno que había perdido ante la competencia francesa, británica y estadounidense $e^{13}$.

Si bien en un principio el gobierno de la RFA consiguió el despegue de las relaciones comerciales entre ambos países, pronto surgieron los obstáculos derivados del escaso grado de apertura económica española y de la no pertenencia a ninguna organización de carácter multilateral. La realidad era que España incumplía las condiciones comerciales acordadas, a lo que se sumaban problemas de liquidez. Al gobierno alemán no le quedó más remedio que hacer concesiones para no perder las relaciones comerciales entre ambos países. A mediados de los años cincuenta, la RFA rediseñó su política económica hacia España, con el objetivo de que a corto plazo el gobierno español cumpliera con las condiciones establecidas en cuanto a volumen, plazos, licencias, etc., y de estimular el aumento de las exportaciones españolas a Alemania occidental. A medio plazo Bonn había decidido apoyar el ingreso de España en la Organización Europea para la Cooperación Económica y la Unión Europea de Pagos. Básicamente suponía fomentar la apertura y liberalización de la economía española, lo cual beneficiaba a los intereses exportadores alemanes ${ }^{14}$.

13. Sobre las inversiones extranjeras en España véase BARCIELA, Carlos et alii (coords.), La España de Franco (1939-1975). Economía, Madrid, Síntesis, 2001, pp. 233-238.

14. SAnz, Carlos, España y la República Federal de Alemania..., pp. 271 y 275; ASCHMAnN, Birgit, "Treue Freunde..."?..., pp. 286-311; Aschmann, B., "The Reliable Ally: Germany Supports Spain's European Integration Efforts, 1957-1967", Journal of European Integration History, vol. 7, $\mathrm{n}^{\circ} 1$ (2007), pp. 37-51. 
En 1958, el problema entre la RFA y España sobre las propiedades alemanas incautadas en territorio español quedó solucionado con la firma de dos acuerdos entre ambos países: el Convenio sobre ciertos efectos de la Segunda Guerra Mundial entre España y la República Federal de Alemania y el Convenio para la rehabilitación de derechos de propiedad industrial entre España y la República Federal de Alemania ${ }^{15}$. El desenlace fue muy bien valorado por parte del gobierno federal, más por lo que significaba como restitución moral que por suponer una ganancia económica significativa. La resolución del contencioso, la entrada de ministros tecnócratas en el gobierno español y la aplicación del Plan Nacional de Estabilización Económica de 1959 contribuyeron a la intensificación de las relaciones bilaterales desde finales de los años cincuenta. Los cambios aperturistas por parte del régimen franquista se produjeron a raíz del tratado de Roma y ante el temor de un mayor aislamiento de la economía española en el ámbito europeo. El resultado fue la admisión de España en los organismos económicos internacionales, produciéndose a lo largo de los años sesenta una mayor liberalización económica ${ }^{16}$.

\section{La profundización de las relaciones bilaterales durante los años sesenta}

En los años sesenta, la RFA era ya una gran potencia económica occidental presente en la mayoría de los organismos técnicos internacionales. Además, se había convertido en un gran aliado para la defensa del bloque anticomunista. El riesgo de que los Estados Unidos dejaran de apoyar la política de Bonn respecto a la "cuestión alemana", así como el favorecimiento invariable del gobierno español a la doctrina Hallstein se tradujeron a lo largo de esta década en un mayor estímulo de la RFA a la inserción de España en el bloque occidental. El gobierno de Ludwig Erhard (1963-1966) mantuvo la continuidad política hacia el régimen de Franco, apoyando la aproximación de España a Europa, el desarrollo de su economía y la mejora de su situación en la escena internacional. Erhard no mostró durante su gobierno un especial interés por España; pero su visión de una "Europa de países libres e iguales", unida en estructuras de integración económicas más amplias que las existentes hasta el momento, incluía también a las dictaduras ibéricas, fundamentalmente por coherencia con su visión económica y librecambista. A diferencia de Adenauer, España y

15. Convenio sobre ciertos efectos de la Segunda Guerra Mundial entre España y la República Federal de Alemania y el Convenio para la rehabilitación de derechos de propiedad industrial entre España y la República Federal de Alemania, firmados el 8 de abril de 1958 en Madrid. Editados en Madrid, Ministerio de Asuntos Exteriores, 1959 (Registro de Tratados $\left.\mathrm{n}^{\circ} 119\right)$.

16. aschmann, Birgit, "Treue Freunde...”?..., pp. 258-259. 
Portugal jugaron un papel menos importante en las consideraciones de seguridad de este canciller ${ }^{17}$. Tampoco hubo cambios en la línea de actuación hacia España durante el gobierno de la "gran coalición" (1966-1969), caracterizándose las relaciones entre ambos países, a finales de los años sesenta, por la sintonía, el rechazo al comunismo y el continuo apoyo de la asociación española a la CEE. Por lo tanto, la llegada de los socialdemócratas alemanes al poder no supuso un cambio esencial en la estrategia de Bonn hacia Madrid. Kiesinger fue el primer canciller de la RFA en realizar un viaje oficial a España a finales de octubre de 1968 y de hecho fue el único jefe de gobierno europeo que visitó oficialmente el territorio español durante el periodo franquista ${ }^{18}$.

En el aspecto económico, el abandono de la autarquía, en gran medida gracias a la ayuda alemana, supuso el inicio de la integración de España en las instituciones económicas internacionales, desarrollando la vía del multilateralismo. A lo largo de los años sesenta y hasta 1973, España vivió su "edad dorada" económica gracias al turismo, al fuerte aumento de las exportaciones, al incremento de la inversión extranjera y a una positiva evolución del producto nacional bruto, del consumo público y del privado. A ello se sumó la absorción del excedente de mano de obra por el mercado europeo, jugando Alemania occidental también un gran papel en este ámbito ${ }^{19}$. En 1960, los gobiernos de Bonn y Madrid firmaron un acuerdo de emigración que posibilitó, a lo largo de los siguientes quince años, la salida oficial de unos 770.000 trabajadores y sus familias para trabajar en la RFA ${ }^{20}$.

Bonn esperaba beneficios de esa multilateralización dado el prestigio de los productos alemanes en España. A lo largo de todo el periodo las relaciones comerciales entre ambos países se intensificaron. Se firmaron diversos acuerdos que facilitaron el comercio bilateral y la inversión alemana en la industria española. La RFA fue en estos años el segundo comprador de sus exportaciones, mientras que realmente el significado de España como socio comercial para

17. sanz, Carlos, España y la República Federal de Alemania..., pp. 390-392.

18. "Kiesinger llega mañana", ABC, 27-X-1968; MUÑoz, Antonio, El amigo alemán. El SPD y el PSOE de la dictadura a la democracia, Barcelona, RBA Libros, 2012, pp. 21-32.

19. Sobre el desarrollo económico de España en los años sesenta véase CARRERAS, Albert y TAFUNELL, Xavier, Historia económica de la España contemporánea, Barcelona, Crítica, 2004, pp. 331-364; GIL, Alfonso J., Causas del desarrollo económico. España en Europa, 1900-2000, Madrid, Minerva, 2001, pp. 95-133; SIMÓN, Francisco, Manual de Historia económica mundial y de España, Madrid, Editorial Centro de Estudios Ramón Areces, 1991, pp. 652-653.

20. MUÑOZ, Antonio, "Una introducción a la historia de la emigración española en la República Federal de Alemania (1960-1980)", Iberoamericana: America Latina-España-Portugal, ${ }^{\circ}$ 46 (2012), pp. 23-42; SANZ, Carlos, "Illegale", "Halblegale", "Gastarbeiter". Die irreguläre Migration aus Spanien in der Bundesrepublik Deutschland im Kontext der deutsch-spanischen Beziehungen 1960-1973, Berlín, edition tranvía-Verlag Walter Frei, 2010. 
aquélla fue mucho más secundario. Sin embargo, la apuesta por la multilateralización de la economía española mereció la pena, ya que los intercambios comerciales crecieron y España experimentó un boom económico que mudó radicalmente el país y sentó las bases de la sociedad moderna y la futura democracia ${ }^{21}$.

\section{La posición de la socialdemocracia alemana hacia España}

Tras haber analizado las relaciones de los gobiernos demócrata cristianos alemanes hacia España en los años cincuenta y sesenta es necesaria una reflexión sobre la evolución del posicionamiento de la socialdemocracia alemana hacia el régimen franquista durante aquellos mismos años. A lo largo de los años cincuenta, la posición del Sozialdemokratische Partei Deutschlands (SPD) hacia la España de Franco fue de abierta y activa hostilidad. El partido no estaba dispuesto a olvidar tan fácilmente la ayuda prestada por Hitler a Franco durante la Guerra Civil. Algunos militantes e incluso dirigentes destacados (comenzando por el propio Willy Brandt) habían estado en España durante la guerra española y mantenían posiciones muy críticas hacia el régimen y sus representantes. Durante la Era Adenauer las críticas en el Bundestag del SPD al partido demócrata cristiano -Christlich-Demokratische Union Deutschlands (CDU)-, por apoyar al régimen franquista, fueron continuas, aunque sin efecto alguno en la sociedad alemana. El SPD denunció la responsabilidad de Alemania en la destrucción de la democracia española republicana y fomentó el aislamiento del régimen de las organizaciones europeas, pretendiendo con ello que el sistema franquista se colapsara y el país recuperase la democracia ${ }^{22}$.

El SPD modificó su actitud hacia la España de Franco desde mediados de los años sesenta. Tras la conversión de los socialdemócratas en un partido de masas, a raíz del congreso extraordinario de Bad Godesberg de 1959, se produjo un cambio de rumbo en sus principios de política exterior. Éste se reforzó con la llegada de Willy Brandt a la presidencia del partido en 1964, apuntalando un posicionamiento constructivo en línea con la política de distensión que el partido defendía, por aquel entonces, hacia las dictaduras comunistas. Todo ello tuvo repercusiones a medio plazo en las relaciones de la RFA con España.

Siguiendo el principio de cambio mediante acercamiento que el SPD reclamaba para la Ostpolitik y la Westpolitik, los socialdemócratas alemanes fueron modificando su radical oposición hacia la dictadura de Franco comenzando a favorecer, al igual que venía haciéndolo la $C D U$, la evolución del franquismo

21. SANZ, Carlos, España y la República Federal de Alemania..., p. 748.

22. MUÑOz, Antonio, El amigo alemán..., pp. 19-21. 
hacia la democracia y la aproximación de España a la $\mathrm{CEE}^{23}$. A mediados de los años sesenta, el SPD ya admitía las relaciones diplomáticas y comerciales de la RFA con el Estado español y apoyaba el incremento de las relaciones económicas y políticas bilaterales, si bien no se debían establecer con Madrid alianzas de otro tipo que pudieran interpretarse como una amistad hacia el gobierno de Franco ${ }^{24}$. El SPD cambió su estrategia hacia España basándose en la idea de que el aislamiento del régimen, defendido por el socialismo europeo, acabaría favoreciendo los extremismos de derecha e izquierda. Los socialdemócratas alemanes pedían un cambio en la forma de proceder para favorecer el surgimiento de una izquierda moderada en España. Con esta forma de actuar se convertían en el partido socialdemócrata europeo menos combativo con la dictadura de Franco y se mostraban consecuentes con su estrategia de distensión europea. Convergían con la línea política seguida por los gobiernos de la CDU hacia España, aunque introducían un elemento novedoso: la promoción en España del europeísmo democrático, confiando en que el incentivo de la adhesión diera preminencia a los sectores europeístas y aperturistas del régimen, allanando así el camino hacia la democracia ${ }^{25}$. También por parte española se habían producido ciertos signos aperturistas que contribuyeron al cambio en la forma de proceder del partido, como fue la promulgación en 1967 de la Ley Orgánica del Estado ${ }^{26}$.

Dentro de la amplia familia socialdemócrata alemana hubo diversidad de opiniones respecto a la línea pragmática y moderada marcada por la dirección del SPD. Especialmente a partir de finales de los años sesenta, la dirección del partido se encontró con las críticas crecientes de las juventudes (Jusos) y del gran sindicato del metal (IG Metall), por su falta de combatividad contra el franquismo ${ }^{27}$. En cualquier caso, siempre prevaleció la línea moderada marcada por Willy Brandt y la dirección del SPD, en consonancia con la distensión defendida a través de su Ostpolitik. Por ello, durante el gobierno de la "gran coalición" no se planteó ningún conflicto entre la $C D U$ y el SPD en cuanto a la forma de actuar hacia el régimen franquista.

23. Ibid., p. 67.

24. SANZ, Carlos, España y la República Federal de Alemania..., p. 485.

25. MUÑOZ, Antonio, "Europeizar es democratizar. El SPD y la España del tardofranquismo", Historia del Presente, no 17 (2011/1), p. 97.

26. Ley Orgánica del Estado num. 1/1967, de 10 de enero, en Boletín Oficial del Estado (BOE) $\mathrm{n}^{\circ}$ 9, 11-I-1967.

27. ABELSHAUSER, Werner, Nach dem Wirtschaftswunder. Die Gewerkschafter, Politiker und Unternehmer Hans Matthöfer, Bonn, Dietz, 2009, pp. 216-240. 


\section{Los vectores de la ayuda alemana a España en los años setenta}

La formación de la coalición social-liberal alemana (1969-1974) coincidió con un profundo cambio de gobierno en España. Si hasta 1969 Franco había mantenido equilibrado el poder de las diferentes familias en el gobierno, es decir fundamentalmente falangistas y opusdeistas, en el nuevo gabinete hubo una clara preponderancia de ministros tecnócratas vinculados al Opus Dei. Éstos, que habían sido los responsables de la exitosa política económica de los años sesenta, contribuyeron a relegar las sombras falangistas al pasado ${ }^{28}$.

El objetivo de este nuevo gobierno fue preparar el futuro del país sin Franco, convirtiendo la vicepresidencia, ostentada por el vicealmirante Luis Carrero Blanco desde 1967, en buena medida en una presidencia de hecho. A su vez, Franco designó a don Juan Carlos de Borbón sucesor a título de Rey, depositando a partir de entonces tanto los Estados Unidos como las grandes potencias europeas todas las esperanzas de reforma gradual democrática en el joven príncipe $^{29}$.

El canciller Willy Brandt y el ministro de Asuntos Exteriores Walter Scheel, mantuvieron hacia España la estrategia iniciada por el partido socialdemócrata desde mediados de los años sesenta. Continuaron con la "tradicional amistad" al igual que durante los gobiernos demócrata cristianos, sustentada por el buen recibimiento de las actuaciones españolas. A principios de los años setenta, España favorecía la distensión: apoyaba la normalización de las relaciones de la RFA con los países del Este, cooperaba en la preparación de la Conferencia de Helsinki y contribuía a la estabilización del Mediterráneo. La insistencia española de acercamiento a la CEE y el desarrollo económico, que desde hace años se venía produciendo en España, eran igualmente bien recibidos por el gobierno alemán. Bonn consideraba a los nuevos ministros tecnócratas moderados y europeístas capaces de protagonizar una transición democrática tras la muerte de Franco.

Willy Brandt mantuvo una postura oficial hacia el régimen de Franco, mientras que a la vez fomentó el diálogo con los antifranquistas y posibles futuros

28. MARín, José María, YSÀs, Pere y MOLInero, Carme, Historia política (1939-2000), Madrid, Istmo, 2001, pp. 187-190; PRESTON, Paul, Franco, caudillo de España, Barcelona, RBA, 2005, pp. 803-807; TUSELL, Javier, Dictadura franquista y democracia (1939-2004), Barcelona, Crítica, 2005, pp. 224-228 y 236-237.

29. Sobre el papel del Rey en el cambio democrático véase POWELL, Charles, El piloto del cambio. El rey la monarquía y la transición a la democracia, Barcelona, Planeta, 1991; POWELl, Ch., Juan Carlos. Un rey para la democracia, Barcelona, Ariel/Planeta, 1995; POWELl, Ch., El amigo americano. España y Estados Unidos: de la dictadura a la democracia, Barcelona, Galaxia Guttemberg, 2011; PRESTON, Paul, Juan Carlos: El rey de un pueblo, Barcelona, Círculo de Lectores, 2003. 
dirigentes del país. Existieron momentos de tensión entre ambos gobiernos que fueron hábilmente manejados por Bonn, bien ampliando el flujo de visitas políticas a España o, en momentos de mayor tensión, relajando las reuniones de los visitantes oficiales alemanes con la oposición ${ }^{30}$.

El canciller no visitó España durante su gestión para evitar dar una imagen de respaldo a la dictadura; sí lo hizo Walter Scheel en abril de 1970, con motivo de la concesión de un crédito alemán a España, fomentando así esa postura de apoyo al cambio mediante acercamiento ${ }^{31}$. El ministro aprovechó la visita para reunirse en casa del embajador alemán con destacados miembros de la oposición moderada y más o menos tolerada: el demócrata cristiano Joaquín Ruiz Giménez, Enrique Tierno Galván, dirigente del Partido Socialista del Interior, José María de Areilza y Joaquín Satrústegui, líder de los monárquicos democráticos, pudiendo comprobar la debilidad de estos aperturistas. Scheel fue la primera figura política europea que se entrevistaba con miembros de la oposición al régimen franquista ${ }^{32}$. Este hecho insólito fue realmente una señal táctica y motivó el malestar del gobierno español, ya que suponía legitimar por parte de Europa a la oposición política ${ }^{33}$.

Otra forma de apoyar los cambios que se estaban forjando en España fue la invitación oficial de Bonn a don Juan Carlos para visitar la RFA a finales de septiembre de 1972. El príncipe fue recibido por el canciller, el ministro de Asuntos Exteriores y el presidente de la República, Gustav Heinemann ${ }^{34}$. Con la invitación la RFA daba al príncipe el crédito que ningún otro país europeo le había dado hasta entonces, ya que estaba bastante aislado y era presentado tanto por la oposición como por la opinión pública como una "marioneta" de Franco. La amistad que se forjó tendrá un efecto muy importante en las relaciones bilaterales a partir de 1975.

La política exterior de Bonn desde mediados de los años setenta tuvo una línea de actuación innovadora: su implicación en el final de las dictaduras del sur de Europa. Como consecuencia del colapso del sistema monetario de Bretton Woods y la crisis mundial del petróleo de 1973, surgió un clima de inesta-

30. MUÑOZ, Antonio, El amigo alemán..., pp. 64-70.

31. Sobre el viaje de Scheel a España en abril de 1970: "Alemania otorgará a España un crédito de doscientos millones de marcos para las obras del trasvase Tajo-Segura", $A B C$, 24-IV-1970.

32. "Scheel traf spanische Oppositionelle", Die Zeit, 1-V-1970.

33. KNEUER, Mariane, Demokratisierung durch die EU. Süd- und Ostmitteleuropa im Vergleich, Wiesbaden, VS Verlag für Sozialwisenschaften, 2007, p. 179; ORTUÑO, Pilar, Los socialistas europeos y la transición española, Madrid, Marcial Pons, 2005, p. 193.

34. "Los príncipes han sido acogidos con medido protocolo y extrema cordialidad", $A B C$, 27-IX-1972. 
bilidad en todo el continente, que afectó especialmente a los países del sur, acabando con su prosperidad económica de los últimos veinticinco años. Tanto los EEUU como las principales potencias europeas habían confiado hasta entonces en la estabilidad política garantizada por el sistema capitalista. Una vez que ésta se quebró, un nuevo foco de preocupación surgió en el área mediterránea: el miedo a un posible avance del eurocomunismo por Europa y más concretamente sobre países inestables por el fin de sus dictaduras: Grecia, Portugal o España ${ }^{35}$. El peligro que la RFA percibía era que el eurocomunismo, tras la apariencia de una organización moderada con principios democráticos y rechazo al modelo comunista de la Unión Soviética, aspiraba a contribuir a la superación de las crisis políticas y económicas de países como Francia e Italia. Pero tras esa fachada Bonn veía el referente de Moscú. La vulnerabilidad de las democracias nacientes podía convertirse en un caldo de cultivo perfecto para el avance eurocomunista. Por esta razón, tanto el gobierno de Bonn como los partidos y fundaciones políticas alemanas buscaron desde 1974 contrarrestar el poder comunista, ayudando en los países en transición democrática a la creación de partidos políticos sólidos, tanto de derechas como de izquierdas ${ }^{36}$.

Helmut Schmidt, como canciller (1974-1982), y Hans Dietrich Genscher, como ministro de Asuntos Exteriores, continuaron con la línea establecida por Brandt de ayuda a las transiciones ibéricas y el empeño del gobierno alemán por contribuir al éxito de la implementación de las democracias. La Cancillería siguió apoyando las negociaciones españolas con la CEE. Aprovechando la confianza que el gobierno de Madrid tenía en Bonn, Schmidt se preocupó por promover el contacto entre los sectores evolucionistas del régimen y la oposición democrática, cosa de la que hasta entonces no se había preocupado ningún otro gobierno europeo ${ }^{37}$. Esa línea de actuación también se sostuvo a

35. Sobre la crisis de mediados de los años setenta en el sur de Europa véase KOHLER, Beate, Politischer Umbruch in Südeuropa. Portugal, Griechenland, Spanien auf dem Weg zur Demokratie, Bonn, Europa Union Verlag, 1981.

36. Sobre la actuación de la RFA en Portugal y España durante los procesos democratizadores véase STENGER, Matthias, Transnationale Parteienzusammenarbeit. Die Beziehungen der deutschen und portugiesischen Christlichen Demokraten von der Nelkenrevolution bis zum Vertrag von Maastricht (1974-1992), Düsseldorf, Droste, 2011; FONSECA, Ana Monica, «É Preciso Regar os Cravos!» A Social-democracia alemã e a trasição para a Democracia em Portugal (1974-1976), tesis doctoral inédita, ISCTE - Instituto Universitario de Lisboa, 2011; KAISER, Wolfram y SALM, Christian, "Transition und Europäisierung in Spanien und Portugal. Sozial- und christdemokratische Netzwerke im Übergang von der Diktatur zur parlamentarischen Demokratie", Archiv für Sozialgeschichte, no 49 (2009), pp. 259-282.

37. Durante la Cumbre de Helsinki, Schmidt intentó convencer a Arias Navarro de la necesidad de establecer un diálogo con la oposición no comunista. MUÑOz, Antonio, El amigo alemán..., pp. 204-206. 
nivel internacional ${ }^{38}$. El gobierno alemán tuvo que intensificar su apoyo a España durante la escalada de violencia de los últimos meses de 1975, intentando convencer a los países europeos de que la presión externa era contraproducente en aquellos momentos tan delicados ${ }^{39}$.

Tras la muerte de Franco, la RFA aprovechó la gran confianza que se había ganado a lo largo de los años en que había cooperado con todos los sectores, desde el mismo régimen hasta el Rey, pasando por la oposición moderada, para intentar contribuir al proceso de transición hacia la democracia. Bonn observaba la situación española bajo la óptica de los acontecimientos portugueses tras la Revolución de los Claveles y con el temor a que la deriva comunista del país vecino pudiera contagiarse a España. Por esta razón, el gobierno federal siguió muy de cerca los hechos que se iban produciendo en España, mientras que a su vez mediaba a todos los niveles (Cancillería, embajada, partidos políticos alemanes y fundaciones políticas) para conseguir una transición ordenada. Aparece por lo tanto un nuevo vector en las relaciones bilaterales de ambos países: el papel de consejero que la RFA desempeñó durante los primeros gobiernos de la transición, fomentando el diálogo con los grupos políticos demo$\operatorname{cráticos}^{40}$. A nivel internacional Alemania Occidental continuó apoyando la entrada de España en la CEE, pero supeditando la adhesión a que se dieran los pasos necesarios en favor de la democracia ${ }^{41}$.

Aun no estando exento de dudas en un principio, el apoyo al Rey fue continuo. Este espaldarazo comenzó con el aval que supuso la presencia del presidente Scheel en el acto de su coronación en noviembre de 1975 -al que no acudieron la mayoría de los Jefes de Estado europeos ${ }^{42}$ - o una nueva invitación para otra visita oficial a la RFA en abril de 1977, a dos meses de las primeras elecciones democráticas ${ }^{43}$.

38. A nivel internacional el canciller siempre se mostró partidario del acercamiento a las nuevas fuerzas emergentes y no tanto al régimen, con el objetivo de asegurar una salida democrática. A este respecto véase LEMUS, Encarnación, Estados Unidos y la Transición Española. Entre la Revolución de los Claveles y la Marcha Verde, Madrid, Silex Ediciones, 2011, p. 36; ORTUÑO, Pilar, Los socialistas europeos..., pp. 204-205; POWELL, Charles, El amigo americano..., pp. 213-214; sCHMIDT, Helmut, Hombres y poder, Barcelona, Plaza y Janes/Cambio 16, 1989, pp. 180-181.

39. MUÑoz, Antonio, Europeizar es democratizar..., p. 115.

40. NIEHUS, Gerlinde Freia, Außenpolitik im Wandel..., pp. 478-479.

41. MUÑOz, Antonio, El amigo alemán..., p. 279.

42. Además del presidente alemán, las únicas personalidades europeas de peso que estuvieron en los actos fueron el presidente francés Giscard d'Estaign, el príncipe Felipe de Edimburgo y el presidente de Irlanda Cearbhall O'Dalaig. "Todo a punto para las ceremonias de hoy", $A B C$, Madrid, 27-XI-1975.

43. Informe del Ministerio de Asuntos Exteriores alemán (Auswärtiges Amt) sobre el viaje de los Reyes a la RFA, 22-IV-1977, Politisches Archiv-Auswärtiges Amt (PAAA), Berlin, Zwischenarchiv 110249. 
Helmut Schmidt visitó Madrid a principios de 1977, seis meses después de la elección de Adolfo Suárez como presidente del Gobierno La negativa a realizar ese viaje con anterioridad, a pesar de la insistencia del presidente español, fue una forma de alentar a Suárez para que llevara a cabo las medidas reformistas. Schmidt se entrevistó con el dirigente del Partido Socialista Obrero Español (PSOE), Felipe González, además de con Suárez y don Juan Carlos de forma individual ${ }^{44}$. El canciller sugirió fórmulas para atajar la crisis económica con éxito y puso el modelo de diálogo social alemán como el ejemplo que España podía seguir; además, a esas alturas mostró ya su apoyo a la legalización del Partido Comunista de España (PCE) e insistió para que Suárez llevara a cabo la reforma sindical, con unos sindicatos moderados con los que existiera una comunicación fluida. Con ello el gobierno conseguiría limitar la gran influencia de los comunistas en el ámbito sindical ${ }^{45}$.

\section{El papel de los agentes políticos alemanes en la transición española}

Tras casi cuarenta años de dictadura en España, el alcance limitado de los partidos políticos era un gran problema para la consecución y mantenimiento de la democracia. Uno de los escasos intentos de aperturismo por parte del régimen franquista había sido la Ley de Asociaciones Políticas de 1974, cuyo objetivo era crear un sistema de asociaciones, aunque por encima se mantuviera el régimen de partido único ${ }^{46}$. Dadas sus grandes limitaciones y escaso aperturismo, el intento fracasó y la mayoría de los grupúsculos políticos se mantuvieron en la ilegalidad hasta poco antes de las elecciones generales de 1977. Sin embargo, el ambiente de apertura que comenzó a extenderse en la política española, desde poco antes de 1975, favoreció que los diferentes partidos y fundaciones políticas alemanas comenzaran a interesarse por buscar en España grupos afines a su ideología, dentro de las asociaciones y partidos políticos que se fueron formando. Su intención era ayudar al desarrollo y consolidación de un sistema partidista, sin el cual sería inviable una transición pacífica a la democracia. Ante el temor a que en España pudiera crearse una situación semejante a la de Portugal tras la Revolución de los Claveles, la colaboración de los agentes políticos alemanes tuvo una gran importancia en la creación de una clase política española capaz de llevar a buen término el proceso de democratización.

44. "Bundeskanzler Schmidt zu politischen Gesprächen in Madrid", Deutsche Presse-Agentur (dpa), 6-I-1977.

45. El embajador alemán en España, Georg von Lilienfeld, al Auswärtiges Amt, 7-I-1977, PAAA, Zwischenarchiv 115896.

46. Decreto Ley 7/1974 de 21 de diciembre por el que se aprueba el Estatuto Jurídico del Derecho de Asociación Política, en BOE nº 306, 23-XII-1974. 
Conviene explicar brevemente la naturaleza e importancia de las fundaciones políticas, agentes transnacionales característicos del sistema político alemán. Se crearon después de la Segunda Guerra Mundial como organizaciones para la educación política interna, un cometido imprescindible tras doce años de nacionalsocialismo. Están financiadas con fondos públicos, aunque utilizan el status de ONGs. Actúan en el ámbito de la RFA, pero son también muy activas en proyectos políticos internacionales. Por cada partido político existe una Fundación de ideología cercana, aunque legalmente son independientes. En las siguientes líneas se va a hacer un recorrido por la labor desarrollada por las cuatro fundaciones presentes en España durante el proceso de democratización: la Fundación Friedrich Ebert cercana al SPD, las fundaciones Konrad Adenauer y Hanns Seidel, de ideología demócrata cristiana ambas y cercanas a los partidos CDU y Chrislich-Soziale Union in Bayern (CSU) respectivamente; finalmente la Fundación liberal Friedrich Naumann, afín al Freie Demokratische Partei (FDP).

\section{El SPD y la Fundación Friedrich Ebert}

Los socialdemócratas alemanes, que ya mantenían relación con varios grupos socialistas españoles, incrementaron en 1975 sus contactos y decidieron, en el mes de abril de ese mismo año, dar su apoyo definitivo al PSOE. La obsoleta y radical dirección del partido en el exilio, la cual permanecía anclada en su rechazo completo al régimen franquista, había sido sustituida poco antes. La nueva cúpula estaba formada por una joven generación pragmática encabezada por Felipe González, cuyos objetivos eran totalmente compatibles con las ideas de los socialdemócratas alemanes. Fue decisiva la determinación que, a esas alturas, tenía el líder socialista de construir la democracia desde la monarquía y sin ruptura con el régimen anterior. Además de ello, otros dos factores contribuyeron al apoyo definitivo del SPD: el recrudecimiento de la situación en Portugal con el avance de los comunistas en el gobierno y el convencimiento de que el supuesto aperturismo del que fue el último gobierno franquista era un puro espejismo. El SPD quiso ayudar a los socialistas españoles a instaurar la democracia en España, al igual que lo estaban haciendo en Portugal. La meta final era mantener la distensión en el marco de la Guerra Fría. En los años finales del franquismo, el PCE era el grupo mejor configurado, debido a la buena organización, disciplina y capacidad de sacrificio de los cuadros comunistas, además de los amplios recursos que recibía del exterior. Por esta razón, los socialdemócratas alemanes decidieron fomentar la organización de un partido moderado de izquierda, capaz de atraer al potencial socialista español ${ }^{47}$.

47. MUÑOz, Antonio, El amigo alemán..., pp. 183-195. 
El SPD ayudó a la articulación territorial del PSOE por España y a la excarcelación de militantes socialistas. También se encargó de la formación de cuadros del partido en los valores del socialismo. Por otro lado, ayudó a lanzar a Felipe González a nivel europeo y mundial, fomentando las visitas de delegaciones socialistas europeas a España y organizando giras del líder del partido por Europa para darse a conocer. Gran parte de la ayuda del SPD al PSOE se materializó a través de la Fundación Friedrich Ebert. Su representante en España, Dieter Koniecki, abrió la oficina en Madrid a principios de 1976 y comenzó a organizar el apoyo al partido y al sindicato afín, la Unión General de Trabajadores. Para la expansión del PSOE, la Fundación alemana colaboró mediante una serie de aportaciones: la ayuda a la apertura de oficinas por todas las provincias de España; la organización de conferencias, seminarios de formación y cursos en el extranjero sobre cómo llevar a cabo campañas electorales; la creación de una línea de becas; la edición de libros informativos para los nuevos afiliados; y la ayuda a proyectos de investigación de instituciones españolas, útiles para el partido socialista ${ }^{48}$.

Con la colaboración de los socialdemócratas alemanes, los socialistas de Felipe González consiguieron las metas que se habían impuesto para las elecciones de 1977. El partido se había convertido en el punto de encuentro de la izquierda no comunista y se había consolidado como alternativa de poder frente al gobierno. A una gran distancia de los comunistas, el PSOE fue la mayor fuerza de la izquierda española. Pero faltaba aún una fuerte consolidación del partido, que se produciría en los años siguientes mediante la absorción de otros pequeños grupos socialistas, la ampliación de la base social del partido y la formación de cuadros. Para ello siguieron contando con la ayuda del SPD y de la Fundación Friedrich Ebert ${ }^{49}$.

\section{La CDU y la Fundación Konrad Adenauer}

La actuación de los agentes políticos demócrata cristianos alemanes en los procesos de transición peninsulares ha sido mucho menos estudiada que la de los socialdemócratas. Salvo para el caso portugués ${ }^{50}$, apenas existen análisis profundos sobre la implicación de la CDU y la Fundación cercana al partido, Fundación Konrad Adenauer (KAS), en las transiciones ibéricas ${ }^{51}$. Sin embar-

48. Ibid., pp. 231-277.

49. MUÑOZ, Antonio, Von der Franco-Diktatur zur Demokratie. Die Tätigkeit der FriedrichEbert-Stiftung in Spanien, Bonn, Dietz, 2013, pp. 136-214.

50. STEnger, Matthias, Transnationale Parteienzusammenarbeit...

51. Sobre las relaciones de la $C D U$ en España durante los primeros años de la transición y sobre la visión que los demócrata cristianos alemanes tenían de los acontecimientos 
go, en el caso español sí mantuvieron relación con personalidades y grupos políticos que aparentemente podrían protagonizar, tras la desaparición de Franco, un cambio político hacia la democracia. Inicialmente fueron los grupos demócrata cristianos en la oposición al régimen franquista -a su vez miembros de la Unión Europea Demócrata Cristiana desde 1965, a través del Equipo Demócrata Cristiano del Estado Español- los interlocutores principales de la CDU. Tras las elecciones de junio de 1977, los demócrata cristianos alemanes centraron su relación en el partido centrista en el gobierno, la Unión de Centro Democrático.

Un serio problema al que se tuvo que enfrentar la $C D U$ fue la gran dispersión del ámbito demócrata cristiano español. La Unión Europea Demócrata Cristiana (UEDC), heredera de los Nouvelles Equipes Internationales ${ }^{52}$, había exigido a los pequeños grupúsculos españoles su unión en un solo grupo, el Equipo Demócrata Cristiano del Estado Español (Equipo), para poder ser reconocido oficialmente como su interlocutor en España y a su vez estar éste representado en la organización europea ${ }^{53}$. El Equipo, formado en 1965, se componía de cinco grupos democristianos españoles, dos de ellos de ámbito nacional (Izquierda Democrática y Democracia Social Cristiana) y otros tres regionalistas (Partido Nacionalista Vasco, Unió Democràtica de Catalunya y Unió Democràtica del País Valencià). El empeño que pusieron los partidos integrantes de la UEDC, para conseguir que el Equipo se convirtiera en un potencial partido político fuerte y consolidado, resultó un fracaso. Esa unión, más ilusoria que real, fue un acuerdo de mínimos y pronto dejó ver las fracturas entre sus miembros, ocasionadas por el rechazo dentro del Equipo a las propuestas federalistas de catalanes y vascos, además de por el personalismo de los líderes de los partidos de ámbito nacional, José María Gil Robles y Joaquín Ruiz Giménez, dirigentes de Democracia Social Cristiana e Izquierda Democrática, respectivamente ${ }^{54}$. La actividad del Equipo quedó limitada a la represen-

españoles en aquellos años véase SARTORIUS, Nicolás y SABIO, Alberto, El final de la dictadura. La conquista de la democracia en España (noviembre de 1975-junio de 1977), Madrid, Ediciones Temas de Hoy, 2007, pp. 665-672.

52. Sobre los Nouvelles Equipes Internationales véase BECKER, Winfried, "Die Nouvelles Equipes Internationales und der Föderalismus", Historisch-Politische Mitteilungen. Archiv für Christlich-Demokratische Politik, no 15 (2008), pp. 81-102. Sobre éstos y la Unión Europea Demócrata Cristiana véase JANSEN, Thomas, Die Entstehung einer Europäischen Partei. Vorgeschichte, Gründung und Entwicklung der EVP. Bonn, Europa Union Verlag, 1996; PAPINI, Roberto, La internacional Demócrata Cristiana, Caracas, IFEDEC, Centro Internacional de Formación "Arístides Calvani”, 1986.

53. BARBA, Donato, La oposición durante el franquismo. La democracia cristiana, Madrid, Encuentro, 2001, p. 129.

54. UEDC/EUCD, Procès-verbal de la reunión du bureau, Rome, 17-XII-1966, Archiv für christlich-demokratische Politik (ACDP) 09-004-030. 
tación conjunta de la democracia cristiana española en los organismos y reuniones internacionales, ya que dentro de España fue muy escasa ${ }^{55}$.

Siendo consecuente con la línea seguida por la Unión Europea Demócrata Cristiana, la $C D U$, a pesar de lo confuso del espectro político del centro derecha español, mantuvo como interlocutor oficial al Equipo desde $1974^{56}$. La relación de los demócrata cristianos alemanes con los partidos afines en España se mantuvo fundamentalmente a través de la KAS, que si bien no abrió su delegación en España hasta octubre de 1976, había comenzado a interesarse por la situación española desde mediados de 1975. Josef Thesing, responsable del área de solidaridad internacional, fue el encargado del proyecto español ${ }^{57}$. Los intereses de la Fundación en España fueron principalmente dos: favorecer la democratización del país con fuerzas democráticas españolas, evitando así la continuidad del franquismo sin Franco y fomentar la entrada de España en la CEE ${ }^{58}$.

En septiembre de 1975 Thesing realizó su primer viaje a España como representante de la Fundación Konrad Adenauer. Tenía clara la idea de que para poder llevar a cabo la democratización era absolutamente necesario contar con personas que no hubieran pertenecido al régimen franquista. Con anterioridad a este primer viaje, en junio de 1975, ya había estado reunido en Bonn con uno de los miembros de Izquierda Democrática, Íñigo Cavero, habiendo elaborado un programa de trabajo conjunto para los partidos del Equipo y la Fundación ${ }^{59}$.

Los objetivos del viaje de Thesing eran dos: concretar definitivamente con los grupos demócrata cristianos españoles la posibilidad de que la Fundación

55. BARBA, Donato, La oposición durante el franquismo..., p. 215.

56. NIEHUS, Gerlinde Freia, Außenpolitik im Wandel..., p. 515.

57. En 1961 se creó en la RFA el Ministerio de Cooperación Económica con los países en vías de desarrollo (Bundesministerium für wirtschaftliche Zusammenarbeit und Entwicklung - BMZ-). En paralelo la KAS creó - en julio de 1962 - su propio Instituto de solidaridad internacional, el Institut für Internationale Solidarität. A través de esta entidad la Fundación canaliza las ayudas recibidas del ministerio y desarrolla los contactos con partidos demócrata cristianos, sindicatos y otras instituciones en los países en vías de desarrollo. La idea general es ayudar a quienes lo necesitan, bajo las premisas de un entendimiento cristiano de los derechos humanos, democracia y justicia social. Sobre el trabajo que se desarrolla a través del Institut für Internationale Solidarität véase THESING, Josef, "Die Konrad-Adenauer-Stiftung in der Welt. Der Beginn der Arbeit des Instituts für Internationale Solidarität", Historisch-Politische Mitteilungen. Archiv für Christlich-Demokratische Politik, no 19 (2012), pp. 305-318; THESING, J. (coord.), In der Welt und für die Welt. 40 Jahre internationale Zusammenarbeit, Sankt Augustin, KonradAdenauer-Stiftung, 2002.

58. Entrevista personal con Josef Thesing, Sankt Augustin, 31-X-2012.

59. Informe de Josef Thesing sobre su viaje a Madrid del 7 al 10 de septiembre de 1975, Institut für Internationale Solidarität der Konrad-Adenauer-Stiftung e.V., en Sankt Augustin (Bonn), ACDP 12-001-1261. 
colaborara con ellos y la preparación de un proyecto de trabajo conjunto. A lo largo de tres días se entrevistó con varios miembros de Izquierda Democrática y de Federación Popular Democrática (anteriormente Democracia Social Cristiana). Los grupos regionalistas estuvieron representados por los anteriores. Las conversaciones que el representante alemán mantuvo con los integrantes de la democracia cristiana española dieron su fruto, puesto que a partir de entonces comenzó a materializarse la ayuda de la KAS para la creación de un sólido partido demócrata cristiano de carácter federativo ${ }^{60}$.

La Fundación demócrata cristiana alemana comenzó a colaborar en la organización de actividades de formación política a través del Instituto de Investigación Socio-Política (INDESP), creado en septiembre de 1975 en el seno de la Fundación Universitaria San Pablo y concebido como centro de formación política para el Equipo. Por otra parte, la KAS también organizó seminarios y conferencias en su academia de Eichholz para los miembros de los diferentes partidos del Equipo ${ }^{61}$.

A finales de 1976, la Fundación encargó a la empresa DATA, presidida por el sociólogo y politólogo español Juan Linz, la realización de un sondeo de opinión pública muy extenso sobre la realidad política del momento y la intención de voto en España ${ }^{62}$. Uno de los mayores problemas que observaba Josef Thesing era la falta de conocimiento de los miembros del Equipo sobre el comportamiento político de los españoles. Por ello era necesario mentalizar a los cinco partidos demócrata cristianos de las necesidades y voluntad de la sociedad española, antes de las elecciones de junio. Los resultados de dicho sondeo, basado en 8.837 entrevistas, se presentaron en enero de 1977: la mayoría de los españoles querían la democracia, pero rechazaban cualquier política radical y cualquier tipo de experimento en sentido revolucionario. La época de Franco había pasado aunque, en general, la gente valoraba los beneficios de la reconstrucción económica que se había producido. Especialmente la fuerte clase media, que era la mayor beneficiada del desarrollo económico a todos los niveles, no quería correr ningún riesgo político. Nuevas caras como la de Adolfo Suárez imprimían un nuevo estilo político con el que se identificaban muchos españoles. Con estas premisas se llegó a la conclusión de que, únicamente, un partido de centro sería capaz de ganar las primeras elecciones democráticas. Aun presentando estos datos tan relevantes y realizando un gran esfuerzo a todos

60. Ibid.

61. Informe personal de Josef Thesing para Bruno Heck (presidente de la KAS), 21-VI-1976, ACDP 12-001-1261.

62. Informe confidencial de Josef Thesing para Helmut Kohl, presidente de la CDU (19731998), sobre el desarrollo político en España, 10-V-1977, archivo privado de Josef Thesing. 
los niveles, la Fundación Konrad Adenauer no fue capaz de convencer a Gil Robles y Ruiz Giménez de la necesidad de incorporar al Equipo a un gran partido de centro. Fundamentalmente, fue el primero quien no quiso juntarse con políticos que hubieran tenido algo que ver con el régimen franquista. El resto de los componentes regionalistas del Equipo no tuvieron la fuerza suficiente para cambiar la decisión de los dos anteriores ${ }^{63}$.

En primavera de 1977, Izquierda Democrática y la Federación Popular Democrática se unieron en la Federación de la Democracia Cristiana y juntas se presentaron a las elecciones generales de junio. Los resultados fueron desastrosos, obteniendo solamente un 1,18\% de los votos y ninguna representación parlamentaria ${ }^{64}$.

Puede por lo tanto afirmarse que en España los democristianos estuvieron perfectamente identificados desde el inicio de la transición, a diferencia del caso portugués, donde la democracia cristiana alemana tuvo serios problemas para identificar a un interlocutor de ideología afín, dado que no existía ningún grupo de ese país representado en la UEDC cuando se produjo la Revolución de los Claveles. El fracaso de los españoles en las primeras elecciones democráticas se debió, fundamentalmente, a la ineficacia de los líderes de la Federación de la Democracia Cristiana, que no tuvieron la amplitud de miras suficiente para comprender lo que realmente quería y necesitaba el pueblo español tras cuarenta años de régimen dictatorial, e hicieron prevalecer sus propios intereses. La Fundación Konrad Adenauer, desde principios de 1977 y con los resultados del sondeo en la mano, había predicho con acierto la voluntad de los españoles y había recomendado insistentemente a los demócrata cristianos su integración en una formación centrista. Por lo tanto la Fundación había realizado un buen análisis político de la situación española. De hecho, de los interlocutores habituales de la KAS hubo un grupo, liderado por Fernando Álvarez de Miranda $^{65}$, que se había escindido de Izquierda Democrática en primavera de 1976 y había creado el Partido Demócrata Cristiano. Este grupo sí aceptó los

63. Ibid.

64. Informe de Josef Thesing "Die Wahlen in Spanien", IIS-Info Auslandsinformationen, 4VII-1977.

65. Fernando Álvarez de Miranda había formado parte del grupo de Gil Robles hasta 1964 y posteriormente de Izquierda Democrática hasta abril de 1976, momento en que se decide el ingreso del partido en Coordinación Democrática. Este organismo, que exigía al gobierno una serie de medidas democráticas, estaba formado por varios partidos políticos entre ellos el PCE. Por esta razón se produjo la escisión de un grupo de políticos, encabezado por Álvarez de Miranda, que crearon el Partido Demócrata Cristiano. Véase ÁlVAREZ DE MIRANDA, Fernando, Del contubernio al consenso, Barcelona, Planeta, 1985; ÁlVAREZ De miranda, F, La España que soñé. Recuerdos de un hombre de consenso, Madrid, La Esfera de los Libros, 2013. 
consejos de la Fundación ${ }^{66}$. El partido de Álvarez de Miranda se integró en Unión de Centro Democrático (UCD), conglomerado de quince partidos muy heterogéneo -en su seno había grupos políticos que iban desde la socialdemocracia hasta los demócrata cristianos, pasando por los liberales- que se había creado pocos meses antes de las elecciones generales. UCD, un partido de centro con apenas tres meses de vida, ganó las primeras elecciones democráticas consiguiendo 165 escaños para el Congreso de los Diputados, de los cuales 34 estuvieron ocupados por el grupo demócrata cristiano de Álvarez de Miranda ${ }^{67}$. ¿Se puede realmente hablar de un fracaso del trabajo de la Fundación Konrad Adenauer en España?

Tras las históricas elecciones generales de junio de 1977, que supusieron la derrota de Gil Robles y Ruiz Giménez, la Fundación Konrad Adenauer decidió centrar su apoyo en la Unión de Centro Democrático, intentando fomentar a su sector demócrata cristiano y ayudando a su fortalecimiento ${ }^{68}$. La contribución de la democracia cristiana alemana comenzó a materializarse pocos meses después de las elecciones, a principios de octubre de 1977, con la organización de un seminario para cuarenta dirigentes de Unión de Centro Democrático, sin distinción de sus ideologías políticas ${ }^{69}$. A finales de año la Fundación ayudó a los democristianos integrados en el partido, Iñigo Cavero, Oscar Alzaga y Fernando Álvarez de Miranda, a crear la Fundación Humanismo y Democracia, diseñada para la formación política de los militantes de Unión de Centro Democrático y por lo tanto para ampliar la ideología demócrata cristiana en el seno del partido ${ }^{70}$. La Fundación Konrad Adenauer también estuvo en contacto con los principales redactores de la Constitución de 1978, basada en muchos aspectos en la Ley Fundamental alemana de 1949. Varios miembros de la Comisión Constitucional del Congreso viajaron a la sede de la Fundación en Bonn, donde se organizaron encuentros con profesores alemanes de derecho constitucional ${ }^{71}$.

66. En una entrevista personal con Fernando Álvarez de Miranda el 14-II-2013, éste reconoce agradecido la gran ayuda de la Fundación Konrad Adenauer y la CDU durante la transición española. 67. <http://www.juntaelectoralcentral.es/portal/page/portal/Junta ElectoralCentral/JuntaElectoralCentral/ResultElect/ElGeneral/15Junio1977> (Consultado el 21-I-2014).

68. Carta de Henning Wegener, director del Departamento de Relaciones Internacionales de la CDU a Karl Carstens, presidente del Bundestag, 11-XI-1977, ACPD 07-001-16009.

69. Informe del Departamento de Relaciones Internacionales de la CDU para Helmut Kohl: Reunión del Präsidium del 17-X-1977; puntos fuertes y problemas del trabajo internacional de la CDU, 12-X-1977, ACDP 07-001-16026.

70. ÁlVAREZ de miranda, Fernando, Del contubernio..., p. 142.

71. Entrevista personal con Josef Thesing, Sankt Augustin, 31-X-2012. 
Durante la transición, la Fundación invitó a destacados intelectuales, políticos y periodistas españoles a viajar a la RFA, en gran medida por razones psicológicas. Su intención era eliminar de las mentes españolas la sensación de aislacionismo y mostrar el pensamiento abierto alemán. Por ello, el abanico de invitados no sólo se limitó a gente de ideología demócrata cristiana ${ }^{72}$. A su vez, la Fundación Konrad Adenauer realizó un gran esfuerzo para convencer a los políticos españoles de finales de los años setenta de la necesidad de que España entrara a formar parte de la OTAN, ya que por aquella época todavía era necesario combatir las reticencias españolas hacia la Alianza Atlántica ${ }^{73}$.

Hasta su disolución en febrero de 1983, la Unión de Centro Democrático contó con el fiel apoyo de la CDU. Se trataba de ampliar el sector demócrata cristiano en su seno y finalmente poder integrar al partido en la UEDC y en el Partido Popular Europeo, una vez que España entrara a formar parte de la CEE. Sin embargo, esto no fue posible al fracasar el proyecto de Unión de Centro Democrático ${ }^{74}$. Tras un apoyo inicial de la CDU al nuevo partido demócrata cristiano creado por Oscar Alzaga en 1982, el Partido Demócrata Popular (PDP), avanzados los años ochenta acabará siendo Alianza Popular (después Partido Popular) el partner español de la CDU.

\section{La CSU y la Fundación Hanns Seidel}

Existía a finales de 1975 otra fuerza política que se consideraba a si misma demócrata cristiana y que se había formado en el marco de la Ley de Asociaciones Políticas de diciembre de 1974, la Unión Democrática Española. Su líder Federico Silva Muñoz, había sido Ministro de Obras Públicas durante el franquismo. El partido estaba dispuesto a trabajar en conjunto con los demócrata cristianos de la oposición y en concreto con los dos grupos de ámbito nacional, Izquierda Democrática y Federación Popular Democrática. Como uno de sus objetivos era la realización de una política centralizada, no contemplaba la colaboración con los partidos vascos y catalanes ${ }^{75}$. De cualquier manera, ninguno de los líderes del Equipo, al igual que otros partidos integrantes de la Unión Europea Demócrata Cristiana, estaban dispuestos a trabajar con un partido cuyo líder había colaborado con el régimen franquista ${ }^{76}$.

72. Sirva como ejemplo la invitación a Bonn de doce periodistas de diversos rotativos españoles en enero de 1976. Archivo privado de Josef Thesing.

73. Entrevista personal con Josef Thesing, Sankt Augustin, 31-X-2012.

74. Huneeus, Carlos, La Unión de Centro Democrático y la transición a la democracia en España, Madrid, Centro de Investigaciones Sociológicas, 1985.

75. SILVA, Federico, Memorias políticas, Barcelona, Planeta, 1993.

76. Informe de Klaus Weigelt, representante de la KAS en Venezuela entre 1975-1981, tras una estancia en España de tres meses (6-IV-1975 al 6-VII-1975), ACDP 12-001-1261. 
La relación de Unión Democrática Española con el partido demócrata cristiano bávaro era estrecha, en buena parte debido a la larga amistad de Silva Muñoz con Franz Josef Strauss (dirigente de los bávaros desde 1961). A la altura de diciembre de 1975 la Fundación Hanns Seidel, cercana a la CSU, ya contemplaba la realización de programas políticos para la asociación española, en paralelo o como contraste a los que la Fundación Konrad Adenauer estaba preparando con los miembros del Equipo ${ }^{77}$.

La Fundación Hanns Seidel abrió su oficina de representación en España en 1977 y colaboró en la creación del nuevo espectro político. La Fundación apoyó en las elecciones de 1977 a Alianza Popular (AP), partido político que había creado en octubre de 1976 el exministro de Gobernación Manuel Fraga Iribarne $^{78}$. AP integraba a siete grupos políticos (incluido el partido de Silva Muñoz), cuyos dirigentes habían sido en su mayoría afamados ministros franquistas $^{79}$. Fraga, que hasta entonces se había declarado centrista, daba un giro hacia la derecha y aunaba así bajo un único partido a las fuerzas más reacias al cambio, para poderlas controlar y convertir en una "derecha civilizada". La Fundación Hanns Seidel ayudó a la creación del Instituto de Estudios Sociales (IESO), centro de formación política de AP, que organizaba encuentros con periodistas, seminarios para mujeres y diversos cursos de índole política para simpatizantes del partido ${ }^{80}$.

A pesar de los malos resultados de Alianza Popular en las elecciones de 1977 y $1979^{81}$, la Fundación Hanns Seidel mantuvo su apoyo a su partner español durante los siguientes años. Muchos de los seminarios que se organizaron a través de la Fundación Cánovas del Castillo -creada en los años ochenta en el seno del partido-, tuvieron como objetivo dividir a la Unión de Centro Democrático, con el fin de captar para AP tanto votos como nuevos miembros ${ }^{82}$.

77. Informe de Heinrich Böx respecto un sondeo realizado en España sobre la situación política, entre el 8 y 10 de diciembre de 1975, ACDP 12-001-1261.

78. "Eine neue Partei stellt sich in Madrid vor", Die Welt, 10-XI-1976.

79. Los partidos políticos que se integraron en Alianza Popular fueron los siguientes: Reforma Democrática (liderada por Manuel Fraga), Unión del Pueblo Español (Cruz Martínez Esteruelas), Democracia Social (Licinio de la Fuente), Acción Regional (Laureano López Rodó), Unión Social Popular (Enrique Thomas de Carranza), Unión Nacional Española (Gonzalo Fernández de la Mora) y Acción Democrática Española (anteriormente Unión Democrática Española liderada por Federico Silva Muñoz).

80. Mager, Friedrich y mauter, Paul, Stiftungen im Dienst der Politik. Am Beispiel Spanien, Bayerischen Rundfunks, República Federal de Alemania, 12 de Julio de 1977.

81. En las elecciones de 1977 Alianza Popular sólo logró un 8\% de los votos y 16 escaños, mientras que en las elecciones generales de 1979 el porcentaje de votos se redujo al 6\% y su representación en el Congreso a 9 diputados.

82. NIEHUS, Gerlinde Freia, Außenpolitik im Wandel..., p. 521. 


\section{El FDP y la Fundación Friedrich Naumann}

En palabras de su representante en Madrid, Fritz E. Steinberg, la Fundación Friedrich Naumann tuvo poco que celebrar respecto al objetivo de fomentar un partido liberal en la transición española. Sin embargo, hay que tener muy en cuenta el punto de partida. Era prácticamente imposible conseguir la creación de un partido de ideología liberal en España, donde el liberalismo arrastraba una percepción negativa desde el inicio del siglo, la cual el franquismo se había encargado de desacreditar. A pesar de ello existía una gran variedad de organizaciones, clubs y grupos liberales ${ }^{83}$.

A finales de 1975, uno de analistas políticos de la embajada alemana informó a los líderes del FDP en Bonn del interés que habían mostrado varios españoles, al acudir a la embajada para interesarse por la ideología liberal. Tras un viaje a Bonn de varios representantes de los grupos liberales españoles, durante el cual se reunieron con miembros de la Fundación Friedrich Naumann, ésta decidió proceder a la apertura de una delegación en Madrid en julio de 1976, si bien ya existían contactos, desde poco antes de la muerte de Franco, entre los liberales alemanes y españoles en el marco de las organizaciones liberales internacionales ${ }^{84}$.

Steinberg se encontró con un amplio espectro de pequeños grupos, la mayoría de los cuales no estaban dispuestos a cooperar entre ellos. El contacto más importante de la Fundación Friedrich Naumann fue el grupo liberal del político Joaquín Garrigues Walker, aunque también apoyaron a otros grupos como los regionalistas Esquerra Republicana de Catalunya o Esquerra Democràtica de Catalunya. En concreto, estos dos partidos catalanes fueron integrados en la Internacional Liberal gracias a la intercesión del partido liberal alemán ${ }^{85}$. En 1976, la Fundación organizó once seminarios, dos de ellos en la RFA y el resto en Madrid, Barcelona y Bilbao. Los primeros informes de Steinberg reflejaban una: la carencia de estructuras organizativas de los grupos liberales y la negativa de éstos a unirse en un solo partido. Otro de los problemas con el que se encontró el representante de la Fundación fue el choque cultural español con el procedimiento administrativo del sistema alemán: retra-

83. BORGER, Sebastian, Germany's party political foundations in Spain: a case-study of quasiofficial foreign policy, Londres, 1998, inédito, p. 20.

84. Solicitud de la Fundación Friedrich Naumann al Bundesministerium für wirtschaftliche Zusammenarbeit und Entwicklung del 19-III-1976 para la apertura de una delegación en Madrid, Bundesarchiv, Coblenza, B213-21277.

85. "Bruselas: la Internacional Liberal ratifica su deseo de democratización para España", La Vanguardia, 2-X-1976; "Los liberales deberán prestar una ayuda especial a España", Ya, 3-X-1976. 
sos, recibos mal presentados o liquidaciones de cuentas que no cumplían las normas contables ${ }^{86}$.

Antes de las elecciones de 1977, la mayoría de los interlocutores españoles de la Fundación decidieron unirse a Unión de Centro Democrático, una decisión recomendada por el Ministro de Exteriores alemán, Hans Dietrich Genscher, ante la ausencia en España de un partido liberal fuertemente consolidado. La muerte prematura de Joaquín Garrigues en 1980 y la disolución de UCD supusieron temporalmente el fin de la influencia de la Fundación liberal alemana en España. No obstante, al haber estimulado a los partidos regionales, la Fundación Friedrich Naumann ayudó a exportar a nivel regional el sistema federalista de administración alemán ${ }^{87}$.

\section{Conclusión}

El análisis de la evolución de la política exterior de la RFA hacia España a lo largo de sus primeros treinta años de existencia permite extraer tres conclusiones fundamentales. La primera y más extendida es la necesidad de adecuación de la política exterior de una nueva democracia hacia una dictadura, con el agravante de que la nueva república federal se constituía sobre las ruinas de un régimen del que esa dictadura había sido un gran amigo. Que además estas relaciones se encontraran enmarcadas dentro del contexto general de la Guerra Fría y del periodo de reconstrucción de postguerras y conformación del proyecto europeo, determinó un acicate especial para la superación de las diferencias ideológicas.

El segundo vector está constituido por la positiva evolución de las relaciones bilaterales hispano-alemanas durante los primeros veinticinco años de existencia de la RFA; lo que fue determinante para que, a mediados de los años setenta, ésta se convirtiera en un gran apoyo para la España que comenzaba su andadura democrática. En los años cincuenta España jugó un papel secundario en la política exterior de la RFA, al tener Alemania occidental otras prioridades post-bélicas más urgentes. No obstante esta década sirvió para reestablecer las bases de la amistad entre ambos países. Las relaciones se intensificaron a lo largo de los años sesenta, en los que la RFA se convirtió definitivamente en un gigante económico y España comenzó a disfrutar de los beneficios de su salida de la autarquía, experimentando una gran recuperación económica. El gobierno de Bonn apoyó en todo momento a España y su solicitud de adhesión a la CEE ya que, siguiendo su férrea Westpolitik de los años setenta,

86. BORGER, Sebastian, Germany's party political ..., p. 21.

87. Ibid., p. 22. 
veía en el europeísmo español la solución para la democratización del país a la muerte de Franco. En ese aspecto, tanto la CDU como el SPD, a diferencia de otros partidos políticos europeos, habían entendido con acierto que el aislamiento europeo del régimen franquista no era positivo y podría acabar favoreciendo la aparición de extremismos de derecha e izquierda.

El tercer vector a tener presente lo conforman las actuaciones paraoficiales de las fundaciones políticas germanas. En todo el proceso de transición democrática jugaron un papel muy importante que ha sido valorado por la historiografía de forma muy positiva como ejemplo de éxito de la labor de dichos agentes políticos en su actividad transnacional. En el caso español, el esfuerzo realizado por las fundaciones no se debió a un plan preconcebido para la democratización del país. Su actividad estuvo más bien encaminada a llevar a cabo con discreción una serie de acciones concretas, en un momento decisivo de la transición, para facilitar la actividad de los partidos políticos. Sin embargo, la dimensión de la labor realizada por estos actores con el objetivo de crear una alternativa política real tras cuarenta años de dictadura franquista, todavía no ha sido suficientemente investigada y valorada, salvo en el caso de los socialdemócratas alemanes y el PSOE. 



\title{
El «derecho penal del enemigo»: de la teoría actual a la práctica represiva del «Nuevo Estado» franquista The «Enemy's Criminal Law»: From current theory to the repressive practice of the Francoist «New State»
}

\author{
Ignacio Tébar Rubio-Manzanares \\ Universidad de Alicante
}

Recibido: 17-III-2014

Aceptado: 20-VI-2014

\section{Resumen}

El objetivo de este artículo es descartar las críticas de contenido moral que se le han hecho al llamado «Derecho penal del enemigo» por los supuestos lazos con el «decisionismo soberano» de entreguerras. Sin entrar en el debate entre juristas acerca de si es «Derecho» legítimo o no lo es, se va a defender la idoneidad del uso de la categoría jakobsiana para caracterizar el Derecho penal totalitario, en este caso el Derecho penal del primer franquismo. A modo de aproximación, se van a enumerar algunas de las técnicas punitivas de la dictadura desde los elementos que definen hoy al Derecho penal del enemigo, con el objetivo de defender la utilidad del concepto como categoría comparable, no solamente con el presente, sino entre los distintos-ismos históricos.

Palabras clave: Derecho penal del enemigo, Represión, Franquismo, Gubernamentalidad.

\begin{abstract}
The aim of this paper is to discard the moral content criticism that has been made to the so-called "The Enemy's Criminal Law » given its alleged bonds with the interwar's «Sovereign Decisionism». Rather than entering the debate amongst jurists about whether it is legitimate Law, the suitability of using the jakobsian category will be put forward to characterize totalitarian Criminal Law, in this particular case, early Francoism Criminal law. To start with, some of Franco's dictatorship punitive techniques will be revised beginning with the elements that nowadays define 'the Enemy's Criminal Law in order to defend the usefulness of the concept as a comparable category, not only with today's, but with other historical -isms.
\end{abstract}

Keywords: Enemy's Criminal Law, Repression, Francoism, Government. 


\section{Introducción}

Las formas semblantes al viejo hostis romano han seguido existiendo a lo largo de la historia del Derecho occidental. En el Derecho penal moderno, quizá la principal influencia en ese sentido fueron los planteamientos doctrinales de Von Liszt, con los que se continuó justificando y legitimando el trato a ciertas personas como «enemigos», por su supuesta peligrosidad. Aquella doctrina influyó sobre las legislaciones y prácticas penales del siglo XX, en las que se planteaba la «inocuización» de los «incorregibles», como por ejemplo en el caso español con la famosa Ley de Vagos y Maleantes de 1933. Pero no fue hasta que esas propuestas penales se encontraron con formas de gobierno totalitarias cuando alcanzaron su expresión más nociva. No es de extrañar que, con la aparición en la actualidad de una justificación doctrinal a la nueva legislación «defensista», se haya vuelto a generar debate entre los juristas. El primero en emplear la expresión «Derecho penal del enemigo» fue el profesor Gunther Jakobs, para defender la necesidad de un Derecho penal distinto del Derecho penal de «ciudadanos» en la «lucha» contra la delincuencia organizada desde el Estado de derecho ${ }^{1}$.

La actualización de ese tipo de normas y de teorías ha provocado toda clase de posicionamientos, reflexiones y críticas entre los juristas, pero también puede aportarse algo desde la historiografía. En este artículo se va a tratar de hacer una breve descripción del planteamiento moderno de Jakobs y de las críticas que ha recibido, para incidir sobre las comparaciones con el «decisionismo» jurídico de Carl Schmitt. Se sostiene que, más que una actualización de la idea de «lo político» de Schmitt, en Jakobs puede haber elementos útiles para analizar «retrospectivamente» el Derecho penal de entreguerras, siendo el Derecho penal fascista un «Derecho penal del enemigo» paroxístico, al que se llegó no como resultado de una escalada punitiva de unas democracias a la defensiva, sino de la introducción de una nueva «gubernamentalidad» totalitaria. Por último, se van a señalar las relaciones de los teóricos del Derecho franquistas con las doctrinas de Schmitt y se marcarán las principales leyes con que el «nuevo

1. Cancio Meliá, Manuel, Jakobs, Gunther, Derecho penal del enemigo, Madrid, Civitas, 2003. Según Portilla Contreras, Guillermo, "La legitimación doctrinal de la dicotomía schmittiana en el Derecho penal y procesal penal del «enemigo»", en CANCio Meliá, Manuel y Gómez-Jara Díez, Carlos (coords.), El Derecho penal del Enemigo. El discurso penal de la exclusión, Madrid, Edisofer, 2006, vol. 2, pp. 657-658, ésta es su principal novedad: proporciona un sustento doctrinal que avala la necesidad de dos tipos de derecho. Se suma al Derecho de dos velocidades planteado por SiLVA SÁncheZ, Jesús María, en La expansión del Derecho Penal: aspectos de la política criminal en las sociedades postindustriales, Madrid, Civitas, 1999. 
Estado» franquista se fue dotando de un Derecho penal «de combate» contra sus enemigos.

\section{El «Derecho penal del enemigo»}

El concepto planteado por Jakobs en los ochenta ha resurgido con fuerza en el contexto moderno de «gestión de riesgos» de la «era global», sobre todo tras el rearme punitivo que se está registrando en varios países democráticos después del 11-S. Para este autor, el ordenamiento jurídico democrático se fundaría «sobre la base de un consenso o corroboración social y cognitiva por parte de los ciudadanos» ${ }^{2}$. Los «enemigos» se enfrentarían a ese «consenso», a un ordenamiento en teoría legítimo ${ }^{3}$, que giraría alrededor de un «acto comunicativo» entre ciudadanos, y cuyas leyes habrían sido supuestamente otorgadas a sí mismos. «Enemigos» serían por tanto aquellos que quebrasen de una manera continuada la confianza social, codificada en el Derecho. Para apoyar su argumento, cita algunos ejemplos en que esto ya ocurre, como el tratamiento que reciben en la actualidad los delitos de terrorismo, las bandas organizadas o casos de pederastia ${ }^{4}$.

Siguiendo con la descripción de esta teoría, uno de los aspectos que más críticas ha generado es que considera que el «enemigo» no puede ser tratado como «persona» en virtud de la extrema gravedad y su incorregibilidad delictiva:

«Quien no presta una seguridad cognitiva suficiente de un comportamiento personal, no sólo no puede esperar ser tratado aún como persona, sino que el Estado no debe tratarlo ya como persona, ya que de lo contrario vulneraría el derecho a la seguridad de las demás personas» ${ }^{5}$.

Concepto polémico, que se explica si se atiende a la idea funcionalista del Derecho penal que tiene el autor. Según su propia «teoría de la prevención general

2. Polaino-OrTs, Miguel, Lo verdadero y lo falso en el Derecho penal del enemigo. Prólogo de Günther Jakobs, Azángaro, Universidad de Huánuco, Editorial Grijley, 2009, p. 192-193. Para exponer los puntos de vista de los autores favorables a las tesis de Jakobs se ha utilizado conscientemente la obra de POLAINO-ORTS, por considerarse de la mejor síntesis al respecto en castellano.

3. En su favor hay que decir que la excepcionalidad democrática de este modelo pocas veces es respondida por la ciudadanía, cuando no es apoyada por la mayoría, MiRó LiNARES, Fernando, «Democracias en crisis y Derecho penal del enemigo. Política criminal frente al terrorismo en los Estados democráticos antes y después del 11 de septiembre de 2001», en Cuadernos de Política Criminal, no 87 (2005), p. 211.

4. JaKoBS, Gunther, "Derecho penal del ciudadano...", p. 39. En la legislación española actual, habría que añadir otros ámbitos como la violencia de género, delitos contra la seguridad vial, medidas de seguridad o delitos de posesión.

5. Ibid., p. 47. 
positiva ${ }^{6}$, el Derecho penal cumple la misión de confirmar el mandato jurídico, por encima de la protección de bienes jurídicos, y busca principalmente el «aseguramiento de las expectativas normativas esenciales frente a sus defraudadores ${ }^{7}$, esto es, la vigencia de la norma, que permita el desarrollo normal de las actividades ciudadanas. Dentro de este esquema, la «persona» es el «ser humano» mediado por la norma y el Derecho ${ }^{8}$. Así, un «individuo» se comporta como «persona» mientras actúa de acuerdo a las «expectativas sociales institucionalizadas en las normas», o dicho en otras palabras: «sólo es persona quien ofrece una garantía cognitiva suficiente de un comportamiento personal, y ello como consecuencia de la idea de que toda normatividad necesita de una cimentación cognitiva para poder ser real» ${ }^{9}$. Por poner un ejemplo, lo importante para Jakobs es que si no estamos seguros de que al pasar por una zona de la ciudad no va a sucedernos nada, el derecho a la libertad de movimiento es papel mojado, por lo que es ahí donde debe actuar el Derecho penal, asegurando y actualizando las expectativas «normales». Lo mismo vale para el individuo, que debe asegurar cierta "predictibilidad» ${ }^{10}$.

Fuera del estatus de «persona», habría una suerte de degradación en la que se encontrarían los «individuos»-i.e. menores, enfermos mentales, etc.-, a los que se juzgaría menos fiables o capaces y que serían neutralizados mediante la custodia de seguridad. Más allá, se situarían aquellos que a pesar de tener plenas capacidades cognitivas, se apartan conscientemente y de forma profesional o como modus vivendi de la norma aprobada por la sociedad, y que por ello salen de la esfera de lo que se concibe como «persona», esto es, los «enemigos» ${ }^{11}$. En definitiva, para dicho autor, lejos de ser siquiera peyorativa, la de «enemigo» es una categoría estrictamente jurídica -y no una definición esencialista, religiosa,

6. Jakobs, Gunther, Derecho Penal. Parte General. Fundamentos y teoría de la imputación, Madrid, Marcial Pons (2 edic.), Madrid, 1997.

7. Cerezo Mir, Juan, Curso de Derecho penal español. Parte General, Vol.1, Introducción, Madrid, Editorial Tecnos, 2005 (6 $6^{\text {a }}$ edic.), p. 13.

8. Un «ser humano» pasa de un hipotético «estado natural» al «ser social», esto es, a ser «persona». Tiene un carácter normativo que es equiparable a la dicotomía de los antiguos teóricos liberales, al dividir entre el «hombre» (en un hipotético estado de naturaleza) y el «ciudadano» (regido por relaciones normativas).

9. Cancio Meliá, Manuel, Jakobs, Gunther, Derecho penal del enemigo, Madrid, Civitas, 2003 , p. 51.

10. Ibid., pp. 37 y 38.

11. Según Polaino-OrTs, Miguel, Lo verdadero y lo falso, pp. 174 y ss., esas diferenciaciones son «garantistas», se garantiza el rol social de la «persona» que ocupa una posición dentro de la sociedad, que cumple con unos derechos y unos deberes, pero también del «individuo», quien puede no participar en el contexto social -por ejemplo el menor de edad en ciertos campos del Derecho-, o infringir la norma, pero no hasta niveles que le sitúen en el territorio del «enemigo». 
bélica o filosófica-, que parte de la idea del Derecho penal va dirigido a confirmar la norma entre «ciudadanos», aquellos que respetan sus obligaciones y conservan los derechos, aunque puntualmente puedan cometer una desviación. Asegura, por tanto, que no tienden a desaparecer las garantías legales ni los límites a la punición que se marque el Estado de derecho, los «enemigos» no pierden por completo sus derechos civiles, es una «guerra refrenada». Se reconoce en última instancia una relación individuo-Estado en la que la de-personalización es parcial, voluntaria ${ }^{12}$, temporal, y sólo en ciertos campos del Derecho penal. En cualquier caso, ni los límites ni los criterios para constatar los rasgos del «enemigo» quedan del todo aclarados, ni se ha comprobado la efectividad de estas legislaciones, según sus críticos ${ }^{13}$.

En cuanto a las características específicas del «Derecho penal del enemigo», hay que señalar tres elementos definitorios sobre los que establecer comparaciones: en primer lugar, éste se concreta por un amplio adelantamiento de la punibilidad (que alcanza a los actos preparatorios, previos a la lesión del bien jurídico; el hecho futuro, en lugar del habitual punto de referencia en el hecho). En segundo lugar, las penas previstas son «desproporcionadamente» elevadas (penas como medida de contención sin proporción con la lesión realmente inferida). En tercer lugar, determinadas garantías procesales son relativizadas o incluso suprimidas. A estas tres características, sus críticos le añaden una cuarta, a partir de dos precisiones; la primera es que no se dirigen operaciones de combate contra un enemigo reconocible, sino que se «desarrolla una cruzada contra malhechores archimalvados», bajo el influjo de las imágenes de los «enemigos de la sociedad». El objetivo sería lograr el reconocimiento (o legitima-

12. Se puede argumentar que son «potestativos» o voluntarios el pensamiento y los actos del sujeto, pero no el ser tratado como enemigo o el ser excluido, que pertenece en última instancia al legislador. Los defensores del Derecho penal del enemigo contestan a esta objeción que en el ámbito concreto de la juridicidad, sí sería potestativo. Parten de la creencia en una suerte de pacto social por el cual la sociedad se otorga unas leyes para garantizar la seguridad cognitiva que todos los ciudadanos tienen depositada en la norma. El problema es que dicho pacto es «ideal», descargan toda responsabilidad del sistema normativo existente, tanto a nivel político como a nivel penal, y cargan armas contra el autor, sin contemplar el fenómeno delictivo en toda su complejidad. Cfr. Diez Ripollés, José Luis, «De la sociedad del riesgo a la seguridad ciudadana: un debate desenfocado», en Revista Electrónica de Ciencia Penal y Criminología, 07-01, (2005), p. 17 y ss. [http://criminet.ugr.es/recpc/07/recpc07-01.pdf]

13. Por ejemplo, MuÑoz CONDE, Francisco, «El nuevo Derecho penal autoritario», en Losano, Mario, MuÑoz CONDE, Francisco, El derecho ante la globalización y el terrorismo, Valencia, Tirant lo Blanch, 2004, p. 174 y ss. Las categorías que se emplean además en este tipo de legislaciones suelen ser vacías, con elementos subjetivos y valorativos, que llevan a interpretaciones en ocasiones conspirativas, como ocurre con las «finalidades del terrorismo». 
ción) del agente represor mediante la atribución de perversidad del otro, mediante la «demonización». Es decir, junto con el punitivismo, es también un Derecho penal simbólico ${ }^{14}$. En segundo lugar, esta propiedad simbólica abre otro rasgo fundamental; si «el hecho» no es lo que está en la base de la tipificación penal, sino que se añaden otros elementos para caracterizar el autor como perteneciente a la categoría de los enemigos, entones es un Derecho penal de autor ${ }^{15}$ y se invierte la carga de la prueba. Según esta perspectiva, no se estabilizarían normas, sino que se demonizaría un determinado grupo de infractores $^{16}$, al que se intentaría «inocuizar» antes de que haya cometido delito alguno, y por ello dejaría de ser considerado Derecho como tal, sino nuda fuerza. Polaino-Orts responde a tales acusaciones que aun aceptando que contiene ciertos elementos valorativos del autor, el Derecho penal actual ya reconoce ciertas circunstancias personales para determinar la pena, pero se trata de circunstancias «externamente manifestadas», no lesionándose así el principio del hecho, ni se valora la mera perversidad subjetiva o la desobediencia interna, sino que se acomoda a la «peligrosidad real» que conste en el sujeto ${ }^{17}$.

Algunos autores denuncian la lógica de la «perenne emergencia» a la que se van acogiendo los Estados democráticos ${ }^{18}$, o la normalización de la «excepcionalidad» como la sanción de un «espacio vacío de derecho» ${ }^{19}$. Todo ello lleva a sus críticos a afirmar que un Derecho penal «del enemigo» sería un oxímoron.

14. Es evidente que todo Derecho penal -y todo Derecho- es en buena medida «simbólico». Cancio Meliá, Manuel, “ $i$ «erecho penal» del enemigo?”, en Cancio Meliá, Manuel, JakoBs, Gunther, Derecho penal del enemigo..., p. 65 y ss, hace referencia en un sentido crítico a los excesos del agente político por lanzar con sus medidas mensajes a la población; para aparentar ser «un diligente guardián», «un legislador decidido», etc. No obstante, el «Derecho penal del enemigo» no contiene únicamente consecuencias tranquilizadoras, a través de normas hechas para no ser aplicadas, sino que efectivamente existen procesos de criminalización a través de la aplicación de nuevas normas o por medio del endurecimiento de penas en normas ya existentes: un incremento cuantitativo y cualitativo de la criminalización como criterio político-criminal.

15. Ver la descripción que de los enunciados de Jakobs hace Manuel CanCio Melí en "La expulsión de ciudadanos extranjeros sin residencia legal (Art. 89 CP)" en VV. AA. Homenaje al profesor Dr. Gonzalo Rodríguez Mourullo, p. 206 y ss.

16. Cancio Meliâ, Manuel, “ $i$ «Derecho penal» del enemigo?”..., Madrid, Civitas, 2005, pp. 93-94.

17. «El enemigo en sentido funcionalista no es, en absoluto, un muerto en vida, un homo sacer "al que cualquiera puede dar muerte", sino únicamente un delincuente peligroso que es tratado penalmente de acuerdo a las reglas del Estado de Derecho» PolainoOrts, Miguel, Lo verdadero y lo falso..., p. 252, refiriéndose a PORTILla Contreras, Guillermo, "La configuración del 'homo sacer' como expresión de los nuevos modelos del Derecho penal imperial", en Pérez Álvarez, Fernando (coord.), Serta in Memoriam Alexandri Baratta, Salamanca, Ediciones Universidad de Salamanca, 2004, pp. 1401-1403.

18. Silva SÁnchez, Jesús María, La expansión del Derecho Penal..., pp. 166-167.

19. Agamben, Giorgio, Homo sacer II. Estado de excepción, Valencia, Pre-Textos, 2004, p. 38. 
Se ha criticado también que la teoría de la «prevención general positiva» sobre la que se cimenta el «Derecho penal del enemigo» de Jakobs, podría ajustarse a «cualquier tipo de sociedad y para la protección de cualquier tipo de normas ${ }^{20}$, incluidas las de una dictadura. Esto se debe a que el Derecho penal según Jakobs no se ocupa en primer lugar de la defensa del bien jurídico, sino que se encarga de actualizar la norma como un acto comunicativo, justificándose la pena dentro de las llamadas teorías relativas sobre la prevención gene$\mathrm{ral}^{21}$. Es una crítica que advierte a futuros penalistas y legisladores sobre los posibles excesos «funcionalistas», pero explica también por qué la teoría de Jakobs encajaría perfectamente en el estudio de otros tipos de Derecho penal del pasado: su definición utilitarista del Derecho penal es válida para prácticamente cualquier contexto, del mismo modo que su categoría de «Derecho penal del enemigo» es suficientemente amplia para aplicarse a diferentes periodos históricos.

\section{Teoría del estado de excepción y «Derecho penal del enemigo»}

Relacionadas con esa capacidad de aplicarse como categoría válida en el análisis del pasado, algunos de sus críticos apelaron a las leyes y a la doctrina jurídica de los Estados totalitarios, basadas en el combate de «enemigos», para atacar el «Derecho penal del enemigo» jakobsiano y situarlo fuera del Derecho penal de un Estado de derecho. Después de los avances en la extensión de la ciudadanía civil, política y social a toda la población, es lógico percibir su suspensión parcial contra la delincuencia como «concesiones del estado liberal al estado absoluto $[s i c]_{»^{22}}$. Ese lenguaje bélico de Jakobs se ha utilizado para establecer paralelismos con el Derecho penal del enemigo de los Estados totalitarios, por su presunto carácter «contractualista, schmittiano y estructuralfuncionalista»:

«Han pretendido ofrecer legitimación al violento reingreso de la teoría del estado de excepción schmittiana, del concepto del enemigo injusto y de la guerra justa como manifestación primigenia de un Derecho penal que, de ese modo, se militariza. Se justifica así la acción bélica preventiva que se plantea en

20. GIL GIL, Alicia, «Prevención general positiva y función ético-social del Derecho Penal», en Díez Ripollés, José Luis, La Ciencia del Derecho Penal ante el nuevo siglo, Libro Homenaje al Profesor Doctor Don José Cerezo Mir, Madrid, Tecnos, 2002, p. 11, nota 5.

21. En el «Derecho penal del ciudadano» la función es «comunicativa», respuesta al hecho de una «persona racional», mientras que para el «Derecho penal del enemigo» tiene la función de eliminar un peligro, de combatirlo, no pretende comunicar nada, sino ser «efectiva», se niega por tanto la capacidad de razonar al enemigo.

22. ZafFaroni, Eugenio Raúl, El enemigo en el Derecho penal, Madrid, Dykinson, 2006, p. 13. 
el estado de naturaleza, un escenario en el que todo es válido contra el enemigo. En definitiva, se brinda la cobertura perfecta al reingreso del decisionismo soberano $»^{23}$.

Sin embargo, no está de más señalar las diferencias entre la noción de Jakobs y la de los autores fascistas de entreguerras. Efectivamente, el «Derecho penal del enemigo» reintegra una peligrosa retórica bélica en el interior del Derecho penal moderno, pero la confusión es en buena medida semántica, debido al uso de los conceptos polémicos de «enemigo» y de «persona» por parte de Jakobs. En cuanto a las acusaciones de «decisionismo», o de «schmittiano», caen en el anacronismo. Si acudimos a Carl Schmitt, principal autor que dio un sustento doctrinal al tratamiento penal del «enemigo» en la época, las diferencias son evidentes. Schmitt, cuyos objetivos superaban ampliamente la teoría del Derecho penal, trató de dar toda una nueva justificación del Estado contraria al liberalismo y la que consideraba una democracia «procedimental», en su conocido enfrentamiento con Hans Kelsen.

Para Schmitt, la neutralidad presupuesta en un Estado de derecho hacia su ciudadanía, paralela a una mayor intervención del Estado en la vida cotidiana, eran una contradicción insalvable, propia de un sistema pluralista y de una Constitución aprobada por puro compromiso, que llevaban al desorden y la desintegración del propio Estado. En un contexto de inestabilidad política, el expropagandista católico apeló a la eliminación de la pluralidad en una única política constituyente. Para ello, trató de encontrar la fundamentación del Estado, y consideró que ésta debía hallarse en la esencia de lo político: la «decisión» constitutiva del soberano. Si el criterio para definir qué es lo político no podía ser «lo estatal», por estar el «Estado» y la «sociedad» interconectados, ni en la simplificación «los partidos políticos», debía de estar en otra vía: constatar cuáles eran las categorías específicamente políticas. Y encontró que tal categoría, fundada sobre la decisión soberana, surge del enfrentamiento «amigo»-«enemigo» ${ }^{24}$, previa al propio Estado, tal como sirven los opuestos bello-feo, bueno-malo, útil-dañoso para lo estético, moral o económico respectivamente.

La aparición de una verdadera comunidad «política» se origina según Schmitt del enfrentamiento existencial -vivir o no vivir-, del estado de excepción en que sólo cada uno de las partes puede decidir por sí misma quién es el enemigo que hace peligrar el propio modo de existencia -si bien, añade, en el

23. Portilla Contreras, Guillermo, "La legitimación doctrinal"..., p. 662 y ss.

24. Para una mejor comprensión de este criterio, Sснмiтt, Carl, El concepto de lo político: texto de 1932 con un prólogo y tres corolarios, Madrid, Alianza, 1991, ver sobre todo "Corolario II", p. 131 y ss. 
plano psicológico es fácil que se añadan otras distinciones del tipo «feo», «inútil»o «malo»-. Son categorías de amistad y enemistad públicas, el grado máximo de intensidad de una unión o separación, de una asociación o disociación, entre las que subyace una posibilidad real de eliminación física, de una guerra. La guerra, advierte, no como necesidad cotidiana ni real, ni siquiera, dice, deseable, pero sí es una realidad óntica, hay una posibilidad efectiva, es el presupuesto que determina una conducta política. Para ejemplificar la diferencia entre la enemistad pública de la rivalidad privada, recurre a la conocida cita de los evangelios; cuando se dice «amad a vuestros enemigos» se refiere al inimicus, al enemigo privado, no al hostis, el enemigo político, para el que no es necesaria el odio y la animadversión personal ${ }^{25}$. Mientras el liberalismo es «despolitizante» y sólo percibe rivales parlamentarios o competidores económicos, un verdadero poder soberano no rehúye el enfrentamiento ni la decisión política, la lucha contra el «enemigo».

Únicamente en la guerra, ese agrupamiento político alcanza sus últimas consecuencias: en la intensificación de las hostilidades, aquellos aspectos no políticos, no militares, pueden acabar también entrando en la confrontación política cuando ganan suficientemente fuerza para agrupar en amigos y enemigos, ya que según el jurista alemán la destrucción física de la vida humana sólo puede tener lugar como afirmación de la propia forma de existencia. En otras palabras, lo político puede extraer sus fuerzas de otros sectores (moral, estético, económico, religioso...), surgir y originarse de cada una de estas esferas, hasta lograr un nivel de hostilidad que presuponga la posibilidad de enfrentamiento físico. Sólo entonces alcanza el estatus de político. La llamada «guerra total» acaba por cancelar la distinción entre combatientes y no combatientes, «ámbitos de la realidad de suyo no militares (economía, propaganda, energías psíquicas y morales) se ven involucrados en la confrontación hostil», en una clase de guerras especialmente inhumanas, que degradan al enemigo, ya que el enfrentamiento brota de lo existencial.

Para el totalitarismo nazi, esta visión de lo político como división amigoenemigo se traducía en la apropiación «total» del Estado por parte del Volk, encuadrado en el NSDAP y dirigido por el Führer, que aniquilaban al «Estado neutral» de Weimar. La concepción de lo político de Schmitt tuvo también consecuencias en lo penal, y por ejemplo se convirtió en la mejor justificación de las leyes raciales de Núremberg de 15 de septiembre de 1935, al separarse al enemigo «existencial»-en este caso racial- ${ }^{26}$ del pueblo alemán. Además,

25. Ibid., p. 53 y ss.

26. Así lo sostiene Zarka, Yves-Charles, Un detalle nazi en el pensamiento de Carl Schmitt, Barcelona, Anthropos, 2007. 
contrarios al positivismo jurídico, el delito para los autores fascistas se concibe como «un ataque o puesta en peligro de la norma penal que ordena moralmente a esa comunidad y realizado por una persona que existe y pertenece, por tanto, a esa comunidad, enlazada por la unidad y el destino de su Historia $»^{27}$. Para decidir si un criminal debía recibir un tratamiento penitenciario o la eliminación física, la doctrina desarrolló un sistema que recordaba a los procedimientos disciplinarios para el funcionariado o el ejército, fundado en la creencia en la lealtad debida al Estado y a sus líderes. Este tipo de procedimientos no trataban de determinar la responsabilidad del autor de una falta en particular, sino si el «comportamiento en general» del sancionado le permitía seguir en el círculo de sus colegas. Al extenderlo a la Volksgemeinschaft, la justicia se encargaba de discernir si un delincuente debía ser tolerado como parte de la sociedad o si debía ser apartado temporal o permanentemente. Como el propio Carl Scmitt señalaba en su teoría del «Orden concreto», todo ello atravesado por vagas categorías morales como «honor», «lealtad», o «deber ${ }^{28}$. El propósito del Tribunal era por tanto discernir no ya si el acusado había violado alguna Ley, sino si merecía seguir perteneciendo a la comunidad, el hecho dejaba de ser el principal argumento, para juzgarse al autor ${ }^{29}$. Las viejas teorías ilustradas que convertían en «enemigo» al delincuente se habían radicalizado en una determinada representación -teológica, étnica, racial- de la «comunidad política», en que «el otro» puede convertirse en «enemigo», hostis, criminalizado en la Ley positiva o simplemente declarado hors la loi, como homo sacer ${ }^{30}$.

La defensa de la civilización, el orden económico, la cristiandad, la comunidad étnica o del «Estado totalitario» contemplaba la desaparición de la división de poderes en nombre de la decisión soberana y la pérdida de Derechos individuales a discreción del Ejecutivo para combatir a los «enemigos» de la comunidad nacional. El concepto de «enemigo» empleado por el Derecho penal

27. Del Rosal, Juan, "Política y criminalidad", Revista de Estudios Políticos, nº 4 (1941), p. 757.

28. Schmitt, Carl, Sobre los tres modos de pensar la ciencia jurídica, Madrid, Tecnos, 1996 (edic. orig. 1934).

29. MüLlER, Ingo, Hitler's Justice. The Courts of the Third Reich, Londres, Taurus, 1991, p. 77 y ss.

30. En el Derecho romano arcaico, la persona que era declarada sacer (sagrado, en el sentido de "puesto aparte») por haber cometido un delito, quedaba fuera de toda protección civil, su vida, familia y propiedades quedaban confiscadas, y podía ser ejecutado con total impunidad por cualquier miembro de la comunidad. En la actualidad, el filósofo italiano Agamben, Giorgio, Homo sacer. El poder soberano y la nuda vida, Valencia, Pre-Textos, 1998, lo ha rescatado para señalar la persistencia de la vida humana como simple «materia», sujeta a la decisión del poder soberano, que condujo al exterminio de masas durante el siglo XX. 
totalitario surge de la política como estado de excepción permanente, de una decisión soberana encarnada en el Führer, Duce o Caudillo. Compararlo con la noción funcionalista de Jakobs, que pretende regular esferas del «estado de excepción» dentro de la normalidad del Estado de derecho, se hace extremadamente complicado. El propio Schmitt consideraba que las normas de excepción dentro de la Constitución de Weimar eran un vano intento por circunscribir casos en que el derecho se suspende a sí mismo ante la puesta en peligro del mismo Estado ${ }^{31}$. Aunque las «técnicas» jurídicas del Derecho penal del enemigo pudieran ser comparables en términos generales (adelantamiento de la punición, relajamiento de garantías, elementos valorativos del sujeto), mientras Jakobs sostiene su Derecho penal «de combate» con el objeto de salvaguardar ciertas esferas de libertad del «ciudadano»-o de lo contrario, advierte «se mezclan los conceptos "guerra" y "proceso penal" »- ${ }^{32}$, Schmitt o los penalistas del momento fabricaron un Derecho penal que podía suspenderse en manos del Führer, y que corregía las desviaciones individuales en favor de una forma concreta de ser de la «comunidad», que se situaba en lo trascendente.

La diferencia, pues, más allá del uso de un determinado «juego del lenguaje», es en última instancia de gobernabilidad o gubernamentalidad ${ }^{33}$. Conocida también como racionalidad de gobierno o arte de gobierno, la gubernamentalidad define un modo o sistema de pensamiento acerca de la naturaleza y la práctica del gobierno, en el sentido amplio de conducción de conductas (quién puede gobernar, qué se entiende por gobernar y qué o quienes son los gobernados), dentro de cada contexto histórico ${ }^{34}$. Mientras que la «guberna-

31. En su caso además son normas constitucionales, no penales: «¿Dónde toma el derecho esa virtud y cómo es posible lógicamente que una norma tenga validez excepto en un caso concreto que ella misma no puede prever de hecho?». Schmitt, Carl, Teología política, Madrid, Trotta, 2009, p. 26.

32. JAKOBS, Gunther, "Derecho penal del ciudadano y Derecho penal del enemigo", en Cancio Melié, Manuel, Jakobs, Gunther, Derecho penal..., p. 42. La crítica a esta postura - «o nosotros o el caos»- es muy evidente.

33. En el sentido de «gubernamentalidad» que le da Foucault, Michel, "La gubernamentalidad", en Foucault, Michel, et alii, Espacios de poder, Madrid, La Piqueta, 1991, pp. 9-26, y VÁzQuez García, Francisco, La invención del racismo, Madrid, Akal, 2009, pp. 11 y 12.

34. GORDOn, Colin, "Governmental rationality: an introduction", en Burchell, Graham, Gordon, Colin y Miller, Peter (eds.), The Foucault Effect. Studies in Governmentality, Chicago, University of Chicago Press, 1991, p. 3 y ss.; VÁzQuez García, Francisco, La invención del racismo..., p. 12. Sin embargo, hay que añadir que en esa serie de preguntas se dio más relevancia al «cómo», de clara inspiración nietzscheana, por encima del «quién», el problema de la soberanía y del enfoque jurídico tradicional. Estas «precauciones metodológicas» partían de una serie de principios que no se abandonan y que 
mentalidad» totalitaria aplica a través del Derecho penal un programa de «disciplinamiento» sobre toda la población, mediante la división bélica «amigo»-«enemigo» o la clasificación por adhesión, consentimiento o enemistad, la «gubernamentalidad» liberal que representa el modelo jakobsiano, trata de sostener y alentar espacios de actuación individual -sirva la metáfora del mercado económico-, neutralizando para ello los riesgos y las amenazas que pueden aparecer desde fuera o en su interior, obviando la creciente criminalización de los «excluidos» desde el punto de vista socioeconómico, pero reconociendo ciertas esferas de libertad de los gobernados. Resulta, pues, un error abandonar el uso nominalista e histórico de las categorías en cada tipo de razón gubernamental, como ocurre también cuando se comparan las políticas natalistas totalitarias con las ayudas a la familia en la política actual o con las del Estado del bienestar de posguerra. Aunque se trate en general de "políticas de ayuda a la natalidad», contienen racionalidades gubernamentales completamente distintas.

Por otro lado, el proyecto totalitario podía entrañar medidas extremas de inocuización del delincuente común, y la prevención/retribución en lo penal no tenía problemas en aniquilar sectores amplios de la población, algo que en las propuestas actuales obviamente es rechazado de pleno, manteniendo la reintegración voluntaria en la ciudadanía del «enemigo». En definitiva, «sólo desnaturalizando uno de los dos conceptos, o los dos al tiempo, pueden buscarse $-\mathrm{y}$ menos aun hallarse- semejanzas entrambas nociones ${ }^{35}$. La exacerbación punitiva, la de-personalización parcial o los usos simbólicos de sujetos «archimalvados», no convierten al «Derecho penal del enemigo» de Jakobs en «decisionista», pues su combate es contra el inimicus, no el hostis, aunque no esté de más recordar que las estrategias generales de las políticas totalitarias no hicieron más que recombinar y llevar al extremo los mecanismos disciplinarios (y jurídicos) existentes en el Estado libera ${ }^{36}$.

\section{Una teoría del Estado nacionalcatólica}

El Derecho penal del franquismo se construyó ad hoc en una situación de absoluta excepcionalidad. Desde los primeros asesinatos «en caliente», hasta el pleno

se resumen en la capilaridad (el cómo de las instituciones frente al dónde y al cómo fundador de la soberanía), en el análisis ascendente del poder (mecanismos infinitesimales que son utilizados por los mecanismos generales) y en los dispositivos de saber. Cfr. Foucault, Michel, Hay que defender la sociedad. Curso del Collège de France (19751976), Madrid, Akal, 2003, p. 35 y ss.

35. Polaino-OrTs, Miguel, Lo verdadero y lo falso en el Derecho penal del enemigo. Prólogo de Günther Jakobs, Azángaro, Universidad de Huánuco, Editorial Grijley, 2009, p. 157.

36. Foucault, Michel, Genealogía del racismo, Madrid, La Piqueta, 1992, pp. 247-273. 
funcionamiento de los tribunales militares, pasó un largo periodo de entre seis y ocho meses ${ }^{37}$, en que los bandos de declaración del estado de guerra de cada provincia -luego unificados y extendidos al resto de la Península- sirvieron como rudimentos legales para justificar la conquista violenta del poder. La violencia de guerra convivió también con los primeros juicios sumarios que con un mismo fin-administrar la limpieza política en la retaguardia-, se dictaron contra algunas autoridades leales a la II $^{a}$ República. Este tipo de justicia expeditiva no era nueva para los militares, tampoco el «enemigo» al que se enfrentaban, pero desde aquel momento pudieron aplicarla en todo el territorio y sin las cortapisas de ningún poder civil. El triunfo del Consejo de Guerra frente al paseo se enmarca dentro del proceso de centralización y construcción del Nuevo Estado, alrededor del primer Gobierno de Franco y con las primeras decisiones de la Junta Técnica, pero también se ha destacado que la extensión de un aparato judicial castrense vino precipitada en gran medida por el curso de los acontecimientos, como el impacto negativo sobre la opinión pública internacional de matanzas como la de Badajoz ${ }^{38}$.

A pesar de algunos intentos por jugar la partida de la legitimidad en el mismo terreno que el gobierno del Frente Popular ${ }^{39}$, las fuentes del Derecho y la justificación del Estado franquista tuvieron que convivir con su carácter «decisionista» radical y antidemocrático, apelando al derecho de rebelión cristiano, y según avanzó la guerra, a los delitos cometidos por los republicanos ${ }^{40}$.

37. Julià, Santos (coord.), Víctimas de la Guerra Civil, Madrid, Temas de Hoy, 1999, p. 171 y ss., que fechan en el mes marzo en el ensayo de Gómez BraVo, Gutmaro, MArCo, Jorge, La obra del miedo. Violencia y sociedad en la España franquista (1936-1950), Barcelona, Ediciones Península, 2011, p. 79 si bien, como señalan los estudios locales, continuaron existiendo asesinatos fuera de los consejos sumarísimos, como en Sevilla, Badajoz o Huelva.

38. Y que hubo de ocultarse bajo la cobertura de un supuesto derecho -además de con la posterior elaboración de la Causa General-. Ver Espinosa Maestre, Francisco, Contra el olvido, Barcelona, Crítica, 2006, p. 96 y ss. y Sevillano Calero, Francisco, Rojos. La representación del enemigo en la guerra civil, Madrid, Alianza, 2007, pp. 43-61.

39. Por ejemplo, la propagandística obra El Movimiento Nacional ante el Derecho y la Justicia, Real Academia de las Ciencias Morales y Políticas, Santander, 1938, que sería un avance de la publicación de la conocida «Comisión Bellón» establecida por Orden del Ministerio del Interior de 21 de diciembre de 1938, encargada supuestamente de «demostrar» algo que ya incluía en su título: «la ilegitimidad de los poderes actuantes en la República Española de 18 de Julio de 1936», y en la que había numerosos miembros que pertenecían a la R.A.C.M.P, Dictamen de la Comisión sobre ilegitimidad de poderes actuantes el 18 de Julio de 1936, Barcelona, Ministerio de Gobernación, Ed. Nacional, 1939.

40. Ministerio de Justicia, Causa General. La dominación roja en España. Avance de la información instruida por el Ministerio Público, Ministerio de Justicia, 1943, y sus posteriores ediciones. 
De ese acto fundador del «nuevo Estado», a partir de la voluntad de quienes tenían fuerza armada para efectuarlo, se derivan una serie de consecuencias primordiales para comprender la construcción del Estado franquista, ya sea el carácter militar de la dictadura, la teoría del Caudillaje, el Decreto de Unificación y el régimen de partido único, o el reparto de poderes de la «coalición reaccionaria» ${ }^{41}$. En ese proceso había que pasar del «Estado campamental» a una maquinaria política permanente, similar a los fascistas, como defendió Serrano Suñer ${ }^{42}$.

Es obvio por tanto que el discurso bélico tuvo que representar un aspecto central para explicar su naturaleza. La concepción del «enemigo», elemento fundamental de toda "cultura de guerra $»^{43}$, existente desde antes del golpe en las culturas políticas de la extrema derecha, servía como reafirmación de una determinada comunidad (un «nosotros»), y por otro lado en el extrañamiento y separación del enemigo del resto de la comunidad nacional. Consecuentemente, no es de extrañar que las concepciones políticas de Schmitt ejercieran un gran impacto sobre sus coetáneos españoles ${ }^{44}$.

41. Últimamente, han desarrollado el concepto SÁnCHEZ ReCio, Glicerio, "La coalición reaccionaria y la confrontación política dentro del régimen franquista", en TUSELL, Javier et alii (eds.), Estudios sobre la derecha española contemporánea, Madrid, UNED, 1993, pp. 551-562 y en Sobre todos Franco. Coalición Reaccionaria y Grupos Políticos en el Franquismo, Barcelona, Flor del Viento, 2008; y Ugarte Tellería, Javier, La nueva Covadonga insurgente. Orígenes sociales y culturales de la sublevación de 1936 en Navarra y País Vasco, Madrid, Biblioteca Nueva, 1998. En algunos aspectos resultan paralelas, aunque la concepción de Javier UGARTE TELLERía parte de un análisis más «social» y «cultural» que político. Se centra en comportamientos y formas de relación social dentro del universo de significados de la población conservadora a la hora de explicar esa «coalición», también como fenómeno europeo

42. Casanova, Julián, República y guerra civil, en Fontana, Josep, Villares, Ramón (dirs.), Historia de España, vol. 8, Barcelona, Crítica/Marcial Pons, 2007.

43. Definida como «el campo de todas las representaciones de la guerra forjadas por los contemporáneos (...) antes de su estallido y después», en Audoin-Rouzeau, Stéphane y BECKER, Annette, "Violence et consentement: la «culture de guerre» du premier conflit mundial", en Rioux, Jean-Pierre y SiRINELli, Jean-François (dirs.): Pour une historie culturelle. París, Seuil, 1997, p. 252. En otras publicaciones se precisa más el término, véase 14-18, retrouver la Guerre. París, Gallimard, 2000. Como balance de la importancia historiográfica de este concepto, SмIтн, Leonard V., "The 'Culture de guerre' and French Historiography of the Great War of 1914-1918", History Compass, vol. 5, no 6 (noviembre 2007), pp. 1967-1979 y Prost, Antoine, "La guerre de 1914 n'est pas perdue", Le Mouvement Social, $\mathrm{n}^{\circ} 199$ (2002), pp. 95-102. Se ha de añadir que la distinción entre el «amigo» y el «enemigo» fundamenta y establece los límites de dicha «cultura de guerra», según Sevillano Calero, Francisco, en Rojos..., p. 19 y ss.

44. Véase la influencia del pensamiento de Carl Schmitt en los principales juristas del régimen: Rodríguez González, Jesús P., Filosofía política Luís Legaz Lacambra, Madrid, Marcial Pons, 1997; sobre Legaz Lacambra y Francisco Javier Conde, LóPEz GARCía, José Antonio, Estado y Derecho en el franquismo: el nacional-sindicalismo. Francisco Javier 
Los autores franquistas aceptaron la «militarización» del sentido de la política que supone la división schmittiana: «de un realismo y de una agudeza magníficas (...) aun cuando lamentemos el impudor de su desnudez filosófica (que no la franqueza y sinceridad de la teoría misma) $»^{45}$, e incluso apoyaron su pesimismo antropológico como condición sine qua non para toda teoría política: las concepciones que presuponen en su base la bondad del hombre son de tipo liberal, y atacan la intervención del Estado en la vida social, con mayor virulencia según su radicalismo, si bien el liberalismo «no fué [sic] radical en su crítica al Estado, sino sólo despolitizante» ${ }^{46}$.

También sirvió de base teórica para las más importantes obras justificadoras del Estado nacional-sindicalist $\mathrm{a}^{47} \mathrm{o}$ para lanzar sus críticas contra el liberalismo jurídico, filosófico y político. Por ejemplo, su mayor discípulo en España, Francisco Javier Conde, rechazaba con Schmitt el positivismo jurídico y acusaba de «fantasmagoría» a su principal representante, Hans Kelsen, por levantar el orbe jurídico en un sistema de normas puras asentado en una norma hipotética. «No se hace la imputación con el auxilio de una norma, sino viceversa: sólo desde un centro de imputación se puede determinar qué es una norma y en qué consiste la regularidad normativa ${ }^{48}$. La cúspide del orden jurídico no es una norma hipotética, sino una «instancia decisoria suprema», soberana, y calcan su análisis del liberalismo, que ocultaba tras lo stato neutrale ed agnostico las fuerzas que buscaban despolitizar al Leviathan, al Estado ${ }^{49}$, fuerzas políticas al fin y al cabo, aunque rehuían el riesgo del mando político, al no reconocer enemigos.

Con todo, como señaló López García, hay que matizar la recepción que los teóricos franquistas hicieron del pensamiento schmittiano. Creían también que en Kelsen lo político «representa algo pecaminoso» ${ }^{50}$, pero tampoco había que

Conde y Luís Legaz Lacambra, Madrid, Centro de Estudios Constitucionales, 1996. De especial interés resulta para este trabajo el artículo del mismo autor "La presencia de Carl Schmitt en España", Revista de Estudios Políticos, n 91 (enero-marzo de 1996), pp. 139168. Versa sobre el mismo tema la obra de JimÉnEz SEGADO, Carmelo, Contrarrevolución o resistencia. La teoría política de Carl Schmitt (1888-1985), Madrid, Tecnos, 2009.

45. Galán, Eustaquio, "El criterio de lo político", Revista General de Legislación y Jurisprudencia, t. 1, no 169 (abril 1941), p. 306.

46. Ibid., pp. 306-307.

47. Por ejemplo en Legaz Lacambra, Luis, Introducción a la teoría del Estado nacionalsindicalista, Barcelona, Bosch, 1940.

48. CONDE, Francisco Javier, Introducción al derecho político actual, Madrid, Eds. Escorial, 1942, p. 196. Su deuda aquí con SchmitT y su obra Sobre los tres modos de pensar la ciencia jurídica, Madrid, Tecnos, 1996 (ed. or. 1934), es muy clara.

49. Ibid., p. 198.

50. Galán, Eustaquio, "El criterio...", p. 309. 
«politizarlo» todo. Hasta Conde, el otro Kronjurist del régimen junto con Legaz, le achacó su peor error, en el que coincidieron todos los demás: Schmitt se había convertido en positivista al vaciar de contenido trascendente sus categorías $^{51}$. Según este autor, «la distinción del amigo y del enemigo se convierte en pura característica formal de una esfera pública a diferencia de una esfera privada, en la cual no hay "enemigo" propiamente dicho, sino inimicus», por lo que se pregunta qué diferencia entonces la guerra de civil y la guerra exterior; la lucha de clases y la lucha entre Estados. De hecho, Schmitt había dicho que «una guerra no necesita ser piadosa, moralmente buena o rentable $»^{52}$. Para Conde y discípulos, no era tolerable que el centro del acontecer político dejara de ser un «orden de coexistencia vinculado al orden universal del cosmos, metafísicamente fundado por virtud del acto divino de la creación». Schmitt, como Hobbes y demás autores seculares, habían pasado a pretender la organización de la convivencia política desde la pura razón, en «técnica para la lucha», convirtiéndose la lucha en «la esencia de la política " ${ }^{53}$. No podían aceptar tal «secularización» de lo político, y achacaron a Schmitt, también católico, ese yerro.

Sin embargo, las diferencias teóricas no ocultaban el hecho de que la «dictadura soberana $»^{54}$ franquista se fundó en las dinámicas «decisionistas» descritas por Schmitt. En Legaz podía leerse que la misión de los pueblos seguía siendo la lucha contra sus enemigos ${ }^{55}$, pero pasada por la retórica de la «unidad de destino en lo universal» y el nacionalcatolicismo. Conde y el resto de iusfilósofos del momento insistieron en la superación de los errores de Schmitt a través de los clásicos católicos, para asentar así el concepto de lo político en la idea de destino, un principio teleológico, místico ${ }^{56}$. La idea de que esa unidad existía previamente parece más cercana al tradicionalismo reaccionario o legitimista, en que el enemigo «existencial» en todo caso es un estímulo «que aprieta las filas de los enlazados en el común destino», según Galán. El acto político debe llevar a la consecución de esa unidad, no ser un acto de una esfera parcial del individuo como proponía Schmitt, pero las conclusiones siguen

51. Un distanciamiento que aumentaba conforme los fascismos europeos eran derrotados en la Guerra Mundial, según JimÉnez SEGAdo, Carmelo, Contrarrevolución o resistencia..., p. 247 y ss.

52. Schmitt, Carl, El concepto de lo político..., p. 65.

53. Conde, Francisco Javier, Introducción al derecho político..., p. 332.

54. Según las definiciones del propio Schmitt, Carl, La dictadura. Desde los comienzos del pensamiento moderno de la soberanía hasta la lucha de clases proletaria, Madrid, Alianza, 1985 (ed. or. 1931).

55. Legaz Lacambra, Luis, Introducción a la teoría del Estado nacionalsindicalista..., p. 122.

56. López García, José Antonio, Estado y Derecho en el franquismo..., p. 69. 
siendo similares: «una doctrina pluralista del Estado» les parece algo equivocado, incluso patológico ${ }^{57}$.

Ahora bien, en aquella «hora atribulada y tremenda», era una exigencia «ineludible» envolver, «no en odio, sino en misericordia y caridad, al enemigo político cuando deja de serlo, cuando la paz suprime la distancia inmensa que había abierto la guerra $»^{58}$. Estas concepciones pueden leerse como un distanciamiento del enemigo absoluto o «racial», por otro de tipo «trascendente», inspirado en los clásicos del catolicismo, y que supone una posibilidad abierta para la reconversión que no contenía el enemigo «biológico» del totalitarismo nazi. Son las mismas concepciones que nacen del concepto también religioso de redención, y que explican por ejemplo la lógica de la obra del Patronato de Redención de Penas por el Trabajo, a través de discursos tomistas que permiten articular la represión y ejecución de miles de «enemigos» con representaciones de caridad y perdón cristianos, «el dogma de la redención universal y de la gracia, que restablece el orden universal perturbado por el hombre $»^{59}$. La «de-personalización», por absoluta que pudiera resultar para algunos líderes republicanos y obreros, no tenía por qué ser total e irreversible para la gran masa de «enemigos», si se arrepentían, expiaban sus pecados y se «convertían».

Casualmente, regresando a Jakobs, lo más parecido al concepto de sujeto de derecho para los dos principales teóricos del Estado franquista era la «persona». Aunque guarde ciertas concomitancias con el concepto funcionalista - «persona» como «hombre» mediado por la comunidad y que responde positivamente a lo que el «sentido común» espera- tampoco son equiparables. De nuevo, tiene un contenido esencialista, teológico y católico, que conduce a la superación del individuo liberal de las declaraciones de Derechos del hombre y del ciudadano, como al de la Constitución republicana de 1931, que «presenta simultáneamente una serie de sistemas de valores perfectamente contradictorios entre sí», carentes de «armonía» o de «nexo esencial ${ }^{60}$. La idea más cercana a la «ciudadanía» para la iusfilosofía franquista, representada por Conde y Legaz, era una ciudadanía católica, desde una concepción confesional del individuo que lo conecta con la visión organicista del Estado y del Derecho

57. Galán, Eustaquio, "El criterio de lo político"..., p. 303.

58. Loc. cit.

59. La obra de redención de penas. Doctrina, práctica, legislación, Patronato Central para la Redención de las Penas por el Trabajo, Madrid, 1941, p. XI. Ver Gómez Bravo, Gutmaro La Redención de Penas. La formación del sistema penitenciario franquista, 1936-1950, Madrid, Los libros de la Catarata, 2007.

60. Conde, Francisco Javier, Representación política y régimen español. Ensayo Político, Madrid, Eds. de la Subsecretaría de Educación Popular, 1945, p. 137 y ss. 
político. Quedaba, así, un espacio indefinido para el sujeto de derecho, siempre católico y bajo el arbitrio del Estado y la autoridad política, organizado «necesariamente» entre el Estado nacional, el sindicato vertical y familia ${ }^{61}$.

Siguiendo a José Antonio y la mixtura teórica nacionalcatólica, los juristas del régimen concibieron la «unidad de destino» como principio generador de la unidad orgánica del Estado. Frente al individualismo constitucional, la «persona»; y frente a la instrumentalización positivista del «Estado totalitario», Conde insistió en la idea de destino y en la doctrina tomista como fundamentos de una organización política que debía reducir a «unidad» toda la pluralidad de actos sociales antagónicos ${ }^{62}$. La doctrina oficial consideraba a los individuos como «células vivas y orgánicas» que conducen «una doble vida: la propia y la de la comunidad». El individuo sólo es comprensible en el marco del servicio a un "destino colectivo» ${ }^{63}$. En definitiva, un constructo ideológico similar a la comunidad homogénea y excluyente -aunque no biológica- del resto de fascismos, puesto que se ha «atrevido» a combatir a su enemigo, pero se justificaba con un contenido teológico.

Esta idea señalada de «comunidad» organicista tuvo su reflejo evidente en el Derecho penal, al entrecruzarse dos tendencias inversas. Por un lado, el «enemigo» existencial fue ilegalizado, la mera expresión de una personalidad izquierdista o masónica pasó a ser delictiva, y el propio Estado republicano fue declarado ilegal e ilegítimo, de ahí que fueran juzgados sus sostenedores como «rebeldes», llegando algunos a ser ejecutados por ello. Por otro lado, en determinadas esferas el delincuente común pasó a convertirse en «enemigo». Desde la criminalística, se desarrollaron nuevas teorías que defendían que el delito no era una aparición individual, sino un hecho social, pero sin veleidades socialistas, ya que «toda teoría sociológica del delito era profundamente subversiva ${ }^{64}$. Aunque no se llegó al extremo nazi de un Derecho penal racial, ni al principio de analogía, los resultados en cuanto a los límites procesales, el fin retributivo de las penas, la valoración de la voluntad y no del hecho, fueron

61. Como explícitamente recogía el Fuero de los Españoles de 1945 en su artículo 33º , «el ejercicio de los derechos que se reconocen (...) no podrá atentar a la unidad espiritual, nacional y social de España». La tarea principal del Nuevo Estado era articular la nueva relación con el «hombre íntegro», encuadrado de un modo orgánico en la comunidad. La naturaleza especial de las instituciones nacionalsindicalistas está para sus teóricos en que unen a los hombres mediante lazos no jurídicos, sino vínculos de «comunidad», por tanto también de «personas».

62. Conde, Francisco Javier, Teoría y sistema de las formas políticas, Instituto de Estudios Políticos, Madrid, 1944, p. 81.

63. López García, José Antonio, Estado y Derecho en el franquismo..., p. 73.

64. Del Rosal, Juan "Política y criminalidad", Revista de Estudios Políticos, nº 4 (1941), p. 762. 
comunes entre los Estados totalitarios, en un Derecho penal defensista y cercano al «Derecho penal de lucha» ${ }^{65}$.

\section{Algunos ejemplos de «Derecho penal del enemigo» en el primer franquismo}

Estas teorías del Estado y la «comunidad» justificaron un determinado tipo de gobierno que se estaba poniendo en práctica. Antes de que fueran formuladas, existía ya un régimen de caudillaje, de partido único, y un Estado que trató de encuadrar y movilizar a toda la población en su esfuerzo bélico ${ }^{66}$. En lo represivo, esa «totalización de la guerra» se había traducido en una red para el control y el castigo del enemigo que, aunque modificándose de acuerdo con los intereses del régimen, se mantuvo invariable hasta el final de la dictadura. En el caso del «Derecho penal del enemigo» de posguerra, se puede hablar de un «Derecho penal del enemigo» extraordinario y otro ordinario. En el primero, aprobado ad hoc durante la guerra y la inmediata posguerra, reforzó una jurisdicción militar omnipotente, levantó nuevas jurisdicciones extraordinarias, y recurrió a reformas y nuevos decretos en materia de delitos políticos; en el segundo tipo, se crearon nuevos tipos delictivos de acuerdo con las ideas ultraconservadoras de orden público o moralidad, se adelantó la punición, aumentaron las penas y se relativizaron garantías contra malhechores nocivos al Estado, dentro de los delitos que se pueden considerar «comunes».

La jurisdicción militar fue el centro de la represión y obviamente es el mayor exponente de un Derecho penal que combate enemigos bajo cualquier contexto. El conflicto secular entre las dos jurisdicciones ${ }^{67}$ se solucionó de forma fulminante con la aplicación de los bandos de declaración del estado de guerra del 17 de julio de 1936, pero lo que resulta interesante es que se siguiera empleando en aquellos delitos considerados sensibles para la estabilidad del Estado, una vez acabado el enfrentamiento armado -el Estado de Guerra continuó oficialmente hasta 1948-, fueran o no militares o políticos. Para que funcionara, tuvieron que obviar cualquier «normativismo», y mediante un criterio claramente extrajurídico se encajaron los delitos políticos que se perseguían en el Código de Justicia Militar. Así, se convirtió en «rebelde» a todo aquel que

65. El mismo Juan Del Rosal lo resaltaba en fechas tan tardías como en 1948, al analizar las reformas del Código penal de 1944, en «Estimación de la teoría del 'tipo de autor' en la legislación penal española», Anuario de Derecho penal y ciencias penales, Tomo I, Fascículo I, Enero-Abril 1948, Instituto Nacional de Estudios Jurídicos, Madrid, pp. 38-60.

66. RAnzato, Gabriele, «The Spanish Civil War in the Context of Total War» en BAumeISTER, Marti y SCHÜLER-Springorum, Stefanie (eds.) "If you tolerate this..." The Spanish Civil War in the Age of Total War, Frankfurt/Nueva York, Campus, 2008, p. 237.

67. Ballbé, Manuel, Orden Público y militarismo en la España constitucional (1812-1983), Madrid, Alianza Editorial, 1983. 
se opusiera a los rebeldes, como es de sobra conocido. El bando de 28 de agosto significó una extensión sin precedentes de mecanismos punitivos e incluyó la motivación política entre los delitos. Produjo un adelantamiento de la tutela penal al ampliar la definición de las conductas punibles, como actitudes de simple pasividad ante el golpe, aumentó las penas de los delitos comunes al ser la justicia castrense tradicionalmente más dura en ese sentido, y minimizó (o directamente hizo desaparecer) las garantías procesales ${ }^{68}$.

Un ejemplo claro de la preponderancia militar en el «nuevo Estado», lo aporta la «Ley de 12 de julio de 1940 restableciendo, en todo su vigor, el Código de Justicia Militar», y que supuestamente devolvía a la «normalidad» al Derecho castrense. Restablecía del proceso sumarísimo y anulaba el Decreto $\mathrm{n}^{\circ} 55$ que creó el sumarísimo abreviado «de urgencia». En la práctica, no hubo tal «restauración», sino que se normalizaba un derecho de excepción militar a delitos no militares, ni flagrantes o que les correspondiera pena capital, como hubiera sido preceptivo según la legislación existente. Destaca también como ejemplo extremo de Justicia de excepción la Ley para la Seguridad del Estado de 29 de marzo de 1941, acogida por algún jurista de entonces como un buen ejemplo del «defensismo» totalitario ${ }^{69}$. Aunque redundante, pretendía rellenar algunas lagunas legales para la lucha contra el maquis y los sabotajes en un contexto internacional convulso, atrayendo a la jurisdicción militar toda una serie de delitos comunes que podían tener consecuencias políticas.

En lo que se refiere a las jurisdicciones especiales encargadas de combatir «enemigos», son de sobra conocidas la de Responsabilidades Políticas ${ }^{70}$ y

68. Se ha destacado también el incumplimiento de las Leyes de Guerra de la época en Anderson, Peter, «Francisco Franco, ¿criminal de guerra?» en Hispania Nova. Revista de Historia Contemporánea, $\mathrm{n}^{\circ} 10$ (2012) [http://hispanianova.rediris.es]. Procesalmente destacan las acusaciones colectivas, la elección y formación del defensor, la imposibilidad de preparar una defensa, la parcialidad evidente de todos los juzgadores y testimonios, la importancia desigual que se daba a estos últimos, o la mera duración de los consejos de guerra. Cualquier trabajo que estudie los Consejos de Guerra llega irremediablemente a la conclusión de que eran más cercanos a una representación que a un juicio justo y serio. La bibliografía es extensa, ver por ejemplo GIL VICO, Pablo, "Derecho y ficción", en Espinosa MAestre, Francisco (ed.), Violencia Roja y Azul, Barcelona, Crítica, 2010, p. 259 y ss., o una síntesis en MARCO, Jorge, "«Debemos condenar y condenamos»... Justicia Militar y represión en España”, en Aróstegui, Julio (coord.), Franco: La represión como sistema, Barcelona, Flor del Viento, 2012, pp. 190-229.

69. González Llana, José, «La seguridad del Estado y la Ley de 29 de Marzo de 1941», en Revista General de Legislación y Jurisprudencia, t. II, no 170 (1941), p. 113.

70. Álvaro DueÑas, Manuel, Por ministerio de la ley y voluntad del Caudillo. La Jurisdicción Especial de Responsabilidades Políticas (1939-1945). Centro de Estudios Políticos y Constitucionales, Madrid, 2006. Una aproximación a los primeros capítulos de esta obra se pueden ver en el artículo «Los militares en la represión política de posguerra: la Ley de Responsabilidades Políticas hasta la reforma de 1942», Revista de Estudios Políticos (Nueva Época), nº 69 (julio-septiembre 1990), pp. 141-162. 
la de Represión de Masonería y Comunismo ${ }^{71}$. En la primera, a pesar de las sorprendentes dudas formales que mostraron algunos ministros ante la Ponencia previa de la Ley ${ }^{72}$, se confirmaba que las ideas delinquen, como afirmaba el propio Blas Pérez, ante el «mentís rotundo» de la «insuperable realidad trágica $^{73}$. También surgieron discrepancias en cuanto a la posibilidad de quebrar el non bis in idem, pero ni siquiera se nombró el principio de irretroactividad en el Derecho penal cuando calificaron de delictivos hechos legales en el pasado. Aunque nacía de la aplicación de una larga tradición jurídica española, por la cual los autores de hechos criminales eran a su vez responsables civilmente, lo cierto es que fue otra legislación represiva que se complementaba con la militar. Se aplicó en su gran mayoría como continuación a los Consejos de Guerra, y mediante medidas de seguridad y multas económicas, completaba la depuración y marginación socioprofesional, además de infringir un daño económico sobre el «enemigo». Respecto a la de Represión de Masonería y Comunismo, cumplía la misma función que estaban realizando ya los tribunales militares de persecución política -aunque sin imponer penas de muerte-, pero cubría el agujero legal que dejaba el caso de los miembros de las logias masónicas, ya que en ocasiones no podían calificar de delito de rebelión militar la simple pertenencia a una logia, pese a que se empleó como elemento de cargo de forma repetida, incluso para la aplicación de la pena de muerte. La nueva Ley eliminó por completo el principio del hecho e imponía castigos que podían llegar a los 30 años de prisión a través de un Derecho claramente «de autor». En ninguna otra Ley quedaba tan claro que formar parte de la representación del «enemigo» pasaba a ser delictivo.

En el que hemos llamado «Derecho penal del enemigo» ordinario, hay que hacer referencia al agravamiento de penas como la de la Ley de 5 de julio de $1938^{74}$, que reintroducía la pena de muerte en la escala general. Se consideró que era lo propio de la «seriedad de un Estado fuerte y justiciero», ya que, como

71. Portilla Contreras, Guillermo, La consagración del Derecho Penal de autor durante el franquismo. El Tribunal Especial para la Represión de la Masonería y el Comunismo, Granada, Comares, 2010, y en su artículo "Orígenes de la Ley de 1 de marzo de 1940 y criterios penales y procesales adoptados por el Tribunal Especial para la Represión de la Masonería y el Comunismo", en Fernández-Crehuet López, Federico y García LóPEZ, Daniel J. (coords.): Derecho, memoria histórica y dictaduras, Granada, Comares, 2009, pp. 327-366.

72. Archivo General de la Administración, PG/4022.

73. Pérez GonzÁlez, Blas, «Prólogo», en Benítez de Lugo y Reymudo, Luis, Responsabilidades civiles y políticas. Indemnización de los daños y perjuicios ocasionados por el Frente Popular y sus afines en España y su exigibilidad jurídica por el Estado Nacional, Barcelona, Bosch, 1940, p. XIV.

74. BOE de 7 de julio de 1938. 
afirmaba el anteproyecto de Código penal de FET y de las JONS de 1938, un Estado fuerte debía contar con un endurecimiento y ampliación de la penalidad, para amparar, no sólo con las armas, sino «con el imperio de las leyes, la existencia de la Patria organizada jurídicamente bajo una nueva forma de Estado ${ }^{75}$. Por otro lado, la nueva «política racial», que se manifestó en toda una serie de nuevos mecanismos de control de la sexualidad y la natalidad, elevó el castigo y adelantó la punición del delito de aborto y del uso o la publicidad de anticonceptivos, quedando insertos también en la categoría de Derecho penal del enemigo, al considerarse un «delito social». Lo hizo mediante la Ley de 24 de enero de 1941 «para la protección de la natalidad contra el aborto y la propaganda anticoncepcionista» ${ }^{76}$. Por último, pueden citarse otros ejemplos que, como en el caso de la persecución del aborto, registran un adelantamiento de la punición a la mera tentativa, un agravamiento de penas desorbitado o la relativización de garantías, como en la serie de leyes contra el estraperlo de 1939-1941 ${ }^{77}$ y la de 1941 sobre accidentes ferroviarios ${ }^{78}$. Además de crear nuevos delitos, podían convertirse en delitos de rebelión militar dependiendo de su gravedad, pasando a la jurisdicción castrense, de acuerdo con elementos valorativos del autor.

\section{A modo de conclusión}

La elección de categorías analíticas no es nunca un hecho neutro, y en el caso de Jakobs parece evidente que ha decidido emplear conceptos polémicos para defender la escalada punitiva contra cierto tipo de delincuentes. No obstante, eso no debería impedir que el debate jurídico mantenga el rigor terminológico exigible o que se centre en hechos contrastados, y no en descalificaciones morales o en paralelismos que simplifican o mezclan significantes con significados. Guste más o menos, sea legítimo o ilegítimo, una hipérbole de amenazas más retóricas que reales; el actual Derecho penal del enemigo se enmarca en una teoría general del Derecho penal positivista, y se presenta a sí mismo como respetuoso con los puntos críticos del Estado de derecho. El «enemigo» en Jakobs no es «existencial» como en el modelo schmittiano -o nacionalcatólico-, sino normativo, definido jurídicamente. La Constitución sigue defendiéndose «neutra», por lo que no se pretende facilitar el reingreso del «decisionismo». No

75. Anteproyecto de Código Penal de FET y de las JONS, p. 3.

76. BOE de 2 de febrero de 1941.

77. Leyes de 26 de octubre de 1939, 30 de septiembre de 1940, 4 de enero y 24 de junio de 1941, contra delitos relacionados con el estraperlo y de creación de la Fiscalía de Tasas. 78. Ley de 18 de febrero de 1941, BOE de 19 de febrero de 1941. 
está vinculado a una racionalidad política totalitaria que trata de construir un consenso o una comunidad política en el enfrentamiento contra el enemigo, a pesar de que tenga elementos simbólicos propios de una extensión demagógica del punitivismo. Tampoco reintroduce el homo sacer. En teoría, los límites a la punición se respetan, y aunque se relajen las garantías, se funda en el hecho delictivo, si bien en su enjuiciamiento puedan incluirse elementos valorativos del autor.

En definitiva, el Derecho penal de los regímenes totalitarios es necesariamente un Derecho penal que combate enemigos, pero es otro Derecho penal, un «Derecho penal del enemigo» paroxístico, fundado en una excepción permanente, que establece la norma y que divide radicalmente a la población de acuerdo con el criterio «amigo»-«enemigo». Un reingreso político al «decisionismo» implicaría una extensión desorbitada de ese tipo de Derecho de dos velocidades, o la desaparición del «Derecho», sin más. Ninguno de los límites que afirma respetar el actual «Derecho penal del enemigo» fueron respetados en los regímenes totalitarios, «decisionistas». En la realidad de los regímenes de excepción históricos, existió una amplia tolerancia con la punición extrajudicial, policial o parajudicial. La sustitución durante la Guerra Civil de los asesinatos «en caliente» por ejecuciones judiciales fueron un cambio cualitativo importante, pero se emplearon instrumentos legales preexistentes para poder continuar con las ejecuciones de varios miles de «enemigos existenciales», con apariencia de legalidad. Asimismo, y en aquellos casos donde la interpretación de la Ley no fue suficiente, se crearon nuevas jurisdicciones y reformas ad hoc para hacer cumplir el principio del Derecho penal máximo de «ningún delito sin pena».

Por otro lado, la propuesta de definición de Jakobs de un «Derecho penal del enemigo» resulta útil para analizar características clave de un aspecto del Derecho tan sensible a los cambios políticos como es el Derecho penal. En el caso del Derecho penal totalitario, además de los atajos extrajurídicos y del empleo de la nuda fuerza, es un «Derecho penal del enemigo» que se caracteriza por la defensa de una comunidad encuadrada en un Estado de excepción permanente, y que en algunos casos puede salpicar al Derecho penal ordinario. El caso español es, en cuanto a su génesis, distinto a los regímenes totalitarios coetáneos, pero eso no debe llevar a separar la violencia en guerra de la represión vista como un fenómeno complejo de eliminación -física o sociopolíticadel enemigo. La legislación igualmente levantó límites entre su población, separando, clasificando y controlando, e incluso comunicando a través de todos los tipos de Derecho (penal, civil, laboral, etc.) la nueva «norma». 
En los casos más extremos, esta gobernabilidad pudo desarrollar una «tanatopolítica ${ }^{79}$, una política de eliminación física contra los elementos considerados nocivos para el «cuerpo sano» de la población, sea por motivos raciales, políticos, sociales, religiosos, etc. Es por eso que no debe estudiarse la política penal como un elemento aislado de la "gobernabilidad», ya que es una consecuencia pero a la vez un indicador de las políticas que aplica cada tipo de racionalidad gubernamental, del tipo de discursos y prácticas que se desarrollan en las relaciones entre un Estado y su población. Un estudio comparativo de los diferentes Derechos penales del enemigo coetáneos, así como el de la evolución del mismo «defensismo» franquista, podría resultar interesante a la hora de analizar la evolución de los espacios de la ciudadanía, e incluso de la compleja genealogía del Derecho penal internacional durante el siglo XX hasta la actualidad.

79. Cayuela Sánchez, Salvador, “¿Biopolítica o Tanatopolítica? Una defensa de la discontinuidad histórica", $\Delta \alpha \iota^{\prime} \mu \omega v$. Revista de Filosofía, no 43 (2008), pp. 33-49. 


\title{
Del antifranquismo al feminismo: la búsqueda de una nueva ciudadanía del movimiento democrático de mujeres en la Transición democrática
}

From Antifrancoism to Feminism: The search for a new Citizenship of Women's Democratic Movement in Spanish Democratic Transition

\author{
Ana Belén Gómez Fernández \\ Universidad de Jaén
}

Recibido: 11-IX-2013

Aceptado: 7-IV-2014

\section{Resumen}

El objetivo de este artículo es analizar el papel del Movimiento Democrático de Mujeres en la construcción de la democracia. Una organización formada por varias generaciones de mujeres que lucharon contra la dictadura y por la construcción de un marco igualitario entre hombres y mujeres. Se analiza la evolución de este movimiento desde la denuncia de la política represiva del régimen franquista, destacando el papel de solidaridad y labor asistencial a los presos políticos, pasando por la labor en los barrios contra la carestía de vida y la falta de infraestructuras, para terminar con planteamientos plenamente feministas, desarrollando un discurso compatible con la lucha por la democracia y la libertad.

Palabras clave: Mujeres, Solidaridad, Movilización femenina, Antifranquismo, Feminismo.

\begin{abstract}
The purpose of this paper is to analyze the role of the Women's Democratic Movement in the building of democracy. An organization formed by several generations of women who fought dictatorship and struggled to develop an equal status for men and women. The analysis of the movement evolution begins with the their denunciation of repressive policies in Franco's regime, highlighting their supportive role and assistance with political prisoners. Their work in low-income districts against the high cost of living and the lack of infrastructure will be revised next. Finally. A final stage deals with the
\end{abstract}


organization's fully feminist approaches by developing solid arguments in support of the struggle for democracy and freedom.

Keywords: Women, Solidarity, Women's mobilization, Antifranco-movement, Feminism.

\section{Introducción}

A pesar de que cada vez son más abundantes los estudios relacionados con el final de la dictadura franquista y la llegada de la democracia, la bibliografía sobre el protagonismo de las mujeres durante los últimos años del régimen y su contribución a la construcción de la democracia se ha caracterizado tradicionalmente por una falta de visibilidad historiográfica. Este hecho se debe por un lado a que la transición democrática ha sido analizada en buena medida desde un punto de vista que sobrevalora el papel de ciertas personalidades y entiende el cambio de régimen como un fenómeno meramente político, dejando a un lado todo un conjunto de condicionantes que estuvieron presentes en esos años. En esta interpretación los deseos y aspiraciones de la sociedad apenas si aparecen, quedando al margen de los acuerdos y acciones llevadas a cabo por los líderes políticos. Y por otro lado, frente a esa interpretación no dejan de aparecer en los últimos años diferentes trabajos que enfatizan el papel jugado por los movimientos sociales de oposición al franquismo, el comportamiento colectivo y en definitiva la construcción de la democracia ${ }^{1}$. Es preciso señalar como la movilización y la protesta colectiva contribuyeron a facilitar el camino de la transición a la democracia al desgastar políticamente la dictadura franquista, desafiando su capacidad para mantener el orden social sobre el que fundamentó su propia existencia y erosionando su cohesión conforme se enfrentó a dicha amenaza ${ }^{2}$. La oposición franquista de los años sesenta y setenta aglutinaba tanto a trabajadores, como a la nueva y vieja izquierda, estudiantes, vecinos, amas de casa, organizaciones de mujeres, organizaciones autonómicas e independentistas y una nueva generación de católicos y representantes de la Iglesia, que aspiraba y manifestaba de forma expresa el deseo de transformación y democracia ${ }^{3}$.

1. Cruz, Rafael y Pérez, Manuel (eds.), Cultura y movilización en la España contemporánea, Madrid, Alianza Universidad, 1997, p. 38.

2. Collier, Ruth B., Paths Toward Democracy. The Working Class and Elites in Western Europe and South America, Cambridge, Cambridge University Press, 1999, p. 20.

3. Para esta cuestión, véase Maravall, José $\mathrm{M}^{\mathrm{a}}$, Dictadura y disentimiento político. Madrid, Alfaguara, 1978; del mismo autor La política de la transición, Madrid, Taurus, 1981; Míguez, Santiago, La preparación de la transición a la democracia en España, Zaragoza, Universidad de Zaragoza, 1990; PÉREZ-DíAz, Víctor, The return of civil society: the emergente of Democratic Spain, Cambridge, Harward University Press, 1993; FisHman, Robert, 
En este sentido, afortunadamente en los últimos años se está produciendo una renovación metodológica proporcionada por la historiografía de género, al igual que la reformulación de la historiografía de la resistencia como categoría, concediéndosele un mayor sentido e importancia a otros agentes sociales. Así pues, está surgiendo una importante bibliografía que se ha aproximado a las luchas concretas de mujeres en los últimos años del franquismo, centrándose sobre todo en el papel del movimiento de mujeres y en el resurgir del feminismo con la llegada de la democracia ${ }^{4}$. Nuestra intención es prestar atención a aquella etapa de toma de conciencia de las mujeres a finales de la dictadura enmarcada en el espacio socio-político del antifranquismo. Es preciso entender la resurrección del feminismo español dentro del marco de oposición social contra el franquismo, situación que influirá directamente en la naturaleza del movimiento feminista, que luchará no sólo por la defensa de valores feministas, sino también por aquellos propiamente democráticos y que llevaron a un variado repertorio de formas de lucha contra la dictadura. En palabras de Mary Nash "el feminismo surgió como una respuesta individual y colectiva contra el régimen de Franco como sistema político dictatorial y, también, contra la misoginia y la discriminación sexista inherente en el sistema jurídico y político patriarcal del franquismo"s.

Organización obrera y retorno a la democracia en España, Madrid, CIS, 1996; HamanN, Kerstin, "Civil society and democratic transisition in Spain", Perspectives on Political Science, Washington, 27/3 (1998), p. 135-141; McAdam, Doug, Tarrow, Sidney y Tilly, Charles, Dinámica de la contienda política, Barcelona, Hacer, 2005.

4. A modo de ejemplo destacan especialmente las publicaciones de NASH, Mary, Dones en Transició. De la resistència política a la legitimitat feminista: les dones en la Barcelona de la Transició, Barcelona, Ajuntament de Barcelona y Regidoria de la Dona, 2007; de la misma autora, "El moviment feminista durant la Transici", en PAGÉs I Blanch, Pelai (ed.), La transició democrática als Paisos Catalans. Història i memoria, Valencia, Publicacions de la Universitat de València, 2005, así como la coedición con TORRES, Gemma, Feminismo en la transición, Barcelona, Grup de Recerca Consolidat Multiculturalisme I Genere-Universitat de Barcelona, Sociedad Estatal de Conmemoraciones Culturales, 2009; LARRUMBE, Ma Ángeles, Una inmensa minoría: influencia y feminismo en la transición en la transición, Zaragoza, Prensa Universitaria de Zaragoza, 2002; de la misma autora, Las que dijeron no. Palabra y acción del feminismo en la transición, Zaragoza, Prensa Universitaria de Zaragoza, 2004; Agustín PuerTa, Mercedes, Feminismo: identidad personal y lucha colectiva, Granada, Universidad de Granada, 2003; SuÁREZ, Carmen, Feministas en la transición asturiana (19751983), Oviedo, KFK, 2003; Escario, Pilar, AlBERDI, Inés y LóPeZ, Ana Inés, Lo personal es político: el movimiento feminista en la transición, Madrid, Instituto de la Mujer, 1996; AsoCiación de Mujeres en la Transición Democrática, Españolas en la Transición: de excluidas a protagonistas (1973-1982), Madrid, Biblioteca Nueva, 1999; Moreno, Amparo, Mujeres en lucha. El movimiento feminista en España, Barcelona, Anagrama, 1977; CUESTA, Josefina (dir.), Historia de las mujeres en España: siglo XX, vol. II, Madrid, Instituto de la mujer, 2003; Martínez, Carmen, GutiérRez, Purificación y GonzÁlez, Pilar, El movimiento feminista en España en los años setenta, Madrid, Cátedra, 2009.

5. NASH, Mary, "La construcción de una cultura política desde la legitimidad feminista durante la transición política democrática", en AgUAdo, Ana y ORTEGA, Teresa Mª, 
Nuestro objetivo, por tanto, es tratar de analizar ese período de formación de la conciencia feminista a través del estudio del Movimiento Democrático de Mujeres, representante de la lucha por los derechos civiles y la democracia, además de los específicos femeninos, destacando su doble lucha: política y social. Política en función de su importante oposición al régimen a partir de su labor por la amnistía y por los presos políticos, siendo un espacio de encuentro y aprendizaje político para aquellas mujeres que se adentraron en la militancia político-feminista a finales de los sesenta y principios de los setenta; y social a partir de su batalla por un reconocimiento social basado en la igualdad. Es básico a la hora de definir el propio concepto de ciudadanía, tener en cuenta que no sólo se ciñe únicamente a la esfera de reivindicación evidente y consciente de derechos de ciudadanía, sino también a la interacción compleja de diferentes movimientos sociales y grupos que trabajan en la esfera de la política y de lo público. La definición clásica de ciudadanía de T. H. Marshall se centra en tres dimensiones básicas política, civil y social ${ }^{6}$, de forma que permite identificar dos tipos de democracia. La democracia formal que reconoce los derechos civiles y políticos en igualdad de condiciones, y la democracia sustantiva, que reconoce junto a los anteriores los derechos sociales en igualdad de condiciones. Pero además, la ciudadanía necesita el funcionamiento de una colectividad que reconozca la subjetividad activa de los ciudadanos ${ }^{7}$. Como indica Mary Nash "la ciudadanía tiene que ver con la pertenencia a una comunidad que confiere derechos y responsabilidades" un sentimiento de pertenencia a una sociedad que hace partícipe a sus miembros en la práctica de la ciudadanía. En este contexto, sería interesante analizar si las mujeres fueron cooperantes a la hora de levantar una comunidad ciudadana que les hiciera partícipes, y si sus acciones y reivindicaciones fueron capaces de ensanchar el espacio de la ciudadanía para agregar derechos en el proceso de la transición democrática. No se pretende hablar de ellas como un apéndice y algo más, sino de analizar el proceso histórico teniendo en cuenta que los actores principales van a tener distintas experiencias de vida y sociales en función de su diferente identidad de género. En este sentido, es interesante ver como las múltiples identidades feministas, lo que nos lleva es a "refle-

Feminismos y antifeminismos. Culturas políticas e identidades de género en la España del siglo XX, Universitat de València y Universidad de Granada, Valencia, 2011, p. 285.

6. Marshall, Thomas Humphrey, Class, Citizenship ans Social Development, Cambridge, Cambridge University Press, 1950.

7. García, Soledad y LuKES, Steven (comps.), Ciudadanía, justicia social, identidad y participación, Madrid, Siglo XXI, 1999.

8. NASH, Mary, "La construcción de una cultura política..., p. 286. 
xionar sobre la historicidad del propio feminismo como cultura política en sí misma, con sus propios lenguajes y prácticas discursivas"9. Además, en un contexto de represión, la simbiosis de un enfoque de clase junto con un análisis de género puede permitir dar luz a ciertas zonas en las que mujeres de una determinada clase social defendieron sus intereses de género y de clase, pusieron en marcha ciertas estrategias de lucha, o algo tan simple como la supervivencia ${ }^{10}$.

\section{De la solidaridad a la movilización de la mujer: el nacimiento del MDM}

Aquellas mujeres que se involucraron con la oposición antifranquista en los primeros años de la dictadura lo tuvieron que hacer acomodándose no sólo al modelo nacional-católico patriarcal, sino también en medio de la lucha clandestina donde su posición era secundaria. El PCE, abanderado de la resistencia antifranquista, pese a su llamamiento para incorporarlas a la lucha contra la dictadura, siguió la línea de que sólo bajo la lucha de la clase trabajadora era posible el éxito socialista y acabar con cualquier tipo de esclavitud, incluida la femenina. En esta época las militantes comunistas a pesar de realizar una importante labor en la clandestinidad, tuvieron un escaso reconocimiento, ya que su tarea era considerada como algo secundario y auxiliar dedicándose a la distribución de propaganda, enlaces, ayuda a los presos políticos... Esta situación fue asumida por éstas ya que "su conciencia de género estaba claramente supeditada a su conciencia de clase"11.

Sin embargo, fueron muchas, algunas militantes, las que se hicieron cargo no sólo del núcleo familiar, sino también de llevar a cabo toda una red asistencial y de solidaridad a favor de sus familiares encarcelados, llegando incluso a protagonizar una intensa actividad reivindicativa ${ }^{12}$. Podemos plantearnos si

9. Aguado, Ana, "La historia de las mujeres y del género", Ortega, Teresa Ma (coord.), Historia global. El debate historiográfico en los últimos tiempos, Granada, Prensas Universitarias de Zaragoza, 2007, p. 124.

10. Sobre el género y la formación de la clase, véase AGuADo, Ana, "Las relaciones de género y la nueva historia social. Identidad y prácticas culturales", en El siglo XX: balance y perspectivas, Valencia, Fundación Cañada Blanch, Universitat de València, 2000, pp. 159-164; de la misma autora, "La historia de las mujeres y del género"... Igualmente, destacan los trabajos recogidos en CAmpos, Concepción y GonZÁlez, Ma José (coord.), Mujeres y dictaduras en España y América Latina: el largo camino, Universidad de Málaga, Málaga, 1996.

11. Miguel GonZÁLEZ, Román, "Las culturas políticas del republicanismo histórico español", Ayer, $\mathrm{n}^{\circ}$ 53, (2004), p. 213.

12. Moreno, Amparo, "La réplica de las mujeres al franquismo", en Folguera, Pilar, El feminismo en España: dos siglos de historia, Madrid, Siglo XXI, Madrid, 2007, pp. 123-156; CABRERO, Claudia, Mujeres contra el franquismo (Asturias 1937-1952): vida cotidiana, repre- 
pudo o no existir una resistencia al franquismo específicamente femenina, destacando en este momento la toma de conciencia de muchas mujeres anónimas que nunca habían desarrollado una actividad militante durante la República, pero que fueron testigos de cómo la represión caía directamente sobre sus familiares. Además, sobre ellas comenzó a extenderse una mancha, que les haría más difícil si cabe no sólo la lucha por asegurar la supervivencia de la familia sino también contra el olvido de los suyos, convirtiéndose en un acto de rebeldía frente a la realidad existente. Será precisamente en medio de este tipo de acciones, realizadas de forma colectiva, donde se manifiesta la conciencia femenina a la que se refiere Temma Kaplan ${ }^{13}$. Es así como, en una sociedad donde la convivencia y las formas de sociabilidad se quebraron por la guerra civil y la represión, esposas, madres e hijas encontraron especialmente en las puertas de las cárceles un punto en el que se reconocieron y establecer lazos de solidaridad y afinidad, dando comienzo a algo parecido a un sistema de resistencia propiamente femenino. Así pues, se fueron tejiendo unas redes de solidaridad, que les dio la posibilidad de organizar colectivamente un entramado asistencial a los presos, que en ocasiones fue más allá de la simple ayuda material, colaborando con la introducción de propaganda o viceversa, siendo el enlace entre el interior y el exterior. Poco a poco diversos actos de protesta reivindicando la mejora de las condiciones de vida de los presos fueron tomando paulatinamente un carácter más político, señalando como dice Giulana di Febo "para la mujer del detenido empezó una nueva forma de vivir, de actuar, de pensar: ser mujer de preso, además de símbolo y testimonio de la represión se convertía en estos años en una función política"14. Es así como nacieron las "mujeres de preso", que a través de la creación de fuertes vínculos de solidaridad que fortalecieron su movilización política en pro de la libertad de sus familiares

sión y resistencia, Oviedo, KRK, 2006; YUSTA, Mercedes, "Las mujeres en la resistencia antifranquista, un estado de la cuestión", Arenal, 12 (2005), pp. 5-24; ABAD, Irene, "El Movimiento Democrático de Mujeres de Zaragoza y su función en torno a los presos políticos del franquismo", VI Encuentro de Investigadores sobre el franquismo, Zaragoza, 2006, pp. 635-650; GARCíA, Ramón, "Mujeres en vanguardia. La resistencia femenina al franquismo en la cuenca minera asturiana, 1962-1967", en Tiempos de Silencio. Actas del IV Encuentro de Investigadores del franquismo, Valencia, 1999, p. 341-345; Díaz, Pilar, "La lucha de las mujeres en el tardonfranquismo: los barrios y las fábricas" Gerónimo de Uztariz, 21 (2005), pp. 39-54.

13. Kaplan, Temma, "Conciencia femenina y acción colectiva: el caso de Barcelona, 19101918” en S. Amelang, James y NASH, Mary (eds.), Historia y género: las mujeres en la Europa Moderna y Contemporánea, Valencia, Alfons el Magnànim, Institució Valenciana d'Estudis i Investigació, 1999, pp. 267-295.

14. Di FeBo, Giulana, Resistencia y movimiento de mujeres en España, Icaria, Barcelona, 1976, p. 87. 
presos, pasaron a un objetivo general de amnistía a los presos, suponiendo salir del campo asistencial de ayuda para formar parte activa del movimiento de oposición antifranquista ${ }^{15}$.

Su importante labor, generó un cierto cambio en la táctica del PCE respecto a la militancia femenina. Una de sus primeras iniciativas fue la creación en 1959 del boletín clandestino Mujer. En su primer número quedaron establecidos los objetivos de la publicación, centrados en la creación de grupos desde los que incorporar a las mujeres a la lucha contra la dictadura y potenciar su presencia en los comités del partido ${ }^{16}$. Es en ese entramado de lucha antifranquista donde comienza a gestarse en Madrid el inicio de una organización en la órbita del PCE, destacando el papel que tuvieron entre otras Carmen Rodríguez o Dulcinea Bellido, bajo la idea de luchar por los presos políticos, denunciar la represión y configurarse como una plataforma de solidaridad ${ }^{17}$. El aumento de la conflictividad y su papel apoyando las reivindicaciones del movimiento obrero propiciaron que los dirigentes del PCE intentaran reorganizar a las militantes que habían desarrollado labores de apoyo a los presos y al partido. En 1962 la dirección del PCE decidió reconstruir las juventudes del partido y crear una nueva asociación de mujeres que aglutinase a las mujeres de preso, a militantes y simpatizantes del PCE y a aquellas disidentes de los círculos intelectuales y el catolicismo progresista. Sin embargo, la idea no cuajó y muchas de las asistentes se desvincularon del proyecto ${ }^{18}$.

A pesar de esa contrariedad, las militantes más activas de ese momento siguieron tanteando la posibilidad de crear una organización femenina a partir de sus contactos con las mujeres de preso. Poco a poco y a partir de diferentes reuniones, trabajos de solidaridad y apoyo se fue gestando un embrión de organización, que nació en 1964 en Madrid bajo el nombre de Movimiento Democrático de Mujeres. Una organización clandestina que emergía destacando su naturaleza plural e interclasista, su apoyo a los presos y a sus familiares, su lucha antifranquista y su preocupación por los problemas de las mujeres.

15. ABAD, Irene, En las puertas de prisión. De la solidaridad a la concienciación política de las mujeres de los presos del franquismo, Barcelona, Icaria, 2012.

16. Mujer, $\mathrm{n}^{\circ} 1$, IX-1959.

17. Sobre esta cuestión veáse: ABAD, Irene, En las puertas de prisión...; CABrero, Claudia, "El PCE y las mujeres. La actitud del Partido respecto a la militancia femenina durante el primer franquismo", I Congreso sobre la Historia del PCE, 1920-1977, Oviedo, 2004, p. 427-440; SCAlon, Geraldine M., La polémica feminista en la España contemporánea, 1868-1974, Madrid, Akal, 1986, NASH, Mary, Rojas. Las mujeres republicanas en la Guerra Civil, Madrid, Taurus, 2000, pp. 111-127.

18. Arriero, Francisco, "El Movimiento Democrático de Mujeres: del antifranquismo a la movilización vecinal y feminista", Historia, Trabajo y Sociedad, nº 2 (2011), pp. 33-62. 
El PCE desde el primer momento dejó claro su papel como tutor, combinando la creación de un frente femenino que ampliara la influencia social del partido, junto con el deseo de luchar contra la discriminación sufrida por la mujer ${ }^{19}$. Así pues, Mary Nash destaca como el MDM surgió con una clara conexión con el PCE pero "fomentando desde la clandestinidad política, la movilización de las mujeres en las asambleas y vocalías de barrios (...) y desempeñó un rol decisivo al movilizar a las mujeres trabajadoras en los barrios periféricos en la lucha antifranquista. Además, su práctica facilitó una cierta incorporación de peticiones específicas" ${ }^{20}$. Del mismo modo, Mónica Tehrelfall señala que aunque el MDM no fue una creación exclusiva del PCE, sí que nació en sus filas y contó con su aprobación, sentando las bases de la participación de la mujer en la esfera pública de la oposición política ${ }^{21}$. Sin embargo, Romeu Alfaro apunta que la creación del MDM está más relacionada con la FDIM y la UME que con el PCE, y que su nacimiento está vinculado directamente con el contexto de agitación social de Madrid en los años sesenta formado por las militantes comunistas, pero al mismo tiempo "con el deseo de que se abriera a mujeres de distinta ideología y con el objetivo prioritario de sensibilizar a las mujeres tanto en los temas sociales y políticos de carácter general como en los más específicos femeninos como podía ser la discriminación legal y social"22. Desde esta misma óptica Sara Iribarren indica la particularidad del MDM teniendo en cuenta la realidad política del país $^{23}$. Así pues, se puede afirmar que precisamente esa combinación entre lo político y el feminismo fue su peculiaridad durante toda su existencia. Un complejo camino que no siempre fue entendido por todas sus militantes, que estuvo supeditado por la tutela del PCE y por los diferentes momentos por los que transcurrió la lucha antifranquista. De forma que, "el MDM es un movimiento de masas cuyo campo específico de acción es la masa femenina (...). El MDM liga este trabajo a la lucha socio-política general del país contra el franquismo (...); conscientes de que la liberación de la mujer va indisolublemente ligada a la liberación de la clase trabajadora"24.

19. Romeu Alfaro, Fernanda, Silencio roto... Mujeres contra el franquismo, Oviedo, edición de la autora, 1994.

20. NASH, Mary, Mujeres en el Mundo. Historia, Retos y Movimientos, Madrid, Alianza, 2004, p. 68.

21. Threlfall, Mónica (ed.), Mapping the women's movement. Feminist Politics and Social Transformation in the North, Londres y Nueva York, Ed. Verso, 1996.

22. Romeu, Fernanda, El silencio roto, mujeres... p. 74.

23. IribarRen, Sara, La liberación de la mujer, París, Ebro, 1972, p. 128-129.

24. ¿Qué es el MDM? Mujeres, sin fechar, Caja 117, carpeta 2. Archivo Histórico Partido Comunista de España (a partir de ahora AHPCE). 
Aunque desde el inicio la organización estuvo en manos de las militantes del PCE, desde muy pronto se fueron incorporando activistas socialistas, católicas e independientes, que de hecho no estaban en minoría respecto a las militantes y simpatizantes del $\mathrm{PCE}^{25}$, de forma que como señala $\mathrm{M}^{a}$ Ángeles Larrumbe el origen del MDM se debió a la iniciativa tomada por las militantes comunistas, uniéndose mujeres de otros sectores situación que le daría un carácter más plura ${ }^{26}$. Esta diversidad del movimiento quedó reflejado en varios números del boletín La mujer y la lucha indicando que "mujeres de diversas ideologías pero con los mismos problemas hemos trabajado juntas, codo con codo, sin reservas ni prejuicios anacrónicos, dando cada una lo mejor de nosotras mismas en la realidad de la lucha diaria"27, de modo que "tal fórmula bien puede ser un movimiento democrático de mujeres en el cual tengan cabida diferentes concepciones políticas y religiosas, condición indispensable para que se desarrolle y pueda aportar su influencia en el presente y futuro inmediato del país"28.

Aparte de la estrategia de movilización es importante destacar como empezaron a hacer públicas y a canalizar la lucha que los presos políticos no podían realizar desde el interior de las cárceles, entrando de lleno en un nuevo mundo, pasando de la sombra de sus casas a la luz de la calle, tratando de recuperar derechos y redefiniendo su posición dentro de la sociedad. Era bastante habitual que se reunieran para estudiar y planificar las tareas económicas, médicas y legales relacionadas con los presos. A partir de aquí se realizaba un intenso trabajo centrado en visitar a personalidades del régimen, el clero y diferentes centros oficiales, con el objetivo de plantear los problemas que los presos políticos sufrían en las cárceles, como malas condiciones, incomunicación con el exterior y sobre todo condenas excesivamente largas, para lo cual solicitaban una plena amnistía política. Un arduo trabajo que no siempre conseguía lograr sus objetivos, ejemplificado en una carta que se envía desde Jaén, señalándose la ingratitud de esta actividad, ya que tanto esfuerzo no se veía recompensado con grandes éxitos, aunque tampoco caía en saco roto ${ }^{29}$.

Tal fue la importancia de la ayuda a los presos y sus familiares que la Comisión de Solidaridad en 1968 se creó con el objetivo de realizar esa labor, aunque pronto se extendería a despidos por huelga y a la asistencia jurídica y médica en casos necesarios. Se demuestra el gran esfuerzo del MDM en este sen-

25. Informe de la organización de mujeres de Madrid. Madrid, 1969. Mujeres: Caja 117, carp. 2/3. AHPCE.

26. LARRUMBe, $\mathrm{M}^{\mathrm{a}}$ Ángeles, Una inmensa minoría...

27. La mujer y la lucha, XII/I-1969.

28. La mujer y la lucha, V-1971.

29. Correspondencia. Jaén. 1973. Represión franquista: Caja 40, carpeta 4. AHPCE. 
tido, ya que la recaudación solidaria entre familias obreras, de bajos ingresos y trabajadores podía pasar en cualquier momento de ser donantes a beneficiarios de estas ayudas. Pero, además esta comisión de solidaridad llegó a suponer para el MDM un espacio idóneo para captar aquellos lugares donde se iba a repartir el dinero y así extender la organización ${ }^{30}$. Como uno de los diferentes ejemplos podemos analizar el caso de Jaén. Esta práctica de solidaridad tenía sus precedentes antes de la creación del MDM. Rosario Ramírez, activa militante del PCE, llegó a realizar una tarea básica en beneficio de los presos y sus familiares ${ }^{31}$, destacando entre sus prioridades la distribución de alimentos a la vez que favorecer la estancia de los familiares, generalmente esposas, madres o hijas, que venían a la cárcel de Jaén a visitarlos. Solidaridad entre mujeres que iban tejiendo toda una red asistencial básica para su supervivencia, ya que "si no existían puntos de apoyo entre ellas, muchas de estas mujeres dormían en la estación, porque no tenían dinero ni para pagarse una pensión. Además había un gran esfuerzo de estas mujeres por sacar adelante a la familia y ayudar al preso"32. Pero además, esta intensa actividad no sólo reforzó sus lazos de unión, sino que también comenzó a crear una serie de intereses comunes diferentes a los tratados hasta ese momento de forma que "las reuniones que teníamos las mujeres de presos eran para hablar de las cárceles, pero el tema estaba tan sabido que empezamos a discutir otras cosas"33.

La importancia y diferencia del MDM respecto a otras organizaciones surgidas durante los primeros años sesenta fue su capacidad para desarrollar un movimiento a nivel nacional, estructurado a partir de pequeñas delegaciones de barrio, especialmente en las grandes ciudades. Este carácter urbano permitió al MDM servirse de la Ley de Asociaciones del 24 de diciembre de 1964 para constituirse legalmente como Asociaciones de Barrio, Asociaciones de Amas de Casa o Asociaciones de Amas de Hogar, fomentando de este modo la agrupación y politización de los barrios populares. En Madrid se crearon las primeras asociaciones de Getafe, Chamartín, Carabanchel y Ventas a lo largo de 1969 y 1970 inscribiéndose como asociaciones de Amas de Casa contando con 17 grupos que se reunían semanalmente ${ }^{34}$. A partir de este momento se

30. Informe de la Organización de Mujeres de Madrid. Madrid. 1969. Mujeres: Caja 117, carp. 2/3. AHPCE

31. Entrevista a Cayetano Rodríguez, Jaén, 31-V- 2007.

32. Entrevista realizada por Irene Abad a Carmen Casas recogida en ABAD Irene, "Las mujeres de presos republicanos: movilización política nacida de la represión franquista" en Documentos de Trabajo, $\mathrm{n}^{\circ} 2$ (2004), Fundación $1^{\circ}$ de mayo, p. 14.

33. Entrevista a Natalia Joga. Carpeta 285, cinta 314. Centro Documental de la Memoria Histórica (CDMH), Centro de Información y Formación Feminista (CIFFE).

34. Informe de la organización de mujeres de Madrid. Madrid. 1969. Mujeres, Caja 117, Carpe. 2/3. AHPCE. 
fue iniciando una labor de puerta a puerta de forma que "la utilización de plataformas legales nos permitirá llegar a esas miles de mujeres diseminadas y agruparlas en torno a problemas concretos. Hay una serie de Asociaciones de Amas de Casa distribuidas por todo el país que no hacen nada en torno a los problemas de la mujer (...) en los lugares que no existían, sería interesante estudiar la posibilidad de crear nosotras" 35 . El MDM entendía a la mujer como un "ser social afectado por la ausencia de libertades generales y doblemente discriminada por su condición de mujer"36 y en esa discriminación existe un protagonista que se convierte en su primer objetivo de captación: el colectivo de amas de casa. Para el MDM era el sector más numeroso y el más injustamente discriminado: "el ama de casa, a la que la sociedad actual imposibilita a participar en las tareas colectivas, mientras la agobia con problemas domésticos (...), acaparando todo su tiempo y mutilando su proyección humana, tiene la posibilidad y el deber de participar en la lucha reivindicativa (...) que le hace tomar parte activa $y$ consciente en los problemas comunes, consigue vincularla como ser social, sacándole del individualismo en que se haya sumergida con las tareas domésticas que le producen soledad, tedio y nerviosismo" 37 . El MDM buscaba la forma de que se sintieran "útiles, ser algo más que una máquina de fregar y coser... revelarles la importancia de la participación y la unión", aún cuando para las militantes del movimiento "es un trabajo ingrato, en ocasiones aburrido y que produce desazón"38. Utilizando una serie de mecanismos para concienciarlas como movilizaciones, protestas, manifestaciones y charlas en los barrios denunciando la carestía de vida, mejora en los salarios, o la falta de infraestructuras y equipamientos, el MDM pretendió poner sobre la mesa otras reivindicaciones sociales y políticas, que fueron planteadas de forma específica, ya que sin renunciar a sus "responsabilidades de género", solicitaban una mayor facilidad para mantener e incrementar su participación política, adaptándose cada vez más a un discurso feminista. La creación de las vocalías de la Mujer sentaron las bases para seguir luchando en un movimiento asociativo supuestamente igualitario, empezando a poner en marcha experiencias que convirtieron una reclamación feminista, como el derecho al propio cuerpo, en proyectos del Estado de Bienestar ${ }^{39}$.

35. Reunión Nacional de Mujeres de Madrid. Madrid. 1971. Mujeres: Caja 117, carp. 2/2. AHPCE.

36. Primera reunión general de las mujeres demócratas. Mujeres: Caja 117, carp. 2/2. AHPCE.

37. Tercera reunión general del Movimiento Democrático de Mujeres. Madrid. Mujeres: Caja 117, carp. 2/2. AHPCE.

38. Reunión Nacional de Mujeres, Madrid. 1971. Mujeres: Caja 117, carp. 2/2. AHPCE.

39. Muñoz, A. y Ramos, M.D., "Mujeres, política y movimientos sociales. Participación, contornos de acción y exclusión", BORDERÍAS, Cristina, (ed.), La historia de las mujeres: perspectivas actuales, Barcelona, Icaria, 2009, p. 102. 
Además, el hecho de que no se llegara a romper ese carácter de continuidad entre el espacio doméstico y el barrio da lugar a que las diversas reivindicaciones sean una prolongación más de las necesidades del hogar. El barrio pasa a ser el lugar ideal para la progresiva toma de conciencia femenina con el objetivo de ir venciendo el aislamiento ${ }^{40}$. Las asociaciones de los barrios sirvieron de plataforma para solucionar ciertas carencias en su formación y concienciación que impedían su capacidad para incorporarse al ejercicio de su derecho como ciudadanas $^{41}$. Ese hecho fue más que relevante a la hora de formar su propia conciencia en un escenario regulado por la falta de libertades, la oposición antifranquista y la lucha por la democracia, centrándose precisamente esa conciencia femenina en los derechos de género, en los intereses sociales y en la propia supervivencia, de forma que el principio que la legitima es la necesidad de conservar la vida, poniendo el acento en la lucha por el mantenimiento de la vida cotidiana que realizan las mujeres, en la línea seguida por Temma Kaplan ${ }^{42}$.

Ante su incorporación a la industria a lo largo de los años sesenta, las militantes de MDM, en su idea de crear un movimiento de masas de mujeres, también miraron con especial atención a la mujer trabajadora, criticando su destino laboral, ya que a pesar de su independencia económica y personal, en muchas ocasiones llegó a convertirse en un trabajo en cadena, de baja cualificación, e incluso en ocasiones vejatorio y que su participación en huelgas o sindicatos era algo ajeno a ellas, de forma que "cuando hay convocatorias de huelga se nos hacen advertencias que no se atreverían a hacer a nuestros compañeros. Se nos quiere hacer ver que tales problemas no son cosa nuestra, que nos son femeninos (...) organicemos en cada empresa o colegio, para unir nuestros esfuerzos a toda la lucha general, encabezada ya por grandes sectores del movimiento obrero del cual somos un destacamento más"43.

40. Sobre el papel de las mujeres en la lucha en los barrios, véase Di FEBO, Giulana, "La lucha de las mujeres en los barrios en los últimos años del franquismo. Un ejemplo de utilización de la "Historia de género", Tusell, Javier, Alted, Alicia y Abdón Mateos, La oposición al régimen de Franco. Estado de la cuestión y metodología de la investigación, t. II, UNED, Madrid, 1991, pp. 251-160; DOMĖNECH, Xavier, "Género antifranquismo y ciudadanía. Mujeres y movimiento vecinal en la Asturias del desarrollismo y el tardofranquismo", Historia del Presente, 16 (2001), pp. 9-26.

41. García-Nieto, Ma Carmen, "Marginalidad, movimientos sociales, oposición al franquismo. Palomeras, un barrio obrero de Madrid, 1950-1980", en Tusell, Javier, Alted, Alicia y ABdón Mateos, La oposición al régimen de Franco. Estado de la cuestión y metodología de la investigación, tom II, UNED, Madrid, 1991, p. 278.

42. Kaplan, Temma, "Luchar por la democracia: formas de organización de las mujeres entre los años cincuenta y los años setenta", AGUADo, Ana, Mujeres, regulación de conflictos sociales y cultura de la paz, Publicacions de la Universitat de València, 1999, pp. 89-109.

43. ¡Trabajadoras! ¡Compañeras! Madrid.1971. Mujeres: Caja 117, carp. 2/6. AHPCE. 
En este sentido, el MDM concebía que la mujer sufría una doble explotación, patriarcal y capitalista, debiéndose sumar a las reivindicaciones y movilizaciones sindicales. Así pues, es importante destacar el cambio de registro que el MDM usaba dependiendo del colectivo que se refiriera. Si al colectivo de amas de casa le apela desde reivindicaciones de barrio y prácticamente sin entrar en concepciones de género, cuando se refiere a la mujer trabajadora, desarrolla un discurso propiamente marxista, insistiendo en su doble explotación, mientras que cuando se refiere a estudiantes universitarias y a profesionales el discurso es plenamente feminista de forma que "el ser biológico de la mujer es el que determina su ser social" ${ }^{44}$. El objetivo, por tanto, era buscar una nueva ciudadanía, luchando por la capacidad de crear un movimiento de masas de mujeres siendo necesaria la unión interclasista, de ahí su importancia por aglutinar tanto a mujeres de diferente ideológica como de todo tipo (obreras, amas de casa, estudiantes, profesionales... $)^{45}$, "no porque seamos mujeres sino porque estamos discriminadas" ${ }^{46}$, encabezando según Giulana di Febo la mayor movilización de las masas femeninas desde la posguerra ${ }^{47}$.

Así, un sector del MDM fue evolucionando de la lucha contra la represión, la amnistía y la red asistencial a los presos políticos y a sus familiares hacia la formación de un discurso más comprometido con el feminismo a finales de los sesenta y a lo largo de los primeros años de la década de los setenta, ya que para muchas el MDM fue el mecanismo utilizado para colocar la movilización feminista dentro de la órbita del PCE contra la dictadura franquista. Exigir la amnistía para los presos políticos y las libertades se incluía dentro de un escenario más amplio que pasaba por terminar con el franquismo e iniciar una sociedad socialista. Sin embargo, otro sector señalaba que todo aquello también era compatible con la denuncia de la situación de la mujer. A partir de aquí su camino estuvo señalado por una contradicción interna entre la búsqueda de su discurso de clase y de género.

A raíz de la publicación del boletín La mujer y la lucha en 1968 comenzó a señalarse las dificultades que entrañaba ser mujer en la línea iniciada por Simón de Beavoir donde la subalternidad femenina es una construcción social y por Betty Friedan indicando en estos años que ellas tienen "problemas muy concretos, discriminaciones claras y una mística encubridora y ensalzadora de esa situación" ${ }^{48}$, destacando esa mística de la feminidad que denunciaba el malestar de

44. ¡A todas las mujeres universitarias! Mujeres: Caja 117, carp. 2/6. AHPCE.

45. Informe de Amaya. Madrid. 1970, Mujeres: Caja 117, carp. 2/3. Ref. 187/14, Cop. $23-$ 4-70. AHPCE.

46. La mujer y la lucha, X-1968.

47. Di Febo, Giulana, Resistencia... p. 158.

48. La mujer y la lucha, IV- 1968. 
la mujer y su sometimiento. Este proceso hacia posiciones feministas también se vio contribuido por la llegada al MDM de una nueva generación de jóvenes tanto católicas, como socialistas, sin partidos y estudiantes universitarias que tenían otra visión de la organización, iniciando un verdadero aprendizaje feminista a través su esfuerzo personal. A partir de aquí, una parte del MDM fue evolucionado hacia un feminismo moderado que no siempre fue entendido por el PCE, porque demostraba la fractura entre el discurso marxista de la mujer y la tónica habitual sexista en los partidos de izquierda y porque el MDM defendía la necesidad de las organizaciones de mujeres, aunque estaba de acuerdo con el PCE en unir fuerzas para luchar contra la dictadura.

En este punto de inflexión hacia el feminismo la celebración en febrero de 1970 de la primera reunión general del MDM marcó un antes y un después. A partir de aquí, sin abandonar la lucha por los presos y pro amnistía, se fue incorporando oficialmente la cuestión de género, de forma que el objetivo principal era "estudiar los problemas que afectan a la mujer en general, como ser social afectado por la ausencia de libertades generales y doblemente discriminada por su condición de mujer" ${ }^{\prime \prime 9}$. Para esa fecha ya existían en España numerosos grupos, asistiendo a esta reunión delegadas de varias provincias como Asturias, Alcoy, Guipúzcua, Madrid, Puertollano, Santander, Tarrasa, Valencia, Valladolid, Vizcaya y Guipúzcua. El resultado fue una enumeración de facilidades que Estado y Empresas debía ofrecer para que fuera posible la emancipación de la mujer como guarderías, escuelas públicas, plena admisión de la mujer casada al trabajo, fin de leyes discriminatorias..., destacando que junto a este tipo de demandas y "ligadas a la problemática general (...) entendemos que las exigencias de estos sectores son nuestras".

\section{La llegada de la democracia y el fin del MDM}

Los informes de las distintas reuniones generales celebradas entre 1970 y 1975 señalan como fueron numerosos los grupos del MDM que surgieron por toda la geografía, aunque solamente fueron algunas ciudades las que consiguieron un movimiento consolidado y estable, siendo allí donde se llegó a iniciar una búsqueda del discurso reivindicativo que incorporase las experiencias feministas que llegaban del exterior. El MDM intentó convertirse en un movimiento de carácter estatal, impulsando un discurso político coherente y estructurando una estrategia común. Prueba de ello fue que en la Segunda Reunión General del Movimiento Democrático de Mujeres celebrada en 1971 surgieron nuevos gru-

49. Primera Reunión General de las Mujeres Democráticas, Madrid. 1970. Mujeres: Caja 117, carp. 2/2. AHPCE. 
pos, acudiendo delegaciones de Galicia, Murcia, Córdoba, Sevilla, Asturias, País Valencia, Madrid y Zaragoza, destacando la ausencia de País Vasco y Cataluña. Sin embargo, aunque llamó la atención esta proliferación de delegaciones, lo más significativo fue la composición de muchas de ellas, integradas por una nueva generación de jóvenes mujeres, sobre todo estudiantes de universidad, lo que implicó un cambio sustancial en la evolución del MDM.

La movilización del MDM en su lucha contra la represión franquista se compaginaría con otras reivindicaciones, ampliando el campo de acción femenino. Además, no debemos de olvidar que a lo largo de los setenta las integrantes del MDM empezaron a entablar relaciones con grupos feministas como el Movimiento de Liberación de la Mujer. Este doble discurso tendría repercusiones en el interior del MDM, llegándose a producir un choque generacional, puesto que algunos planteamientos más avanzados del feminismo como la defensa del aborto, la autodeterminación del cuerpo y la sexualidad femenina junto con una actitud más autónoma fueron defendidos por las militantes más jóvenes, muchas de ellas también integradas en el $\mathrm{PCE}^{50}$, mientras que las más mayores pensaban que esos temas asustaban a las amas de casa y tenían una menor importancia en relación con la reivindicación política y la lucha en los barrios. Esta situación provocó en el seno del MDM que muchas de sus componentes, sobre todo las que consideraban que el feminismo era incompatible con el comunismo, decidieran abandonar el grupo.

Sin embargo, a pesar de las disidencias internas, el objetivo del MDM seguía siendo la lucha por la emancipación femenina, aunque la amnistía política de presos y exiliados protagonizó buena parte de las movilizaciones y acciones del grupo, y es que no debe extrañar la atención que el MDM prestó durante los años setenta a la amnistía. Como se señala en un artículo del Mundo Femenino en 1971: “(...) ¿Cómo, pues, podemos las mujeres asturianas participar directamente en la lucha por la AMNISTÍA? Llevando esta exigencia a todos los lugares posibles, a las fábricas, a las tiendas, a las oficinas, a la calle; explicando a todo el mundo el por qué de la amnistía, ayudando en la recogida de fondos para las familias de presos y despedidos; enviando cientos de cartas o telegramas (a poder ser colectivos) a las diversas autoridades españolas, solidarizándose con las mujeres de los presos, que de diversas maneras tratan de conseguir su libertad; o participando en las manifestaciones, huelgas, encierros o cualquier otra forma de lucha"51. El MDM se centró en hacer ver a la sociedad y a la oposición antifranquista la

50. ERICE, Francisco, "Mujeres comunistas. La militancia femenina en el comunismo asturiano, de los orígenes al final del franquismo", en ERICE SEBARES, Francisco (coord.), Los comunistas en Asturias (1920-1982), Gijón, 1996, p. 334.

51. Mundo Femenino. Portavoz del Movimiento Democrático de Mujeres. Asturias. IX-1971. 
importancia de la reclamación de los derechos de la mujer para conseguir la igualdad. De hecho en la tercera reunión general que tuvo lugar en octubre de 1971 se decidió la "constitución de una coordinadora general que agilice los contactos e intercambios de experiencias de unos y otros lugares para impulsar decisivamente la incorporación de la mujer a la lucha"52. A la vez se insistía en la independencia y autonomía del movimiento, y la incorporación al mismo de todas las mujeres "sin distinción de ideologías o credo religioso".

Si en dos años se habían celebrado tres reuniones generales, no fue hasta agosto de 1975 cuando tuvo lugar la cuarta reunión general del MDM y última en la dictadura. Se difundió la idea de unidad social en torno al concepto de democracia por métodos pacíficos. Conceptos como unidad y democracia se emplearon para sustituir a independencia, lucha de clases y socialismo. Junto a la continuidad del discurso de amnistía, destacó también la lucha contra la pena de muerte. Es ahora por primera vez cuando en una reunión general no se trató el tema de los movimientos feministas, sino que se habló del Movimiento de Liberación de la Mujer, dejando claro que su objetivo de crear un movimiento de masas de mujeres estaba superado, dando paso a una reflexión sobre la discriminación de la mujer.

La concepción del capitalismo como base de todas las discriminaciones sociales, convertiría cualquier conquista femenina alcanzada dentro de dicho sistema en derechos formales de la burguesía, que beneficiaban sólo a un reducido número de mujeres. Como indica María José Valverde la actitud de las propias militantes, silenciadas durante años por el Régimen y sometidas a la conciencia de partido, fue la de aparcar sus "demandas específicas", mientras no se alcanzasen los mínimos generales ${ }^{53}$. Ante este hecho, aquellas militantes del PCE que no estuvieron de acuerdo con la decisión y no aceptaron que un partido se adjudicara un derecho que no le correspondía, rompieron con el PCE y decidieron seguir trabajando en el MDM, que siguió desempeñando un destacado papel en el conjunto del movimiento feminista ${ }^{54}$. A pesar de ello, las que se quedaron en el PCE trabajaron por introducir un profundo debate sobre la opresión de la mujer con posiciones muy avanzadas. Además, en el partido se cuestionaba el papel secundario de la militancia femenina afirmándose que "somos conscientes de que en nuestras filas, la discriminación de la mujer es una

52. Tercera Reunión General del Movimiento Democrático de Mujeres. Madrid. 1971. Mujeres: Caja 117, carp. 272. AHPCE.

53. Valverde, $M^{a}$ José, "La Mujer y el Partido Comunista de España", en JimÉnez, $M^{a}$ Jose (coord.), Pensamiento, imagen, identidad: a la búsqueda de la definición de género, Málaga, Servicio de Publicaciones de la Universidad de Málaga, 1999, pp. 111-115.

54. Larrumbe, $\mathrm{M}^{\mathrm{a}}$ Angeles, Una inmensa minoría... p. 156. 
realidad", así hay que luchar para que "las mujeres sean tenidas en cuenta en toda la vida y actividad de los comités del partido y no sólo para ayudar con trabajos prácticos" $" 55$. El MDM se enfrentó a los problemas de una doble militancia debido a la falta de solidaridad de los movimientos sociales y políticos que entendían su lucha como algo auxiliar. A pesar de ello, cada vez se hizo más frecuente la idea de que el proletariado no podía alcanzar el éxito completo sin la libertad de la mujer ${ }^{56}$, de forma que la contribución del feminismo se debía incorporar para impedir un socialismo a medias, definiéndose el propio PCE como un partido feminista y de liberación de la mujer ${ }^{57}$.

Sin embargo, realmente no se fomentaron acciones que incrementase la presencia femenina en el seno del PCE entre otras razones porque se priorizó la lucha contra la dictadura franquista y el pensamiento marxista clásico y por el peso que seguía teniendo el estereotipo de género en la militancia comunis$\mathrm{ta}^{58}$. En la práctica el PCE estimó que la función del MDM había de darse por concluida. Además, fue bastante frecuente que buena parte de las integrantes mejor formadas del MDM fueran captadas por el PCE u otros partidos. E incluso desde los partidos y comisiones se consideraba que sus militantes más activas no deberían perder el tiempo en organizaciones de mujeres ${ }^{59}$.

La lucha por la mujer tras la muerte de Franco siguió su curso hasta que en 1976 y en medio de la coyuntura de efervescencia del feminismo el Movimiento Democrático de Mujeres unió sus siglas a las del Movimiento de Liberación de la Mujer constituyéndose el MDM/MLM. El objetivo fundamental del grupo fue desarrollar una estrategia con un perfil más feminista, creando nuevas comisiones de enseñanza y universidad, para trabajar de forma más específica en estos sectores. Prueba de ello fue su participación en las Jornadas Nacionales por la Liberación de la Mujer, celebradas en el contexto del Año Internacional de la Mujer en Madrid entre el 6 y el 8 de diciembre de 1975, donde se constituyó una Coordinadora de Organizaciones Feministas a nivel nacional, y donde se excluía a Sección Femenina. Después vendrían los encuentros de las Jornadas Catalanas de la Dona en mayo de 1976, y las II Jornadas Estatales de la Mujer, que tuvieron lugar en Granada en 1979. Es en este escenario donde las mujeres debatieron sobre feminismo y trataron de buscar pun-

55. Mundo Obrero, $\mathrm{n}^{\circ}$ 32, X-1975.

56. El Correo del Pueblo, $\mathrm{n}^{\circ} 47,29-06-1976$.

57. Mundo Obrero, no 29, IX-1975 y no 30, X-1975

58. Para estas cuestiones véase VAlVerde, $\mathrm{M}^{\mathrm{a}}$ José, "La mujer y el Partido Comunista"...; CABrero, Claudia, "El PCE y las mujeres"... y Erice, Francisco, "Mujeres comunistas"...

59. Entrevista a Begoña San José, (BIO-003), realizada por Benito Bermejo y José Babiano. Madrid. 2002. Fundación Primero de Mayo. 
tos de encuentro en relación a las reivindicaciones, tácticas y estrategias necesarias para lograr la liberación de la mujer. Sin embargo, es preciso indicar que todos aquellos colectivos de mujeres que fueron surgiendo en el ocaso de la dictadura coincidieron en señalar un objetivo común: el fin de la dictadura y el desmontaje de su estructura era una condición básica para la supervivencia del movimiento feminista. Es más el hecho de que en estos momentos la campaña por la amnistía política siguiera ocupando una posición fundamental dentro de toda la movilización antifranquista, hizo que la nueva organización MDM-MLM no dejara de formar parte de campo de acción que constituía la oposición, aportando su presencia en la movilización pro-amnistía. Así, se empezó a converger en las propuestas del feminismo de la igualdad que defendía la democracia y aprobaba la participación de las mujeres en los partidos, señalando que la lucha por la democracia se completaba con la lucha feminista, defendiendo la doble militancia política y feminista. Esta postura fue criticada por el feminismo radical que defendía una militancia única en los grupos u organizaciones políticas de mujeres ya que cuestionaba los modelos de sociedad capitalita y comunista por no ofrecer soluciones a la opresión de la mujer, debido a que era la clase oprimida y explotada por el hombre. Sin embargo, las integrantes del MDM se justificaron del ataque de las feministas radicales señalando que éstas no tenían en cuenta el contexto político de España, ya que sin democracia y libertad la liberación femenina era imposible. Finalmente, esta línea del feminismo radical dio lugar a la creación en 1979 del Partido Feminista, ayudando al desarrollo de una nueva cultura política feminista ${ }^{60}$.

La propia dinámica de la democracia y la llegada de las elecciones de 1977 fueron apagando lentamente la actividad del MDM/MLM debido fundamentalmente al hecho de que la doble militancia se fue decantando hacia la estrategia de los partidos políticos, ya que buena parte de las militantes del Movimiento se inclinaron por los partidos políticos para luchar por la igualdad desde el poder, priorizaran el apoyo a las estrategias de los partidos de izquierda durante la Transición y relegando a un segundo plano su propia lucha ${ }^{61}$. El hecho de

60. GrAU, Elena, "De la emancipación a la liberación y la valoración de la diferencia. El movimiento de mujeres en el Estado español, 1965-1990", Duby, Georges y Perrot, Michelle (dir.), Historia de las mujeres. El siglo XX. Vol. 5, Madrid, Taurus, 1993, pp. 673-683; FAGOAGA, Concha y LunA, G. Lola, "Notas para una historia social del movimiento de las mujeres: signos reformistas y signos radicales", GARCíA-NiETO, Ma Carmen, Ordenamiento jurídico y realidad social de las mujeres. Siglos XVI- XX, Madrid, U.A.M., 1986, p. 453-462; Agustín, Mercedes, Feminismo: identidad personal y lucha colectiva (análisis del movimiento feminista español en los años 1975 a 1985), Granada, 2033; NASH, Mary, Mujeres en el mundo. Historia, retos y movimientos, Alianza, 2004.

61. Entrevista a Rosario Vicente, Jaén, 29-IX- 2008. 
que muchas mujeres se decidieran a luchar por la democracia y los derechos de género en sus propios partidos dio lugar a que creasen otros movimientos femeninos que quedaron insertados dentro de sus grupos políticos ${ }^{62}$. Una práctica habitual en los partidos de izquierda fue la creación de comisiones específicas para la mujer, que consiguieron de alguna forma introducir reivindicaciones feministas en sus programas. Ese fue el caso del PCE, que con la Comisión para la Liberación de la Mujer o para la Cuestión Femenina consiguió introducir reivindicaciones feministas reclamando "el final de la derogación de todas las discriminaciones jurídicas y la amnistía para todas las mujeres condenadas por motivos políticos, abandono de hogar, adulterio y aborto"63. Por su parte, el PSOE se decidió en 1976 a crear el colectivo Mujer y Socialismo cuyo objetivo fue crear centros asesores de la mujer para ayudarlas a resolver sus problemas en diferentes aspectos como profesionales, formativos o familiares. Igualmente, en partidos de extrema izquierda como el PTE o el MC se puso el acento en apoyar toda propuesta sobre el avance de la liberación de la mujer, de forma que el PTE llegó a asumir el programa de las Jornades Catalanes de la Dona y el MC destacaba que alrededor de un tercio de sus militantes eran mujeres. Sin embargo, en ambas organizaciones se seguía insistiendo en que aunque de forma más sutil se seguía manteniendo la subordinación de la mujer, situación que se debía remediar ${ }^{64}$, aunque en los programas políticos se fueron incorporando reivindicaciones básicas del movimiento feminista como la ley del divorcio, la igualdad ante la ley, el aborto, el uso de anticonceptivos, etc.

Así pues, poco a poco desde los inicios de la transición hasta los años ochenta el MDM fue desapareciendo de la geografía española. Los diferentes grupos fueron concluyendo sus actividades, quedando tan sólo algunos testimonios orales de cómo se fue diluyendo en el tiempo la actividad del MDM. En este sentido, por ejemplo en Jaén el MDM "ya no tenía sentido seguir luchando, además estaba el hecho de que se creía que se había conseguido ya sus objetivos"65, o lo señalado por Rosalía Sender en Valencia "dejé de participar en el MDM a principios de 1980 (...) el Movimiento Democrático de Mujeres siguió existiendo unos pocos años más, pero cada vez acudían menos mujeres a las reuniones, faltaba dinamismo y entusiasmo (...), poco a poco se fueron espaciando las reuniones"66.

62. SENDER, Rosalía, Luchando por la liberación de la mujer. Valencia. 1969-1981, Valencia, Publicacions de la Universitat de València, 2006, pp. 177-178.

63. Mundo Obrero, $n^{\circ}$ 43, 01-12-1976.

64. Ruiz, Fernando y Romero, Joaquín, Los partidos marxistas. Sus dirigentes, sus programas, Barcelona, 1977.

65. MARTínez, Irene "Tomar conciencia", Alsur, 11 (1993), p. 35.

66. SENDER, Rosalía, Luchando por la liberación..., p. 178. 


\section{Conclusiones}

En las páginas anteriores hemos analizado como el MDM fue una organización donde se encontraron varias generaciones de mujeres que lucharon contra la dictadura franquista. Su nacimiento se encuentra ligado al trabajo de muchas mujeres en el entorno del PCE, que realizaron toda una labor asistencial y de solidaridad a favor de sus familiares encarcelados. Así, llevaron a cabo una red de denuncia de la política represiva del régimen, trasladando a los barrios obreros la conflictividad social de finales del franquismo. Sin embargo, muchas de estas mujeres que se integraron en el MDM comenzaron a desarrollar un discurso feminista compatible con la lucha por la democracia y la libertad. Poco a poco el MDM se fue extendiendo por la geografía española, aunque sólo en algunas ciudades se alcanzó un movimiento estable y consolidado. En estos nuevos grupos que fueron apareciendo se integraron una nueva generación de jóvenes mujeres que implicaron un cambio fundamental en la evolución del Movimiento. A partir de estos momentos la lucha por el feminismo iba a tener cada vez más influencia. El MDM comienza a considerar un elemento básico la participación de la mujer en la oposición al franquismo, pero desde una posición de igualdad respecto al hombre. En este escenario fueron surgiendo un conjunto de protestas que influirían en todos los niveles en los que la mujer empezaba a estar representada, no sólo en la familia, sino también en la esfera laboral, en los barrios... La movilización de las mujeres del MDM en su lucha contra la represión franquista comenzó a compaginarse con otras reivindicaciones, ampliando su campo de acción. Así, se manifestaron contra la carestía de vida, la falta de guarderías, zonas verdes, además de denunciar la falta de posibilidad de la mujer y algunos planteamientos más avanzados del feminismo. En definitiva, protestas y luchas que fueron planteadas de forma específica, ya que sin llegar a renunciar a "sus responsabilidades de género" solicitaban una mayor facilidad para mantener e ir incrementando su participación política. 


\title{
La actividad rogatoria de las Cortes durante la Legislatura Constituyente (1977-1979) \\ The Enquiring Activity of the Spanish Parliament during the Constituent Legislature (1977-1979)
}

\author{
Miguel Ángel Giménez Martínez \\ Universidad de Castilla-La Mancha
}

Recibido: 12-X-2013

Aceptado: 7-IV-2014

\section{Resumen}

El Parlamento ejerce su función de control sobre el Gobierno, entre otras herramientas, a través de la denominada actividad rogatoria, es decir, la formulación de preguntas e interpelaciones. Ambas figuras suponen, además, expresión de la filosofía política democrática, por cuanto contribuyen al impulso del proceso político, aumentan la información del ciudadano sobre la gestión de los asuntos públicos y ayudan a consolidar la centralidad del Parlamento dentro del sistema institucional. La puesta en práctica del fenómeno rogatorio fue, así pues, de especial valor en el contexto político de la transición y, en concreto, de las Cortes Constituyentes (1977-1979), primera experiencia parlamentaria democrática en España después de cuarenta años de dictadura. Mediante el análisis de los boletines oficiales y diarios de sesiones, la exégesis de los textos legales y el contraste con las aportaciones doctrinales, este articulo trata de dilucidar la trayectoria de las preguntas e interpelaciones durante este período, en sus vertientes teórica y práctica.

Palabras clave: Parlamento, Transición española a la democracia, Función de control, Preguntas e interpelaciones.

\begin{abstract}
Parliaments exercise an oversight function over governments, among other means, through the so-called enquiring activity. In other words, by addressing questions and interpellations. Both institutions also represent an expression of democratic political philosophy, as they contribute to stimulate the political process, they increase citizens' information on public affairs management and help to consolidate Parliaments centralising
\end{abstract}


importance within the institutional system. Thus, the implementation of the enquiry phenomenon was especially significant in the political context of the Spanish transition and, in particular, of the Constituent Cortes (1977-1979), the first democratic parliamentary experience in Spain after forty years of dictatorship. By analysing official bulletins and journals of debates, interpreting legal texts and contrasting doctrinal contributions, this article seeks to elucidate the development of questions and interpellations during this period, both in their theoretical and practical aspects.

Keywords: Parliament, Spanish transition to democracy, Oversight function, Questions and interpellations.

\section{Introducción}

Desde el siglo XVIII se sientan las bases de unos regímenes participativos donde es clave el concepto liberal de división de poderes, el cual, sin embargo, quedaría huérfano de contenido si no estuviera acompañado de una técnica que garantizase su efectivo cumplimiento, es decir, el control de esos poderes ${ }^{1}$. Puede decirse en este sentido que un sistema democrático reconocerá controles jurídicos, controles políticos y controles electorales. Se tratará aquí de los segundos, aquellos que suponen el control del Parlamento sobre el Gobierno y que nacen de la política como criterio de oportunidad. Nos encontramos, así pues, ante un «control interórganos» ${ }^{2}$, el de la Asamblea frente al Gabinete, que constituye «la fase central de la relación entre el Parlamento y el Gobierno, aquella que [...] alcanza una mayor duración y se lleva a cabo de un modo continuado» ${ }^{3}$. Todo ello permite calificar al control parlamentario como el núcleo esencial de las relaciones entre el Legislativo y el Ejecutivo y, al mismo tiempo, como una de las piezas básicas del edificio teórico del parlamentarismo.

Respecto a la naturaleza del control parlamentario puede hablarse de la discusión doctrinal sobre naturaleza jurídica versus naturaleza política. La recepción de la doctrina foránea, especialmente la italiana, permite a Joaquín García Morillo caracterizar el control parlamentario como «una subespecie concreta de los controles jurídicos» ${ }^{4}$. Sin embargo, siguiendo la línea de reflexión de Manuel Aragón, se defiende la idea del carácter político del control parlamen-

1. El propio Montesquieu escribía que «el cuerpo representante [...] debe ser elegido [...] para promulgar leyes o para ver si se han cumplido adecuadamente las que hubiera promulgado, cosa que no solo puede realizar muy bien, sino que solo él puede hacer». Vid. MONTESQuieu, Charles de Secondat, barón de, Del espíritu de las leyes (1782), Madrid, Tecnos, 1972, p. 154.

2. Loewenstein, Karl, Teoría de la Constitución (1959), Barcelona, Ariel, 1964, p. 68.

3. MONTERO GIBERT, José Ramón y GARCÍA MORILlO, Joaquín, El control parlamentario, Madrid, Tecnos, 1984, pp. 17-18.

4. GARCía MORILLO, Joaquín, El control parlamentario del Gobierno en el ordenamiento español, Madrid, Congreso de los Diputados, 1985, pp. 54-67. 
tario básicamente por tres razones: la compatibilidad de la presencia del Derecho en la regulación procedimental del control con la diversidad de sus manifestaciones con naturaleza perfectamente distinguible; el criterio utilizado en el ejercicio del control; y las consecuencias que se derivan del mismo, siendo estos dos últimos factores los que propiamente lo definen ${ }^{5}$. Así pues, el control parlamentario se configura como una función de naturaleza política, necesaria en los sistemas representativos; de vital importancia para los Parlamentos modernos, relegados en el proceso decisional por el predominio de la mayoría parlamentaria-gubernamental; y cuya titularidad corresponde muy especialmente, si no exclusivamente, a las minorías parlamentarias, a la oposición. Una función que los Parlamentos tienen atribuida en tanto que órganos de representación, antes que de decisión ${ }^{6}$.

De acuerdo con esto, los Parlamentos se han dotado de diversos instrumentos y herramientas de control que en su conjunto posibilitan la realización de esta tarea. Ahora bien, dentro de esta finalidad global a la que todos ellos responden, es cierto que pueden establecerse diferencias atendiendo a su efecto inmediato. De esta forma, pueden distinguirse aquellos procedimientos de «control-fiscalización», que no implican necesariamente una decisión del Parlamento y en los que lo fundamental es el examen y la crítica de la actuación del Ejecutivo (preguntas, interpelaciones, sesiones informativas, Comisiones de investigación); y los de "control-orientación», en los que el debate concluye con una votación que sirve de orientación al Gobierno, incluso poniendo en juego la relación fiduciaria entre éste y el Parlamento: proposiciones no de ley, mociones de censura y cuestiones de confianza ${ }^{7}$. Se trata, en todo caso, de una diferencia no tajante, de modo que un mismo instrumento puede participar de caracteres propios de ambas categorías. Porque, en definitiva, la ratio de su exis-

5. ARAGÓN, Manuel, «El control como elemento inseparable del concepto de Constitución», Revista Española de Derecho Constitucional, no 19 (1987), pp. 12-37.

6. SÁNCHEZ NAVARRO, Ángel J., "Control parlamentario y minorías», Revista de Estudios Políticos, $n^{\circ} 88$ (1995), pp. 237-238.

7. En parecidos términos, ALONSO DE ANTONIO, Ángel Luis ( EEl control parlamentario de la política exterior en la Constitución española de 1978», Revista de la Facultad de Derecho de la Universidad Complutense, $\mathrm{n}^{\circ} 15$ (1989), pp. 40 y ss.) distingue entre el «controlorientación», el «control-inspección» y el «control-sanción». También XIFRA HERAS, Jordi («La información como arma del Parlamento», en Las Cortes Generales, vol. X, Madrid, Instituto de Estudios Fiscales, 1977, pp. 2.323 y ss.) parece adoptar una postura similar, al señalar que «el control es una creación que se traduce en una pluralidad de gradaciones, que van desde la simple información a los efectos de verificación o cotejo, hasta la dominación coactiva». En distinto marco conceptual, FERNÁNDEZ SEGADO, Francisco (El sistema constitucional español, Madrid, Dykinson, 1992, pp. 649 y ss.), habla de «control-inspección» y de «control-autorización». 
tencia es la misma: hacer posible que el Gobierno, o la mayoría parlamentaria-gubernamental, sea controlado en última instancia por el pueblo directa y/o indirectamente.

En este artículo nos ceñiremos estrictamente a los procedimientos de «control-fiscalización» y, en concreto, a la actividad rogatoria del Parlamento, la cual se manifiesta a través de la formulación de preguntas e interpelaciones; unos instrumentos que, en efecto, no producen sanción alguna, pero que están ligados a lo que Giuseppe Ugo Rescigno denomina «responsabilidad política difusa ${ }^{8}$. La importancia de estas dos instituciones se deriva de la doble condición que las acompaña. En primer lugar, la que hace de las preguntas e interpelaciones, del fenómeno rogatorio en suma, una expresión de la filosofía política democrática. El fenómeno rogatorio es, así, un instrumento que, desenvolviendo sus posibilidades de control del poder ejecutivo, contribuye al impulso y a la dirección del proceso político y aumenta los conocimientos del ciudadano sobre la gestión de los asuntos públicos: se ubica, necesariamente, en un lugar central dentro de la construcción técnico-jurídica que el parlamentarismo pone al servicio de los valores democráticos. Y en segundo término, porque el fenómeno rogatorio es el que vitaliza al parlamentario individual en tres direcciones fundamentales: la que le marca su relación con el electorado, con el partido al que pertenece, y finalmente con el Gobierno y la Administración. En este sentido, la participación del parlamentario individual, a través de las preguntas e interpelaciones, en las funciones de control del Ejecutivo y de publicidad y diafanidad de la gestión pública contribuye, a la postre, a consolidar la centralidad del Parlamento dentro del sistema político ${ }^{9}$. Y todo ello sin que puedan menospreciarse, sino todo lo contrario, valorarse con espíritu crítico, aquellas advertencias que, como la de Maurice Duverger, achacan a las preguntas el convertirse con frecuencia en «consultas jurídicas gratuitas» ${ }^{10}$, o que, como la realizada por Pierre Birnbaum, estiman que «los diputados continúan, muy a menudo, jugando el papel de asistentes sociales» ${ }^{11}$.

Partiendo de esta concepción del fenómeno rogatorio y de su posición en el centro de las relaciones electorado-Parlamento-Gobierno se va a abordar, primero, el estudio de su naturaleza jurídica, tal y como se desprendía del

8. RESCIGno, Giuseppe Ugo, La responsabilità política, Milano, Giuffrè, 1967, pp. 113-130.

9. MÉNDEZ LÓPEZ, Luis, «La actividad rogatoria del parlamentario como parte del derecho a participar en los asuntos públicos», Revista de las Cortes Generales, nº 80 (2010), pp. 223 y ss.

10. DUVERGER, Maurice, Instituciones politicas y derecho constitucional, $5^{\mathrm{a}}$ ed., Barcelona, Ariel, 1970 , p. 132

11. birnbaum, Pierre, hamon, Francis y troper, Michel, Réinventer le Parlement, Paris, Flammarion, 1977, p. 33. 
Derecho positivo durante el período de vigencia de las Cortes Constituyentes (julio de 1977-enero de 1979), para, a continuación, realizar un análisis de lo que vino siendo su práctica en los primeros dieciocho meses de vida parlamentaria desde las elecciones de junio de 1977. Un análisis en el que, a través del estudio de diversos factores, las preguntas e interpelaciones desvelen sus potencialidades y, como es natural, los obstáculos que impidieron su desarrollo hasta convertirse en un instrumento importante en la vida parlamentaria de la naciente democracia española.

\section{El control parlamentario en las Cortes Constituyentes}

La transición de la dictadura franquista al régimen democrático, como es conocido, se llevó a cabo sin previa ruptura política ${ }^{12}$. La originalidad del cambio político español reside en que éste no constituyó «un proceso de sustitución radical de un orden jurídico por otro, como había ocurrido en los períodos constituyentes de signo democrático de nuestra historia constitucional (1812, $1869,1931) »^{13}$. El instrumento jurídico que se utilizó a tal fin fue la Ley para la Reforma Política (LRP), «ley-puente» que permitió el paso pacífico de la legalidad franquista a la legalidad democrática ${ }^{14}$. En efecto, esta ley de carác-

12. Entre la ingente producción sobre la materia, nos limitaremos a reseñar solo las obras que consideramos más significativas: TEZANOS, José Félix, COTARELO, Ramón y BLAS Andrés de (eds.), La transición democrática española, Madrid, Sistema, 1989; TUSELL, Javier, La transición española a la democracia, Madrid, Historia 16, 1991; COTARELO, Ramón (comp.), Transición política y consolidación democrática. España (1975-1986), Madrid, Centro de Investigaciones Sociológicas, 1992; PRIETO, Joaquín, JULIÁ, Santos y PRADERA, Javier (coords.), Memoria de la transición, Madrid, Taurus, 1996; sото CARMONA, Álvaro, Transición y cambio en España (1975-1996), Madrid, Alianza, 1996; POWELL, Charles, España en democracia, 1975-2000, Barcelona, Plaza \& Janés, 2001; SARTORius, Nicolás y SABIO, Alberto, El final de la dictadura. La conquista de la democracia en España (noviembre de 1975-junio de 1977), Madrid, Temas de Hoy, 2007; y GALLEGO, Ferran, El mito de la transición. La crisis del franquismo y los orígenes de la democracia (1973-1977), Barcelona, Crítica, 2008.

13. SOLÉ TURA, Jordi, «El control parlamentario en el período constituyente y en la Constitución de 1978», en APARICIO PÉREZ, Miguel Ángel (coord.), Parlamento y sociedad civil, Barcelona, Universidad de Barcelona, 1980, p. 31. No parece correcto poner al mismo nivel las Constituciones de 1812, 1869 y 1931. De todas ellas, solo la última puede en puridad considerarse democrática. La misma afirmación para la de 1869 es cuestionable, en tanto que para la de 1812, texto liberal que no democrático, es manifiestamente incorrecta.

14. ESTEBAN, Jorge de y LóPEZ GUERRA, Luis, El régimen constitucional español, vol. I, Barcelona, Labor, 1983, p. 15. En el mismo sentido, MORODO, Raúl, La transición política, Madrid, Tecnos, 1984, p. 122. Vid., especialmente, PÉREZ TREMPS, Pablo, «La Ley para la Reforma Política. Aspectos de la transición política española», Revista de la Facultad de Derecho de la Universidad Complutense, $\mathrm{n}^{\circ} 54$ (1978), pp. 125-127. 
ter instrumental iba a posibilitar la posterior instauración de la democracia, al establecer sus bases, desde la legalidad de la dictadura, para la elección de unas Cortes compuestas por dos Cámaras, elegidas por sufragio universal directo y secreto de los españoles mayores de edad, a las que correspondería afrontar el tránsito a un nuevo régimen democrático ${ }^{15}$.

La puesta en marcha de estas Cortes democráticamente legitimadas no nos permite hablar, sin embargo, de la inauguración en España de un Estado plenamente democrático y, es obvio, aún mucho menos de un régimen parlamentario $^{16}$, lo que obligó a un largo proceso, que Jordi Capo Giol ha llamado «autoconstituyente» ${ }^{17}$, durante el cual se enfrentaron las diversas concepciones de los partidos sobre el Parlamento y su funciones en el sistema político. Ciertamente, y en cuanto a la primera afirmación, baste recordar que las elecciones del 15 de junio de 1977 constituyeron una «cuña democrática» en un conjunto de aparatos e instituciones que seguían siendo los de la dictadura en su estructura y dirección y, efectivamente, la concentración en el exclusivo ámbito de las Cortes de las innovaciones reformadoras del sistema imprimió a éstas el carácter de elemento aislado de legitimación democrática, en contraste con un entramado institucional absolutamente extraño a principios vinculantes de orden constitucional alguno y anclado orgánicamente en la distribución de competencias del autoritarismo ${ }^{18}$. Así pues, las nuevas Cortes, pese a estar fundadas en un principio de legitimidad radicalmente contrario a las del período dictatorial, vivieron hasta ser una de las instituciones recogidas formalmente en la Constitución de 1978 en una situación de provisionalidad, funcionando con una mezcla de elementos de ruptura y de continuidad respeto a las anteriores.

Otra consecuencia de la peculiaridad de la transición fue que las propias Cortes tuvieron, de entrada, una doble naturaleza: fueron a la vez Cortes ordinarias

15. Sobre la LRP, junto a los clásicos trabajos de LUCAS VERDÚ, Pablo (La octava Ley Fundamental. Crítica jurídico-política de la reforma Suárez, Madrid, Tecnos, 1976), GONZÁlez naVarro, Francisco (La nueva Ley Fundamental para la Reforma Política, Madrid, Servicio Central de Publicaciones de Presidencia del Gobierno, 1977), MíguEZ GonZÁLEZ, Santiago (La preparación de la transición a la democracia en España, Zaragoza, Universidad de Zaragoza, 1990) y SÁNCHEZ NAVARRO, Ángel J. (La transición política en las Cortes de Franco: hacia la Ley para la Reforma Política (1975-1976), Madrid, Instituto Juan March, 1990); merece destacarse el reciente ensayo de SÁNCHEZ-CUENCA, Ignacio, Atado y mal atado. El suicidio institucional del franquismo y el surgimiento de la democracia, Madrid, Alianza, 2014.

16. LÓPEZ AGUILAR, Juan Fernando, La oposición parlamentaria y el orden constitucional, Madrid, Centro de Estudios Políticos, 1988, p. 25.

17. CAPO GIOL, Jordi, La institucionalización de las Cortes Generales, Barcelona, Universidad de Barcelona, 1983, p. 8.

18. SOLÉ TURA, Jordi, «La Constitución y la lucha por el socialismo», en PECES-BARBA, Gregorio y otros, La izquierda y la Constitución, Barcelona, Taula de Canvi, 1978, p. 22. 
y Cortes constituyentes. La propia LRP parecía fundamentar jurídicamente este carácter, al prever en su artículo 3 la posibilidad de una reforma de las Leyes Fundamentales franquistas. Ahora bien, las nuevas Cortes no fueron elegidas específicamente como constituyentes, sino que esa fue la consecuencia política de las elecciones de 1977 , las cuales significaron un claro rechazo de toda posible continuidad con el sistema anterior. Este carácter bifronte, visible incluso en su composición bicameral, totalmente atípica desde la perspectiva constituyente, condicionó sensiblemente el propio funcionamiento del Parlamento y repercutió de manera directa en la problemática del control del Ejecutivo.

Por otro lado, en íntima conexión con lo anteriormente mencionado, mientras que la LRP articuló aquellos aspectos básicos en orden a la elección de las nuevas Cortes y algunas de las funciones a desempeñar, así como ciertas normas acerca de su funcionamiento, no configuró en modo alguno, en contraste, el sistema de relaciones que debía darse entre el Gobierno y las Cámaras ${ }^{19}$, de forma que las relaciones Gobierno-Cortes se mantuvieron durante los primeros meses de la Legislatura en un nivel de indefinición elevado ${ }^{20}$. En tanto que Cortes ordinarias, necesitaban articular enseguida mecanismos de fiscalización. En tanto que Cortes constituyentes, toda regulación sobre el control efectuado por el Legislativo debía subordinarse al resultado final del proceso constituyente. Esta disyuntiva amenazaba con privar de toda efectividad a la noción misma de la función de control, de capital importancia en cualquier Parlamento democrático. Si la creación de los mecanismos de control se supeditaba a la terminación de la labor constituyente y ésta se alargaba -como de hecho sucedió-, el Ejecutivo podía encontrarse totalmente libre de control parlamentario durante un largo período. Dado que, a la vez, seguían vigentes algunos de los instrumentos de acción legislativa del régimen anterior, y muy particularmente la posibilidad indiscriminada de la legislación de urgencia, la propia labor de las Cortes como ordinarias podía quedar profundamente mediatizada ${ }^{21}$. De ahí que, a pesar de la ausencia de normas que coordinasen la relación entre ambos órganos en un primer momento, situaciones de diversa índole abocaron irremediablemente a la articulación legal de aquellos mecanismos a través de los cuales el Gobierno estuviese sujeto a la acción controladora del Parlamento, así como a la exigen-

19. Hecho que algún autor calificó como «importante laguna». Vid. AGUILó LÚCIA, Lluís, «La Ley para la Reforma Política como precedente de la actual desigualdad en la representación política», en APARICIO PÉreZ, Miguel Ángel (coord.), Parlamento y sociedad civil..., p. 180.

20. vírgala foruria, Eduardo, La moción de censura en la Constitución de 1978, Madrid, Centro de Estudios Constitucionales, 1988, p. 150.

21. SOLÉ TURA, Jordi, «Democracia y eficacia en las Cortes españolas de la transición», en threlfall, Mónica (ed.), Parlamento y democracia. Problemas y perspectivas de los años 80, Madrid, Fundación Pablo Iglesias, 1982, pp. 104-105. 
cia de responsabilidad política22. Por este motivo, a lo largo de la Legislatura Constituyente la cuestión del control parlamentario revistió una importancia particular y dio lugar a momentos de grave tensión parlamentaria.

La disposición transitoria tercera de la LRP establecía que las nuevas Cortes surgidas tras las elecciones de 1977 siguieran funcionando con el Reglamento de 1971, «sin perjuicio de la facultad de acordar, de un modo inmediato, las modificaciones parciales que resulten necesarias o se estimen convenientes». Sin embargo, «la imposibilidad de trabajar en el seno de un contexto democrático con normas pensadas para operar dentro de la lógica de un régimen de corte autoritario ${ }^{23}$ impulsó al presidente de las Cortes, Antonio Hernández Gil, a dictar las Disposiciones provisionales de 30 de junio y 11 de julio de $1977^{24}$, que rigieron la constitución del nuevo Parlamento democrático y su puesta en funcionamiento hasta la aprobación por cada Cámara de su respectivo Reglamento. Estas Disposiciones de la Presidencia de las Cortes, suma y compendio de la transición en el plano reglamentario, excluían la regulación de ningún mecanismo de control sobre el Ejecutivo. Pero la urgencia de los problemas políticos planteados y la contradicción provocada por el doble carácter de las mismas Cortes (constituyentes y ordinarias) obligaron a forzar el contenido de las previas normas de transición desde el punto de vista de la labor fiscalizadora, tolerando la formulación de preguntas e interpelaciones sin los condicionantes que en las Cortes franquistas habían privado a ambas instituciones de sus «sustantivas consecuencias procedimentales $»^{25}$. En cualquier caso, las Disposiciones de la Presidencia no daban lugar al ejercicio reglado de una auténtica función de control parlamentario y, por ello, el tema se trasladó a otro nivel: el de los Reglamentos provisionales del Congreso (RCD) y del Senado (RS), que no serían definitivamente aprobados hasta octubre de 1977.

\section{Las preguntas, en la teoría}

Las preguntas son posiblemente la modalidad de control parlamentario más antigua ${ }^{26}$. Recordemos el significado del derecho de petición en las Asambleas

22. MONTERO GIBERT, José Ramón «La moción de censura y la simbolización del control parlamentario: los preliminares del caso español», en RAMíreZ, Manuel (ed.), El control parlamentario del Gobierno en las democracias pluralistas, Barcelona, Labor, 1978, p. 262.

23. HERNÁNDEZ GIL, Antonio, El cambio político español y la Constitución, Barcelona, Planeta, 1982, pp. 149-150.

24. Boletín Oficial de las Cortes Españolas (BOCE), $\mathrm{n}^{\circ}$ 1.581, de 30 de junio de 1977, pp. 38.131-38.134; $\mathrm{y} \mathrm{n}^{\circ} 1.583$, de 11 de julio de 1977, pp. 38.143-38.146.

25. FRAile Clivillés, Manuel, Comentario al Reglamento de las Cortes, Madrid, Instituto de Estudios Políticos, 1973, p. 1.014.

26. Un excelente recorrido lo proporciona VARELA SUANZES-CARPEGNA, Joaquín, «El control parlamentario del Gobierno en la historia constitucional española», en RAMírEZ, Manuel 
medievales y cómo precisamente a través del ejercicio de este derecho se introdujeron en España, en la época del Estatuto Real (1834), los principios del sistema parlamentario ${ }^{27}$. En cuanto a su naturaleza jurídica, la cuestión dependerá de la propia naturaleza de la pregunta, ya que ésta puede consistir en una información o en exigir una determinada actuación de la Administración, teniendo una finalidad variable según la función parlamentaria a que se aplique $e^{28}$.

El RCD definía las preguntas en la forma siguiente: «La pregunta consiste en la simple cuestión, planteada por escrito, de si un hecho es cierto, si alguna información ha llegado al Gobierno, o si es exacta, o si ha tomado o va a tomar alguna providencia sobre un tema $»^{29}$. El RS, por su parte, no contaba con una paralela definición. En cuanto al sujeto activo de las preguntas, se reconocía tanto en una Cámara como en la otra que era el parlamentario individual. Así, el RCD disponía: «Los diputados podrán presentar al presidente del Congreso preguntas formuladas al Gobierno o a cada uno de sus miembros» ${ }^{30}$. Por su parte, y en el mismo sentido, el RS establecía: «Los senadores podrán dirigir a la Mesa o al Gobierno ruegos y preguntas $»^{31}$. De los preceptos anteriores se deduce que mientras en el Congreso el sujeto pasivo de las preguntas solo podía ser el Gobierno, en el caso del Senado se admitía también que lo fuera la Mesa. A esos efectos, el RS señalaba: «Las dirigidas a la Mesa serán contestadas por los miembros de ésta que la misma designe ${ }^{32}$. Otra peculiaridad de la Segunda Cámara era la posibilidad de sustitución para la contestación. Así, se disponía que «los ruegos y preguntas formulados al Gobierno serán contestados por un ministro, pudiendo ser sustituido a estos efectos por un secretario de Estado o por un subsecretario» ${ }^{33}$. Tal posibilidad no se encontraba recogida en el RCD.

El plazo que debía mediar entre la presentación de la pregunta oral y la fecha de su contestación era de 20 días en el caso del Senado. En este senti-

(ed.), El Parlamento a debate, Madrid, Trotta, 1997, pp. 59-71. También hay interesantes referencias en FERNÁNDEZ SARASOLA, Ignacio, Reglamentos Parlamentarios (1808-1977), Madrid, Iustel, 2012.

27. Vid. al respecto los clásicos trabajos de tOMÁs VILLARROYA, Joaquín, «Los orígenes del control parlamentario en España», Revista de Estudios Políticos, no 132 (1963), pp. 103 y ss.; y El sistema político del Estatuto Real (1834-1836), Madrid, Instituto de Estudios Políticos, 1968.

28. PORTERO MOLINA, José Antonio, «La actividad rogatoria en el Congreso: 1979-1981», Revista de Estudios Políticos, no 24 (1981), pp. 93 y ss., considera las preguntas como actos de indirizzo político.

29. RCD, art. 128.2.

30. RCD, art. 128.1.

31. RS, art. 129.

32. RS, art. 130.

33. RS, art. 130.2. 
do, su Reglamento decretaba: «El Gobierno puede declarar no haber lugar a contestar, razonando el motivo. El plazo será de 20 días. Si declara que debe aplazar la respuesta, señalará el día, dentro del plazo de un mes, en que esté dispuesto a responder $»^{34}$. La redacción de este precepto resultaba algo confusa, pues en una primera lectura podría pensarse que el mencionado plazo de 20 días solo se refería al supuesto en que el Gobierno declarara no haber lugar a contestar. Ahora bien, la ausencia de otra disposición más directa en el RS conduce a la conclusión de que al precepto señalado había de dársele un carácter general. Por otro lado, puede estimarse que el plazo de 20 días, en comparación con los establecidos en otras Cámaras, resultaba algo largo ${ }^{35}$. El RCD no regulaba directamente dicha cuestión. Sin embargo, preceptuaba: «En lo no previsto en los artículos siguientes [relativos a las preguntas] se aplican las normas de los tres artículos precedentes sobre interpelaciones ${ }^{36}$. Ha de acudirse entonces al artículo que establecía a este respecto: «Transcurridas dos semanas desde su presentación, se pondrán sin más en el orden del día de la primera sesión siguiente ${ }^{37}$. Por tanto, había de respetarse un plazo mínimo de dos semanas desde su depósito.

Respecto a las preguntas escritas y al plazo para su contestación, el RS establecía: «El autor del ruego o pregunta podrá optar, al formularlos, por la respuesta escrita del mismo. En tal caso, el ruego o pregunta se publicarán en el Boletín Oficial de las Cortes y habrán de contestarse, mediante la inserción de la respuesta en el mismo Boletín, dentro de los 15 días siguientes ${ }^{38}$. En relación a la misma cuestión, el RCD prescribía: «En la presentación de una pregunta, o después, el diputado puede declarar que pretende obtener una respuesta por escrito. En este caso, dentro de 20 días, el Gobierno debe dar la respuesta y comunicarla al presidente del Congreso. Esa respuesta se incluye en el acta taquigráfica de la sesión en que se anuncia a la Cámara ${ }^{39}$. Este último es uno de los puntos que, como consecuencia de una apresurada traslación de lo dispuesto en el Reglamento de la Cámara de Diputados italiana de 1971, resultaba incoherente. La publicidad de las preguntas escritas y respuestas se efectuaba en España a través del Boletín Oficial de las Cortes (BOC), y así lo dis-

34. RS, art. 131.3.

35. La mayoría de los países occidentales integrados en la Unión Interparlamentaria daban en aquel entonces menos de 15 días al Gobierno para contestar. Vid. YAмAмOTO, Hironori (ed.), Instrumentos de control parlamentario. Estudio comparativo de 88 Parlamentos nacionales, Ginebra, Unión Interparlamentaria, 2007, pp. 61 y ss.

36. $R C D$, art. 128.3.

37. RCD, art. 126 .

38. RS, art. 129.2.

39. RCD , art. 133.1. 
ponía el propio $\mathrm{RCD}^{40}$. Por eso resultaba absurdo que posteriormente se dispusiera que la respuesta hubiera de insertarse también en el acta taquigráfica de la sesión en que se anunciaba a la Cámara ${ }^{41}$.

En relación al question time, el RCD preceptuaba que: «Un día a la semana, siempre que el Pleno esté reunido, será dedicado al desarrollo de preguntas, a menos que el orden del día no esté enteramente reservado a otros temas. Trascurrido dicho tiempo, el presidente remite las interpelaciones y preguntas no desarrolladas a la sesión siguiente ${ }^{42}$. Se establecía, pues, la reserva de un día por semana para el desarrollo de las preguntas, pero siempre que el orden del día correspondiente a dicha sesión no estuviera ocupado completamente por otras cuestiones. Se trataba, por tanto, de un principio no vinculante, sino meramente orientativo. Era, en definitiva, la Junta de Portavoces, como órgano competente para fijar el orden del día, quien decidía sobre la reserva comentada. Además, la misma aparecía sujeta a una segunda condición, al exigirse que «el Pleno esté reunido». Esta expresión, aparte de no resultar del todo clara, parecía referirse a la necesidad de que el Pleno celebrara sesión a lo largo de todos los días de la semana parlamentaria. No es de extrañar que, al exigirse esta pluralidad de condiciones, la dificultad de cumplimentar todas ellas determinara que no se celebrara ninguna sesión enteramente reservada a las preguntas. Éstas, normalmente, se incluían junto con otros asuntos en el orden del día de la sesión que solía celebrarse cada semana, la cual podía abarcar, según los casos, uno o dos días.

En relación a la misma materia, el RS disponía: «A las intervenciones que como consecuencia de ello [ruegos y preguntas] se originen se reservará con prioridad la sesión del Pleno de los martes ${ }^{43}$. Dado que esta Cámara se reunía normalmente en una única sesión semanal, en días distintos al martes, es por lo que el artículo permaneció inaplicado. Además, tampoco aquí se estipulaba una reserva con carácter absoluto: el giro «se reservará con prioridad» suponía la posibilidad de dejar en suspenso esta reserva. Téngase en cuenta, en este sentido, que el RS prescribía más adelante que «cuando la urgencia de los asuntos en tramitación lo aconseje, la Cámara, a propuesta del presidente, podrá suprimir determinado número de sesiones el tiempo destinado a ruegos y preguntas orales», y que «en el supuesto al que se refiere el párrafo anterior, si hubiere ruegos y preguntas pendientes de respuesta, la Mesa, oída

40. RCD, art. 90.

41. Sobre esta cuestión, vid. Il nuovo Regolamento della Camera dei deputati, ilustrato con i lavori preparatori, Roma, Camera dei deputati, 1971, pp. 986 y ss.

42. RCD, art. 129 .

43. $R S$, art. 129.1. 
la Junta de Portavoces, habrá de habilitar, en el plazo más breve posible, una sesión para su respuesta» ${ }^{44}$.

Por supuesto, el Gobierno no quedaba inerme frente a las preguntas de los parlamentarios. Así, el RCD disponía que «el Gobierno puede declarar que no puede contestar, indicando el motivo. Si declara que debe aplazar la respuesta, debe precisar en qué día, dentro del plazo de un mes, está dispuesto a responder. Si el autor de la pregunta no está presente cuando el Gobierno se disponga a responder, se entiende que ha renunciado a la pregunta $»^{45}$. El RS contenía una norma muy similar ${ }^{46}$. Indudablemente, las facultades que se atribuían al Ejecutivo por estas disposiciones no podían usarse de forma arbitraria o injustificada. Así, si las razones invocadas por el Gobierno para no responder eran consideradas insuficientes, tanto los parlamentarios como los Grupos podían acudir a diversos procedimientos contenidos en los Reglamentos (interpelaciones, mociones de censura, proposiciones no de ley) con vistas a exigir la responsabilidad por el mal uso de tales facultades. De todas formas, no existía ninguna sanción jurídica para el Gobierno que no efectuara o retrasara la contestación. Y ello porque las preguntas estaban concebidas como un «control-fiscalización»y no un «control-responsabilidad» ${ }^{47}$.

En cuanto a la exposición y desarrollo de las preguntas orales, en el caso de la Cámara Baja el Reglamento provisional señalaba que «el que ha presentado una [...] tiene derecho a desarrollarla durante no más de 15 minutos» ${ }^{48}$. Por tanto, el interrogante podía exponer su pregunta durante 15 minutos como máximo. Respecto a las intervenciones ulteriores había de ceñirse a este procedimiento: «Después de la respuesta del Gobierno sobre cada pregunta, su autor puede replicar para declarar si ha quedado o no satisfecho, por un tiempo no superior a los 5 minutos $\rtimes^{49}$. En el caso del Senado, el RS establecía que «la distribución del tiempo en las sesiones será la siguiente: 5 minutos para la formulación del ruego o pregunta por los interesados, 5 minutos para la contestación al mismo, 2 minutos de réplica y 2 minutos de dúplica» ${ }^{50}$. A la vista de la diferente regulación de esta cuestión por ambos Reglamentos, puede estimarse como más apropiada la establecida para la Cámara Alta, ya que el plazo de 15 minutos para la exposición de la pregunta establecido en el Congreso

44. RS, art. 134.1 y 2 .

45. RCD, art. 130.

46. «Si el autor de la pregunta no estuviese presente cuando el Gobierno se dispusiese a responder podrá entenderse que ha renunciado a la pregunta». Vid. RS, art. 131.4.

47. Sobre esta problemática, vid. PORRAS NADALES, Antonio, «Las preguntas escritas en la práctica parlamentaria», Revista de Estudios Políticos, nº 19 (1981), pp. 107 y ss.

48. $R C D$, art. 127.

49. $R C D$, art. 131.

50. RS, art. 132. 
resultaba algo amplio si se tiene en cuenta el carácter conciso y breve de la figura examinada. Además, la mayor limitación del tiempo de exposición permitía aprovechar de forma más intensa las sesiones, al tiempo que impedía que este procedimiento se utilizara con fines obstruccionistas.

Por otro lado, el RCD, en relación a las preguntas en las Comisiones, disponía que «al presentar una pregunta, el diputado puede declarar que su deseo es recibir la respuesta en Comisión. En tal caso, el presidente del Congreso la transmite al presidente de la Comisión competente por razón de la materia, y da cuenta de ella al Gobierno. La pregunta se inscribe en el orden del día de la primera sesión de la Comisión $»^{51}$. El Senado, en cambio, fuera del cauce formal de las sesiones informativas ${ }^{52}$, no contaba con un procedimiento de análogo sentido. Finalmente, se echaba de menos en ambos Reglamentos una disposición específica que arbitrara un régimen peculiar para las preguntas con carácter de urgencia. Casi todos los Parlamentos admitían este tipo de preguntas $^{53}$, que no se sujetan a ciertos requisitos normalmente exigidos. La introducción de este procedimiento particular habría permitido dar mayor espontaneidad a las relaciones Cortes-Gobierno, así como que las Cámaras hubieran reflejado de forma más inmediata el estado de ánimo de la opinión pública ${ }^{54}$.

\section{Las preguntas, en la práctica}

Durante la Legislatura Constituyente, en el Congreso de los Diputados se formularon 398 preguntas, de las cuales 273 eran de respuesta escrita y 125 de respuesta oral. Las preguntas escritas tuvieron, por tanto, una aceptación considerablemente mayor que las orales, porque por sus propias características no se veían interferidas por otros asuntos de interés preferente. Los parlamentarios constituyentes dieron su aceptación a esta vía en lugar de a la más llamativa, pero más arriesgada, de las preguntas orales, sacrificando la posibilidad de réplica, típica de estas últimas, a la seguridad de contar con la respuesta del Gobierno en un plazo más o menos breve.

Así, el Gobierno contestó a 267 preguntas (el $67,1 \%$ ): 212 por escrito y 55 oralmente, 40 de las últimas en Comisión y 15 en el Pleno. No obtuvieron contestación 115 preguntas (el 28,8\%): 51 de naturaleza escrita y 54 orales (47 en Comisión y 7 en el Pleno), mientras que 10 respuestas quedaron pendientes de publicación en el BOC. Por último, 16 preguntas (14 escritas y 2

51. RCD, art. 132.

52. $R S$, arts. 70 y 71 .

53. Así, entre otros, el Bundestag alemán, la Cámara de Diputados italiana, la Cámara de Representantes belga y la Cámara de los Comunes británica.

54. SANTAOLALla, Fernando, «Las preguntas, instrumento parlamentario de control», Documentación Administrativa, no 178 (1978), p. 87. 
de carácter no especificado) no llegaron a elevarse al Gobierno debido a que se depositaron pocos días antes de la disolución de la Cámara. La mayoría de las preguntas cuya respuesta se solicitó recibir en Comisión se remitieron a la de Agricultura (23). La distribución de las restantes, por Comisiones, fue la siguiente: Cultura, 14; Obras Públicas y Urbanismo, 13; Sanidad y Seguridad Social, 9; Educación y Ciencia, 8; Asuntos Exteriores, 6; Industria y Energía, 5; Interior, 5; Trabajo, 3; Transportes y Comunicaciones, 2; Presidencia, 2; Comercio y Turismo, 1; y Medio Ambiente, 1. No se tramitó ninguna pregunta en las Comisiones de Asuntos Constitucionales y Libertades Públicas, Defensa, Hacienda, Justicia y Presupuestos.

Por Grupos Parlamentarios, destaca la actividad del Grupo Parlamentario Socialista del Congreso (GS) con 192 preguntas presentadas, de las cuales 116 eran de respuesta por escrito y 77 orales. Todas las preguntas estaban previamente autorizadas, como se preveía en el Reglamento del GS (RGS), por el Comité Permanente del Grupo ${ }^{55}$, el cual se encargaba de evitar que se formalizaran propuestas contraproducentes con la línea política del Partido Socialista Obrero Español (PSOE), bien porque objetivamente chocaran o no se ajustaran al contenido del programa y a las directrices de la fuerza política, bien porque estrictas razones de oportunidad desaconsejaran su presentación. A distancia del GS se encontraba el Grupo Parlamentario de Unión de Centro Democrático (GUCD), con un total de 41 preguntas. Como es habitual en aquellas minorías que sostienen al Gobierno, la actividad de filtro era realizada de una manera cuidadosa y rígida, dado que las preguntas del GUCD podían comprometer no ya el cumplimiento del programa electoral, sino la propia estabilidad del Gobierno $^{56}$. En este sentido, el Reglamento del GUCD (RUCD) concebía como un deber ineludible de todos sus miembros el sometimiento a las acciones parlamentarias que propusiese el presidente del Grupo ${ }^{57}$. También correspondía al presidente la determinación de la persona que había de intervenir en los debates, la aprobación de las proposiciones de ley y no de ley, las enmiendas legislativas, las interpelaciones y las preguntas que deseasen formular los miembros del $\mathrm{GUCD}^{58}$. Finalmente, las preguntas pasaban una última revisión en la Secretaría General de Relaciones con las Cortes ${ }^{59}$.

55. RGS, art. 22.

56. Sobre el filtrado de las preguntas, vid. JOVER, Pedro y MARCET, Joan, «Teoría y realidad de las relaciones del Gobierno con el Grupo Parlamentario y el partido mayoritarios», en Alonso García, Enrique (ed.), El Gobierno en la Constitución Española y en los Estatutos de Autonomía, Barcelona, Diputación de Barcelona, 1985, pp. 279 y ss.

57. RUCD, art. 6.1, c.

58. RUCD, art. 9.3, b y f.

59. LÓPEZ GARRIDO, Diego, «Gobierno y Parlamento: dos modelos de relaciones internas (UCD y PSOE)», en AlONSO GARCÍA, Enrique (ed.), El Gobierno en la Constitución..., pp. 231-243. 
Especialmente llamativo es el caso del Grupo de Alianza Popular (GAP), que a pesar de ser la cuarta fuerza del Parlamento y contar con solo 16 diputados dio entrada a 115 preguntas (107 escritas y 8 orales). Este estatus de segunda fuerza rogante se debe, en buena medida, a la incesante actividad inquisidora de la diputada por La Coruña María Victoria Fernández-España, que depositó nada menos que 52 preguntas, lo que la convirtió en el parlamentario más activo de las Cortes a la hora de ejercer las tareas de control. Entre los restantes 119 diputados que formularon alguna pregunta (el 32,9\% del total de miembros de la Cámara), destacan por la intensidad de su trabajo los socialistas Ciriaco de Vicente, que presentó 15; Carlos de Luxán, que depositó 11; Virgilio Zapatero y Enrique Sapena, que efectuaron, cada uno, 10; y Miguel Riestra, del GAP, también con 10.

En el Senado, el número de preguntas orales expuestas durante la Legislatura Constituyente fue de 50, aunque 2 no llegaron al Pleno por haber sido retirada, en un caso, y por haberse disuelto las Cortes, en el otro. Si se tiene en cuenta que en el Senado no existían las preguntas en Comisión, puede considerase bajo el resultado alcanzado. En esta situación influyeron las mismas causas que en el Congreso de los Diputados, antes expuestas. Por el contrario, las preguntas escritas fueron mucho más utilizadas que las orales. Así, a lo largo de la Legislatura se publicaron 180 preguntas, de las cuales la inmensa mayoría recibieron respuesta del Gobierno. Solo 23 no fueron contestadas, debiendo añadirse que 14 de éstas se vieron afectadas por la disolución de las Cortes que entró en vigor el 2 de enero de 1979. No obstante, en 4 casos el secretario general de la Cámara remitiría personalmente al senador rogante la respuesta del Ejecutivo ${ }^{60}$.

Los Departamentos ministeriales más afectados por estas herramientas de fiscalización del Senado fueron los de Educación y Ciencia, que recibió 36 (27 escritas y 9 orales), Agricultura, que absorbió 27 (18 escritas y 9 orales), Obras Públicas, que acumuló 24 (20 escritas y 4 orales) y Sanidad y Seguridad Social, que recogió 23 (19 escritas y 4 orales). A cierta distancia quedaron Hacienda, con 15 (11 escritas y 4 orales), Presidencia del Gobierno, con 13 (10 escritas y 3 orales), Transportes y Comunicaciones, con 12 (8 escritas y 4 orales) y Cultura, con 10 ( 7 escritas y 3 orales). Menos de 10 preguntas recibieron, finalmente, los Ministerios de Industria (6 escritas y 3 orales), Interior ( 9 escritas), Trabajo ( 4 escritas y 2 orales), Defensa (6 escritas), Economía ( 3 escritas y 2 orales), Justicia ( 3 escritas y 1 oral), Comercio y Turismo ( 2 escritas y 1 oral) y Asuntos Exteriores (2 escritas).

60. Memoria del Senado. Legislatura 1977-1979, Madrid, Senado, 1979, p. 268. 
Casi todos los ruegos y preguntas del Senado iban apoyados por una sola firma (el 89,2\%), mientras que en los casos restantes lo estaban por dos o más senadores $(8,2 \%)$ o por un Grupo Parlamentario (2,6\%). Solo 87 del total de 250 parlamentarios que integraron la Cámara Alta preguntaron al Gobierno, muchos de ellos (38) en una sola oportunidad y la gran mayoría (70) en menos de 5 ocasiones. El senador más activo fue Félix Pérez y Pérez, del GUCD, que depositó 20 preguntas, seguido de Benito Huerta Argenta, del Grupo Parlamentario Progresistas y Socialistas Independiente (GPSI), que formuló 13. Once preguntas cada uno realizaron Francisco Cacharro (Grupo Mixto) y Cipriano Morales (Grupo Parlamentario Socialistas del Senado, GSS); 8, Francesc Ferrer (Grupo de Entesa dels Catalans, GEDC) y Rogelio Borrás (GSS); 7, Alberto Ballarín (GUCD), Lorenzo Martín-Retortillo (GPSI), Francisco Ramos Fernández-Torrecilla (GSS) y José María Suárez (GUCD); y 6, Ricardo Manuel Bueno (GUCD), Celso Montero (GSS), Rafael de Mora-Granados (GSS) y Joaquín Navarro Estevan (GPSI/GSS).

Como ilustración de la relativa importancia de las 628 preguntas que, en total, se depositaron durante la Legislatura Constituyente, puede resaltarse que estas magnitudes no resistían la menor comparación con las de otros Parlamentos. Así, en el Reino Unido el número de preguntas escritas subió de un promedio de 31 por día en 1962-1963 a 133 en 1974; y aunque el de preguntas orales presentadas no creció tan velozmente, siguió siendo muy alto: aproximadamente unas 12.000 preguntas al año ${ }^{61}$. Igualmente eran numerosísimas las preguntas presentadas por escrito en la Asamblea Nacional francesa: 7.282 en el año 1971 y 7.575 en 1972, por poner un ejemplo ${ }^{62}$. En la Cámara de Representantes belga, de las dos modalidades de preguntas estudiadas, la primacía la ostentaban las de respuesta escrita. Los siguientes datos lo ponen de relieve. En el período de sesiones de 1971-1972 se presentaron 1.528 preguntas escritas; en el de 1974-1975, 3.149; en el de 1975-1976, 3.192 y en el de 1976-1977, 3.323. En cambio, el número de preguntas orales era mucho más reducido. De este modo, en el período 1971-1972 se formularon 106 preguntas orales ordinarias, más de 67 por vía de urgencia; en el de 1974-1975, 171 ordinarias y 145 de urgencia; en el de 1975-1976, 122 y 103, respectivamente, y

61. FitzmauricE, John, «Parliamentary Questions at Westminster», Studi Parmensi. Le interrogazioni al Parlamento Europeo, vol. XXIII (1978), pp. 101 y ss.

62. Esta situación influyó, sin duda, en el incumplimiento por parte del Gobierno francés de los plazos reglamentarios para responder: del total de preguntas formuladas en 1972, solo 469 obtuvieron respuesta exacta en el plazo de un mes, 2.235 tuvieron que aguardar dos meses y 1.262 tres meses, mientras que el resto de las preguntas tardaron aún más en ser contestadas. Vid. BREDIN, Jean-Denis, «Les questions écrites dans la vie parlementaire française», Studi Parmensi..., p. 60. 
en el de 1976-1977, 85 y 5463. Con respecto a Italia, la vía de las preguntas escritas era más utilizada por los parlamentarios que la de las preguntas orales, sobre todo en el Senado. Así, durante la primera parte de la VII Legislatura (1976-1978) se presentaron en la Cámara de Diputados 6.806 preguntas, de las cuales 3.866 fueron de respuesta escrita, lo que suponía el 57\%. En el Senado, las escritas fueron 1.480 de un total de 2.251, lo que representaba el $66 \%{ }^{64}$. Por último, en Alemania, aproximadamente 3.500 preguntas orales eran presentadas anualmente, aunque buena parte de ellas eran contestadas por escrito ${ }^{65}$.

Por otra parte, no se produjo un avance significativo respecto de la situación en que se encontraban los ruegos y preguntas de las últimas Cortes orgánicas. Este aserto se ilustra, primero, atendiendo a la cantidad de parlamentarios que ejercieron sus obligaciones fiscalizadoras; y, segundo, observando el compromiso del Gobierno a la hora de contestar a las preguntas que se le formulaban. Así, de los 561 procuradores de la X Legislatura (1971-1977), 239 (el $42,6 \%)$ no realizaron ni una sola pregunta, ya por escrito ya por vía oral, en el Pleno o en las Comisiones ${ }^{66}$; mientras que de los 611 diputados y senadores de la Legislatura Constituyente, 405 (el 66,2\%) se abstuvieron de formular preguntas. En cuanto al número de preguntas sin contestar, el Gobierno renunció a responder a 271 de las 1.045 que se le remitieron en la última etapa legislativa de las Cortes franquistas, lo que equivale a un $25,9 \%{ }^{67}$; un porcentaje no muy superior al que se produjo en el primer Parlamento democrático (21,9\% entre ambas Cámaras, 28,8\% en el Congreso y 10,8\% en el Senado).

\section{Las interpelaciones, en la teoría}

Las interpelaciones son preguntas que versan sobre temas de especial trascendencia política. No puede sorprender que se hable de pregunta, pues entre las preguntas parlamentarias en sentido estricto y las interpelaciones hay una dife-

63. DENEulin, Philippe, «La procédure des questions parlementaires en Belgique», Studi Parmensi..., pp. 77 y ss.

64. MANZELLA, Andrea, «Linterrogazione a risposta scritta nel Parlamento italiano», Studi Parmensi..., pp. 117-126.

65. Johnson, Nevil, Government in the Federal Republic of Germany, Oxford, Pergamon Press, 1973, pp. 177 y ss.; LOeWEnberg, Gerhard, Parliament in the German Political System, Ithaca (NY), Cornell University Press, 1966, p. 410.

66. Aguilar tremoya, Miguel Ángel, Las últimas Cortes del franquismo, Madrid, Avance, 1976, p. 75 .

67. GarRoRena morales, Ángel, Autoritarismo y control parlamentario en las Cortes de Franco, Murcia, Departamento de Derecho Político de la Universidad de Murcia, 1977, pp. 357 y ss. 
rencia solo cuantitativa ${ }^{68}$. Ambos procedimientos tienen un tronco histórico común que, andando el tiempo, se fue bifurcando hasta dar lugar a estas dos figuras $^{69}$; son, pues, manifestaciones del fenómeno rogatorio parlamentario.

Así como las preguntas deben tener un objeto concreto y preciso, las interpelaciones deben versar sobre cuestiones generales de la política gubernamental. Este último procedimiento es la modalidad más importante de la actividad interrogatoria parlamentaria y, por eso, debe reservarse para los asuntos importantes. Las interpelaciones implican, lógicamente, cuestiones más genéricas, más amplias, y se relacionan directamente con la médula de alguna política del Ejecutivo. Junto a lo anterior, hay también hechos concretos y determinados que pueden ser objeto de interpelaciones. Nos referimos a aquellas materias que, aun no afectando a las líneas básicas de una política gubernamental, tienen una gran importancia. Hay sucesos perfectamente aislables, no conexionados con la actuación general del Gobierno o de algún Ministerio que, sin embargo, tienen una gran resonancia política y social, haciéndose posible su enjuiciamiento y debate a través de una interpelación.

De lo anterior se deduce que la diferenciación por el objeto entre las preguntas y las interpelaciones es tautológica y aproximativa. No hay un criterio absoluto que sirva para decidir cuándo corresponde uno u otro procedimiento. Así, puntos concretos de la actividad administrativa, que normalmente solo requerirían una pregunta para su esclarecimiento, pueden adquirir, en contacto con determinados hechos, una mayor dimensión que justifique el empleo de la interpelación. De otra parte, no siempre es fácil decidir lo que afecta a la política del Gobierno o de un Ministerio. Precisamente esta ausencia de fronteras nítidas entre preguntas e interpelaciones favorece su uso indistinto. De esta forma, son muchos los Parlamentos que se enfrentan con el problema del abuso de las interpelaciones, esto es, del tratamiento mediante esta vía de cuestiones que por su interés limitado deberían exponerse a través de preguntas, circunstancia debida al deseo de procurarse la mayor audiencia o resonancia que proporciona el planteamiento de una interpelación. Así, muchas veces, los parlamentarios utilizan esta vía en lugar de la de las preguntas porque electoralmente les parece más provechoso ${ }^{70}$.

68. MANZELLA, Andrea, «Interrogazione e interpellanza parlamentare», en Enciclopedia del Diritto, vol. XXII, Milano, Giuffrè, 1972, pp. 425 y ss.

69. MICELI, Vincenzo, Il diritto d'interpellanza, Milano, Società Editrice Libraria, 1908, p. 78.

70. MOUREAUX, Charles, «Le contrôle de la politique générale», en Le contrôle parlementaire de l'action gouvernementale, Bruxelles, Institut Belge de Science Politique, 1957, pp. 14 y ss. En esta misma obra se pone de manifiesto que las interpelaciones deben limitase a lo que afecta a la política general, sea del Gobierno sea de un Departamento ministerial, mientras que las preguntas deben utilizarse para el tratamiento de puntos de la actividad gubernamental, restringidos a intereses locales o a intereses de categorías de ciudadanos. 
Por otro lado, el fin de las interpelaciones, al igual que el de las preguntas, es obtener información mediante la fiscalización de una postura o actuación gubernamental. Al mismo tiempo, este procedimiento podrá ser utilizado como medio de control, de expresión política o de información para el desarrollo de otras funciones. Pero estas últimas notas son eventuales, a diferencia del fin de información, que siempre estará presente, al menos desde una perspectiva formal. Esta misma es la conclusión a la que parece llegar Andrzej Gwizdz, quien, tras señalar una serie de posibles funciones de las interpelaciones, termina diciendo que «en la mayor parte de los países es sobre todo un medio de obtener información y en particular aclaraciones de parte del Gobierno o del ministro interesado sobre una cuestión de su competencia» ${ }^{71}$.

Una de las características más extendidas de las interpelaciones es que provocan una discusión en la que pueden intervenir diversos parlamentarios ${ }^{72}$. A diferencia de las preguntas, donde normalmente solo hacen uso de la palabra el interrogante y el miembro del Gobierno afectado, aquí se admiten las intervenciones de otros miembros de la Cámara ${ }^{73}$. La existencia de este debate se corresponde con la importancia que debe tener el tema objeto de la interpelación, el cual suele provocar el deseo en otros parlamentarios o Grupos distintos al interrogante de expresar su posición al respecto ${ }^{74}$. De otra parte, las interpelaciones no admiten otro lugar de exposición que los Plenos de las Cámaras. Así como las preguntas pueden formularse en el seno de las Comisiones, no ocurre lo mismo con las interpelaciones, como lógica consecuencia de la importancia y relevancia política de su objeto, que aconseja que su debate se haga en el órgano político por excelencia, esto es, en el Pleno. Las Comisiones, como órganos fundamentalmente de estudio, quedan limitadas al tratamiento de cuestiones técnicas o de importancia secundaria ${ }^{75}$.

71. GWIZDZ, Andrzej, «Les interpellations», Informations constitutionnelles et parlementaires, $n^{\circ} 53$ (1963), p. 21.

72. Ameller, Michel, Parlements, Paris, Presses Universitaires de France, 1966, p. 333.

73. Si se examinan los Reglamentos históricos de las Cámaras europeas se puede comprobar que en su mayor parte se preveía la apertura de un debate. Tal es el caso de los Reglamentos del Reichstag alemán, de 1876, de la Cámara de los Diputados austriaca, de 1875, de la Cámara de Representantes belga y del Senado italiano, de 1883. Vid. MOREAU, Félix, DELPECH, Joseph y BENOIST, Charles, Les Règlements des Assemblées Législatives, 2 vols., Paris, Giard \& Brière, 1906.

74. La doctrina suele incluir la importancia de la materia como uno de los rasgos definitorios de las interpelaciones. Así, FRIEDRICH, Carl Joachim, Constitutional Government and Democracy: Theory and Practice in Europe and America, Waltham (MA), Blaisdell Publishing Company, 1968, pp. 152 y ss.; y PÉREZ SERRAno, Nicolás, Tratado de Derecho Político, $2^{a}$ ed., Madrid, Civitas, 1984, pp. 813 y ss.

75. NAVAS CASTILlo, Florentina, Las Comisiones parlamentarias en el ordenamiento jurídico español, Madrid, Universidad Complutense, 2000, pp. 15 y ss. 
Por último, las interpelaciones pueden provocar una sanción política, en cuanto el debate es susceptible de terminarse mediante la presentación y votación de una moción, en la que se expresa la conformidad o disconformidad de la Cámara con las explicaciones del Gobierno. También éste es un rasgo que diferencia a las preguntas de las interpelaciones, dotando a éstas de un mayor rigor y poder de fiscalización ${ }^{76}$. Dentro del parlamentarismo clásico, estas mociones subsiguientes a las interpelaciones servían de vehículo de expresión de la confianza parlamentaria. En cambio, la racionalización del parlamentarismo a lo largo del siglo XX comportó que la exigencia de la responsabilidad política del Gabinete solo pudiera operarse a través de cauces expresamente establecidos con este fin, como las mociones de censura y las cuestiones de confianza. El Gobierno queda obligado a dimitir solo cuando se aprueban estas concretas decisiones. Por consiguiente, la simple aprobación de una moción sucesiva a una interpelación, que resulte contraria a la postura del Ejecutivo, no implica que éste tenga que renunciar ${ }^{77}$.

El RCD contemplaba la posibilidad de que los diputados pudieran presentar interpelaciones al Gobierno o a cada uno de sus miembros. La interpelación había de ser presentada por escrito, por medio del presidente del Congreso, debiendo versar sobre los motivos o propósitos de la conducta del Ejecutivo en cuestiones referentes a determinados aspectos de su política ${ }^{78}$. Las interpelaciones se publicaban en el acta de la sesión en que se anunciaban. Trascurridas dos semanas desde su presentación, las interpelaciones se ponían sin más en el orden del día de la sesión siguiente. No podían incluirse en el orden del día de la misma sesión más de dos interpelaciones presentadas por el mismo diputado o Grupo Parlamentario ${ }^{79}$. El que presentaba una interpelación en el Congreso tenía derecho a desarrollarla durante no más de 15 minutos y, después de las declaraciones del Gobierno, a exponer, por no más de 10 minutos, las razones por las cuales estaba o no satisfecho. El presidente podía conceder mayor tiempo a los interpelantes si la cuestión revestía excepcional relevancia política. Por último, siempre que el interpelante no quedara conforme con las explicaciones dadas por el Gobierno, podía presentar una moción ${ }^{80}$.

En cuanto a la regulación de las interpelaciones contenida en el Reglamento provisional del Senado, ésta se ajustaba enteramente a lo que hemos descrito como líneas características de dicha figura en el Derecho. En este sentido,

76. BUCCISANO, Iole, Le interrogazioni e le interpellanze parlamentare, Milano, Giuffrè, 1969, pp. 102 y ss.

77. AMATO, Giuliano, L’ispezione politica del Parlamento, Milano, Giuffrè, 1968, pp. 87 y ss.

78. $R C D$, art. 125 .

79. $R C D$, art. 126.

80. $R C D$, art. 127. 
conviene resaltar la configuración de la interpelación como un derecho individual, la apertura de un debate y la eventual presentación de una proposición o moción. Destaca la afirmación del RS de que cualquier senador «tiene derecho a interpelar al Gobierno, expresando, en todo caso, de un modo explícito, el objeto de la interpelación ${ }^{81}$. De otra parte, era el Ejecutivo quien fijaba cuál de sus miembros había de contestar ${ }^{82}$, determinación importante, porque al referirse a «miembros del Gobierno» excluía la contestación por medio de un secretario de Estado o de un subsecretario, como, empero, se admitía para las preguntas ${ }^{83}$.

En cambio, no contenía el RS una regla diferenciadora del objeto de las interpelaciones, omisión importante que afectó a un uso adecuado de este procedimiento. Tampoco figuraba el plazo mínimo que debía mediar entre la presentación de una interpelación y su inclusión en el orden del día: solo establecía que la Mesa, oída la Junta de Portavoces, «procederá a fijar, dentro de los diez días siguientes a su presentación, la fecha en que deberá ser expuesta la interpelación $»^{84}$. Esta norma se hizo inaplicable, dado el elevado número de interpelaciones presentadas y el consiguiente retraso en su tramitación, que impidió fijar tan temprano dicha fecha. En cuanto a la regulación del debate, debe observarse que se siguió muy de cerca la contenida en el artículo 97 del Reglamento de las Cortes republicanas de 1934, lo que abrió la posibilidad a una discusión general sobre el tema interpelado ${ }^{85}$. Al amparo de lo establecido por el RS, el debate se desarrollaba de la siguiente manera: 30 minutos para que el senador expusiera su interpelación, 10 minutos para que el miembro del Gobierno contestara, tres turnos a portavoces de los Grupos Parlamentarios de 10 minutos cada uno, con la posibilidad de que la Cámara acordara ampliarlos, y rectificación del interpelante por un tiempo no superior a 5 minutos ${ }^{86}$. Normalmente, las intervenciones de los portavoces tenían lugar en orden inversamente proporcional a su importancia numérica. Con el fin de concluir el debate, se preveía la prolongación del mismo en la sesión inmediata e, incluso, la habilitación de una sesión extraordinaria ${ }^{87}$. Por último, y como consecuencia de la interpelación, estaba prevista la posibilidad de que se promoviera una proposición no de ley ${ }^{88}$.

81. RS, art. 135.1.

82. RS, art. 135.2.

83. RS, art. 130.

84. RS, art. 135.3.

85. molero Alonso, Diego, Las interpelaciones parlamentarias, Madrid, Congreso de los Diputados, 2003, pp. 172-175.

86. RS, arts. 136.1.

87. RS, art. 136.2.

88. $R S$, art. 136.3 . 


\section{Las interpelaciones, en la práctica}

En cuanto al resultado obtenido por las interpelaciones durante la Legislatura Constituyente en el Congreso de los Diputados, es evidente «tanto el elevado número de interpelaciones presentadas (102) como el retraso con que, en general, se produjo su debate» ${ }^{89}$. La consecuencia de este retraso no fue solo la de que únicamente la mitad aproximadamente de las interpelaciones presentadas (55, exactamente) hubiera llegado al Pleno de la Cámara, sino la de que solo se debatieran y votaran 21 de las mociones presentadas a consecuencia de las interpelaciones. En la práctica, las interpelaciones del Congreso no fueron otra cosa que preguntas importantes, puesto que la posibilidad que dejaba el RCD para la presentación de una moción tras el debate interpelacional fue interpretada restrictivamente $y$, por otra parte, las mociones derivadas de interpelaciones casi siempre carecieron de interés por el tiempo transcurrido desde que se formulaba la interpelación, además de por la frecuente poca importancia del tema objeto de la misma ${ }^{90}$.

El GS y el Grupo Parlamentario Comunista (GCO) fueron los que con más frecuencia utilizaron esta herramienta de fiscalización en el Congreso de los Diputados, con 31 y 26 interpelaciones enviadas a la Cámara, respectivamente. En tercer lugar se situaba el Grupo de Minoría Catalana (GMC), que remitió 15. Menos actividad demostró el GAP, con 8, y el Grupo de Socialistes de Catalunya (GSC), con 7, así como el GUCD y el Grupo Parlamentario Vasco (GPNV), que presentaron 2 cada uno. Las restantes 11 interpelaciones fueron presentadas por diputados del Grupo Mixto. Excepto en 5 casos, todas las interpelaciones fueron formuladas a título individual. El diputado más activo fue Marcelino Camacho, del GCO, que presentó 9 interpelaciones; seguido de Miquel Roca, del GMC, que formuló 6; y de María Victoria Fernández-España (GAP) y Nicolás Redondo (GS), con 5 cada uno. Un total de 4 interpelaciones depositó Ramón Tamames (GCO). Con 3 quedaron Ciriaco de Vicente (GS), Manuel Sánchez Ayuso (Grupo Mixto y luego GS), Marta Mata (GSC), Francisco Letamendia (Grupo Mixto), Ramón Trías (GMC), Jordi Pujol (GMC) y Emérito Bono (GCO). 2 interpelaciones formularon Pilar Brabo (GCO), Rafael Ballesteros (GS), Enrique Barón (GS), Manuel Chaves (GS), Joaquín Arana (GMC), Josep Maria Riera (GCO) y Francisco Javier Iturrioz (Grupo Mixto). Los restantes 40 diputados que hicieron uso de esta herramienta de control elevaron a la Cámara una interpelación cada uno de ellos.

89. RUBio llorente, Francisco, «Introducción», en Memoria del Congreso de los Diputados. Legislatura 1977-1979, Madrid, Congreso de los Diputados, 1979, p. 17.

90. CAZORLA PRIETO, Luis María, «Un año de control parlamentario», Triunfo, no 809 (1978), p. 33. 
En cuanto a los destinatarios de las interpelaciones, una buena parte se dirigieron a los ministros de Trabajo (23) y de Industria y Energía (16). Los Ministerios de Obras Públicas y Urbanismo y de Sanidad y Seguridad recibieron 9 interpelaciones, respectivamente; y los de Educación y Ciencia, y Transportes y Comunicaciones, 8 cada uno. Una menor cantidad estuvieron dirigidas a los Departamentos de Agricultura (6), Autonomías (5), Presidencia (4), Interior (3), Cultura (3), Comercio y Turismo (2), Defensa (2), Economía (2), Justicia (1) y Asuntos Exteriores (1). Por su temática, se advierte una mayoría de cuestiones relacionadas más o menos directamente con la crisis económica que estaba atravesando el país: reducción de las pensiones ${ }^{91}$, aumento del desempleo ${ }^{92}$, elecciones sindicales ${ }^{93}$, alzas salariales ${ }^{94} \mathrm{o}$ deterioro de ciertos sectores industriales (por ejemplo, el texti ${ }^{95}$ y el siderúrgico ${ }^{96}$ ). Los diputados, sin embargo, no incidieron excesivamente en materias de trascendencia nacional, sino que se centraron, por lo común, en cuestiones particulares o de tipo local que difícilmente justificaban la utilización de un instrumento reservado, como dijimos anteriormente, a temas enjundiosos. Caben apuntarse, no obstante, algunas excepciones, que por su relevancia política adquirieron especial notoriedad. Es el caso de las interpelaciones ligadas a la creación de un servicio de planificación familiar que dispensara anticonceptivos a los beneficiarios de la Seguridad

91. Sobre la necesidad de aumentar las pensiones, presentaron sendas interpelaciones Marcelino Camacho (GCO), Ciriaco de Vicente (GS) y Ángel Perera (GMC). Los debates en Diario de Sesiones del Congreso de Diputados (DSCD), Sesión Plenaria, ${ }^{\circ} 21$, de 22 de febrero de 1978 pp. 751-759; y no 26, de 1 de marzo de 1978, pp. 1.006-1.023.

92. En especial la relativa a la situación del paro agrícola redactada por Alfonso Guerra (GS) y formulada ante el Pleno por su compañero de Grupo Juan Luis Colino. Vid. DSCD, Sesión Plenaria, $\mathrm{n}^{\circ}$ 74, de 24 de mayo de 1978, pp. 2.667-2.675.

93. Explanadas por el diputado comunista Marcelino Camacho (DSCD, Sesión Plenaria, $\mathrm{n}^{\circ}$ 42, de 13 de abril de 1978, pp. 1.492-1.503) y el socialista Nicolás Redondo (DSCD, Sesión Plenaria, no 57, de 4 de mayo de 1978, pp. 1.951-1.959).

94. Las de Carlos Cigarrán Rodil (GS), en torno a la regulación de empleo en SEAT (DSCD, Sesión Plenaria, $\mathrm{n}^{\circ}$ 23, de 23 de febrero de 1978, pp. 817-826), y la de Marcelino Camacho (GCO) sobre la preparación de una ley de flexibilización de plantillas (DSCD, Sesión Plenaria, $\mathrm{n}^{\circ} 13$, de 8 de febrero de 1978, pp. 424-432).

95. Ramón Trías Fargas presentó dos, de las que solo llegó al Pleno una de ellas, referida a la industria textil algodonera. Vid. DSCD, Sesión Plenaria, no 74, de 24 de mayo de 1978, pp. 2.709-2.715.

96. Fueron reiteradas las interpelaciones sobre la factoría Babcock \& Wilcox, instalada en Sestao (Vizcaya), que suspendió pagos y hubo de ser rescatada por el Estado para evitar que fueran despedidos sus más de 5.000 empleados. Vid. interpelaciones de Nicolás Redondo, Xabier Arzálluz, Ignacio Gallego, Eduardo Martín Toval, Miquel Roca, Emilio Gastón y Francisco Letamendía debatidas en DSCD, Sesión Plenaria, $\mathrm{n}^{\circ}$ 57, de 4 de mayo de 1978, pp. 1.968-1.987. 
Social $^{97}$, la amnistía de maestros represaliados ${ }^{98}$, los bienes de entidades apropiados tras la Guerra Civil ${ }^{99}$, las limitaciones a la libertad de expresión con motivo del Consejo de Guerra contra los miembros del grupo teatral Els Joglars ${ }^{100}$, la educación en lengua materna ${ }^{101}$, la reforma universitaria ${ }^{102}$ o la llamada «guerra sucia» contra el terrorismo ${ }^{103}$.

Respecto a la vida práctica de las interpelaciones en el Senado, debe destacarse que durante la Legislatura Constituyente tuvieron un «resultado aceptable» ${ }^{104}$, pues se presentaron 50 y se llegaron a debatir 36 en Sesión Plenaria. Si se tiene en cuenta que varias de las presentadas fueron retiradas posteriormente (7), o fueron afectadas por la disolución anticipada de las Cortes (6), se puede comprobar el alto porcentaje de las tramitadas efectivamente. El ministro más interpelado fue el del Interior, que fue interrogado hasta en 7 ocasiones, seguido del de Educación y Ciencia (5), Presidencia (4), Obras Públicas (3), Justicia (3), Cultura (3), Agricultura (2), Trabajo (2), Economía (1), Regiones (1) y Sanidad y Seguridad Social (1).

Casi todas las interpelaciones fueron presentadas por un parlamentario individual, 5 por dos o más senadores y solo 1 por un Grupo Parlamentario ${ }^{105}$. De los 250 senadores que pasaron por la Cámara durante la Legislatura, solo

97. Formulada por Carlota Bustelo y Asunción Cruañes, del GS. Vid. DSCD, Sesión Plenaria, $\mathrm{n}^{\circ} 95$, de 22 de junio de 1978, pp. 3.573-3.588.

98. Presentadas por los diputados socialistas María Izquierdo Rojo y Manuel Sánchez Ayuso. Vid. DSCD, Sesión Plenaria, no 46, de 19 de abril de 1978, pp. 1.669-1.679.

99. A cargo de Joan Reventós (GSC). Vid. DSCD, Sesión Plenaria, ${ }^{\circ}$ 52, de 27 de abril de 1978, pp. 1.841-1.846

100. Tres interpelaciones sobre este objeto presentadas por Marta Mata (GSC), Pablo Castellano (GS) y Jordi Solé Tura (GCO). Véanse los debates recogidos en DSCD, Sesión Plenaria, $\mathrm{n}^{\circ}$ 52, de 27 de abril de 1978, pp. 1.835-1.841; y nº 74, de 24 de mayo de 1978, pp. 2.675-2.682.

101. La de Ramón Trías Fargas (GMC), cuya explanación se recoge en DSCD, Sesión Plenaria, $\mathrm{n}^{\circ} 74$, de 24 de mayo de 1978, pp. 2.683-2.695.

102. Diversas interpelaciones presentadas por Jordi Solé Tura (GCO), Miquel Roca (GMC), Julio Busquets y Marta Mata (GSC), debatidas conjuntamente. Vid. DSCD, Sesión Plenaria, $n^{\circ} 121$, de 28 de septiembre de 1978, pp. 4.843-4.861.

103. La de Francisco Letamendía (Grupo Mixto), sobre irregularidades cometidas por las policías española y francesa en la detención del terrorista Vicente Aldalur (DSCD, Sesión Plenaria, $\mathrm{n}^{\circ} 126$, de 18 de octubre de 1978, pp. 5.017-5.023) y las depositadas por Francisco Javier Iturrioz (Grupo Mixto) relativas a las medidas de orden público en el País Vasco y la conspiración de jefes militares, que no fueron aceptadas por la Mesa.

104. Santaolalla, Fernando, El Parlamento y sus instrumentos de información. (Preguntas, interpelaciones y Comisiones de investigación), Madrid, Edersa, 1982, p. 148.

105. El GPSI, «sobre medidas que piensa adoptar el Gobierno para la solución de los problemas planteados por los profesores de Educación General Básica», publicada el 6 de mayo de 1978 (BOC, $\mathrm{n}^{\circ}$ 92, pp. 1.867-1.868) y debatida el 9 de mayo (Diario de Sesiones del Senado (DSS), Sesión Plenaria, nº 24, pp. 963-985). 
37 (el 14,8\%) interpelaron al Gobierno. El senador más activo fue Manuel Villar Arregui, del GPSI, que presentó 4 interpelaciones y firmó otra junto a Lorenzo Martín-Retortillo. Alfonso Moreno de Acevedo, del mismo Grupo, presentó otras 4 interpelaciones. Con 2 figuran Valentín Paz Andrade, también del GPSI, los parlamentarios del GEDC Carles Martí y Jaume Sobrequés, el senador de Alianza Popular integrado en el Grupo Mixto Abel Matutes, y los socialistas Joaquín Martínez Bjorkman, José Vicente Mateo, Fernando Morán, Joaquín Navarro Estevan, Francisco Ramos y Francisco Javier Yuste. Los demás 25 interpelantes formularon una sola interpelación cada uno.

Por Grupos Parlamentarios, el más activo resultó el GSS, con 18 interpelaciones presentadas por senadores pertenecientes al mismo. A corta distancia se situaba, dentro de esta clasificación, el GPSI, con 14, y el GEDC, con 11. Menor intensidad en el uso de este instrumento de control al Ejecutivo desplegaron el Grupo de Senadores Vascos (GSV) y el Grupo Mixto, con 3 interpelaciones cada uno de ellos. Aunque no es extraño que el Grupo mayoritario, el GUCD, no presentara ninguna interpelación, sí resulta significativo que ningún miembro del Grupo Parlamentario Independiente y del Grupo Parlamentario Agrupación Independiente, interpelara al Gobierno. El hecho de que renunciaran a sus obligaciones fiscalizadoras confirma el sesgo derechista y la docilidad al poder de los senadores de designación real, que integraban en su práctica totalidad ambos Grupos. La temática de las interpelaciones refuerzan la idea de un Senado conservador: sobreabundancia de cuestiones relativas a temas agropecuarios, pesqueros y medioambientales, y poco interés por asuntos estrictamente políticos, lo que ahorró al Gobierno tener que argüir sobre elementos que resultaban «vidriosos». Señálense, no obstante, algunas interpelaciones singulares por su trascendencia, como las relativas al aumento del tráfico y consumo de drogas ${ }^{106}$, aplicación de la Ley de Amnistía ${ }^{107}$ o igualdad de los derechos de mujeres y hombres en la función pública ${ }^{108}$.

\section{Conclusiones}

Pese a su falta de virtualidad jurídica, las preguntas e interpelaciones constituyen mecanismos de gran importancia política potencial. Y decimos potencial porque es evidente que solo revisten importancia política verdadera si se

106. Formulada por Francisco Javier Yuste (GSS). Vid. DSS, Sesión Plenaria, no 6, de 9 de febrero de 1978, pp. 262-268.

107. Presentada por José Antonio Baixeras (GEDC). Vid. DSS, Sesión Plenaria, no 8, de 23 de febrero de 1978, pp. 375-377.

108. Explanada por José María Suárez Núñez (GUCD). Vid. DSS, Sesión Plenaria, nº 8, de 23 de febrero de 1978, pp. 381-384. 
correlacionan con unas formas superiores de control eficaces (censura o confianza). En este caso, la interpelación y la pregunta, jurídicamente ineficaces en sí mismas, pueden transformarse en mecanismos estrictos de control. Pero si éstos no existen o se hallan recortados, el valor de las preguntas e interpelaciones queda fuertemente reducido. Este fue, precisamente, el primer obstáculo con que se encontró la actividad rogatoria en la etapa que hemos analizado: la Ley 51/1977, de 14 de noviembre, de relaciones entre las Cortes y el Gobierno $^{109}$ no constituía un mecanismo suficiente para poder hablar de un auténtico control parlamentario del Gobierno ${ }^{110}$. La carencia de efectos jurídicos inmediatos de la moción de censura aprobada, la exigencia de mayoría absoluta de los componentes de ambas Cámaras, la complejidad del proceso mismo, que podía producir un considerable alargamiento de la discusión de la moción, y la posibilidad misma de que el Gobierno invadiese una parte de la potestad legislativa de las Cortes a través de la cuestión de confianza, pese a su gran limitación final, convertían el mecanismo en «un ensamblaje pesado, difícil y carente de fuerza» ${ }^{111}$. En palabras de Jorge de Esteban, «no se trataba más que de un remedo de control parlamentario ${ }^{112}$.

Dicho esto, es indudable que la ambigüedad misma con que estaba redactada la regulación de las interpelaciones y las preguntas en los Reglamentos del Congreso y del Senado podía prestarse a una interpretación y una utilización elásticas de las mismas, hasta el punto de convertirlas en auténticas mociones de censura en algunos casos. Su valor como tales era jurídicamente nulo, pero políticamente importante. Ahora bien, la práctica de la Legislatura Constituyente mostró que el principal inconveniente de estas herramientas de fiscalización radicaba en su propia concepción reglamentaria. Las interpelaciones y preguntas carecían de la virtualidad operativa que les da, por ejemplo, la institución del question time en la Cámara de los Comunes británica, por la extrema lentitud de su proceso.

Esta circunstancia se explica, en parte, por el hecho de que las Cámaras estuvieran absorbidas por un intenso trabajo legislativo, agravado, además,

109. Boletín Oficial del Estado, no 274, de 16 de noviembre de 1977, p. 24.951.

110. Vid. sobre este tema los estudios de RIPOLlÉS SERRANO, María Rosa, «La regulación vigente de las relaciones Legislativo-Ejecutivo (La Ley de 17-11-77 y los Reglamentos provisionales del Congreso y del Senado de 13 y 18 de octubre de 1977)», en RamíREZ, Manuel (ed.), El control parlamentario..., pp. 194-205; ARCENEGUI, Jesús J. de, «La ley de relaciones Gobierno-Cortes de 14 de noviembre de 1977», en RAMírEZ, Manuel (ed.), El control parlamentario..., p. 186; y SÁNCHEZ DE DIOS, Manuel, La moción de censura, Madrid, Congreso de los Diputados, 1992.

111. SOLÉ TURA, Jordi, «El control parlamentario...», pp. 37-38. RUBIO LLORENTE, Francisco, «La relación entre Gobierno y Cortes», en Constitución, Economía y Regiones, vol. III, Madrid, Ibérico Europea de Ediciones, 1978, p. 67.

112. esteban, Jorge de, Por la senda constitucional, Madrid, El País, 1987, p. 71. 
por el proceso de elaboración de la Constitución. En principio, las Cortes trabajaron de martes a viernes, aunque en la práctica se tendió a reducir la labor del viernes únicamente a la mañana, cuando no a prescindir totalmente de la jornada. Los martes y los jueves se dedicaban al trabajo de las Comisiones, los miércoles por la tarde a los Plenos y los miércoles por la mañana a las reuniones de los Grupos Parlamentarios. A finales de la Legislatura, ante la necesidad de dar salida a la tarea acumulada, se amplió la celebración de los Plenos a los jueves por la tarde, e incluso por la mañana. Dado el carácter doble que tuvieron las Cortes, constituyentes y ordinarias a la vez, los Plenos resultaron muy cargados de tarea propiamente legislativa, con lo cual se hizo literalmente inviable el cumplimiento del question time previsto en el artículo 129 de los dos Reglamentos. No hay que obviar, de todos modos, ciertas inercias del pasado, sobre todo entre los escaños de la mayoría, donde se sentaban numerosos antiguos procuradores ${ }^{113}$.

Por otro lado, las propias insuficiencias de la anteriormente citada Ley de relaciones entre las Cortes y el Gobierno en materia de moción de censura y cuestión de confianza obligaron a intensificar la presentación de preguntas para intentar someter a fiscalización la labor del Ejecutivo. Esto provocó una inflación en las preguntas de respuesta oral, con el consiguiente atasco en su discusión. Además, se estableció una jerarquía entre las interpelaciones y las preguntas orales que perjudicó a la tramitación de estas últimas. Dado que las interpelaciones podían dar lugar a la presentación de una moción, la mayoría de las cuestiones se presentaban bajo la forma de interpelaciones. Éstas se colocaban siempre antes que las preguntas en el orden del día y su discusión en el Pleno se convertía a menudo en un largo y complejo debate, que se volvía a reproducir con ocasión de la presentación de la correspondiente moción. En consecuencia, las preguntas quedaban relegadas y se posponían constantemente de sesión en sesión. Por todas estas razones, las preguntas orales se acumularon en las Mesas, sobre todo en la del Congreso. En numerosas ocasiones el plazo transcurrido entre la presentación de una pregunta y su discusión en el Pleno fue de hasta 8 meses. Con ello, las preguntas orales perdieron su eficacia controladora y se convirtieron a menudo en meros ejercicios formales sin trascendencia política ni jurídica ${ }^{114}$.

113. 44 diputados y senadores de UCD habían sido procuradores en Legislaturas anteriores. Vid. GIMÉNEZ MARTíneZ, Miguel Ángel, Las Cortes Españolas en el régimen de Franco. Nacimiento, desarrollo y extinción de una Cámara Orgánica, Madrid, Congreso de los Diputados, 2012, p. 241.

114. SOLÉ TURA, Jordi, «El control parlamentario...», pp. 39-40. 
Así, durante la Legislatura Constituyente se asistió a un aluvión de interpelaciones en base a temas que a lo sumo eran acreedores de una modesta pregunta y se utilizó la interpelación como cauce que posibilitaba el acceso a la tribuna de las Cámaras y que deparaba, por ello, publicidad. Dada la estructuración de los Grupos Parlamentarios, las interpelaciones podían ser una vía de escape para el protagonismo personal de algunos diputados y senadores, especialmente en relación con problemas específicos de su circunscripción o de una localidad de la misma. El resultado: la interpelación, más que el resto de los instrumentos de control, se desprestigió y desvirtuó, generando desconfianza en su potencialidad ${ }^{115}$.

Hay razones que explican esta forma de proceder. Ante todo, fue tan reducido el papel de la mayoría de los diputados y senadores en el ámbito legislativo que éstos encontraron un desahogo en el marco del control político. Por otro lado, dada la defectuosa regulación de la interpelación, que distaba mucho de ser tal en sentido estricto, sus normalmente inocentes iniciativas en este terreno no revistieron demasiado peligro para el Gobierno, lo que habría sido perjudicial para la táctica del consenso. Las mociones de ellas derivadas poco afectaron a los cimientos del Gabinete a causa de la relativa importancia de los problemas que fueron objeto de las interpelaciones y del método de «enfriamiento político» al que se las sometió. De cualquier manera, sería ingenuo achacar meramente la desvirtuación de las herramientas de control parlamentario durante la etapa de las Cortes Constituyentes a una deficiente regulación o a la falta de criterio, fruto de la inexperiencia de los parlamentarios. Detrás de todo ello estaba el método seguido durante la transición para abordar las grandes cuestiones políticas: el consenso. No interesaba poner en la picota al Gobierno a través de una férrea fiscalización, que habría potenciado los instrumentos parlamentarios. Al revés, hubo una complacencia general con los que gobernaban a cambio, evidentemente, de importantes contrapartidas, sobre todo en materia constitucional.

115. CAZORLA PRIETO, Luis María, «Un año de control...», p. 33. 


\title{
L'assassinat d'Ernest Lluch: les interpretacions diferenciades de Gara i El Temps, dos mitjans de l'esquerra nacionalista
}

\author{
Ernest Lluch's assassination: Contrasting interpretations \\ in two Left-wing Nationalist Media Publications
}

Recibido: 14-II-2014

\author{
Manuel Lillo i Usechi \\ Universitat Miguel Hernández, Elx
}

Aceptado: 21-VII-2014

\section{Resum}

El 21 de novembre de l'any 2000, ETA va cometre un dels assassinats que més va commocionar la societat espanyola. Ernest Lluch moria al garatge de sa casa i tant la població com els mitjans de comunicació van reaccionar amb un gran rebuig davant d'este nou assassinat. Este article pretén analitzar el tractament que dos mitjans de l'esquerra nacionalista van donar a este succés: Per un costat, El Temps, setmanari d'informació general, catalanista i simpatitzant amb l'esquerra nacionalista i independentista; per l'altre, Gara, que podríem qualificar-ho com el seu homòleg a Euskal Herria, simpatitzant amb l'esquerra abertzale. Larticle analitza com van reaccionar ambdós mitjans immediatament després de l'assassinat d'Ernest Lluch, exministre de sanitat amb Felipe González (1982-1986), economista, historiador i reconegut per la seua activitat intel-lectual i per la seua voluntat de diàleg amb ETA, que va acabar amb la seua vida quan tenia 63 anys.

Paraules clau: Ernest Lluch, ETA, Catalunya, PSOE, Terrorisme, Assassinat, Diàleg, Pau, Periodisme, Gara, El Temps, Nacionalisme, Independentisme.

\section{Resumen}

El 21 de noviembre del año 2000, ETA cometió uno de los asesinatos que más conmocionó a la sociedad española. Ernest Lluch moría en el garaje de su casa y tanto la población como los medios de comunicación reaccionaron con un gran rechazo ante este nuevo asesinato. Este artículo pretende analizar el tratamiento que dos medios de la izquierda nacionalista dieron a este suceso: Por un lado, El Temps, semanario de información general, catalanista y simpatizante con la izquierda nacionalista e indepen- 
dentista; por otro, Gara, que podríamos calificarlo como su homólogo en Euskal Herria, simpatizante con la izquierda abertzale. El artículo analiza como reaccionaron ambos medios de comunicación inmediatamente después del asesinato de Ernest Lluch, exministro de sanidad con Felipe González (1982-1986), economista, historiador y reconocido por su actividad intelectual y por su voluntad de diálogo con ETA, que acabó con su vida cuando tenía 63 años.

Palabras clave: Ernest Lluch, ETA, Cataluña, PSOE, Terrorismo, Asesinato, Diálogo, Paz, Periodismo, Gara, El Temps, Nacionalismo, Independentismo.

\begin{abstract}
On November 21st 2000, ETA committed one of the most shocking assassinations in the Spanish society. Ernest Lluch was killed in his home garage and both the population and the media reacted massively rejecting this new murder. This article is intended to analyse the treatment given to this event by two left nationalist ideology media: On the one hans El Temps, general weekly publication, Catalan nationalist and close to pro-independence left ideology; on the other hand, Gara, which could be define as the former's counterpart in the Basque Country, close to Abertzale left ideology. The article analyses how both media reacted to the assassination of Ernest Lluch, -a former Health Minister under Felipe González (1982-1986)-, an economist, a historian fully acknowledged by his intellectual activity and his willingness to dialoguing with ETA, the organisation that extinguished his life when he was 63.
\end{abstract}

Keywords: Ernest Lluch, ETA, Catalonia, PSOE, Terrorism, Assassination, Dialogue, Peace, Journalism, Gara, El Temps, Nationalism, Pro-independence.

\title{
1. Introducció: hipòtesi i metodologia
}

Este article té com objectiu observar, estudiar i exposar les reaccions que dos mitjans de comunicació quasi idèntics ideològicament van tindre davant un fet que va commocionar la societat espanyola: l'assassinat d'Ernest Lluch.

Gara, diari basc relacionat amb l'esquerra abertzale difós al territori denominat com Euskal Herria ${ }^{1}$. El Temps, setmanari valencià, catalanista i d'esquerres, difós a l'àmbit territorial dels Països Catalans². Dos mitjans de comu-

1. «La Euskal Herria de HB [Herri Batasuna] es un amplio mapa que además de la Comunidad Autónoma comprende Navarra y los territorios del País Vasco Francés. Ese es el mapa de la nación que reivindica el nacionalismo vasco. Pero especialmente en el caso de HB». aulestia, Kepa, HB, Crónica de un delirio, Temas de Hoy, 2 Edición, 1998, p. 154.

2. «(...) l'esforç historiogràfic fet en relació a la història dels Països Catalans (...) les necessitats que tenim plantejades com a poble -un de sol, no tres ni quatre-generen unes exigències pròpies, que, des del meu punt de vista, ens obliguen a avançar en la interpretació de la història del nostre poble, més enllà de les històries parcials: País Valencià, Principat, Illes, Catalunya Nord [zona de parla catalana situada a l'Estat francès]; més enllà d'històries diacròniques i separades, tendents més a discursos narratius i paral-lels que a una interpretació integradora global». SERRA, Eva., Els Països Catalans: Un debat obert, Ed. Tres i Quatre, 1984, p. 53. 
nicació d'ideologia política idèntica, que recolzen un objectiu comú: la independència política d'allò que ells consideren territori nacional. Tot i compartir objectius polítics, no proposen els mateixos mitjans per aconseguir-los, o millor dit: no coincideixen en rebutjar determinats mètodes per assolir tal objectiu. Es allò que es tracta de demostrar en este article, i per fer-ho, posem un exemple transcendent que va commocionar la societat espanyola: l'assassinat d'Ernest Lluch al novembre de l'any 2000.

La hipòtesi, per tant, d'este article, és demostrar com El Temps condemna la violència dins de les estratègies nacionalistes i independentistes, en este cas, en la banda terrorista ETA; i verificar també com Gara, mitjà d'idèntica ideologia al setmanari esmentat, no es pronuncia al respecte d'estes estratègies violentes i, per tant, no les condemna. Per confirmar la hipòtesi, hem escollit el cas de l'assassinat d'Ernest Lluch, que va tindre un gran ressò en la societat espanyola per motius que explicarem més endavant.

Com a metodologia, hem realitzat una lectura i la posterior anàlisi comparada dels discursos del diari Gara i dels del setmanari El Temps en els dies posteriors a l'assassinat d'Ernest Lluch per part d'ETA. Els articles publicats pels dos mitjans són molt rics per a poder contrastar la nostra hipòtesi de partida, que consisteix en demostrar que El Temps, amb el seu discurs de la seua línia editorial, condemna la violència d'ETA; mentre que Gara, als seus articles, no ho fa. Dos mitjans de comunicació que persegueixen el mateix objectiu polític suggereixen dues estratègies diferents per aconseguir-ho. L'objectiu: assolir la independència política d'allò que consideren els seus respectius territoris nacionals: Gara, amb Euskal Herria; i El Temps amb els Països Catalans. Paradoxalment, i davant de l'atemptat contra Ernest Lluch perpetuat per una banda independentista com és ETA, ambdós mitjans van reaccionar d'una forma prou distinta. Un, condemnant clarament l'atemptat. Altre, referint-se al fet sense cap valoració de condemna al respecte, com veurem més endavant. La idea: escollir dos mitjans de comunicació d'idèntica ideologia política però que tracten de distinta forma la temàtica del terrorisme: un la condemna clarament i altre no ho fa.

A més de la versió de cadascun dels mitjans, he utilitzat bibliografia útil complementària per tal de contextualitzar l'article en l'àmbit polític, històric i social.

La figura d'Ernest Lluch va ser molt valorada dins de l'àmbit polític i acadèmic espanyol. Prova d'açò són les reaccions que va tindre el seu atemptat, que es mostren en este escrit. Com a mostra d'allò que simbolitza l'assassinat d'Ernest Lluch, afegim la següent dada: dels 858 morts que ha provocat la banda ter- 
rorista ETA durant la seua història ${ }^{3}$, només dos han ocupat càrrecs ministerials a l'Estat espanyol. Un, Luis Carrero Blanco, quan exercia d'almirall president del govern durant la dictadura franquista, assassinat al desembre de 1973. I l'altre, el nostre protagonista, Ernest Lluch, que havia ocupat el càrrec de ministre de sanitat quinze anys abans de la seua mort amb el govern de Felipe González, entre desembre de 1982 i juliol de $1986^{4}$.

\section{Els fets}

El professor de la Universitat d'Alacant, José Carlos Rovira Soler, fa un bon resum de com va morir Ernest Lluch i d'allò que el seu assassinat va suposar:

«El 21 de novembre de 2000, a les 10 de la nit i en el garatge de sa casa, era assassinat Ernest Lluch, exministre socialista i intel-lectual compromès amb la història i la política. ETA havia colpejat de nou, i aquesta vegada, a més, ho feia demostrant -ho ha fet diverses vegades- que també eren el seu blanc aquells que havien lluitat amb força per portar la democràcia i s'havien compromès en la política des de posicions democràtiques i socialistes. Lluch, crec, era un dels principals emblemes d'actituds i reflexions que ara per ara continuen sent molt necessàries. Possiblement, crec que tots en destacarem l'actitud negociadora, l'actitud de debat d'idees fins i tot en els moments més difícils, que ha de ser tinguda en compte ara precisament que els termes de la qüestió basca, que va ser una de les preocupacions centrals de la seua vida política i ciutadana, sembla que estiga abocada a un conflicte sense solució, en el qual a les raons s'oposen actes de força, no a la força criminal representada per ETA, sinó a la força de fets consumats que -ara és solament la meua opinióve determinada tant per l'actitud del govern del Sr. Ibarretxe com per l'actitud del govern del Sr. Aznar» ${ }^{5}$.

\section{L'antipatia d'El Temps cap a Ernest Lluch en el passat}

Tot i que l'assassinat de Lluch va suposar, com veurem a continuació, una gran reacció condemnatòria d'El Temps, durant anys passats, quan Ernest Lluch exercia de ministre de sanitat en el govern de Felipe González ${ }^{6}$, el setmanari valencià no li tenia molta estima al polític socialista.

3. Font: <http://www.avt.org/victimas-del-terrorismo/> [Consultat: 30-VI-2014].

4. Ibid.

5. JimÉNEZ RANEDA, Ignacio, Ernest Lluch: un exemple de tolerància al País Valencià. Homenatge a Ernest Lluch a la Seu Ciutat d'Alacant, Universitat d'Alacant, 2004, p. 17. Capítol escrit per José Carlos Rovira Soler, professor de la Universitat d'Alacant.

6. Per consultar l'obra de Lluch com a Ministre de Sanitat, cf. PASCUET, Rafael, EntreLluchs: una aproximació empordanesa a Ernest Lluch, $1^{\mathrm{a}}$ ed., El Brau, 2001, p. 27. Capítol «Ernest Lluch, polític: compromís i proximitat», escrit per Joan Manuel del Pozo, Professor de 
Ho podem comprovar als articles d'opinió que trobem als primers números d'El Temps. Casualment, al número $0^{7}$, el primer article del columnista Ramon Barnils, està precisament dedicat al nostre protagonista, Ernest Lluch. Larticle pertany a la secció 'Arròs a banda', que consistia en una columna d'opinió redactada per Barnils. La primera es va titular «Ni idea», i començava així:

«L'altra setmana el "menistro" de Sanitat espanyol, Ernest(o) Lluch, que si fos d'aquí ja tindria nom, ministre Draps Calents, deia que aquí hi ha poques idees noves, vist de Madrid estant; i, també, "manca d'iniciatives que puguin ser lliçó per a Espanya" [sic]»".

Quan Barnils parla «d'aquí» sembla referir-se als territoris dels Països Catalans que formen part de l'Estat Espanyol, ja que l'article continua així:

«La notícia del "menistro" Lluch és la millor notícia que ens ha arribat en molt de temps, i l'únic que en rebaixa l'alegria i l'esperança en un futur millor és que potser no acaba de ser ben bé veritat: al cap i a la fi, al Principat mana el President Pujol, que diu que ser català és la seva manera de ser espanyol; al País Valencià mana el Psoespanyol, Ave Maria Puríssima; i a les Illes, Aliança Popular, sens pecat fou concebuda $[\text { sic }]^{10}{ }$.

Qualificatius satírics com «Psoespanyol» o l'intencionat malnom d' «Ernest(o)» deixen en evidència com El Temps critica la absència de nacionalisme dins del govern del PSPV de Joan Lerma al País Valencià de l'època en la que va governar ${ }^{11}$, així com la crítica a un ministre català que exercia el seu càrrec des de Madrid i conjuntament amb un partit espanyolista, com ho era el PSOE, cosa que es demostra també en este altre article, molt més curt que apareix a la secció 'Cartes dels lectors'12 del número 241 d'El Temps.

«Segons sembla, el fet que un desconegut prengués l'Ernest Lluch per un català (al camp de l'Independiente d'Avellaneda, a l'Argentina), ha estat objecte de comentari i sorpresa (Diari de Barcelona, 2.1.89). Es veu que portar dos llibres

Filosofia i vicerrector de la Universitat de Girona. Per consultar l'obra d'Ernest Lluch com a polític i com a intel-lectual, consultar també JIMÉNEZ RANEDA, Ignacio., Ernest Lluch: un exemple de tolerància al País Valencià. Homenatge a Ernest Lluch a la Seu Ciutat d'Alacant, Universitat d'Alacant, 2004, pp. 25-34, redactat per Josep V. Bevià Pastor.

7. 4-10/IV/1984.

8. El Temps, Número 0, 4-10/IV/1984, p. 30.

9. Ibid.

10. Ibid.

11. Hi ha diversos exemples en els que El Temps acusa al PSPV de partit espanyolista o poc valencianista: Número 0, 4-10/IV/1984, p. 12; Número 2, 4-10/VI/1984, p. 20; Número 7, 9-15/VII/1984, p. 25; Número 11, 6-12/VIII/1984, p. 12; Número 15, 1-7/X/1984, p. 25; Número 19, 29-4/X-XI/1984, p. 19; i molts més.

12. El Temps, número 241, 30-5/I-II/1989, p. 4. 
sota el braç -i no altra cosa- ha estat la prova que ha permès de discernir la catalanitat de l'ex-ministre. Ens n'anelegrem per ell, que així ja sabrà què portar sota el braç quan convingui semblar català arreu, i, alhora, de què caldrà desprendre's quan interessi una altra nacionalidad més d'acord amb el seu comportament polític $[\mathrm{sic}] \gg^{13}$.

Sembla, doncs, que també als articles d'opinió d'El Temps, allò més criticat d'Ernest Lluch era el seu espanyolisme, almenys pels exemples mostrats.

De fet, Ernest Lluch era més vinculat encara a l'espanyolisme més "ranci" quan al primer article esmentat, escrit per Ramon Barnils al número 0, continuava diguent:

«(...) diuen que volen entrar a Europa, després d'haver foragitat moros, jueus, protestants, capitalistes, invents, francesos, maçons i republicans, després d'haver-se embolicat amb la barbàrie hitleriana, la tragicomèdia feixista, la poesia machadiana, el psitacisme orteguià; després d'haver-se convertit en un magatzem de bombes EUA avariades a canvi de no vendre'ls ni un trist avió. Tenim massa poques idees, nosaltres, i poquíssimes iniciatives per malgastarles amb qui des de sempre ni les aprofita ni ens les deixa aprofitar; no es poden donar margarides a segons qui $[$ sic $] \gg^{14}$.

Esta antipatia cap a l'exministre va convertir-se en reconegut homenatge quan va ser assassinat al novembre de l'any 2000.

\section{L'assassinat: reacció d'El Temps}

Ernest Lluch moria assassinat el 21 de novembre de l'any 2000. El primer homenatge d'El Temps es mostrava a la portada del número 859, on apareixia una foto del protagonista amb l'únic text de la seua rúbrica. Cap titular, cap destacat, cap altre anunci més enllà de l'habitual capçalera on s'escriu el títol del setmanari, la data, el número i el preu, a més de l'anunci d'un fascicle que s'observa quasi invisible.

Leditorial, redactat en la cinquena pàgina, titula «Diàleg ja!» i està dedicat a Lluch. Larticle critica el govern del PP per la seua "incapacitat" de diàleg, així com per les seues "tergiversacions":

«Els lectors d'ELTEMPS saben prou bé que als Països Catalans no s'entén -és una manera de dir-ho- que el govern espanyol pose en el mateix sac el nacionalisme democràtic basc i el violent. No s'entén que, al cap de vint-i-cinc anys de la mort de Franco, encara es lluite contra ETA amb els mateixos mètodes que tan poc han contribuit a pacificar el País Basc fins ara. Estem convençuts

13. L'article el signava Juli Sanchis, de València (l'Horta).

14. El Temps, Número 0, 4-10/IV/1984, p. 30. 
que el diàleg i la negociació que propugnava $\mathrm{Lluch}^{15}$, i que cada vegada defensen més sectors democràtics, és la clau de volta, però el Partit Popular (PP) ha demostrat fins ara ser incapaç de fer el gest, confonent diàleg amb claudicació, i negociació amb rendició [sic] ${ }^{16}$.

Tota esta argumentació ve a propòsit d'una frase que, segons el propi setmanari, va fer la periodista Gemma Nierga a la manifestació de Barcelona en resposta a l'assassinat de Lluch: «Ernest hauria intentat dialogar fins i tot amb l'etarra que el va matar» $^{17}$.

Com es pot comprovar, El Temps és partidari del diàleg entre ETA i el govern per tal d'arribar a la solució del conflicte.

Però la crítica no només afecta al govern del Partit Popular. També carrega contra ETA i les seues accions, assegurant que el govern "s'alimenta" política i electoralment de les actuacions de la banda armada i que esta, per actuar com actua, afavoreix les tesis "contundents" i "intransigents" del govern popular:

«(...) no hi ha dubte que encara hi ha un factor pitjor que el PP per avançar cap a una situació de respecte amb totes les sensibilitats i que admeta una visió plurinacional de l'estat espanyol: aquest factor és ETA. Amb la seua actuació, a part de matar, l'organització armada no solament frustra els esforços dels partidaris del diàleg i la negociació a favor de la pau. També alimenta l'actitud intransigent de la dreta espanyolista, que enarbora Constitució i estatuts com si foren l'única veritat possible en democràcia, l'única bandera a favor de la pau. Sí, ETA és la coartada del PP per a proscriure totes les alternatives polítiques que no es combreguen amb una visió unívoca de l'estat, començant pels partits polítics majoritaris al País Basc. En suma, ETA és el millor aliat de la política del PP i no calen més assassinats per a confirmar-ho» ${ }^{18}$.

En definitiva, El Temps responsabilitza del conflicte en general i de l'assassinat d'Ernest Lluch en particular tant a ETA per les accions com al PP per "aprofitar-se" del conflicte per "reforçar les seues tesis i accions polítiques", així com als dos per les "mútues incapacitats" de diàleg.

Esta conclusió es resumeix perfectament a l'últim paràgraf del text, part del qual apareix com a destacat a la mateixa pàgina de l'editorial:

«El partit d'Aznar i Mayor Oreja acusa el Partit Nacionalista Basc (PNB) de compartir l'independentisme amb ETA, mentre ells mateixos comparteixen amb ETA el rebuig al diàleg, que ha acabat amb la vida d'Ernest Lluch» ${ }^{19}$.

15. La filla del nostre protagonista, Rosa Lluch, també aposta pel diàleg, com es pot comprovar en este enllaç: <http://www.lavanguardia.com/politica/20121122/54355738738/hijaernest-lluch-pide-dialogo-duda-otegi-deba-estar-prision.html> [consultat: 30-VI-2014].

16. El Temps, Número 859, 28-4/XI-XII/2000, p. 5.

17. Ibid.

18. Ibid.

19. Ibid. 
A la pàgina següent trobem la secció 'Cartes', on escriu tant el director d'El Temps, que en eixe número era Jordi Fortuny; com els lectors habituals que escriuen les seues columnes. Dels quatre articles, dos van dedicats a Ernest Lluch. Són els dos primers i encapçala l'escrit pel director del setmanari, sota el títol «Als nostres lectors», es pot llegir:

«No els ha sortit bé. La força d'Ernest Lluch no era el poder. Ell no tenia poder executiu: tenia la reflexió, les idees i la paraula. Volia el diàleg, la pau, el respecte i el progrés. Tenia la força de la raó. Si el seu assassinat, a part d'atemptar contra la seva vida, pretenia atemptar contra la seva força, no els ha servit per a res. Al contrari. Cap de les morts d'ETA ja no serveix de res, però l'assassinat d'Ernest Lluch contribueix precisament a amplificar les seves idees, a reforçar-les més que mai, tant entre els seus partidaris com entre els qui hi discrepaven. Aquesta és la gran diferència entre la raó i la intolerància: la raó no mor mai (...) dediquem la portada d'aquesta setmana a la seva aportació i a les idees que defensava, a l'herència que ens ha deixat $»^{20}$.

A banda de la condemna a l'atemptat, queda clar que la personalitat d'Ernest Lluch era prou valorada per El Temps.

Davall d'esta petita columna del director dedicada als lectors, trobem un article d'un seguidor d'El Temps titulat «Coincidències» i signat per Jordi Casals, de Balaguer, capital de la comarca ilerdenca de Noguera.

«És esgarrifós veure la demagògia amb què el PP criminalitza el PNB i EA per la seua coincidència en objectius amb ETA. O són uns totals ignorants o són els polítics més vils i maquiavèl.lics que poden existir; (...) el PNB i EA posen com a última instància de decisió al poble basc en un plebiscit en exercici del dret a l'autodeterminació on tothom podria votar, els qui estan a favor i els qui estan en contra. Els altres no» ${ }^{21}$.

Si l'article del director anava més dedicat a la personalitat d'Ernest Lluch, este apunta més cap a la "responsabilitat" del govern del PP i la seua "incapacitat" per resoldre el conflicte. Estos dos articles són, llavors, dos resums de l'editorial, que al cap i a la fi apunta cap a estes dues qüestions: l'estima personal cap a la víctima i la responsabilitat política del fet, així com també la condemna a ETA.

A la pàgina 10 del número 859 d'El Temps tornem a trobar referències a la mort d'Ernest Lluch, dins de la secció de 'La Setmana', a l'apartat de 'La crònica', on trobem un total de sis notícies, dos d'elles dedicades al nostre tema central. Destaca a la pàgina el titular «Seny i soroll en l'adéu a Ernest Lluch ${ }^{22}$.

20. Ibid., p. 6.

21. Ibid.

22. Ibid., p. 10. 
Sota el titular de «Dimarts, 21», trobem la notícia de l'assassinat d'Ernest Lluch, on després de contar molt breument els fets, fa referència a la personalitat del protagonista:

«La participació de Lluch en molts i molts diversos camps de la vida social, política i cultural del país crea un rebuig generalitzat a l'atemptat que culmina en la manifestació de dijous» ${ }^{23}$.

I continua amb una conseqüència de l'assassinat:

«El seguiment informatiu de l'atemptat per part de la Televisió de Catalunya -molt criticat- provocà, dijous, la dimissió del cap d'informatius de TV3, Josep Maria Torrent $»^{24}$.

Altres mitjans de comunicació, com podem comprovar a la web www.laxarxa.com, expliquen este fet: «La cobertura informativa que va fer TV3 la nit que van assassinar Ernest Lluch, forçava la dimissió de l'aleshores cap d'informatius de la televisió autonòmica, Josep Maria Torrent. La descoordinació en aquell moment, el fet de proseguir amb l'emissió enregistrada -el programa 'La cosa nostra' d'Andreu Buenafuente-i programar després una pel.lícula, va ser la raó per la qual TV3 va ser objecte de dures crítiques [sic] $\gg^{25}$.

El reconegut diari privat de difusió estatal, El País, també va anunciar este fet en la seua edició del 25 de novembre de l'any 2000, quatre dies després de l'assassinat. Sota el titular «El director de TV-3 admite que la cobertura del atentado a Lluch fue "inadecuada"», qualifica el seguiment de l'atemptat com a «pèssim» $\mathrm{i}$ «pobre», entre altres adjectius negatius ${ }^{26}$.

Tornant al número 859 d'El Temps, a la mateixa pàgina 10 trobem una petita crònica de la manifestació que es va celebrar a Barcelona per rebutjar l'assassinat i a la vegada retre homenatge a Lluch. Titulat «Silenci i soroll», insisteix en la responsabilitat del govern d'Aznar d'intervenir en el conflicte i critica la seua actitud:

«La paraula diàleg, que havia estat protagonista en els actes d'homenatge a Lluch que el dimecres li havien fet a la Universitat de Barcelona, la de València i el PSC, és també protagonista d'aquest acte i així ho destaca la periodista Gemma Nierga en el parlament que clou l'acte: "Ho dic en castellà perquè tots absolutament ho entenguin: Ernest Lluch hagués dialogat fins i tot amb qui

23. Ibid.

24. Ibid.

25. La notícia es troba al següent enllaç: <http://www.laxarxa.com/noticia/dimitia-el-cap-dinformatius-de-tv3-per-la-cobertura-de-l-assassinat-d-ernest-lluch> [consultat: 30-I-2014].

26. La notícia es troba al següent enllaç: <http://elpais.com/diario/2000/11/25/catalunya/ 975118049_850215.html> [consultat: 30-I-2014]. 
el va matar, vosaltres que poden, dialoguin si us plau". Aquestes paraules provoquen més soroll que el milió de manifestants: Aznar es mostra gairebé ofès, el PP recorda que no dialoga amb els que dialoguen amb ETA i El Mundo veu una obscura conxorxa del grup Prisa (editor d'El País i la Cadena SER) en contuberni amb el PSOE i vehiculada a través de la Nierga, que treballa a la SER. Dos no s'entenen si un no vol» ${ }^{27}$.

I a la pàgina següent trobem una imatge de l'esmentada manifestació.

I és que la política d'Aznar en matèria antiterrorista va ser famosa per la seua "duresa" i la seua "intransigència". Gran part de l'esquerra nacionalista o del nacionalisme en general criticaria la política d'Aznar i del seu ministre de l'interior Jaime Mayor Oreja en la seua particular lluita contra el terrorisme $e^{28}$.

A la pàgina 13 del mateix número, Toni Cañís escriu una columna titulada «El meu Ernest Lluch». El defineix com «un dels economistes més importants que ha donat el segle XX, amb una permanent mixtura de conviccions democràtiques i de risc per fer valdre la idea del diàleg. Això últim crec que li ha costat la vida» ${ }^{29}$.

A més d'esta definició, trobem elogis a la seua persona, la seua intel-ligència i el seu pensament:

«Obert, amb un tarannà exquisit en les formes. Disposat a sentir sempre les raons de l'adversari i, en el sentit més noble de la paraula, un demòcrata (...) [amb] una enorme vocació d'historiador del pensament econòmic, reflectit en la tesi La via valenciana i altres treballs continuats d'estructura i de política econòmica» ${ }^{30}$.

Per trobar més referències al tema que tractem dins del número 859 d'El Temps avancem fins la pàgina 17 , on trobem un article a mitja pàgina escrit per Pere Martí i que titula «Lúltima lliçó de Lluch», on es torna a fer referència a la "voluntat dialogant" de la víctima:

«Ernest Lluch va ser assassinat per defensar el mateix que defensava Arnaldo Otegi fins fa un any, just abans que finalitzés la treva d'ETA. És a dir, defensava una sortida dialogada al conflicte basc mitjançant una negociació política sense límits ni exclusions. Per la mateixa raó que va matar a Lluch, ETA hauria de matar també a Otegi. Però potser ja no cal, perquè Otegi, o allò que representava com a esperança de pau, sembla mort» ${ }^{31}$.

27. El Temps, Número 859, 28-4/XI-XII/2000, p. 10.

28. Per conèixer millor la política interior del govern d'Aznar, cf. TUSELL, Javier., El Aznarato: El gobierno del Partido Popular 1996-2003, Santillana, 2004, pp. 144-145.

29. El Temps, Número 859, 28-4/XI-XII/2000, p. 11.

30. Ibid.

31. Ibid., p. 17. 
Com pot comprovar-se, per primera vegada en este número es carrega també contra qui era el màxim representant polític de l'esquerra abertzale, Arnaldo Otegi, que en aquell moment era membre del Parlament basc i parlamentari de la mesa nacional d'Herri Batasuna. Més tard va ser jutjat i empresonat per vinculació amb ETA ${ }^{32}$.

La crítica a ETA i a l'esquerra abertzale continua a l'article de Martí:

«La reacció que va tenir la societat catalana davant l'assassinat de Lluch hauria de fer reflexionar a tota l'esquerra abertzale i en particular a ETA» ${ }^{33}$.

Potser sense voler ${ }^{34}$, l'autor relaciona directament a l'esquerra abertzale amb ETA, motiu pel qual posteriorment, per via política i judicial, seria il.legalitzat tot l'entramat polític, econòmic i social abertzale ${ }^{35}$.

«Va ser una reacció d'indignació que només té un precedent, la que va seguir al brutal atemptat d'Hipercor. En aquella ocasió, ETA va fer autocrítica i a pilota passada va reconèixer que l'havia vessada. Pel que s'ha vist, no va servir de res. La continua vessant, i curiosament sempre a Catalunya, en una ingerència injustificable. A Euskadi, mai han posat un cotxe bomba a l'aparcament d'un supermercat. Aquí, sí. A Euskadi no han matat mai -per ara- a un militant d'Elkarri ${ }^{36}$. Aquí sí. I ho fa en un dels paiisos que tradicionalment ha mostrat més comprensió i més solidaritat envers Euskadi» ${ }^{37}$.

Una vegada més, es discrepa del mètode d'ETA, tot i que es mostra un paral-lelisme ideològic amb la banda i el seu entorn polític. Tot i aixina, la condemna és clara. I la crítica al govern d'Aznar, també:

«Ernest Lluch era un català solidari amb el País Basc, un militant d'Elkarri, una organització pacifista sincera, que treballa per trobar una solució política a un conflicte polític. Els seus articles a la premsa desafiaven el pensament únic que el govern de José María Aznar ha instaurat en matèria antiterrorista. Els espanyolistes camuflats de pacifistes dins del Foro d'Ermua el perseguien,

32. Per consultar el procés jurídic i parlamentari pel qual va ser il.legalitzat el partit Herri Batasuna i formacions polítiques posteriors relacionades amb el partit esmentat, cf. ESPARZA OROZ, Miguel., La ilegalización de Batasuna: el nuevo régimen jurídico de los partidos políticos, Aranzadi, 2004, pp. 275-304.

33. El Temps, Número 859, 28-4/XI-XII/2000, p. 17.

34. Visió personal i pròpia.

35. Per consultar el procés polític i judicial contra Herri Batasuna i l'entorn abertzale, cf. ZALLO, Ramón., El país de los vascos: desde los sucesos de Ermua al segundo gobierno de Ibarretxe, Fundamentos, 2001, pp. 37-47.

36. Elkarri, «Movimiento social por el diálogo y el acuerdo», tracta de trobar una solució pacífica i dialogada del conflicte basc. S'autodefineixen com a «organización plural e independiente». Font: <http://www.elkarri.org> [consultat: 30-1-2014].

37. El Temps, Número 859, 28-4/XI-XII/2000, p. 17. 
l'insultaven i l'acusaven de ser pròxim a ETA. Tan pròxim que va morir per les seves bales $[$ sic $] »^{38}$.

A partir de la pàgina 20 ens trobem amb onze pàgines seguides dedicades a Ernest Lluch. Les tres primeres ${ }^{39}$ estan dins de la secció de 'Portada' i estan encapçalades pel titular «Un valencià compulsiu». Estes tres pàgines analitzen la vida d'Ernest Lluch a València, quan va ser veí de la capital del Túria entre 1969 i 1977, on va exercir de professor universitari i també es va moure en política, i «s'abocà de ple a l'estudi i la transformació del País Valencià» ${ }^{40}$. El reportatge destaca molt l'activitat intel-lectual d'Ernest Lluch:

«La via valenciana, el llibre amb què va guanyar el Premi Joan Fuster d'assaig dels Octubre de l'any 1975, (...) quan faltaven poques setmanes perquè el "parte médico habitual" comunicara la mort del dictador. El rebombori i la discussió provocada per aquesta obra va ser considerable. Lluch rebatia en aquest llibre algunes de les tesis econòmiques de Fuster. Després d'evidenciar la importància de l'assagista de Sueca ("Fuster separa la prehistòria de la història al País Valencià", escrivia), es disposava a rebatre algunes de les tesis econòmiques incloses a Nosaltres els valencians. Les tesis de Fuster descrivien un país de mentalitat agrària basat en l'economia del camp quan, segons Lluch, l'esclat econòmic de començaments dels 60 ja havia fet del País Valencià una societat industrial. Aquesta controvèrsia encara perdura. Al moment mateix de la seua mort, Lluch encara s'endinsava en les entranyes de les tesis econòmiques del pensador de Sueca en articles publicats a El País» ${ }^{41}$.

Com es pot comprovar, El Temps valorava molt l'herència intel-lectual i acadèmica que va deixar Ernest Lluch. També valoren l'herència política, doncs tal i com es comenta al reportatge, Lluch va ser un dels fundadors del PSPV ${ }^{42}$, absorbit posteriorment pel PSOE ${ }^{43}$. Pérez Benlloch, un dels seus companys polítics a València, comenta l'aportació de Lluch a la política valenciana:

«Amb Ernest Lluch -diu Benlloch- va arribar a València la professionalització de la política ${ }^{44}$. Ell plantejava reunions llargues, d'anàlisi de temes en profun-

38. Ibid.

39. Ibid., pp. 20, 21 i 22.

40. Ibid., p. 20

41. Ibid., p.21.

42. Ibid.

43. Ibid., p. 22. Alfons Cucó explica com el PSPV va abandonar les seues tesis nacionalistes per ser integrat finalment al PSOE centralista. cf. CUCÓ, Alfons, Roig i blau: La transició democràtica valenciana, Tàndem, 2002, p. 158. Els principis del PSPV previs a la seua integració amb el PSOE són clarament nacionalistes i catalanistes, cf. CUCÓ, Alfons, GARCÉs, Vicent, juan, Empar i SANCGIS, Josep, Partit Socialista del País Valencià, Tres Quatre, 1977, p. 63.

44. Per estudiar més encara la relació de Lluch amb la política valenciana durant les acaballes del franquisme, cf. PASCUET, Rafael, EntreLluchs: una aproximació empordanesa a 
ditat, que eren coses que ací no es feien. Era una persona molt preparada, molt dialogant. Tirava sempre cap a casa, però des del diàleg» ${ }^{45}$.

«El treball polític de Lluch va saltar a la llum el 24 de juny del 1975, quan era detingut en una casa d'exercicis espirituals d'Alaquàs ${ }^{46}$ (l'Horta) juntament amb nou representants més de les forces opositores al règim. Enguany es va commemorar el vint-i-cinc aniversari de la detenció dels qui van ser coneguts com els deu d'Alaquàs» ${ }^{47}$.

També s'arrepleguen testimonis d'Alfons Cucó:

«Contribuí políticament a introduir elements de racionalitat. La vida socialista no existia. Havia mort el PSV i no havien eixit a la llum altres partits. Havia impulsat la unió a través de convergència socialista. Va marcar el pas de la visceralitat a la racionalitat. Procedia d'un món més madur, que era el de Barcelona ${ }^{48}$.

Lhomenatge continua a la pàgina 23 amb una entrevista a l'historiador Josep Fontana, «amic i colega d'Ernest Lluch» ${ }^{49}$. L'entrevista, que ocupa quatre pàgines i a la que després es suma el també historiador Joaquim Albereda, duu com a titular «L'Ernest no només era incòmode per a un bàndol» i la signa Enric Rimbau. Fontana destaca també la personalitat del protagonista, així com la seua aportació com a historiador i la seua activitat intel-lectual, de la que Josep Fontana semblava estar-ne més que satisfet. D'esta forma mostra el seu costat més intel-lectual i acadèmic:

«Al marge de la línia de treball sobre història del pensament econòmic, a la qual ja havia fet diverses contribucions, el gran tema de debat en què ara estàvem implicats -amb Joaquim Albereda i d'altres- era la revisió del que havia significat la guerra de Successió, la pèrdua de les llibertats i la mena de societat que havia sortit de tot això. Ell havia fet La Catalunya vençuda del segle XVIII. Després va obrir una mica més les seves tesis, per mostrar que no només havia estat Catalunya on hi havia unes opcions perdudes, en la versió castellana, Las Españas vencidas ${ }^{50}$.

«Tot plegat intentava mostrar una cosa important: aquí hi havia hagut una societat que avançava cap a un camí de modernització amb un projecte de govern representatiu -que no vol dir democràtic- com els que hi havia a

Ernest Lluch, $1^{a}$ ed., El Brau, 2001, p. 95. Capítol «Lluch i el País Valencià», escrit per Vicent Soler, Catedràtic d'Economia Aplicada de la Universitat de València.

45. El Temps, Número 859, 28-4/XI-XII/2000, p. 22.

46. Per conèixer el succés de "Els deu d'Alaquàs", cf. SANTACReu SOLER, José Miguel i GARCía ANDreu, Mariano, La transició democràtica al País Valencià, La Xara, 2002, pp. 15-16

47. El Temps, Número 859, 28-4/XI-XII/2000, p. 22.

48. Ibid.

49. Ibid., p. 23.

50. Ibid. 
Anglaterra o Holanda, que fou derrotat el 1714 per l'absolutisme dels Borbons. Això trenca el mite acadèmic habitual que sosté que la modernització va arribar amb els Borbons. Ell, justament ara, volia anar a un Congrés a Saragossa per discutir aquesta imatge postissa de Felip V, de primer rei il.lustrat, etc. $»^{51}$.

Si altres pàgines mostraven el costat més humà i més polític d'Ernest Lluch, Fontana mostra la seua llavor intel-lectual per damunt de tot. En l'aspecte polític, però, Josep Fontana dóna una valoració similar a la d'El Temps en el que es refereix al conflicte basc:

«No sé què li convé a ETA. Tampoc sé que és el que més li convé al PP. Als uns $i$ als altres sembla que els convingui un escenari proper al caos per sortir per un o l'altre camí. És evident que per al PP una situació insostenible per al PNB és propícia per obtindre el que ells volen, és a dir, el poder al País Basc i deixar la solució del terrorisme en mans de policia i exèrcit. Des del punt de vista d'ETA, un amic meu em comentava que el que busquen és senzillament una persona que doni titulars. Matar Ernest Lluch és primera plana a la premsa internacional. I és la manera amb què ETA fa una manifestació de força, que es pot permetre el luxe de fer una com aquesta» ${ }^{52}$.

A la mateixa pàgina 25, on continua l'entrevista a Josep Fontana, trobem a mitja pàgina un article escrit per Lluís Bonada, titulat «La darrera intervenció», on parla de l'última vegada que Lluch va convocar la premsa i on torna a destacar els seus dos costats que més destaquen en este número d'El Temps, l'humà i l'intel-lectual:

«Amb el senyor Lluch compartíem l'interès per algunes coses. Molta gent compartia amb ell l'interès per les més variades coses. Però era ell el que semblava interessat en les teves i per això despertava tanta estimació. La conversa, com la que ens va ajudar a passar l'estona en un tranquil partit jugat al Camp Nou entre els seus dos equips, Barça i Real Sociedad, basculà amb tota naturalitat entre l'intercanvi de la xafarderia més sarcàstica i l'intercanvi del detall més erudit, en el nostre cas, del món literari» ${ }^{53}$.

L'entrevista acaba amb una declaració de Joaquim Albereda que va molt relacionada amb la línia editorial d'El Temps:

«Cal recordar a la gent, no ens enganyem, que les amenaces contra les quals lluitava l'Ernest no vénen només d'una banda. En la lluita contra la intolerància no només és ETA a qui cal combatre. ETA mata, evidentment, però part de la duresa de la situació ve també de l'altre cantó» ${ }^{54}$.

51. Ibid., pp. 23 i 24.

52. Ibid., p. 25.

53. Ibid.

54. Ibid., p. 26. 
Una vegada més, la condemna es dirigeix tant cap a ETA com cap a l'actitud del govern d'Aznar.

Les quatre pàgines consecutives mostren un article d'Ernest Lluch que va redactar per la revista Pasajes ${ }^{55}$, de la Universitat de València, on el protagonista analitzava el llibre 'España, la evolución de la identidad nacional', de Juan Pablo Fusi. Sota el títol «L'Espanya del basco-espanyolisme segons Fusi ${ }^{56}$, El Temps reflexa l'article d'Ernest Lluch a quatre pàgines per finalitzar l'homenatge que este número 859 li dedica a l'exministre.

A l'article, s'observa certa discrepància de Lluch cap al nacionalisme espanyol de Fusi, cosa per la qual, potser El Temps reflectia este text, per tal de mostrar la cara menys "centralista" d'Ernest Lluch, cosa que, de forma indirecta, faria més inexplicable encara el seu assassinat per part d'una banda armada independentista.

«Fusi, insistim, en la seva versió més suau, situa sense cap dubte Espanya com una nació i els seus components com a regions. Fins i tot abusa de l'ús constitucional de la paraula "regió" o "regional" (...) Aquest costum el porta fins a tal punt que no utilitza la paraula, també constitucional, "nacionalitat". D'aquesta manera, s'arriba a la conclusió, si es camina de la mà de Fusi, que la Constitució espanyola utilitza la paraula "nacionalitat" debades o que li molesta que el terme aparegui en el text. Això podria donar la impressió que la Constitució diu inutilitats. D'altra banda s'ha de recordar que els estatuts d'autonomia formen part del "bloc de constitucionalitat", per la qual cosa amb Fusi es pot arribar a la conclusió que hi ha un lliscament cap a l'exterior de la Constitució espanyola $»^{57}$.

És paradoxal com Lluch critica Fusi pel seu "dramatisme" cap a la situació que poden provocar els nacionalismes a Espanya. Paradoxal perquè Fusi fa comparacions de les quals Lluch es sorprèn i a les quals lleva ferro, ironitzant fins i tot amb elles i pocs mesos després, Lluch seria assassinat pels enemics d'aquells que ell mateix criticava:

«Els temors de Fusi davant l'aplicació autonòmica de la Constitució espanyola són tan greus que pensa que "la possibilitat d'una 'balcanització' del país, una expressió que s'utilitzà en aquell moment, era, doncs, real ${ }^{58}$ (p. 270). Ni

55. Pasajes, V-VIII/2000, segons assegura El Temps, Número 859, 28-4/XI-XII/2000, p. 27.

56. El Temps, Número 859, 28-4/XI-XII/2000, pp. 27-30.

57. Ibid., p. 28.

58. Les paraules exactes de Juan Pablo Fusi són: «En abril de 1979, una mayoría de ayuntamientos de Cantabria se habrían pronunciado, a iniciativa del de Cabezón de la Sal, por separarse de Castilla y León e iniciar los trámites para constituirse en autonomía uniprovincial; los municipios de La Rioja, liderados por Logroño, hicieron lo mismo en octubre. Nadie sabía muy bien el tipo de Estado que resultaría una vez concluido un pro- 
els nefasts assassinats d'ETA que han servit per alimentar a bastament el nacionalisme espanyol contemporani recorden drames com els que s'han viscut i he viscut als Balcans. Un dels drames que els "austro-hongaresos" sentim un poc més en la nostra sensibilitat i que per això no els confonem amb un desordre en la petició d'autonomies (Cantàbria, Lleó, Segòvia) que es va produir sobretot en allò que coneguérem com Regne de Lleó i Castella la Vella. Un desordre que si no es vol excitar els ànims no té res a veure, gràcies a Déu, amb una "balcanització" i sí amb el desig de mantenir les diputacions provincials. Els qui més al-ludiren a aquest dramatisme, i vaig sofrir algunes conseqüències personals per això, foren els qui van donar suport al colp d'estat de febrer de 1981. Fusi, molt allunyat d'aquests intents, com hem dit amb molta claredat, hauria de vigilar l'ús de termes dramàtics per no introduir confusions ${ }^{~}{ }^{59}$.

La paradoxa creix si arribem a pensar que estes paraules, llevant el qualificatiu de «nefasts assassinats d'ETA», podria haver-les signat qualsevol intel-lectual proper o militant a l'esquerra abertzale.

I per últim, a la pàgina 84 del número 859 d'El Temps s'inclou l'habitual tribuna de Joan F. Mira, a la seua secció 'El temps que corre'. Tot i que el seu article no parla de la temàtica que tractem, finalitza amb una curta frase que recorda Ernest Lluch:

«Han assassinat Ernest Lluch. Era un home bo, catalanista, valencianista, amic dels bascos. És un crim contra la nostra humanitat» ${ }^{60}$.

La condemna del setmanari a l'assassinat és òbvia. Ho demostren els articles, notícies i entrevistes esmentats. Com també és clar el total desacord amb la política antiterrorista del govern d'Aznar, que és criticat igualment.

\section{Les reaccions de Gara}

El diari basc Gara anunciava en portada l'assassinat d'Ernest Lluch un dia després dels fets, és a dir, el 22 de novembre de l'any 2000. El titular deia: «El ex ministro del PSOE ErnestLluch, muerto de dos disparos en Barcelona».

El subtítol matisa com va ser l'atemptat: «El atentado se produjo en el interior del parking de su domicilio familiar hacia las 22.00 horas de la noche».

La foto de portada no està relacionada amb el tema central del que parlem, doncs reflexa l'activitat de la Guàrdia Civil en un intent d'atemptat que

ceso autonómico que nacía indefinido y abierto: la posibilidad de una "balcanización" del país, una expresión que se utilizó por entonces, era, pues, real». FUSI, Juan Pablo., España, la evolución de la identidad nacional, Temas de Hoy, 2000, p. 270.

59. El Temps, Número 859, 28-4/XI-XII/2000, p. 29.

60. Ibid., p. 84. 
hi va haver contra la caserna de la benemèrita a la localitat basca d'Irun. Sota el peu de foto sí trobem una breu descripció dels fets que ens ocupen i relata com va ser mort l'exministre i les dades de com van fugir i van eliminar pistes els autors del fet, tot i que en cap moment s'utilitza la paraula ETA:

«El ex ministro socialista ErnestLluch fue muerto anoche en el parking de su domicilio en Barcelona de dos disparos en la cabeza. El atentado se produjo poco antes de las 22.00 horas, aunque el cadáver, oculto entre unos automóviles, no fue encontrado hasta hora y media después por un vecino de Lluch, que residía en el número 36 de la Avenida de Chile. Los autores del atentado habrían huido en un coche Ford Fiesta que fue explosionado poco después en un descampado situado a unos centenares de metros de la vivienda de Lluch. La noticia de la explosión del coche bomba fue conocida antes de la muerte de Lluch y en un principio se especuló con la posibilidad de que la explosión pudiera tener relación con un dirigente del Partido Popular en Catalunya que vive en las inmediaciones. Por la mañana, una granada impactó en el cuartel de la Guardia Civil de Irun» ${ }^{61}$.

A la pàgina 17 de l'edició esmentada amplien la notícia de la mort d'Ernest Lluch sota el titular «Muere el ex ministro Lluch de dos disparos en la cabeza». En esta ocasió sí que afegeixen foto del protagonista de la notícia, que s'inclou dins de la secció 'Euskal Herria'. El subtítol afegeix: «Su cadáver quedó oculto entre coches en el parking de su casa».

És l'única referència que trobem en esta edició ${ }^{62}$ de Gara a la mort de Lluch, ja que tot i anunciar-se en portada, li dediquen només part de la pàgina 17 , que també inclou part de la notícia que comença a la pàgina anterior, que explica l'atemptat de la caserna de la Guàrdia Civil a $\operatorname{Irun}^{63}$ i una altra notícia ${ }^{64}$ que ocupa la cinquena columna de la pàgina esmentada.

La notícia, que no duu signatura personal de cap periodista ${ }^{65}$, es dedica exclusivament, com la portada, a informar de l'atemptat, sempre matisant les fonts oficials que havien facilitat la informació al diari Gara i fa una breu descripció biogràfica del protagonista:

«Doctor en Ciencias Económicas por la Universidad de Barcelona, amplió estudios en la Universidad de La Sorbona de París y era profesor de Economía y especialista en Historia de las Doctrinas Económicas. Seguía siendo militante

61. Gara, 22/XI/2000, portada.

62. Gara, 22/XI/2000.

63. «Atentado contra la Guardia Civil en Irun. Una granada estalló en el acuartelamiento y una bomba fue explosionada por los artificieros».

64. «Gestoras critica la sintonía entre el Ministerio de Interior y Lakua».

65. Apareix com a autora la redacció de Donostia del diari Gara. 
del PSOE y estaba considerado como miembro del sector de este partido más proclive al entendimiento con el $\mathrm{PNV} »^{66}$.

Com s'ha mostrat anteriorment, en El Temps insisteixen en que la voluntat dialogant de Lluch s'estenia cap a ETA i l'esquerra abertzale, cosa que Gara no esmenta i es limita a una suposada voluntat d'entesa entre Lluch i el PNB.

La primera vegada que Gara escriu la paraula ETA relacionada amb este fet és a la mateixa pàgina 17 , dins de la pròpia notícia, quan diu:

«Las mismas fuentes informaron de que el coche tenía placas dobladas -correspondientes a la matrícula de otro vehículo- y todo apuntaba a una acción de ETA. Fuentes policiales también señalaron que se había tratado de un cochebomba ${ }^{67}$.

Dins d'esta mateixa notícia s'obri un apartat que sota el títol «Reunión en Ferraz» arreplega les reaccions del món de la política davant d'este atemptat, concretament les de PSOE, PP i CiU. Ací sí es fa referència a la voluntat dialogant de Lluch, tot i que ho fa des de les declaracions d'un polític, Ramón Jauregui ${ }^{68}$ :

«"ETA mata con la clara intencionalidad de desestabilizar", pero advirtió que "esta vez los terroristas han acabado con la vida de una persona cuyo proyecto y discurso eran nítidamente dialogantes" y "un precursor del entendimiento con el nacionalismo vasco democrático para acabar con ETA" ${ }^{69}$.

Com podem veure, les referències a l'assassinat d'Ernest Lluch un dia després dels fets, al diari Gara ocupen part de la portada i només la major part d'una pàgina interior, tractant la notícia d'una manera totalment informativa, sense entrar en cap tipus de valoració.

A l'edició del dia següent, del 23 de novembre de l'any 2000, dos dies després de l'atemptat que acabà amb la vida d'Ernest Lluch, Gara dedica part de la seua portada al fet que ens ocupa, tot i que no és el titular principal de la portada $^{70}$, sino que apareix en segona plana, davall del tot, en euskera. El titular traduit seria: «L'expresident Felipe González afirma que Lluch era una persona de diàleg ${ }^{71}$.

Esta vegada sí fan més referència a la voluntat dialogant de Lluch, tot i que també des de les declaracions polítiques:

66. Gara, 22/XI/2000, p. 17.

67. Ibid.

68. Qui llavors era diputat del PSOE a les Corts espanyoles per Àlaba.

69. Gara, 22/XI/2000, p. 17.

70. El titular principal de la portada del Gara, 23/XI/2000, és «Garzón imputa a 19 personas en un auto que integra a AEK en ETA».

71. Traducció realitzada per Iudit Aguilar Leoz. 
«La referència al diàleg es va repetir més d'una vegada ahir. Així ho va fer Juan José Ibarretxe declarant "ell va defensar el diàleg". Segons Ibarretxe, "Ernest tenia molt més de respecte per Euskadi que aquells que el van matar". Ibarretxe es va dirigir a Euskal Herritarrok demanant "que reaccionés". Arnaldo Otegi, després de dir que Euskal Herritarrok no practica la lluita armada, va demanar al PNB que mostrés la validesa de la seua estratègia» ${ }^{72}$.

De la mateixa forma que a l'exemplar del dia anterior, esta notícia comparteix portada amb moltes altres ${ }^{73}$, a més de no ser la notícia més destacada de portada de l'edició del 23 de novembre de l'any 2000 al diari Gara, com s'ha assenyalat anteriorment.

Tot i tindre menys protagonisme a la portada, a l'edició del 23 de novembre li dediquen més lletres a l'assassinat d'Ernest Lluch en les pàgines interiors del diari Gara. Així, a la 16, dins de la secció 'Euskal Herria', trobem una notícia a tota pàgina que reflecteix les reaccions a l'atemptat i duu com a titular: «El recuerdo de la figura de Ernest Lluch marcó el XXV aniversario de la coronación del Rey español».

La notícia no la signa cap persona en concret $^{74}$. Una vegada més, s'arrepleguen testimonis dels polítics en l'acte que va servir com a homenatge a la víctima i només s'escriu la paraula ETA quan la pronuncien els testimonis, no directament des del periodista de Gara que redacta esta notícia ${ }^{75}$.

La primera pàgina sencera que dedica Gara a la mort d'Ernest Lluch després del seu assassinat és la número 17 de l'edició del 23 de novembre de l'any 2000. Encara a la secció 'Euskal Herria', trobem una declaració de Felipe Gon-

\section{Ibid.}

73. Llevat del titular principal de la portada, referenciat anteriorment, les altres notícies que comparteixen primera plana amb l'assassinat d'Ernest Lluch al diari Gara, 23/XI/2000, són les següents: «Detectado por primera vez el mal de las vacas locas en el Estado español»; «La caída anual que acumula el Ibex 35 supera ya el 20\%»; «PNV y EA excluyen a $\mathrm{EH}$ y $\mathrm{AB}$ en Udalbiltza»; «Prohibidas las tractoradas de EHNE en Nafarroa»; «Israel bombardea Gaza y explota un coche-bomba en Tel Aviv»; «Enfado de Bush tras el fallo del Supremo de Florida»; «El Congreso de Perú nombra presidente a Valentín Paniagua»; i «Las novedades en euskara aumentan en Durango».

74. Apareix com a autora la redacció de Madrid-Barcelona de Gara.

75. Exemples: «El president retomó las palabras del rey para explicar por qué considera que "faltan y sobran palabras para condenar a ETA: faltan porque la condena de este hecho es bárbara y se necesitaría un largo, sentido y duro discurso, pero por otro lado, sobran palabras porque la magnitud de la barbarie y del hecho hablan por sí solos"»; «El secretario general del PP, Javier Arenas, interpretó, por su parte, el atentado contra Lluch como "un intento de empañar" la celebración del aniversario de la entronización del Rey. También la ex ministra del PSOE Cristina Alberdi comentó que ETA "ha golpeado en un día especialmente significativo"»; «Más conciso fue el líder del PSC, Pasqual Maragall, en sus declaraciones tras una concentración celebrada al mediodía en Barcelona, cuando afirmó que Lluch era consciente de que podía morir en una acción de ETA». 
zález que serveix com a titular i on es pot llegir «Prefería el diálogo a la dialéctica de las pistolas». Esta notícia tampoc està signada per cap persona en concret $^{76} \mathrm{i}$ torna a arreplegar testimonis dels polítics, sense afegir cap element valoratiu propi del diari.

És en esta pàgina quan per primera vegada Gara utilitza el terme "assassinat" i fa referència a la "voluntat negociadora" de Lluch amb ETA, tot i que ho fa des de la recollida de testimonis i no de manera directa, és a dir, no des de les valoracions pròpies del diari basc:

«Almunia también expresó, tal como reiterarían a lo largo de la jornada otros representantes de su partido, que "el mejor homenaje que podemos hacer a Ernest Lluch es defender con tenacidad las ideas, defenderlas en libertad creyendo profundamente en la democracia y diciéndole a ese grupo de asesinos que nosotros somos más fuertes que ellos» ${ }^{77}$.

«La ex secretaria de Estado, Margarita Robles, aseguró que la muerte en atentado de Ernest Lluch demuestra que, "como en el caso del ex gobernador civil de Gipuzkoa, Juan María Jauregi, la estrategia de ETA es romper los puentes que se tienden entre nacionalistas y no nacionalistas". "Los dos apostaban por la línea del diálogo y eran fervientes partidarios de negociar con ETA", destacó la representante del Foro de Madrid $»^{78}$.

A la mateixa pàgina 17 , trobem un apartat petit titulat «Defensor del retorno jeltzale» ${ }^{79}$, on podem observar un obituari de Lluch amb les seues dades biogràfiques i recorda un article que va escriure el 19 d'octubre a La Vanguardia, és a dir, un mes abans de la seua mort:

«No cejaré hasta que el nacionalismo vasco democrático entre a formar parte del bloque constitucional a través de la fórmula de derechos históricos o de cualquier otro tipo de negociación $»^{80}$.

I abans de reflectir este pensament del protagonista, Gara matisa una vegada més que Lluch apostava «por el entendimiento con el $\mathrm{PNV} »^{81}$.

I la pàgina següent, la 18 del mateix número, també està dedicada per complet a l'assassinat d'Ernest Lluch. Un breu d'esta pàgina duu per títol «Más concentraciones», i anuncia les diverses celebracions en memòria de Lluch que van tindre lloc a Euskadi. Altre breu fa referència a algunes declaracions que es van fer des de la política basca sobre l'atemptat que va acabar amb la vida

76. Apareix com a autora la redacció de Madrid del diari Gara.

77. Gara, 23/XI/2000, p. 17.

78. Ibid.

79. Jeltzale es pot traduir al català com nacionalista.

80. Gara, 23/XI/2000, p. 17.

81. Ibid. 
de l'exministre, sota el títol «El Parlamento de Gasteiz opina que ETA no respeta la mayoría social». Precisament sota este breu, per primera vegada es qualifica de manera directa a Ernest Lluch com a "víctima":

«El Parlamento de Gasteiz, además de solidarizarse con la familia de la víctima y el partido político al que pertenecía, afirmó que "estos actos revelan incapacidad para defender por procedimientos democráticos unos determinados posicionamientos políticos" ${ }^{82}$.

Mai abans s'havia descrit Lluch com a tal. Però la notícia més destacada, almenys per l'espai que ocupa a la mateixa pàgina 18 de l'edició del 23 de novembre de l'any 2000, la redacta Carlos Oronda i està escrita en euskera. El titular reflexa una declaració del lehendakari Ibarretxe: «Lluch tenia molt més de respecte per Euskadi que ETA» ${ }^{83}$. La notícia únicament arreplega testimonis de Juan José Ibarretxe i es manté en la mateixa línia que la resta d'informacions que Gara va fer sobre l'assassinat d'Ernest Lluch un dia i dos dies després dels fets.

Al mateix número, ja a la pàgina 29 trobem la secció 'Iritzia' ${ }^{84} \mathrm{~A}$ la dreta de la pàgina trobem l'editorial, titulat «De la conmoción a la búsqueda de salidas». Larticle comença amb el lament del Gara per l'atemptat:

«Hoy es preciso lamentar la muerte de Ernestlluch y ante este tipo de acciones lo primero es mostrar condolencia con sus familiares y allegados $»^{85}$.

Com es pot veure, no existeix condemna cap a ETA, però sí "sentiment de dol" cap a la víctima i l'entorn. A continuació, reconeixen la figura de la víctima:

«Este atentado ha conmovido de forma muy especial a los sectores más diversos de la ciudadanía y a la clase política. A ello ha contribuido la trayectoria de la víctima, ministro del Gobierno de Felipe González en una etapa muy dura, entre los años 1982 y 1986, que desarrolló una intensa actividad intelectual y periodística y que, gracias a las tertulias radiofónicas o a los debates mantenidos a través de artículos de prensa, consiguió que la suya fuera una voz reconocible para amplios sectores de la sociedad vasca, voz que mantenía, en lo referido al conflicto entre EuskalHerria y el Estado, posiciones críticas ante la estrategia del Gobierno de José María Aznar, frente a la que defendía abrir puertas hacia el nacionalismo vasco democrático ${ }^{86}$.

Una vegada més, insisteixen en la voluntat de Lluch de pactar amb el PNV:

82. Ibid., p. 18.

83. Traducció realitzada per Iudit Aguilar Leoz.

84. Iritzia es pot traduir al català com opinió.

85. Gara, 23/XI/2000, p. 29.

86. Ibid. 
«Ernest Lluch, firme defensor del acuerdo entre PNV y PSOE en la CAV, es la última víctima de una escalada sin precedentes de ETA ${ }^{87}$.

Gara critica al govern d'Aznar, però no la banda armada, com podem comprovar a continuació, quan afirma que l'atemptat:

«(...) coloca sobre la mesa todos y cada uno de los elementos que definen el momento actual de la confrontación, desde las exigencias de condena hasta las demandas de una solución dialogada, pasando por la crudeza del Gobierno español al negar la legitimidad a un proceso soberanista en clave democrática y por los grados de confusión y rechazo que generan las acciones violentas ${ }^{88}$.

Sense demanar cap rectificació a ETA, sense exigir cap canvi a la banda i sense condemnar l'acció, l'editorial de Gara conclou que:

«Nos encontramos ante un conflicto que dura décadas, con expresiones durísimas por todas partes, y que hace tiempo que debía estar resuelto en el marco de una Europa democrática» ${ }^{89}$.

A més, demana diàleg, negociació, racionalitat política i solucions. És a dir, la crítica és major cap al govern i només en un moment equipara les accions d'ETA amb les del govern, quan podem trobar la màxima "crítica" cap a la banda terrorista, esmentant les «expresiones durísimas por todas partes ${ }^{90}$, referint-se, segurament, a la "responsabilitat" dels dos bàndols (govern espanyol i ETA) en el conflicte.

A la mateixa pàgina 29 de l'edició esmentada anteriorment trobem altre article d'opinió dins d'una secció anomenada "Paperezko Lupa"91, on Maite Soroa escrivia a diari la seua tribuna d'opinió. En esta edició, la seua columna duu per títol «El atentado contra Lluch». Analitza com va tractar la premsa privada de difusió estatal esta notícia amb certa sàtira:

«La prensa de ayer, como el país en general, no estaba para bromas. El atentado que costó la vida a Ernest Lluch monopolizaba el espacio dedicado a la opinión y a los grandes titulares en las segundas y terceras ediciones de los diarios, que en mucho casos se vieron obligados a cambiar a toda prisa los contenidos fundamentales y, en algunos casos, sus artículos doctrinales» ${ }^{92}$.

Es pot observar una vegada més la crítica a tot allò que no fóra l'atemptat. Un exemple d'esta crítica és:

87. Ibid.

88. Ibid

89. Ibid

90. Ibid.

91. Paperezko Lupa es pot traduir al català com Lupa Paper.

92. Gara,23/XI/2000, p. 29. 
«Desde el otro vértice de la prensa, $A B C$ determinaba que la clave del futuro inmediato está en la convocatoria de elecciones en la CAV y sentenciaba que "toca unidad entre los partidos, apoyo a la política del Gobierno, regeneración de la vida política vasca, actuación firme y coherente de los Tribunales de Justicia y toca -tantas cuantas veces sea necesaria- la movilización social. A la espera de que el PNV evite su suicidio". El suicidio que vaticina es, cómo no, la apuesta por un proceso soberanista en Euskal Herria ${ }^{93}$.

Gara sempre evita la crítica i la condemna a ETA i es decanta més per parlar de la responsabilitat del govern, dels seus altaveus mediàtics i dels polítics contraris als seus plantejaments.

\section{Les perspectives de Gara i El Temps des de la teoria de l'argumentació i del periodisme}

Segons Chaïm Perelman, «toda argumentación pretende la adhesión de los individuos y, por tanto, supone la existencia de un contacto intelectual ${ }^{94}$.

Si prenem esta frase com a exemple de la intencionalitat necessària que tota argumentació posseeix, podem comprendre que tant El Temps, com Gara, com qualsevol altre mitjà de comunicació, tenen la intencionalitat de captar la fidelitat de certs lectors. Això s'aconsegueix gràcies a la ideologia del diari, que capta al públic fidel a tal ideologia. En el cas d'El Temps, el seu públic objectiu són les persones d'esquerres i d'ideologia independentista catalana de tots els Paìsos Catalans. El públic de Gara seria la gent d'ideologia independentista basca, i també d'esquerres. Però, com hem vist en este article, hi ha una diferència fonamental entre ambdós mitjans de comunicació i per tant, segurament, també, entre els seus respectius públics o audiències.

Sembla que el nacionalisme basc d'esquerres està, en ocasions, vinculat a la lluita armada d'ETA. El seu principal mitjà escrit, Gara, no afavoreix ETA, però tampoc condemna les seues accions, pel que podem deduir que l'audiència de Gara tampoc castiga estos atemptats. El contrari passa a El Temps, que rebutja les accions violentes d'ETA, cosa que també segurament faran els lectors. D'esta manera, s'aconsegueix una concordança entre mitjà i públic, una fidelitat que explica molt bé Iñaki Gabilondo:

«Existe, con todo, otro segmento de personas: aquel que acude al periodismo con objeto de confirmar sus propios puntos de vista. Es casi como una misa que por la mañana -se oficia sobre todo por las mañanas-acoge a gente para concelebrar con los suyos el encuentro natural en el que comulga las verdades

93. Ibid.

94. PeRelman, Chaïm, Tratado de la argumentación: la nueva retórica, Gredos, 1989, p. 48. 
que ya sabe, pero que viene a reafirmar a través de los sacerdotes en los que ha depositado su confianza. De ahí sale, en consecuencia, más o menos fortalecido, como un cristiano tras la misa. Y éste es un fenómeno harto habitual en un país como España, donde las posiciones están muy polarizadas y se vive de manera muy agresiva la vida política y la vida pública. De ahí que la población requiera de esa droga para poder respirar en las hostiles realidades del enfrentamiento $»^{95}$.

Per tant, el periodisme viu de l'argumentació; l'argumentació, del convenciment; i el convenciment causa fidelitat. És este el motiu pel qual existeix premsa ideològica. Gent de dretes, d'esquerres, nacionalistes espanyols, bascos, catalans, etc. tenen el seus mitjans de comunicació als quals solen ser fidels perquè les argumentacions d'estos mitjans els resulten confortables, produint-se eixe sentiment d'identificació ideològica que reforça la personalitat política de cada persona.

Es este el motiu pel qual El Temps condemna ETA: la seua línia editorial no comparteix les accions terroristes de la banda, així com el seu públic, pel que transmet un missatge de rebuig cap al terrorisme. Pel seu compte, els lectors de Gara potser discrepen de les accions d'ETA o potser estiguen a favor, motius pel qual el diari basc no es pronuncia al respecte amb valoracions que ens ajuden a sentenciar si este mitjà està a favor o en contra del grup armat. En qualsevol cas, la visceralitat amb la que se viu la qüestió d'ETA a l'Estat espanyol i més encara al País Basc, dóna a entendre en moltes ocasions que, quan no es condemna rotundament la violència d'ETA, s'està a favor de la banda. La societat i el periodisme no solen admetre mitges tintes en este assumpte. És per això que Gara és considerat per una gran part del públic com a mitjà de comunicació proetarra, tot i que este diari mai s'ha definit com a tal ${ }^{96}$.

\section{Conclusions}

En el que respecta a la comparativa del tractament mediàtic entre Gara i El Temps sobre l'atemptat contra Ernest Lluch que li va causar la mort, podem extraure diverses consideracions.

Una són les portades que els dos diaris van dedicar al tema. Mentre que El Temps li va dedicar una emotiva portada on apareixia la seua foto i la seua sig-

95. GABILONDO, Iñaki, El fin de una época: sobre el oficio de contar las cosas, Barril \& Barral, 2011, p. 66.

96. Un exemple ho trobem en este enllaç on podem consultar la noticia de que Gara ha denunciat un periodista per vincular el mitjà de comunicació amb ETA <http://www.eitb. com/es/noticias/politica/detalle/2332498/gara--el-diario-inicia-proceso-judicial-inda-porinjurias/> [Consultat: 1-VII-2014] 
natura, anunciant també i de forma molt discreta un fascicle, Gara li va dedicar el principal titular de la portada el dia següent del seu assassinat, tot i que la notícia no va cobrir la portada sencera. En l'edició del 22 de novembre de l'any 2000, a banda de la mort d'Ernest Lluch, que, com s'ha dit, és la principal notícia de portada al diari, en primera plana també podem observar avanços d'altres notícies que es poden llegir dins del periòdic, com són unes declaracions del llavors lehendakari Juan José Ibarretxe ${ }^{97}$, un titular de temàtica econòmica ${ }^{98}$, un altre sobre Israel i Palestina ${ }^{99} \mathrm{i}$ altres breus que tracten sobre el Partit Socialista d'Euskadi ${ }^{100}$, Pepe Rei ${ }^{101}$, Periko Alonso ${ }^{102}$, Unió Europea ${ }^{103}$ i temàtica cultural ${ }^{104}$. A banda de l'esmentada anteriorment foto de portada, dedicada a l'atemptat contra la caserna de la Guàrdia Civil d'Irun.

Queda clar que, almenys, a priori, el tractament que El Temps li dóna a la notícia és d'emotivitat i serveix com a homenatge a la víctima, així com per condemnar tant als autors materials de la mort de $\mathrm{Lluch}^{105} \mathrm{com}$ al govern d'Aznar per interpretar que no vol o no sap resoldre el conflicte ${ }^{106}$. Gara, per la seua banda, en les seues portades ${ }^{107}$, es dedica única i exclusivament a informar sobre l'atemptat el dia següent d'este, sense incloure cap valoració directa, al igual que a les notícies de les pàgines interiors ${ }^{108}$.

Crida l'atenció també com a la pàgina 17 de Gara, de l'edició del 22 de novembre de l'any 2000, quan fan una petita biografia de Lluch, recalquen dues coses: una, que encara era militant del PSOE; i altra, que estava considerat com a una personalitat procliu a l'entesa amb el PNB. ${ }^{109}$ Crida l'atenció perquè la versió d'El Temps és ben distinta, especialment en l'últim aspecte descrit, ja que el setmanari catalanista insisteix moltes vegades en la voluntat de

97. «Ibarretxe plantea la mediación de Juan Carlos I en el conflicto».

98. «El salario social se quedará en doce pagas de 61.845 pesetas».

99. «Palestins i israelians, en camí de començar la guerra», original en euskera i traduït al català per Iudit Aguilar Leoz.

100. «El IV Congreso del PSE designará el candidato a lehendakari».

101. "Garzón confirma el procesamiento a Pepe Rei en el asunto "Egin"».

102. "Periko Alonso: "No me gusta hablar de herencias"».

103. «La UE da marcha atrás en el control del mal de las vacas locas».

104. «Les cançons més famoses de EtxabunIruri, recopilades en un disc». Original en euskera i traduït al català per Iudit Aguilar Leoz.

105. cf. El Temps, Número 859, 28-4/XI-XII/2000, p. 17, on Pere Martí escriu l'article «Lúltima lliçó de Lluch».

106. cf. El Temps, Número 859, 28-4/XI-XII/2000, p. 5, on està redactada l'editorial, titulada «Diàleg ja!».

107. cf. Gara, 22-23/XI/2000, portades.

108. Ibid.

109. cf. Gara, 23/XI/2000, p. 17. 
diàleg d'Ernest Lluch amb ETA i l'esquerra abertzale ${ }^{110}$, no amb el PNB, tal i com afirma Gara de forma, potser, intencionada.

Destaca també com mentre en El Temps recorren freqüentment al terme "assassinat", Gara no fa ús d'ell mai i utilitza el de "mort": «El ex ministro socialista Ernest Lluch fue muerto anoche en el parking de su domicilio en Barcelona de dos disparos en la cabeza» ${ }^{111}$; «Muere el ex ministro Lluch de dos disparos en la cabeza» ${ }^{112}$; «La celebración del XXV aniversario de la proclamación como Rey de Juan Carlos de Borbón se centró en el acto que tuvo lugar en el Congreso de los Diputados, ya que la recepción que iba a tener lugar por la tarde en el Palacio Real fue suspendida en señal de luto por la muerte en atentado de Ernest Lluch, ministro del Gobierno español entre 1982 y 1986» ${ }^{113}$.

La primera vegada que utilitza el terme "assassinat" és a través el testimoni d'un polític ${ }^{114}$, com s'ha mostrat en este article. El mateix ocorre amb la referència a la "voluntat dialogant" de Lluch amb ETA, que s'esmenta des del testimoni d'un polític ${ }^{115}$ i no des de les valoracions de Gara, com es comenta també a l'apartat quatre. En El Temps sí que recorren al terme "assassinat"116 i a la qüestió de la "voluntat dialogant"117 de Lluch amb ETA des de les valoracions pròpies del setmanari dels Països Catalans.

Cal destacar també com mentre que El Temps critica tant ETA com l'estratègia i l'actitud del govern d'Aznar, Gara es limita a desaprovar el govern i no condemnar ETA, tant a les notícies com als editorials ${ }^{118}$. Eixa és la diferència fonamental entre estos dos mitjans de comunicació, els dos nacionalistes i de tendència esquerrana, els dos amb pensaments independentistes, però que es diferencien en els mètodes per assolir les seues aspiracions polítiques: un condemna les accions d'ETA i l'altre no es pronuncia gaire al respecte d'estes accions i per tant, no les rebutja.

En definitiva, podem concloure que tant el tractament de Gara com d'El Temps a esta notícia que hem comentat, respon a una forma de comprendre la necessitat o no del mètode violent per assolir l'objectiu polític anhelat per

110. cf. El Temps, Número 859, 28-4/XI-XII/2000, p. 17, on Pere Martí escriu l'article «Lúltima lliçó de Lluch».

111. Gara, 22/XI/2000, portada.

112. Ibid., p. 17.

113. Gara, 23/XI/2000, p. 16.

114. cf. Gara, 23/XI/2000, p. 17.

115. Ibid.

116. Ho podem comprovar a El Temps, Número 859, 28-4/XI-XII/2000, p. 5, on s'escriu l'editorial del número, titulada «Diàleg ja!»

117. Un exemple de la voluntat de diàleg de Lluch ho trobem a El Temps, Número 859, 28-4/XI-XII/2000, p. 17, on Pere Martí escriu l'article «Lúltima lliçó de Lluch».

118. Consultar exemplar del Gara, 23/XI/2000, p. 29. 
ambdós mitjans: la independència política del seu territori "nacional". El Temps condemna la violència i Gara no es pronuncia al respecte, pel que no la condemna. I així, en conseqüència, cada mitjà publica el seu contingut.

El Temps li dedica tot un homenatge a Ernest Lluch. Destaca tots els seus valors públics i personals: la seua tasca acadèmica, política i intel-lectual. Tot són bones paraules en memòria de la víctima, tot i que, com hem vist, en dècades passades l'exministre va ser prou criticat pel setmanari catalanista. El record que deixa El Temps sobre Ernest Lluch és, indubtablement, grat, positiu i digne. A més, condemna els seus botxins i tota política que, segons este mitjà, ha fet possible l'assassinat.

Gara, per contra, no realitza cap homenatge. No deixa cap record especial de Lluch, només realitza una petita ressenya biogràfica i condemna l'actitud del govern d'Aznar, cosa que també fa El Temps. Però Gara no condemna la violència d'ETA i tampoc mostra especial afecte per la víctima, pel que el tractament de la notícia no li atorga a Lluch cap tipus de reconeixement per la seua llavor política, acadèmica i intel-lectual.

Per tant, amb este exemple, queda clar que El Temps rebutja la violència com a estratègia per assolir els seus objectius polítics. Tot i solidaritzar-se amb la qüestió nacionalista basca, condemna la violència i ret tribut a la víctima. Gara no condemna la violència, tot i que tampoc afirma afavorir-la. Així i tot, com hem explicat abans, la visceralitat de la qüestió duu a gran part de la societat a considerar proetarra tota actitud que no siga de condemna i rebuig cap a la banda terrorista. Gara i El Temps són dos mitjans de comunicació d'esquerra nacionalista que coincideixen en objectius, però no semblen coincidir en mètodes per aconseguir la fi política. Esta ha estat la raó per la qual han sigut seleccionats ambdós mitjans, per tal d'observar les diferències editorials entre dos mitjans homòlegs ideològicament, cadascú al seu territori, però antagònics envers les accions d'ETA. 

NOTAS BIBLIOGRÁFICAS

Y DE INVESTIGACIÓN

BIBLIOGRAPHICAL NOTES 



\title{
Las minas de Guelaya y la Guerra del Rif The Guelaya mines and the Rif War
}

\author{
Antonio Escudero \\ Universidad de Alicante
}

En el archivo del Quaid'Orsay de París he podido consultar la correspondencia que entre 1907 y 1909 mantuvieron el embajador francés en Madrid y su ministro de Asuntos Exteriores ${ }^{1}$. Aunque existe bibliografía sobre los acontecimientos que condujeron a la campaña de $1909^{2}$, la documentación de las cajas 88-95 (Affaires duRif) de la Correspondance politique et militaire posee una doble virtud: detalla esos acontecimientos y contribuye a esclarecer varios temas polémicos, razón por la que preparo un trabajo basado en esa correspondencia. Esta nota de investigación adelanta algunas de sus conclusiones. La he dividido en dos partes. En la primera, relato los sucesos que originaron la guerra y en la segunda utilizo la documentación para tratar dos temas controvertidos: el problema de las minas como desencadenante de la contienda y el papel que Alfonso XIII jugó en ella. La limitación de espacio que exige una nota de investigación me ha obligado a "comprimir" la primera parte y por la misma razón no he incluido notas a pie de página citando los documentos de donde proviene la información.

\section{Los sucesos que originaron la guerra}

En abril de 1904, Gran Bretaña y Francia firmaron un tratado por el que Egipto pasó a ser zona de influencia inglesa y Marruecos francesa con la condición de

1. Cuando consulté esa documentación, los archivos diplomáticos se hallaban en Quai d'Orsay. Luego fueron trasladados a esta dirección: 3 rue Suzanne Masson, 93126 La Courneuve (Noroeste de París).

2. Entre la bibliografía antigua, destaco los libros de Gallego (1909) y Maldonado (1949). Entre la publicada después, Stephane (1990) y Moga Romero (2010), pero especialmente Sáinz Varela (1999) y Madariaga (1999). 
que Francia reconociera una zona española que limitara su hegemonía al otro lado de Gibraltar. Unos meses más tarde, se firmó un convenio hispano francés por el que Yebala y Rif, regiones limítrofes con Ceuta y Melilla, pasaban a ser zonas de influencia española. Alemania no aceptó el acuerdo y obligó a convocar la conferencia de Algeciras de 1906. En ella se acordó mantener esas zonas de influencia, pero la diplomacia germana logró que se reconociera la libertad económica en Marruecos ${ }^{3}$. La explotación de su riqueza minera fue un asunto especialmente conflictivo que se pospuso hasta que un decreto del sultán determinara el régimen de concesiones ${ }^{4}$.

La política de puerta abierta animó a empresarios de varios países a comprar minas al sultán para obtener derechos de propiedad antes de que se publicara el decreto. Es el caso de los industriales siderometalúrgicos alemanes Reinhard y Max Mannesman, que poco después de celebrarse la conferencia, obtuvieron un firmán para la explotación de un gran número de concesiones en todo el imperio jerifiano. Sin embargo, en el Rif oriental gobernaba desde 1903 un rebelde que se hacía llamar El Roghi y empresarios franceses y españoles optaron por comprarle los criaderos de hierro y plomo cercanos a Melilla. La documentación del Quaid'Orsay informa de todo ello.

Un ingeniero francés ubicado en Argelia llamado Alexandre Baille y un oficial y explorador francés que colaboró con El Roghi llamado Gabriel Delbrel fueron los primeros en conseguir terrenos en las minas de Guelaya. Baille visitó a El Roghi en 1904 y obtuvo una concesión. También Delbrel logró otra que, sin embargo, fue revocada por El Roghi después de que aquél huyera de Zeluán acusado de ser agente del sultán. A principios de 1907, Baille traspasó su concesión al ingeniero francés Alfred Massenet, que en mayo de 1907 se entrevistó con El Roghi, pagándole 250.000 pesetas por los terrenos e iniciando poco después labores con dinero de inversores parisinos, ingleses y belgas. El comandante militar en Melilla general Marina lo comunicó a Madrid y el ministro de Estado Allendesalazar le ordenó que las obstaculizara, cosa que hizo negando visados a los técnicos franceses que debían desplazarse desde la ciudad a las minas. Massenet denunció el hecho ante el embajador francés en Madrid alegando que se vulneraba el acta de Algeciras y Allendesalazar propuso un acuerdo aceptado por París y por el ingeniero. El gobierno permitiría el laboreo si la empresa se domiciliaba en territorio español. Nació así la Compañía del Norte Africano, con sede social en Madrid, y en cuyo consejo de administración Massenet colocó a Antonio García Alix, antiguo ministro y ex gobernador del Banco de España.

3 La bibliografía sobre la Conferencia de Algeciras es abundante, de manera que me limito a recomendar las pp. 224- 345 del volumen 2 de la tesis de Estado de Delaunay publicada en 2010.

4. Este asunto está muy bien estudiado por Madariaga (1999), pp. 133-167. 
Un comerciante judío de Melilla proveedor de El Roghi informó de la riqueza minera de Guelaya a un empresario madrileño dedicado a la importación de carne marroquí llamado Clemente Fernández quien, a su vez, entró en contacto con el comerciante gaditano Enrique Macpherson, decidiendo ambos enviar al ingeniero Alfonso del Valle a inspeccionar la zona a principios de 1907. En junio de ese año, Fernández y Macpherson compraron a El Roghi minas de hierro limítrofes con las de Massenet. Según los servicios secretos franceses, el gobierno español subvencionó la operación con una importante cantidad. Poco más tarde, el conde de Romanones, que había enviado al Rif ingenieros para que inspeccionaran las minas y que tras su informe había comprado su concesión a Delbrel, ofreció a El Roghi 500.000 pesetas por ella. Éste no aceptó ya que esos terrenos eran los que había dado a Fernández y Macpherson, pero vendió a Romanones otros colindantes por 260.000 pesetas, ofreciéndose a mediar para que se creara una empresa española que explotara ambas concesiones. El ministro Alledesalazar también presionó para ello y en julio de 1908 se constituyó la Compañía Española de las Minas del Rif, cuyos principales accionistas eran Fernández, Macpherson, Romanones, su hermano el duque de Tovar y Juan Antonio Güell, tercer marqués de Comillas, que poseía negocios en la zona. El ex ministro Miguel de Villanueva -también con negocios en Melilla- fue nombrado presidente del consejo de administración.

La cesión de minas a extranjeros hizo que algunas cabilas comenzaran a cuestionar la autoridad de El Roghi y, en octubre de 1908, un grupo de rifeños atacó las instalaciones de la empresa española sin que hubiera víctimas. El Roghi los detuvo y castigó con dureza provocando con ello una rebelión que le obligó a huir en diciembre de ese año quedando la zona vacía de poder. El presidente del gobierno Antonio Maura ordenó entonces paralizar los trabajos de las dos compañías para consultar al sultán y a las tribus si podían mantener la seguridad en las minas. Alfonso Merry del Vall viajó a Fez y el sultán le hizo saber que lo haría si las tropas españolas abandonaban la Restinga y Cabo de Agua, indicándole además que la propiedad de las minas era discutible porque la había otorgado un rebelde. Ello no obstante, también le expresó su deseo de enviar una embajada a Madrid para tratar de llegar a un acuerdo. Por su parte, el general Marina se entrevistó con los jefes de las cabilas y comunicó a Madrid que existía división de opiniones entre quienes aceptaban la presencia extranjera porque creaba empleo y quienes se oponían a ella.

Las cartas y telegramas descifrados del embajador citan las personas y grupos que presionaron a Maura para que se reiniciaran las labores: el Rey, el ministro de la Guerra general Linares, el general Marina, Romanones, Villanueva, Güell, García Alix, la Cámara de Comercio de Melilla -interesada en que se 
restableciera el orden en la zona tras la huida de El Roghi-, la prensa del partido liberal, otra vinculada a oficiales y asociaciones africanistas y Massenet, que dio un golpe de efecto intentando llegar a las minas desde Argelia con una expedición de trabajadores indígenas de la tribu de los Guelaya, cosa que no logró por la oposición de otras cabilas. El 31 de mayo de 1909, el embajador francés escribía a su ministro: "Me dice Allendesalazar que por presiones del grupo de la Rif el gobierno ha decidido autorizar a las dos compañías a continuar labores". Un mes más tarde, la Compañía del Rif y la del Norte Africano reiniciaron la construcción de sus ferrocarriles y el 9 de julio rifeños armados atacaron sus instalaciones asesinando a varios obreros de la empresa española. El general Marina respondió bombardeando Nador y comenzó la primera campaña de una guerra que se saldó con más de 20.000 muertos; costó al erario público una enorme suma y marcó profundamente nuestra historia al provocar la Semana Trágica, influir en el golpe de Estado de Primo de Rivera y servir para que surgiera un grupo de militares africanistas que se rebeló contra la República.

\section{Dos temas polémicos}

La documentación del Quai d'Orsay arroja luz sobre varios asuntos: el litigio sobre la propiedad de las minas entre la Compañía del Rif y la Norte Africana, solucionado en 1910 con intervención directa de Alfonso XIII; el litigio de la Rif con los Mannesman también por la propiedad de las minas; el apoyo no sólo político, sino económico del Estado a la empresa minera española; los recelos franceses ante la posibilidad de que el ferrocarril de la Rif encubriera un plan español para penetrar hacia Fez y Taza ya que poseía un ancho superior al de un tren minero; el escaso o nulo entusiasmo que la guerra despertó entre la opinión pública española; las condiciones en las que luchó el ejército español o las razones que, según la diplomacia francesa, hicieron fracasar la penetración pacífica. A todo ello me referiré en un trabajo futuro ya en esta nota me limito a tratar los dos temas que antes he señalado.

La mayoría de los especialistas han sostenido que la guerra se desencadenó por el problema de las minas. Sin embargo, existe una hipótesis digamos que política -los políticos alentaron a los empresarios a explotar las minas- y otra digamos que económica -los empresarios forzaron a los políticos a autorizar el laboreo ${ }^{5}$. Por otro lado, algunos colegas han escrito que lo que realmente provocó la contienda no fue el asunto de las minas, sino la crisis comercial que la

5. La primera hipótesis en, por ejemplo, Seco Serrano (2002 a, p. 266). La segunda en Martín (1973), Morales Lezcano (1975), Sthephane (1990), Sáinz Varela (1999) o Moga Romero (2010). 
huida de El Roghi provocó en Melilla ${ }^{6}$. La bibliografía disponible, la documentación del Quai d'Orsay y la teoría de la Elección Pública me hacen sostener estas hipótesis:

1) Los dos partidos del turno pacífico aceptaron la zona de influencia española establecida en el acuerdo franco-británico de 1904 por razones que les permitían maximizar poder: restaurar el prestigio internacional de España tras la derrota del 98; asegurar Ceuta y Melilla así como las costas insulares españolas tras la destrucción de la marina de guerra (Acuerdos de Cartagena de 1907) y llevar a cabo una penetración pacífica que consideraban económicamente beneficiosa para España y que consistía en pagar con fondos del Estado y de los empresarios a las autoridades tribales para que autorizaran inversiones públicas y privadas que generaran empleo entre los indígenas logrando con ello el tránsito hacia el protectorado. Los políticos establecieron pues el marco institucional que requería la colonización.

2) Establecido ese marco, los empresarios lo utilizaron para explotar las minas y maximizar beneficios.

3) Hubo por lo tanto una unión o confluencia de intereses entre políticos y empresarios que, en el caso que nos ocupa, deja claro la correspondencia del embajador francés: "La Rif no sólo tiene un carácter industrial. Cubre un plan político determinado: inflamar el amor propio nacional y las aspiraciones del Rey". A mayor abundamiento, y como antes dije, el Estado ayudó a Fernández y Macpherson a comprar las minas a El Roghi e intervino después para que éstos y Romanones llegaran al acuerdo de crear una sola empresa.

4) El gobierno recibió presiones de la Cámara de Comercio de Melilla para que el ejército español ocupara el territorio restableciendo el orden y el comercio. El embajador francés informó de ello a su ministro de Exteriores y el asunto influyó sin duda en la decisión de Maura, pero la correspondencia diplomática indica que la causa fundamental de esa decisión fue el problema de las minas. A los textos me remito:

"La partida de El Roghi tendrá como consecuencia que España quiera ocupar toda la región jalonada por Alhucemas, Melilla, Rastinga y Cabo de Agua para dar de este modo seguridad a la explotación de las minas"

(Informe del general Lyautey al ministro francés de Asuntos Exteriores sobre los preparativos militares en Melilla, 9 de enero de 1909).

"Las personalidades que están a la cabeza de la Rif llevan actualmente una lucha encarnizada contra el gabinete Maura" (...) "La Compañía del Rif no se resignará a perder las sumas invertidas en las minas" (...) "Me dice Allendesalazar

6. Saro Gandarillas (1993) y Seco Serrano (2002 a, p. 278). 
que por presiones del grupo de la Rif el gobierno ha decidido autorizar a las dos compañías a continuar labores" (...) "La acción del gobierno ha estado determinada por el poder que tiene el grupo de Romanones, Comillas y Villanueva y la aventura de Massenet les ha beneficiado ya que Allendesalazar me ha hablado de las complicaciones que el gobierno ha tenido por la tentativa de penetrar en las minas por el Muluya"

(Cartas y telegramas descifrados del embajador francés en Madrid al ministro de Asuntos Exteriores francés enviados entre enero y mayo de 1909).

La mención a la aventura de Massenet merece un breve comentario. En los libros de Bécker y de Martínez de Campos, se decía que esa aventura fue la que determinó la decisión de Maura ya que, de no haber autorizado las labores, Francia hubiera ocupado militarmente la zona para que Massenet explotara sus concesiones $^{7}$. Una opinión similar han mantenido después otros especialistas ${ }^{8}$. La documentación diplomática manejada por José Manuel Allendesalazar, por Jean Marc Delaunay y la que yo he obtenido del Quaid'Orsay nada dicen de un plan francés para ocupar la zona de influencia española y califican la aventura de Massenet como un golpe de efecto ideado por el ingeniero ${ }^{9}$. Es cierto, sin embargo, que, como informó el propio embajador francés a su ministro, la aventura causó recelos entre los políticos y los militares; la prensa llegó a publicar que Massenet iba acompañado de tropas indígenas argelinas y Villanueva y otros miembros del partido liberal aprovecharon ese recelo para denunciar en el congreso y en el senado la pasividad de Maura.

El centenario de la coronación de Alfonso XIII originó un debate sobre su persona y uno de los temas polémicos fue el de su actuación en el Rif. Carlos Seco Serrano atribuyó al general Linares los errores de la guerra y Javier Tusell y Genoveva García Queipo de Llano escribieron:"En absoluto intervino Alfonso XIII en inspirar o conducir la acción española en Marrruecos" (...) "Hasta 1909 y, si se apura, hasta 1910, la cuestión marroquí no había figurado entre aquellas a las que dedicó el tiempo Alfonso XIII y, por lo tanto, tampoco había tenido responsabilidad sobre cuanto sucedió"10. Las cartas y telegramas descifrados que el embajador francés en Madrid envió a Pichon entre 1907 y 1909 avalan lo contrario:

"El general Marina ha pagado 520.000 pesetas al Roghi para que acepte la construcción de un ferrocarril por la Compañía del Rif (...) Sabemos que la compañía está subvencionada por un comité oficial de acción española que, a su vez, lo está

7. Bécker (1915, p. 510). Martínez de Campos (1969, p. 65).

8. Por ejemplo, Ayache (1981, p. 190) y Pastor Rodriguez en una separata titulada "Antonio Maura y la reactivación de la política exterior española", de la que rinde cuenta en su tesis doctoral Terrenos Ceballos (2013, p. 121).

9. Allendeslazar (1990, p. 222). Delaunay (2010, vol. 2, p. 328).

10. Seco Serrano (2002 b, p. 29). Tusell y Queipo de Llano (2002, pp. 180 y 225). 
por la Corona”. (...) La Rif no sólo tiene un carácter industrial. Cubre un plan político determinado: inflamar el amor propio nacional y las aspiraciones personales del Rey".

"Allendesalazar me ha dicho que el Rey y los militares desean la guerra mientras que Maura tiene tantos problemas dentro de España que no quiere ninguno grave fuera. También me ha hablado sobre los riesgos de una guerra con grandes gastos que el país no quiere".

"El ministro de Estado me dice que los movimientos que se operan actualmente entre los regimientos están causados principalmente por la actividad del ministro de la guerra y su deseo, estimulado por el Rey, de tener al ejército español en alerta. Se toman medidas para que, en caso de que la reanudación de trabajos en las minas conduzca a algún incidente y obligue a la intervención militar, todo salga bien. Alledesalazar también me dice que no hay que confundir esto con un plan de conquista de Marruecos. Tengo dudas porque la postura del Rey en los asuntos marroquíes está guiada por su deseo de grandeza de su Ejército y de España, aunque creo que el gobierno templará los sentimientos del monarca".

"El ayuda de campo del Rey me ha dicho que en el último Consejo de Ministros se produjo una fuerte discusión. El ardor del Rey por una acción militar más pronunciada fue tal que el gobierno se asustó (...) Maura impuso su punto de vista, pero encontró una resistencia muy viva por parte del Rey, que luego lo llamó aparte y tuvo con él una larga discusión. (...) Dura realidad. El Rey sigue insistiendo en dar una lección al mundo: quiere coronar el esfuerzo hasta el Muluya, pero para ello habría que enviar 50-60.000 soldados y no 35.000. Este plan seduce al Rey. En entrevista con él me volvió a hablar de la orilla izquierda del Muluya, pero es probable que prevalezca la opinión del gobierno. Asustado por lo de Barcelona, quiere terminar la guerra rápidamente y no quiere meterse en la aventura del Rey".

\section{Fuentes y bibliografía}

\section{Fuentes:}

- Archives diplomatiques. Quai d'Orsay. París. La Correspondance politique et militaire. Cajas 88-95 (Affaires duRif).

\section{Bibliografía citada:}

- Allendesalazar, J.M. (1990): La diplomacia española y Marruecos, 1907-1909. Madrid.

- Ayache, G. (1981): Les origines de la guerre du Rif. Paris-Rabat.

- Bécker, J. (1915): Historia de Marruecos. Madrid.

-Delaunay. J.M. (2010): Méfiance cordiale. Les relations franco-esgnoles de la fin du XIXe siècle à la Priemière Guerre Mondiale. Trois volumes. París.

- Gallego, E. (2005, primera edición de 1909): La campaña del Rif. Madrid.

- Madariaga, M.R. (1999): España y el Rif. Crónica de una historia casi olvidada. Melilla.

- Maldonado, E. (1949): El Rogui. Tetuán.

- Martín, M. (1973): El colonialismo español en Marruecos,1860-1956. París. 
- Martínez de Campos, C. (1969): España bélica. El siglo XX. Madrid.

- Moga Romero, V. (2010): Un siglo de hierro en las minas del Rif. Crónica social y económica (1907-1985). Melilla.

- Morales Lezcano, V. (1975): "Las minas del Rif y el capital financiero peninsular, 19061930". Moneda y Crédito, 135, pp. 61-79.

- Sáinz Varela, J.A. (1999): L'implantation minière espagnole au Maroc au début du vingtième siècle. Mémoire D.E.A. Université de Provence-Aix-Marseille.

- Saro Gandarillas, F. (1993): "Los orígenes de la campaña del Rif de 1909”. Aldaba, 22 pp. 97-129.

- Seco Serrano, C. (2002 a): La España de Alfonso XIII. Madrid.

- Seco Serrano, C. (2002 b): "Alfonso XIII, el rey infortunado". La aventura de la Historia, 40, pp.24-39.

- Stephane, D. (1990): La Compagnie Espagnole des Mines du Rif, 1908-1958. Mémoire de maitrisse. Université de Provence-Aix-Marseille

-Terrenos Ceballos, G. (2013): Antonio Maura y la cuestión marroquí. Tesis doctoral. Universidad Complutense de Madrid.

- Tusell, J. y Queipo de Llano, G. (2002): Alfonso XIII. El rey polémico. Madrid. 


\title{
El tránsito en España del liberalismo clásico a la democracia, a través de tres aportaciones bibliográficas recientes* The Spanish transition from classical Liberalism to Democracy
}

\author{
Juan B. Vilar \\ Universidad de Murcia
}

El tránsito del liberalismo clásico a la democracia en la España contemporánea continua atrayendo atención prioritaria de los historiadores interesados por la realidad institucional española actual y sus antecedentes más o menos inmediatos, lo cual ha generado una auténtica eclosión historiográfica. En esa línea investigadora hay que incluir las tres monografías recientes aquí presentadas, de las cuales una incidente en el siglo XIX, y más exactamente en las Cortes de Cádiz y el primer constitucionalismo español, y las otras en el XX y con referencia a dos hitos del devenir histórico hispano en esa centuria: José Canalejas y sus esfuerzos para transformar el liberalismo tradicional heredado del pasado en otro innovador y de signo democrático, y la II República o consecución plena de una realidad democrática para España.

Las Cortes de Cádiz y los significados políticos del primer liberalismo español es aportación colectiva sobre la temática de referencia contemplada en su con-

\footnotetext{
* SABIO AlCUTÉN, Alberto (coord.), Las Cortes de Cádiz y los significados políticos del primer liberalismo español. Absolutistas y liberales aragoneses en Cortes (1810-1814), introducción de A. Sabio Alcutén, Huesca, Diputación Provincial de Huesca-Instituto de Estudios Altoaragoneses, 2013, 136 pp.

FORNER MUÑOZ, Salvador, José Canalejas. Un liberal reformista, Madrid, Fundación FAES, 2014, 196 pp.

CASAS SÁNCHEZ, José Luis; DURÁN ALCALÁ, Francisco (eds.-coords.), España ante la República. El amanecer de una nueva era, 1931, Córdoba, Diputación Provincial de CórdobaPatronato Municipal Niceto Alcalá-Zamora y Torres, 2011, 844 pp.
} 
junto, a cargo de quienes son, sin duda, cuatro máximos especialistas sobre el liberalismo español en su fundamental etapa inicial: Juan Sisinio Pérez Garzón, Emilio La Parra López, Alberto Gil Novales y Javier Fernández López, a quienes se suma el coordinador de la obra, el también notorio investigador Alberto Sabio Alcutén, con una colaboración específica referida al caso aragonés, lo cual se indica ya en el subtítulo de esta aportación: Absolutistas y liberales aragoneses en Cortes (1810-1814). El libro aquí presentado son actas de un ciclo de conferencias celebrado en Huesca en 2014 bajo los auspicios de la Diputación provincial de esa localidad y el Instituto de Estudios Altoaragoneses con ocasión del bicentenario de la abolición de la Constitución gaditana por Fernando VII.

A una clarificadora Introducción del coordinador (pp. 7-12), siguen cinco colaboraciones, cuyos autores y títulos son los siguientes: Juan Sisinio Pérez Garzón, Las Cortes y la Constitución de Cádiz: contenidos sociales y esperanzas populares (13-30); Emilio La Parra López, La censura religiosa en la Ley de Libertad de Imprenta de las Cortes de Cádiz, 1810 (31-44); Javier Fernández López, Los orígenes del Constitucionalismo español: soberanía, división de poderes y representación (45-64); Alberto Sabio Alcutén, Topografía política y terrenos ideológicos de los diputados aragoneses en las Cortes de Cádiz (65-118), y Alberto Gil Novales, La Constitución de 1812 y su vigencia en el Trienio Liberal y en su entorno internacional (117-36).

Como puede verse, aparte del caso aragonés, concreto pero ciertamente relevante, las ponencias restantes son aproximaciones globalizadoras a aspectos fundamentales del primer constitucionalismo español a cargo de máximos especialistas sobre las respectivas temáticas, todos los cuales tienen en su haber extensa y reconocida obra. Por todo ello estamos ante una aportación colectiva que por sus selectos y actualizados contenidos puede ser instrumento de trabajo de preceptiva consulta para especialistas. Amplio aparato crítico de fuentes inéditas, impresas, bibliográficas y hemerográficas. Atrayente cuerpo de láminas originales y útil índice onomástico.

Monografía de signo diferente es la biografía analítica e interpretativa Canalejas. Un liberal reformista que Salvador Forner Muñoz, maestro de historiadores y especialista por definición del proceso modernizador institucional español en el complejo y prolongado tránsito del siglo XIX al XX, dedica a José Canalejas Méndez, ilustre político gallego (nacido en El Ferrol, Coruña, 1854), sin duda con Antonio Maura el estadista español más relevante en esa etapa histórica. Uno y otro encarnarían dos formidables esfuerzos de renovación institucional, aunque de signo diferente (liberal y conservador por Canalejas y Maura respectivamente) llamados ambos a revitalizar el ya semiagotado sis- 
tema político de la Restauración canovista, al que, no obstante limitaciones y fracasos, infundieron nuevo impulso hasta su liquidación final en 1931 coincidiendo con el derrocamiento de Alfonso XIII.

El autor nos aporta en la presente monografía una revisión en profundidad de la personalidad y obra de Canalejas, sus antecedentes familiares, formación académica e ideario político, su labor renovadora en el Partido Liberal como figura emergente en el mismo tras la desaparición de P.M. Sagasta, su infatigable actuación parlamentaria y luego su obra de gobierno, fundamental tras la desaparición de A. Cánovas de la escena política en 1897. También sobre el desastre colonial del siguiente año, y como sucesor y alternativa de A. Maura en el fundamental trienio 1910-1912, etapa esta última cerrada abruptamente al ser asesinado Canalejas. Fase breve pero pródiga en realizaciones transformadoras de largo alcance: desde la implantación de una auténtica tolerancia religiosa, esfuerzo culminante con una Real orden de 10 de junio de 1910 que interpretaba de forma abierta el artículo 11 de la vigente Constitución canovista de 1876, que había implantado en España un estado confesional católico, a una serie de reformas sociales de signo secularizador culminantes en la llamada "Ley del Candado" de 1911, que cercenaba drásticamente derechos y privilegios reconocidos hasta el momento al clero regular o conventual.

Pero sobre todo Canalejas se esforzó en promulgar toda una legislación social avanzada para la época. En particular en lo referente a la implantación de un arbitraje estatal regulando las condiciones de trabajo y en materia salarial, medidas en sí mismas de carácter avanzado y democrático, pero cuyas limitaciones de signo burgués les concitaron animadversión en los ambientes laborales más radicales y el asesinato de su inspirador en Madrid (12 noviembre 1912) por un joven ácrata español exiliado, retornado a España con esa finalidad expresa. Magnicidio que tendría repercusiones institucionales de largo alcance. "La desaparición de Canalejas -refiere S. Forner (p. 11)-, unida al eclipse político de Maura, iba a marcar el inicio de un proceso de agotamiento del régimen y de aguda crisis en el Partido Liberal, uno de los dos pilares del mismo". El desenlace final de esa crisis se dejaría esperar todavía dos décadas, hasta el derrocamiento final de Alfonso XIII y advenimiento de la II República en 14 de abril de 1931.

En suma, la monografía de S. Forner Muñoz es aportación historiográfica innovadora y atrayente que arroja nueva luz sobre el prolongado, agitado e incluso convulso tránsito español desde un liberalismo anquilosado y de signo tradicional a un modelo institucional democrático, proceso centrado por largo tiempo en la figura y obra de José Canalejas. Sólida fundamentación en fuentes documentales inéditas, impresas, bibliográficas y hemerográficas proceden- 
tes de dos decenas de archivos e instituciones nacionales y extranjeras. Amplio aparato de notas y cuerpo de índices finales.

Incidente sobre un tiempo inmediatamente posterior, y a su vez complementaria en su temática de la anterior monografía, es la aportación colectiva España ante la República. El amanecer de una nueva era. 1931, actas de un masivo VI Congreso de Republicanismo que en 10-12 de marzo de 2011 tuvo lugar en Priego de Córdoba, localidad natal de Niceto Alcalá-Zamora y Torres, primer presidente de la II República española, organizado por el Patronato que lleva el nombre del ilustre político natural de esa urbe andaluza, en colaboración con el Ayuntamiento de la misma, la Universidad de Córdoba, Diputación Provincial cordobesa y Fundación Botí. Magno esfuerzo a cargo de dos centenas de congresistas, que con sus aportaciones escritas e intervenciones orales realizaron una magna y encomiable labor, dando a conocer nuevas informaciones sobre el despegue inicial de la española II República.

El Congreso fue estructurado en torno a siete ponencias, veintinueve comunicaciones, dos mesas redondas y varias actividades complementarias. Entre éstas la presentación de las Actas del precedente V Congreso sobre Republicanismo: El Republicanismo ante la crisis de la democracia, una perspectiva comparada. 1909-1939, dos exposiciones documental-fotográficas rotuladas Por la España republicana: los viajes del Presidente de la República D. Niceto Alcalá-Zamora y El legado de Alfredo Cabanillas Blanco: vivencias de un periodista republicano, y un homenaje al activista y librero de Priego, Rogelio Luque Díaz, figura clave en lavanguardia cultural cordobesa, fusilado en agosto de 1936 "por tener libros marxistas en su establecimiento" (Librería Luque). Los congresistas participantes redactaron, a su vez, un Manifiesto en el que solicitaron del Ministerio de Cultura información sobre los documentos robados a N. Alcalá-Zamora al comienzo de la Guerra civil y el motivo por el cual eran silenciados sus contenidos, solicitando la publicación de los mismos.

Fundamental aportación colectiva de casi un millar de páginas, estas Actas del VI Congreso sobre Republicanismo se abren con una bien ajustada Presentación a cargo de José Luis Casas Sánchez y Francisco Durán Alcalá (pp. 7-10), editores-coordinadores de la obra y figuras clave en las dos entidades editoras de la misma: la Diputación Provincial de Córdoba y el Patronato Niceto AlcaláZamora y Torres. Tras la inicial exposición de Gabriele Ranzato, El 14 de abril (pp. 11-30), a modo de conferencia inaugural, siguen 13 ponencias, de las cuales cinco generales y las ocho restantes repartidas por igual entre las dos Mesas $-1^{\mathrm{a}}$ y $2^{\mathrm{a}}-$ del Congreso. Los autores y títulos de unas y otras, por el orden indicado, son los siguientes: Octavio Ruiz Manjón, Partidos, elecciones y nueva clase política (31-62); Julio de la Cueva Merino, La República frente a la cues- 
tión religiosa: Una solución laica y un nuevo problema (63-82); Antonio Ramos Espejo, Rogelio Luque Díaz. En el contexto de la cultura cordobesa. Librero y mártir (83-120); Manuel Aznar, La intelectualidad comunista durante la Segunda República (121-58); Mercedes Cabrera, Las fuerzas económicas ante la República (159-72); Leandro Álvarez Rey, Andalucía en la Segunda República (179-84); Antonio Barragán Moriana, Sobre la implantación de la II República en Córdoba y sus peculiaridades (185-88); Id., Sobre la articulación del subsistema de partidos en Andalucía en los comienzos de la II República: La izquierda obrera y republicana (189-96); Manuel Morales Muñoz, La proclamación de la República en Andalucía: valores y símbolos para un tiempo nuevo (197-202); Mónica Carabias Álvaro, La II República: Un escenario para la eclosión de la fotografía moderna y la fotografía social (207-14); Xavier Pericay, José Pla y la República (215-20); $\mathrm{M}^{\mathrm{a}}$. Isabel Cintas Guillén, Manuel Chaves Nogales, un periodista para la Segunda República (221-30), y Francisco García Muñoz, i"Hambre de radio"! Panorama de la transición de la radiodifusión española entre la dictadura de Primo de Rivera y la II República, 1923-1935 (231-50).

En cuanto a las 29 comunicaciones (pp. 255-838), presentadas en el curso de tres sesiones, incidieron sobre temáticas más o menos específicas referidas tanto al ámbito general como al andaluz. Corrieron a cargo de A. López Castillo, D. Igeño Luque, M $^{a}$.E. Escalera (con J.O. Prieto), F. Carmona Obrero, J. Gil Honduvilla, J.A. Lora Vera, J.F. Fernández (con A.M. Ruiz Jiménez), J.F. Rodríguez Cenizo, M.A. Melero Vargas, M. Pino Abad, R. Mirón, C. Muriel, A. Romero Bernal, A. López Villa, C. Somé, J. Peña González, J. Romero Portillo, J. Terrero, Mª.L. Hernández Ríos (con Ma.G. Tolosa) -dos aportaciones-, M. Requena Gallego, P.J. Carrión Sánchez, P.V. Pires, Mª.C. Aldehuela, F. Durán Alcalá, J. Collado, M $^{a}$. de los A. Corpas, M. Castillo y V. $\mathrm{M}^{\mathrm{a}}$. Sueiro. Aportaciones esas enmarcadas en las líneas de investigación de sus respectivos autores, entre los cuales conocidos especialistas. Cuerpos de tablas, gráficos y láminas. Amplia fundamentación en fuentes documentales, bibliográficas, hemerográficas y orales. Aportaciones novedosas e innovadoras sobre las respectivas temáticas. De cara a una posible reedición, sería deseable la inclusión de un índice onomástico final que facilite y simplifique la consulta de tan amplio, complejo, innovador y atrayente repertorio colectivo. 

TESIS DOCTORALES 

MATAS PUJALTE, Ernesto Manuel, Marginación y trabajo en Callosa de Segura. De la emigración a la inmigración, tesis doctoral dirigida por el Dr. José Miguel Santacreu Soler, defendida el 22 de marzo de 2013 en el Departamento de Humanidades Contemporáneas de la Universidad de Alicante. Accesible en el Repositorio Institucional de la Universidad de Alicante (RUA).

Se resume esta tesis, como pronostica su título, en la marginación y represión laboral de todo un pueblo, Callosa de Segura, en la España de los años 40 y 50 en sus diversos trabajos, agrícolas e industriales, de la ya extinguida y en tiempo pujante industria del cáñamo, así como a la misma marginación laboral y social, unida a una cruel xenofobia, sufrida por este pueblo transterrado forzosamente a los disciplinados y democráticos países europeos, de emergente e imparable industrialización, salidos de una guerra de la que se levantaron con inusitada rapidez y que reclamaban con urgente necesidad la mano de obra sin cualificar de los países mediterráneos meridionales. Pasados los años y re- compuesto ya el país, al igual que la ciudad de Callosa de Segura, con un aceptable grado de desarrollo económico, cultural y social y ya reconvertida la industria, será también objetivo de este trabajo la llegada de nuevos visitantes desde mediados de los años 80 procedentes de 28 países en busca de un mejor trabajo que dignifique sus vidas. La explotación laboral de este nuevo colectivo tanto por parte de los callosinos como de sus propios congéneres dará cumplimiento a este resumen.

La segunda mitad de los años 50 del pasado siglo XX fue el principio de la crisis y de la posterior y definitiva desaparición de la ancestral industria del cáñamo; fibra vegetal cuyo cultivo llenó en un tiempo grandes extensiones de la huerta callosina y de su entorno y cuyo núcleo central se asentaba en la ciudad de Callosa de Segura, en el centro de la comarca del Bajo Segura (también llamada Vega Baja del Segura), extremo más meridional de la provincia de Alicante en la Comunidad Valenciana.

Las distintas labores de esta planta (siembra, siega, embalsado, secado, agramado, transporte, espadado, rastrillado, hilado, etc.), todas ellas 
manuales y que afectaban desde el sector primario al terciario, tenían como objetivo final la fabricación de hilos, cuerdas, calabrotes, redes de pesca, e incluso zapatillas; y dieron trabajo y vida, directa e indirectamente, a la mayor parte de la población y a la casi totalidad de los pueblos de la comarca.

Mientras tanto, y desde la evitable Guerra Civil que sumió a España en unos interminables años de miseria, hambre e incultura, la entera sociedad española, dirigida como un inmenso cuartel, quedó dividida, por obra y gracia del dictador Francisco Franco, y con la anuencia y permanente incensamiento de la Iglesia Católica, en un pueblo de vencedores y vencidos, de delatores y delatados, de humilladores y humillados y de odios y venganzas. Además, política, social, sexual y religiosamente, el país quedó condenado durante muchos años al hambre, la miseria, la represión y el miedo.

Añádase a todo ello el permanente control e intervencionismo económico de los primeros años, producto de la torpe política autárquica del gobierno, jaleada por falangistas y apoyada por el dictador, unido todo a las corruptelas a nivel local de los industriales, las de los sucesivos alcaldes en el río revuelto de la posguerra y al dubitativo y tardío Plan de Estabilización.

La situación general de miseria en la que quedó España unido a la promulgación por el nuevo estado de represivas leyes laborales (ley de Depuración del Funcionariado, ley de
Empleo Público, Fuero del Trabajo, ley de Reglamentaciones del Trabajo, ley de Contrastos de Trabajo, etc.) y a la creación por el gobierno del sindicato único u OSE (Organización Sindical Española) que aglutinaba, o más bien deglutía, a todas las demás asociaciones o sindicatos obreros y cuyo objetivo esencial era "encuadrar, controlar, disuadir y reprimir" cualquier indisciplina en el ámbito laboral, condenaron a toda una generación de mujeres y niños a iniciarse en el duro trabajo desde la temprana edad de 6 o 7 años. Las interminables jornadas de sol a sol, a la intemperie de la sierra como el aporte de una mínima contribución pecuniaria añadida al salario de los padres, les arrebataron a estos niños el gozoso juego y la necesaria escuela.

La primera de las anteriores leyes tuvo la intención de depurar en todas las instituciones del Estado y en las empresas públicas a todas las personas quie no podían demostrar su adhesión al nuevo régimen. La segunda ley reservaba un generoso, por elevado, tanto por ciento de las plazas salidas a oposición pública, a mutilados de guerra, excombatientes, excautivos, alféreces provisionales y huérfanos de padres "adictos" del glorioso ejército vencedor. La ley de Reglamentaciones del Trabajo proclamaba, lisa y llanamente, la exclusiva capacidad del Estado para establecer todo lo relativo a condiciones laborales y la plena subordinación del obrero al patrono. 
Y la ley de Contratos de Trabajo concedía al empresario una absoluta autoridad sobre el obrero, debiendo éste una absoluta obediencia al empresario basjo penas de diversas sanciones, multas e incluso despido.

Fue también, y fundamentalmente, el miedo del empresario a la innovación de sus empresas, al cambio y la escasa creatividad de un pueblo cerrado en sí mismo e inserto en una España que desdeñaba a Europa, la causa más importante de esta crisis. Y fue, definitivamente, el descubrimiento y aplicación industrial de las llamadas fibras sintéticas de las que estaban confeccionadas las redes de pesca de los buques que años antes ya surcaban los mares del planeta, producidas a partir de los polímeros (macromoléculas formadas por la unión de moléculas más pequeñas llamadas monómeros), con unas características y unas propiedades físicas superiores a la fibra natural del cáñamo, las que hicieron entrar en crisis a toda una población y su comarca.

Esta crisis arrastró a todo un pueblo, analfabeto a su pesar, y que sólo conocía las labores de la vieja fibra, a una forzosa emigración laboral hacia los países de Europa Central y del Norte. Francia, Alemania y Suiza, preferentemente, fueron los países donde los callosinos dirigieron sus pasos. El primero (con un 95\% de emigrantes) por razones de cercanía y tradición de lejanas emigraciones "golondrina" a temporales vendimias en el medio- día francés; y Alemania y Suiza en menor proporción.

Este éxodo europeo fue precedido por un emigración interior, no tan masiva a las ciudades industriales y de servicios de la provincia (Elche, Elda, Alicante, Villena), y más tarde hacia el resto de España (Madrid, Barcelona, País Vasco, etc.).

Las vicisitudes, tanto laborales como sociales de estos emigrantes callosinos forman parte de este trabajo así como también poner en evidencia la artera estrategia del gobierno de la dictadura en los convenios con los diversos países de destino de esta emigración.

Estos convenios España-Francia y la política asistencial de la primera sirvieron para mantener alejados a los emigrantes de la posible influencia de antiguos refugiados españoles y de los sindicatos y partidos de izquierda, ante el temor de que al retorno pudiesen influir en los dóciles y despolitizados españoles que quedaron, ya que el objetivo de esta política que ofrecía actividades sociales, educativas, culturales y de ocio en las llamadas "Casas de España" era controlar y vigilar a estos emigrantes y alejarlos de "contaminaciones políticas" e "ideas disolventes".

En Alemania, la vigilancia franquista trató de ser la misma, con las consiguientes dificultades de una vigilancia policial española en un país democrático pero con las ventajas para España de la fobia comunista del país alemán. 
En Suiza se distinguió el Partido Comunista de España como el más importante promotor de las actividades políticas de los trabajadores españoles en el intenso enfrentamiento político y social entre los emigrantes españoles antifranquistas y las administraciones de la dictadura (Organización Sindical, Consulados, Embajada y agregados laborales). Hubo en este país, sin embargo, un apoyo secreto en 1962 entre las policías de ambos países que benefició al gobierno franquista y que también constituía una garantía para los otros países europeos contra la vuelta de la extrema izquierda.

Y en una nueva estrategia, disuasoria y miserable, se difundió la noticia de que los manifestantes españoles eran fotografiados por la policía franquista para posibles represalias al retorno como así fue.

Los resultados económicos del Plan de Estabilización iniciado en 1959, preludio de unos siguientes Planes de Desarrollo Económico y Social, junto a las inversiones extranjeras y al turismo europeo que descubría en España un país atrasado y exótico pero barato, contribuyeron elevar su maltrecha economía. Pero la crisis energética que afectó a Europa en los años 1973 y 1975 obligó al retorno de cientos de miles de españoles y miles de callosinos que con sus divisas contribuyeron a levantar el país y a dinamizar la reconversión industrial de la ciudad de Callosa.
Llegado el año 1985, la antaño llamada "Ciudad del Cáñamo" se había mecanizado con grandes telares que, con las nuevas fibras sintéticas volvía a producir hilos y cuerdas para la confección de redes de pesca y otras aplicaciones. Y fue a partir de ese año cuando comenzó a iniciarse una paulatina pero constante llegada de inmigrantes de los más variados países del planeta. Buscaban los mismos objetivos que los callosinos de los años sesenta: las mismas aspiraciones, necesidades, deseos y esperanzas en un trabajo que les permitiera vivir más dignamente y con una mayor calidad de vida. Llegaron fundamentalmente de Marruecos y de diversos países hipanoamericanos.

Siguiendo vigente la frase latina "Homo homini lupus" también para estos visitantes, enlazadas con generosas situaciones dignas de elogio para ellos, se han llegado a producir situaciones de explotación miserable que, en casos puntuales, han llegado a rozar la semiesclavitud, tanto por los autóctonos como por los mismos congéneres de estos nuevos inmigrantes. Y han llegado a surgir la existencia de pequeñas mafias entre los propios inmigrantes como intermediarios entre jefes en la sombra y los propios inmigrantes.

La sociedad callosina ha quedado dividida entre los partidarios de la repatriación de los inmigrantes y los que se muestran comprensivos y tolerantes apelando al pasado migratorio 
de los callosinos. En un grupo minúsculo existe verdadera xenofobia y racismo. Y para éstos sigue siendo válida la frase del intelectual búlgaro Tzvetan Todorov: "El miedo a los bárbaros es lo que amenaza en convertirnos en bárbaros. El miedo se convierte en peligro para quienes lo sienten, y por ello no hay que permitir que desempeñe un papel de pasión dominante. Todavía estamos a tiempo de cambiar la orientación".

PAYÁ LÓPEZ, Pedro, Ni paz, ni piedad, ni perdón. La guerra después de la guerra y la erradicación del enemigo en el partido judicial de Monóvar: la responsabilidad compartida, 1939-1945, tesis doctoral dirigida por el Dr. Glicerio Sánchez Recio, defendida el 30 de abril de 2013 en el Departamento de Humanidades Contemporáneas de la Universidad de Alicante. Accesible en la Biblioteca Virtual Miguel de Cervantes.

Esta tesis estudia las formas de persecución y eliminación del enemigo político durante la posguerra española en un análisis de caso: el partido judicial de Monóvar. Más concretamente, se pregunta por la responsabilidad de cada uno de los agentes que intervinieron en el proceso represivo, prestando especial atención a los locales y a los resultados que se derivaron de sus acciones y omisiones sobre la vida de sus vecinos.
La delimitación del objeto de estudio queda descrita en el título mismo de la tesis. Así, "ni paz, ni piedad, ni perdón" supone una referencia explícita a las palabras de Manuel Azaña en su discurso del 18 de julio de 1938 en Barcelona y la constatación de su absoluta negación en la realidad de posguerra: se optó por la venganza institucionalizada. Con la afirmación "guerra después de la guerra" -una contradicción en los términoshemos querido dejar constancia de la dificultad de definir un tiempo que no era estrictamente de guerra -tal como ha sido entendida por el derecho internacional- pero tampoco de paz, sino esa situación intermedia de la que ya hablara Carl Schmitt en 1938, diferenciando entre "guerra como acción" y "guerra como situación o estado", caracterizada por la existencia de un enemigo-definido como tal por el Estado-, incluso cuando habían cesado las hostilidades abiertas y las acciones bélicas ${ }^{1}$.

En relación a ello, "erradicación del enemigo" hace referencia a la prolongación de los discursos sobre el mismo en la posguerra y las políticas represivas arbitradas para su reducción y eliminación, sobre tal base justificativa. Se trata de un concepto más apropiado que el de exterminio, pues en el mismo caben diversas acciones,

1. schmitt, Carl, "Corolario II. Sobre la relación entre los conceptos de guerra y enemigo (1938)", en El concepto de lo político, Madrid, Alianza, 1991, pp. 131-132. 
desde la eliminación física total, por medio del fusilamiento, o espaciotemporal, mediante su encarcelamiento, hasta su reeducación, aislamiento (como actor social) y reducción al silencio (como actor político) por medio de la coacción legal y cotidiana. Además, en el mismo concepto de erradicación caben las referencias a la destrucción del capital simbólico republicano y al exilio, motivado por las políticas represivas, y prolongado, en muchos casos, al no permitir el retorno de quienes habían marchado tras el final de la segunda guerra mundial, fecha elegida para cerrar el trabajo como una primera fase significativa de la dictadura: la de la larga posguerra.

La reducción de escala a un ámbito comarcal como universo de análisis nos ha permitido observar conexiones que en principio pasarían desapercibidas en otras más amplias. Hemos podido reconstruir las redes personales que se formaron en relación a los distintos grados de participación en la violencia. También la trayectoria de las víctimas de la represión y la violencia, principales voces de este trabajo, aunque teniendo en cuenta que su experiencia es representativa de la de otras miles, que vieron que su destino quedaba en manos del Estado, sometidos al poder de unas mismas instituciones, pero también a la voluntad de personas concretas que participaron o colaboraron con las mismas, cuyas acciones y omisiones influirían definitivamente sobre sus vidas y las de sus familiares. Finalmente, la reducción de escala ha permitido preguntarnos y evaluar la relación entre violencia y responsabilidad a partir de la actuación de los individuos concretos, con especial atención al papel desempeñado por autoridades locales y vecinos, entre los que se formó una red de informantes a partir de su ingreso en FET y de las JONS, que colaboraron con las autoridades militares judiciales que dirigieron el proceso represivo señalando y declarando sistemáticamente contra sus vecinos, especialmente contra quienes fueron condenados a muerte.

Cualquier pregunta sobre la responsabilidad en la violencia debe partir -con Hanna Arendt- de la constatación de que, desde un punto de vista penal y moral, es siempre individual $^{2}$. En este sentido, cuando hablamos de responsabilidad en la represión de posguerra debemos tener en cuenta que los agentes que intervinieron en la aplicación efectiva de la misma fueron varios, de ahí que deba contemplarse como suma de responsabilidades individuales en relación al poder y a la capacidad de actuar que el Estado delegó o permitió a cada uno de los mismos: denunciantes, autoridades locales, informantes, jueces de instrucción, abogados, fiscalía, consejos de guerra y auditores. La suma de estas responsabilidades perso-

2. ARENDT, Hanna, Responsabilidad y juicio, Barcelona, Paidós, 2007, p. 253. 
nales en el resultado final del proceso represivo es lo que hemos denominado responsabilidad compartida, a diferencia de la responsabilidad fracturada que caracterizaría más adecuadamente la violencia que se dio en la retaguardia republicana.

Especialmente significativa es la responsabilidad de los agentes locales: denunciantes, autoridades e informantes, pues sabían las consecuencias que se podían derivar de sus acciones y declaraciones. Conocían la lógica de funcionamiento de los procesos sumarísimos y los consejos de guerra, desde el tipo de delitos imputables hasta las circunstancias modificativas de la responsabilidad penal contempladas en el Código de Justicia Militar sobre las que se sustentaban las condenas a muerte; desde el lenguaje utilizado, amparando y proyectando los discursos justificativos elaborados por la propaganda, hasta la recluta y asesoramiento en las declaraciones de los familiares de las víctimas de la violencia en retaguardia; desde la formulación de las denuncias que daban lugar a la incoación de los sumarísimos hasta las presiones sobre las auditorías, en los contrapesos de fuerzas, siempre asimétricas, que necesariamente se produjeron tras las condenas. Se erigieron, en definitiva, como una pieza clave en el funcionamiento y aplicación de la justicia militar en el ámbito local.

Una de las herramientas más destacadas entre las utilizadas por los dis- tintos agentes fue el lenguaje. Especialmente significativo es el que se ejemplifica en las declaraciones de los miembros de la red de informantes, de donde se desprende la necesidad de hacer un análisis del discurso en el que cobra validez explicativa el concepto de razón cínica. Para entenderlo, debemos tener en cuenta las diferencias que en relación al concepto de enemigo se dan entre hostis e inimicus. En el primer caso estamos ante el enemigo político total (que únicamente puede ser definido como tal por el Estado en su condición de unidad esencialmente política) con el que se tiene un enfrentamiento público y al que no hace falta odiar personalmente, pues el enemigo no es sino una comunidad de personas a la que se debe combatir por otra comunidad constituida de forma beligerante como tal. Por el contrario inimicus es aquel que se reduce al campo de lo privado y está motivado por razones como la competencia y sentimientos como la antipatía y el odio ${ }^{3}$.

A diferencia de lo visto en escalas más amplias, donde la represión de los líderes políticos perseguía erradicar algo que trascendía la individualidad propia del procesado como hostis (caso paradigmático el del líder socialista Julián Besteiro), a escala local, aunque todo el entramado justificador de las sentencias estaba montado sobre el discurso del enemigo

3. sснмiтt, Carl, El concepto de lo político..., pp. 58-59. 
teorizado como hostis, éste cobraba forma concreta encarnándose en los vecinos de izquierdas "conocidos de toda la vida" por aquellos denunciantes, autoridades e informantes que los contemplaban como inimicus: un vecino, un individuo concreto, del que conocían su trayectoria política, social y personal, con nombres y apellidos que primero se calumniaron y después se pretendieron hacer desaparecer. Esta paradoja, en la que el discurso simplificador sobre un enemigo genérico al que se le debe temer se transfigura en un vecino al que se le odia, pero sin renunciar a las claves descriptivas y representativas proporcionadas por la propaganda, es salvada por medio del concepto de razón cínica defendido por Peter Sloterdijk: el sujeto cínico conoce muy bien la distancia entre el discurso y la realidad, pero cada palabra "oficial" que menciona oculta intereses privados ${ }^{4}$.

Acogiéndose a la razón cínica, quienes informaban trataban de provocar en el destinatario del mensaje -la autoridad judicial militar-, una reacción de repulsa que a su vez confirmara los estereotipos de la imagen que tenía del procesado, cuya despersonalización jurídica se agudizaba. El Estado acometía así su operación de limpieza política, ejecutando o encarcelando a quien antes había definido como enemigo. Las autoridades locales, en cambio, acababan con el veci-

4. SLOTERdijk, Petrer, Crítica de la razón cínica, Madrid, Siruela, 2003, pp. 553-554. no incomodo a sus intereses: quien había sido rival político, defendiendo posiciones contrarias a intereses públicos o particulares, o encabezado los comités de huelga dentro de la conflictividad social y laboral de los años treinta. También aquel hacia el que se tenía una enemistad personal, o sencillamente quien desempeña una misma profesión al que ahora las circunstancias permitían hacerle una "competencia desleal".

Estamos ante dos niveles que se complementaron sellando un pacto no escrito por el que, una vez descabezada la República de sus principales referentes en cada localidad, autoridades y vecinos se pudieron cobrar su cuota particular. Limpieza política y venganza privada confluyeron para prolongar durante la posguerra los procesos iniciados y desarrollados durante el conflicto bélico.

Entre las fuentes utilizadas debemos destacar aquellas emanadas del funcionamiento de los organismos e instituciones de la dictadura, fundamentalmente las que tienen que ver con su aparato represor, tanto en su jurisdicción militar -los procedimientos sumarísimos- como civil, principalmente las del gobierno civil en sus negociados de orden público e instituciones penitenciarias, además de otras jurisdicciones especiales como la ley de responsabilidades políticas. Otro grupo de fuentes de especial relevancia en este trabajo han sido las que hemos denominado fuentes de experien- 
cia, que son todas aquellas que recogen el testimonio del testigo, entendido no como aquel que asiste como tercero a dar cuenta de lo que ha visto (testis), propio del Derecho, sino como aquel que ha vivido un acontecimiento, lo ha hecho suyo como parte de su experiencia y está en condiciones de ofrecer un testimonio sobre el mismo (superstes): $:^{5}$ diarios, correspondencia, declaraciones y pliegos de descargo en los sumarios, memorias y testimonios orales. Mediante las primeras y atendiendo a su fenomenología, comprobamos la forma como es vivido el acontecimiento por el sujeto; con las segundas, cómo se ha elaborado esa experiencia traumática y su persistencia en el tiempo.

En nuestro caso, hemos podido consultar la correspondencia de varios condenados a muerte, gracias a que sus familiares las guardaron durante todos estos años. Su contenido nos permite aproximarnos a diversos aspectos de la experiencia de sufrimiento: material, físico, moral y psicológico.

Además de la correspondencia, otra de las fuentes que nos permite comprobar in situ cómo es vivido el acontecimiento por el testigo es el diario. Hemos contado con dos diarios que fueron publicados, en ambos casos, gracias al cuidado que de los manuscritos hicieron sus hijas, y a su posterior iniciativa de darles luz: así

5. AGAMBEN, Giorgio, Lo que queda de Auschwitz. El archivo y el testigo. Homo Sacer III, Valencia, Pre-Textos, 2005, p. 15. ocurrió tanto con el del diputado de Izquierda Republicana por Alicante, Eliseo Gómez Serrano, que recoge su experiencia en los tres años de guerra civil, como con el del militante de la CNT de Alcoy, Enrique Barberá Tomás, de especial significación al tratarse del diario de un condenado a muerte, escrito en la clandestinidad durante su estancia en el Reformatorio de Adultos de Alicante.

La tercera fuente que hemos utilizado en la que se recoge la voz del testigo requiere una crítica particular, al tratarse de una fuente emitida por el verdugo: el sumarísimo. En ella aparece la voz del testigo de cuatro formas: el interrogatorio al que es sometido en la diligencia de detención, la declaración indagatoria que presta ante el juez de instrucción, el pliego de descargos que en ocasiones enviaron al juez o al auditor y, finalmente, la solicitud de indulto al Jefe del Estado. Esta diversidad nos ha obligado a estudiar el testimonio desde su fenomenología, lo que nos indica tanto su contenido como sus límites.

Por último, debemos hablar de las fuentes que muestran cómo se ha elaborado la experiencia traumática y su persistencia en el tiempo: las memorias y la fuente oral. Investigar sobre procesos traumáticos necesariamente debe suponer tener en cuenta el funcionamiento de la memoria, de ahí que debamos diferenciar, dentro del grupo de las víctimas, entre aquellas que murieron y dejaron su testi- 
monio, y los supervivientes que han dejado su voz en forma de memorias $y$ entrevistas. Aunque en ambos casos estamos ante formas de memoria, difieren en su manera de concretar el recuerdo, mediante un discurso elaborado o como consecuencia de preguntas. Ambas están asimismo sujetas a los condicionamientos de situación: la dimensión espacial y temporal en la que se recuerda, si bien en la segunda son más acusados, al depender de demandas exteriores y no tanto de una decisión tomada por el sujeto en su voluntad de recordar.

Entre nuestras fuentes orales hemos podido comprobar que si hay un trauma es el marcado por la ausencia, el del asesinato del ser querido que no pudo ser elaborado dentro de los trabajos propios de la memoria, al impedirlo la imposición del silencio y el olvido público. Es el trauma del que ha sobrevivido a la pérdida y vuelve a enfrentarse a la misma en el contexto creado por la entrevista.

Algunos entrevistados reflejaron un dolor que hoy perdura al haber crecido sin el padre o la madre y denotan uno de los aspectos más oscuros -por no haber sido suficientemente tomado en consideración por la historiografíay crueles de la represión franquista: en su fuero interno les ha seguido acompañando la duda de aquellas palabras que escucharon y se dijeron a sí mismos: "algo habrá hecho".

En cuanto a la estructura del trabajo, la opción tomada de ir de las vivencias particulares al análisis de lo general ha tenido, como no podía ser de otra manera, una repercusión sobre el método de exposición elegido. Estructurado en tres grandes bloques -introducción, primera parte y segunda parte- además del apéndice documental, en todos ellos se ha buscado dar fluidez a la narración, tratando de reflejar lo más fielmente posible la forma en la que los distintos acontecimientos, acciones y decisiones tomadas por aquellos que detentaban alguna forma de poder influían sobre la vida y el destino común de sujetos particulares. En este sentido, aunque las fuentes están compartimentadas, debemos tener en cuenta que aquellos que sufrieron la violencia vivieron ese destino simultáneamente, sometidos al poder discrecional e incluso a la voluntad de autoridades $y$ vecinos.

En la primera parte, tras reconstruir las circunstancias en las que se llevaron a cabo los asesinatos en la retaguardia republicana durante el verano-otoño de 1936, se aborda la represión de posguerra a partir del análisis y narración de casos particulares -especialmente de condenados a muerte-, que se van sumando a otros tratando de componer un conjunto en el que la violencia se amalgama y amplifica. Como ha escrito Annette Wieviorka, no se trata de trasmitir una desgracia individual, sino de un sufrimiento nacido de un acontecimiento 
histórico que se fragmenta en una serie de historias individuales ${ }^{6}$.

Tras la ocupación de Alicante por las tropas rebeldes y el final de la guerra civil, llegó el momento de aplicar una venganza institucional que no había tenido posibilidad de llevarse a cabo en tiempo de guerra y que rápidamente, en un clima que fomentaba la denuncia, la delación y la impunidad, se iría combinando con una venganza más particular en cada una de las localidades del partido judicial, en las que destacaría el poder de informar reservado a las nuevas autoridades locales. Venganza institucional y privada, y discurso justificativo heredado de la propaganda sobre el enemigo fueron componentes descriptivos y explicativos de las razones y formas de las sentencias de muerte aplicadas por los consejos de guerra.

Dividida en tres capítulos, la segunda parte presta atención a las condiciones físicas y morales en las que se hallaron tanto los condenados en las prisiones como sus familiares más directos fuera de las mismas, asimismo víctimas de la violencia institucionalizada. También a las formas de persecución y control a las que se vieron sometidos quienes volvían a su localidad tras la puesta en libertad condicional y el destierro, y al trauma de los familiares de aquellos que no pudieron volver, al haber sido fusilados tras un periodo de lucha en desigualdad

6. Wieviorka, Annette, L'Ėre du témoin, Paris, Hachette, 2002, p. 159. por conseguir la conmutación de la pena. Una lucha donde predominó una absoluta asimetría en la que se veían implicadas esposas, hijos, hermanos y padres de los condenados, que sufrieron por igual la humillación de los poderes locales, la indiferencia de la burocracia y la venganza institucionalizada del Estado. Además, las familias con derecho a escenificar públicamente su luto se redujeron a las del bando vencedor, realidad que no hizo más que profundizar los efectos duraderos de un trauma de niveles colectivos que se ha terminado extendiendo por varias generaciones.

Entre nuestras principales conclusiones, preguntarnos por la responsabilidad nos ha llevado a resaltar que, en última instancia, no fueron el alcalde o el jefe local de FET-JONS, sino la persona concreta quien, en el desempeño de su cargo, emitía los informes pedidos por los jueces de instrucción; sin embargo, una explicación basada únicamente en criterios intencionalistas menospreciando los funcionalistas se muestra necesariamente insuficiente, pues las motivaciones individuales sólo pudieron dar lugar a acciones a partir de la pertenencia o mediante la complicidad con y de las instituciones. Fue su cargo lo que en última instancia les permitió disponer de un poder de actuación mediante el que pudieron influir sobre el destino final de sus vecinos. Tenían una función dentro del sistema, emitir informes y designar informantes, 
pero los emitían ellos, bajo su responsabilidad. En este sentido, pasar de la actividad (procedimiento administrativo) a la acción (informe político sobre el enemigo), donde juega un papel fundamental la voluntad, supone destacar un criterio subjetivo -cómo debo actuar- y no objetivo -condiciones de posibilidad- siendo ambas las que permiten la toma de su decisión.

Pero esta responsabilidad individual fue compartida, en distintas formas y grados, por todos aquellos que con sus acciones y omisiones promovieron, persiguieron o facilitaron las condenas a muerte y posteriores ejecuciones de los que eran sus vecinos: denunciantes, autoridades locales e informantes. También la de los representantes de la justicia militar -jueces de instrucción, abogados, fiscalía, miembros de los consejos de guerra y auditores-que desde una posición de poder utilizaron la toga para acabar con aquellos a quienes seguían considerando sus enemigos. Y aunque en sus distintas escalas todos estos agentes compartieron diversos grados de responsabilidad sumando una responsabilidad compartida, en ocasiones ésta no quedó reducida a la mera agregación de responsabilidades individuales, sino que debemos hablar de una responsabilidad grupal, en el sentido de que los distintos agentes estuvieron organizados y cooperaron entre sí, con lo que la acción derivaba su propia fuerza del reparto de funciones asignado a cada una de las partes. En este sentido, nada de ello hubiera sido posible si antes el Nuevo Estado no hubiera puesto las condiciones de posibilidad para que dichas funciones pudieran ser desarrolladas dentro del sistema institucional.

En definitiva, la racionalidad instrumental propia de la violencia del Estado se combinó con los odios e intereses locales para llevar a cabo la limpieza que se había perseguido desde el 18 de julio de 1936. En este sentido, el régimen repartió papeles en su afán de "limpiar" España, pero cada una de las personas que, de acuerdo al entramado institucional, intervinieron en el proceso represivo, lo hicieron también a título individual y bajo su responsabilidad personal. Ninguno de ellos se sintió responsable de sus acciones, perseverando en las mismas. 
RESEÑAS DE LIBROS

REVIEWS 

Alonso, Gregorio, La nación en capilla. Ciudadanía católica y cuestión religiosa en España (1793-1874), Granada, Comares Historia, 2014, 376 pp.

$\mathrm{Al}$ acercarnos a las páginas de $\mathrm{La} \mathrm{Na-}$ ción en Capilla sorprende, en primer lugar, la capacidad de su autor para distinguir con precisión los aspectos que rodean la relación entre política y religión, desde la perspectiva de la secularización decimonónica, teniendo en cuenta la complejidad del concepto. A primera vista se trata de un proceso caracterizado por la regresión social de la religión del que deriva una nueva forma de concebir el mundo. Pero la secularización no es un aspecto más ligado a la modernización. La idea de un mundo sacro o plenamente secularizado no se presenta en estado puro. No existe como concepto general, simple y unívoco, corolario del curso modernizador. Se manifiesta más bien como un fenómeno de "guadianización" que obliga a incluir constantes matices y nuevas interpretaciones capaces de ampliar enfoques que giran exclusivamente sobre el estudio de las relaciones Iglesia y Estado.
Un análisis en profundidad nos lleva a tratar de calibrar sus manifestaciones e impacto social, siendo en este sentido el anticlericalismo una de las que ha propiciado más debates en torno a su naturaleza, ya que toca tanto la esfera política y económica como la social. En realidad puede concebirse como una faceta más de la progresiva pero desigual mengua del control eclesiástico sobre la vida de las gentes, visible en muchos campos. Algunas de las posiciones que intentan definirlo o encuadrarlo están impregnadas por una primera interpretación negativa que lo presenta como algo destructivo e irracional. Sin embargo, las variadas dimensiones que adquiere a lo largo del siglo XIX ponen de manifiesto dos elementos clave: por una parte la necesidad de superar tanto las simplificaciones como las categorizaciones excesivas, que establecen tipologías de "anticlericalismos" en función de los discursos que los envuelven y que los interpretan como erupciones inconexas; por otra, que el telón de fondo sobre el que se manifiesta este fenómeno es un desajuste crónico entre una Iglesia identificada con posiciones absolutistas y 
una construcción coherente del liberalismo. Los puntos más álgidos del conflicto clerical-anticlerical ponen de manifiesto la polarización social y la inestabilidad política que caracteriza la construcción del liberalismo hispano en su encuentro con la esfera religiosa. Así pues, la secularización, desde una perspectiva amplia, y el anticlericalismo, en sus momentos de particular intensidad, evidencian que la dinámica política, institucional e identitaria estaban sufriendo una transformación de gran calado que tocará directamente los andamiajes legitimadores de las estructuras sociopolíticas.

La complejidad dialéctica de esta obra se desenvuelve en un marco cronológico amplio que permite al autor realizar un análisis pormenorizado del conflicto, desde los primeros discursos contra el comportamiento del clero, con una clara vinculación moralizante, hasta su punto culminante representado por la Constitución de 1873 y su clara apuesta por la separación de la Iglesia y el Estado. La aparente linealidad cronológica no es más que el escenario sobre el que se sitúan diversos actores y tramas con el objetivo de reflejar y reflexionar sobre los avances y los retrocesos de una pulsión secularizadora con entidad propia que se manifiesta con fuerza frente a la idea de un catolicismo inscrito en el ADN social hispano.

Desde estos planteamientos el libro, a través de un relato atractivo y muy documentado, parte de la géne- sis y el desarrollo de las sucesivas estrategias diseñadas para construir una ciudadanía católica a través del compromiso confesional, visible en los diferentes hitos constitucionales desde 1810. Con mayor o menor intensidad los privilegios cedidos al clero en materia de control social buscaron consolidar un liberalismo fundamentado en el orden y en una idea nacional vinculada al catolicismo como fuerza vertebradora, capaz de definir una realidad nacional única, sin fisuras. Por tanto, con los moderados en el poder la confesionalidad se asume como un referente identitario, consustancial a la idea de españolidad. La enorme ascendencia de la Iglesia en materia educativa y en general social configura un entramado discursivo en torno a un horizonte en el que convergen las creencias y lo valores de la ciudadanía. Pero sus resultados no fueron los esperados ya que no solo quedó excluida la tolerancia religiosa de ese horizonte, sino también la posibilidad de incorporar plenamente conceptos como soberanía nacional o libertades individuales inherentes al propio desarrollo del liberalismo.

A partir del marco cronológico Gregorio Alonso compone tres áreas de estudio bien definidas. En primer lugar dibuja la situación de las relaciones de la Iglesia con el Estado en el último tramo del Antiguo Régimen. Para ello, se centra en la dinámica del sistema regalista y la construcción del 
pensamiento teocrático, un aspecto de gran relevancia, fundamental para comprender la posterior adopción de una estrategia de resistencia violenta a las instituciones liberales por parte de algunos sectores del clero. El segundo campo de análisis se centra en las fórmulas utilizadas en la construcción de una ciudadanía católica durante la etapa moderada. En este sentido el Concordato de 1851 es la expresión más clara tanto de la utilización de la Iglesia como transmisora de los valores liberales como de los privilegios adquiridos por la Institución. En el tercer bloque el autor analiza el impacto social de la dinámica secularizadora impulsada por las fuerzas progresistas, con un claro protagonismo del discurso anticlerical en sus diversas manifestaciones y especialmente su incorporación a la cultura política republicana y laica, como elemento identitario de la misma. Destaca en este sentido el análisis del Sexenio Democrático, un periodo que logró encarnar la fuerza del proceso secularizador en su punto culminante, con la idea de progreso, las aspiraciones modernizadoras y la efervescencia anticlerical que lo representaron en todo momento pero que también dejaron al descubierto sus incoherencias. Las múltiples propuestas sobre cómo materializar el "deber ser abstracto" que diría Aranguren, evidencian la debilidad de un movimiento que oscila entre la convivencia pacífica con una Iglesia y un clero regenerado hasta los más contundentes rechazos a la Institución, como símbolo evidente de los poderes que la revolución debía erradicar si quería ver triunfar el proyecto modernizador. Una dispersión que aprovechó la Iglesia como garante de orden y estabilidad para contrarrestar el embate del progresismo y tratar de proteger sus privilegios.

En definitiva, es un libro que replantea el análisis del catolicismo español en su encuentro con las estructuras del liberalismo, desde una perspectiva temporal y temática amplia, lo que es de agradecer no solo porque trata de superar las simplificaciones derivadas de los análisis exclusivamente políticos o sociales, sino porque los integra en un mismo texto, con el consiguiente esfuerzo de comprensión y síntesis. En suma, un análisis profundo, fundamentado en una profusa y diversa utilización de fuentes, sobre una transformación clave que determinó no solo el devenir político, social o identitario de nuestra historia durante el siglo XIX, sino que como indica el propio autor, ayuda a comprender la importancia y la imbricación del catolicismo en el tejido sociopolítico de la España actual. El libro de Gregorio Alonso es indudablemente una contribución muy importante en esta dirección.

\footnotetext{
ALICIA MIRA ABAD Universidad de Alicante
} 
COletes Blanco, Agustín; LASPRA RODRÍGUEZ, Alicia, (eds. y trads.), Libertad frente a Tiranía: Poesía inglesa de la Guerra de la Independencia (1808-1814). Antología Bilingüe, Madrid y Barcelona, Espasa Libros, 2013, 432 pp.

La Guerra de la Independencia, que los ingleses llaman Guerra Peninsular, tuvo su literatura de primera mano, es decir, literatura de combate y de línea de fuego además de las posteriores recreaciones sobre todo narrativas y más o menos históricas. Fuera de España, el pintoresquismo orientalizante con que la imaginaban muchos escritores, unido a las especiales características de la guerra en este suelo, cuyos aspectos más destacados fueron la guerrilla, en el orden militar y la brutalidad en todos los órdenes, constituyeron un filón muy considerable. Una de las primeras muestras es El manuscrito encontrado en Zaragoza, del conde polaco Jan Potocki, casi interminable narración fantasmagórica, romántica y folklórica, en un sentido mucho más exaltado que el de la obra que se tiene como iniciadora y guía de una visión folklóricamente desencajada de España, la Carmen de Merimée. A esta obra se le echa encima el San Benito de iniciadora del folklorismo andaluz, cuando tan dudoso mérito corresponde más bien a la ópera de Bizet, inspirada en ella, ya que Merimée conocía suficientemente España como para no incurrir en tantas exageraciones. El manuscrito encontrado en Zaragoza procede directamente de la novela picaresca y abre las puertas a muchos tópicos sobre España. Otra novela fantasmagórica, de atmósfera tenebrosa, es El marqués de Bolibar, de Leo Perutz, un excelente narrador checo que, no obstante, nunca alcanzó el reconocimiento que merece. Su mundo literario es muy variado: desde la Praga de la época del extraño emperador Rodolfo II hasta las angustias de un hombre que huye esposado de la persecución policial, Perutz se adentró en episodios históricos de los que pudo sacar material fantástico, y así, en plena guerra napoleónica, aparece el Judío errante en la Bisbal bajo cielos invernales. Otras novelas extranjeras sobre la Guerra de la Independencia que alcanzaron popularidad son Las aventuras de Gérard de Arthur Conan Doyle, sobre un oficial francés fanfarrón e incompetente; $E l$ cañón, de C. S. Forester sobre la que Stanley Cramer dirigió una versión cinematográfica titulada Orgullo y pasión, y el excelente relato Fue a echar una ojeada a los caballos de H. Bean Piper, sobre un cuento clásico de la ciencia ficción, el agujero en el tiempo, por el que un oficial inglés llamado Arthur Wellesley se pregunta quién podrá ser cierto Lord Wellington nombrado con abrumadora insistencia en unos documentos secretos que habían llegado a sus manos. Joseph Conrad, uno de los grandes 
autores del siglo XX y uno de los que verdaderamente merece la pena leer, acudió con frecuencia a las guerras napoleónicas: en El hermano de la costa con el mar como fondo, su escenario favorito y el que mejor conoce, $y$ El duelo que tiene por asunto las campañas de Napoleón, desde las primeras hasta el ocaso de Waterloo, a lo largo de las cuales dos empecinados oficiales sostienen un duelo sin fin a causa de una bagatela. En otra novela corta, La posada de las dos brujas, ofrece un ejemplo literario de la intervención inglesa en la guerra española, $\tan$ profundamente estudiada por la profesora Alicia Laspra en su libro Intervencionismo y revolución. Un oficial británico llamado Edgar Byrne arriba a una costa escarpada y oscura, de altos acantilados y bañada por un mar turbulento, para entrevistarse con un guerrillero que se encuentra en las montañas. Las montañas están a la vista, casi surgiendo de la misma costa, y de manera explícita se declara que aquel lugar es Asturias. No es esta la única ocasión en que Conrad se acerca al Golfo de Vizcaya que nosotros llamamos Mar Cantábrico, y por el cual el novelista había navegado en su juventud, cuando hacía contrabando para los carlistas, y a cuya guerra se refiere en la novela $L a$ flecha de oro y en el episodio El tremolino, que forma parte de El espejo del mar.

A la guerra entre españoles y franceses, y entre españoles y españoles, pronto se agregaron los ingleses, y la intervención británica en la Península Ibérica pondría en movimiento a los poetas ingleses, tanto a los reconocidos como a muchos aficionados. La condición romántica de España les daba una oportunidad que no desaprovecharon. Algunos poetas estuvieron presentes desde los primeros momentos y mantuvieron una actitud decidida en relación con el papel que debía desempeñar Inglaterra en la guerra que comenzaba en España contra la invasión napoleónica. La petición de ayuda por parte de los españoles fue atendida de inmediato. "En un principio, la acogida de las demandas españolas en Inglaterra fue verdaderamente entusiasta y una mezcla de simpatía y cautela las acompañó en otros países -escribe Emilio de Diego en España, el infierno de $\mathrm{Na}$ poleón-. Desde el comienzo, los ministros más influyentes de Jorge III vieron, en la insurrección que sacudía España, una oportunidad de abrir el frente decisivo contra Napoleón. Era la oportunidad de hacer realidad el viejo sueño de Pitt y poner en vías de confirmación la idea de R. Southey, que había escrito a S. T. Coleridge "si Europa ha de ser redimida en nuestros días, sabe usted que siempre he sido de la opinión de que el esfuerzo inicial tendrá lugar en España". De los poetas más conocidos en aquel momento, Robert Southey era quien mejor conocía España y Portugal, a las que había visitado en 1795 y sobre las que 
publicó Letters written during a short Residence in Spain and Portugal, aparecido en 1797. Al lado de Wordsworth y Coleridge, con quienes vivió en la región de los Lagos, iniciándose de este modo el primer romanticismo inglés, su prestigio ha disminuido bastante, y ya en tiempo de Richard Ford critica sus apreciaciones sobre la ciudad española de Benavente, considerándolas "pura imaginación de poeta laureado". Ian Robertson escribe a propósito de su relación con España: "Existen abundantes pruebas de que toda su vida siguió interesado por España, aunque en esta obra se muestra con más frecuencia crítico que elogioso, por mucho que hubiese gozado con su viaje si lo consideramos retrospectivamente; pero, como insinúa Rose Macaulay, Southey era un criticón nato".

Estos poetas, que por patriotas ingleses cantaron como patriotas españoles, son el contenido del bello libro Libertad frente a Tiranía: Poesía inglesa de la Guerra de la Independencia (1808-1814). Antología bilingüe, dedicado precisamente "a los patriotas españoles de todas las épocas", compuesto y escrito por Alicia Laspra y Agustín Coletes, de la Universidad de Oviedo. De la profesora Laspra ya hemos mencionado su fundamental Intervencionismo y revolución; entre las recientes publicaciones del profesor Coletes, autor de un estudio fundamental sobre Pérez de Ayala y Gran Bretaña, se cuenta con las magníficas ediciones y traducciones del Viaje a las islas occidentales de Escocia de Samuel Johnson y de Cartas y poesías mediterráneas de Lord Byron. He escrito "bello libro" a propósito de éste cuyo título abreviado es Poesía inglesa, publicado con esmero, incluso con lujo, por la Fundación Dos de Mayo, creada por la Comunidad de Madrid con motivo de cumplirse los doscientos años del comienzo de la Guerra de la Independencia, con cuidada y clara impresión, bilingüe la de los poemas, con una curiosa y pintoresca estampa a modo de portada: el grabado coloreado a mano que lleva el explicativo título de Los nobles españoles, o Britania prestando ayuda a la causa de la libertad por todo el mundo, ¡sea amigos o enemigos!, de George Cruikshank, y que bien podría representar a la tropa reclutada por Sir John Falstaff. Por lo demás, se trata de un trabajo de importancia tanto literaria como histórica. En numerosos casos, los textos reunidos, aunque vayan en verso, tienen mayor valor como documento histórico que como poesía. Por otra parte, esta poesía, claramente circunstancial, es poco conocida por los españoles, que también desconocen, por lo general, a la propia, reduciéndose a "Oigo, patria, tu aflicción" y poco más. Los autores declaran en el prólogo: "Existe, naturalmente, literatura española sobre la guerra escrita durante los años de conflicto y ha recibido cierto grado de atención por parte de la crítica especializada, pero ha pasado mucho más 
desapercibido el hecho de que también se dio una abundante 'literatura de combate' escrita en otros tantos varios idiomas tanto a favor de la causa aliada como de la napoleónica: principalmente inglés, francés, alemán y portugués en el primer caso, y fundamentalmente francés, italiano, alemán y polaco en el segundo. El libro que el lector tiene en sus manos ha supuesto la elección de una de las múltiples combinatorias de este peculiar fenómeno: a saber, poesía, escrita en inglés, durante la guerra".

En principio estamos ante una antología que es algo más que una antología. Porque también es la documentación histórica de la actitud de algunos poetas ingleses con respecto a los acontecimientos bélicos que tenían lugar más allá de sus fronteras: "poesía comprometida" en una palabra, aunque no lo sea en el sentido sartriano, pero ¿no es comprometida toda poesía que toma posición, y en este sentido deberemos considerar, aunque no sea su aspecto más importante, es obvio, poemas como la Farsalia de Lucano y La divina comedia de Dante? Los poetas reunidos en este libro toman unánimemente partido por la libertad. No por una libertad abstracta, de discurso encendido $u$ oda declamatoria, sino por un concepto más concreto e inmediato. ¿Qué es la libertad para ellos? Estar libres de Napoleón y, en consecuencia, que el resto de Europa lo esté. Para aquellos ingleses que entendían la libertad como manera de vida, de su vida, el Gran Corso representaba todo lo contrario, la tiranía. Siglo y medio más tarde el mismo espíritu se mantiene en pie, enfrentándose la isla a un tirano mucho más cruel y mucho más abyecto que Napoleón y en cuya expresión tampoco faltaron las grandes palabras que Winston Churchill toma prestadas de Shakespeare repitiendo la arenga de Enrique $V$ antes de Azincourt, en términos más dramáticos pero expresando una indestructible confianza como la de aquellos ingleses sobre los campos de Francia que cuando fueran viejos festejarían con sus vecinos el día de San Crispín y San Crispiniano, zapateros: "estoy seguro de que nuestra causa no puede fallar entre los hombres", afirmó Churchill.

Esa misma confianza se advierte en buena parte de los poemas recogidos por Laspra y Coletes. No son poemas de victoria. La poesía que canta la victoria suele ser de rango inferior, porque el ditirambo es menos poético que la elegía. Gilbert Murray señala que en la poesía de la Antigüedad solo los poemas victoriosos alcanzaron una gran altura poética, el canto triunfal de Débora que figura en el Libro de los Jueces y Los persas de Esquilo. Lo demás suele estar invadido por retórica insatisfecha. Por lo que tal vez el poema más intenso de este libro, en el que no faltan las elegías como la dedicada al marqués de la Romana, sea el recuerdo de una desoladora derrota en El entierro de 
Sir John Moore tras la batalla de La Coruña de Charles Wolfe:

No se oyeron tambores ni marchas fúnebres

$\mathrm{Al}$ acarrear presurosos

su cuerpo a la muralla;

Para despedir a nuestro

héroe ante su tumba

No hubo soldados que

descargaran sus armas.

Es, por lo demás, un poema de escenografía plenamente romántica en el que no faltan la noche ("le enterramos en la oscuridad de la noche") ni la luna ("y el rayo de la luna que rasgaba las tinieblas"). Y los versos finales de este breve poema son grandiosos:

No cincelamos una línea, no levantamos lápida alguna

-Le dejamos allí a solas, con su gloria-.

El material sobre el que trabajaron los autores es abundantísimo, por lo que se imponía una selección. Muchos de los poemas fueron escritos a bote pronto, a raíz de la noticia de una victoria o de un desastre, y esta inmediatez, según los antólogos, es poesía: "Poesía porque se trata de un género literario que implica inmediatez y fuerza expresiva en la respuesta, y, por tanto, en la mediación entre el autor y el público". A esta poesía "de combate" concurrieron poetas conocidos, profesionales, por así decirlo, y otros espontáneos, incluso anónimos. Esta característica de los poetas es la base de uno de los criterios sobre los que se asienta la distribución de la antología: de un lado los poetas consagrados (Felicia Hemans, William Wordsworth, Lord Byron, Walter Scott, Charles Wolfe y Robert Southey); de otro los autores relevantes en su época pero poco conocidos en esta (Eyles Irwin, Anna Maria Porter, John Wilson Croker, William Sotheby, John Gwilliam, Anna Laeticia Barbauld, Laura Sophia Temple, Richard Pearson, Anne MacVicar Grant, Thomas Moore y el no identificado refugiado bajo el pseudónimo de Hispanicus) y, en fin, la poesía publicada en la prensa, en la que se repiten los nombres de Thomas Moore y Eyles Irwin junto con otros que firman con las iniciales o van sin firma.

Con buen criterio, cada uno de los "poetas consagrados" va precedido de una introducción; la introducción de los demás apartados es de carácter general. Reparemos, de manera especial, en las introducciones del primer grupo, textos de un interés crítico notable, dado que algunos de los poetas no han sido abordados críticamente entre nosotros. Con las adecuadas síntesis, se resumen las obras de poetas como Wordsworth o Southey, poco frecuentados por la crítica española, o de otros como Sir Walter Scott, evidentemente más conocido por su obra en prosa y por sus novelas históricas, tan populares y que aún se leen con agrado e interés (¿quién puede ignorar al autor de Ivanhoe de Quintín Dur- 
ward, de El talismán, de Rob Roy, de El anticuario, al que debemos tardes inolvidables de amena lectura, por no mencionar las vibrantes adaptaciones cinematográficas de Richard Thorpe que fueron la delicia de nuestra infancia?) y antinapoleónico fervoroso, autor de una extensa biografía de $\mathrm{Na}$ poleón, escrita, según supongo, más que nada para expresar su beligerancia contra el biografiado. No menor en popularidad es Lord Byron, un poeta que, al igual que García Lorca y pocos más, es admirado por personas a las que no les gusta la poesía, lo que no sé si es bueno o no lo es. Byron, es de los poetas "consagrados" antologizados, el único, junto con Southey, que había pisado España, aunque me temo que mientras Southey se daba cuenta de que estaba en España, en la línea de Edward Clark o Joseph Townsend, Byron creía que ya estaba en Oriente, como William Beckford. En Las peregrinaciones de Childe Harold se puede encontrar cualquier cosa que se busque, desde episodios galantes y aventureros hasta la batalla de Waterloo; no faltan el tono declamatorio ni la arenga:

¡Oh bella, admirada

España, romántico país!

¿Dónde está aquella bandera que Pelayo enarboló...?

La contribución de Wordsworth es más reposada, como corresponde a un poeta de costumbres sedentarias (todo lo contrario que Byron). No entro en si se puede ser poeta haciendo la vida de un propietario rural, pero al menos hay más tiempo para escribir que si se anda correteando por el mundo. Al igual que Coleridge se había interesado en la juventud, hasta entusiasmado, con la Revolución Francesa; pero siendo un ejemplo más de que quien no es radical en su juventud no tiene corazón y quien continúa siéndolo a los cuarenta años no tiene cabeza, oportunamente cambió de rumbo a su debido tiempo y, como escriben Laspra y Coletes, "la guerra y lo que ve como malignidad diabólica de Napoleón reemplazarían definitivamente a la Revolución Francesa en sus preocupaciones intelectuales y vitales". Sin necesidad de salir de Inglaterra, Wordsworth le dedicó suma atención a la guerra peninsular escribiendo ya en mayo de 1808 , cuando todavía no se había producido la intervención inglesa, un poema que no publicó. La antología incorpora los catorce sonetos escritos entre 1808 y 1811 pertenecientes a la serie Poemas dedicados a la independencia nacional y la libertad, y es en esta ocasión la primera vez que los catorce sonetos se publican en español, y aparecen reunidos con la numeración, en números romanos, en que figuraban en el conjunto original. Algunos de estos poemas ya habían sido traducidos por Stanley Richardson y Luis Cernuda, como "Cólera de un español altanero", "Sentimientos de un noble vizcaíno en uno de aquellos entierros", ambos de 1810, y "El árbol de 
Guernica". Pero solo cobran sentido al ser publicados los sonetos en su totalidad. Por ejemplo, no se entiende el titulado "El sentir de un noble vizcaíno en uno de aquellos funerales" sin haber leído el soneto que le precede, "Cumpliendo así un rito ancestral".

Southey pone la entonación épica en las inscripciones para el campo de batalla de Talavera y para un monumento en La Albuera: un poco largas para inscripciones destinadas a la piedra, y en una selección del, un poco monótono, Carmen Triumphale para el comienzo de 1814. La contribución de Felicia Hemans es no menos entusiasta y prolija.

Estamos ante una antología importante por muchos motivos. El primero, porque documenta unas actitudes poéticas poco conocidas en español, y, sobre todo, porque algunas de estas muestras poéticas son auténtica poesía.

IGNACIO GRACIA NORIEGA Escritor

Barbastro GiL, Luis, El episcopado español y el alto clero en la Guerra de la Independencia (1808-1814). La huella del afrancesamiento, prólogo de Antonio Moliner Prada, Alicante, Instituto Alicantino de Cultura Juan Gil-Albert, 2013, 407 pp.

El factor religioso tuvo un papel social crucial en el proceso de tránsito del Antiguo Régimen a la contemporaneidad. Se trata, en consecuencia, de un proceso que ha sido estudiado con profusión desde diversos enfoques y disciplinas sociales. La importancia que adquirió la cuestión religiosa, y más concretamente la tradicional catolicidad de la monarquía hispana, desde el mismo inicio de la Guerra de la Independencia española, es un elemento que fue muy discutido e instrumentalizado por quienes vivieron la guerra y vieron brotar en España la revolución liberal y hoy día aún sigue siendo objeto de debate entre los historiadores. La religión se erigió en un instrumento de propaganda de primer orden para los dos bandos enfrentados en la contienda y, por ende, se convirtió en uno de los principales instrumentos legitimadores del poder político y de movilización popular durante la guerra. Para los autodenominados "patriotas" -los antibonapartistas- la guerra tuvo un marcado componente de guerra santa o cruzada, con cientos de frailes y clérigos movilizados paramilitarmente al frente de partidas guerrilleras que luchaban contra el francés y contra el afrancesado. Ni la Constitución bayonense de 1808, otorgada por el emperador Napoleón-aunque nominalmente en el encabezado constara el nombre de su hermano José I- a los españoles, ni la avanzada Constitución gaditana de 1812, gestada por los liberales reunidos en la sitiada Cádiz, cuestionaron la unidad católica de España, sino más 
bien lo contrario: ambas ahondaron en la importancia vertebradora de la religión católica en la sociedad española.

El peso ideológico del episcopado español y del alto clero a lo largo de toda la contienda se nos muestra, en consecuencia, como un asunto clave y de gran calado para una mejor comprensión del grado de socialización del conflicto y muy especialmente entre la gran masa social que componía un mayoritario y analfabeto pueblo llano. Como apuntan la mayor parte de los estudios sobre el particular, el poder de influencia y de control social de la Iglesia católica y de sus ministros en la España de comienzos del siglo XIX era inconmensurable. Fueron numerosos los clérigos que desempeñaron un papel activo o muy activo en los asuntos políticos de los años 1808-1814, tanto en lo que se refiere a la organización de las juntas locales o provinciales, como en la representación en las Cortes de Cádiz -es bien sabido que un tercio del total de los diputados reunidos en Cádiz fueron clérigos-. Los famosos curas guerrilleros movilizaban amplias partidas antifrancesas, los prelados escribían pastorales partidistas, muchos párrocos adoctrinaban a sus feligreses desde el púlpito o a través del confesionario en defensa de la religión y del rey (Fernando VII)...

El catedrático Luis Barbastro Gil, gran conocedor de la época y autor de trabajos que con el andar del tiempo han devenido en referentes histo- riográficos (uno de los más influyentes es, sin duda: Los afrancesados: primera emigración política del siglo XIX español, 1813-1820), nos ofrece en esta sólida monografía un nuevo ejemplo de cómo arrojar nueva luz sobre un aspecto que, aparentemente, no ha sido desatendido en los últimos años conmemorativos del bicentenario de la guerra de la Independencia. Un trabajo de investigación histórico permite avanzar en el conocimiento de un tema por dos motivos principalmente: bien porque utiliza nuevas fuentes primarias y ofrece nuevos datos sobre la materia, bien porque presenta un enfoque del objeto de estudio original y, en cierto modo, novedoso. El presente libro del profesor Barbastro es una buena combinación de ambos supuestos, donde el bagaje del autor es aderezado con el trabajo de muchos años de archivos, bibliotecas, lecturas y reflexión. No se trata, ni mucho menos, del primer estudio sistemático que acomete sobre el protagonismo social y político del clero en los inicios de la Edad Contemporánea. Es también autor, entre otros trabajos, de la monografía Revolución liberal y reacción (1808-1833). Protagonismo ideológico del clero en la sociedad valenciana (Alicante, 1987) y del sugerente artículo "Plan de reforma de la Iglesia española impulsado por Napoleón Bonaparte", (Hispania Sacra, $\left.n^{\circ} 121,2008\right)$.

La obra que aquí reseñamos está estructurada de forma muy clara y 
precisa. En la introducción general el autor trata varias cuestiones generales en torno a la encrucijada que el año 1808 supuso para los españoles, centrándose sobre todo en las diversas actitudes del episcopado y del clero español ante la invasión de los ejércitos imperiales galos, lo cual dependió -como muy bien analiza de forma grupal e individual- de múltiples condicionantes geográficos e ideológicos. Tras la introducción, la monografía se divide en dos grandes bloques. En el primero de ellos se examinan cuestiones como la conducta de los obispos de la cuenca del Duero, las causas del apoyo mayoritario del episcopado español a la "causa nacional" y las vicisitudes de los obispos emigrados y los principales lugares de acogida, así como también se repara en el fenómeno del afrancesamiento eclesiástico en algunos de los territorios ocupados. La segunda parte de la obra supone el grueso de la investigación (pp. 119376) y está dedicada exclusivamente al estudio sistemático de los obispos y clérigos afrancesados, aportando datos relevantes y novedosos acerca de la trayectoria profesional e ideológica de varios eclesiásticos ilustres de la época, como fueron Ramón José de Arce (capellán de palacio y consejero de Estado de José I), Fr. Miguel Suárez de Santander (obispo auxiliar de Zaragoza) y Félix Amat (abad de San Ildefonso y obispo electo de Osma), paradigmáticas personificaciones del puente que muchos españoles hubieron de cruzar en los inicios de la contemporaneidad desde la orilla de la Ilustración hacia el nuevo horizonte del constitucionalismo liberal. Algunos arribaron rápido, otros muchos navegaron a la deriva, sin rumbo definido, o decidieron regresar a la orilla ante el temor de un naufragio. Y es que un buen número de católicos del Ochocientos no supieron muy bien de qué manera encajar y hacer compatibles su tradicional moral y cultura católicas con la nueva doctrina liberal. Máxime si centramos el objeto de estudio en el estamento eclesiástico, en el seno del cual, como es obvio, mayor problemática generó este debate que devino en universal, dentro del particular universo católico decimonónico.

RAFAEL FERNÁNDEZ SIRVENT Universidad de Alicante

Ramírez, Pedro J., La desventura de la libertad. José María Calatrava y la caída del régimen constitucional español en 1823, Madrid, La Esfera de los Libros, 2014, 1165 pp.

Pocas Constituciones históricas han conocido un destino tan cruel como la Constitución de Cádiz, dos veces liquidada por el mismo autor -Fernando VII- y con el mismo móvil -restablecer el absolutismo-. Su primer fallecimiento, del que ahora se cumplen doscientos años, fue en realidad el de un neonato, ya que su articula- 
do no había tenido ocasión de ponerse plenamente en planta debido a las vicisitudes de la guerra de la Independencia. El segundo óbito, sin embargo, se produjo después de tres años de azarosa vida, en los que la Constitución mostró las dificultades prácticas de su diseño, muy ligado al modelo revolucionario francés.

El libro de Pedro J. Ramírez ahonda precisamente en la enorme complejidad de las causas que condujeron a esta segunda defunción de la Constitución de Cádiz: la obstinación de un Monarca nada dispuesto a renunciar a su poder absoluto, el pánico de la Santa Alianza a que la revolución española se extendiese por Europa (como de hecho lo hizo entre los carbonarios italianos, los decembristas rusos y el movimiento ventista portugués), la fractura del liberalismo español otrora uniforme, la oposición de la Iglesia desposeída de su Santo Tribunal, el cambio de mentalidad constitucional de los moderados, o la radicalización de los exaltados son algunos de los muchos factores que, como va desgranando el autor, contribuyeron de forma decisiva a liquidar la más internacional de nuestras Constituciones históricas.

Para desenredar esta urdimbre de circunstancias, Pedro J. Ramírez aporta una fuente documental inédita: el archivo de José María Calatrava, integrado por los Apuntes sobre los principales sucesos del último Ministerio Constitucional y las Notas reservadas, textos elaborados, ambos, durante su desempeño del cargo de Secretario del Despacho de Gracia y Justicia en el último Gobierno del Trienio. En ellos, Calatrava relataba -para su propio recuerdo y no como memorias públicas- los acontecimientos en los que se vio envuelto aquel desdichado gabinete que hubo de afrontar la segunda caída del régimen constitucional gaditano. El archivo, tal y como se desprende de la obra, es de una importancia capital para entender los pormenores de la crisis política suscitada a raíz de la incapacitación del Rey, su traslado a Cádiz, y la ulterior capitulación de aquella plaza ante las tropas lideradas por Angulema.

Por fortuna el archivo cayó en unas manos que han sabido sacarle un extraordinario provecho. Huyendo de lo más fácil -que hubiera sido simplemente transcribir la documentación y publicarla-, Pedro J. Ramírez ha asumido la compleja tarea de reconstruir los últimos meses del Trienio utilizando el archivo de Calatrava como una fuente documental más, sujeta a constante cotejo con las innumerables fuentes doctrinales y bibliográficas que maneja en el volumen. Entre las cuales, por cierto, se incluyen otros recientes hallazgos: los diarios de viaje de Fernando VII y el proyecto constitucional de los anilleros, felizmente recuperados por Emilio La Parra y Clara Álvarez Alonso, respectivamente. Pedro J. Ramírez sale exitoso de la hercúlea tarea, ya que su minu- 
ciosa investigación se ha traducido en un libro imprescindible para todo el que quiera en lo sucesivo estudiar el Trienio Constitucional.

En realidad, el autor ya tiene probada experiencia en el estudio riguroso de etapas convulsas del primer constitucionalismo europeo. No en balde su anterior obra de cariz histórico, El Primer Naufragio (La Esfera de los Libros, Madrid, 2011), abordaba el ascenso al poder de los jacobinos franceses que desembocó en el régimen de la Convención. Una etapa, dicho sea de paso, que para algunos de los actores políticos del Trienio Constitucional albergaba no poca identidad con lo que sucedía en España, como el propio Pedro J. Ramírez se encarga de poner de relieve en su libro ahora recensionado.

La desventura de la libertad es, por tanto, mucho más que el archivo de Calatrava en que trae causa. Se trata de una obra integral, en el sentido más propio del término, ya que constituye una ambiciosa reconstrucción de la época, elaborada con una minuciosidad casi inédita en España, a pesar de los centenares de estudios que han abordado el Trienio Constitucional. Y ese carácter integral al que me refiero se materializa en diversos aspectos de la obra. En primer lugar, en el hecho mismo de que, aunque el objeto principal sean los acontecimientos que mediaron desde el nombramiento de Calatrava como jefe oficioso del último Gobierno liberal el 13 de mayo de
1823 hasta la caída del régimen constitucional en noviembre de ese mismo año, en realidad Pedro J. Ramírez profundiza en la historia de la totalidad del Trienio. Es más, frecuentemente se remonta también al momento primigenio del constitucionalismo histórico español, la Guerra de la Independencia, con constantes referencias a la etapa de la Junta Central y, sobre todo, a las Cortes de Cádiz. De este modo, logra conectar con gran habilidad los debates políticos de 1808-1812 con los del Trienio, mostrando los elementos de su continuidad, evolución y cambio. En este sentido, el libro ofrece mucho más de lo que indica su subtítulo (José María Calatrava y la caída del régimen constitucional español en 1823), porque en realidad es una obra que abarca la totalidad del Trienio Liberal.

Pero el carácter integral del libro también responde a la visión de conjunto que ofrece de la época. Desde luego el núcleo está integrado por los acontecimientos tanto políticos como militares en los que se desenvolvió el Trienio y su caída con la entrada de las tropas de la Santa Alianza. Pero de forma transversal, Pedro J. Ramírez ofrece un relato social y cultural que permite al lector sumergirse en la época: desde la descripción detallada de los emblemáticos edificios donde se desarrollan los acontecimientos, hasta los eventos culturales más destacados de aquel tiempo (el vuelo en globo de madame Coussoul, la navegación por 
el Guadalquivir del barco Trajano, la representación del Pelayo de Quintana o el espectáculo Fantasmagoría de Étienne Gaspard Robertson). Unido al estilo de narrativa histórica empleado por el autor, todo ello permite que el lector se sumerja en la época perfectamente recreada.

También hay un tratamiento integral a la hora de analizar la vida y el pensamiento político de los actores del Trienio. Siendo Calatrava el personaje principal del libro, en ocasiones avanzamos docenas de páginas sin que su nombre ni aparezca. Toman entonces el relevo otros muchos protagonistas de los acontecimientos políticos, cuyas semblanzas intelectuales y personales son relatadas con extraordinario rigor. Yandiola, Antonio Alcalá Galiano, José Canga Argüelles, Falcó, Agustín Argüelles, Rafael del Riego... los principales diputados y cargos públicos del Trienio reciben su correspondiente análisis, en el que no faltan sus intervenciones parlamentarias, pero tampoco un relato personal de sus vivencias e inquietudes, mostrando la parte más humana de cada uno de ellos. Algo que, al mismo tiempo, permite muchas veces entender mejor sus motivaciones políticas.

Entre los muchos personajes cuyas experiencias políticas y vitales encuentran acomodo en el libro se encuentran también los políticos extranjeros que tomaron parte activa en los acontecimientos de la España de 18201823, como Canning, Chateaubriand o Villèle. Algo que me permite entroncar con otra de las grandes virtudes de la obra que evidencia su carácter integral: me refiero a la contextualización del Trienio en el panorama comparado. Bien es cierto que la postura de la Santa Alianza sobre los acontecimientos revolucionarios acaecidos en España ha sido objeto de tratamiento por numerosos estudios. Sin embargo, pocas veces se encuentra un análisis tan completo y en el que se entrelacen con tanta solvencia la correspondencia diplomática (e incluso privada, en el caso de Chateaubriand) con los acontecimientos vividos en el Trienio. Este tratamiento comparado de la historia política española resulta especialmente relevante por infrecuente. $Y$ es que, entre quienes se dedican a la historia política y constitucional española, existe todavía tendencia a analizarla de forma aislada, lo cual entraña incurrir en un evidente problema de descontextualización. Las más de las veces resulta vacuo intentar comprender cabalmente nuestra propia historia sin conectarla tanto con las doctrinas como con los acontecimientos políticos que se desenvolvieron allende nuestras fronteras. Y esto resulta especialmente cierto en una etapa como la del Trienio, en la que el liberalismo español bebía constantemente de las doctrinas francesas e inglesas, a la par que sus propias decisiones eran conocidas y comentadas entre los intelectuales y políticos de Europa quienes, a su vez, 
interferían de forma constante en los acontecimientos españoles, que veían como un asunto propio.

De todo lo anterior puede desprenderse que no resulta posible en una recensión abordar siquiera mínimamente los distintos aspectos que se tratan en La desventura de la libertad. Aun así, no puedo dejar de mencionar algunas aportaciones especialmente significativas del libro de Pedro J. Ramírez.

La primera consiste, obviamente, en la reivindicación de la figura de José María Calatrava. Un personaje de una extraordinaria talla intelectual que, sin embargo, no sólo es "desconocido para los españoles de hoy", como menciona el propio autor del libro, sino que también ha sido injustamente tratado por la historiografía, que le ha prestado muy escasa atención. Disipando al personaje de la niebla en la que estaba envuelto, Pedro J. Ramírez rehabilita la figura de Calatrava y subraya su importancia antes incluso de los momentos más decisivos de su vida política -su jefatura del último Gobierno constitucional del Trienio-, destacando su activa intervención en algunos de los debates capitales de las Cortes de Cádiz y del propio Trienio. No parece tampoco coincidencia que Calatrava -llamado en 1823 a ser él mismo Secretario del Despacho- hubiese prestado como diputado especial atención al modo en que debía configurarse la responsabi- lidad del Ejecutivo en nuestro país. Basta recordar cómo en los debates de las Cortes gaditanas defendió con tesón que los ministros resultasen personalmente responsables de los actos de los regentes, sin perjuicio de que estos últimos también pudiesen ser imputables por infracciones de las decisiones adoptadas por las Cortes. Pero, lo que resulta más importante, ya en 1812, Calatrava había adelantado que la falta de aptitud del Ejecutivo -por ejemplo, su demostrada debilidad a la hora de cumplir con las decisiones de las Cortes- era causa suficiente para que la Asamblea Nacional pudiese remover a los regentes. De este modo, estaba transitando desde una concepción meramente jurídica de la responsabilidad del Ejecutivo, hacia una idea más próxima a la responsabilidad política. Un planteamiento que sobre el que Calatrava profundizaría durante el Trienio, al ser autor de la que en puridad puede considerarse como el primer antecedente de la moción de censura en España.

Por esta sola circunstancia, Calatrava ya parece erigirse en digno merecedor de una consideración que hasta ahora se le había negado. Aun así, Pedro J. Ramírez ha añadido nuevos datos que permiten apuntalar las palabras de Antonio Alcalá Galiano cuando identificaba a Calatrava como perteneciente "a un partido medio entre el moderado y el exaltado" (p. 118). En la obra recensionada, Pedro J. Ramírez muestra la dificultad de ceñir a 
Calatrava a uno de los dos bandos en los que se escindió el liberalismo a partir de 1821 y en este sentido uno de sus grandes aciertos ha sido considerarlo como exponente de lo que el periódico de Alberto Lista y Gómez Hermosilla, El Censor, calificaba como "partido regulador", caracterizado por su capacidad para bascular entre los extremos políticos de las Cortes a fin de lograr un equilibrio de fuerzas.

Otro detalle de gran interés que desgrana el libro de Pedro J. Ramírez es la confirmación de que el modelo constitucional gaditano resultaba de difícil implantación, al basarse en la desconfianza entre los dos órganos políticos principales del Estado, Rey y Cortes. En este sentido, La desventura de la libertad apuntala lo que con gran perspicacia Joaquín Varela Suanzes-Carpegna definió como la "monarquía imposible" del Trienio (Joaquín Varela Suanzes-Carpegna, La Monarquía doceañista, Marcial Pons, 2013). A lo largo de sus páginas, Pedro J. Ramírez nos ofrece constantes ejemplos de los problemas de la Constitución de Cádiz para articular las relaciones entre Ejecutivo y Legislativo. En la base se hallaba la concepción dualista del poder ejecutivo, conforme al cual los ministros (caracterizados constitucionalmente como "Secretarios del Despacho") no eran formalmente más que transmisores de la voluntad regia, de cuya voluntad dependían. Ahora bien, teniendo presente los constantes conflictos entre el Rey y sus ministros, que tan bien describe Pedro J. Ramírez, estos últimos se veían abocados a tratar de imponerle al Monarca sus decisiones políticas o a solicitar que los exonerase del cargo por carecer de apoyo regio. Dicho con certeras palabras del autor: "Según la Constitución el poder del Gobierno solo emanaba del rey, pero en aquellas circunstancias gobernar significaba oponerse cada día a la voluntad íntima del rey, con tal de que esa contradicción no quedara explícita" (p. 520). En esta tesitura, ministros que contaban con el respaldo del Parlamento y que trataban de llevar a efecto la voluntad nacional se encontraban con harta frecuencia imposibilitados para hacerlo debido a la pertinaz oposición del Rey. En sustancia el problema residía en no contar con un sistema de gabinete en el que el Gobierno dependiese exclusivamente de la confianza parlamentaria, recibiendo del Monarca apenas un nombramiento nominal. En ausencia de tal sistema (implantado en Gran Bretaña desde finales del XVIII), la posición de los ministros resultaba extremadamente frágil: desde una perspectiva material debían obedecer la voluntad de las Cortes y contar con su confianza, pero formal, nominalmente, debían llevar a efecto la voluntad del Monarca, único que podía nombrarlos y destituirlos según el tenor constitucional. De hecho, Pedro J. Ramírez expone con detalle algunas de las absurdas situaciones que se produjeron, en las 
que los ministros, incapaces de desarrollar su política, tampoco conseguían obtener del Rey su destitución, hallándose así en una encrucijada imposible.

Otro aspecto extremadamente interesante del libro es la constatación de los diversos intentos de reformar la Constitución de Cádiz en un sentido bicameral que se ajustase más al modelo británico, implantado en Francia merced a la Charte de 1814. En realidad, la idea de superar el unicameralismo de la Constitución del 12 ya había encontrado cierto eco antes incluso del Trienio, por ejemplo en la postura "posibilista" de Flórez Estrada en su Representación a Fernando VII, o en el proyecto constitucional del denominado "Plan Beitia" de 1819, descubierto en su día por Claude Morange, y muy próximo a las teorías de Benjamin Constant y Destutt de Tracy. Sin embargo, fue en el Trienio cuando esta alternativa empezó a cobrar auténtica fuerza, tanto desde el exterior (sobre todo por parte del gobierno británico), como desde el interior (a través de un sector del moderantismo, que había cambiado sus ideas políticas durante el sexenio absolutista). Para los exaltados más extremistas el denominado "plan de las Cámaras" se convirtió en un sinónimo de involución, como evidencian las numerosas referencias de El Zurriago que cita Pedro J. Ramírez. Sin embargo, los moderados llegaron a consideraron que la supervivencia del régimen constitucional dependía de modificar la Constitución de Cádiz, desvinculándola del modelo revolucionario francés de 1791 a fin de tranquilizar a las potencias extranjeras y adaptar el sistema representativo español al "espíritu del siglo", como diría Martínez de la Rosa. En este sentido, Pedro J. Ramírez muestra con maestría hasta qué punto la contienda sobre el modo de organizar las Cortes se convirtió en la línea divisoria del liberalismo. En tanto los moderados, ya más próximos al liberalismo doctrinario, se mostraban partidarios de transitar al bicameralismo (lo cual también permitiría calmar a las potencias extranjeras), los exaltados demonizaron tal opción, considerando que suponía un freno inaceptable para el proceso revolucionario.

En este punto, son muy interesantes los datos que aporta el libro para aquilatar el carácter casi mítico que llegó a adquirir lo que denominaba despectivamente se denominaba como "el plan de las cámaras". Ciertamente, no pocos autores extranjeros veían en el unicameralismo uno de los grandes defectos de la Constitución gaditana. Así lo habían manifestado, por ejemplo, en Inglaterra los tories a través de la Quarterly Review y los whigs mediante la Edinburgh Review, o en Francia desde liberales como Dominique Dufour Pradt, hasta Duvergier de Hauranne y Jean Denis Lanjuinnais, pasando por liberales doctrinarios de la talla de Guizot, Madame de Staël e 
incluso ultrarrealistas como Chateaubriand. Ahora bien, como muestra Pedro J. Ramírez, la presión extranjera para implantar en España el bicameralismo sirvió a la postre como una cortina de humo que legitimó la vuelta del absolutismo. Así se evidencia en la difícil postura que hubo de asumir el duque de Angulema: quizás por ingenuidad, insistió en considerar que la invasión de la Santa Alianza tenía como propósito imponer un cambio constitucional en España que siguiera las pautas bicamerales de la Charte de 1814 . No podía estar más equivocado. Gran Bretaña sí insistía en la solución bicameral, pero Francia no consideraba que esa fuese necesariamente la verdadera solución, sino que apostaba, simple y llanamente, por reinstaurar a Fernando VII en todo el esplendor de su trono, tal y como reivindicaba desde España el periódico absolutista El Procurador General del Rey (p. 652). En este punto, el protagonista del drama, Calatrava, haciendo gala de una extraordinaria flexibilidad, trató de obtener de la Santa Alianza garantías de que España disfrutaría de un régimen representativo (p. 760). Ya no importaba que fuese unicameral o bicameral, sino al menos que se tratase de un régimen en el que la Nación tuviese voz. La respuesta francesa resultó cada vez más descorazonadora: por una parte, Francia proponía que España se gobernase por unas Cortes tal cual habían existido en el pasado, algo, como diría Yandiola, inasumible en el siglo XIX (pp.
688-689); por otra, el país vecino insistía en que la nueva Constitución emanase del propio Monarca (p. 765). Pedro J. Ramírez narra con maestría la desesperación de un Calatrava consciente de que Fernando VII jamás reconocería para España un régimen representativo, de modo que la invasión extranjera y la restitución a Fernando VII sin previas garantías políticas sólo podía deparar el retorno del absolutismo y, con él, la venganza del taimado Monarca.

Finalmente no puedo dejar de destacar un último aspecto del libro especialmente interesante: la reivindicación de la Sociedad del Anillo. Este grupo político, integrado por algunos de los más brillantes líderes del moderantismo, como Toreno o Martínez de la Rosa, hubo de convivir con los furibundos ataques de los exaltados que, sobre todo a través El Zurriago y La Tercerola, cargaron contra él, retratando a sus miembros como "pasteleros" y tibios con el absolutismo. Los anilleros no han recibido mejor trato por parte de la historiografía, que les ha prestado escasa atención. Basta comprobar cómo el mayor experto en el Trienio, Alberto Gil Novales, se han mostrado mucho más inclinado a favor de las sociedades patrióticas exaltadas y, en general, a estudiar y encomiar el pensamiento político del ala radical del liberalismo, desde Rafael del Riego hasta Juan Romero Alpuente. Pedro J. Ramírez demuestra, sin embargo, que la Sociedad del Anillo fue en su composición más plural de 
lo que inicialmente se había pensado. No estaba, pues, integrada sólo por el ala más conservadora del moderantismo, sino que en sus filas se habían integrado, al menos en un primer momento, incluso algunos paladines de la exaltación, como Palarea (p. 139). Pero, sobre todo, Pedro J. Ramírez demuestra que los anilleros defendieron un programa político más posibilista para el Trienio. Su apuesta por el bicameralismo -concretado en el proyecto de Fuero Real de España recientemente hallado por Clara Álvarez Alonso y que maneja Pedro J. Ramírez- se acomodaba mejor a las exigencias exteriores $y$, muy en particular, a las británicas. Es posible que, de haber tenido éxito su propuesta de reformar la Constitución de Cádiz para alejarla del modelo revolucionario francés, la Santa Alianza hubiera tenido menos argumentos para intervenir en España, y la oposición británica a la invasión hubiese resultado también más determinante.

$$
* * *
$$

Lo anterior no es, sin embargo, más que un conjunto de reflexiones que no alcanzan a mostrar la profundidad del libro recensionado. Su estilo narrativo y alejado de los rigores académicos no deben llevar a engaño: se trata de una obra imprescindible, que debe estar en los anaqueles de quienes deseen profundizar en las vicisitudes de la apasionante historia del Trienio Liberal.

IGNACIO FERNÁNDEZ SARASOLA Universidad de Oviedo
QUINTERO, Tomás; FARMER, Thomas, Informes del espía de la República de Colombia en la corte de Fernando VII (1825-1830), edición, presentación y notas por Daniel Gutiérrez Ardila, Bogotá, Universidad Externado de Colombia, 2012, 563 pp.

Este volumen contiene los informes enviados desde Madrid a la embajada en Londres de la República de Colombia por Thomas Farmer, pseudónimo utilizado, en traducción directa de su nombre, por el caraqueño Tomás Jesús Quintero. Comienzan en 1825, a los pocos años de constituirse la República, y finalizan en 1831, una vez esta quedó dividida en las repúblicas de Nueva Granada, Venezuela y Quito.

Quintero llegó a España en 1817 acompañando, en calidad de secretario particular, al arzobispo de Caracas Narciso Coll y Prat. El arzobispo había sido acusado de connivencia con los independentistas por el general Morillo, comandante del ejército español destinado a combatir a Bolívar en el antiguo virreinato de Nueva Granada. Viajaba a la corte con el propósito de reivindicarse, cosa que logró, pero a causa del avance de la insurrección en el territorio de su diócesis no pudo regresar de inmediato y el 28 de diciembre de 1822 le sorprendió la muerte en España. Tampoco Quintero consiguió volver a su tierra, en este caso debido al estado de guerra en España provocado por la invasión en 
abril de 1823 de un ejército francés (los Cien Mil Hijos de San Luis), llegado para derrocar el sistema político constitucional establecido tres años antes. Quintero quedó en Madrid en situación personal precaria, sin oficio y sin protector. Además, sus ideas políticas, claramente liberales (había colaborado en la prensa de este signo y formado parte destacada de la Sociedad Patriótica de Amantes de la Constitución) chocaban con el ambiente represor característico a partir de 1823 de la España de Fernando VII. Como apunta el doctor Daniel Gutiérrez Ardila en su excelente introducción a este volumen, "era uno de los muchos jóvenes neogranadinos y venezolanos que languidecían en la Península empobrecidos y sin destino, y que esperaban encontrar algún empleo en el servicio de la nueva república." (p. 22). No consiguió la ansiada colocación, al menos con carácter oficial, pero trabajó mucho al servicio de la República de Colombia en calidad de informador o agente confidencial en Madrid, en definitiva, como lo califica el editor, de espía.

Dotado de un talento para la observación fuera de lo común y de una asombrosa capacidad de relación humana, Quintero cumplió este cometido con extraordinaria habilidad. Adquirió conocimiento de documentos de muy distinta naturaleza, no pocos oficiales (por ejemplo, en uno de sus informes copia capítulo por capítulo el presupuesto del Estado español para
1830), logró acceder a la correspondencia privada de personas de relevancia y se ganó la confianza de algunas de ellas. Resalta en este punto su estrecha relación con Alexander Everett, embajador de Estados Unidos en Madrid de 1825 a 1829. Gracias a su cargo, Everett, firme partidario del entendimiento entre la monarquía española y las nuevas repúblicas americanas, manejó asuntos reservados y de ellos informó a Quintero, convirtiéndose en una de sus principales y más valiosas fuentes de información, así como en una especie de consejero personal, como el propio Quintero da a entender en distintas ocasiones.

Los informes del espía americano abordan asuntos muy diversos y, debido a lo dicho, presentan un alto grado de fiabilidad. Sus noticias sobre las decisiones políticas de Fernando VII y su gobierno son exactas y acertados sus juicios sobre las personas, en particular sobre algunos de los ministros más influyentes del momento y que por el ámbito de sus competencias más le interesaban (Calomarde, el duque del Infantado, González Salmón...). Siempre se muestra sumamente crítico con ellos y aunque en ocasiones quizá lo sea en exceso, como es el caso de Infantado, sus puntos de vista no deben ser despreciados. Como es lógico, a Quintero y a los destinatarios de sus mensajes (las autoridades de la República de Colombia), preocupaba sobre todo la actitud de Fernando VII ante las nue- 
vas naciones americanas y los movimientos del gobierno español para conservar Cuba y Puerto Rico, únicos restos ya del antiguo imperio hispánico. En lo concerniente a este segundo aspecto, los escritos de Quintero, redactados siempre en tono crítico, están cargados de ironía y a veces, incluso, de altas dosis de burla, pues casi todos los proyectos esbozados, y algunos anunciados, para "recuperar el imperio" eran baladronadas o, simplemente, quimeras, ya que el gobierno de Fernando VII carecía de recursos económicos, de soldados y de navíos para organizar una campaña con visos de éxito. Pero lo más grave -este es un extremo en el que con buen criterio abunda Quintero- era el desconocimiento en la corte y el gobierno acerca de la situación política de América. La constatación de esta realidad es, quizá, una de las aportaciones de mayor interés del espía Quintero y, por ende, uno de los valores más relevantes de este volumen. No fue solo la nulidad de los ministros de Estado de esta década -nulidad, a juicio de Quintero, contrastada por sus actos y sus palabras-, sino también y fundamentalmente la incapacidad del gobierno para organizar algún plan destinado a afrontar la nueva situación creada por la aparición de las repúblicas independientes americanas. Todo se redujo -señala Quintero con no poca amargura- a negar la realidad: ni se reconocieron los reveses militares españoles en América ni el nuevo esta- do político del continente (este fue, según se deduce de la lectura de estos informes, uno de los grandes defectos de la política de Fernando VII), ni se tuvieron en cuenta los cambios experimentados en la situación internacional, ni se tomó en serio a los americanos. Calomarde, el ministro más influyente sin duda de Fernando VII en estos años (así lo hace constar con acierto Quintero), personificó quizá mejor que nadie esta postura. Con su habitual suficiencia, derivada de la ignorancia y de saberse protegido por Fernando VII, Calomarde presumió de ser la única persona capaz de resolver el problema de la independencia de América. En el colmo de la desfachatez, el ministro afirmó en 1828: "Si no se hubiera extinguido el Ministerio Universal de Indias, y quitándoseme por consiguiente la dirección de los negocios de América, hoy sería toda ella una balsa de aceite; pero ya que voy desocupándome de lo que me han dado que hacer las revoluciones de la Península, me consagraré ahora a terminar las de allá" (p. 324). Nada más expresivo que esta frase para dar cuenta del talante de los gobernantes españoles del momento.

La ceguera del rey y de su gobierno, junto a su ignorancia sobre América, fueron factores de mucho peso para no resolver, sino más bien agravar, un problema político de enorme importancia. Pero por lo que se acaba de ver, no fue solo eso. Sobró petulancia. No es de extrañar, por tanto, que el 
espía de la República de Colombia exprese una opinión muy desfavorable de los gobernantes, pero también, fundamentalmente por efecto de la actuación de estos, sobre España, que califica de "país miserable". Su primer informe lo fecha el 9 de mayo de 1825 en "Caligulópolis", es decir, Madrid, ciudad que puebla "gente necia e imbécil". En otra ocasión, aludiendo a su lucha contra Napoleón tilda a los españoles, en general, de "pueblo feroz", dado al vandalismo y al pillaje, aunque a continuación, en el mismo escrito, de 1826, matiza que se refiere "al populacho" y a los frailes, pero no a "la clase instruida de la nación", a la cual atribuye un sincero deseo por dotar de "estabilidad y consistencia a los gobiernos libres de América" (pp. 122-123).

El punto de vista de Quintero es, sin duda, especialmente valioso para comprender el significado inmediato en España de la independencia de América y la reacción, sin lugar a dudas desatinada, del rey y de sus ministros. Pero el interés de sus informes no termina ahí. Estos son asimismo una fuente muy apreciable de noticias sobre el estado político de la monarquía española en la última década del reinado de Fernando VII. Por lo general, Quintero pone mucho cuidado en ofrecer información contrastada y cuando solo puede basarse en rumores, lo hace notar, preocupándose por confirmarlos o desmentirlos, según el caso. Aparte de las referencias sobre cambios ministeriales, la camarilla real, los movimientos de personas muy variadas (por ejemplo, las rocambolescas maniobras emprendidas por unos supuestos enviados por el dictador paraguayo doctor Francia, uno de los cuales llegó incluso a entrevistarse con el rey), etc., el lector hallará interesantes novedades, por ejemplo un importante informe sobre la política española en 1824 entregado al rey por el conde de Dernath, quien acababa de dejar la embajada danesa en Madrid, o las actuaciones para suscribir un empréstito internacional a favor de la monarquía protagonizadas por Louis Tassin, un curioso y poco conocido personaje implicado con diversos planes económicos relacionados con Fernando VII durante su estancia en el château de Valençay, en el tiempo de la guerra contra Napoleón.

El volumen se cierra con la reproducción de dos escritos emitidos por otros agentes de Colombia, anónimos, cuyo contenido no es menos interesante que el de los textos de Quintero. La edición está muy cuidada. Los informes editados, que son -en resumen- una fuente muy relevante tanto para la historia de la República de Columbia como para la de la España de Fernando VII, están precedidos por una extensa y erudita Introducción y van acompañados de notas muy oportunas, sustentadas en estudios recientes, todo ello a cargo del historiador Daniel Gutiérrez Ardila, autor de un importarte estudio sobre la República 
de Colombia publicado en 2012 por la misma editorial que saca la obra comentada (El reconocimiento de Colombia. Diplomacia y propaganda en la coyuntura de las Restauraciones).

EMILIO LA PARRA LÓPEZ Universidad de Alicante

PAstor garRigues, Francisco Manuel, A las puertas del Protectorado. Las negociaciones secretas hispanofrancesas en torno a Marruecos (1901-1904), presentación por Alberto M. Pérez Calero, prólogo de Juan Ortiz Villalba, Sevilla, Universidad de Sevilla-Ateneo de Sevilla, 2013, 253 pp.

En el marco del imperialismo colonial europeo del siglo XIX figuró entre sus objetivos preferentes el reparto del continente africano. Así se hizo en efecto, fundamentalmente entre Francia y el Reino Unido, con participación en un plano más secundario de Alemania, Bélgica, Portugal, España y luego Italia, para satisfacer reivindicaciones históricas e intereses económicos ya introducidos. Todo ello según lo convenido en la Conferencia internacional de Berlín de 1885.

A comienzos del siglo $\mathrm{XX}$, asignado Egipto al control británico, tan solo habían logrado librarse del reparto colonial tres estados con entidad propia: Abisinia (actual Etiopía), Liberia y Marruecos. El primero termina- ría siendo sojuzgado por Italia; el segundo, país de acogida de colectivos norteamericanos de color allí reasentados tras la abolición de la esclavitud en los Estados Unidos, garante de su independencia, y Marruecos, sultanato reunificado y regido por la actual dinastía alauí, si bien hundido en el estancamiento y atraso bajo un régimen casi medieval. El control de este último era disputado por Francia, España y el Reino Unido con argumentos históricos y socioeconómicos diversos, terminando imponiéndose los dos primeros, si bien otorgando a los intereses británicos un tratamiento preferente.

Aunque España había logrado con su triunfo bélico sobre Marruecos de mediados del siglo XIX ("Guerra de África" de 1859-1860) una situación de máxima influencia sobre ese país, tal hegemonía fue más teórica que real, dado que sus prioridades en materia internacional se circunscribían al mantenimiento de su soberanía en Cuba y restantes restos de su perdido imperio ultramarino con la consiguiente reticencia a la posibilidad de nuevas adquisiciones territoriales. Tan solo aceptó hallarse presente allí donde le fue señalado al aplicársele los criterios convenidos para todos los estados con pretensiones coloniales. En el presente caso con referencia a Marruecos, Sáhara Occidental y Guinea, áreas de tradicional proyección española, en donde, pese a todo, España procuró ahora autolimitar su 
presencia así como los compromisos que le fueron impuestos internacionalmente. Y ello incluso después de que con la quiebra de 1898 hubo de renunciar a sus anteriores dominios coloniales. Se entiende, por tanto, el escaso empeño puesto por los sucesivos gobiernos de Madrid, ahora atraída su atención por asuntos internos que no internacionales, en ocupar la Zona Norte del Protectorado en Marruecos que finalmente le fue asignada en sus acuerdos con Francia de 1912, y a la consiguiente prolongación durante una década de la cruenta resistencia rifeña ante la falta de voluntad española en controlar la situación. A su vez esa dejación explica la tardía presencia española en Sahara Occidental y Guinea, presencia reducida a territorios casi testimoniales.

El autor de la presente monografía es un reconocido especialista sobre la proyección hispano-francesa en Marruecos en el tercio inicial del siglo $\mathrm{XX}$, y muy especialmente en el prolongado y complejo proceso negociador culminante en la declaración del Protectorado franco-español sobre Marruecos en 1912. Realiza aquí un detallado y bien documentado análisis del definitivo replanteamiento en España de lo que se dio en llamar "cuestión marroquí", es decir la delimitación de un nuevo estatuto para un Marruecos sujeto a influencia europea. En lo que a España concierne, analiza la actitud ante esa cuestión de los dos grandes partidos políticos es- pañoles del momento, el Conservador y el Liberal, y consiguientes visiones contrapuestas de conservadores y liberales respecto al presente y futuro marroquí, o lo que es igual del eje Maura-Silvela frente a Sagasta y colaboradores, así como de los respectivos continuadores de unos y otros a su paso por el Ministerio de Estado.

También es otorgada atención preferente a la determinante actuación de Francia, que llevó siempre la iniciativa en este asunto, y que para alejar pretensiones del Reino Unido procuró el apoyo de la Entente Cordiale al objeto de diseñar e implantar un modelo colonial en Marruecos acorde con los intereses galos: el país mantendría su integridad territorial y teórica independencia bajo la soberanía de la dinastía alauí reinante en el mismo, pero sometido a régimen de Protectorado franco-español con control por Francia de la totalidad del territorio salvo una testimonial presencia española en el norte marroquí, área inmediata a España, exceptuado el fundamental puerto de Tánger, sujeto a régimen internacional. Esas negociaciones a cuatro bandas de París con Madrid, Londres, Berlín y el Majzén marroquí, entre 1901 y 1904, que prefiguran el definitivo Convenio hispano-francés de 1912, contempladas desde el ángulo de la diplomacia española, son analizadas con todo detalle en la presente monografía. Aproximación franco-española esa que, como subraya el autor, a nivel internacional 
más amplio tuvo también efectos destacados, dado que Madrid logró así superar sus secuelas de aislamiento, y sin perjuicio de mantener su básica neutralidad, vincularse indirectamente a la Entente Cordiale.

Estamos por tanto ante una excelente e innovadora aportación sobre la temática de referencia, elaborada con sólido apoyo documental fundamentado en la consulta amplia y sistemática de los fondos inéditos, impresos, hemerográficos y bibliográficos españoles, franceses y británicos conservados en una decena de archivos e instituciones afines. Inclusión de un denso aparato crítico, de una amplia y actualizada bibliografía, y de atrayentes y útiles cuerpos de cartografía y láminas originales.

\section{JUAN B. VILAR Universidad de Murcia}

Fuentes Codera, Maximiliano, España en la Primera Guerra Mundial. Una movilización cultural, Madrid, Akal, 2014, 238 pp.

Cada vez es más frecuente que la producción historiográfica se mueva a golpe de efeméride o de aniversario de un acontecimiento relevante. En 2014, sencillamente, es inevitable que esto ocurra. El centenario de la Primera Guerra Mundial, el conflicto bélico que inauguró la llamada "era de las catástrofes", será sin duda una exce- lente oportunidad para reflexionar sobre los hechos que se produjeron entre 1914 y 1918. Pero, al mismo tiempo, no hay ninguna duda de que la historiografía especializada ofrecerá también nuevas lecturas sobre una guerra que no ha dejado de recibir preguntas prácticamente desde el momento en que la "chispa" iniciada por Gavrilo Princip prendió la mecha de la barbarie.

Durante los cien años que han transcurrido desde que se iniciaron las hostilidades, la Gran Guerra ha estado sujeta a múltiples explicaciones y análisis, y ni siquiera hoy existe un consenso total acerca de los orígenes y las responsabilidades de los Estados. Las primeras interpretaciones clásicas, en las que la práctica totalidad de fuentes eran diplomáticas o militares, han dejado paso a enfoques más vinculados con la historia cultural y centrados, por tanto, en el impacto de la guerra en las mentalidades, la circulación de las ideas o las movilizaciones intelectuales. Esta evolución es, en realidad, el reflejo de los cambios producidos en el seno de la ciencia histórica a lo largo del siglo XX. Incluso en aquellas obras que se dedican a desgranar los orígenes de la Primera Guerra Mundial desde un punto de vista diplomático y político, se advierte la presencia de este enfoque más cultural ${ }^{1}$.

1. Me refiero, por ejemplo, al libro de MACMILLAN, Margaret, 1914. De la paz a la guerra, Madrid, Turner, 2013. 
La obra reseñada es fiel reflejo de este cambio paradigmático, pero al mismo tiempo representa una novedad dentro de la historiografía española, tradicionalmente poco interesada en conflictos bélicos ajenos. Afortunadamente, esta tendencia se ha revertido en las últimas décadas. El caso de la Gran Guerra es, sin embargo, especial. A pesar de la no participación de España, la contienda sí influyó de manera notable en el pensamiento político e intelectual del país. El autor de este libro, Maximiliano Fuentes Codera, ofrece una visión global que contrasta con otros análisis e investigaciones que sólo se habían acercado a este asunto de manera parcial. Nos encontramos, pues, ante una novedad editorial que solventa un vacío historiográfico que ha tardado un siglo en ser reparado.

Tras un breve capítulo introductorio, en el que el autor realiza un estado de la cuestión sobre las aportaciones (y carencias) sobre la Primera Guerra Mundial en España, el autor entra de lleno en el debate que se generó sobre la participación española en el conflicto. El gobierno conservador de Eduardo Dato decretó la neutralidad oficial rápidamente, nada más iniciarse las hostilidades entre los países beligerantes (p. 39). Esta decisión fue respaldada por la práctica totalidad de las fuerzas políticas y apenas tuvo contestación durante los primeros días. Lerroux fue, de hecho, una de esas escasas excepciones. El amplio consenso alcanzado se explica por la ausencia de obligaciones diplomáticas del Estado (pese a que España estaba más próxima a la órbita anglo-francesa) y por la situación del ejército español, muy atrasado en comparación los de otras potencias, como pudo comprobarse durante la guerra hispanoamericana de 1898.

Sin embargo, como bien precisa el autor, este consenso inicial sufrió una importante modificación conforme se fue prolongando el conflicto. Aunque la gran mayoría de fuerzas políticas seguía optando por la no participación de España en la guerra, a partir de 1915 salieron a la luz los primeros matices. No se trataba de proponer una intervención armada en el conflicto, una opción que estaba totalmente descartada al menos a corto o medio plazo. En cambio, afloraron dos bloques antagónicos: germanófilos y aliadófilos (p. 63). Aunque el autor no profundiza demasiado en la composición de estos dos grupos, las ideologías y simpatías de cada uno están suficientemente explicadas. El primero estaba formado por políticos e intelectuales próximos a posiciones conservadoras o al carlismo, que a lo largo del conflicto desearon la victoria de Alemania sobre la entente aliada. El bloque aliadófilo, por el contrario, aglutinaba a representantes del republicanismo, el partido liberal, el socialismo y el reformismo político al que se había adherido la Generación del 14 liderada por Ortega y Gasset. 
Con diferentes matices, la aliadofilia abogó durante toda la contienda por la victoria de Francia o Reino Unido, es decir, las naciones que despertaban más simpatías en este grupo. Como se puede observar, la estricta neutralidad que se quiso imponer desde el gobierno no impidió que surgieran interpretaciones dispares de lo que estaba aconteciendo más allá de los Pirineos. En realidad, la guerra se estaba leyendo en clave nacional. Declararse aliadófilo o germanófilo era, en realidad, otra forma de significación política.

Pese a esta polaridad, el ambiente cultural e intelectual fue mucho más complejo de lo que a priori puede parecer. De hecho, podría decirse que cada personalidad pública tenía su propia opinión sobre la guerra. Por poner un ejemplo -que aparece en la obra-, Pío Baroja se definió como germanófilo a pesar de que ideológicamente estaba mucho más próximo al liberalismo democrático. Fuentes Codera recompone en su libro todo este panorama, esta "movilización cultural", citando a un extenso número de intelectuales y utilizando, para ello, una amplia cantidad de ejemplos extraídos principalmente de los periódicos y las revistas de la época.

Precisamente, el uso de las fuentes periodísticas es continuo a lo largo de todo el texto. La intelectualidad y la clase política fueron conscientes desde el primer momento de la importancia de los medios de comunicación, de ahí que durante la guerra se desatara en España una auténtica "guerra de manifiestos" de la que da rendida cuenta el autor en uno de los capítulos del libro. También centra su investigación en el inusual desarrollo editorial y mediático que se produjo entre 1914 y 1918, ya que aparecieron nuevas cabeceras que prestaron atención no sólo al desarrollo del conflicto, sino a las consecuencias que, seguro, tendría en el país (Es el caso, entre otras, de las revistas España e Iberia) Por otra parte, el autor pone en valor las subvenciones que algunos países beligerantes -Alemania, Francia o Reino Unido- dieron a varias cabeceras para que publicaran noticias favorables a sus intereses. España, pese a ser territorio neutral, vivió su particular guerra a través de la prensa.

Uno de los aspectos clave recogidos por Fuentes Codera, en los capítulos cuarto y quinto, es el desarrollo de esta movilización cultural a partir de 1917, un año especialmente convulso para España desde el punto de vista económico, político y social. La batalla dialéctica entre aliadófilos y germanófilos se recrudeció todavía más y entró de lleno en la arena política. De hecho, los dos grandes acontecimientos políticos que se realizaron en la primera mitad del año tuvieron mucho que ver con la Primera Guerra Mundial. A finales de abril, Antonio Maura lideró un mitin antialiadófilo ante unas 20.000 personas en la plaza de Toros de Madrid. Un mes después, 
y en el mismo escenario, un selecto grupo de aliadófilos, entre los que destacan Azaña, Lerroux o Unamuno, organizó un acto con un marcado carácter antigermanófilo en el que se llegó a insinuar, metafóricamente, que España estaba a las puertas de una guerra civil (págs. 160-164).

En relación a esto último, algunos historiadores han apuntado que este clima de crispación que se generó a raíz de la Gran Guerra puede entenderse como un anticipo de la Guerra Civil que tendría lugar dos décadas después (p. 220). Fuentes Codera afirma que no debe exagerarse esta cuestión y que, aunque existieron algunas correlaciones con la futura contienda fratricida, la división entre aliadófilos y germanófilos ni constituyó una división estrictamente ideológica ni tampoco tuvo una gran repercusión más allá del ámbito intelectual o político.

El autor dedica una especial atención a la interpretación de la guerra en Cataluña, un asunto que, aunque ya se había debatido durante las últimas décadas en la historiografía catalana, no ha tenido demasiada presencia en la del resto del Estado. A pesar de que en Cataluña también se repitió el esquema germanofilia-aliadofilia, existieron notables diferencias, como la mayor presencia de intelectuales que apoyaban a Francia, o la existencia de una tercera vía que defendía la vigencia de la idea de Europa por encima de las legítimas preferencias hacia uno de los dos bandos. El promotor de esta idea fue el influente intelectual Eugeni d'Ors. Fuentes Codera ha publicado varios trabajos -incluida su tesis doctoral- sobre D'Ors, por lo que su presencia en uno de los subapartados de este libro está más que justificada.

Los últimos compases de la guerra y las consecuencias de ésta en España y Europa centran el capítulo final y el epílogo del libro. El autor se detiene brevemente en explicar el wilsonismo, un fenómeno que surgió tras la entrada de Estados Unidos en la contienda. La decidida participación del presidente Wilson fue recibida de manera muy positiva entre la intelectualidad aliadófila, que lo encumbró como el garante de las libertades y la democracia. Su proyecto estrella -la Sociedad de Naciones- fue interpretado como el punto de partida para la regeneración del sistema de la Restauración, pero este clima de optimismo político pronto fue decayendo.

Los cambios asociados a la Primera Guerra Mundial no desembocaron, para decepción de la aliadofilia, en la definitiva democratización de un régimen que desde 1917 atravesaba una aguda crisis. Esto no significa que se esté negando el poder transformador de un acontecimiento que, como se ha dicho antes, condicionó el devenir del siglo XX. Con el final de la Gran Guerra se inició un intenso debate sobre la sociedad futura (p. 201) La crisis de la democracia liberal, el impulso 
de los movimientos revolucionarios (sobre todo después del éxito de Lenin en Rusia) o el auge de los movimientos fascistas no se pueden explicar sin la Primera Guerra Mundial. España, tal y como sostiene Fuentes Codera, ocurrió algo parecido, a pesar de que en España el impacto de la contienda fue, como no puede ser de otra forma, mucho menor. De hecho, el autor alude a una "decepción" general -u "oportunidad perdida"- (p. 213) en la inmediata posguerra, ya que ni se llevó a cabo la ansiada regeneración ni se consiguieron aplacar las protestas de signo nacionalista o revolucionario. El autor, por tanto, insiste en que la Gran Guerra influyó de forma notable en España, entre 1914 y 1918 y también posteriormente.

Esta obra reivindica los puntos de conexión que existieron entre una España aparentemente aislada y el contexto bélico europeo. Por otra parte, también pone en valor el papel que jugó un mundo intelectual que intentó darle un significado a la primera gran guerra del siglo XX. El esfuerzo de Fuentes Codera en sintetizar todas las corrientes de opinión, la posición -no siempre cómoda- del Ejecutivo o el peso creciente de la prensa para conformar una opinión pública, ha dado como resultado un libro que, sin lugar a dudas, será imprescindible para iniciar nuevas investigaciones sobre los múltiples lazos que existieron entre una España neutral -pero con de- recho a opinar- $y$ un mundo exterior que empezaba a resquebrajarse.

GUILLERMO J. PÉREZ CASANOVA Universidad de Alicante

HeARd, Martha E., Salir del silencio. Voces de Càlig. 1900-1938, Benicarló, Onada edicions, 2013, 216 pp.

Lautora d'aquest llibre és una hispanista romàntica, que com altres nordamericans i nord-americanes tenen la segona residència a Càlig i volen gaudir del nostre clima, de la nostra gent i de la nostra cultura i manera de viure. Martha estima aquestes terres i també el Mediterrani blau, lluminós, tranquil i gens melancòlic com pot ser l'Atlàntic, més gris i revolt.

A lo llarg del seu llibre, l'autora afirma la sort que ha tingut de trobar un poble que li ha contat històries utòpiques del període de la República i de la Guerra Civil, que els seus veïns i veïnes van mostrar en aquell període un compromís ètic i polític per a transformar la societat. Però jo crec que també Càlig ha tingut la sort de comptar amb una americana que al 1978 ja es va enamorar d'aquest entorn i va decidir fer estades temporals, però continuades. La que era filòloga es va convertir en historiadora al parlar amb els veïns i veïnes i començar des de 1988 i 1991-92 -amb les beques 
de la fundació Rockefeller i la Fundació Nacional d'Humanitats- a interrogar eixes veus, eixes experiències tant impactants, que ara, amb la publicació del llibre, ixen a la llum. El mateix li va passar a l'historiador francès Pierre Vilar: era geògraf i va vindre a Barcelona en el període de la Guerra Civil i quan va veure l'entusiasme nacionalista dels catalans, va fer la seva tesi sobre els orígens històrics d'aquesta consciènciació.

L'historiador Sánchez Cervelló, de la Universitat Rovira i Virgili de Tarragona, en la presentació de l'obra que ressenyem, fa una lloança molt justa a Martha i comença el seu pròleg amb la mateixa afirmació que hem fet nosaltres: els ciutadans i ciutadanes de Càlig es deuen sentir molt orgullosos de tindre una cronista estrangera tant respectuosa amb els records del poble, tant des de la vessant conservadora com revolucionària, amb l'exercici de una metodologia cuidada, científica i rigorosa, fruit de fer moltes entrevistes amb temps i paciència, durant més de vint-i-cinc anys. Igual que li ha passat a Martha, multitud d'hispanistes han quedat enlluernats per l'experiència revolucionària de la Guerra civil: Gerald Brenan, Ronald Fraser, Paul Preston, Walther Bernecker, Jacques Maurice...

En un recent article publicat per la revista d'Història Contemporània Ayer, l'historiador Luis Martínez del Campo, de la Universitat de Saragossa, ha destacat que els més actius i influents hispanistes han sigut els anglesos, francesos i nord-americans. Ja al segle XVII i XVIII viatgers procedents de les Illes Britàniques van recórrer Espanya i l'interès per la cultura i les llengües castellana, catalana o gallega van començar amb el Romanticisme. Varies causes van contribuir a aquesta atracció per la cultura hispànica: l'alçament de totes les capes socials d'Espanya contra Napoleó i les seves gestes heroiques. La francesa duquessa d'Abrantes conta en el seu viatge la gesta de Dolores en un poble d'Extremadura, moren el fill i el pare i ella enverina amb el vi a diversos soldats francesos. Un altre motiu és el component exòtic i indòmit dels personatges populars: els bandolers que roben als rics per a donar als pobres; els guerrillers; el torero i la seua valentia; Carme la cigarrera, protagonista de l'òpera de Bizet. Com comenta l'historiador Carlos Serrano es desvetlla "La naturaleza erótica, la singularidad étnica y el colorido propio de la parte subdesarrollada del sur de Europa". Stendhal, Víctor Hugo, Prosper Merimé, Gautier, Alejandro Dumas, Laborde, Edgard Quinet, Flaubert, George Sand... mostren una fascinació per la cultura espanyola.

En l'actualitat també trobem altres hispanistes romàntiques, com és el cas que vaig llegir en la premsa d'Anna Kemp, anglesa, que viu en l'Alpujarra de Granada i havia aconseguit que tots els veïns i veïnes del poble col.laboraren en la construcció d'un teatre 
a l'aire lliure per a representar en estiu i primavera les obres de Federico García Lorca.

Podem situar a Martha en l'ampli llistat de romàntics i romàntiques que els agrada Espanya i els atrau la seva història i cultura. En el llibre de Martha encontrem que li captiva lo local, la màgia, el món mític dels contes de Càlig. Ella comenta que li recorda les històries de la seva àvia sobre la vida rural d'Indiana després de la guerra civil dels Estats Units. En certa manera, en els primers capítols intenta rescatar la cultura oral dels pobles agraris, on no havien llibres en les cases i es codificaven verbalment les experiències. En aquestos primers relats, ens revela la realitat de la misèria, malalties com el còlera, tifus, mortalitat molt temprana i situacions extremes com la dona vídua, amb tres fills, que deixa la xiqueta abandonada en l'estació de Vinaròs perquè no pot alimentar-la.

La gran atracció que Martha sent per l'anarquisme, transformador del món, es mostra en el relat minuciós que fa en diversos capítols de l'arribada de la Segona República i sobretot de la Guerra civil quan afirma que "Al estallar la guerra las ideas se convierten en acciones". Molts veïns i veïnes de Càlig somien en tindre una vida millor, major educació, uns sous més dignes i un món menys competitiu i més preocupat per les necessitats humanes. Lautora desgrana com es va organitzar la col-lectivitat a Càlig de la mà dels seus amics anarquistes: Amador Bonet, José Manuel Borrás i Joaquín Querol. Intenta demostrar que la violència no la van exercir tots els anarquistes, ni tots els que van muntar la col-lectivitat i altres accions revolucionàries.

La minuciositat científica de Martha fa que contínuament investigue per mitjà de les entrevistes orals els motius de la mobilització revolucionària de Càlig. I apareix la misèria. Els xiquets que arreplegaven fem pels camins per a l'adob; les actuacions del cacic; el sou miserable per a les dones que treballen l'ametlla (6 quinzets al dia i 12 hores de treball. En les seves reivindicacions demanen dos pessetes i 8 hores de treball). Davant de la necessitat, moltes famílies emigren a França i comproven com allà la democràcia és més sòlida i la llibertat i els drets naturals són més respectats que a Espanya, l'educació arriba fins i tot a les capes populars. La consciència revolucionària es desenvolupa a França quan veuen el contrast amb Espanya. Per la crisi del 29 han tornat molts de França i quan s'instaura la democràcia en la Segona República creuen que hi ha que començar la revolució.

Martha també troba una altra causa de la mobilització política i és la familiarització amb fullets i llibrets populars anarquistes. "La lectura los hace revolucionarios, y cuando estalla la guerra todos se alistan para defender la República y luchar contra 
el fascismo". Un dels protagonistes del llibre, Amador Bonet, conta que repartien revistes pels pobles del voltant (Cervera, Canet, Traiguera) en bicicleta: revistes Agitación de Vinaròs, Tierra y Libertad de València o Solidaridad Obrera de Barcelona. De Màlaga arriben refugiats a Càlig i munten una escola racionalista que els ensenya teories revolucionàries. També l'emigració a Barcelona i altres pobles de Catalunya els ha conscienciat per a passar a l'acció.

En definitiva, l'autora del llibre que ressenyem ens ha donat moltes contestacions sobre els factors que expliquen la gran mobilització que diversos pobles del Baix Maestrat van dur a terme per a canviar una societat que no volien $i$ ens ha presentat les accions que van emprendre per a realitzar la seva utopia.

Hi ha que reconèixer que Martha Heard va ser pionera en l'utilització de les fonts orals. Als anys setanta li van qüestionar aquesta tècnica en algunes universitats d'Espanya. Actualment s'ha demostrat la gran vàlua de la seva pràctica per a conèixer la repressió de les dictadures, la vida quotidiana, el dolor de les guerres o els canvis socials, culturals i la manera de viure de les classes populars en moments revolucionaris. Els invite a que s'endinsen en les transformacions de tot tipus que es van produir durant la Guerra civil a Càlig a partir de diverses entrevistes orals, sempre contrastades amb altres fonts, i que ens demostra que aquesta font és imprescindible i un privilegi de la Història Contemporània que ens apropa de manera més profunda en les actuacions dels subjectes anònims, que com, a hores d'ara, s'ha demostrat són igual o més importants que els subjectes públics per a compondre el canemàs de la Història.

ROSA MONLLEÓ PERIS Universitat Jaume I de Castelló

Ramos Palomo, María Dolores (coord.), Andaluzas en la historia. Reflexiones sobre política, trabajo y acción colectiva, Sevilla, Centro de Estudios Andaluces, 2012, 182 pp.

En junio de 2012 se organizó en Málaga el cuarto de los talleres científicos que desde febrero de 2011 impulsa el Seminario Permanente de Historia Contemporánea de Andalucía, con el objeto de poner en valor y difundir los resultados de la investigación histórica que se realiza en esa comunidad autónoma. En esta ocasión, la reunión se dedicó a los avances logrados en los estudios de historia de las mujeres y de género, realizados con la premisa de que las diferencias entre lo masculino y lo femenino se construyen histórica, social y culturalmente. Bajo la dirección de María Dolores Ramos, catedrática de la Universidad de Málaga, los textos presentados fueron debatidos por un grupo de especialistas 
de varias universidades entre quienes se contaba Mary Nash, pionera a la que tanto debe la historiografía española en esta materia.

Los trabajos discutidos se reúnen ahora en un volumen coordinado también por la profesora Ramos, quien manifiesta que tienen en común subrayar "la necesidad de formular hipótesis innovadoras, de interrogar a las fuentes desde perspectivas diferentes, atrevidas, y de situar a las mujeres en el centro de los historia contemporánea, utilizando, sobre todo, enfoques de género y clase". Los avances experimentados por estos planteamientos en nuestro país han sido más que notables durante las últimas tres décadas. Aún queda mucho por hacer, pero el camino recorrido arroja un balance extraordinariamente positivo. Y una parte significativa de dicha labor corresponde a profesoras e investigadoras de Andalucía. En esta región, el interés por la historia de las mujeres emergió en la década de 1970, en buena medida ligado a las circunstancias políticas que se vivían, se consolidó en los ochenta y luego se enriqueció en los noventa desde el punto de vista temático, conceptual y metodológico, creando escuelas que llegan hasta nuestros días. En tal proceso, la Universidad de Granada y la de Málaga desempeñaron un papel esencial, secundadas luego por otras.

Andaluzas en la historia es una obra sintética integrada por cinco capítulos que se presentan estructurados en dos bloques: el primero se dedica al poder y la política; el segundo, al trabajo en los medios urbanos y agrarios.

El capítulo inicial lo ha redactado Gloria Espigado, profesora de la Universidad de Cádiz. Con gran esfuerzo de síntesis, lo que ofrecen estas páginas es un balance de la participación de mujeres en las luchas por ensanchar la ciudadanía desde el liberalismo, el socialismo utópico, la democracia y el republicanismo; en suma, lo que considera "los hitos más significativos del emancipismo femenino decimonónico". Son las antecesoras de las grandes figuras del librepensamiento de entresiglos, sin las cuales no se pueden comprender bien los orígenes del feminismo en España, porque ocupan un lugar vertebral en el encadenamiento de luchas que desembocan en la exigencia del voto, de la ciudadanía política. Estas mujeres, en palabras de la autora, "iniciaron el camino para recabar las condiciones de individuación necesarias para representarse como sujetos de plenos derechos". El relato tampoco se olvida de otras mujeres que ciñeron sus escritos al modelo de feminidad representado por el "ángel del hogar" y al género moralizante que le era propio.

Del segundo capítulo se encargan la propia Dolores Ramos y Sofía Rodríguez López, del Grupo Consolidado de Investigaciones Históricas Andaluzas HUM-331, una joven doctora 
que ilustra lo que se decía antes: que la tarea comenzada hace más de treinta años la prosiguen admirablemente nuevas generaciones de historiadoras. Lo que presentan es un verdadero estado de la cuestión, sintético pero muy completo para quien necesite un balance historiográfico sobre la acción política y los movimientos de mujeres partiendo de una concepción amplia del poder y de lo político. Se bosquejan las realizaciones de las diferentes universidades andaluzas y también las obras más señaladas de un buen número de especialistas. El texto sugiere, además, varias tareas pendientes o incompletas y periodos que todavía requieren análisis profundos, como la Restauración o la dictadura de Primo de Rivera; de ello podrán tomar nota quienes se planteen acometer una investigación sobre estos temas. Las autoras, que demandan "una historia realmente social", son tajantes: "queda mucho por hacer". Particularmente fructífera resulta la conjugación de las categorías de género y clase, que aconseja una relectura de muchos aspectos del movimiento obrero y sindical, donde las trabajadoras se vieron obligadas a demorar sus aspiraciones como mujeres ante los previsibles costes afectivos y de otro tipo.

Encarnación Barranquero aborda en el tercer capítulo la represión franquista. Esta profesora de la Universidad de Málaga combina la síntesis del tema con el balance historiográfico.
Los estudios documentan una represión cualitativamente diferenciada, al infligírseles a ellas castigos específicos: desde el rapado o la ingesta de aceite de ricino, humillaciones de fuerte valor simbólico, a la violación o el fusilamiento. Desaparecidos sus esposos o parientes varones, muchas supervivientes tuvieron que hacerse cargo de la supervivencia familiar, desplegando estrategias que en su mayoría surgieron en espacios femeninos, lo que hizo que se convirtieran en protagonistas. Mientras, el racionamiento devino una herramienta de control político y de dominación. La autora recuerda asimismo la pujanza de algunos estudios, como los relativos a las cárceles o la depuración en la enseñanza. Y, sin dejar de apuntar los obstáculos que halla la investigación, bosqueja también lo realizado y otras posibles líneas de trabajo en las que se puede avanzar, como el número de mujeres asesinadas y las violaciones o presiones sexuales, nunca fáciles de recordar para quienes aún podrían legar su espeluznante testimonio.

Las teorías y la realidad laboral de las mujeres en Andalucía es el objeto del siguiente capítulo, a cargo de Concepción Campos Luque, profesora igualmente de la Universidad de Málaga. Se centra en los siglos XVIII y XIX y arranca con una reflexión que conserva su vigencia en la actualidad: ¿qué es el trabajo? Cuestión relevante, ya que el uso de un concepto reduccionista provocará forzosamente la 
invisibilidad de las trabajadoras. La asignación de la reproducción social exclusivamente a las mujeres cimentaba, en dicha época y en otras, las diferencias de género; pero además se escamoteaba su valor, su función económica, ya que sin la esfera reproductiva no se podría entender la de la producción. Ese menosprecio acarreaba consecuencias salariales incluso cuando el trabajo se desarrollaba fuera de casa, algo habitual en el caso de las obreras, cuyas ocupaciones diarias contravenían de hecho el ideal de la domesticidad. Limitar el acceso a la instrucción y a las enseñanzas técnicas era otra forma de perpetuar semejante estado de cosas. Lo que deberá tener en cuenta quien investigue el trabajo de las mujeres es la ocultación que se produce en los censos, bien demostrada por la autora, que subraya la necesidad de buscar pistas o fuentes alternativas que permitan inferir la tasa de actividad femenina, reconstruirla empezando por el ámbito local. No hacerlo originaría consecuencias que van más allá de la historia de las mujeres, porque se "desvirtúan los indicadores económicos en general".

El último capítulo se aproxima al mundo rural y subraya el papel de las mujeres como agentes de cambio en ese medio. Lo firma Teresa $\mathrm{M}^{\mathrm{a}}$ Ortega López, profesora de la Universidad de Granada. En estas páginas se pone de relieve la escasa atención que ha despertado el papel de las campesinas tanto en la historia agraria como en la de género. El objetivo es mostrar su relevancia como sujetos históricos activos, sociales y políticos, que contribuyeron decisivamente a la transformación de las comunidades rurales y al afianzamiento de la democracia en España. La imagen que se ha venido transmitiendo guarda escasa relación con esto: acomodaticias, expectantes, pasivas... Sin embargo, las hallamos reivindicando el acceso a la formación profesional y la cultura en igualdad de condiciones que los hombres y denunciando la precariedad laboral, la discriminación salarial, la exclusión social, la carencia de recursos y servicios, la falta de asistencia médica, etcétera. Al decir de la autora, "se convirtieron, a veces sin quererlo, en portavoces de los problemas del campo y de los municipios rurales". Estas páginas, además, son buena muestra de que no estamos ante un libro dirigido exclusivamente a quienes investiguen en Andalucía, ya que también recoge datos valiosos concernientes a otras regiones. Al respecto, destaca el fenómeno de la emigración del campo a la ciudad, un éxodo que se consideraba en esencia masculino. Esto lo pone en duda la autora con sólida argumentación.

En apenas 180 páginas, pues, se traza un estado de la cuestión, se revisan planteamientos y se proponen líneas de trabajo. El cuarto volumen de la colección de Cuadernos de Andalucía en la Historia Contemporánea es algo más que un libro divulgativo y 
que un trabajo colectivo sobre el caso andaluz. En primer lugar, porque una parte relevante de los datos que contiene desborda ese marco regional. En segundo lugar, porque sugiere hipótesis y orientaciones válidas para quienes investiguen en otras provincias. Al iluminar una parte de lo excluido, la obra cumple uno de los objetivos que señala Dolores Ramos en la introducción: contribuye dentro de sus posibilidades a levantar "una nueva arquitectura del conocimiento", en el sentido de "replantear los saberes desde una óptica que integre a los dos sexos".

\section{SERGIO SÁNCHEZ COLLANTES Universidad de Burgos}

Aguado, Ana; SANFELIU, Luz (eds.), Caminos de democracia. Ciudadanías y culturas democráticas en el siglo XX, Granada, Comares Historia, 2014, 296 pp.

El concepto de democracia, entendido como régimen que apela al desarrollo de libertades civiles y políticas, en el marco de un ideal de identificación entre gobernados y gobernantes se encuentra sujeto a lo largo del siglo $\mathrm{XX}$ a continuas reformulaciones, especialmente evidentes cuando nos acercamos a procesos estrechamente vinculados a la construcción histórica de la ciudadanía y su relación con las diversas culturas democráticas. Como señala Arendt la ciudadanía es un proceso de deliberación activa sobre proyecciones identitarias competitivas con el objetivo de establecer formas de identidad colectiva que pueden ser reconocidas, probadas y transformadas en una forma discursiva y democrática. De manera que la noción de ciudadanía permite abordar las transformaciones sociales del siglo desde dos perspectivas simultáneas: la construcción de identidades colectivas asociadas al sentido de pertenencia (a una nación, a una comunidad, a una opción política), y como otorgamiento y usufructo de derechos. Evidentemente existen interpretaciones minimalistas de la democracia cuyo correlato es una visión más elitista del concepto. En este sentido Rosanvallon pone de manifiesto que los continuos embates contra el principio rector del ideal democrático conllevan el consiguiente "desencanto democrático" y a su vez interpretaciones más restrictivas del concepto de ciudadanía que en esencia debería fundamentarse en un sentido de igualdad y de superación de las diferencias de toda índole, por la vía de los derechos.

Los conceptos de democracia y ciudadanía están sujetos, por tanto, al propio devenir histórico, pero su estudio debe adaptarse además a diversos enfoques que incorporen, junto a las tradicionales categorías políticas, aquellas que se fundamentan en aspectos sociales, de clase, de género o 
culturales. La interpretación de aspectos tan variados permite comprender qué nivel de compenetración existe entre el ideal democrático y la práctica social. Una construcción de sujetos simbólicos tan amplia en torno a ambos conceptos se convierte así en un sugerente pero a la vez complejo objeto de estudio porque no se trata evidentemente del análisis de un universo social integrado frente a una cultura dominante, construida por los grupos más cercanos al poder y a sus instituciones, sino que es más bien todo lo contrario. Estamos hablando de un universo segmentado, a pesar de que en sus capas más superficiales se presente como un imaginario colectivo, reificado, cohesionado y nítidamente delimitado a partir de los principios que se oponen a las estructuras, valores o prácticas establecidas. Si acercamos nuestro punto de mira podemos observar matices y diferencias que obligan a llevar a cabo una profundización historiográfica que permita poner de relieve las diversas culturas democráticas, vinculadas a lugares, temporalidades y espacios de socialización y sociabilidad determinados y también los referentes identitarios derivados que intervienen en la construcción del concepto de ciudadanía.

El trabajo colectivo Caminos de Democracia, coordinado por Ana Aguado y Luz Sanfeliu, puede considerarse una nuevo punto de inflexión y una valiosa aportación en este terre- no, teniendo en cuenta que el eje que vertebra su coordinación gira en torno a la reflexión sobre el concepto de ciudadanía y su vinculación al desarrollo de las diversas culturas democráticas en el siglo XX. Su estructura en tres campos de análisis bien definidos -político, social y género- sin renunciar a una visión holística, contribuye a mostrar un panorama amplio, lleno de matices, sobre los avances y retrocesos de la democratización como producto histórico.

En el primer bloque temático la noción de ciudadanía se analiza en el seno de culturas políticas, espacios y tiempos diversos que evidencian la multiplicidad de interpretaciones y derivaciones sociopolíticas que pueden determinarla. Sergio Valero la encuadra en la crisis del socialismo español de los años treinta, derivada del enfrentamiento entre los presupuestos socialistas más clásicos, que abogaban por la revolución y el rechazo del capitalismo y aquellos que aceptaban los nuevos principios propugnados por la socialdemocracia. Por su parte Ana Aguado analiza el desarrollo de la ciudadanía desde una perspectiva feminista en el contexto de la Segunda República. El estudio de algunas de las figuras femeninas más relevantes del socialismo de esos años pone de manifiesto las aspiraciones feministas desde una posición de clase. El trabajo de Aurelio Martí aborda, en ese mismo periodo, la retórica nacionalista adoptada por el socialis- 
mo como estrategia de oposición a la CEDA y la consiguiente fractura en su seno, derivada del supuesto internacionalismo inherente al discurso socialista. Desde un marco espacial muy distinto, Aurora Bosch vertebra su trabajo en torno a la transformación del concepto de libertad, democracia y ciudadanía en relación al desarrollo del liberalismo americano y en concreto vinculándola a la Segunda Declaración de Derechos Económicos impulsada por Roosevelt.

La segunda unidad temática se centra en las relaciones de género y su impacto en el desarrollo de la idea de ciudadanía y democracia en varios momentos claves de la historia de España. El estudio realizado por José Ignacio Cruz trata el tema del exilio republicano a través de un recorrido biográfico de cinco maestras valencianas que desde su republicanismo expresaron diversas formas de entender el compromiso político. Igualmente Melani Ibáñez estudia la evolución de las políticas de género entre la Segunda República, momento en el que la ciudadanía política y social de las mujeres adquiere un gran impulso, y los primeros años del franquismo en los que como la propia autora señala tuvo lugar una "contrarrevolución" de género. Vicenta Verdú se centra en el Movimiento Democrático de Mujeres que entre los años sesenta y setenta impulsó la concienciación y politización femenina. En su estudio pone de relieve la confrontación entre dos visiones distintas del compromiso político ligadas al relevo generacional entre unas mujeres que encuadraban su activismo en el marco de los tradicionales roles de género y una nueva generación de mujeres más jóvenes, que entendían la lucha política en clave feminista. Cierra este bloque el trabajo de Mónica Moreno que se adentra en la trayectoria de mujeres que militaron en partidos de extrema izquierda durante los años setenta y las contradicciones derivadas de su propia evolución. Sus actuaciones se movieron entre un referente revolucionario e internacionalista que daba pleno sentido a su militancia y la necesaria participación en el modelo democrático que se estaba asentando en la España de esos años. A pesar de las contradicciones discursivas resulta evidente su contribución al desarrollo del feminismo en España.

Los trabajos que integran el siguiente apartado temático sitúan el punto de mira en las formas de entender la ciudadanía desde el universo libertario. En este sentido Javier Navarro analiza el surgimiento del movimiento libertario en España y las dos grandes posiciones que marcaron su desarrollo desde la Segunda República hasta el exilio. Su enfrentamiento se materializará en estrategias organizativas distintas, consideradas incluso como dos culturas políticas en el seno del anarcosindicalismo español: por una parte, los ortodoxos o "antipolíticos" frente a los "políticos" o "colabo- 
racionistas". Sin embargo el análisis de Navarro supera esta perspectiva dicotómica y pone de relieve que los cambios de posicionamiento a lo largo del tiempo forman parte de la evolución de una sola cultura política, compleja y plural, lo cual obliga a seguir profundizando en el estudio para romper con la pervivencia de los viejos estereotipos sobre el anarquismo español. El estudio de Ángel Herrerín también sitúa su objeto de estudio en la evolución del anarcosindicalismo durante la Segunda República $y$ en concreto en el enfrentamiento entre faístas y cenetistas. Los primeros se oponían a la Alianza Obrera como sinónimo de renuncia a las aspiraciones revolucionarias, mientras que la postura que defendían los segundos implicaba un pacto con los socialistas ante el avance del fascismo en Europa y las consecuencias negativas que supondría el triunfo de las derechas en materia de libertades y derechos. José Luis Oyón centra su análisis en una obra de Kropotkin, La conquista del pan, con un gran impacto entre los obreros españoles de principios del siglo XX. En ella se presenta un proyecto utópico de sociedad cuya organización parte de la satisfacción de las necesidades básicas como concepto fundante sobre el que se construye la verdadera libertad y la plena realización de los individuos-ciudadanos. El trabajo de Mónica Granell sobre la prensa contracultural en la Transición es el último que integra este bloque.
La autora estudia la evolución de la revista Ajoblanco en la década de los setenta, como manifestación contracultural ligada primero al movimiento estudiantil y posteriormente a los sectores más radicales de la ciudadanía, convirtiéndose en la voz de movimientos sociales como el ecologismo o el feminismo.

El último apartado está dedicado a la educación y su vinculación con el desarrollo del concepto de ciudadanía. Se inicia con el trabajo de Luz Sanfeliu que analiza el impulso del proyecto educativo republicano blasquista a través de las Agrupaciones Femeninas Republicanas y su objetivo de construir una ciudadanía activa de las mujeres, durante la segunda República. El desarrollo del mismo se verá determinado por la vinculación del PURA con la CEDA y la consiguiente radicalización de las mujeres blasquistas, muchas de las cuales se alinearon con la Agrupación de Mujeres Antifascistas, poniendo en evidencia la interiorización de las prácticas políticas democráticas. Continúa con el estudio que hace Sara Ramos de las ciudadanas rurales durante el franquismo en el que se exponen las actuaciones de la Sección Femenina cuyo objetivo era consolidar la imagen de la mujer tradicional, vinculada al hogar y la maternidad, pero también fomentar la autonomía y la autosuficiencia de las mujeres campesinas. Asimismo esta organización protagoniza el último trabajo que cierra el 
bloque. Su autor es Enrique Bengochea que analiza, en un ámbito espacial muy distinto, la actuación de la Sección Femenina en el Sáhara, después de la provincialización española de 1957 y la consiguiente consideración de los saharauis como "ciudadanos" españoles. En el contexto de una previsible retórica asimilacionista, el objetivo de esta organización fue tratar de asentar en la zona el modelo de feminidad hegemónico de la metrópolis, teniendo en cuenta, no solo las diferencias religiosas sino también de base respecto a al resto de sus "conciudadanas".

ALICIA MIRA ABAD Universidad de Alicante

De la Granja Sainz, José Luis (coord.), Indalecio Prieto. Socialismo, democracia y autonomía, Madrid, Biblioteca Nueva, 2013, 248 pp.

La historiografía del movimiento obrero, entendida ésta en sentido amplio, que en general no pasó de ser durante el franquismo sino una historia positivista a la que se le aplicaron unos esquemas ideológicos que partían de concepciones preestablecidas, que provenían, normalmente, de la órbita del marxismo, sufriría una paulatina renovación a partir de los años ochenta hasta llegar a homologarse con las historiografías que en este campo se habían desarrollado en el mundo académico de los países de nuestro entor- no europeo. Pero, aunque pueda resultar paradójico, la renovación de la historiografía del movimiento obrero se llevaría a cabo en España, al igual que ocurriera fuera de nuestras fronteras, a través de un proceso en el que el peso cuantitativo de dicha historiografía se redujo muy notablemente en relación al conjunto de la historiografía producida. El interés de los historiadores por la temática del movimiento obrero español disminuyó de forma muy considerable y en la actualidad son muy pocos los que a la misma dedican el grueso de su tarea investigadora.

El importante libro que aquí se comenta sobre la vida y la obra de Indalecio Prieto es, en efecto, uno de los escasos trabajos aparecidos en nuestro país en los últimos tiempos que aborda una temática que tiene como referencia el movimiento obrero (pese a que este año pueda ser una excepción dado que se ha producido también la publicación de la biografía de Julio Aróstegui sobre Largo Caballero), aunque desde sus páginas se analizan otros muchos y variados aspectos de una buena parte de la historia de España del siglo XX (fundamentalmente de la de su primera mitad). Y es un libro que se inserta en el quehacer de una historiografía que ha asumido el proceso de renovación antes señalado. Un proceso en el que muchos de los autores que participan en el libro habían tenido un protagonismo más o menos destacado. 
El libro es, por lo demás, el resultado de un ciclo de conferencias que se celebró en Bilbao en el mes de febrero del 2012 con el objetivo de conmemorar el cincuenta aniversario de la muerte de Indalecio Prieto en México y que fue coordinado por José Luis de la Granja y Pedro Barruso, profesores del Departamento de Historia Contemporánea de la Universidad del País Vasco. Los autores fueron escogidos entre aquéllos que contaban de antemano con una investigación muy reconocida sobre el tema (no podían ser todos, lógicamente) y el libro se ha terminado por configurar como una excelente síntesis de lo mucho que hoy se puede conocer sobre el líder socialista y su obra. Una síntesis, en suma, que incorpora también en algunos casos aspectos de la obra de investigadores que no forman parte de los colaboradores que la han elaborado.

No fueron pocos, en efecto, los historiadores (algunos extranjeros) que dedicaron desde la década de los setenta muchos de sus esfuerzos investigadores al estudio de la trayectoria vital y política de Indalecio Prieto y que consiguieron generar sobre la misma un conocimiento de gran importancia. Y ello porque se vieron atraídos por una figura histórica que había alcanzado una indudable relevancia. Una figura que tendría un papel muy sobresaliente tanto en el seno del PSOE, que poco a poco pasaría a tener un fuerte peso político en el país, como en la vida institucional. No hay que olvidar que Indalecio Prieto sería, junto con Largo Caballero y Julián Besteiro, uno de los más destacados dirigentes socialistas sucesores de Pablo Iglesias y que su ejecutoria política se proyectó desde el ámbito local hasta más allá de las fronteras nacionales. Así las cosas, la lista de autores que directa o indirectamente se han topado con su figura en el desempeño de su tarea investigadora supera el elenco de participantes en las páginas de este libro. Nos vienen en este sentido de inmediato a la memoria los nombres de E. Malefakis, P. Preston, J. C. Gibaja, A. Mateos, J. Sánchez Cervelló, J. Aróstegui, O. Cabezas y A. Saiz Valdivieso.

El libro puede de esta forma ser considerado como una biografía sobre Indalecio Prieto que pretende ofrecer, a pesar de ser de realización colectiva, una perspectiva coherente y global del personaje en cuestión. Se articula en torno a 10 capítulos, una introducción, que bien podría ser tenida como un capítulo más, y un prólogo, de carácter introductorio y muy clarificador, del propio coordinador. Toda esta urdimbre responde a la idea de plantear el libro situando al personaje y la acción que llevó a cabo en los ámbitos local (Bilbao), regional (País Vasco), nacional (conjunto de España) e internacional (exilio). El libro destina además un capítulo al legado de Prieto y otro a la Fundación que lleva su nombre. El libro presenta a Indalecio Prieto como un socialista 
cuya trayectoria estuvo guiada por una lógica en la que la defensa de la democracia sería un elemento fundamental (la excepción se materializó con su participación en la revolución de octubre de 1934). Un socialista que desde las instituciones democráticas intentó avanzar en el reconocimiento de derechos sociales y la regeneración de España y que afrontó con realismo e inteligencia el problema de la autonomía para el País Vasco.

Indalecio Prieto había nacido en Oviedo en 1883 pero a los siete años abandonó Asturias y, de la mano de su madre, se instaló en Bilbao, una ciudad que estaba experimentando un fuerte proceso industrializador y en la que comenzó a desarrollar su actividad política. Prieto sería, como afirma J. P. Fusi en su trabajo, un hombre hecho en la capital vizcaína y acabaría representando el espíritu liberal y democrático, una de las culturas más significativas, de aquélla y de su área de influencia. La línea política de Prieto, que representaba una opción moderada del socialismo, se enfrentó en Vizcaya a la más radical que representaba Facundo Perezagua y, según indica J. A. Pérez Pérez, lograría sobreponerse de forma nítida a partir de 1915. Desde algún año antes, no obstante, la capacidad de maniobra de Perezagua en el socialismo vizcaíno se había ido debilitando, a pesar de su importante papel en la huelga de 1910. Prieto se enfrentaría a la tendencia izquierdista del PSOE en la coyuntu- ra de la creación de la Tercera Internacional y Perezagua se acabaría pasando al PCE. Indalecio Prieto se enfrentó también hasta principios del siglo XX con los republicanos. Pero desde entonces la colaboración con ellos sería una constante apenas alterada de su actuación política. Logró, tal y como mantiene J. Penche, sintetizar ambas culturas y convertirse en las Cortes en el representante del socialismo y del republicanismo local. La Conjunción republicano-socialista de Vizcaya se caracterizó hasta 1917 por una cierta preeminencia de los republicanos pero éstos fueron desde esta fecha a remolque del líder socialista. Éste, según explica P. Barruso, logró proyectar igualmente su influencia en el socialismo guipuzcoano, un socialismo moderado que adoptó en general sus posiciones políticas (no solo en su trayectoria diaria sino también en momentos decisivos, como el que supuso tener que definirse ante la incorporación a la Tercera Internacional).

Indalecio Prieto y los socialistas fueron durante mucho tiempo muy ajenos al mundo nacionalista y se enfrentaron a él. Pero no pasaría desapercibido para ellos el hecho de que desde 1912 los republicanos (algunos) empezaran a pensar en la autonomía. $\mathrm{Y}$, como expone A. Rivera en el correspondiente capítulo, evolucionaron poco a poco incorporando dicho planteamiento y lo hicieron, al igual que los republicanos, reafirmando su espa- 
ñolismo. Prieto fue muy consciente desde 1918 de que el tema territorial tenía que ser abordado de frente para poder contrarrestar una posible deriva irredentista del nacionalismo vasco. Prieto, que, al parecer de J. L. de la Granja, sería, junto con Aguirre, el político vasco más relevante, acabaría siendo el impulsor del Estatuto aprobado por las Cortes en 1936. Pero, como insiste de la Granja, el Estatuto fue posible por el acuerdo entre ambos líderes, un acuerdo que contemplaba la autonomía vasca dentro de la democracia española. Aguirre y Prieto llegaron a "confluir desde la discrepancia”, como reza el título del capítulo de L. Mees. El dirigente socialista se esforzó ya en el exilio en evitar conflictos entre sectores diversos pero estuvo condicionado por su animadversión a Negrín y a los comunistas. Con los nacionalistas llegó a "confluir desde la discrepancia", según reza el título del capítulo de L. Mees. Prieto no estaría de acuerdo en que los socialistas vascos se alejaran del PSOE nacional para que pudieran actuar dentro del ámbito de "obediencia vasca", como quería el PNV, pero éste entró en la JARE y acabó apostando por la vía monárquica de la opción prietista.

Prieto dio en 1918 el salto a la política nacional. Ese año llegó al Parlamento y fue nombrado vocal de la Ejecutiva del PSOE. Muy pronto destacó en sus denuncias de la campaña militar en Marruecos, se opuso más tarde a la Dictadura y en la República ocuparía el Ministerio de Hacienda y el de Obras Públicas. Prieto, como resalta A. Martín Nájera, se encontró más cómodo en este último y puso desde él un gran entusiasmo en la política de obras públicas. La llegada de la Guerra Civil le llevó otra vez al Gobierno. Se hizo cargo de la cartera de Marina y Aire en el Gobierno de Largo Caballero y de la de Defensa en el de Negrín. Contribuyó mucho a hacer un auténtico ejército pero consideró desde bastante pronto que la República tenía muy difícil ganar la contienda. No en vano, como explica R. Miralles, tenía datos para ser pesimista. Indalecio Prieto deja, en fin, un legado que, desde la perspectiva de S. Juliá, está estrechamente unido a la forma como vivió sus experiencias políticas más importantes. Dicho legado, en palabras del propio autor, contendría: "un sentimiento de solidaridad con la clase obrera y de rebelión frente a la injusticia; la primacía de los valores de libertad y democracia como fundamentos del socialismo; las políticas de acuerdos y alianzas de las organizaciones obreras con los partidos de las clases medias por la instauración de la democracia; la pasión por la política y el gobierno como arte de realidades; el reconocimiento del error y la propia culpa cuando de la acción emprendida se ha seguido un desastre que es necesario reparar; la llamada a la piedad a ya la clemencia con el enemigo; y en fin, una vez sufrida la derrota, la política de reconci- 
liación con vistas a la reinstauración de un sistema democrático sostenido en la voluntad de los españoles".

En fin, la valoración globalmente positiva que del libro se ha transmitido al lector en los comentarios realizados hasta el momento no debe suponer el ocultamiento de algunas reservas que ante el mismo se puedan tener. La síntesis que de la trayectoria de Indalecio Prieto representa el conjunto del libro hubiera podido ser completada con una mayor dedicación al estudio de su dimensión nacional e internacional. La estructura del libro está un tanto desequilibrada al potenciar el análisis de la acción política prietista en temas que tienen que ver con asuntos muy centrados en Bilbao y en el País Vasco. Es especialmente notorio en el caso del exilio, tratado solo en un capítulo, lo que necesariamente ha impedido abordar otros posibles aspectos del mismo. El libro peca también de contener ideas excesivamente repetidas. El elevado número de autores que participan y la coherencia que en general mantuvo Indalecio Prieto en su actuación y en su pensamiento político explican este hecho. No parece tampoco muy acertada la colocación del trabajo de Santos Juliá sobre el legado de Prieto al comienzo del libro. La temática que aborda y las reflexiones que el autor desgrana parece que podrían tener un mayor sentido al final de sus páginas.

\section{MANUEL REDERO SAN ROMÁN Universidad de Salamanca}

Eiroa San Francisco, Matilde, Isabel de Palencia. Diplomacia, periodismo y militancia al servicio de la República, Málaga, Atenea. Estudios sobre la Mujer - Universidad de Málaga, 2014, 310 pp.

La biografía que nos ofrece Matilde Eiroa permite seguir profundizando en el siempre interesante mundo de las "modernas" de Madrid, cosmopolitas y cultas, que en los años veinte y treinta, en palabras de Mary Nash, "ocuparon las tribunas públicas, mostraron la capacidad y creatividad femenina en la construcción de la ciudadanía y asumieron el liderazgo político"1. Esta obra completa la detallada investigación de Olga Paz Torres², otros trabajos sobre aspectos parciales del multifacético itinerario vital de Isabel Oyarzábal y sus propias memorias, ya traducidas ${ }^{3}$. Una de las aportaciones fundamentales del libro que nos ocupa es el amplio uso de fuentes, en ocasiones no muy utilizadas hasta ahora, dispersas en diversos archivos, como el del Ministerio de

1. NASH, Mary, "Introducción" a NASH, Mary (coord.), Ciudadanas y protagonistas históricas. Mujeres republicanas en la II República y la Guerra Civil, Madrid, Congreso de los Diputados, 2009, p. 16.

2. PAZ TORRES, Olga Paz Torres, Isabel Oyarzábal Smith (1878-1974), una intelectual en la Segunda República española. Del reto del discurso a los surcos del exilio, Sevilla, Consejo Económico y Social de Andalucía, 2010.

3. OYARZÁBAL SMITH, Isabel, He de tener libertad, Madrid, Horas y Horas, 2010 y Rescoldos de libertad, Málaga, Alfama, 2008. 
Asuntos Exteriores o del Ateneo de Madrid. Eiroa también rescata algunas publicaciones poco conocidas de Oyarzábal y maneja las abundantes colaboraciones en prensa nacional y británica de esta intelectual que fue pionera en muy diversos terrenos, como conferenciante con una notable proyección internacional, inspectora de Trabajo, representante española en la OIT y la Sociedad de Naciones, y embajadora.

La trayectoria fragmentada y polifacética de Isabel Oyarzábal, atravesada de múltiples actividades e intereses, plantea un reto para la narración historiográfica, que se solventa con acierto en el libro al profundizar la autora en cada uno de estos aspectos, conjugándolos de manera apropiada con las etapas más destacadas de su vida. Sin descuidar ninguna de estas facetas, Eiroa no se centra en los aspectos ya más conocidos, como su participación en las principales organizaciones feministas del momento, su experiencia durante la República o el largo exilio en México hasta su fallecimiento en 1974, donde continuó con sus actividades periodísticas, políticas y asociativas.

Por el contrario, en esta biografía se presta especial atención a dimensiones menos tratados en obras anteriores, como el interés regeneracionista de Oyarzábal por el folklore, que difundió más allá de nuestras fronteras, o sus numerosos escritos de ficción y ensayo en los que se aprecia su evolu- ción ideológica, desde posiciones conservadoras y convencionales a la militancia en el feminismo, el socialismo y en la defensa de la República, en consonancia con un creciente interés social, que reflejó en su novela En mi hambre mando yo.

Cabe reseñar, en el mismo sentido, el interés que la autora presta a la labor diplomática de Isabel Oyarzábal como embajadora en Suecia durante la Guerra Civil, donde compartió con Alexandra Kollontai dificultades en un mundo masculino y donde tuvo que lidiar con graves problemas por la falta de medios, la acción de elementos profranquistas y el apoyo del gobierno sueco a la No Intervención, pero donde también participó de las numerosas iniciativas que la población civil de los países nórdicos emprendió en solidaridad con la República.

Como subraya Eiroa, más que aportaciones intelectuales o políticas novedosas, la tarea más destacada de Oyarzábal fue su gran capacidad de difusión de valores progresistas y feministas dentro y fuera del país. Conocida por sus dotes como oradora, subió a la tribuna en incontables ocasiones a lo largo y ancho del territorio nacional e impartió numerosas conferencias en el extranjero, que le llevaron a ser elegida por el gobierno para una gira propagandística por EEUU y Canadá en octubre de 1936, convirtiéndose ante la opinión pública norteamericana en referente de la República en guerra. Como periodista, 
publicó en periódicos de tirada nacional muy influyentes como El Sol o en revistas feministas como Mundo Femenino, y fue corresponsal de diversos medios internacionales.

Isabel Oyarzábal compartió espacios, debates e inquietudes con muchas de las políticas e intelectuales más conocidas de la época, como vicepresidenta del Lyceum Club o presidenta del Consejo Feminista de España. Su bilingüismo y su compromiso social y feminista le acercan a las trayectorias de Margarita Nelken, Lidia Falcón o Constancia de la Mora, con quienes coincidió en asociaciones como la Agrupación de Mujeres Antifascistas. Como muchas de ellas, participó en debates en el seno de foros internacionales feministas y pacifistas, estableciendo lazos con mujeres y hombres progresistas de otros lugares, no solo de Europa sino también de América.

La autora, lejos de la hagiografía, valora con rigor académico la figura que estudia, recalcando sus contradicciones y límites, como el uso de su apellido de casada en su época de militante socialista y feminista. De hecho, a lo largo de la biografía se recurre a los tres nombres que esta intelectual utilizó: el seudónimo periodístico Beatriz Galindo, Isabel de Palencia, denominación por la cual era conocida en los años veinte y treinta, e Isabel Oyarzábal, su nombre real. La misma honradez historiográfica se aprecia cuando se señalan aspectos que no se han podido desarrollar, por falta de fondos documentales en los que sustentarlos, como sus relaciones con personajes de la política y el feminismo del momento, su participación en el PSOE o su opinión ante las decisiones del gobierno republicano y la marcha de la guerra.

En suma, nos encontramos ante un sólido trabajo que se inserta en la ya abundante bibliografía sobre el tema, que Eiroa maneja con soltura, para presentar la biografía de una destacada intelectual que, como tantas otras, en el primer tercio del siglo pasado creyó posible que la cultura, la tolerancia y la justicia podían mejorar la vida de mujeres y hombres en España.

\section{MÓNICA MORENO SECO Universidad de Alicante}

Monlleó, Rosa; Fornas, Alfredo; MADALL, Iván (eds.), Biografies rescatades del silenci. Experiències de guerra i postguerra a Castelló, Castelló de la Plana, Publicacions de la Universitat Jaume I, 2014, 283 pp.

Estem davant d'un llibre que compila les biografies de set persones que van viure un període de ruptura i violència durant la Guerra Civil i el Franquisme a les comarques del nord del País Valencià i que, a més a més, van ser víctimes innocents castigades per 
actuacions injustes. És un text col-lectiu que explica els fets més importants en la vida d'aquestes persones i narra les seves experiències a partir dels records enregistrats en diverses entrevistes pel Grup d'Estudis d'Història Local i Fonts Orals que es va formar l'any 1995 a la Universitat Jaume I de Castelló sota la direcció de la doctora Rosa Monlleó.

La primera persona biografiada és Enriqueta Querol Sales nascuda en 1922 a Salzadella, la qual va tenir una vida marcada per l'ideal republicà a les comarques de Castelló. L'autora de la biografia, Rosa Monlleó, en destaca les ganes de viure de la biografiada i la necessitat de fer desaparèixer la pobresa i les guerres amb una narració emotiva i de lectura àgil, que relata els patiments de la vida quotidiana d'Enriqueta marcada per la repressió $\mathrm{i}$ la fam.

La segona biografia és la de Concepció Betí Beltrán nascuda en 1918 a Castelló de la Plana, que redacta Iván Medall Chiva. És la història de vida d'una dona que va viure l'alegria de la Segona República de jove, els anys durs de la guerra i la misèria i la pèrdua de les llibertats durant el franquisme. La seua vida va ser una vida de superació i supervivència contra els temps que li va tocar patir.

El tercer biografiat és José de Ramón Torrent nascut a Castelló de la Plana en 1915, un destacat milicià comunista durant la guerra, que va lluitar en les batalles de Madrit, Terol i Llevant com a més destacades, i que va ser condemnat per un consell de guerra durant el Franquisme. Lautor de la biografia, Vicent Grau Reig, en destaca la seua activitat com a jove comunista en els anys de la Segona República a Castelló i la seua participació com a combatent en els fronts de Terol, Madrid, Andalusia i Castelló. El relat es paradigmàtic per a seguir un combatent que va ser milicià de la Columna Casas Sala, voluntari de la III Brigada Mixta de l'Exèrcit Popular, caporal del Cos de Carrabiners de Castelló i combatent del XIV Batalló de la Brigada de Xoc, etc.; però també per a conèixer la repressió franquista i la capacitat de supervivència i superació de José de Ramón Torrent.

Alfredo Fornas Pallarés és l'autor de la quarta biografia dedicada a Miguel Miravet Doñate, un soldat de 17 anys en el fronts de Llevant i Extremadura nascut a Eslida en 1920 i reclutat en 1938 en la lleva coneguda com del biberó. Fornas dedica una atenció especial a les penúries del soldat en la Batalla de Llevant, les experiències en el front d'Extremadura, el camí del retorn a casa i els difícils anys de la postguerra durant els qual miquel va haver de fer també el servei militar.

La cinquena biografiada és Antònia Fonfría Villaroya nascuda a Borriana el 1915 i infermera durant la guerra a Borriana i Lorca. Aquesta biografia, escrita per Rosa Monlleó, és la historia de vida d'una jove que, com moltes joves de la rereguarda republicana, va decidir de fer-se infermera 
durant la guerra. El relat és apassionant per les aventures que passà fins els inicis de la postguerra, que la pillà a Múrcia amb una terrible postguerra on la incansable supervivent lluità per tirar endavant.

La sisena és la d'Abelardo Ripoll Segarra nascut a la Salzadella el 1929. Era el major de cinc germans i, durant la postguerra, va haver de fer-se càrrec dels treballs de la família perquè el pare fou empresonat a causa de la repressió franquista. La seua història ens mostra el camí dels refugiats que van abandonar el poble a causa dels combats de la guerra i la vida d'uns xiquets sense el pare empresonat en la postguerra. La biografia se centra en els anys de la guerra i la postguerra amb unes pinzellades breus dels anys posteriors perquè segons l'autor del text, Alfredo Fornas Pallarés, són estos anys foscos els que susciten un major interés.

La setena biografia, redactada per Ivan Medall Chivas, és la del futbolista Antonio Pérez Balada, un porter de fama en el Castelló, l'Atlético de Madrid i el València. Va nàixer a Nules el 1919 i va ser enrolat en la quinta del biberó per a combatre en la Batalla de l'Ebre. Després va travessar la frontera francesa i va passar pels camps de concentració, on va estar sis mesos fins que la família li va aconseguir els avals necessaris per a tornar a Nules. La seua destresa com a porter de futbol li va permetre de viure una postguerra amb menys penúries que altres excombatents republicans.
Lobjectiu principal d'aquest llibre, que està precedit per una suggerent presentació col-lectiva dels tres editors, és mostrar el camí de la memòria històrica com un instrument perquè els testimoniatges de la història col-lectiva dels castellonencs tinguen la possibilitat de comunicar les seues vivències positives i negatives, recordar i eixir del silenci. Es tracta en definitiva, con titulen el text de la presentació, de demostrar la validesa dels subjectes anònims com a constructors de la Història i la memòria del record.

JOSÉ MIGUEL SANTACREU SOLER Universitat d'Alacant

Monlleó, Rosa; OlIVER, David (eds.), Vides truncades per la Guerra Civil a Castelló. Entre la repressió latent i la resistència quotidiana, Castelló de la Plana, Publicacions de la Universitat Jaume I, 2014, 337 pp.

El volum que ressenyem és el $n^{\circ} 4$ de la col-lecció "Història i Memòria. Testimonis" mantinguda pel Grup d'Estudis d'Història Local i Fonts Orals de la Universitat Jaume I de Castelló que, des de l'any 1995 i sota la direcció de la doctora Rosa Monlleó, enregistra entrevistes de persones de Castelló la vida de les quals va ser truncada per la Guerra Civil i la postguerra. És una prova de que la His- 
tòria i la Memòria caminen juntes, perquè es complementen segons afirmen i demostren els autors del text en la presentació del llibre redactada pels editors, Rosa Monlleó i David Oliver.

El llibre compila les biografies de 8 persones elaborades pels investigadors del Grup que dirigeix Rosa Monlleó. La primera està dedicada a les vivències de guerra i postguerra d'una nena, Manuela Fernández Suárez, refugiada a Castelló durant els moments més durs dels bombardejos de la Guerra Civil. Manuela va nàixer a Obona, Concejo de Tineo d'Astúries l'any 1927 i era la menor de huit germans d'una família de llauradors. Quan va començar la guerra estava a Madrid a casa d'uns familiars i, pel març de 1937, va ser evacuada cap a Castelló amb una trentena més de nens. Llavors tenia 10 anys d'edat. Hi va viure amb una família d'acollida i és un testimoni molt valuós sobre les vivències de la guerra i la postguerra a Castelló, segons ens demostra l'autora de la biografia, María Amparo Valls Tomàs. La guerra va truncar la seua vida des de petita i va lligar el seu futur a Castello i a la família d'acollida. Es va casar amb una castellonenc d'aquest grup familiar l'any $1952 \mathrm{i}$ ha tingut cinc fills propis més els que ja cuidava.

Les següents persones biografiades són Teresa Vela i el seu fill Manuel Salvador sobre les quals la mateixa Rosa Monlleó redacta un text ric en informació testimonial sobre el racio- nament i l'estraperlo de postguerra. Teresa va nàixer a Alcalà de Xivert l'any 1911 i el seu fill Manuel, el 1936. Teresa va quedar viuda ben jove i tant el testimoni seu com el del fill serveixen per a demostrar que la majoria de l'estraperlo el practicaven les dones. El capítol ofereix també una informació molt interessant sobre les múltiples i molt imaginatives tàctiques per a practicar-lo i sobre els hàbits alimentaris de la postguerra contats per dos testimonis que van regentar una tenda de comestibles.

La quarta biografia és la de Dolores Tortajada Sornichero, la major de quatre germans nascuda el 1914 a Sogorb. Lautora de la biografia, Eva Alcón, ens conta com Dolores cuidava de la mare que patia albúmina i, a través del seu testimoni, ens parla de les dolències habituals de l'època com la tuberculosi i la sarna. És una història de vida que relata la seua adolescència a Sogorb, la percepció dels avanços que va suposar la Segona República per a les dones, els efectes en la seua família de la col-lectivització forçada de les terres promoguda per la CNT en començar la guerra, l'arribada i intensificació dels bombardejos sobre Sogorb l'any 1938 i l'evacuació cap a València, com s'ocupa del fill sense el marit que marxa al front i és empresonat fins que aconsegueix tornar i retornen a les terres castellonenques en la postguerra on patiran una repressió psicològica i una vigilància latent. 
La cinquena està dedicada a Germán Renau Forcadell, un espia republicà demòcrata del Servei d'Intel-ligència Militar nascut a Castelló el 1920, i la redacta Vicent Grau Reig. Lautor ens conta com va ser la infantesa i joventut d'este socialista republicà, com es va implicar en la FUR i el seu ingrés en el SIM creat l'estiu de 1937 i com va acabar la guerra immers en la tragèdia del port d'Alacant. Les seues vivències el converteixen en un testimoni de primera mà per a conèixer la guerra a Castelló, el procés revolucionari i les experiències traumàtiques les republicans atrapats en el port d'Alacant i empresonats. Ell mateix en va ser un, que ho va perdre tot a conseqüència de la repressió econòmica i física que va patir.

La sisena biografia l'escriu David Oliver Expósito i està dedicada a Manuel Peirats Ramón, veí i alcalde de Mascarell, que va patir el saqueig de casa fet pels moros en ocupar el poble. Li van llevar fins i tot el vestit de la comunió. Va nàixer el 1927 en una família d'agricultors i recorda els dos primers anys de la guerra al poble de Mascarell com a tranquils amb una vida quotidiana de rereguarda, que contrasta amb l'evacuació esdevinguda en arribar el front al poble l'any 1938. En tornar a casa, van trobar un poble devastat. Ens relata la vida al poble amb les modalitats de repressió patida i la reconstrucció, en la que va destacar fins ocupar l'Alcaldia el 1967.
La setena biografiada és Mercedes Álvares, una joveneta evacuada de Madrid igual que Manuela, però Mercedes era més major i és un exemple de fidelitat al Partit Comunista amb reunions clandestines per a ballar, prendre el bany a Cullera o escoltar Radio Pirenaica durant la postguerra. Els autors del text són els mateixos editors, Rosa Monlleó i David Oliver, els quals destaquen el valor del testimoni de Mercedes perquè és una dona intel-ligent i observadora de la realitat de manera crítica. Va nàixer a Madrid el 1914 i s'hi va educar en un barri benestant. La família estava acomodada i ella sempre ha estat una dona molt elegant i va sobreviure a Cullera com a modista d'èxit durant el Franquisme, amb el qual va ser sempre crítica. El seu pare va organitzar l'evacuació de xiquets de Madrid cap a Llevant i tota la família es va traslladar a Benicàssim en novembre de 1936, primer, i a Cullera el 1938, motiu pel qual Mercedes és un testimoni molt valuós per a conèixer el desenvolupament de l'ajuda humanitària a Benicàssim i Cullera durant la guerra. I també ho és per a la vida de la postguerra a Cullera, on va sobreviure com a modista.

La darrera de les biografies és la dedicada a Vicent Varella Navarro, que treballava per a Salvador Dávalos, l'empresari propietari de diversos cinemes i concessionari del Teatre Principal de Castelló. És un testimoni que ens relata formidablement la repres- 
sió patida a Castelló en els espais d'oci de la postguerra. Els autors del text, Fàtima Agut Clausell i Luís Jesus Mediano Moraira, ens expliquen com funcionava la censura a partir del relat de Vicent i la contextualitzen històricament. Vicent va nàixer a Castelló el 1918 i va heretar la ideologia socialista del pare. Quan va començar la guerra tenia 18 anys $i$ es va allistar com a motorista voluntari. Va estar a Brunete i en l'Estat Major de Madrid. L'estiu de 1938 va ingressar en l'Escola d'Aviació de Sabadell i quan va acabar la guerra aconseguí sobreviure tot i la repressió patida pel pare. En les primeres eleccions municipals democràtiques de 1979 va ser elegit regidor pel PSOE a Castelló.

Lobjectiu principal d'aquest llibre que recull les biografies comentades és mostrar que la Història y la Memòria caminen juntes perquè es complementen, perquè la memòria històrica també permet una aproximació a la realitat del passat feta des de la construcció social del record. Però no és l'únic, els autors també volen contribuir a tancar la ferida dels vençuts deixant-los parlar i traient a la llum les situacions traumàtiques que van patir. Es tracta de demostrar la validesa dels subjectes anònims com a constructors de la Història i la memòria del record con venen fent els membres del Grup d'Estudis d'Història Local i Fonts Orals de la Universitat Jaume I de Castelló que des de l'any 1995 van començar les seues investigacions plas- mades en diversos volums com el que ara ressenyem. A més a més, inclouen nombroses fotografies per a donar una visió més completa de la Història i la memòria de la Guerra Civil i el Franquisme amb aquest documents de primera magnitud, que els autors tracten com un document autònom en la construcció de la història.

\section{JOSÉ MIGUEL SANTACREU SOLER \\ Universitat d'Alacant}

García-Orellán, Rosa, Carmen Facal. Buscando mis recuerdos, León, Everest, 2013, $304 \mathrm{pp}$.

El libro Carmen Facal. Buscando mis recuerdos, escrito por la antropóloga Dra. Rosa García-Orellán, funde la biografía de la empresaria Carmen Facal con la de la empresa de su familia, Remolcadores Facal, sita en el puerto pesquero de Pasajes (Guipúzcoa) España. Asimismo, es un recorrido por la historia de este puerto desde el primer tercio del XX, mostrándonos el asentamiento de la inmigración gallega, el auge y declive de la pesca industrial, los cambios en las relaciones intergeneracionales, los cambios sociales, y el alto empoderamiento mostrado por las mujeres.

En este trabajo, García-Orellán vuelve a mostrar su preocupación por cómo se producen las relaciones intergeneracionales, sumergiéndose por tanto en el mundo de la historia. Así 
pues, ¿cómo clasificar este libro? ¿relato histórico, trabajo etnográfico, biografía? Lo cierto es que las tres definiciones son válidas y aparecen fundidas en este trabajo. Además, y dentro ya del género biográfico, este trabajo presenta una peculiaridad y un auténtico desafío metodológico, y es la de ser una biografía cuyos recuerdos vienen evocados y rememorados desde las personas del contexto. El trabajo arranca con un relato de cuatro páginas narradas por la propia Carmen, en las cuales ella condensa todo su relato biográfico. A partir de ahí, y ante la imposibilidad de seguir construyendo su memoria, llama a cuarenta y cuatro personas que han recorrido con ella partes de su ciclo vital. Son estas diferentes voces las que le hacen rememorar y construir su memoria y por tanto su biografía. Un fantástico ejemplo de la fusión entre memoria individual y memoria colectiva, y que muestra además que la biografía es un género pertinente a la hora de mostrar que la experiencia individual y la experiencia colectiva son dos elementos indisociables en la experiencia humana.

La metodología de este trabajo es la propia de la historia oral. Un punto de interés de este libro es la polifonía de voces mostrada a la hora de construir este texto biográfico. La autora apenas contextualiza los hechos, sino que deja hablar, desvelando la subjetividad en estado puro, sin analizarla ni tamizarla, ya que su objetivo es mostrar el ambiente narrado, interpretado por los propios protagonistas. Este aspecto es seguramente lo que más aleja a este trabajo de ser un texto histórico, y más cerca está de ser un texto antropológico. Sin embargo, sí entra en el ámbito de la historia, y en este sentido, resalta el muy original e insólito corpus empírico que puede abrir nuevas reflexiones sobre cómo era la sociedad en los años sesenta y setenta, cómo se configuró la subjetividad de las personas que la vivieron, y por qué se optó por unas opciones políticas, sociales y de comportamiento.

Este trabajo además, supone un doble reconocimiento, tanto social como histórico, a la inmigración gallega en la zona de Pasajes. Por una parte, se muestra cómo se produjo la inmigración gallega al puerto de Pasajes desde los años 30, y cómo este colectivo fue el que mayormente contribuyó al auge de la actividad portuaria. Se resalta así la gran influencia socioeconómica de los y las gallegas en la costa guipuzcoana, llenando así un vació dentro de la historiografía y la antropología vascas, que no han prestado la debida atención a este tema. Por otra parte, se hace un reconocimiento expreso a las mujeres, olvidadas artífices de empresas y del dinamismo económico que se vivió en Pasajes, como es el caso de la madre y abuela de la biografiada. En este sentido, es interesante observar que no se analizan acciones o proyectos concretos capitaneados por mujeres, sino 
que se muestra su subjetividad, cómo se sintieron, cómo percibieron, cómo experimentaron el momento histórico que les tocó vivir. Se muestra así a la mujer desde dentro.

El libro está dividido en cinco capítulos. Las divisiones de los mismos corresponden a los diferentes ciclos vitales de Carmen, los cuales además se funden con la evolución de la empresa familiar, y van acompañados de los cambios sociales, políticos y económicos que se produjeron entonces.

El primer capítulo está consagrado a la infancia de Carmen en los años cincuenta. Eso sí, se retrotrae a la época del asentamiento de la primera emigración gallega en Pasajes -más concretamente en Trintxerpedurante los años treinta, y a la dura posguerra durante los cuarenta. Los años cincuenta, tal y como aparecen narrados, pueden resultar un tanto diferentes a la visión general que se tiene de este periodo, aunque compartiendo el silencio político al que se abocaba a muchos republicanos, como es el padre José Facal. Los relatos del muelle, en torno al cual gira toda la vida del pueblo y que comienza su despegue económico ahora, nos lleva a un ambiente de abundancia económica. Son los años de mayor afluencia de inmigrantes gallegos, que van a trabajar en los barcos o en sectores relacionados con el puerto. Se muestra además el gran poder de las mujeres a la hora de manejar negocios, de ejercer de prestamistas, todo basado en unos lazos de confianza. Se nos introduce así en un mundo en el que la vida de las personas pivota sobre una visión de grupo, de lo comunitario.

El segundo capítulo es el de los años sesenta, década de grandes cambios. Por una parte se muestra cómo tímidamente emerge el individualismo y se van deshaciendo los lazos comunitarios que habían prevalecido hasta entonces. El final de la emigración gallega marca otro de los momentos de la década. Además, el despegue económico de los años anteriores consagra a este pueblo como "la ciudad del Dólar", y el consumo se consolida. El pluriempleo para mantener los niveles de consumo es propio de estos años, cuando comprar la televisión, el frigorífico o un coche es signo de triunfo social. Ese cambio en el perfil del consumo también se muestra en el ocio, ya que comienzan a aparecer tímidamente discotecas y bailes donde la música difiere de la que hasta entonces se escuchaba. Por otra parte, comienzan a emerger preguntas sobre la identidad en la segunda generación, hijos de inmigrantes, que por primera vez comienzan a ir al lugar de origen de sus padres. ¿De dónde es la primera generación nacida fuera de Galicia?, es una pregunta que se han hecho todos los entrevistados con estos orígenes, y que comparten muchos de los hijos de inmigrantes que en aquellos años se movieron a diferentes regiones de España. Otro elemento interesante que se muestra de estos 
años sesenta es la diferencia entre la subjetividad de las mujeres, entre aquellas que aceptan e incorporan el discurso del nacionalcatolicismo, y aquellas que no lo hacen. En este sentido, una de las virtudes de este libro es mostrar un amplio espectro de mujeres que no solamente no renuncian a ocupar el espacio público, no convirtiéndose en amas de casa consagradas al cuidado de los hijos, sino que aún teniendo ese rol, serán mujeres profundamente respetadas por el contexto en el que viven.

El tercer capítulo está dedicado a los chicos y las chicas modernas de los años setenta. Es este un capítulo apasionante, donde se muestra la gran apertura que había en Pasajes y lo avanzada que resultaba esta zona. La música rock, los pantalones Levis, una nueva de ocio, y de ver la vida penetra y permea en muchos jóvenes de estos momentos. Las discotecas modernas, y no ya lo bailes, harán auténtico furor entre estos jóvenes. Son también los años de probar drogas, de experimentar nuevas sensaciones, de trasgredir con el cuerpo mostrando nuevas formas de ver el mundo y de mostrarse al mundo. También es un momento donde tímidamente comienza la liberación sexual, y en este libro se muestra cómo muchas madres dejarán que sus hijas decidan sobre sus prácticas sexuales, sin constricciones ni reprimendas. Esta permisividad enlaza y es coherente con la trayectoria de esas mujeres que nunca habían aceptado el ideal de ama de casa.
El capítulo cuatro se centra en mostrar las dinámicas de la empresa familiar, que en los años setenta inicia su expansión. Se analizan también algunas de las coyunturas económicas que les toca vivir, como la primera crisis del petróleo de 1973, que hunde a algunas de las más consagradas casas armadoras de Pasajes. Por otra parte, estos años comienza un cambio en el comportamiento de los trabajadores de la empresa, que obliga a una metamorfosis de la misma. Además, el final de la flota pesquera y el declive de Pasajes como principal puerto bacaladero de España hacen que Remolcadores Facal se tenga que internacionalizar, comprando nuevos barcos que se adapten al nuevo contexto. Brasil, Buenos Aires o el Índico son nuevos escenarios que nada tienen que ver con lo narrado hasta ese momento. Los desafíos económicos y las nuevas dinámicas del mundo financiero como modelo de productividad son reflexionados en la última parte del trabajo. En definitiva, se muestran los cambios económicos y sociales que se viven en España no solo a nivel interno, por el fin de la dictadura, sino también a nivel externo, con el asentamiento de la globalización y las crisis cíclicas que ésta padece. Se cierra así un recorrido biográfico que se funde con la historia de uno de los puertos pesqueros más importantes del País Vasco, el puerto de Pasajes.

SARA HIDALGO GARCÍA Universidad de Santiago de Compostela 
VILAR, Juan Bautista, La diócesis de Cartagena en el siglo XX. Una aproximación histórico-sociológica, Madrid, Biblioteca de Autores Cristianos, 2014, 153 pp.

La fecunda pluma del profesor Vilar Ramírez nos regala en este libro una sugerente síntesis de nuestra historia eclesiástica contemporánea. Considerando la obra en conjunto, observamos su carácter de aproximación global a una temática amplia y compleja, cuyo detallado tratamiento hubiera requerido un espacio mucho más extenso. Por tanto tiene más de aproximación indicativa, que de estudio terminado que aspire a aprehender e interpretar toda la información disponible al respecto. Con todo, el trabajo no ha dejado de ser ambicioso en cuanto al asunto propuesto, una panorámica histórica que abarca un complicado reto, cual es el devenir de la Diócesis de Cartagena a lo largo de todo el siglo XX. Estructurado en tres bloques, los capítulos conservan por separado su unidad monográfica, aunque están hábilmente dispuestos en una secuencia temática, en torno a tres aspectos fundamentales de la Diócesis: la actuación pastoral de sus obispos, la configuración del clero y la proyección social, y de este modo consiguen sostener, como las columnas de un templo griego, el arquitrabe de la continuada evolución histórica. Esta peculiaridad, unida a la riqueza bibliográfica del estudio convierten al libro en un excelente instrumento informativo del estado de la cuestión y de las principales aportaciones a la misma.

Otra cualidad del libro viene anotada por el mismo autor cuando nos avisa en la introducción que la historia que nos ofrece no es la descripción pormenorizada de los eventos, sino más bien el planteamiento básico de los problemas más grávidos de resonancias en su tiempo y en la posteridad. Aquí radica una de las originalidades del profesor Vilar, perceptible tanto en ésta como en otras de sus obras, en las que cumple la misión de oteador de nuevos horizontes históricos. No sólo en el sentido del pionero que rotura nuevos campos para posibles investigaciones venideras, sino también del guía experto que, con sus sugerencias, hace reparar en nuevos detalles, enfoques, perspectivas. Esta capacidad de sugerencia -posible sólo 'ex abundatia scientiae'- suscita la reflexión, el pensamiento. Por ello el lector podrá debatir interactivamente con el libro sobre algunos puntos de vista del autor, pero siempre le encontrará interpelante y cercano. Hallará a un historiador que ante todo hace pensar y que, por añadidura, escribe con brillante elegancia y soltura.

El trabajo, fundamentado en bibliografía especializada y con un aparato crítico basado en documentación de primera mano, no sólo aporta conocimientos nuevos, sino que destaca por su metodología. El autor, en este 
sentido analiza la comunidad diocesana aplicando los métodos y criterios que los sociólogos utilizan en el estudio de las colectividades humanas. Pero, con todo, en el libro no se ignora ni se niega al alma de la comunidad cristiana, que es la fe de los creyentes, pero se prescinde de ella en la presentación de las personas eclesiásticas o de las instituciones religiosas. Se logra así un aire de libertad, en el que no faltan toques críticos sobre algunas actitudes de los dirigentes que parecen menos conformes con los ideales evangélicos, o sobre algunas costumbres populares contaminadas por una religiosidad aparente, superficial. De todas formas, el investigador alicantino se deja llevar por la vertiginosa épica del sentimiento, es tierno con la debilidad humana y duro con la falta de compromiso. Su obra lejos de un férreo hermetismo y de un tratamiento simbólico, críptico o metafórico se decanta -por el contrariopor un tratamiento epidérmico e inmediato de lo analizado, en el que los seres, los protagonistas de la historia viven entre las páginas del libro.

La obra comienza trazando el marco geográfico y contexto histórico que repercuten en la organización diocesana. La disminución territorial de la diócesis desde el Concordato con el régimen franquista de 1953 produjo un descenso demográfico en los sacerdotes, aunque fue la explosión anticlerical de 1936 (127 eclesiásticos asesinados) la que suscitó el mayor desastre. El marco histórico queda perfectamente trazado por el autor: en una Europa de entreguerras -la Europa de la guerra civil (Enzo Traverso, etc)- donde la lucha de clases rebrota con virulencia (su agudización es periódica en diversos decenios del siglo XX: mayo del 68, huelgas de los obreros de la Renault en Francia en la misma década, encrespamiento de los conflictos sociales de los años 70), y en la que sin embargo la Iglesia católica soslaya con suma inteligencia las dificultades, no sólo haciendo suyo el mensaje de Cristo, sino también la frase del pintor y poeta visionario romántico británico William Blake de respetar como sagrado todo aquello que tiene vida: en la Baviera soviética, el obispado católico solicita de los feligreses que legitimen el nuevo régimen político, participen en el sistema de elecciones libres vigente, y se presenten a él, con su propio partido, el de los demócratas-cristianos bávaros; en la España donde el hambre de terrenos de cultivo, el desequilibrado reparto de la propiedad de dichas tierras y la existencia de bolsas de miles de jornaleros sin propiedad alguna son la clave de bóveda del principal problema socio-económico, la Iglesia intenta ajustarse a su tarea pastoral, en una sociedad desgarrada entre dos mundos, y donde entre un mundo y el otro surge un muro de desconfianzas, de incompatibilidades, de vigilancias y de represiones. 
De hecho la guerra civil del 36 al 39, apuntó el sociólogo Rogeli Duocastella, supuso dentro de la Iglesia española una línea divisoria más profunda aún que la marcada años más tarde por el Concilio Vaticano II $^{1}$. Para los católicos más tradicionales, la proclamación de la Segunda República equivalía a una catástrofe ${ }^{2}$. República, en su imaginario, significaba persecución contra la Iglesia. Es por ello que algunos católicos no podían, por tanto, aceptar el nuevo régimen; dicho de otra manera, para ellos fe y republicanismo resultaban difícilmente compatibles en las circunstancias concretas de la España de 1931, en la que República y anticlericalismo van de la mano. Sin embargo, otro sector de la Iglesia, más pragmático, aceptó el nuevo orden constituido. Para ellos, los principios cristianos constituían -en puridad-y en su opinión, el fundamento de una democracia auténti$\mathrm{ca}^{3}$. A su juicio, no solamente era lícito, sino exigible, que un creyente respaldara a la naciente República. Con un apoyo activo, no pasivo, ya que estaban en juego la paz y el orden del país. De hecho, la mayoría de los católicos se decantó por esta aceptación

1. vV. AA., La Iglesia católica y la guerra civil (cincuenta años después), Madrid, Fundación Dietrich Ebert-Instituto Fe y Secularidad, 1990.

2. Véase RAGUER, Hilari, La espada y la cruz (la Iglesia de 1936 a 1939), Barcelona, Bruguera, 1977.

3. Véase martínez hoyos, Francisco, La Iglesia rebelde, Madrid, Punto de Vista Editores, 2013. del status quo, aunque sin renunciar a cambiar, desde dentro del sistema, la legislación que se interpretara como hostil a la Iglesia.

El Vaticano, obrando del mismo modo que en Baviera, amparó esta línea de pragmatismo, de cara a pacificar los ánimos y garantizar el mantenimiento del orden. Por el contrario los republicanos, mientras tanto, consideraban que, si se quería modernizar el país, resultaba esencial limitar el poder de la Iglesia. Ésta, a juicio de la izquierda, constituía el gran obstáculo que impedía homologar España con el resto de Europa. Por tanto, había que separarla del Estado, alejarla de los centros educativos y limitar su poder económico. Sin embargo, faltó diplomacia y sentido de las prioridades en la actuación de las fuerzas progresistas. El hispanista Nigel Townson tiene razón cuando señala que se quiso ir demasiado ràpido. De 1931 a 1933, los republicanos intentaron alcanzar una separación entre la Iglesia y el Estado que en Francia se había efectuado en veintiséis años, en un contexto de estabilidad constitucional que aquí brillaba por su ausencia. Por otra parte, los políticos franceses dieron muestras de un pragmatismo que contrastaba con la inflexibilidad de sus homólogos peninsulares. Vilar acaba recalcando que una explosión anticlerical como la del verano de 1936 fue, en parte explicable, atribuyéndola a la existencia en la diócesis de Cartagena de una masa popu- 
lar mayoritaria, presa de la miseria y la ignorancia, diezmada por las endemias y la emigración, y en considerable medida desatendida pastoralmente, que identificaba a un clero distante, rutinario y acomodaticio con la minoría dominante, los caciques tradicionales de la región, unas pocas familias emparentadas todas entre sí que practicaban las grandes virtudes burguesas: la honradez profesional, los vínculos familiares estables, la práctica religiosa, una ética sexual muy rígida, casi victoriana, y el ejercicio de la caridad hacia los pobres. Pero poco sensibles a los grandes problemas estructurales de un mundo en vísperas de revolución, y a los gritos de las grandes masas desfavorecidas pidiendo una sociedad más justa e igualitaria (p. 8).

A partir de ahí, comienza el segundo bloque del volumen, dedicado a los obispos de Cartagena y a su actuación pastoral. Al respecto, el autor es un maestro en el tratamiento de las biografías ambientales. Por ello, la galería de los obispos del siglo XX no carece de una problemática que se quede en las simples semblanzas biográficas, porque en realidad van más allá: ofrecen los datos personales de cada uno y de su estrecha conexión con los momentos políticos, sociales y eclesiales del tiempo en que ocuparon el obispado. Vilar se ocupa no sólo de sus acciones o actuaciones prácticas, sino también de su proyección como escritores, a lo largo de una labor digamos topológica: de localización de la conciencia espiritual con respecto al pensamiento; de este con respecto a la palabra, y en otros casos a la técnica literaria, y de la palabra respecto al conocimiento y a la labor eclesial como tales. De ese modo, la biografía de los obispos se convierte en el soporte de la historia diocesana.

El primero de los estudiados es Vicente Alonso y Salgado (1902-1931), "entre la tradición y la modernidad" en la España de Alfonso XIII, escolapio gallego, que alentó los fervores corazonistas y marianos, y promovió los círculos obreros en la renovación de las actividades apostólicas. A continuación se pasa a la figura de Miguel Díaz y Gómara (1935-1949), que encarna la etapa del "nacional-catolicismo", navarro intelectual y publicista, que escapó disfrazado en 1936 y regresó después de la guerra mostrando una sintonía total con el régimen. Son años en la diócesis de Cartagena propios de un contexto de miseria material y moral, de opresión y represión, en que tuvieron lugar con total impunidad abusos de todo tipo, encausamientos y ejecuciones sumarias, o simplemente brutales ajustes de cuentas, ante el silencio de la autoridad eclesiástica, plenamente identificada en esta diócesis con la nueva situación política y que en el mejor de los casos se limitó a ignorar cuanto acontecía en derredor. Una actuación que fue la mayoritaria en ambientes eclesiales españoles del momento y 
por la cual la propia Iglesia pediría públicas disculpas años más tarde (p. 29). El siguiente prelado analizado es Ramón Sanahuja (1950-65), entre la involución y el cambio, catalán de origen campesino, conservador como su antecesor, pero más pastoral y humilde, que en sus últimos años, postrado por la enfermedad, alcanzó los comienzos del Vaticano II. Es sucedido por Miguel Roca Cabanellas (1966-78), bajo el signo del Concilio y de la Transición a la democracia, un mallorquín intelectual y aperturista, que se esforzó por acomodarse a los nuevos tiempos, llevando a cabo un nítido distanciamiento respecto del régimen franquista cuando éste tuvo no menos de 30 curas en la cárcel por motivos políticos, negándose siempre a dar su consentimiento para que los procesos contra estos sacerdotes fueran adelante, y que no dudó en enfrentarse a la patronal conservera murciana denunciando los abusos de que eran objeto los trabajadores del sector (elevada proporción de mujeres y menores subcontratados, jornada laboral de hasta 10, 12 y más horas, bajos salarios con recortes ilegales y frecuente ausencia de seguros sociales, pésimas condiciones de trabajo en cuanto a seguridad, higiene, etc.) (pp. 44-45). Toda una sutil y sugerente metáfora de cómo se posiciona la Iglesia católica a partir de los años 60 frente al régimen autoritario franquista y sobre cómo no se produjo la claudicación de la inteligencia creadora fren- te a la fuerza bruta del régimen surgido de la guerra civil que, usando una lógica fría y correosa, se convertía en imparable apisonadora. La larga historia de los católicos progresistas españoles, desde 1812 y desde sacerdotes de la talla de Diego Muñoz Torrero, el liberal defensor de la Constitución de Cádiz queda así vivídamente reflejada.

Se nos invita a pensar, pues, sobre cómo en el seno de la Iglesia los creyentes más contestatarios han buscado desde nuestra primera Constitución la manera de armonizar fe y liberalismo, así como en el siglo XX muchos católicos españoles -bebiendo en este caso del primitivo franciscanismo- han intentado hacer compatible fe y marxismo (adelantándose a los esfuerzos del notable pensador Leonardo Boff, de la Teología de la Liberación o del propio sandinismo nicaragüense de los años 70). Y de hecho en el período de la dictadura franquista, militantes de diversos grupos confesionales se implicaron decisivamente en la oposición al régimen ${ }^{4}$. Los dos últimos prelados analizados son Javier Azagra (1978-98), obispo posconciliar, y Manuel Ureña (1998-2005). El primero es presentado como un pamplonés de vocación tardía, animoso impulsor de los decretos conciliares y de medidas valientes que provocaron la oposición de algunos sectores.

Las semblanzas y biografías de estos obispos son encajadas perfectamente en el ambiente de cada época.

4. Ibid. 
Los problemas que se planteaban en la diócesis eran los mismos que se vivían en la Iglesia en general o en España en particular. Cada obispo los encajaba a su manera de ser y gobernar, con los aditamentos específicamente murcianos de las festividades locales o de las tradiciones populares. El monarquismo episcopal produce la sensación de que la biografía del obispo determina la historia de la diócesis; aunque en el fondo se adivina la presencia del pueblo creyente, que soporta el entramado jerárquico. En este sentido, son semblanzas ambientales las que este libro nos ofrece. El espíritu de cada época se refleja en los obispos. Hasta el punto de que uno se pregunta si es el obispo el que imprime carácter a la diócesis, o es la diócesis, el pueblo cristiano, el que impone el ambiente a sus prelados. Las semblanzas de los obispos se complementan con la atención a tres instituciones eclesiásticas: el cabildo catedralicio, el seminario y las congregaciones religiosas. La primera de ellas, el cabildo con sus dignidades y canónigos, forma la aristocracia del alto clero, una minoría dirigente que influye en el culto y liturgia de la diócesis. El autor resalta la valía de estos hombres, entre los que hubo buenos predicadores y publicistas, y dedica sabrosas pinceladas a los cinco decanos vitalicios, capaces de competir con los obispos o de convertirse en su mano derecha.

El análisis de los sacerdotes diocesanos se fundamenta en el origen de su formación, en los dos seminarios, mayor y menor. Las tablas estadísticas confirman la abundancia de vocaciones en los años 40, 50 y 60, mientras se apunta al anquilosamiento de los estudios y al rigorismo disciplinar de aquellos años. Las estadísticas descubren el grado de perseverancia de los seminaristas, que, cuando llegaron a sacerdotes, sufrieron el impacto de la secularización posconciliar, especialmente en los años 70. Entre 1964 y 1999 se secularizaron 118 sacerdotes (19,6\%). El claroscuro tiene aspectos positivos, como la atención misional, docente o educativa en Iberoamérica, pero el descenso de vocaciones en el último tercio del siglo no deja de ser preocupante. Sobre el clero regular masculino y femenino se ofrece la tabla de 134 comunidades, de las que 107 son de religiosas.

Por último, la proyección social se estudia principalmente a través de las asociaciones de seglares, cuya andadura sigue las pautas cronológicas de la Iglesia española. Tras el paréntesis de la República, siguió el auge de las movilizaciones católicas de la posguerra y la reorganización de las asociaciones, empezando por la Acción Católica. A Murcia llegaron los movimientos apostólicos especializados (HOAC, JOC), pero también llegó la gran crisis que no logró detener el talante conciliador y progresista del obispo Roca. De los 71 sacerdotes comprometidos entonces con el movi- 
miento obrero, 34 pidieron la secularización. El investigador alicantino, en este punto, nos recuerda asimismo cómo las manifestaciones de religiosidad fluctúan entre los afanes de renovación y la persistencia de la rutina. El autor se vale de una encuesta de 1970 sobre las prácticas religiosas, y otra de 1989 sobre la religiosidad popular, con resultados no muy halagüeños (p. 98). Así, cuando se analiza el espectro de las procesiones de Semana Santa, las fiestas religiosas anuales más relevantes por la movilización de fieles que conllevan, con mucha finura y perspicacia, los sacerdotes encuestados -dotados asimismo de una visión muy intelectualista de la religión- critican su excesiva secularización, el nulo recogimiento, el ritualismo externo, un cierto culto exterior y vacío, y el afán de figurar y de profana competitividad de los feligreses; en su contra, abogan con sagacidad -parafraseando a ese intelectual marxista, P.P. Pasolini, que con tanto acierto aunó marxismo y cristianismo- por convertir la Semana Santa en algo parecido a una hierofanía, una purificación ritual, solemne y austera, mística, de vivencia interior del feligrés. Con todo, Vilar considera que, a finales de siglo $\mathrm{XX}$, el asociacionismo gozaba de buena salud, pues surgieron otros movimientos apostólicos alternativos: Opus Dei, Camino Neocatecumenal, Renovación Carismática y otros varios, más o menos impulsados por la jerarquía eclesial. Entre estos movimientos re- novadores destaca la creación de la Universidad Católica.

En definitiva, nos encontramos ante un libro de referencia que ante todo integra, selecciona, pauta, y además invita a abrir nuevas investigaciones que arrojen luz sobre cuestiones vinculadas a la construcción identitaria de la nacionalidad española durante el siglo XX. La explicación histórica debe integrar las aportaciones de la historiografía que abren nuevos campos a la reflexión histórica. Debe incluir, por ejemplo, la historia de las religiones y sus aspectos clave de repercusión en la estructuración de la trama social, y esta obra, que tiene el mérito de invitar al pensamiento y a nuevas lecturas, en particular no se ciñe en exceso a las interpretaciones que ajustándose demasiado a lo antropológico, psicológico o espiritual ofrecen un paradigma difícilmente historizable; por el contrario presenta la estructura religiosa no como una célula aislada, sino vinculada a una determinada organización de la producción, a una estructura de clases, es decir nos ofrece una perspectiva de explicación social.

FRANCISCO MANUEL PASTOR GARRIGUES

IES Sanchis Guarner, Silla, Valencia

Rodriguez BRanchat, Rosa, La construcció d'un mite. Cultura i franquisme a Eivissa, 1936-1975, Catarroja, Editorial Afers, 2014, 186 pp. 
Quan els historiadors escriuen sobre els mites s'ocupen, generalment, de llegendes o explicacions poc verificables que fan referència a herois relacionats amb els temps fundacionals molt llunyans d'un poble. Però Rosa Rodríguez, en la història recent que ha escrit d'Eivissa, demostra que el mite "Ibiza" no és cap fabulació poc creïble, que parla d'uns fets gens verificables, sinó un mite creat i consentit pel franquisme que s'hi ha imposat contra una realitat objectiva-Eivissa- diluïda entre una amalgama de gent hi arribada fruit del turisme de masses.

Rosa és llicenciada en Història de l'Art per la Universitat de Barcelona i doctora en Ciències Socials i Humanitats per la Universitat de les Illes Balears. Viu a Eivissa des del 1982 i la coneix pam per pam. El llibre està basat en la tesi doctoral que l'autora va llegir a la Universitat de les Illes Balears sota la direcció del doctor Antoni Marimon Riutort el 7 de juny de 2013 i és l'essència d'aquella tesi, la qual vaig tenir el plaer de llegir com a membre del tribulat davant el qual la defensà. La publicació que ressenyem ha incorporat les indicacions que li varem fer i ha guanyat en qualitat i contundència a l'hora de demostrar la seua hipòtesi i descobrir aspectes fins ara desconeguts de la història de la cultura de l'illa d'Eivissa per al continentals.

El llibre està dividit en tres capítols perfectament articulats per a demostrar la hipòtesi: En el primer ana- litza la cultura provinciana des de la Segona República fins la mort dels intel-lectuals legitimadors. S'ocupa de la desaparició de la cultura de la Segona República y estudia la Sociedad Ebusus i la revista Ibiza, l'Instituto d'Estudios Ibicencos i les activitats i vivències dels intel-lectuals legitimadors: Isidor Macabich i Marià Villangómez amb la seua poderosa personalitat. En el segon, ens mostra les claus del desenvolupament d'una cultura cosmopolita com a fenomen peculiar a partir d'una investigació centrada en la presència ininterrompuda a Eivissa durant 30 anys d'artistes i escriptors d'arreu del món, el desenvolupament de les biennals d'art universitari i del Museu d'Art Contemporani i l'arribada posterior dels beatniks i dels hippies, que tindran unes implicacions culturals vitals per al mite Ibiza com a illa de llibertat cosmopolita. El tercer capítol està centrat en les activitats de la intel-lectualitat eivissenca crítica des de l'Institut d'Estudis Eivissencs, amb una tasca cultural valuosíssima per a la catalanitat de l'illa, i el paper fonamental de la tercera època de la revista Eivissa encetada en 1972.

El llibre acaba amb unes conclusions contundents on l'autora denúncia que l'Eivissa pertanyent a l'espai de la catalanitat està greument amenaçada per la marca Ibiza de l'hedonisme vacacional que va alimentar el franquisme i que va tenir les seues bases en un estrangerisme heretat i prota- 
gonitzat pels intel-lectuals i pintors de la primera meitat del segle XX que hi van arribar d'arreu del món. El text és força interessant no només per al eivissencs sinó sobre tot per als continentals que tenen una imatge de l'illa exclusivament centrada en el mite Ibiza on la llibertat cosmopolita ha contrastat amb la repressió franquista patida pels aborígens.

JOSÉ MIGUEL SANTACREU SOLER Universitat d'Alacant

CALVEIRO, Pilar, Política y/o violencia. Una aproximación a la guerrilla de los años setenta, Buenos Aires, Siglo XXI Editores, 2013, 160 pp.

Vivir el miedo, la tortura, el exilio o la pérdida de seres queridos, es siempre doloroso y difícil. Recordarlo en soledad o narrarlo a otros, es volver a sufrir. Pensar, en cambio, esos negros años '70 argentinos, desde la memoria propia, intentando entender y explicar cómo y por qué los muertos (propios y ajenos), parece ser una tarea necesaria para los sujetos que atravesaron esa experiencia. Tal vez, hasta reparadora.

Por ello, resulta más que valioso tener entre manos un texto que, desde el interior de la militancia en Montoneros, busca analizar "las circunstancias que llevaron al momento de mayor violencia política en la Argentina (...) y el papel que les cupo en ellas a las organizaciones armadas" (p. 11).
Y tanto más, si la mirada crítica se anuncia desde sus primeras páginas.

Pilar Calveiro escribió las líneas de Política y/o violencia... durante los años noventa, y las pensó como complemento de Poder y desaparición..., su estudio sobre los campos de concentración creados por las Fuerzas Armadas durante el autodenominado "Proceso de Reorganización Nacional". Que esta segunda parte viera la luz en 1998, mientras que la dedicada a la violencia de la guerrilla tuviera que esperar hasta 2005, es botón de muestra de una de las mayores virtudes del texto reeditado en julio pasado por Siglo XXI. El análisis crítico respecto del rol jugado por las organizaciones político-militares durante aquellos años tuvo que esperar pacientemente a que al menos la mayoría de la sociedad argentina reconociera y condenara el horror de la represión del Estado dictatorial, luego de décadas de lucha de los organismos de derechos humanos. Pensar en tándem la violencia proveniente del poder dominante y la surgida desde los aparatos de resistencia, rechazando la teoría de los dos demonios, pero indagando al mismo tiempo la responsabilidad de los actores políticos nacionales, implica preguntarse "qué nos pasó". Y es eso precisamente lo que se cuestiona Calveiro, abriendo también a sus lectores el interrogante.

Hablar como miembro activo de aquellas organizaciones armadas, como prisionera del infierno de los cen- 
tros clandestinos de detención, como sobreviviente del terrorismo de Estado, como exiliada que aún no puede (ni desea, quizás) despertar cada día en su país natal, es otro gran mérito de la autora. Calveiro decide (idecide?) pensar-se a partir de lo vivido, pero también más allá de esa experiencia, buscando respuestas, explorando en el (su) pasado argumentos que expliquen cómo convicciones tan profundas se convirtieron, casi en un abrir y cerrar de ojos (o en el tiempo que toma cargar el arma o encontrar la pastilla de cianuro en el bolsillo), en tragedias tan dolorosas.

Para ello, la autora organiza su "aproximación a la guerrilla de los años setenta" en dos apartados centrales, precedidos por una apertura explicativa y clausurados por un posfacio pensado y escrito especialmente para esta segunda edición, es decir, 15 años más tarde que el texto original. Las páginas iniciales llevan el título de "Memorias", queriendo explicar anticipadamente esta palabra las intenciones de Calveiro de acercar un relato que, lejos de ser fiel, aparece como un ejercicio de evocación. Sin embargo, la autora adelanta que no será la suya una "memoria individualizante y privada" que pierda "los sentidos políticos de la acción" (p. 15), sino una que buscará "deshacer y rehacer sin tregua aquello que evoca", revisitando el pasado como "algo cargado de sentido para el presente" (p. 11).
Desde este punto de partida, entonces, Calveiro inicia su recorrido describiendo, en los cinco capítulos que componen el primero de los apartados, el contexto político y socioeconómico en el que (y por el que) surgieron las organizaciones armadas cuyo rol y responsabilidad históricos busca descifrar. Así, comienza su análisis explicando el "mesianismo autocrático" de las Fuerzas Armadas argentinas, que las colocaba constantemente en el lugar de salvadoras de la patria, y las consecuencias que esas intervenciones generaban. La autora define la etapa iniciada con el golpe de 1966 como un período de creciente militarización del Estado, que desplazó lo político del centro de la escena, para colocar en él a la propia guerra, en la que antiguos adversarios devenían ahora enemigos.

El segundo capítulo del apartado, titulado sugerentemente "Segundas partes...", se adentra en el breve interregno peronista iniciado en mayo de 1973, apuntando la "poca probabilidad" de éxito de la política de unificación nacional propuesta, debido al "grado de conflicto no resuelto, que [aún] persistía, bastante abiertamente, en la sociedad" (p. 43). Definiendo inicialmente esas disputas como " $f u$ gas" en el modelo de concertación, Calveiro afirma luego, sin embargo, que las organizaciones armadas (y también los sindicatos) comenzaron rápidamente a perder posiciones en el campo social, dejando avanzar al 
poder militar. Logró imponerse entonces una fuerte disciplina, explica la autora, que no tardaría en instalar los campos de concentración y la desaparición de personas como metodología de represión de los grupos enemigos. El gobierno de Isabel Perón caía así, "sin sorpresa de nadie" (p. 54).

Los otros tres capítulos que componen el primer apartado, destinado a contextualizar históricamente el análisis posterior, se proponen describir las características del "poder desaparecedor" de las Fuerzas Armadas en el Estado. Esta búsqueda de una "nueva sociedad ordenada, controlada y, sobre todo, aterrada" (p. 56) no se presenta como algo enteramente novedoso para Calveiro, aunque tampoco como una continuación o una repetición exagerada de algo previo. Es parte, según la autora, de la dimensión más íntima de nuestra sociedad, algo gestado a lo largo del tiempo, que aparece y desaparece a través de la historia. "Los golpes de Estado vienen de la sociedad" (p. 59), resume, mostrando y denunciando no sólo la complicidad institucional, sino también la convalidación social del maltrato y la subordinación absoluta exigida al interior de las Fuerzas.

El núcleo central de la obra, sin embargo, parece ubicarse en su segundo apartado, titulado "La desobediencia armada", en el que Calveiro concentra su comprensión crítica del rol histórico de las organizaciones armadas (y, en particular, de Monto- neros). A lo largo de cinco capítulos, la autora desmenuza no sólo el funcionamiento interno de lo que denomina "la más radical y confrontativa" de las "numerosas formas de desobediencia que se practicaron en la sociedad" (p. 77), sino también la participación que les cupo en el devenir-violencia de la historia argentina reciente. Respecto a esto último, Calveiro juzga como erradas distintas posiciones y decisiones de los grupos armados en relación a la situación nacional: critica la "táctica de ataque indiscriminado a las Fuerzas Armadas", que, dice, favoreció "la cohesión de las instituciones militares en torno a la necesidad de producir un golpe de Estado" (p. 82) y hasta al propio foquismo, que pareció saciar a una "generación impaciente", que comenzó a creer que "la lucha revolucionaria misma podía generar conciencia per se, sin necesidad de aguardar a que las condiciones objetivas, materiales, económicas, <maduraran>" (p. 95).

El análisis del funcionamiento interno de las organizaciones armadas, por su parte, se desarrolla en los capítulos tercero y cuarto de este segundo apartado, que Calveiro encabeza de manera contundente con los títulos "Atrapados" y "Una lógica cerrada". En ellos, la autora revela su faceta sociológica más positivista, al agrupar en categorías los distintos "mecanismos (...) que (...) asfixiaron la práctica" (p. 112) de esos grupos, enumerando pormenorizada- 
mente al interior de cada una de ellas los diferentes rasgos, cuya combinación condujo a la tragedia final. Así, 35 páginas condensan el también acelerado pasaje de estas organizaciones desde su valioso y profundo trabajo de base, hacia la urgente priorización de la acción militar, a partir de la construcción de un ejército popular, que igualara, enfrentara y derrotara al regular. Las consecuencias no se harían esperar, afirma Calveiro: el retroceso de aquel espíritu desobediente vería, en la importancia dada a la superflua etiqueta militar, su más inocuo resultado. El fortalecimiento de "los lazos de autoridad en detrimento de los vínculos de compañerismo" (p. 103); "la mentira desde las conducciones", intencional o no, en relación a la propia fuerza de las organizaciones y su "convicción del triunfo inexorable" (p. 119-120); su centralismo, que impedía la participación de los militantes en la toma de decisiones y disciplinaba el desacuerdo, con penas de expulsión y fusilamiento (p. 129); son observaciones que llevan a la autora a afirmar no sólo que "la descomposición interna estaba bastante avanzada en el momento del golpe militar", sino también que fueron las armas la que "terminaron por convertirse en una muralla de arrogancia que encubría (...) cierta ingenuidad política" (p. 104).

Es difícil explicar, e incluso comprender uno mismo, el gusto amargo que se sufre al terminar la última pági- na de Política y/o violencia. Parece una segunda derrota escuchar (sí, escuchar, porque se leen tonos, gritos y murmullos, en algunos tramos del libro de Calveiro) a una militante de Montoneros decir que fue una doble víctima: de la política represiva de los militares en el poder y de la de su propia organización. Para la Real Academia Española, una víctima es precisamente una persona que padece daño por culpa ajena, pero otra acepción es incluida en el diccionario. Víctima es también aquella persona destinada al sacrificio. ¿Era entonces un destino de esos militantes de base el convertirse en ofrendas de una causa? ¿Era necesaria su inmolación como símbolo de lucha? ¿Quiénes resultaron ser los elegidos? ¿Por qué no pudieron evitarse sus muertes, por qué no hubo una reacción social masiva contra la matanza? ¿Cuál es entonces el rol de la memoria hoy, cómo deben recordarse esas muertes? ¿Y sus vidas? ¿Qué nos dejan sus experiencias como aprendizaje para los años que corren?

Calveiro busca responder a cada uno de esos interrogantes, justamente desde ese lugar doblemente agredido. A la inevitable pregunta sobre la permanencia de esos militantes en las organizaciones, a pesar de verse sometidos a aquel verticalismo autoritario, la autora responde que era un pacto de sangre con los compañeros muertos y los "otros" asesinados lo que los mantenía atados a la responsabilidad colectiva. "Atrapados", dice, en una 
"sensación de deuda moral o culta, una construcción artificial de convicciones", a la que agrega además una dolorosa percepción de "no retorno" (p. 138). En relación a los elegidos, tampoco deja dudas sobre la responsabilidad de la conducción, que "retaceó recursos con los que contaba y dejó indefensos a militantes populares que hubiera podido proteger" ( $p$. 126). Y finalmente, respecto del silencio social, Calveiro encuentra sus causas en las nuevas formas que adoptó la política desde mediados de los 60. Aquella "sociedad en constante fuga" (p. 28) que describe al inicio del texto, en referencia a las movilizaciones de aquellos años, hace efectivamente "reaparecer" la política, dice la autora, pero "mutada", "a pedradas y a tiros" (p. 32).

Ahora bien, encontrar la(s) respuesta(s) sobre el rol actual de la memoria, sobre las formas en las que debe ser recuperada aquella fugaz y profunda militancia político-social, sobre cómo debe ser abordado y comprendido ese período brillante y oscuro a la vez, tiene que incluir necesariamente a las nuevas generaciones. Superando la denuncia, el reproche o el auto-escrache (que Calveiro propone, al inicio de su texto, en referencia a su propia participación, pero que finalmente no logra construir en su argumentación), es probable que los niños de aquellos años y los siguientes hijos de la democracia reelaboremos mejor lo sucedido. La díada
Política y/o violencia que propone la autora es un importante punto de partida. Calveiro concluye que no debe ser negado el núcleo violento de la política, pero que debe exigirse al mismo tiempo un fuerte contrapeso de la ética, que sustituya "el combate por el debate" (p. 150). Lejos de las armas, con las manos libres para escribir, para ser solidarios, para sellar compromisos, nosotros debemos recuperar de aquella política, su militancia. Y construir verdaderas convicciones en amplios sectores de la sociedad, creencias que obliguen a defender lo logrado y a ir por más.

\section{MARÍA FLORENCIA REYES SANTIAGO}

Universidad de Buenos Aires

REQUENA GALlEGo, Manuel, Diccionario Biográfico de los parlamentarios de Castilla-La Mancha, 1977-2007, Albacete, Altabán Ediciones, 2013, 448 pp.

En este último cuarto de siglo, los estudios de prosopografía política han experimentado un importante auge en España. Resulta evidente que este hecho aparece vinculado al surgimiento y a la consolidación de un sistema descentralizado de administración que ha generado las élites gubernamentales y parlamentarias más numerosas y diversificadas (en extracción geográfica, social o ideológica) de nuestra 
historia contemporánea. Los estudios sobre las élites políticas de la actual monarquía democrática han ido cobrando consistencia a escala provincial o regional, y resultaba previsible la convergencia de esfuerzos a escala estatal como el que, bajo el patrocinio de las Cortes Españolas y la dirección de Mikel Urquijo Goitia, ha derivado en la publicación en 2010 del Diccionario biográfico de parlamentarios españoles para la Cortes de Cádiz (1808-1814), y en 2012 de la entrega referida al período 1820-1854.

Pocos historiadores parecen tan preparados como Manuel Requena, catedrático de escuela universitaria en la Universidad de Castilla-La Mancha, para abordar un estudio de esta naturaleza que cubriese la totalidad del ámbito regional. Su profundo conocimiento de los procesos electorales ${ }^{1}$ y de la clase política castellano-manchega en perspectiva transecular ${ }^{2}$ le hacen el especialista más adecuado para abordar esta tarea, que ya han

1. Sin ánimo de exhaustividad, véanse REQUENA GALLEGO, Manuel y IZQUIERDO COLLADO, Juan de Dios, "Estado actual de la investigación electoral en Castilla-La Mancha", Revista de Estudios Políticos, 75 (1992), pp. 259-270; SEPÚLVEDA LOSA, Rosa María y REQUena GALlego, Manuel, "Elecciones a Cortes en Albacete durante el Sexenio democrático", Al-Basit, 44 (2000), pp. 215-233, y REQUENA GALLEGO, Manuel, "Las elecciones del Frente popular en Albacete", Al-Basit, 11 (1982), pp. 27-72 y "La hegemonía liberal en las elecciones a Cortes en el distrito electoral de Hellín, 1918-1923", Al-Basit, 26 (1990), pp. 139-149.

2. REQUENA GALlEGo, Manuel, "La clase política y las contiendas electorales en las abordado con anterioridad Joseba Agirreazkuenaga para el País Vasco entre 1808 y 1939, Pedro Carasa para Castilla y León durante la Restauración, Aurora Garrido para Cantabria entre 1902 y 2002, Diego Caro Cancela para Andalucía entre 1810 y 1869 o Xosé Ramón Barreiro para Galicia durante todo el período constitucional, entre otros.

El presente libro es, casi en exclusiva, una recopilación de las biografías de los 400 parlamentarios que han representado a las provincias de Castilla-La Mancha entre 1977 y 2007 tanto en las Cortes Españolas como en el parlamento regional, que es una de las cámaras autonómicas con menor número de diputados, a pesar de que ahora se pretenda restringir aún más esta representación. La obra trata, simplemente, de cubrir un vacío documental que ya estaba cubierto en la mayor parte de las regiones, donde se conocen desde hace años los rasgos más destacados del personal político parlamentario de la etapa democrática. Para el caso castellano-manchego,

provincias de Castilla-La Mancha 19311933”, I Congreso de Historia de CastillaLa Mancha, Toledo, Junta de Comunidades de Castilla-La Mancha, 1988, vol. 10, pp.15-37; Partidos, elecciones y élite política en la provincia de Albacete, 1931-1933, Albacete, Instituto de Estudios Albacetenses, 1991 y "Las élites castellano-manchegas en el período contemporáneo, 1810-1936", en LÓPEZ VILLAVERDE, Ángel Luis y GARCía MARCHANTE, Joaquín Saúl (coords.), Relaciones de poder en Castilla: el ejemplo de Cuenca, Cuenca, Eds. de la Universidad de Castilla-La Mancha, 1997, pp. 231-250. 
ya había esbozos en la obra que yo mismo abordé hace veinte años con Javier Moreno Luzón ${ }^{3}$, y en el Atlas Electoral de Castilla-La Mancha (19761993) elaborado en 1994 por la empresa Demoscopia por encargo de la Junta de Comunidades 4 .

Como ya señala el autor en la introducción, la obra no es sino un primer paso necesario para abordar un auténtico estudio prosopográfico, que Requena ya esboza al final del texto que encabeza el libro: escasa continuidad de la representación, bipartidismo claramente dominante en todas las provincias, creciente presencia femenina (casi igualitaria en las actuales Cortes regionales), edad media decreciente de los representantes y mayoría de titulados superiores, con un 36\% de abogados que deja entrever una embrionaria profesionalización y burocratización de la actividad política. A ello se podría añadir el creciente arraigo de estos representantes en la vida local y provincial como parte obligada de su cursus honorum. A diferencia, por ejemplo, de la Restauración e incluso de la República, el "cunerismo" parece ahora la excep-

3. Elecciones y parlamentarios. Dos siglos de historia en Castilla-La Mancha, Toledo, Cortes de Castilla-La Mancha, 1993, especialmente su segunda parte y el apéndice $\mathrm{n}^{\circ} 5$.

4. Toledo, Servicio de Publicaciones de la Junta de Comunidades de Castilla-La Mancha/Cortes de Castilla-La Mancha, 1994, 2 vols. Por ese entonces, el consejero delegado de Demoscopia era José Ignacio Wert. ción a una regla universalmente observada, si bien aún pueden detectarse casos flagrantes en el caso del Partido Popular (Rafael Arias-Salgado, Gustavo de Arístegui, Enrique FernándezMiranda -de quien, sorprendentemente, no se menciona su vinculación paterna con la política-, Luis M. Fraga, Margarita Mariscal de Gante, Ana Palacio, Javier Rupérez o Isabel Tocino) y el Partido Socialista (Gregorio Peces-Barba, Alfredo Pérez Rubalcaba o Virgilio Zapatero).

La relación biográfica se estructura en datos esenciales de índole personal, entorno familiar (a la sazón, resulta muy interesante ver la conexión de muchos representantes -sobre todo de la izquierda- con la ejecutoria política de sus padres o abuelos, que Requena conoce a la perfección), formación académica, militancia partidista y actividades políticas desde el nivel local al nacional o al internacional (como los cosos muy relevantes de Manuel Marín o Javier Rupérez), en la doble faceta gubernamental o parlamentaria.

Aunque toda obra de esta naturaleza puede ser perfectible (se podría haber incorporando, por ejemplo, la bibliografía o las fuentes específicas utilizadas para la elaboración de la semblanza biográfica de cada personaje), el presente trabajo es y será un instrumento imprescindible para abordar futuras investigaciones sobre las élites políticas de Castilla-La Mancha.

EDUARDO GONZÁLEZ CALLEJA Universidad Carlos III de Madrid 


\section{AUTORES / AUTHORS}

Pedro Rújula López es profesor titular de Historia Contemporánea de la Universidad de Zaragoza. Sus investigaciones se han dirigido a estudiar los fenómenos políticos, sociales y culturales en los orígenes del mundo contemporáneo. Autor de libros como Contrarrevolución. Realismo y Carlismo en Aragón y el Maestrazgo (1820-1840) (1998) y Constitución o Muerte. El Trienio liberal y los levantamientos realistas en Aragón (1820-1823) (2000). Coordinador, con Jordi Canal, de Guerra de Ideas. Política y cultura durante la Guerra de la Independencia (2012) y, con Gonzalo Butrón, de Los Sitios en la Guerra de la Independencia: la lucha en las ciudadades (2013). Editor, con estudio introductorio, de la obra de Antonio Pirala, Vindicación del general Maroto (2005), de F. Cabello, F. Santa Cruz y R.M. Temprado, Historia de la guerra última en Aragón y Valencia (2006), los Diarios de Faustino Casamayor (2008), Los Sititos de Zaragoza del barón Lejeune (2009) y de las Memorias del mariscal Louis-Gabriel Suchet (2012). E-mail: rujula@unizar.es

Jean-Claude Caron es profesor de Historia Contemporánea de la Université Blaise-Pascal (Clermont-Ferrand) y miembro sénior del Institut Universitaire de France. Ha trabajado especialmente sobre las violencias socio-políticas en el siglo XIX. Algunas de sus obras más destacadas son: L'Été rouge. Chronique de la révolte populaire en France (1841) (Aubier, 2002), Les Feux de la discorde. Conflit et incendie dans la France au XIXe siècle (Hachette-Littérature, 2006), Frères de sang. La guerre civile en France au XIXe siècle (Champ Vallon, 2009). Es autor de una biografía del general Foy: Les deux vies du général Foy (17751825). Guerrier et législateur (Champ Vallon, 2014). E-mail: J-Claude.CARON@ univ-bpclermont.fr 
Francis Démier es profesor de Historia Contemporánea de la Université de Paris Ouest Nanterre-La Défense. Ex vicepresidente de la Université de Paris Ouest, miembro del Institut des Sciences Sociales du Politique (UMR-CNRS). Sus trabajos tratan diversos aspectos de la historia económica y social de Francia y de Europa en el siglo XIX y sobre la historia de la instituciones económicas. Algunas de sus numerosas publicaciones son: La liberté guidant le peuple, la Révolution de Juillet 1830 (Hatier, 2014), La France de la Restauration (18141830). L'impossible retour du passé (Gallimard, 2012), Les maux et les soins. Médecins et maladies dans les hôpitaux parisiens du XIXe siècle (direction de l'ouvrage), Action artistique à la ville de Paris (Paris, 2007), Les campagnes en Europe, 1830-1930 (en colaboración con G. Sanz y E. Musiani, Atlande, 2006), Louis Blanc, un socialiste en République (CREAPHIS, 2006), Histoire de la Chambre de commerce de Paris (la Monarchie constitutionnelle, 1814-1848) (Droz, 2003). E-mail: francis.demier@u-paris10.fr

Gonzalo Butrón Prida es profesor titular de Historia Contemporánea de la Universidad de Cádiz. Sus investigaciones han girado principalmente en torno a la crisis del Antiguo Régimen en los años finales del reinado de Fernando VII, prestando especial atención a su implicación internacional en el contexto de Trafalgar, la Guerra de la Independencia, la repercusión europea de la Constitución de 1812 y la ocupación francesa de 1823 a 1828. Ha participado en numerosos proyectos de investigación nacionales e internacionales y ha publicado una larga serie de libros, capítulos de libros y artículos en revistas indexadas, entre ellas Ayer (2001), Trienio (2002), Spagna Contemporanea (2004), Mélanges de la Casa de Velázquez (2008), Cuadernos Dieciochistas (2011) e Historia Constitucional (2012). E-mail: gonzalo.butron@uca.es

Carmine Pinto es doctor en Historia y profesor de la Universidad de Salerno (Italia). Ha trabajado en numerosas universidades italianas e internacionales. Sus líneas de investigación son la historia política y la historia de los partidos en Europa después de la Segunda Guerra Mundial, así como las guerras civiles y la formación de los estados nacionales en el Mediterráneo y en el Atlántico en el siglo XIX. Es miembro de varias instituciones de investigación, comités científicos y comités de redacción de revistas. Autor de numerosos libros, artículos y ensayos sobre estos temas, forma parte actualmente de la dirección de la Sociedad Italiana de Historia Contemporánea y es miembro de la Sociedad de Historia Militar. E-mail: cpinto@unisa.it 
Javier Esteve Martí es doctorando en el Departamento de Historia Contemporánea de la Universitat de València con una beca FPU. Su tesis se centra en el devenir del tradicionalismo político español en las décadas finales del siglo XIX y las iniciales del siglo XX. Ha analizado el discurso de católicos ultramontanos en "El tradicionalisme en l'ascens del nacionalisme de masses: el pare Corbató" (Recerques, n 65) y también estudia la cultura política tradicionalista desde una perspectiva trasnacional, atendiendo a los casos francés y portugués. E-mail: javier.esteve@uv.es

Javier Navarro Navarro es profesor titular del Departamento de Historia Contemporánea de la Universitat de València. Sus investigaciones se han centrado principalmente en temas relacionados con la historia sociocultural del movimiento obrero español, en especial por lo que se refiere al anarquismo, así como en el campo de estudios sobre la Segunda República y la guerra civil. Entre su producción cabe destacar sus libros El paraíso de la razón. La revista Estudios, 1928-1937, y El mundo cultural anarquista (1997), Ateneos y grupos ácratas (2002), A la revolución por la cultura. Prácticas culturales y sociabilidad libertarias en el País Valenciano, 1931-1939 (2004), Valencia, capital antifascista. Visiones e impresiones de una ciudad en guerra (conjuntamente con Antonio Calzado, 2007), Valencia, capital cultural de la República, 19361937 (junto a Manuel Aznar y Josep Lluís Barona, eds., 2007), Fa setenta anys. Memòria i Història de la Guerra Civil al País Valencià, 1936-1939 (junto a Albert Girona, eds., 2009), así como diversos artículos en revistas especializadas y en obras colectivas, entre ellas Tierra y Libertad. Cien años de anarquismo en España (Julián Casanova, coord., 2010), Entre la reforma y la revolución. La construcción de la democracia desde la izquierda (Aurora Bosch, Teresa Carnero, Sergio Valero, eds., 2013) o L'Anarchie et le problème du politique (Alfredo Gómez-Muller, dir., 2014). E-mail: francisco.j.navarro@uv.es

Roberto Villa García es profesor titular del Área de Historia del Pensamiento y de los Movimientos Sociales y Políticos de la Universidad Rey Juan Carlos de Madrid. Sus trabajos se han centrado fundamentalmente en el estudio de las elecciones y la vida política en la España contemporánea. Ha dedicado a estos temas cinco monografías y varios capítulos de libro y artículos científicos. Sus libros más recientes son La República en las Urnas. El Despertar de la Democracia en España (Marcial Pons, 2011) y, junto con Manuel Álvarez Tardío, El Precio de la Exclusión. La Política durante la Segunda República (Encuentro, 
2010). Ha sido investigador invitado en las Universidades de WisconsinMadison (EE.UU.) y París IV-Sorbonne (Francia). E-mail: roberto.villa@urjc.es

Natalia Urigüen López de Sandaliano es licenciada en Historia por la Universidad Nacional de Educación a Distancia (UNED) y máster por la misma universidad sobre "La España contemporánea en el contexto internacional". Desde 2012 tiene una beca de investigación FPI de la UNED y está ultimando la tesis doctoral sobre "El papel de la democracia cristiana alemana en la Transición española". E-mail: nuriguen@bec.uned.es

IgNACIO TÉbAr Rubio-Manzanares es licenciado en Historia por la Universidad de Alicante y licenciado en Antropología Social y Cultural por la Universidad Miguel Hernández de Elche. Actualmente está finalizando su tesis doctoral como becario FPU de la Universidad de Alicante, integrado en el grupo de investigación de "España Contemporánea". Ha realizado estancias de investigación en el Centro de Ciencias Humanas y Sociales del CSIC, en la Universidad Carlos III de Madrid y en la Universidad de York (Canadá). Sus investigaciones se centran en el Derecho penal y el sistema represivo del primer franquismo. E-mail: nacho.tebar@ua.es

Ana BelÉn Gómez Fernández es doctora en Historia por la Universidad de Jaén. En la actualidad ejerce como profesora ayudante doctor en el Área de Historia Contemporánea en la Universidad de Jaén. Se ha ocupado del análisis del comportamiento político y electoral durante la transición democrática y la construcción de la ciudadanía y movilización social en el tardofranquismo y la democracia. Entre sus trabajos destacan La transición a la democracia en Jaén: partidos y elecciones (2010); y Parlamentarios de Jaén en la Transición Democrática (2009) en colaboración con Francisco Acosta Ramírez. Ha publicado varios artículos sobre las transiciones democráticas y la lucha social en la transición. E-mail: abgomez@ujaen.es

Miguel Ángel Giménez Martínez es licenciado en Humanidades (2006) y doctor en Historia Contemporánea (2011) por la Universidad de Castilla-La Mancha. Ha recibido diversos premios por su rendimiento académico y ha trabajado como becario FPI e investigador contratado en la Universidad de 
Castilla-La Mancha, bajo la dirección del Dr. Juan Sisinio Pérez Garzón. En la actualidad colabora con el Departamento de Historia de la Universidad Autónoma de Madrid, bajo la dirección del Dr. Álvaro Soto Carmona. Especialista en historia política e institucional del franquismo y la transición a la democracia en España, ha publicado varias obras sobre la materia, entre las que destaca su libro Las Cortes Españolas en el régimen de Franco. Nacimiento, desarrollo y extinción de una Cámara Orgánica (Madrid, Congreso de los Diputados, 2012). E-mail: miguelangelgimenezmartinez@gmail.com

Manuel Lillo i Usechi es licenciado en Periodismo por la Universitat Miguel Hernández d'Elx y posee un máster universitario en "Historia de la Europa contemporánea: identidades e integración", cursado en la Universitat d'Alacant. Actualmente es doctorando en la UA y se encuentra desarrollando su proyecto de tesis doctoral titulado "Mil números d' El Temps: el compromís d'una línia política catalanista", bajo la dirección del Dr. José Miguel Santacreu Soler. Entre sus trabajos destaca "La prensa alicantina en valenciano (1884 1936) y otros nacionalismos coetáneos", que obtuvo la máxima calificación en el trabajo fin de máster presentado en el citado máster de la UA. E-mail: mlillousechi@gmail.com 

Pasado y Memoria, revista de periodicidad anual, pretende extender el cauce de comunicación entre los historiadores e investigadores dedicados al análisis e interpretación de los sucesos y procesos históricos del mundo contemporáneo. Es precisamente aquí, en la delimitación del campo de estudio, donde el título de la revista encuentra su significado: el pasado es el ámbito de estudio de la historia y la memoria es uno de los factores que configura nuestro conocimiento del pasado próximo.

\section{NORMAS PARA LA PRESENTACIÓN DE ORIGINALES}

El Consejo de Redacción de Pasado y Memoria establece las siguientes normas para el envío de trabajos originales:

Presentación.- Los artículos de investigación deberán ser inéditos, con una extensión máxima de 9.000 palabras. Se añadirá un resumen del contenido del trabajo en español y en inglés (incluido el título en ambas lenguas), con una extensión máxima de 150 palabras, especificándose unas palabras clave en español y en inglés, además de una breve nota curricular, de una extensión aproximada de unas 10 líneas, sobre la formación académica, situación profesional y labor investigadora del autor/autora. Cualquier contacto, así como el envío de originales, se realizará a través de la dirección de correo electrónico:

\section{pasadoymemoria@ua.es}

Admisión.- El trabajo será sometido, mediante el sistema de doble ciego, a los dictámenes de dos especialistas en la materia externos al Consejo de 
Redacción y al Departamento de Humanidades Contemporáneas de la Universidad de Alicante y, a la vista de los mismos, el Consejo de Redacción decidirá si procede o no su publicación, lo que será notificado al autor/autora en un plazo máximo de seis meses.

Referencias bibliográficas.- Las citas bibliográficas se colocarán en notas a pie de página. Todas las referencias bibliográficas se atendrán a la siguiente secuencia: APELLIDO/s del autor/a o autores, en versalitas, el nombre completo del autor/autora o autores, en minúscula, seguido de coma; luego, en cursiva, el título de la obra, seguido de coma; a continuación y separados por comas, el lugar de edición, la editorial y la fecha de publicación; por último, la p./pp. de referencia.

Ej.: hOBSBawm, Eric J., Historia del siglo XX, Barcelona, Crítica, 1995, pp. 29-30.

Si una obra ha de ser citada varias veces, se pondrá el nombre del autor/ autora, el comienzo del título de la obra, seguido de puntos suspensivos y el número de p./pp. referidos.

Ej.: HOBSBAwm, Eric J., Historia del siglo XX..., pp. 42-53.

En caso de cita consecutiva:

Ej.: Ibid., p. 275.

Para la cita de fechas (prensa, documentación de archivo, día de consulta de sitio en Internet, etc.) se seguirá el siguiente modelo: 19-III-1812.

Cuando se trate de artículos de revistas: APELLIDO/s del autor/autora o autores, en versalitas; el nombre completo del autor/a/res, en minúscula, seguido de coma; luego, entre comillas, "título", seguido de coma; título de la revista en cursiva, seguido de coma; tomo (t.) o volumen (vol.) correspondiente; número de la revista $\left(\mathrm{n}^{\mathrm{o}}\right)$; año, entre paréntesis; finalmente, p./pp. de referencia.

Ej.: Redero san román, Manuel y garcía GonzÁlez, Gloria M., "Prensa y opinión en la transición política", Anales de la Universidad de Alicante. Historia Contemporánea, no 8-9 (1991-1992), pp. 85-119. 
Citas electrónicas.- Los recursos electrónicos que hayan sido consultados deberán ser citados especificando la dirección de Internet encerrada entre los símbolos "<" y ">", indicando, entre corchetes, la fecha en que fue visitado el recurso citado.

Ej.: <http://www.historiaconstitucional.com> [consultado: 14-VII-2008]

Iconografía, cuadros y gráficos.- Deberán aparecer insertados en su lugar correspondiente en el texto, siendo claramente identificados y explicados, y, en el caso de ilustraciones, habrán de tener una resolución óptima para su impresión en blanco y negro. Se recomienda adjuntar las imágenes también por separado en formato jpg, tiff o similar.

Notas bibliográficas y reseñas de libros.- Las notas sobre el estado de la cuestión de un tema referido al período contemporáneo tendrán una extensión máxima de 4.000 palabras, acompañándose una bibliografía final según las normas especificadas.

Las reseñas de libros de reciente publicación tendrán una extensión máxima de 1.500 palabras, especificándose el autor/autora, título, lugar de publicación, editorial, fecha de publicación y número de páginas, así como el nombre y apellidos de quien realiza la crítica e institución a la que pertenece al final de la misma.

\section{INSTRUCCIONES PARA EVALUADORES DE ARTÍCULOS}

Los evaluadores externos, que serán doctores especialistas en la temática y periodo histórico sobre el que verse el trabajo de investigación, recibirán una solicitud de revisión de artículo vía correo electrónico remitido por algún miembro del Consejo de Redacción, normalmente su secretario. Si el encargo no fuese aceptado en el transcurso de una semana, se entenderá declinada la solicitud y se procederá a su remisión a otro/otra experto/ experta.

Una vez aceptado, el revisor o la revisora dispondrá de un plazo de 4 semanas para emitir su informe razonado, que habrá de remitir a la secretaría de la 
revista (pasadoymemoria@ua.es) utilizando para ello el modelo-plantilla que le será enviado junto con el artículo objeto de evaluación. Asimismo, se garantiza un total anonimato por ambas partes (sistema de doble ciego): ni autor ni revisores tendrán conocimiento el uno del otro. El dictamen de los informantes podrá ser: aceptado sin modificaciones, aceptado con modificaciones, rechazado.

Todos los artículos de investigación serán remitidos a dos revisores/as (proceso de revisión por pares). En caso de que sendos informes fuesen muy dispares, se podrá solicitar un tercer informe.

Los revisores podrán ser requeridos en una segunda ocasión para dictaminar si el/la autor/autora ha efectuado los cambios sugeridos para la mejora del texto. La decisión de su publicación o su rechazo definitivo corresponderá en última instancia al Consejo de Redacción de Pasado y Memoria, cuyo dictamen será argumentado apoyándose en los informes realizados por los/las evaluadores/as externos/as.

\section{INDICADORES DE LA DIFUSIÓN Y LA CALIDAD EDITORIAL Y CIENTÍFICA DE PASADO Y MEMORIA}

\section{Orientación para evaluadores, autores e investigadores}

Índice de impacto RESH (2004-2008): 0.077

Latindex (2013): cumple todos los criterios de calidad editorial (33). A falta de actualización

Categoría ERIH (2011): INT2

Criterios calidad editorial ANECA (2013): 21. A falta de actualización

Criterios calidad editorial CNEAI (2013): cumple todos los criterios de calidad editorial (18). A falta de actualización

Catalogada en DICE (fecha de actualización 4-XII-2012):

-valoración difusión internacional: 1.5

-internacionalidad de las contribuciones: 12.5

MIAR - difusión ICDS (2013): 3.541

Clasificación CARHUS Plus 2010: grupo C

Clasificación CIRC (2011): grupo B

Otros catálogos: COPAC (Reino Unido), SUDOC (Francia), ZBD (Alemania), OCLC WorldCat (mundial) 
Pasado y Memoria, revista de periodicitat anual, pretén estendre les vies de comunicació entre els historiadors i investigadors dedicats a l'anàlisi i interpretació dels successos i processos històrics del món contemporani. És precisament ací, en la delimitació del camp d'estudi, on el títol de la revista troba el seu significat: el passat és l'àmbit d'estudi de la història i la memòria és un dels factors que configura el nostre coneixement del passat pròxim.

\section{NORMES PER A LA PRESENTACIÓ D'ORIGINALS}

El Consell de Redacció de Pasado y Memoria estableix aquestes normes per a l'enviament de treballs originals:

Presentació. Els articles d'investigació hauran de ser inèdits, amb una extensió màxima de 9.000 paraules. S'hi afegirà un resum del contingut del treball en espanyol i en anglès (que incloga el títol en les dues llengües), amb una extensió màxima de 150 paraules, i s'hi especificaran unes paraules clau en espanyol i en anglès, a més d'una breu nota curricular, d'una extensió aproximada d'unes 10 línies, sobre la formació acadèmica, situació professional i tasca investigadora de l'autor o autora. Qualsevol contacte, com també l'enviament d'originals, es farà a través de l'adreça de correu electrònic:

\section{pasadoymemoria@ua.es}

Admissió. El treball serà sotmès, mitjançant el sistema de doble cec, als dictàmens de dos especialistes en la matèria externs al Consell de Redacció i al Departament d'Humanitats Contemporànies de la Universitat d'Alacant. 
A la vista dels dictàmens, el Consell de Redacció decidirà si escau o no publicar-lo, i ho notificarà a l'autora $o$ autor en un termini màxim de sis mesos.

Referències bibliogràfiques. Les citacions bibliogràfiques es col-locaran en notes a peu de pàgina. Totes les referències bibliogràfiques s'atindran a aquesta seqüència: COGNOM O COGNOMS de l'autor o autors, en versaletes, el nom complet de l'autor o autors, en minúscula, seguit de coma; després, en cursiva, el títol de l'obra, seguit de coma; a continuació i separats per comes, el lloc d'edició, l'editorial i la data de publicació; finalment, la p./pp. de referència.

Ex.: HOBSBAWM, Eric J., Historia del siglo xx, Barcelona, Crítica, 1995, pp. 29-30.

Si una obra ha de ser citada diverses vegades, es posarà el nom de l'autor o autora, el començament del títol de l'obra, seguit de punts suspensius i el nombre de p./pp. referits.

Ex.: HOBSBAwm, Eric J., Historia del siglo xx,..., pp. 42-53.

En cas de cita consecutiva:

Ex.: Ibid., p. 275.

Per a la citació de dates (premsa, documentació d'arxiu, dia de consulta de lloc en Internet, etc.) se seguirà aquest el model: 19-III-1812.

Quan es tracte d'articles de revistes: COGNOM o COGNOMS de l'autor o autors, en versaletes; el nom complet de l'autor o autors, en minúscula, seguit de coma; després, entre cometes, «títol», seguit de coma; títol de la revista en cursiva, seguit de coma; tom (t.) o volum (vol.) corresponent; nombre de la revista (núm.); any, entre parèntesis; finalment, p./pp. de referència.

Ex.: Redero SAn RomÁn, Manuel y garcía GonzÁlez, Gloria M., «Prensa y opinión en la transición política», Anales de la Universidad de Alicante. Historia Contemporanea, no 8-9 (1991-1992), pp. 85-119. 
Cites electròniques. Els recursos electrònics que hagen sigut consultats hauran de ser citats amb l'adreça d'Internet tancada entre els símbols $<$ i $>$, i caldrà indicar entre claudàtors la data en què va ser visitat el recurs citat.

Ex.: <http://www.historiaconstitucional.com> [consultat: 14-VII-2008]

Iconografia, quadres i gràfics. Hauran d'aparèixer inserits en el seu lloc corresponent en el text, clarament identificats i explicats, i, en el cas d'illustracions, hauran de tenir una resolució òptima per a imprimir-les en blanc i negre. Es recomana adjuntar les imatges també per separat en format jpg, tiff o similar.

Notes bibliogràfiques i ressenyes de llibres. Les notes sobre l'estat de la qüestió d'un tema referit al període contemporani tindran una extensió màxima de 4.000 paraules, i s'acompanyaran d'una bibliografia final segons les normes especificades.

Les ressenyes de llibres de recent publicació tindran una extensió màxima de 1.500 paraules; s'hi especificarà l'autor o autora, títol, lloc de publicació, editorial, data de publicació i nombre de pàgines, i també el nom i cognoms de qui fa la crítica i la institució a què pertany al final de la ressenya.

\section{INSTRUCCIONS PER A AVALUADORS D'ARTICLES}

Els avaluadors externs, que seran doctors especialistes en la temàtica i període històric sobre el qual tracta el treball de recerca, rebran una sol-licitud de revisió d'article via correu electrònic remès per algun membre del Consell de Redacció, normalment el secretari. Si l'encàrrec no és acceptat en el transcurs d'una setmana, s'entendrà declinada la sol-licitud i es remetrà a un altre expert o experta.

Una vegada acceptat, el revisor o la revisora disposarà d'un termini de 4 setmanes per a emetre un informe raonat, que haurà de remetre a la Secretaria de la revista (pasadoymemoria@ua.es) utilitzant el model plantilla que s'adjuntarà a l'article objecte d'avaluació. Així mateix, es garanteix un total anonimat per les dues parts (sistema de doble cec): ni l'autor ni els 
revisors tindran coneixement l'un de l'altre. El dictamen dels informants podrà ser: acceptat sense modificacions, acceptat amb modificacions, rebutjat. Tots els articles d'investigació seran remesos a dos revisors (procés de revisió per parells). En cas que els dos informes siguen molt dispars, se'n podrà sol-licitar un tercer.

Els revisors podran ser requerits en una segona ocasió per a dictaminar si l'autor o autora ha incorporat els canvis suggerits per a millorar el text. La decisió de la seua publicació o el seu rebuig definitiu correspondrà en última instància al Consell de Redacció de Pasado y Memoria, el dictamen del qual serà argumentat i es basarà en els informes realitzats pels avaluadors o avaluadores externs.

\section{INDICADORS DE LA DIFUSIÓ I LA QUALITAT EDITORIAL I CIENTÍFICA DE PASSAT MEMÒRIA} Orientació per a avaluadors, autors i investigadors

Índex d'impacte RESH (2004-2008): 0.077

Latindex (2013): compleix tots els criteris (33)

Categoria ERIH (2011): INT2

Criteris qualitat editorial ANECA (2013): 21

Criteris qualitat editorial CNEAI (2013): compleix tots els criteris (18)

Catalogada en DICE (data d'actualització 4-XII-2012):

-valoració difusió internacional: 1.5

-internacionalitat de les contribucions: 12.5

MIAR - difusió ICDS (2013): 3.541

Classificació CARHUS Plus 2010: grup C

Classificació CIRC (2011): grup B

Altres catàlegs: COPAC, SUDOC, ZBD, OCLC WorldCat 
Pasado y Memoria is an annual journal that aims to broaden the channels of communication between historians and researchers who are devoted to the analysis and interpretation of historical events and processes in the contemporary world. It is precisely within the definition of this field of study that the sense of this journal's title lies: the past (pasado) is the sphere studied by history while memory (memoria) is one of the factors that constitute our knowledge about the recent past.

\section{INSTRUCTIONS FOR AUTHORS}

The Pasado y Memoria Editorial Board has established the following guidelines for the submission of original works:

Presentation.- Research articles must be previously unpublished works, with a maximum of 9,000 words. The paper will include an abstract of no more than 150 words summarising the article content, in Spanish and English (including the title in both languages). Key words must also be given in Spanish and English. A short biography of approximately 10 lines should also be included containing relevant information about the author's academic background, professional status and research work. All correspondence, including the submission of the originals, must be sent to the following e-mail address:

\section{pasadoymemoria@ua.es}

Acceptance for publication.- Based on a double-blind peer review, the article will be evaluated by two experts in the field, who are independent from the Editorial Board and the Department of Contemporary Humanities of the University of Alicante. Based on these reviews, the Editorial Board will 
decide whether to proceed with publication or not, notifying the author of its decision within six months of submission.

Bibliographical references.- Bibliographical citations must be included in foot notes. All bibliographical references will be set out as follows: author/s SURNAME/s in small capitals and the author/s full name in lower case followed by a comma; the title of the article in italics, followed by a comma; then separated by commas, the place of publication, the publisher and year of publication; and finally the pg. or pp. reference.

E.g.: hobsbawm, Eric J., Historia del siglo XX, Barcelona, Crítica, 1995, pp. 29-30.

If an article is to be cited several times, it is only necessary to indicate the author/s' name, the beginning of the article's title, followed by ellipsis (...) and the page numbers referred to.

E.g.: hobSBAwм, Eric J., Historia del siglo XX..., pp. 42-53.

In case of a consecutive citation:

E.g.: Ibid., pg. 275.

When citing dates (press, archive documents, web retrieval date, etc.) the following model will be applied: 19-03-1812.

When citing articles in a journal: author/s SURNAME/s in small capitals and the author/s full name in lower case and followed by a comma; the "title" in quotes, followed by a comma; title of the journal in italics, followed by a comma; the corresponding book (b) or volume (vol.); issue of the journal (no.); year, in brackets; finally the pg. or pp. reference

E.g.: Redero san román, Manuel and García GonzÁlez, Gloria M., "Prensa y opinión en la transición política", Anales de la Universidad de Alicante. Historia Contemporánea, no. 8-9 (1991-1992), pp. 85-119.

Electronic references.- Any electronic resources that have been consulted should be cited, specifying the web page address between the symbols 
"<" and ">", and indicating the date said resource was accessed, in square brackets.

E.g.: <http://www.historiaconstitucional.com> [Accessed: 14-07-2008]

Illustrations, tables and graphics.- These should appear in their corresponding place within the text and be clearly labelled and explained. Any illustrations must have an optimum resolution for printing in black and white. Please send any images separately in jpg, tiff or other format.

Bibliographic notes and book reviews.- Notes about the state of the question related to a topic based on the contemporary period will be no longer than 4,000 words and will be accompanied by a bibliography at the end of the document, according to the established guidelines.

Book reviews of recent publication will contain a maximum of 1,500 words. The author, title, place of publication, publisher, date of publication and number of pages must be specified at the end of the document, as well as the name and surnames of the person responsible for the review and the institution to which he/she belongs.

\section{INSTRUCTIONS FOR REVIEWERS OF ARTICLES}

The external reviewers, who will be expert doctors in the topic and historical period analysed in the research article, will receive a request for an article review by e-mail from the Editorial Board secretary, or an occasion from another member. If the reviewer does not accept the request within a week, it will be understood that the request has been declined and it will be sent to another expert.

Once the reviewer agrees to undertake the request, he/she will have 4 weeks to submit a well-reasoned report, which he/she must send to the journal secretary (pasadoymemoria@ua.es) using the model-template which he/ she will have received along with the article for review. Furthermore, total anonymity is guaranteed for both sides (double-blind peer review system): neither the author nor the reviewers will know each other's identity. 
The decision of the reviewers may be: accepted without modifications, accepted with modifications, rejected.

All research articles are sent to two reviewers (peer review process). If significant differences are found between the two reports, a third review may be requested.

Reviewers may be required to carry out a second review to determine whether the author has introduced the suggested changes to improve the text. It is the Pasado y Memoria Editorial Board that makes the final informed decision as regards acceptance or rejection of an article based on the reports submitted by the external reviewers.

\section{INDICATORS RELATED TO THE DISSEMINATION AND PUBLICATION AND SCIENTIFIC QUALITY OF PASADO Y MEMORIA}

Guidelines for reviewers, authors and researchers

Impact factor RESH (2004-2008): 0.077

Latindex (2013): fulfils 33 criteria (out of 33)

ERIH category (2011): INT2

ANECA quality criteria (2013): 21

CNEAI quality criteria (2013): 18

Catalogued in DICE (updated 4-XII-2012):

- international dissemination valuation: 1.5

- internationality of contributions: 12.5

MIAR -ICDS dissemination (2013): 3,541

CARHUS Plus 2010 classification: group C

CIRC classification (2011): group B

Other catalogs: COPAC (United Kingdom), SUDOC (France), ZBD (Germany), OCLC WorldCat 


\section{POLÍTICA DE SECCIONES / SECTIONS POLICY}

Propuestas de monográficos / Proposals of monographics dossiers: envíos abiertos sometidos a la aprobación del Consejo de Redacción.

Artículos del dossier monográfico / Articles of monographic dossier: sometidos a revisión por pares con sistema de doble ciego; indexados.

Artículos / Studies: envíos abiertos; sometidos a revisión por pares con sistema de doble ciego; indexados.

Notas bibliográficas / Bibliographical notes: envíos abiertos; sometidas al parecer del Consejo de Redacción; indexadas.

Reseñas de libros / Reviews: envíos abiertos; sometidas al parecer del Consejo de Redacción; indexadas.

\section{TASA DE ACEPTACIÓN DE ARTÍCULOS ACCEPTANCE RATES \\ (2010-2014)}

\begin{tabular}{|l|c|c|}
\hline \begin{tabular}{l|c} 
ARTíCULOS DE INVESTIGACIÓN \\
INVESTIGATION ARTICLES
\end{tabular} & $\mathrm{N}^{\circ}$ & $\mathbf{1 0 0 \%}$ \\
\hline$\frac{\text { Artículos recibidos }}{\text { Received articles }}$ & 75 & $33,33 \%$ \\
\hline$\frac{\text { Artículos rechazados }}{\text { Rejected articles }}$ & 25 & $66,67 \%$ \\
\hline$\frac{\text { Artículos aceptados y publicados }}{\text { Accepted and published articles }}$ & 50 & \\
\hline
\end{tabular}




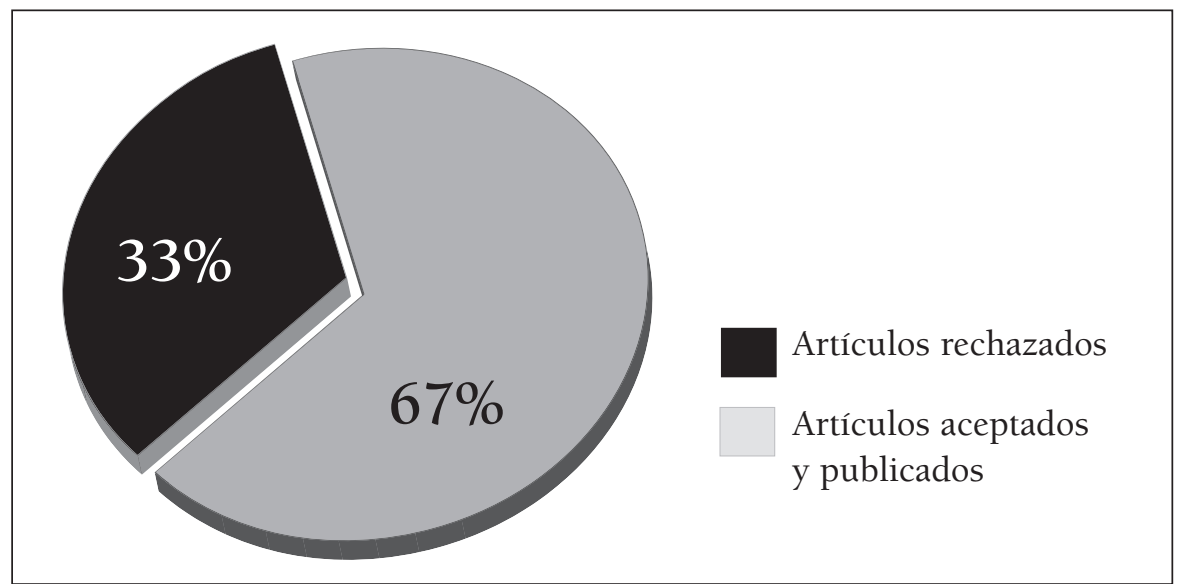

\section{EVALUADORES EXTERNOS DE LOS ARTÍCULOS DE INVESTIGACIÓN \\ EXTERNAL REVIEWERS OF INVESTIGATION ARTICLES (2013-2014)}

Ana Aguado Higón, Universitat de València

Manuel Álvarez Tardío, Universidad Rey Juan Carlos, Madrid

Aurora Bosch Sánchez, Universitat de València

Roberto Breña, El Colegio de México

Antonio F. Canales Serrano, Universidad de La Laguna, Tenerife

Francisco Carantoña Álvarez, Universidad de León

Alejandro Cattaruzza, Universidad de Buenos Aires, Argentina

Francisco Javier Caspistegui Gorasurreta, Universidad de Navarra

Ángela Cenarro Lagunas, Universidad de Zaragoza

Richard Cleminson, University of Leeds, Gran Bretaña

Julián Chaves Palacios, Universidad de Extremadura

María Liliana Da Orden, Universidad Nacional de Mar del Plata, Argentina 
Jorge de Hoyos Puente, Hispanic Institute at Columbia University, New York

Gregorio de la Fuente Monge, Universidad Complutense de Madrid

Francisco de Luis Martín, Universidad de Salamanca

Nicola A. del Corno, Università degli Studi di Milano, Italia

Rubén Domínguez Méndez, Instituto Universitario de Historia de Simancas, Valladolid

Montserrat Duch i Plana, Universitat Rovira i Virgili, Tarragona

Alejandro Fernández, Universidad Nacional de Luján, Argentina

Ana Isabel Fernández Asperilla, Fundación 1 de Mayo, Madrid

Ignacio Fernández Sarasola, Universidad de Oviedo

Silvana Gabriela Ferreyra, Universidad Mar del Plata, Argentina

Marina Franco, Universidad Nacional de San Martín, Argentina

Ivana Frasquet Miguel, Universitat de València

Juan Francisco Fuentes Aragonés, Universidad Complutense de Madrid

Encarna García Monerris, Universitat de València

Eduardo González Calleja, Universidad Carlos III de Madrid

Emilio Francisco Grandío Seoane, Universidad de Santiago de Compostela

Fernando Hernández Holgado, Universidad Complutense de Madrid

Ángel Herrerín López, UNED, Madrid

Emmanuel Kahan, Universidad Nacional de La Plata, Argentina

Pierre Karila-Cohen, Université Rennes 2, Francia

Antonio Laguna Platero, Universidad de Castilla la Mancha

José Luis Ledesma Vera, Universidad de Zaragoza

Pablo León Aguinaga, Georgetown University, Washington, USA

Natacha Lillo, Université Paris Diderot, Francia

Javier López Alós, University of Leeds, Gran Bretaña

Ricardo Martín de la Guardia, Instituto Universitario de Estudios Europeos de la Universidad de Valladolid

Juan Martínez Leal, Doctor en Historia

Jesús Martínez Milán, Universidad de Las Palmas

Darina Martykánová, Centro de Ciencias Humanas y Sociales-CSIC, Madrid Abdón Mateos López, UNED de Madrid 
Jesús Millán y García-Varela, Universitat de València

Carme Molinero Ruiz, Universitat Autònoma de Barcelona

José Antonio Montero Jiménez, Universidad Complutense de Madrid

Víctor Morales Lezcano, UNED, Madrid

Toni Morant i Ariño, Universität Münster, Alemania

Alejandro Hernán Morea, CONICET-Universidad Nacional de Mar del Plata

Francisco Morente Valero, Universitat Autònoma de Barcelona

Javier Navarro Navarro, Universitat de València

Encarna Nicolás Marín, Universidad de Murcia

Javier Pérez Núñez, Universidad Autónoma de Madrid

Natalie Petiteau, Université d'Avignon, Francia

Julio Prada Rodríguez, Universidad de Vigo

Rafael Quirosa-Cheyrouze y Muñoz, Universidad de Almería

José Reig Cruañes, Universidad de Castilla la Mancha

Marcos Roitman Rosenmann, Universidad Complutense de Madrid

Severiano Rojo Hernández, Aix Marseille Université, Francia

Lluís Roura Aulinas, Universitat Autònoma de Barcelona

Coro Rubio Pobes, Universidad del País Vasco

Pedro Ruiz Torres, Universitat de València

Carlos Sanz Díaz, Universidad Complutense de Madrid

Franco Savarino Roggero, Escuela Nacional de Antropología e Historia, México

Vittorio Scotti Douglas, Università degli Studi di Trieste, Italia

Juan David Sempere Souvannavong, Universidad de Alicante

Álvaro Soto Carmona, Universidad Autónoma de Madrid

Josep Maria Tamarit Sumalla, Universitat Oberta de Catalunya

Javier Ugarte Tellería, Universidad del País Vasco

Bruno Vargas, Centre Universitaire Jean-François Champollion, Albi, Francia

Vicenta Verdugo Martí, Universitat de València

Juan Bautista Vilar Ramírez, Universidad de Murcia

Roberto Villa García, Universidad Rey Juan Carlos, Madrid 


\section{NÚMEROS PUBLICADOS}

$N^{o}$ 1, 2002: Instituciones y sociedad en el franquismo

No 2, 2003: La II República española

$\mathrm{N}^{\circ}$ 3, 2004: La memoria del pasado

$N^{0}$ 4, 2005: Represión y violencia (1936-1945)

$N^{0}$ 5, 2006: España en los años 60. La percepción de los cambios

No 6, 2007: II República y Transición

$\mathrm{N}^{\circ} 7$, 2008: Mujeres y culturas políticas

No 8, 2009: Economía y Guerra Civil española

$N^{\circ}$ 9, 2010: Consenso y enfrentamiento en la Democracia española

No 10, 2011: Los políticos europeos y Napoleón

$\mathrm{N}^{\mathrm{o}}$ 11, 2012: Emigración y fascismo en el mundo latino

No 12, 2013: Miscelánea

No 13, 2014: Recomponer el mundo después de Napoleón. 1814 y las restauraciones

En preparación:

$N^{0} 14,2015$ : Reyes sagrados. Los usos de la religión en las monarquías europeas del siglo XIX

$N^{o}$ 15, 2016: Mentalidades en guerra. Siglo XX 

Universitat d'Alacant 